Hot

Af

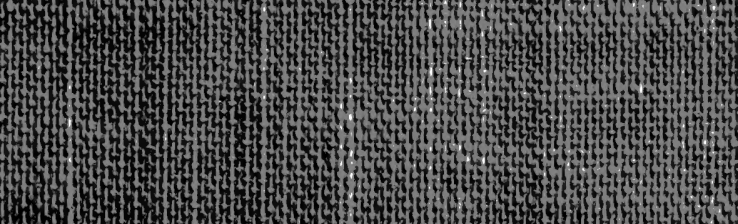

15

(1)

H.

3)

H.th

sith

(1.

tht

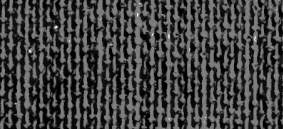

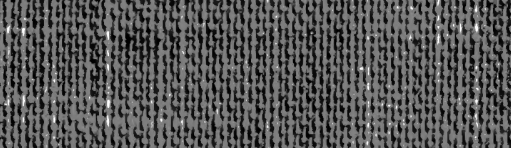

Hth

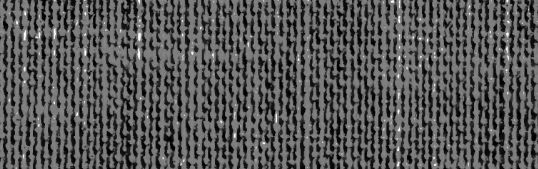

(w) bishth 


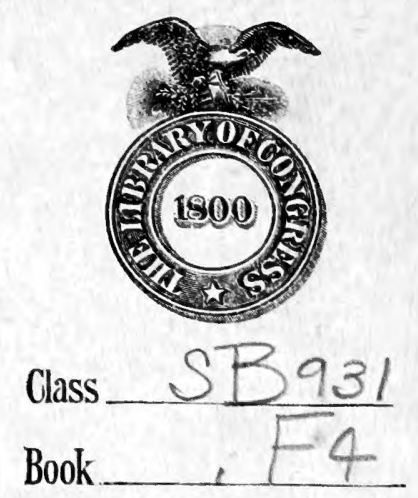

Copyightit No.

COPYRIGHT DEPOST. 
$y$ 

AGRICULTURAL AND BIOLOGICAL PUBLICATIONS CHARLES V. PIPER, Consulting Editor

\section{APPLIED ENTOMOLOGY}




\section{Me Graw-Fill Book Co.The PUBLISHERS OF BOOKS FOR}

Coal Age $\quad \nabla$ Electric Railway Journal Electrical World $\nabla$ Engineering News-Record American Machinist $\nabla$ Ingeniería Internacional Engineering \& Mining Journal $\nabla$ Power Chemical \& Metallurgical Engineering Electrical Merchandising 


\section{APPLIED ENTOMOLOGY}

AN INTRODUCTORY TEXT-BOOK

$O F$

INSECTS IN THEIR RELATIONS TO MAN

BY

H. T. FERNALD, Рн.D.

PROFESBOR OF ENTOMOLOGY, MASSACHUSETTS AGRICULTURAL COLLEGE, AND ENTOMOLOGIST OF THE MASSACHUSETTS AGRICULTURAL

EXPERIMENT STATION

First Edition

MCGRAW-HILL BOOK COMPANY, INC.

NEW YORK: 370 SEVENTH AVENUE

LONDON: $6 \& 8$ BOUVERIE ST., E. C. 4 


$$
\frac{S B 931}{F 4}
$$

Copyright, 1921, by the

McGraw-Hill Book Company, Inc.

AUG 251921

THE MAPIE PRESS YORK PA

\section{(C) CIA624096}


TO THE . MEMORY OF

\section{Sty Frather}

Professor Charles H. Fernald:

the first teacher of Economic Entomology to college students, in this country. 



\section{PREFACE}

If one can judge from the answers to about fifty letters of inquiry sent to teachers of Entomology in colleges in the United States, the teaching of Entomology in this country at the present time is in a rather chaotic condition. Very few of the answers received show much in harmony in subject matter, methods of presentation, or even the line of training the students should receive by a course in the subject.

The author believes that in agricultural colleges at least, two distinct groups of students need a knowledge in Entomology, and rather early in their course. One of these groups is composed of students who will never specialize in the subject but need it as part of an agricultural education, and particularly as a tool which they can use wherever insects are related to their special lines of work. They are not particularly interested in such details as the number of antennal segments in insects, the number of branches of the radial vein, or how important a pest on pigweed the insect is: they do not expect to identify insects beyond the order or family at most, relying on specialists available at the State Experiment Stations for such information. But they do desire a general knowledge of the broad outlines of the subject, and a rather complete knowledge of, and if possible, the ability to recognize particularly important insect pests they are liable to meet in the course of their work.

The other group consists of those who expect to specialize in the subject, becoming professional entomologists. Their needs will, of course, be different from those of the other group, but an introductory survey such as will meet the requirements of the rest will give the members of this group an excellent foundation for further and more detailed work.

The present book is therefore offered as a classroom text for an introductory course in the subject, which shall give a general idea of insects, their structure, life histories and habits, with methods for the control of insect pests in general, followed by a more thorough study of the more important ones found in this country. For use, the writer believes that in few places will all of the text be assigned. Instead, the pests of the country as a whole (treated in large type) and those of the particular region concerned (selected from among those printed in smaller type) would naturally be the parts used in any one place, though the book as a whole should be fairly well applicable to all sections of the country.

The author is of the opinion that to avoid too much monotony, it may prove wise to assign Chapters VI to IX inclusive, among those 
immediately following. The treatment of the subject matter is such as to permit this.

Many of the illustrations included are familiar. Where satisfactory illustrations are already available, it is questionable whether new ones are any gain, particularly when all are new to the student. In this connection the author desires to express his grateful appreciation of the kindness of Dr. W. E. Britton and the Connecticut Experiment Station, and of Prof. J. S. Houser and the Ohio Experiment Station, for the provision of cuts from the publications of those Stations. He is much indebted to Prof. E. D. Sanderson for the use of cuts taken from "Insect Pests of Farm, Garden and Orchard" and from Sanderson and Jackson's "Elementary Entomology," and to the publishers of these books, John Wiley and Sons, Inc., and Ginn and Company respectively, as well as to Dr. E. P. Felt who has kindly allowed the use of reproductions of illustrations taken from his publications. Dr. J. W. Folsom's kindness and that of his publishers, P. Blakiston's Sons and Company in permitting the use of illustrations from Dr. Folsom's book "Entomology with Reference to its Biological and Economic Aspects," is also much appreciated. Ginn and Company have kindly consented to the use of several illustrations from Linville and Kelly's "Textbook in General Zoölogy," and the side view of the parts of a grasshopper has been obtained by permission of those in charge of the Natural History Survey of Connecticut. The largest number of illustrations secured, however, has been obtained through the kind permission of Dr. L. O. Howard of the U. S. Bureau of Entomology to use many which are the property of the Bureau. Photographs from various Experiment Station Reports and Bulletins have also been freely drawn upon. The source from which each illustration has been obtained is indicated in every case. To all the persons and companies above named, I desire to express my thanks.

Any book such as this is necessarily a compilation. Probably there are very few if any entomologists in this country who have worked personally on all the insects treated here. The only originality for it. which can be claimed therefore, is in the selection of the various topics and their method of presentation. Errors have undoubtedly crept in, and the author will appreciate having his attention called to any which may be found.

The author desires to express his appreciation of the aid in the preparation of this book given him by his associates, Dr. G. C. Crampton, Dr. W. S. Regan, and Mr. A. I. Bourne, who have gone over various parts of it and have eriticized and advised on those which they have examined. Much of any value it may have is due to them, but for any errors and incorrect statements which may be found, the author assumes full responsibility.

Amherst, March 1, 1921.

H. T. Fernald. 


\section{CONTENTS}

PAGE

Preface. . . . . . . . . . . . . . . . . . . vii

\section{CHAPTER I}

Insects and other Animals. . . . . . . . . . . . . . . . . . . . . . .

The larger groups of animals - Their distinctive characters-The Arthropoda -Its characters-Animals included-Subdivisions of the group-Their distinctive characters-Tabular statement of the distinctive characters.

\section{CHAPTER II}

The Insect: Its External Structure.

The characters of insects-Number of segments in the embryo-In the adult-The hypodermis-Sutures-Plates-Form of head-Structures on the body-The antennæ-Eyes--Mouthparts-Chewing mouthpartsThe thorax-Its appendages-Legs-Wings-The abdomen-Abdominal feet-Ovipositor-Other appendages.

\section{CHAPTER III}

The Insect: Its Internal Structure. . . . . . . . . . . . . .

Digestive organs-Breathing organs-Circulatory organs-The bloodExcretory organs-Nervous system-Sense organs-Reproductive organs.

\section{CHAPTER IV}

The Development of Insects.

Egg-laying and viviparous insects-Description of insect eggs-HatchingDevelopment of the insect-The Ametabolous development-Hemimetabolous development--Holometabolous development-Pupation and cocoon making-Transformation of the pupa-Emergence-Common names of Holometabolous larvæ.

\section{CHAPTER V}

Losses Caused by Insects: Nature's Control Methods . . . . . . . . . Amount of the loss not generally realized-Its average amount-To cropsTo animals and their products-To forests and their. products-To stored materials-By disease-Total loss-Losses increasing-Causes-Introduction of foreign insect pests-Reduction in abundance of insectivorous birds-A theoretic state of equilibrium upset by civilization-Nature's methods too slow-Artificial methods necessary.

\section{CHAPTER VI}

Artificial Methods of Control . . . . . . . . . . . . . . . . . . .

Two groups of methods-Farm practice-Healthy crops-Crop rotationPlowing - Time of planting-Resistant varieties of plants-Trap cropsSpecial methods-Hand picking-Repellents-Trap lanterns-BurningHeat-Miscellaneous methods. 


\section{CHAPTER VII}

Insecticides in General: Stomách Poisons . . . . . . . . . . . . . . . 43

Materials classified-Conveyance-Dusts-Sprays-Arsenic-Disadvantages-Paris green-Disadvantages-Standard formula-VariationsArsenate of lead-Standard formula-Arsenate of lime-Standard formulaPoison baits-Hellebore-Commercial Sodium Fluorid.

\section{CHAPTER VIII}

Contact Insecticides . . . . . . . . . . . . . . . . . . .

Purposes of contact insecticides-Kerosene emulsion-Miscible oilsWhale-oil soap-Common soap-Nicotine-Nicotine sulfate-Lime sulfur wash-Dry sulfur compounds-Sulfur-Pyrethrum, insect powder, or buhach.

\section{CHAPTER IX}

Insecticides and Fungicides: Fumigation. . . . . . . . . . . . . . . Combinations of spray materials-Of insecticides-Of insecticides and fungicides-Injurious combinations-Fumigation-Nature of its actionLimits of availability-Carbon disulfid-Nicotine-Sulfur-Hydrocyanicacid gas.

\section{CHAPTER X}

The Relationships of Insects

Classification-The development of animals in the past-Artificial and natural classifications-The original insects-The development of diversity - Resultant groups--Relations of species, genera, families etc.-A sample tree-like classification-Table of classification.

\section{CHAPTER XI}

The Apterygota. . . . . . . . . . . . . . . . . . . . . . . . . . . . General structure-Distinctive characters-General description-Divisions of the group-Order Thysanura-Distinctive characters-The Silver FishOrder Collembola-General features-Distinctive characters-General account.

\section{CHAPTER XII}

The Pterygota. The Ephemerida . . . . . . . . . . . . . . . General considerations on the Pterygota-The Ephemerida-General description and structure-Distinctive characters-Life and habitsImportance.

\section{CHAPTER XIII}

The Odonata . . . . . . . . . . . . . . . . . . . . . General description and structure-Distinctive characters-Groups of dragon-flies-Habits-Their life and food-Importance-Abundance.

\section{CHAPTER XIV}

The Plecoptera.

General description of the group-Distinctive characters-Life and habitsAbundance-Economic importance. 
CHAPTER XV

The Embitdina.

General description-Economic importance.

\section{CHAPTER XVI}

The Orthoptera . . . . . . . . . . . . . . . . . . . . .

General description-Structure-Division into two sections-The Cursoria -Distinctive characters-Families considered-The Blattidæ-Description of Roaches-The German Roach-The American Roach-The Australian Roach-The Oriental Roach or "black beetle"-Control of Roaches -The Mantidæ-General considerations-Common Mantids-The Phasmidx-General description of appearance, life history and habits-Economic importance - Control-The Saltatoria-General features-The Acrididæ-Description of grasshoppers-Abundance-Economic importanceControl-Kinds of grasshoppers-Sounds produced-Organs of hearingThe Tettigoniidæ-General description of the family, habits, life history, etc.-Economic importance-The Gryllidæ-General statements-SoundsEars-Economic importance-Kinds of crickets-Tree crickets-Control.

\section{CHAPTER XVII}

The Isoptera . . . . . . . . . . . . . . . . . . . . . . . . The colony-Its compesition-Castes-Structures-Distinctive characters -Food-Swarming-Common species-Life and habits-Injuries-Control -Zoraptera.

\section{CHAPTER XVIII}

The Dermaptera.

General deseription-Distinetive characters-Importance-HabitsDifferent species-The European earwig-Injuries-Control.

\section{CHAPTER XIX}

The Coleoptera.

Structure-Distinctive characters-Life histories and habits-Division into Coleoptera vera and Rhynchophora-Coleoptera vera-LampyridxCarabidæ- Cicindellidæ-Dytiscidæ-Gyrinidæ-Hydrophilidæ-Staphylinidæ-Silphidæ-Dermestidæ-Larder beetle-Buffalo Carpet beetle-Black Carpet beetle-Control-Buprestida-Flat-headed Apple-tree Borer-Elateridæ-Wireworms-control-Scarabæidæ-June bugs-Rose chafer-Japanese Beetle-Chrysomelidæ-Colorado Potato BeetleChange of food a possible pest producer--Striped Cucumber Beetle--Cornroot Worms-Flea Beetles-Asparagus Beetles-Grape Root Worm-Elm Leaf Beetle-Tortoise Beetles-Bruchidæ-Pea Weevil-Bean WeevilBroad Bean Weevil-Control of Weevils-Cerambycidæ-Round-headed Apple-tree Borer-Coccinellidæ-Tenebrionidæ-Yellow Meal-wormMeloidæ-Rhynchophora-Plum Curculio-Plum Gouger-Cotton Boll Weevil-White Pine Weevil-Alfalfa Weevil-Potato-stalk Weevil-Sweetpotato Weevil-Ipidæ-Fruit-tree Bark Beetle. 
CHAPTER XX

The Strepsiptera . . . . . . . . . . . . . . . . . 150

General description-Distinctive characters-Habits-Life history-Abundance-Importance.

\section{CHAPTER XXI}

The Thysanoptera. . . . . . . . . . . . . . . . . . 153

General features-Structure-Distinctive characters-Habits-Subdivisions -Wheat Thrips-Onion Thrips-Pear Thrips-Citrus Thrips.

\section{CHAPTER XXII}

The Corrodentia . . . . . . . . . . . . . . . . . . . . . . 159

General description-Structure-Distinctive characters-Book licePsocids-Importance of the group.

\section{CHAPTER XXIII}

The Mallophaga .

General features-Distinctive characters-Habits-Poultry lice-Control.

\section{CHAPTER XXIV}

The ANopldra. . . . . . . . . . . . . . . . . . 16

Description-Distinctive characters-Distribution-Life history-Body louse-Relation of lice to disease-Crab louse-Lice on domestic animalsControl.

\section{CHAPTER XXV}

The Hemptera

General characters-Structure of mouthparts-Distinctive charactersDistribution-Habits-Pentatomidæ-Harlequin Bug-Cydnidæ-Coreidæ -Squash Bug-Pyrrhocoridæ-Cotton Stainer-Lygæidæ-Chinch Bug - The diseases of Insects - Tingitidæ-Miridæ-Meadow Plant Bug-Tarnished Plant Bug-Phymatidæ-Reduviidæ-Cimicidæ-Bedbug-Gerridæ -Notonectidæ-Corixidæ-Nepidæ-Belostomidæ.

\section{CHAPTER XXVI}

The Homoptera.

General statements-Distinctive characters-Variations in habits etcHoney dew-Classification of the order-Cicadidæ-Periodical Cicada or 17-year Locust-Leaf Hoppers and Tree Hoppers-Apple Leaf hoppersRose Leaf hopper-Chermidæ-Pear Psylla-Aphididæ in general-Apple Aphids-Grape Phylloxera-Corn Root Aphis-Aleyrodidæ-Coccidæ in general-Armored Scales-Oyster-shell Scale-Scurfy Scale-San José Scale-Rose Scale-Pine Leaf Scale-Purple Scale-Red Scale-Soft Scales-Black Scale-Terrapin Scale-Cottony Maple Scale-Hemispherical Scale-Mealy Bugs-Citrus Mealy Bug-Long-tailed Mealy Bug-Cottony Cushion Scale-Introduction of enemies of introduced pests. 


\section{CHAPTER XXVII}

General features-Distinctive characters-Economic value-SialidaCorydalis-Chrysopidx or Aphis lions-Raphidiida - Mantispida-Myrmeleonidx or Ant lions.

\section{CHAPTER XXVIII}

The Trichoptera .

General description-Distinctive characters-Life and habits-Larval cases -Importance.

\section{CHAPTER XXIX}

The LePidoptera

General features-Structure-Mouthparts-Distinctive characters-Diversity in the order-Life history and development in general-CossidxLeopard Moth-Tineidæ-Clothes moths and their control-Codling Moth - Egeridæ-Peach Borers-Squash-vine Borer-Gelechiidæ-Angoumois Grain Moth-Pterophoridæ-Pyralidæ-Bee Moth-European Corn Borer -Limacodidx - Psychid $x$-Geometrid $x$ - Canker worms-Bombycid $x$ Lasiocampidæ-Apple-tree Tent-caterpillar-Forest Tent-caterpillar-Lymantriidæ-White-marked Tussock Moth-Antique or Rusty Tussock Moth-Gypsy Moth-Brown-tail Moth-Notodontidæ-Dioptidæ-California Oak Worm-Noctuidæ in general-Cotton Worm-Corn-ear Worm -Army Worm-Fall Army Worm-Cutworms-Aretiidx-Fall Web-worm - Ceratocampidx-Saturniidx-Sphingidæ-Tobacco and Tomato Worms — The Butterflies - Hesperiidæ - Lyeænidæ-Danaid $x$ - Nymphalid Satyridæ-Pieridæ--Imported Cabbage Butterfly-Sulfur butterflies-The spreading over the country of introduced insects-Papilionidæ-Black Swallow-tail butterfly.

\section{CHAPTER XXX}

The Mecoptera.

General features-Distinctive characters-Habits-lood-Importance.

\section{CHAPTER XXXI}

The Diptera

General description-Structure-Mouthparts of adult-Larvæ-PupæDistinctive characters-Size and importance of the group-TipulidæCulicidæ-House Mosquito-Malarial Mosquitoes-Relation to malariaYellow Fever Mosquito-Control of mosquitoes-Itonididæ-Cloverflower Midge-Hessian Fly-Wheat Midge-Tabanidæ-SimulidæAsilidæ-Syrphidæ-Estridæ-Ox Warbles-Trypetid - -Apple MaggotMuscida-House Fly-Its relation to disease-Screw Worm Fly-Sarcophagid $x$-Tachinid $x$-Tsetse Flies-Anthomyiid -Cabbage MaggotOnion Maggot-Pupipara-Sheep Tick.

\section{CHAPTER XXXII}

The Siphonaptera.

General description--Structure-Distinctive characters-Food-Life history and habits-Relation to disease-Control- "Sticktight flea"-Chigoe. 


\section{CHAPTER XXXIII}

The Hymenoptera. . . . . . . . . . . . . . . . . . . . . . . . . . . 338

General description and structure-Terebrantia and Aculeata-Development - Distinctive characters - Importance - Tenthredinoidea - Currant Worm--Pear Slug-Wheat Stem Borers-Horn-tails-IchneumonoideaTheir importance-Methods of work - Long-tailed Thalessa-CynipoideaGall production-Alternation of generations-Inquilines-Parasites-Importance of galls-Chalcidoidea-Habits-Wheat Straw Worm-Wheat Joint worm-Clover-seed Chalcis-Fig Blastophaga-Pteromalus puparumSerphoidea-Long-tailed Pelecinus-Variation in habits of parasitic Hymenoptera-Chrysidoidea-Sphecoidea-Vespoidea-Progressive development as illustrated by Wasps-Apoidea-Solitary bees-Leaf-cutter beesCarpenter bees-Bumble bees-Honey bee-Life of a Honey bee colonySwarming-Value of bee products-Formicoidea-Composition of ant colonies-Location of colonies-Swarming-Establishment of new coloniesAnts and plant lice, etc.-Unusual habits-Argentine Ant-House AntsAnts in lawns. 


\section{APPLIED ENTOMOLOGY}

\section{CHAPTER I}

\section{INSECTS AND OTHER ANIMALS}

Among the larger groups of animals now recognized by science, the one known as the Chordata is naturally the most familiar, including the mammals, birds, reptiles, fishes, besides numerous forms less well known. Another group, also familiar, and called the Mollusca, includes the snails, clam etc., while a third, the Annulata, contains most of the more commonly seen worms. The starfish and sea urchins, often seen at the seashore, belong with other similar animals, to a fourth group called the Echinodermata, and a multitude of tiny beings almost all too small to be seen without the aid of a microscope, are included in the group Protozoa. A sixth large group is composed mainly of soft, jelly-like animals, the more common larger members being called jelly-fish, and to this the name Cœlenterata is applied, and several other groups of less familiar forms are also known.

The largest group of all, however, is the Arthropoda, its members found in the seas, in fresh water, on land, or even flying freely; a group with remarkable differences of structure, and so abundant that all the other animals taken together are less than one-sixth as many as the Arthropods. Well-known members of this group are the lobsters, crayfish and crabs; scorpions, spiders, mites, ticks and "daddy long legs;" the centipedes and millipedes; and last and most abundant of all, the Insects.

No one feature will serve to separate the Arthropods from all other animals, but the possession by an animal of several of those here described will enable the observer to determine in each case whether he is examining one of this group. In Arthropods the body is composed of a series of more or less similar pieces or segments, placed one behind another, the line of attachment of these to each other being usually somewhat evident on parts of the body at least. This character is also shown, and indeed more clearly, in some members of the Annulata, such as the common earthworm. Another character of the Arthropods is the presence of jointed legs (or appendages of some kind), as is indicated by the name of the group, and these are not possessed by Annulates. The surface of the body is covered by a secretion which hardens on exposure to the air, 
forming an outside shell or external skeleton (exo-skeleton), there being practically no internal supporting structures except as ingrowths from the outside. In the possession of this external skeleton these animals

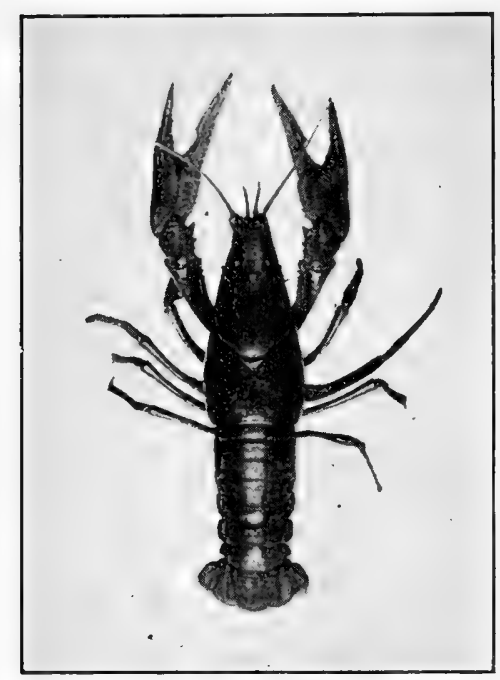

Fig. 1.-Crayfish (Crustacea); about one-half natural size. (Original.) have a seeming resemblance to the shells (Mollusca), but the materials of which it is composed are quite different, being largely calcium carbonate in the Mollusca, and chitin which somewhat resembles horn in its nature, sometimes with calcareous salts deposited in it, in the Arthropoda. In its simplest members the Arthropod body is also practically bilaterally symmetrical, though this condition is concealed somewhat by secondary changes in many of the group. The possession of a bilaterally symmetrical body consisting of a series of segments; an exoskeleton of chitin, and the presence of jointed legs, are then, distinctive features of the Arthropods.

To separate the various groups of Arthropods, other characters must be used. Aside from several small sections not often seen, there are five large and important divisions which call for recognition. These are the Crustacea, including the lobster, crab, beach flea, sow bug and many

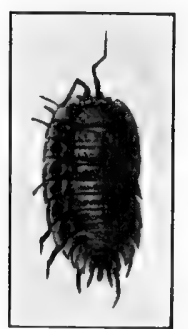

FIG. 2.-"Sow-bug; a crustacean living on land; about natural size. (Original.)

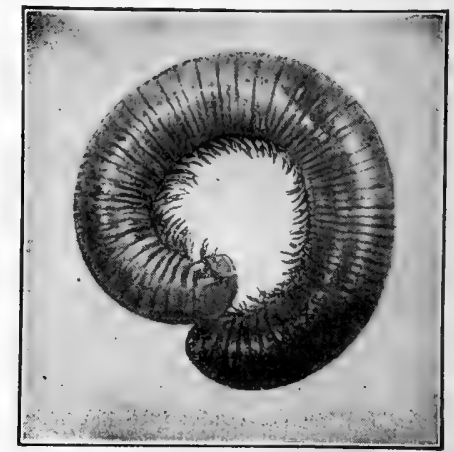

FIG. 3.-Millipede (Diplopoda); natural size. (From Folsom.)

others; the Diplopoda or Millipedes; the Chilopoda or Centipedes; the Hexapoda or Insects; and the Arachnida, including the scorpions, pseudoscorpions, spiders, mites, ticks, etc. 
The Crustacea (Fig. 1) are mainly water-inhabiting animals which breathe either by gills, or, in the smaller forms, through the surface of the body. In those cases where its members live on land (Fig. 2) the gills are still present, though in a somewhat modified condition. They have numerous pairs of legs and generally two pairs of antennæ (jointed "feelers"). Often some of the body segments are fused with the head to form a cephalothorax.

The Diplopoda (Fig. 3) are land animals breathing by air tubes opening on the sides of the body and permitting the air to pass in to all the internal parts of the animal. The head bears a pair of antennæ and is followed by a series of segments all practically alike and each, except

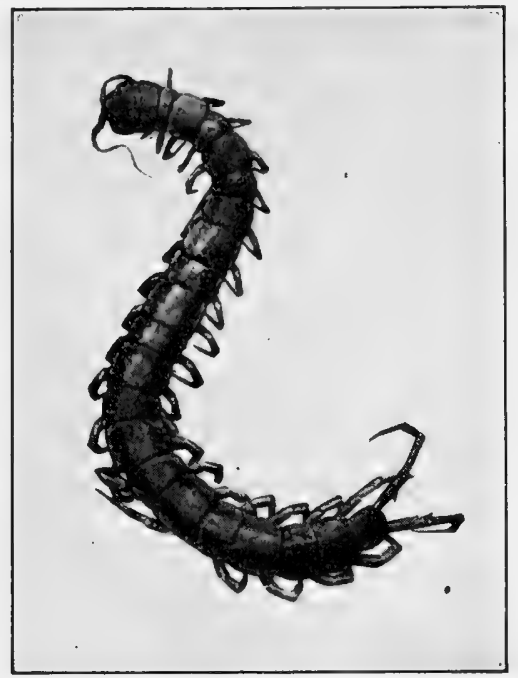

Fig. 4.-Centipede (Chilopoda); about three-quarters natural size. (Original.)

the first three, with two pairs of legs. The reproductive organs open far forward on the body. In most of the more common members of this group the body is quite cylindrical and when disturbed the animal usually curls up in a sort of close spiral. Small Diplopods about the diameter of the lead of a pencil and gray in color are often found boring into potatoes and roots in the ground in the fall, and are sometimes wrongly called wireworms. The common name "millipede" refers to the large number of legs possessed by these animals.

The Chilopoda are also land animals (Fig. 4). Like the Diplopods they have antennæ; breathe by air tubes, and the body segments are practically all alike. The general form, however, is rather flattened; each segment bears only one pair of legs, and the reproductive organs open at the hinder end of the body. The front leg on each side is modi- 
fied to serve as a poison claw. The numerous legs present in these animals has resulted in their receiving the common name "centipede."

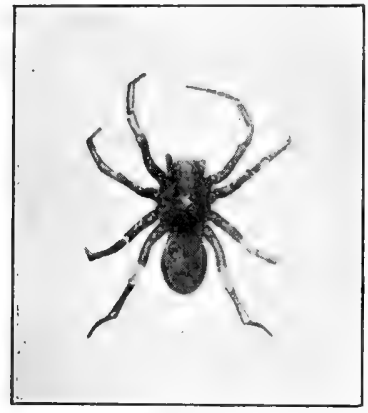

Fig. 5.-Hairy Spider (Arachnida); about natural size. (Original.)

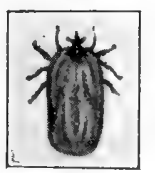

FIG. 7.-Adult female castor-bean Tick (Arachnida); natural size. (From U.S. D. A. Farm. Bull. 1057.)

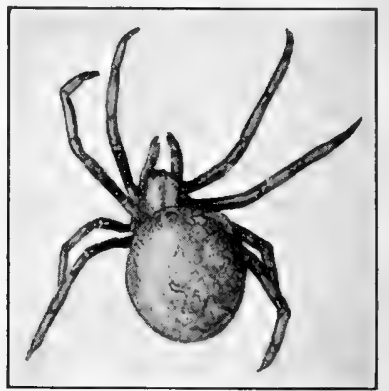

FIG. 6.-Large bodied Spider (Arachnida); about natural size. (Original.)

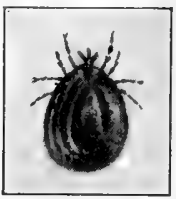

Frg. 8.-Adult female European dog Tick (Arachnida); natural size. (From U.S. D. A. Farm. Bull. 1057.)

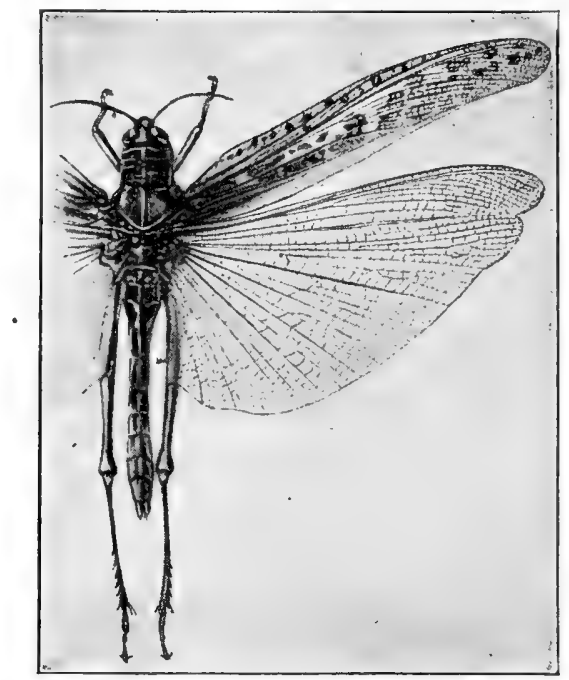

FIG. 9.-Grasshopper (Insecta); with wings spread. (From Folsom.)

The Arachnida (Figs. 5, 6, 7 and 8) generally have the segments of the body grouped into two sections called the cephalothorax and abdomen. 
No antennæ are present and the eight legs are all attached to the firstnamed section. They breathe either by air tubes somewhat similar to those of the other groups; by sacs containing many thin plates resembling leaves of a book, whence these structures take the name of book-lungs; or, in the smallest forms, directly through the body surface. In the mites there is no evident division of the body into sections. Though most of the group are land forms, a few are aquatic.

In the Hexapoda or Insects (Fig. 9) the segments of the body are grouped in three distinct sections; the head, thorax and abdomen. A pair of antennæ is (with rare exceptions) present on the head; the six legs are attached to the thorax as are the four wings usually present; the animals breathe by air tubes; and while living under a great diversity of conditions, the group as a whole is emphatically a terrestrial one, though in many cases their early life is spent in water.

\section{Distinctive Characters of the Main Arthropod Groups}

\begin{tabular}{|c|c|c|c|c|c|c|}
\hline & $\begin{array}{l}\text { Where } \\
\text { found }\end{array}$ & Body divisions & Antennæ & Legs & Breathe by & $\begin{array}{l}\text { Reproduc- } \\
\text { tive organs } \\
\text { open }\end{array}$ \\
\hline Crustacea.... & $\begin{array}{l}\text { Mainly in } \\
\text { water }\end{array}$ & $\begin{array}{l}\text { Head and body: } \\
\text { often a cepna- } \\
\text { lothorax }\end{array}$ & $\begin{array}{r}\text { Two pairs } \\
\text { generally }\end{array}$ & $\begin{array}{l}\text { Numerous: may } \\
\text { be built for } \\
\text { swimming }\end{array}$ & $\begin{array}{l}\text { Gills or through } \\
\text { body surface } \\
\text { (rarely by air } \\
\text { tubes) }\end{array}$ & Well forward \\
\hline Diplopoda... & On land & Head and body & One pair & $\mid \begin{array}{l}\text { Many: two } \\
\text { pairs on most } \\
\text { body seg - } \\
\text { ments }\end{array}$ & Air tubes & Near head \\
\hline Chilopoda.... & On land & Head and body & One pair & $\begin{array}{c}\text { Numerous: one } \\
\text { pair on each } \\
\text { body segment }\end{array}$ & Air tubes & $\begin{array}{l}\text { Next to last } \\
\text { body seg- } \\
\text { ment }\end{array}$ \\
\hline Arachnida... & $\begin{array}{l}\text { Mainly on } \\
\text { land }\end{array}$ & $\begin{array}{r}\text { Cephalothorax } \\
\text { and abdomen } \\
\text { (no divisions } \\
\text { in a few cases) }\end{array}$ & None & $\begin{array}{l}\text { Eight: joined } \\
\text { to cephalo- } \\
\text { thorax }\end{array}$ & $\begin{array}{l}\text { Air tubes, book- } \\
\text { lungs or body } \\
\text { surface }\end{array}$ & $\begin{array}{l}\text { Front part of } \\
\text { a bdomen } \\
\text { (a few ex- } \\
\text { ceptions) }\end{array}$ \\
\hline Hexapoda.... & $\begin{array}{l}\text { Mainly on } \\
\text { land }\end{array}$ & $\begin{array}{l}\text { Head, thorax, } \\
\text { abdomen }\end{array}$ & One pair & $\begin{array}{l}\text { Six: joined to } \\
\text { thorax }\end{array}$ & Air tubes & $\begin{array}{l}\text { Near hind end } \\
\text { of abdomen }\end{array}$ \\
\hline
\end{tabular}




\section{CHAPTER II}

\section{THE INSECT : ITS EXTERNAL STRUCTURE}

Bringing together the facts about insects already stated, we find that an adult insect is a bilaterally symmetrical animal consisting of a series of segments one behind another, and that these segments are grouped into three regions, the head in front, followed in order by the thorax and the abdomen (Fig. 10). Covering the animal is a skeleton, shell-like in that it encloses the body, but horny in its nature. Attached to the seg-

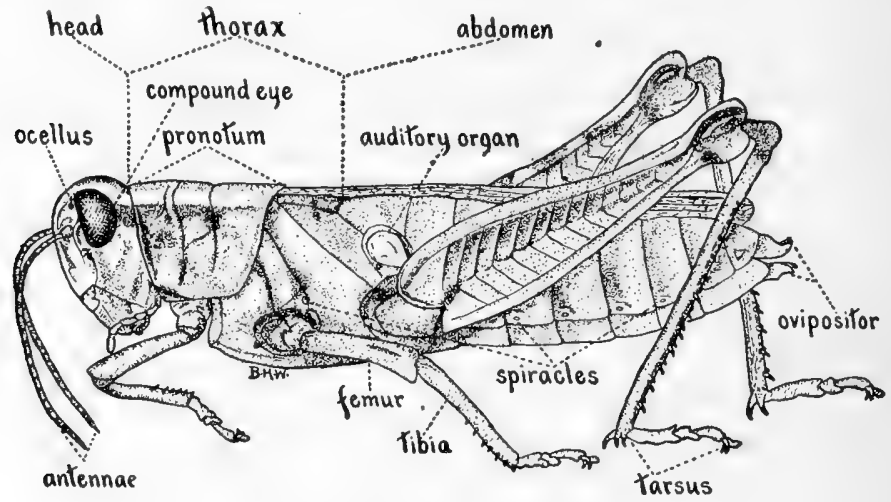

FIG. 10.-Side view of Grasshopper with parts named. (From Walden, Conn. Geol. \& Nat. Hist. Surv., Bull. 16.)

ments are three pairs of jointed legs, a pair of antennæ, mouth parts and usually two pairs of wings. It breathes through air tubes, and the reproductive organs open near the hinder end of the body.

The adult insect does not show all the segments of which its body is composed. In the embryo evidences of 21 have been found, ${ }^{1}$ but as the animal progresses toward maturity some of these fuse with others. The head of the adult, though apparently consisting of only one segment, is now believed to be the product of the fusion of six: the three found in the adult thorax seem to have always been that number; and the abdomen, composed of 12 segments in the embryo appears to have been reduced in the adult to a number varying from three to 11 , partly by a

1 Some investigators believe that 22 segments are present, the head consisting of seven, but this view is not universally accepted. 
process of fusion, partly by a sort of telescoping or the gradual shifting of one segment within another until it is partly or entirely concealed.

The skeleton covering the body is generally considered to be a secretion from the outside living layer of cells, the hypodermis. This secretion gradually hardens on exposure to the air, providing the support necessary for the soft parts within. Chemically it consists of chitin $\left(\mathrm{C}_{15} \mathrm{H}_{26} \mathrm{~N}_{2} \mathrm{O}_{10}\right)$, which remains thin and flexible at the movable joints and wing articulations, but elsewhere becomes thicker and usually darker in color. Here and there over its surface are impressed lines like scratches, very definite and fixed in position in most insects, and these are termed sutures, and are of great use as landmarks in description. These sutures have such an arrangement that in an ordinary segment of the body its

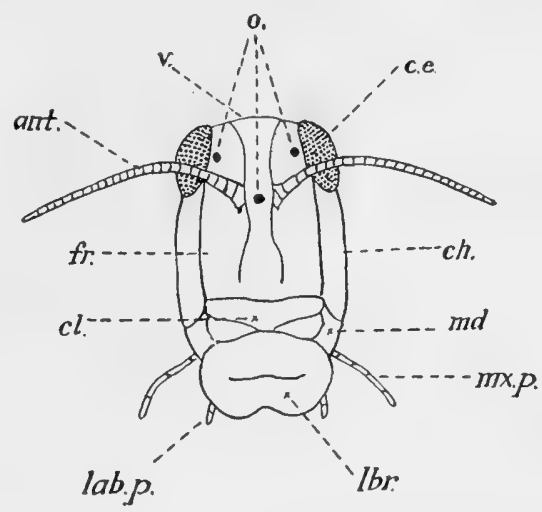

Fic. 11.-Front view of head of a Grasshopper showing a hypognathous head; ant, antenna; c. $c$. , compound eye; ch, cheek; $c l$, clypeus; $f r$, frons; lab. p., labial palpus; $l b r$., labrum; $m d$, mandible; $m x$. p., maxillary palpus; $o$, ocelli; $v$, vertex. upper surface has often been regarded as a plate or sclerite, the notum; one at each side, the pleuron; and one beneath, the sternum. These plates may have sutures subdividing them.

In the head the sutures are few in number, and only a few plates or sclerites are generally in evidence. In the thorax they are more numer-

FIG. 12.-Side view of Beetle (Lucanus dama $F a b$.$) showing a prognathous head.$ (Original.)

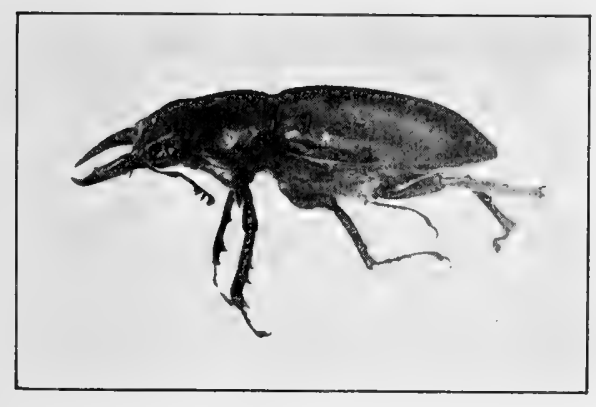

ous, while in the abdomen often only a dorsal and ventral sclerite for each segment are found. Occasionally the weakly chitinized areas are quite large (queen white ant) and elastic. Usually the elasticity of these places, as for example, the portions connecting the segments, is rather slight. Spines, hairs, scales or other structures are often present on the chitin, sometimes entirely concealing its surface and its sutures.

The heads of different insects vary much in form and in the location of the mouth (Fig. 11). In some cases this is on the underside (see Fig. 10), while in others (Fig. 12) it is practically on the front. Heads with 
the mouth beneath are called hypognathous: those with it in front are prognathous.

Structures found on the head are a pair of antennæ, the two compound eyes, ocelli, and the mouth parts. On the thorax are the wings and legs; and on the abdomen are various organs such as the ovipositor, sting, cerci, styli, etc., present in some cases; absent in others.
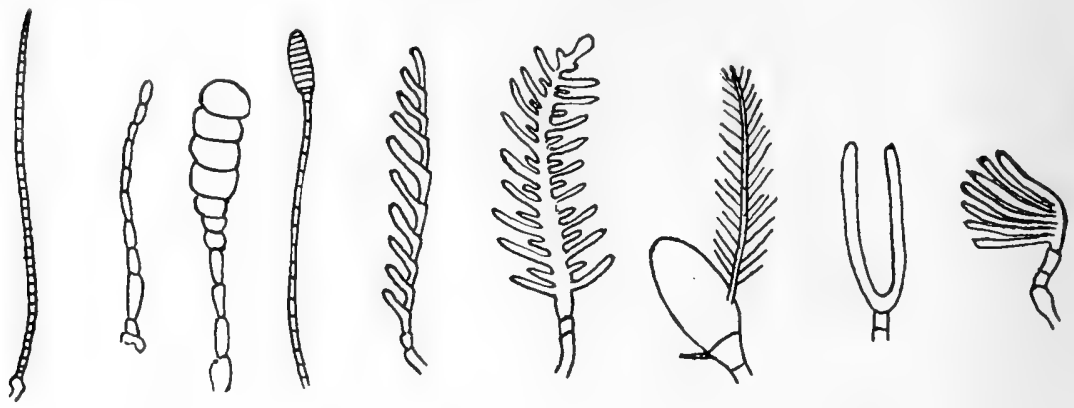

Fig. 13a.-Different forms of insect antennæ. (Original.)

Antenn:e are nearly always present. They are usually slender, jointed and therefore more or less flexible organs, varying greatly in the number of segments composing them. They are sometimes very short; sometimes long; often thread-like; sometimes enlarged near the tip; in many cases with fine branches either on one or both sides, so that they resemble

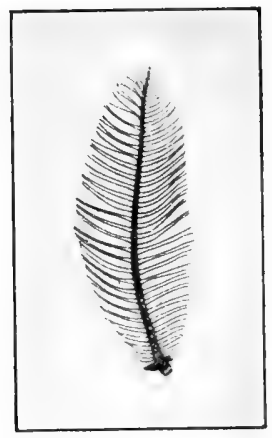

FI . $13 b$ - Antennæ of Cecropia Moth. (Samia cecropia L.) A bout twice natural size. (Original.) feathers or plumes; rarely they fork; in fact are of many forms (Fig. 13). Sense organs are present on them for the sense of touch, and probably also for smell and hearing, at least in some cases.

The eyes are of two kinds. There is a pair of compound eyes, each of which is a group of similar structures which usually are like tall, slender pyramids in form. Only the bases of these pyramids show on the surface; the remainder being within the head. The bases, closely pressed together, are usually more or less hexagonal, and their outlines can often be easily seen with a magnifying glass. They are called facets, and the eyes themselves are sometimes termed the facetted eyes.

The other kind of eyes, called ocelli, may be absent, or if present, may vary in number in different insects, three being perhaps the most usual. Each, as seen from the surface, is a nearly circular, convex spot about the size of one of the facets of a compound eye. It may be larger than this, but is never equal to an entire compound eye in size. In some cases a cluster of ocelli or of the pyramids of the compound eyes is found, not closely pressed together 
but somewhat separated, and such groups are called agglomerate eyes. The chitin of the surface of the body is transparent where it covers the surface of an eye, permitting access of light to the sensory structures within: elsewhere it is usually pigmented and rather opaque.

The mouth parts of insects vary extremely in their structure. Apparently the original mouth parts were for biting and chewing, and this type is very common. In some groups, however, they have been transformed into a sucking apparatus. Biting mouth parts, being the more
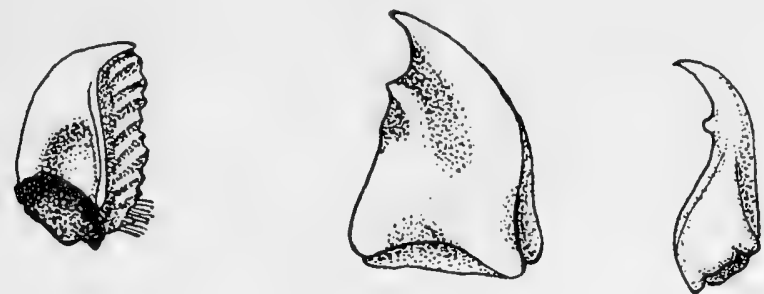

FIG. 14.-Three types of insect mandibles, greatly enlarged. Somewhat diagrammatic. (Original.)

primitive and simple, are described here, while sucking mouth parts having been differently transformed in different groups will be taken up in connection with those groups.

In front of (in hypognathous heads), or above the mouth opening (prognathous heads) is the front lip or labrum. It is a thin flap, hinged to the skeleton of the head and moves forward and backward. It is often more or less divided by a central notch at the middle of its free edge. Its inner surface, forming the roof of the mouth, is often called the epipharynx.

At the sides of the mouth opening, immediately behind the labrum, is a pair of jaws, the mandibles. These differ greatly in form in different insects (Fig. 14). They are often stout, heavy structures with crushing faces bearing blunt projections or teeth; sometimes they are long, curved and rather slender.
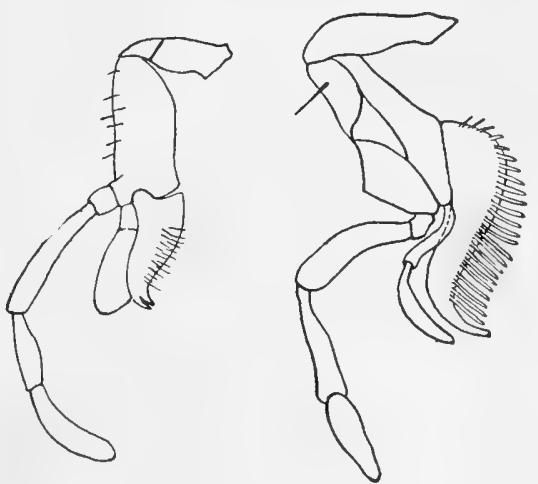

FIG. 15.-Two types of insect maxilla greatly enlarged. Somewhat diagrammatic. (Original.) In general their form is adapted to the feeding habits of the insect.

Immediately behind each mandible at the side of the mouth is a second appendage, the maxilla. This differs markedly from the mandible, being much weaker, and composed of a number of pieces (Fig. 15). The tips and outer internal margins of the maxillæ usually bear numerous 
spines or hairs, but this condition varies according to the nature of the food of the insect. Attached on the outer side of each maxilla not far from where the latter articulates with the head, is a sort of tiny antennalike structure consisting of from one to six (usually five) segments, which is called the maxillary palpus. The function of the maxillæ appears to be to hold and retain the food in the mouth while it is being worked upon by the mandibles, and also to aid these in breaking it up. The presence of sense organs on the maxillary palpi suggests that these are possibly concerned with the sense of smell. Both mandibles and maxillæ move sideways.
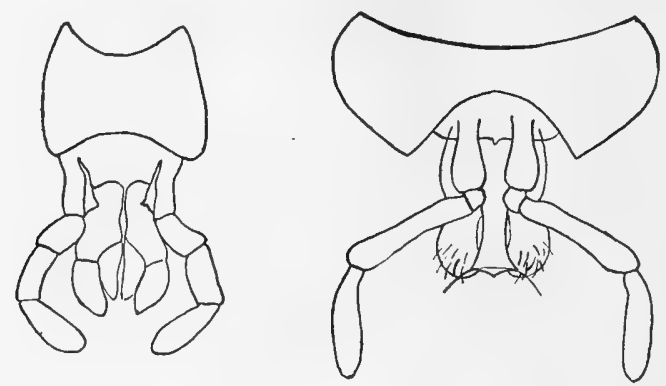

FIG. 16.-Two types of insect labium much enlarged. Somewhat diagrammatic. (Original.)

Behind the maxillæ and closing the mouth opening behind, is the hinder lip or labium (Fig. 16). This was evidently once a pair of jaws somewhat similar to the maxillæ, but with no mouth cavity between to separate them, their inner edges have grown together to varying degrees in different insects. In some, only one or two of the pieces nearest the head have fused: in others, fusion all the way to the tip has been accomplished, and all intermediate stages also occur, thus producing a structure which now moves forward and backward like the front lip, but which may be complete, partially, or almost entirely cleft in the middle line.

Like the maxilla the labium has a palpus on each side arising from near its base, and composed of three (rarely four) segments. The function of these labial palpi appears to be similar to that of the maxillary palpi.

Near the base of the labium on its inner or mouth side there is frequently a fleshy swelling more or less covered by bristles or hairs, which is called the hypopharynx, lingua or tongue. It varies greatly in size and form.

The thorax has its three segments usually quite clearly marked. Each segment bears a pair of legs, but the prothorax, or first of the three behind the head, bears no wings. On the second or mesothorax, and on the third or metathorax, both wings and legs occur in the majority 
of insects. There is a tendency in some groups, carried farthest in the higher Hymenoptera, for the first segment of the abdomen to consolidate more closely with the metathorax than with the second abdominal seg-
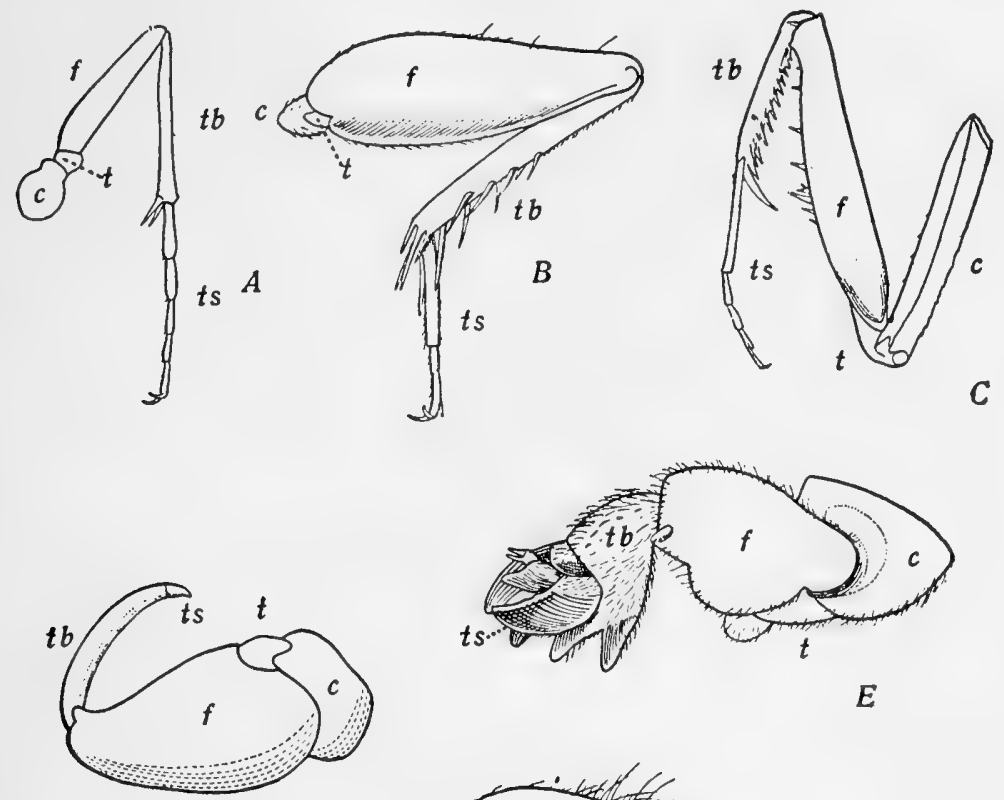

E
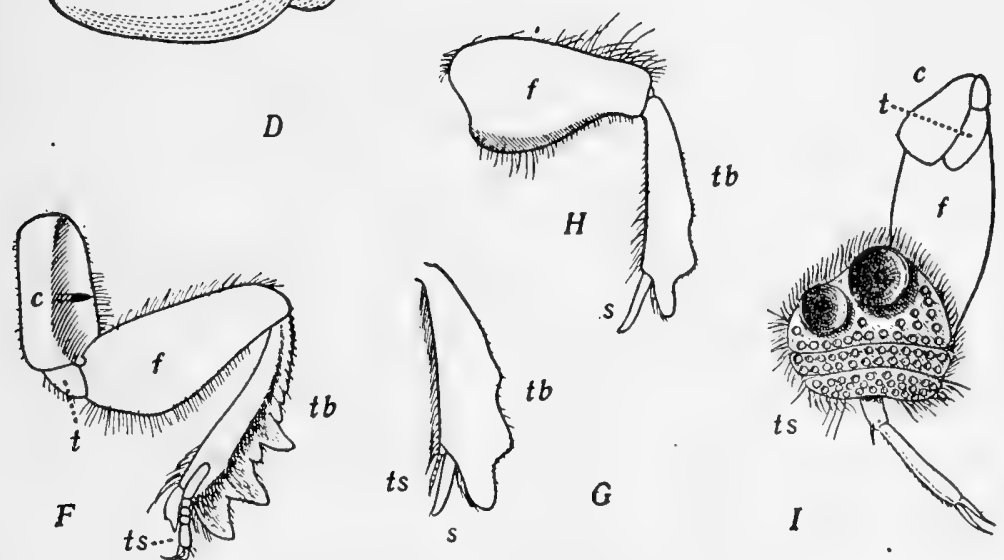

FIG. 17.-Different forms of insect legs. $A_{1}$ Cicindela sexgullala Fab. (beetle); $B$, Nemobius fasciatus De G. (cricket) hind leg; $C$, Stagomantis carolina L. (Mantis) fore leg; $D$, Pelocoris femoratus P. B. (carnivorous bug) fore leg; E, Gryllotalpa borealis Burm. (mole cricket) fore leg; $F$, Canthon lavis Dru. (a digging beetle) fore leg; $G$, Phancus carnifex L. (a digging beetle) fore tibia and tarsus of female; $H$, same, fore tibia of male; $I$, Dytiscus fasciventris Say, male (water beetle) fore leg; $C$, $\operatorname{coxa} ; f$, femur; $s$, spine; $t$, trochanter; $t b$, tibia; $t s$, tarsus. (From Folsom.)

ment, which in such cases is often slender and gives thereby a semidetached appearance to the rest of the abdomen, as though the line of division between thorax and abdomen were at that place instead of 
farther forward. The first abdominal segment when seemingly more a part of the thorax than of the abdomen is called the median segment or propodeum.

The three pairs of legs may be quite similar, or differ widely, according to the uses to which they are put. In running and walking insects they are usually most similar; but when for example, the fore legs are used for capturing other insects, their form will depart greatly from that of the others. The jumping power of the grasshopper is

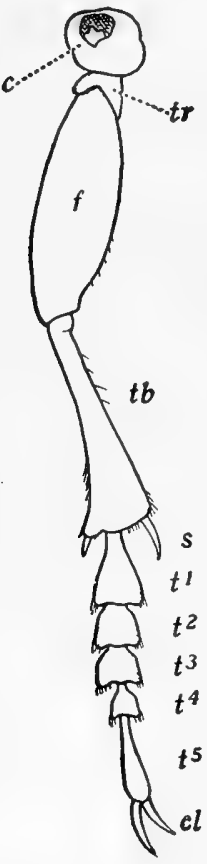

FIG. 18.-Leg of a Beetle showing parts. c. coxa, $c l$, claws; $f$, femur; $s$, spine or spur; $t^{1-} t^{5}$, tarsal segments; $t b, \mathrm{tibia}$; tr, trochanter. (From Folsom.) due to the great development of its hind legs as compared with its others. Different types of legs are shown in Fig. 17.

Whatever may be the variations in form and details of the legs, all are composed of a definite number of pieces or segments, connected by hinge joints so arranged that by combining the motions of these, a leg can be placed in nearly any position desired.

The leg (Fig. 18) is composed of a coxa, a trochanter (two in a few cases), a femur, a tibia and a tarsus. The last is really not a single segment but a row of from one to five, small, and on the whole rather resembling each other.

The coxa is the segment which articulates with the body, frequently partly lying in a more or less cup-shaped hollow of the latter. It may be short or long, is generally freely movable on the body, and powerful. The trochanter is usually small and may not be visible on all sides of the leg. It is followed by the femur, generally the largest and stoutest, but not often the longest leg segment. The tibia is in most cases quite long, more slender than the femur, and often provided with downwardly projecting spines or other structures which are of assistance to the insect in climbing plant stems and other objects, to help prevent slipping. The tarsal segments are generally rather small, short, tend to be broadest at their outer ends, and vary greatly in details of structure. At the end of the last a pair of claws is generally found, and between them a sort of pad or cushion, the pulvillus. Sometimes there are three of these, in which case the outer ones are called the pulvilli and the middle one the empodium. Where the tarsi are reduced to a small number of segments, only one claw may be present.

The wings are chitinous outgrowths from the body which vary much in size and form in different insects. Each consists of two delicate 
membranes in contact with each other except along certain lines (Fig. 19). Along these lines each membrane thickens and also rises above the general surface, so that if the two membranes could be separated and examined from the inner surface, they would appear uniform except for grooves with thickened sides and bottoms, running here and there.

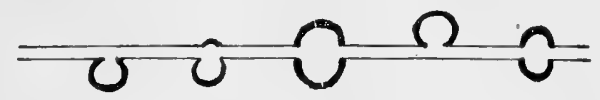

FIG. 19.-Diagram of cross-section of an insect wing showing the two membranes somewhat separated and the ways in which the veins are formed. (Modified from Woodworth.)

When the membranes are brought together again, these grooves combining form hollow rods which, being stronger than the rest of the membrane, serve as its support and hold it stiff. These hollow rods are usually called veins or nerves, though they are nothing of the sort. The main and largest veins arise at the base of the wing and extend outward, diverging as they go, and some branch several times before they

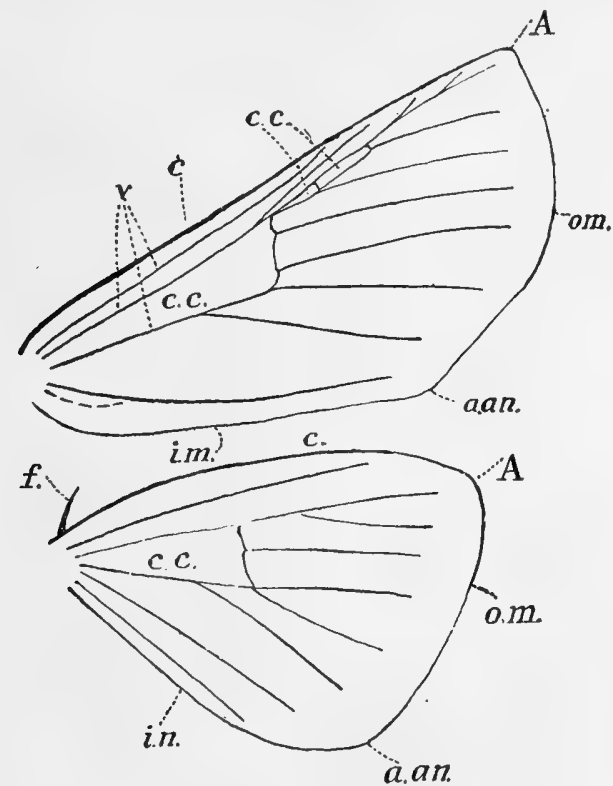

FIG. 20.-Diagram of the margins and veins in the wings of moths. A, apex; $a$. an, anal angle; $c$, costa; $c . c$., closed cell; $f$, frenulum; $i . n$, inner margin; $o . m$, outer margin; $v$, vein. (Original.)

reach the wing margin (Fig. 20). Cross veins also occur, connecting the radiating main veins or their branches. Areas of membrane between veins are termed cells and where entirely surrounded by veins are called closed cells. These may be relatively few or many, according to the number of veins and their branches present. The arrangement and number of the chief veins and their branches are of importance in identifying insects. 
There is usually a point or tip called the apex, somewhere along the margin of the wing, though frequently the outline is so rounded that the exact apex is uncertain. The front margin of the wing from where it joins the body to where the edge begins to turn backward (in an extended wing) is called the costa.

Wings are entirely absent in some groups of insects, and it is probable that these are the direct descendants of the earliest forms, before wings were developed. In other cases where they are absent this is associated with a parasitic life where wings might be a distinct disadvantage, or with peculiar habits which would render them useless or even inconvenient, and in such cases they appear gradually to have become lost. In the flies the hinder pair is modified, forming small structures not wing-like, called halteres.

The abdomen does not usually show great differences in its segments except those near the hinder end, which may be modified for various purposes. Generally a dorsal plate and a ventral plate are the only two skeletal plates evident in a segment. Small openings, usually a pair in each, or at least in most, of the segments are the openings of the breathing organs, and these also occur on some of the thoracic segments where they are ordinarily less noticeable than on the abdomen.

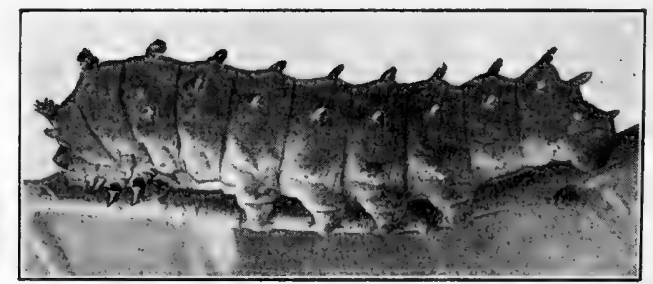

Fig. 21.-Larva of Cecropia Moth showing abdominal legs. Two-thirds natural size. (Original.)

Legs are very rarely present on the abdomen in adult insects, but are often found in the earlier stages (Fig. 21). At the end of the abdomen in the females of those insects which lay their eggs within objects, is a combination of pieces known as an ovipositor. It usually consists of about three pairs of parts, long or short, slender or stout as the case may be, for the purpose of making a hole or sawing a slit in the object in which the eggs are placed and in guiding the eggs into the hole thus made. In one group which has apparently changed its habits and no longer needs to make holes for egg laying, the ovipositor being unnecessary for this purpose, has been transformed into a sting.

A pair of many-segmented, antenna-like structures, sometimes short, sometimes long may occur at the end of the abdomen, and these are called cerci. They probably serve as organs of touch, and possibly also of smell in some cases. 


\section{CHAPTER III}

\section{THE INSECT : ITS INTERNAL STRUCTURE}

Few of the internal structures of insects are of any great importance from the standpoint of control methods, but some knowledge of them and their arrangement is desirable.

Digestive Organs (Fig. 22).-The alimentary canal extends from the mouth through about the center of the body to the anus at the hinder end. In those insects whose food is most concentrated (Fig. 23), it is in its simplest form and is but little if any longer than the body. In those which feed on less concentrated food (Fig. 24), the necessity for a greater digestive and absorptive surface has resulted in an increase of its length and the accommodation of this within the body by the production of loops and coils.

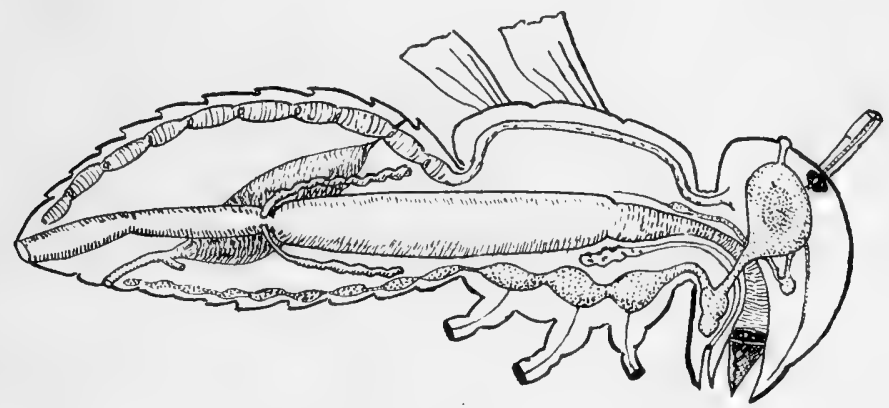

FIG. 22.-Diagrammatic longitudinal section of an insect to show the arrangement of the internal organs. (After Berlese.)

In the embryo the alimentary canal forms as three separate sections which connect later. One of these is an ingrowth from the surface where the mouth is to be; another and similar ingrowth occurs where the anus forms; and a third forming earlier than the other two, arises as two masses of cells, one near each end of the embryo, which move inward and toward each other, unite, and surround the yolk. Later, when this has been absorbed, a space is left with which the two ingrowths already mentioned connect, the hollow centers of all three joining to form the tube through which the food travels. The ingrowth from the mouth is usually called the fore-intestine, the central portion the mid-intestine, and the ingrowth from the anus the hind-intestine. The first and last 
of these begin to grow inward from the surface of the body after that surface has begun the formation of its chitinous exo-skeleton, and accordingly also have this power, and line the inside of the parts of the canal which they form, with chitin. In that portion of the canal termed the mid-intestine, however, this power does not appear to be present, and the mid-intestine is without this lining.

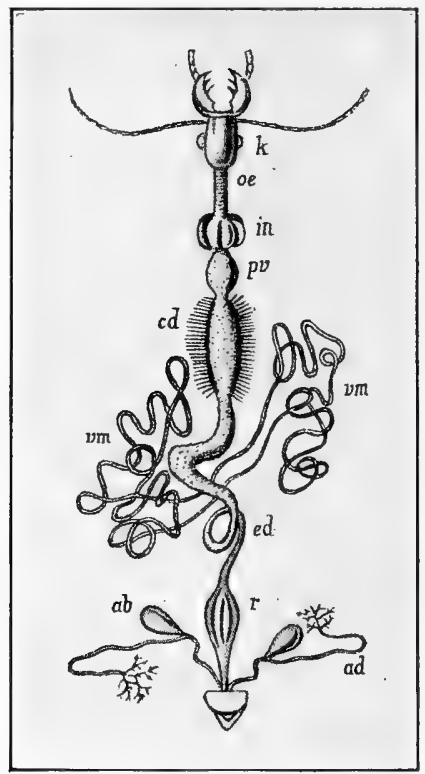

FIg. 23.-Alimentary canal of a Carnivorous Beetle. ad, anal glands; cd, stomach; $c d$, hind intestine; $i n$, crop; $k$, head and mouth parts; $\infty$, œsophagus; $p v$, proventriculus; $r$, rectum; rm, malpighian tubes. (Modified from Lang's Lehrbuch.)

The mid-intestine forms the. stomach of the adult insect; the fore-intestine forms those parts of the alimentary canal from the mouth to the stomach; and the hind-intestine those from the stomach to the anus. Each of these sections may sometimes have portions differing in structure, producing a greater or lesser number of subdivisions. Thus the fore-intestine, by differences of structure, may sometimes consist of a mouth cavity, oesophagus, crop and proventriculus: the stomach may develop side pouches or gastric caeca; and the hind-intestine is often separable by differences of structure into an ileum, colon and rectum.

Lined as these parts are by chitin which often bears rough, tooth-like projections and spines, some persons have suggested that in insects where these structures are present in the fore-intestine, the food is masticated more thoroughly and mixed with digestive juices before it reaches the stomach. In the stomach digestion is probably completed and absorption at least begun, but the length of the hind-intestine in many insects 
suggests the idea that absorption in those cases has not been completed when the food leaves the stomach but continues in the hind-intestine.

Opening into the mouth is a tube leading to the salivary glands, which generally lie in the front of the thorax and appear to have a similar function to those in man. In some cases other glands for different purposes are also present in the head or front of the thorax and open into the mouth.

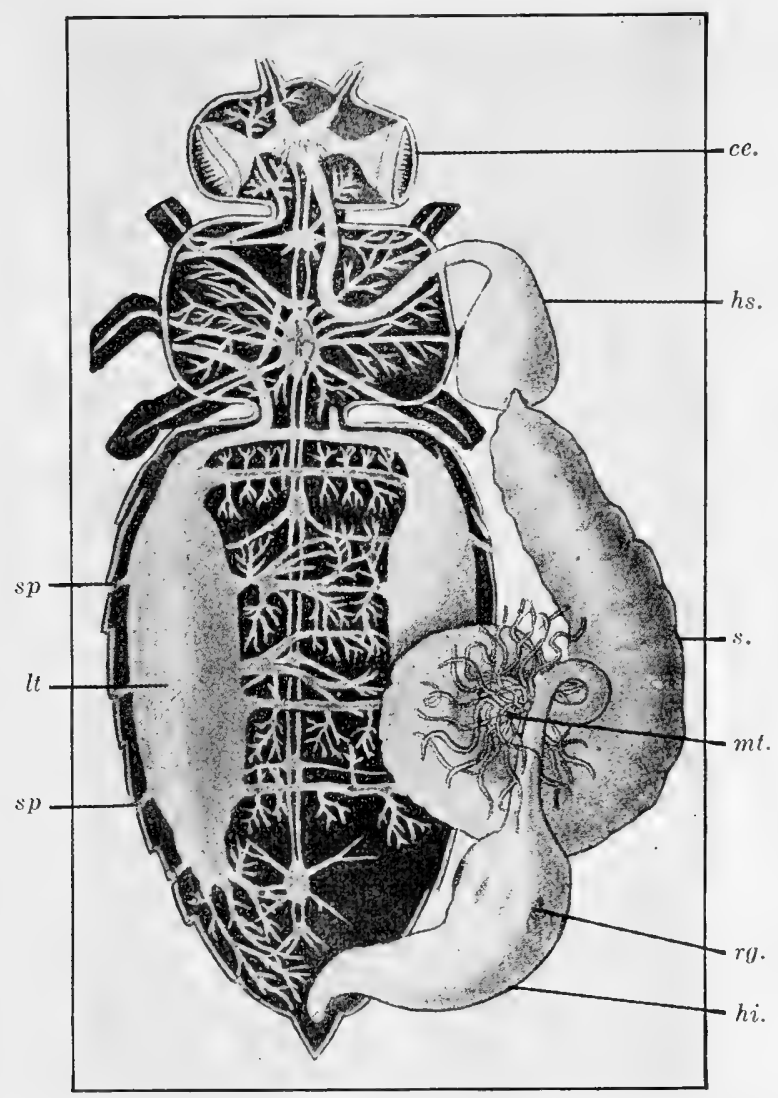

FIG. 24.-Internal anatomy of the Honey Bee showing alimentary canal, tracheal and nervous systems. $c e$, compound eye; $h i$, hind intestine; $h s$, honey sac; $l t$, lateral trachea (enlarged); $m t$, malpighian tubes; $r g$, rectal glands; $s$, stomach; sp, spiracles. (Modificd from Leuckart's Wandtafeln.)

Some of the poisons used in control measures are swallowed by the insect, passing to the stomach and there are dissolved by the digestive juices. Thus dissolved, they set up inflammation of the stomach walls and finally cause death. Poisons acting in this way are called "stomach poisons."

Breathing Organs.- Respiration in insects is accomplished by a method which is nearly unique. The oxygen needed, instead of being 
drawn into lungs and there being taken up by the blood and carried to the parts of the body where it is needed, as in man, is carried directly to those parts by a system of air tubes which open along the sides of the body (Fig. 25). Here the air enters the tubes and proceeds through them to where it is utilized. The openings by which the air enters are

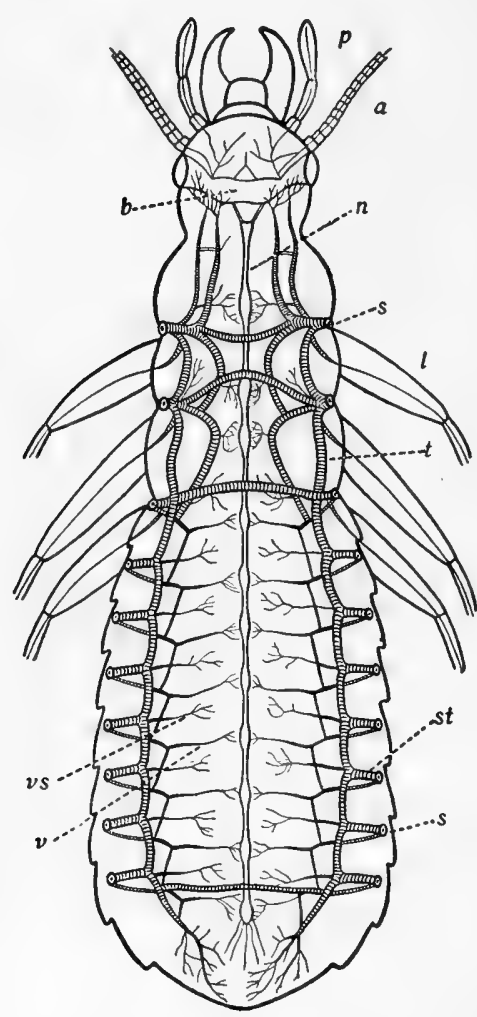

FIG. 25.-Diagram showing arrangement of the main tracheal tubes in an insect. $a$, antenna; $b$, brain; $l$, leg; $n$, nerve cord; $p$, palpus; $s$, spiracle; st, branch from main lateral trunk, $t$, to spiracle; $v$, ventral branch; $v s$, visceral branch. (After Kolbe, from Folsom.) called spiracles, and these occur in pairs on some of the thoracic and most of the abdominal segments, varying somewhat in number and in position on the segment in different insects. The spiracles often have valves by which they can be more or less completely closed at will.

Each spiracle opens into a short tube or trachea which, with the others of that side, soon joins a similar tube running along the side of the body and quite close to its surface. From these longitudinal tracheæ, branches pass off in various directions, and in turn branch again and again until every part of the body is reached by its air supply. The tracheæ frequently enlarge here and there, forming so-called air sacs.

The tracheæ are lined by chitin connected with that of the surface of the body. In these tubes, however, it is formed with spiral thickenings which act like a spring, keeping the tracheæ open when not under pressure. There is probably considerable pressure on them in different places by the movements of various parts of the body in walking and other activities, as well as by regular respiratory movements, and the resulting temporary variations in diameter aid in the circulation of air in these tubes.

Not only are the tracheæ of use in carrying oxygen to all parts of the body, but they also receive the carbon dioxid gas produced by the activities of the cells and permit it to escape through the spiracles from the body, thus performing both of the functions which the blood, so far as gases are concerned, accomplishes in man. Blood then, in insects, does not (except in a few cases perhaps) have a respiratory function.

The destruction of insects by fumigation is accomplished by the substitution of a gas destructive to life, for the air, and this gas enters the 
spiracles and follows along the tracheæ to the living tissues, which take it in place of the oxygen usually received in this way, and are killed.

It was formerly supposed that certain materials called contact insecticides which kill insects by contact with their bodies, caused death by entering the spiracles and closing them up, thus producing suffocation. 'This has now been proved to be incorrect.

Insects which in their early stages live in water, cannot of course breathe air into their bodies through spiracles during that period of their lives. These are closed in such cases and the animal obtains air usually through special structures called tracheal gills. These will be described in connection with the insects which possess them. In a few small water-inhabiting forms, the chitin covering the surface of the body is so thin that oxygen present in the water can pass directly through it into the body and to the parts there which need it, and carbon dioxid passes in the reverse direction.

Circulatory Organs.--Insects have only an incomplete system of blood vessels. A tube lies in the middle of the body close beneath the back, beginning near the hinder end of the animal and extending forward into the head (Fig. 26). In the abdomen this tube is constricted, forming chambers, and the chambered portion is called the heart. There is a pair of openings on the sides of each chamber through which blood can enter, and valves there which prevent its going out again. The walls of the heart contain muscles and these contract one after the other, forming a sort of wave of contraction which begins at the hinder end and travels forward. Blood in the heart, being unable because of the valves, to pass out at the sides, is pressed forward by this contraction wave, and at the front end of the heart finds itself in a tube without chambers or valves, called the aorta, through which it is led to the head where the aorta may divide into a few short branches or may be unbranched. In either case, at this point the blood pours out of it into the body, the system of blood vessels coming to an end. There is now no definite and particular path for the blood to follow, but it would, in theory at least, remain near where it escaped from the aorta, or gradually pass into any spaces it might find unoccupied between the different structures in the head. With each heart-beat, however, more blood is poured out of the aorta, increasing the pressure upon that already in the head. It therefore is gradually forced backward and to other parts of the body, each particle probably taking the path where there is least resistance to its passage. In this way a general backward direction is given to the flow.

As it approaches the heart, another influence appears. During each contraction of the heart, it occupies less space, which leads to less than normal pressure near it, and blood close by naturally flows closer to it. Upon its expansion again and the opening of its valves, the direction of least resistance is now through the valves and into the heart.

As the blood passes back through the body, a given particle may at one circuit go over certain organs and at the next, over entirely different ones. All the internal organs, however, have their surfaces bathed by blood and this as it passes over the stomach or other parts of the alimentary canal will pick up any 
food which having been digested has passed through the canal walls. Likewise in passing over any organ needing this food, it is given up to those organs. The blood therefore serves as a distributor of food from the place where it is digested to all the parts which need it.

We have already seen that the living parts of the body-the cells-need oxygen, and as the result of their activities give off carbon dioxid gas, but that this exchange is accomplished by the aid of the tracher. In a somewhat parallel way, the cells which need food obtain it from the blood. The cells by their

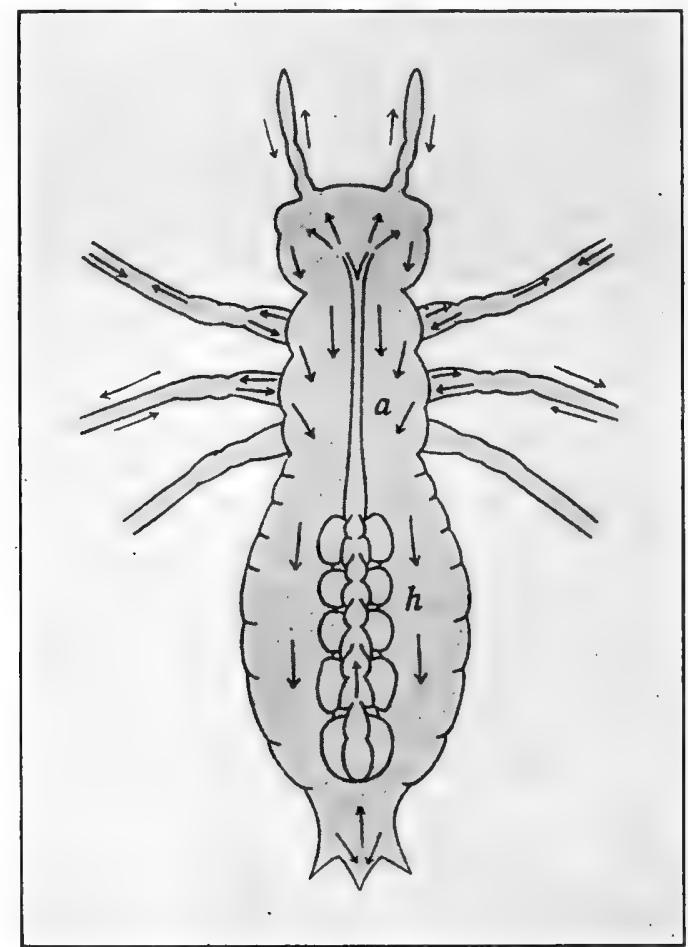

FIG. 26.--Diagram showing by the direction of the arrows the general course of the blood flow in a Dragon fly nymph. $a$, aorta; $h$, heart. (Modified from Kolbe.)

activities produce not only carbonic acid gas but also waste material nitrogenous in nature which must be removed like all wastes, from the body. This nitrogenous waste is picked up at the cells by the blood and carried along, perhaps for some time before a place to dispose of it can be found. Sooner or later, however, a particle of blood containing this waste material will wash over certain structures called Malpighian tubes, to be described in the next section, and the cells which form these tubes have the power to collect this waste material from the blood as it flows over them, thus purifying it.

The blood itself is usually a colorless (though sometimes yellowish, reddish or greenish) fluid, in which are corpuscles resembling the white corpuscles of human blood. It appears to serve to carry food to the tissues, and waste matter from them, and therefore has no need of structures in it like the red blood corpuscles of man, the work of which in insects is done by the trachex. 
Excretory Organs.- The organs which eliminate the nitrogenous wastes from the body and correspond in function to the human kidneys, are known as Malpighian tubes. These are blind-ended tubes, the walls of which consist of a single layer of cells surrounding a central channel which at one end opens into the hind-intestine, usually near its front, just behind the stomach (Fig. 27). When blood containing nitrogenous waste matter washes over the outer surface of a Malpighian tube, the cells of which it is composed have the power of taking this matter out of the blood into their own substance and passing it through themselves into the channel between them, down which it moves until it enters the mid-intestine, from which it is finally expelled at the anus.

The Malpighian tubes may be few or many; long or short (see Figs. 22, 23, 24). They show a tendency to collect in groups and to unite near the hind-intestine, so that their outlets into this are much fewer than the number of tubes. It seems possible that a certain amount of poison entering the body by way of the stomach can be eliminated by the Malpighian tubes, which may explain the varying degree of resistance to such poisons by different insects.

Nervous System.-The nervous system of insects is located along the middle line of the body quite near its under surface (Fig. 22). As in animals generally, it is composed of cells and fibres. The former are for the most part gathered together in clusters which are called ganglia, and from each of the cells in a ganglion, one or more nerve fibres

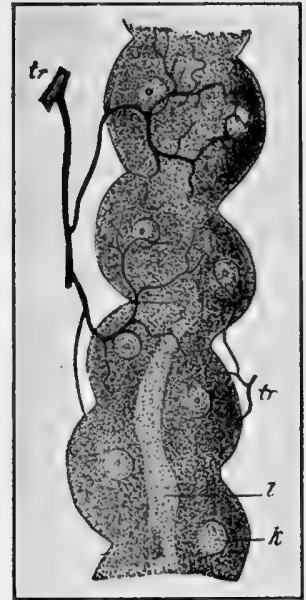

Fig. 27.-Portion of the Malpighian tube of a fly, greatly enlarged. $k$, c ell nucleus; $l$, lumen of the central canal; $t r$, tracheæ. (Modified from Gegenbaur.) pass out, either to connect with some other nerve cell or with some structure of the body. The larger nerves are really bundles of these fibres running side by side like the wires of a telephone cable.

Apparently each segment of the insect body once had a nerve ganglion, but with the fusion of the segments, many of these have also fused, reducing the separate ganglia in adult insects to a smaller number, which varies in different kinds. This fusion has been produced by the hinder ganglia moving forward until in some cases none are found in the abdomen. Different degrees of this are shown in Fig. 28.

Each ganglion is connected to the one in front and the one behind by one or two bundles of nerve fibres which are called commissures. Each consists of numerous fibres and these taken together form the means of communication between the different parts of the system.

In the head, in front of or above the osophagus, is the largest ganglion of the body, called the brain, produced by the fusion of several ganglia. In addition to its two commissures, which connect it with the ganglion next behind, it has nerves which lead to the eyes, to the antennæ and to other parts of the front of the head. 
Below or behind the osophagus is a second ganglion, also in the head, called from its position the subœsophageal ganglion. As the œsophagus lies directly between this and the brain, the commissures connecting the two do not lie close together, but separate far enough to permit the œsophagus to pass between them. The subœesophageal ganglion besides being connected with the brain in front, and the first thoracic ganglion behind it, by commissures, sends nerves to the mouth parts and other nearby regions of the head.
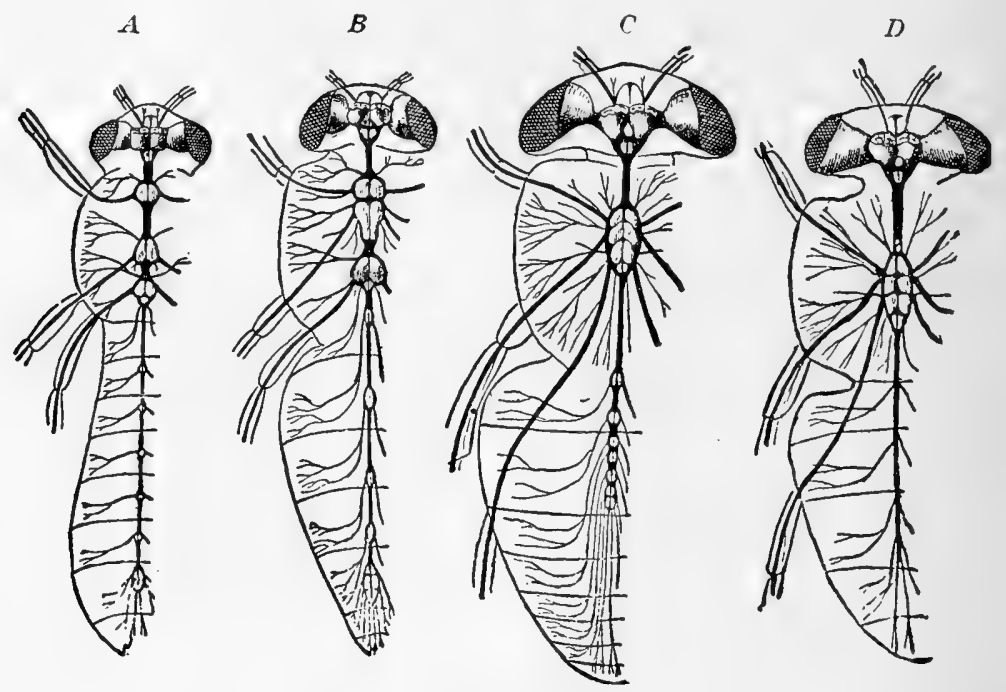

FIG. 28.-Diagram showing various degrees of concentration forward of four species of flies. A, of Chironomus plumosus, little concentrated; B, Empis stercorea; C, Tabanus bovinus; D, Sarcophaga carnaria, most concentrated. (After Brandt, from Lang's Lehrbuch.)

The thoracic ganglia may be more or less separate or fused and may have fewer or more of the abdominal ganglia added. Commissures, however, connect all separate ganglia, and these also send out nerves to all the parts of the segments to which they belong, no matter what their final location may be. In this way, the wings, legs, muscles and other parts receive their nerve supply. A small "sympathetic nervous system" also present, appears to be concerned chiefly with the nerve supply of the alimentary canal and trachex.

Sense Organs.-All the more evident senses possessed by man appear to be present in insects, but not in all cases in the same individual. Thus some caveinhabiting insects have no eyes. It is at least probable that insects may have other senses not possessed by man.

Reproductive Organs.-Insects are of distinct sexes, male and female. In many cases, however, individuals occur, incapable of reproduction, their sexual organs not having become fully developed, and such insects may be termed neuters. Most of these appear to be really undeveloped females, though undeveloped males are also known. They are found in colonial insects where division of labor occurs, as in the honey bee, ants, termites, etc., and are known according to their duties, as workers, soldiers, 
or by other names. Conventional signs for the various forms of insects as a convenience, are: $0^{\top}$ male; ㅇf female; 9 worker.

In the female (Fig 29) the eggs are produced n a pair of ovaries located in the upper front part of the abdomen. Each is a cluster of ovarian tubes whose walls are cells. Some of these cells grow and separate from the others to lie in the central cavity of the tube and then pass downward, growing till they reach its hinder end, which connects with the similar ends of all the ovarian tubes of that side to form a single tube called the oviduct. This extends downward and back-

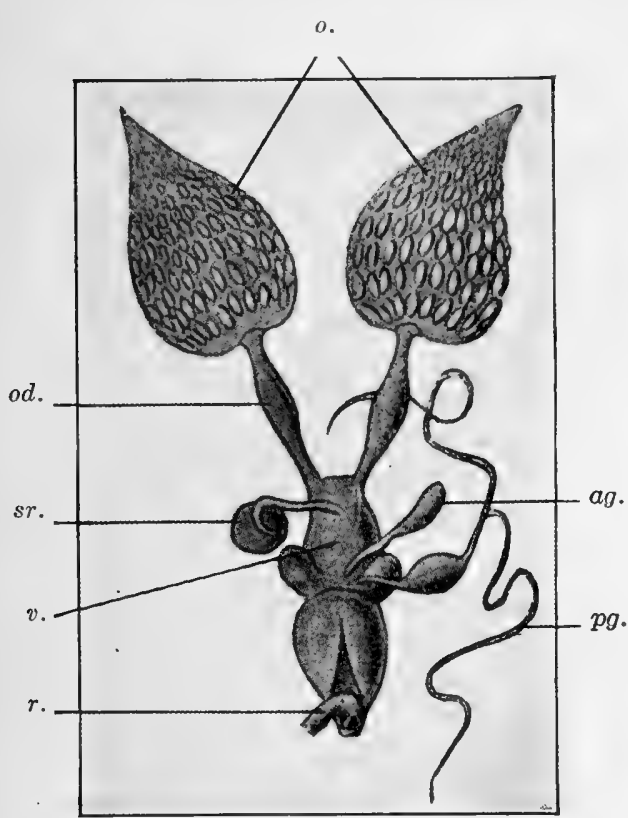

FIG. 29.

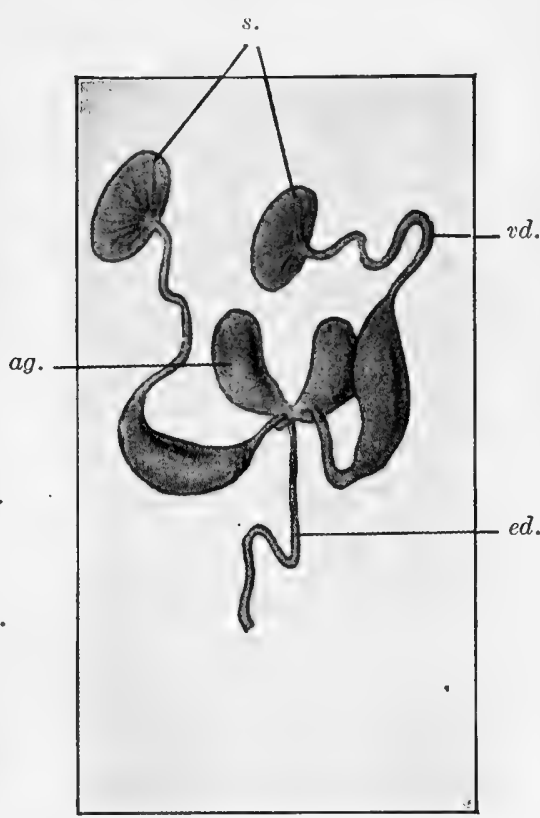

FIG. 30 .

FIG. 29.- Female reproductive organs of Honey Bee (Apis mellifera L.); ag, accessory gland; $o$, ovaries; od, oviduct; $p g$, poison gland; $r$, rectum, cut off and end bent back; $s r$, seminal receptacle; $v$, vagina. (Modified from Leuckart's Wandtafeln.)

FIG. 30.-Male reproductive organs of Honey Bee (Apis Mellifera L.); ag, accessory gland; $e d$, ejaculatory duct; $s$, spermaries; $v d$, vasa deferentia. (Modified from Leuckart's Wandtafeln.)

ward around the side of the alimentary canal, below which it joins with a similar oviduct from the other side of the body to form a single duct, the vagina, which lies below the alimentary canal, and extends backward to its outer opening which is located in most cases, in front of the next to the last abdominal segment. Surrounding this opening may be external structures (an ovipositor) for the purpose of together making holes in some object (the ground, wood, etc.) in which to deposit the eggs. A side pouch (seminal receptacle) connected with the vagina is for the storage of the sperms wh ch fertilize the eggs; a gland producing material which forms the egg shell and is known as the shell gland, also opens into this portion, and other glands similarly connected with the vagina, may also be present. 
In the male (Fig. 30) the arrangement of the organs closely corresponds to that in the female. A pair of spermaries or testes is present in the upper front part of the abdomen, each consisting of a rather closely-coiled mass of tubes, in which the sperms are produced. The tubes on each side unite to form a single tube, the vas deferens. These differ from the oviduct usually, in being much longer and coiled or twisted. They pass downward and backward, however, and unite on the middle line of the body below the alimentary canal, forming a single tube, the ejaculatory duct, corresponding to the vagina in position, which leads backward to an opening in front of the last segment. An enlarged portion of the vas deferens is often present, for the temporary storage of the sperms, and is termed the seminal vesicle. Accessory pouches opening into the ejaculatory duct appear to be in part at least, for the production of mucus and secretions to mix with the seminal fluid. 


\section{CHAPTER IV \\ THE DEVELOPMENT OF INSECTS}

Most insects lay eggs which hatch after a longer or shorter time into the young. In some cases the egg appears to be retained within the body of the parent until after it has hatched, and then the young are produced in a stage able to move about. Insects in which this is true are termed viviparous, the others being oviparous.

Insect eggs are usually very small; vary greatly in form, and may be laid singly or in clusters (Fig. 31). They are covered by a chitinous shell, the chorion, which often bears markings in the form of ridges,
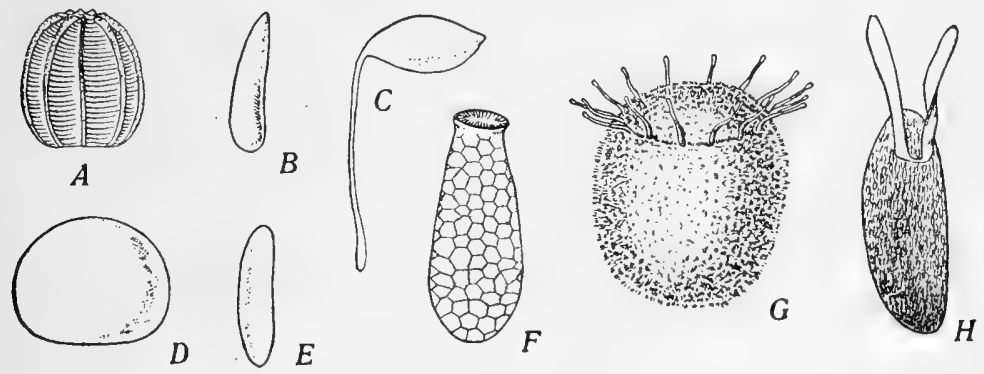

FIG. 31.-Eggs of various insects. $A$, butterfly; $B$, house fly; $C$, chalcid (Bruchophagus); $D$, butterfly; $E$, midge; $F$, bug (Triphleps); $G$, bug (Podisus); $H$, Pomace fly. All much enlarged. (From Folsom.)

reticulations, etc., and frequently they are also colored. At one place on the surface is a minute opening or group of openings through the shell, called the micropyle, believed to be for the entrance of the fertilizing sperm. The length of time spent in the egg differs in different insects from a few hours to many months, and in some cases the eggs do not hatch until the second season after they are lair.

In hatching, the shell breaks and out of it crawls the young insect, in the majority of cases quite unlike the adult it is to become. In order to reach maturity it must now grow, and undergo changes in structure and appearance. These together are expressed by saying that most insects in order to become adult undergo a metamorphosis. In some of the simpler insects, a few changes and growth only, are needed to make them mature, and these are therefore usually grouped together as the Ametabola, or insects having practically no metamorphosis. 
The remaining insects, from this standpoint, form two groups: those which on hatching show some resemblance to the adults and reach maturity by a certain series of changes; and those which on hatching are totally unlike the adults and attain that condition in a different way. These groups are known as the Hemimetabola or Heterometabola, and the Holometabola respectively, these names suggesting the amount of metamorphosis required for members of each group to become adult.

A member of the group Ametabola, upon hatching, will begin to feed and grow. Growth, however, is restricted because the insect is enclosed by chitin which, while elastic to some extent, at least at its thinner portions, has its limitations in this regard. In some cases the insect is able to reach its adult size within the chitin, but in other cases this proves impossible, and a process called molting takes place. This is begun by pouring out of fluid by the outside layer of living cells, the hypodermis, between it and the chitin, separating the two. Next a split in the chitin appears somewhere, usually along the back, and the insect crawls out of its skin, i.e., molts. It is now soft and unrestricted by an outer shell and grows rapidly. A new chitinous shell begins to appear and is completed in a short time (within a day or so) and thereafter only such growth is possible as the elasticity of the new shell will permit.

In most of the Ametabola, molting as thus described is not usual, the shell being sufficiently thin to stretch the amount needed for growth to adult size, though sometimes two or even three molts may occur. In both cases, however, the reproductive organs appear not to be mature at the time of hatching, and only gradually become so during the period following. In a few cases molting seems to occur at intervals throughout life.

In the Hemimetabola (or Heterometabola) the young insect on escaping from the egg, though resembling its parent to some extent, must nevertheless undergo many changes in structure and a considerable increase in size as well, before reaching maturity. Thus a young shorthorned grasshopper, on hatching, will need to grow to be about ten times as long before becoming adult; it is without wings, which will need to be developed; its reproductive organs are not mature and must become so, and other differences occur. All of these must be transformed into their condition in the adult, and to accomplish this, energy is necessary. In the egg the energy for development had been provided by the yolk: after hatching the young insect must provide it by gathering food.

The young insect therefore, soon after hatching seeks for food, and having found it begins feeding. The nourishment thus obtained results in growth so far as this is possible within a shell which is tightly fitting and only to some degree elastic. When no further growth in this way can occur and the body has stored within it all the materials needed for a greater increase in size, it proceeds to molt in the manner already de- 
scribed for the Ametabola. On escaping from its old skin or shell, however, besides a rapid increase in size, changes of structure also occur, so that a difference in appearance now becomes evident. These changes must be produced quickly, as the hypodermal cells of these parts, as well as of all the surface, are producing a new chitinous skin, and when this has once hardened, no further changes and little further growth are possible. Molting then, marks the beginning of a brief period-a day, more or less - of increase in size and of changes in appearance, these last all being in the direction of making the young insect more nearly like the adult it is to become. When the new shell has become hardened the insect resumes its feeding.

After another feeding period the young insect is again confronted with the same difficulties as before, and it meets them in the same way, by molting, and immediately thereafter, before its new shell has hardened it seizes the opportunity to grow and change its appearance further. Finally, after some molt, full adult size for the insect is attained and all its organs have also fully developed and matured, producing the adult insect itself.

Thus the young insect becomes an adult by alternating periods of feeding, with brief periods of molting, following which growth and change take place, the total of which produces the adult.

The number of molts and consequent opportunities for change which occur, varies in different Hemimetabola. There may be only two or three in some kinds: five is perhaps the average number though more are not uncommon, and 21 are known to occur in one species.

Certain names for these different conditions are convenient for use.

The feeding periods between the molts (or ecdyses) are called instars, so that the progress of an insect from hatching to adult is by an alternation of instars and molts. The insect itself, from hatching until maturity is generally called a nymph. Figure 32 shows the changes in size and appearance of a grasshopper after each molt.

With the remaining group of insects, the Holometabola, while there is a little similarity in the metamorphosis to that in the Hemimetabola, there are also many differences.

When a young Holometabolous insect hatches, it in no way resembles its adult. A caterpillar is totally different in appearance from the butterfly it finally becomes: the white grub in the earth is in no way suggestive of the June bug (May beetle) into which it transforms. Nevertheless it has to meet the same problems of growth and transformation to the adult condition as do the Hemimetabola, and uses the same means for accomplishing the needed results, viz., the utilization of the energy derived from its food.

Accordingly, upon hatching, in the Holometabola, a feeding period or instar comes first, followed by a molt and growth. At this point the 
story of the metamorphosis differs from that of the Hemimetabola, for after the molt no change in appearance to make the young insect more nearly like the adult takes place. It may be different in some regards besides size, from what it was before the molt, but these differences do not increase its resemblance to what it finally becomes. This holds throughout the feeding period of its existence, so that after three, four or more molts, a caterpillar is still a caterpilar, a grub is still a grub, and this is equally true for all Holometabolous insects. Within the insect during this period, however, changes not perceptible on the surface are taking place, by the construction of portions of the adult which are forming as

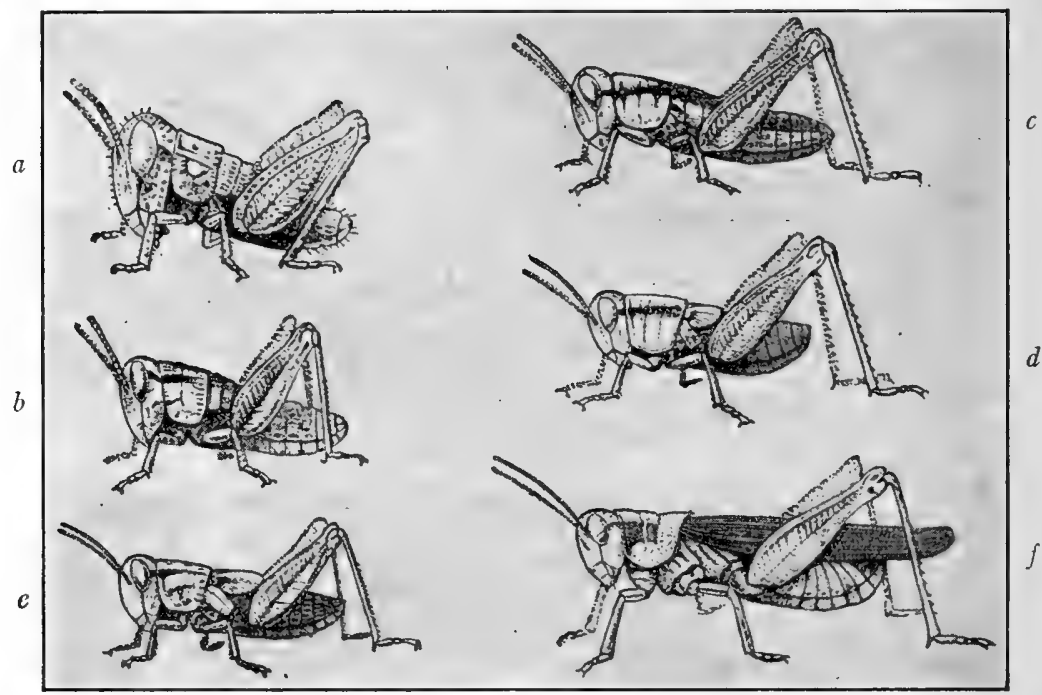

FIG. 32.-Incomplete metamorphosis of a Grasshopper. $a$, first nymphal instar; $b$, second instar; $c$, third instar showing beginning of wings; $d$, fourth instar; $e$, fifth instar; $f$, adult. Figures not drawn to same scale. (Modified from Packard's Text-book of Entomology by permission of the MacMillan Company, Publishers.)

buds or ingrowths from various parts of the body, and are termed imaginal buds (from "imago," the adult). They are closely compacted and many at least are infolded somewhat like buds, becoming finally ready to open when the proper time comes. And during its feeding instars, the larva, as the young insect in the Holometabola is called, is not only storing energy from its food for its growth at each molt, but also to carry it on through a period yet to be described, during which it must transform into the adult condition while unable to feed and obtain the energy needed for this purpose.

After a varying number of feeding instars and molts, the young insect or larva has grown sufficiently and has stored within it energy enough to carry it through the remainder of its changes, and internally the essential parts for the adult condition have been formed as far as 
possible under existing conditions. As the next change will produce an animal practically helpless in most cases, and unable to protect itself from its enemies, its next step is to find as much protection as possible. Accordingly, the full-grown larva usually, though not always, leaves the place where it has been feeding and elsewhere prepares for its next change. Many larvæ begin this by spinning around themselves a thread of silk, produced by glands within the body and opening to the surface on the lower lip. This thread is spun backward and forward and around the body until it sometimes forms a complete outer covering, entirely concealing the larva within, from view. This case or cocoon appears to be protective in its function.

Some larvæ go under ground for this change. Here a cocoon, as such, seems unnecessary, but after digging into the earth a few inches, the insect forms a little earthen chamber or cell in which to lie, and generally lines this more or less densely with silk, probably to keep the earthen walls from falling in and crushing it. A larva transforming in tunnels in wood where it has fed, may make a partial cocoon with more or less of the chewed-wood fragments mixed in. One staying above ground but not in tunnnels or otherwise protected, will spin more or less of a cocoon as already described.

The completeness of the cocoon, however, varies greatly with different insects. Instead of being a thick, dense wrapping which entirely conceals the insect, it may be so scanty that the animal within can be seen to some extent. In other cases it is merely a sort of network, in no degree giving concealment; and in still others, a few scattered threads to hold the insect in place are all that represent it. Sometimes hairs from the body of the larva, held together by silk, form most of the cocoon, and in the case of butterflies, only threads enough to attach the hinder end of the body at the place where it is to transform, and to form a supporting loop around its middle, the ends of the loop also being fastened to what it rests on, are produced. In some flies the larva shrinks within its larval skin and transforms, this skin, now called a puparium, functioning like a cocoon (see Fig. 33c).

The reason for such variations in a structure presumably formed for the purpose of protection, can only be guessed at. Possibly in the course of generations, some insects found less need of this than others and gradually reduced it, thereby saving the vital energy so much needed for transformation, which would otherwise be expended in cocoon making.

Whether the larva forms a dense or scanty cocoon, or none whatever, the next step in the process is a molt. When the insect escapes from this skin, however, a great change in its appearance is evident, and it is now called a pupa (Fig. $33 a$ and $b$ ). In a general way it may be said that it has at this one molt changed more than half way to its adult condition. This is due in part at least to the unfolding of the imaginal buds already 
referred to, which contribute largely to form the new surface of the body in which head, thorax and abdomen are evident, as are also the antennæ, legs, stubs of wings and other adult structures. Many of the internal organs of the larva though, were necessary for use till the last moment before it became a pupa. Then too, tha arrangement of the muscles, in the larva, would not be that needed by the adult. Accordingly, most of the internal organs now gradually break down, losing all their earlier form and structure, and new ones to meet the needs of the adult are constructed to take their place.

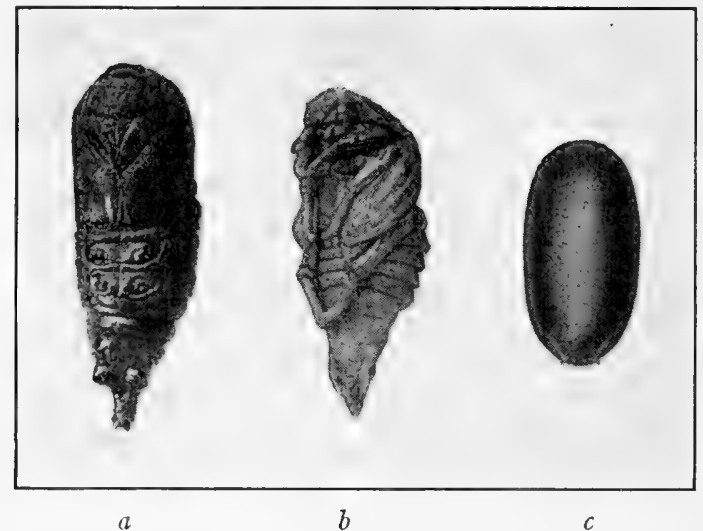

FIG. 33.- Different types of pupation. $\quad a$, pupa obtecta of a moth; $b$, pupa libera of a beetle; $c$, puparium of a fly. $a$ and $b$ about natural size; $c$ much enlarged. (Original.)

During this breaking down and the reconstruction period, the pupa is practically helpless in most cases, hence generally the need for the protecting cocoon or earthen cell it constructs.

When the structure of the adult insect has been completed, another molt takes place, the pupa skin splitting and setting free the insect. If it was enclosed in a cocoon it now produces a fluid which sufficiently softens the silken threads so that it can push its way out and it escapes or "emerges." It is now soft, its wings are only partly expanded, as in most cases there would be no room for full-sized wings in a pupa, and because of its reconstruction there is considerable waste matter in its body. The insect crawls upon whatever it may find to hold on to, expels the waste matter, and its wings begin to grow rapidly. Drying out also takes place and in a short time (a few hours) the adult thus produced is in every way fully matured.

To summarize the differences in metamorphosis of the three groups it may be said that in the Ametabola the insect hatches from the egg practically in an adult condition, i.e., there is little or no metamorphosis. In the Hemimetabola the insect hatches from the egg in a form somewhat resembling the adult but much smaller. It becomes adult by alternating 
periods of feeding with molts, at which times growth and changes bringing it nearer to the adult occur, the last molt completing the growth and adult structure. In this life history we have a change, but as there was a resemblance to the adult from the start, the change to it (metamorphosis) is only an incomplete or partial one.

In the Holometabola the insect hatches from the egg in a form totally unlike the adult, and while feeding periods followed by molts and growth give increase in size, no external evidence of any changes making the insect more like the adult can be found. These changes are largely made after the end of the feeding and growing periods during a pupa (generally quiet) stage, in which the breaking down of the larval, and construction of the adult structures is completed. The difference between the larva on hatching and the adult is so great that an entire change (complete metamorphosis) takes place.

It should be evident from the foregoing that when the adult condition is once reached, little if any growth is possible (except in rare cases) and that the belief so common, that "big flies grow from little flies," is without any basis of fact.

The nymphs of the Hemimetabola appear not to have attracted sufficient attention to have received any special common names. In the Holometabola the larvæ of various groups differ greatly in appearance; many are large and noticeable and some of them have, as a result, received special names. Larvæ of butterflies and moths are commonly called caterpillars; those of beetles are usually called grubs; those of flies are called maggots. Larvæ found boring in wood, however, whether they will become moths, beetles or other insects, are uniformly called borers.

In the Hemimetabola then, the stages of life are: egg, nymph, adult; in the Holometabola they are: egg, larva, pupa, adult. Whether 'or not the pupa is enclosed by a cocoon depends upon circumstances. 


\section{CHAPTER V}

\section{LOSSES CAUSED BY INSECTS : NATURE'S CONTROL METHODS}

To ascertain how much man loses by the attacks of injurious insects is a difficult task. The destruction, either partial or entire, of his crops both growing and in storage; of household goods and of food; of our forests and of the wood cut therefrom; injuries to our domestic animals and their products: these and other injuries can be more or less accurately estimated. But when we consider the attacks upon man by diseasecarrying insects, resulting in loss of time from productive labor, or even by death, and the actual costs connected with illness, the problem becomes extremely complicated, and to determine how much financial loss this country suffers from insects is a matter for the economist as much as the entomologist.

Much of this loss we fail to appreciate, never having had a season free from the attacks of insects which might serve as a standard for comparison. If we could once have such a year entirely insect free, however, the difference would at once force itself upon our notice.

Crop Losses.-Careful studies of the crops injured by insects have now extended over quite a term of years, and the general conclusion rached is that in an average year with no unusual attack, a crop will generally produce only about nine-tenths as much as would probably have been the case had insects not been present. When an outbreak occurs, this will decrease production below that point, and instances are far too frequent where for a single crop of some kind, production has been only 20 or 30 per cent of the normal, and many cases are on record where in some localities the destruction has been complete.

This estimate covers field crops; destruction of forests and forest products; attacks on domestic animals and their products; articles in storage; on shade trees, shrubs and ornamental plants; on farm wood lots which are not included with the forests; on household goods and foods. With fruit and truck crops the destruction and injury is believed to be more than one-tenth generally.

Health Losses. - A number of serious diseases of man are due to insects which serve as carriers of the disease-producing organisms. Among these are malaria, the typhoid, typhus and yellow fevers, and the bubonic plague, besides others of less importance. Illness with any of these diseases means that the patient is not only unable to work but is an actual cause of outlay for nursing, treatment, and possibly death cxpenses also. With hundreds of thousands of illnesses from these 
diseases each year, the loss of time from productive labor is, of course, very large, and the country is that much poorer than it should be. Death puts an end to any further production by those concerned, and here also is a loss to the country. It has been estimated that the loss of labor by sickness and death, caused by malaria alone, is at least $\$ 100,-$ 000,000 , and by all insect-borne diseases is over $\$ 350,000,000$ each year in the United States.

In addition, there are many places in this country where the soil is rich and would pay well if cultivated, but where man cannot live under existing conditions because of the presence there of insects and the diseases they carry.

Difficulties in Estimating Losses.-To fix a monetary value for all this destruction and injury, however, is a difficult problem, so many factors enter into it. It cannot be denied that insect attacks result in a direct reduction of wealth to the country as a whole; that whatever food material has been consumed by insects is not available for consumption by the people, is self-evident; and that if on account of a resulting scarcity of any food the consumer pays more for it, he is thereby paying toward the cost of the ravages by the insects. The producer of this food though, may because of the reduced amount available, be getting as much or even more than he would have received had insects not destroyed any of it. In other words, while the destruction of any crop caused by insects is certainly a loss to the nation as a whole, those fortunate individuals who succeed in raising that crop may receive as much or more for the amount they did produce than would otherwise have been the ease. On the other hand the man who starts to raise such a crop and loses a large percentage of it by insect ravages, may not have a sufficient amount left to repay him even at the higher prices, for his expenses.

It is evident then, that insect ravages while meaning a loss to the country as a whole, may also mean either a loss to producers, a normal profit because of a higher price on what part of the crop they have been able to save, or even a better profit, due to higher prices than could otherwise have been obtained.

No crop producer can as yet foretell whether he in any given year will be one who will lose, receive a normal return, or do better than usual on any of his crops. He can only be prepared for insect attacks if they come, and save all he can by proper methods of protection and repression, knowing that the vast majority of the people will do little or nothing in this line and that in consequence he will be among those losing least; will have proportionally more to sell, and that he will th $\lrcorner$ refore receive the benefit of any higher prices coming from a reduced production.

Against what he will gain in this way must be offset the cost of his protective and control measures. If these are too expensive he will gain nothing, but in most cases their cost is small as compared with the value 
of the product saved, and such measures used with judgment represent one of the cheapest and most successful forms of crop insurance.

It is certain that the time will never come when protection of crops from insect ravages will ever be so universal and successful that to produce crops will not pay, for with our increasing industrial population to be fed the demand is more likely increasingly to exceed the supply, even though every crop producer should finally come to the protection of what he raises, from insects. At present the farmer who adopts modern methods against insect injuries is certain in any term of years to raise more and to sell at higher prices than one who trusts to chance or "luck" in this phase of his industry.

Figures on Losses.-From the above it becomes evident that no accurate figures as to the losses caused by insects can be given. We can only recognize that everything produced which is destroyed by these pests is thereby lost to the country as a whole, even though some individuals may profit. To value this destruction we have only the prices for which crops sell, as a criteirion, and the point has already been brought out that if the tenth destroyed had been saved, the price of the whole might have been no greater than it was for the nine-tenths actually produced. Taking this unreliable standard, however, in order to get some slight idea of the amount of destruction ordinarily caused by insects, we may bring together the following statement, based on the average value of the crops for the five years 1913-1917 as given in reports of the United States Department of Agriculture and from other sources.

Field crops. .

$\$ 833,660,000$

Animals and their products.

$431,450,000$

Forests, forest products and materials in storage..... $300,000,000$

Loss by human disease and death............ $350,000,000$

Farm wood lots

$100,000,000$

Extra losses on fruit and truck crops.

?

Shade trees and ornamental shrubs and plants.

Household goods and foods.

?

?

Altogether, if we may accept figures based on the assumption, as has been indicated, that if no losses had occurred the value of the whole would be at the same rate as the actual price for what was obtained, it is safe to estimate the loss in the United States due to injurious insects as being not far from two billion dollars each year. How nearly correct this is, however, no one can tell, so many factors enter into the problem.

Causes of Increased Injury.-Losses to crops, forests and other materials are increasing, for several reasons. Before the settlement of this country there were, of course, native insects attacking the various plants growing here. When settlements were established new plants were introduced by the settlers and grown in greater abundance than if they were 
wild and scattered. An insect finding in any of these a food acceptable to it, would at once also find a more abundant supply, and a rapid multiplication would become possible, resulting in their increase to injurious abundance. A second factor has been the introduction of many insects from foreign countries. In the United States such forms have sometimes entirely failed to maintain themselves. Unfortunately, as has more frequently happened, they have found all conditions favorable to a rapid increase, unchecked by their enemies which in most cases have not also been brought to this country with them. A third factor has been that with the increasing occupation of this country, much of its wild bird life has either been destroyed or has been driven away from the neighborhood of man. Many insect feeders among birds, once quite common, must now be sought in remote woodlands and thickets, and rarely show themselves near settlements. Some kinds have adjusted themselves to the new conditions and among these may be mentioned the robin, chipping sparrow, blue bird and a few others. But to too great a degree the insectivorous birds are becoming either fewer in number or afraid to visit the settled districts where cats and people are numerous, even though in such places the gardens and trees may be thickly populated with insects.

With modern agricultural methods distinctly favoring a rapid increase of insects by providing an enormous acreage of a single crop $;^{1}$ with an addition to our worst native pests of at least as many more from other countries, which have escaped their enemies by coming here; and with our birds becoming less effective in their work, it is only natural that losses by the attacks of insects should be great and increasing in importance.

Control by Natural Methods.-In countries undisturbed by man and his industries it is probable that destruction or serious injury from insect attacks would usually be rather small, particularly in a series of years. The saying in Physics that "Nature abhors a vacuum" seems to be paralleled in Biology by the paraphrase, "Nature abhors extermination." Accordingly, insects appear to be more or less completely held in balance by natural factors, some of which may be briefly considered here.

Plants of various kinds form the food of most of the insects which we regard as pests, and in a country entirely under natural conditions, - plants of any one kind are liable to be more or less scattered, no large number being close together. Under such conditions a search for the proper food plant is necessary to an insect as a preliminary to egglaying, and in many instances these may be too scarce to provide for all the insects. In any case, where the food supply is scanty, an insect

${ }^{1}$ As an example of this, apple orchards containing thousands of trees are now common. It is stated that one year in a single valley in California, there were three wheat fields each containing over twenty thousand acres. 
species feeding wholly on that kind of plant will be more rare than where its food is abundant. If, on the other hand, there is an abundance of the food plant, there is a greater probability of the survival of more of the insects. But this brings its disadvantages. Increase in the number of the insects will result in more food being needed, and finally this will become insufficient and will be followed by the failure of many to find food, death resulting. In this way a balance may be finally secured, though it will not be permanent, the process being repeated in the subsequent years.

Weather conditions are also a factor in Nature's control. Some insects find in a wet season conditions favoring the survival of a large proportion of those which appear, while for others such a season produces heavy mortality. A severe winter with many and marked fluctuations of temperature may put an end to the rapid increase of some species which because of preceding favorable winters, has been becoming more abundant. Other meteorological factors also enter into the subject of insect control.

Birds and other animals which feed on our insects must also be considered in this connection. When insects acceptable to these animals are abundant, more will be eaten and in any case many will be destroyed in this way. Where insectivorous birds have an abundant food supply more will survive, which will result in more individuals to be fed. Thus an abundance of insects may lead to a corresponding increase in abundance of their enemies.

Parasites and diseases play their part too in this competition. The more abundant an insect becomes, the more food is thereby available for its parasites, and fewer of these will fail to find an insect to attack. Finally the parasites may become so numerous that practically all the insects of the kinds they attack will be found and killed. The next generation of parasites following this, will, of course, consist of many more individuals than the one preceding, but now so many of their food insects or "hosts" have been killed in producing them that there are practically none left, and most of these parasites die for lack of food. Thus, under these conditions, a sort of "balance of Nature" develops, and though the scales may tip first to one side and then to the other, this balance is usually preserved if periods of a number of years at least, . are considered.

But when man with his many lines of activity appears in the field, introducing and raising millions of plants of the same kind in small areas, instead of scattering them here and there, thus furnishing enormous quantities of food for insects; and when he brings in many pests from foreign countries, no matter how unintentionally, which in their new home are not beset by the foes present in their native land; and when 
his manner of life is such as to drive away birds which might be valuable aids in his struggle against pests, the situation changes rapidly for the worse.

Those who look on the bright side are confident that in time Nature will reëstablish a balance, and this is probably true. But Nature works in centuries, and man cannot wait so long for results.

Under these conditions artificial measures as contrasted with natural ones must be taken if crops are to be raised, food obtained, and if health is to be preserved, and these artificial methods for the control of injurious insects need to be known, and the nature of their action understood. 


\section{CHAPTER VI}

\section{ARTIFICIAL METHODS OF CONTROL}

It has been indicated that Nature has methods for the control of any continued undue abundance of insects, by a resulting scarcity of food; by weather conditions; by insectivorous birds and other animals; by parasites and diseases; and probably in other ways also. But it seldom pays to wait for the results so obtained, as they generally require a number of years for completion, and measures which may be termed artificial, inasmuch as they are used by man, also have their value.

These measures may be divided into two groups, viz., those which aim to establish conditions unusually favorable to the plants or unfavorable to the insects; and those which attempt either to poison or otherwise directly kill the insects. In some cases perhaps, a given treatment might seem to belong as properly in on` of these groups as in the other, but in general the line of separation is quite distinct.

Whatever the method and its effectiveness may be, there is always the cost of using it to bear in mind. When this cost is greater than the loss would otherwise probably amount to, it is evident that little will be gained by treatment, except that in such cases possibly, omitting it for this reason one year may result in such an increase of the pest as to produce serious results the following season. In other words, treatment costing more than the probable loss may sometimes pay as a sort of insurance. In general, though, in every case where insect attack occurs, the estimated cost of the treatment should be weighed against the probable loss without it, in deciding whether to treat or not.

\section{GENERAL FARM PRACTICES}

These are chiefly methods for raising crops which distinctly increase their vigor and growth or remove conditions favorable to insects. Healthy crops, clean culture, the rotation of crops, late or early plowing, and the time of planting are the chief farm practices which belong here. Special methods for particular cases, directed more with reference to the insects than to the handling of the plants, such as hand picking, the use of repellents, burning insects, heat, trap lanterns, etc., may also be included here, leaving the measures dealing with insects by the use of poisons and by fumigation for later consideration. 
Healthy Crops.-In the majority of cases a vigorous, thoroughly healthy plant is not only better able to withstand insect injury but is also less liable to attack than one enfeebled or not thriving for any reason. Thorough cultivation, the use of fertilizers and the removal or repair of injured or diseased parts or plants as soon as these appear, will aid greatly in insuring the desired results.

Clean culture is also an important factor. Weeds not only interfere with successful crop growth but may in some cases at least, consume plant food in the soil which might otherwise be utilized by the crop, thus reducing its vigor, and in addition they provide wintering places for many insects. Rubbish left on a field after the harvesi often serves the same purpose: insects frequently find protection during the winter in tall grass too often left surrounding the trunks of fruit trees, and many serious pests winter close to the ground in grass fields. Decaying fruits and vegetables harbor insects and should be composted. Weeds should therefore be killed and burned and the grass kept down in orchards. Burning over grass fields in early spring in the Northern states at least, choosing a time when the dead growth is dry enough to burn while the living parts of the grass are still so wet as to be uninjured by the heat is often a valuable way in which to destroy many pests which winter there. Clean culture in all its forms, not forgetting fence-line and roadside growth will do much to reduce loss by insects.

Crop Rotation.-The rotation of crops often has an important bearing on insect control. Any crop attacked by a particular species of insect should not be followed by another, either of the same kind or by a different one which is also fed upon by that species of insect. How far this principle can be carried out in practice, however, is a different matter. To break up sod land and plant corn for the first crop is merely to follow a mixture of grasses with a single kind of a grass and from the standpoint of insect control at least, is unwise. It is the usual practice though, and how far it would be wise to depart from it, planting beans, buckwheat or perhaps potatoes instead, is a question, though these last-named crops would be much more likely to be free from insects. The entire subject of crop rotations which are satisfactory from the standpoint of agriculture and are also correct when insect problems are considered, is still in a far from settled condition, and needs prolonged investigation.

Plowing.-Many serious pasts winter in the ground. Fall plowing after they have formed the cells in which they pupate or winter, as the case may be, will break many of these and remove the protection they give: eggs faid in the ground will often be buried so deeply that the larvæ if they hatch in spring will be unable to reach the surface. Similarly, thorough cultivation in the summer, where it is possible, besides being good for the crop, has an injurious effect on insects there.

In some cases early fall plowing gives the best results: in others, late 
fall is the best time. Sometimes disking with a harrow can be done where plowing cannot, and is of value.

Time of Planting. - This is sometimes of importance as a protection against pests. Thus, in general, wheat sown after September 20 will escape the attacks of the Hessian fly: early planting will often give cotton an opportunity to obtain the greater part of its growth before the boll weevil has progressed far in its ravages, particularly if early maturing varieties of cotton are planted. It follows from this that a choice of the variety to plant is also often of importance, and insect-resistant varieties of our various crop plants and trees should be selected as far as any are known, if they are otherwise satisfactory. The "bugless potato," while perhaps non-existent, expresses an idea which should be kept in mind, and resistant varieties of plants should be watched for and preserved.

Trap Crops.--In some cases trap crops can be made use of to advantage. A small patch of kale planted in the fall, or of mustard planted early, in spring will attract the Harlequin cabbage-bugs as they leave their winter quarters, and on these they can be destroyed, as they seem to prefer such plants to the young cabbages. Several similar cases are also known where trap crops work well.

Hand Picking.-In some cases, where the pest is large, easily seen, or not present in large numbers, hand picking is the easiest method of control. Egg clusters are often of such a color, size, or have such noticeable features that they are not difficult to find, and the convenience of destroying several hundred eggs at a time, as compared with killing the same numbər of insects after the eggs have hatched and the young have scattered, is evident. Larvæ feeding in groups together are also often most easily destroyed by hand picking.

Repellents.--Inert materials, such as air-slaked lime, flour, or even fine road dust, thickly spread over plants will, in certain cases, act as repellents, driving insects elsewhere to a greater or lesser degree. Carbolic acid, naphthaline, oil of citronella, and other materials having an objectionable odor act as repellents to some insects.

Trap Lanterns.- These have been quite extensively tested, but have failed to be as successful as was expected. Though many insects are attracted to such lights, the greater number are found to be beneficial, while of the injurious kinds a large number have already laid their eggs and are therefore no longer of any importance, and most of the-serious pests are not attracted at all. On the whole it is doubtful if the use of trap lanterns ever pays.

Burning Insects.-Gasoline torches for burning egg clusters, caterpillars, scale insects, etc., on trees, have also been tried, but the time necessary to kill the insects in this way is often long enough to injure the tree where the blast hits it, and this method must be regarded as at 
least exposing the plant treated, to the risk of greater injury than that caused by the insects.

Heat.-Heat can sometimes be used to advantage for the destruction of insects. A temperature of $125^{\circ} \mathrm{F}$. is enough, if maintained for 3 or $4 \mathrm{hr}$, to kill insects infesting grain, seeds, etc., and also almost all household pests at least. Where heat can be applied in this way, therefore, it is a special method of control of considerable value.

Miscellaneous Methods.-Borers in trees present particular difficulties, being so hard to reach, and cutting them out by hand is frequently the best control method. Protective coverings over or around plants may sometimes be used to advantage, as for example, netting over young cucumber and squash plants. Sticky bands placed around the trunks of trees keep insects which cannot fly from crawling up to the leaves. Pieces of bark or boards on the ground near plants, under which insects may crawl for protection at night, as some do, are good traps for such insects, if these traps are visited early in the morning and the insects destroyed before they scatter again for the day. Burlap bands around tree trunks attract many caterpillars as being good hiding places during the day. These and numerous other special methods for the control of insects are made use of, many being based on some peculiarity of habits of the special pest for which they are used.

Still other methods will be considered later, in connection with the insects against which they are used.

In order to make proper use of the above methods of Farm Practice, a clear understanding of the life and habits of the insect to be controlled, must be had. Failure in this might easily lead to doing just the wrong thing.

The control of insects is at the present time very unequally developed for different crops. Naturally the insects of those which are most valuable have been most carefully studied, those of less importance having been given much less attention. Fruit and market-garden crops have a high value and the insects which attack them have been carefully investigated, though the area they cover is very small as compared with the wheat acreage of this country, for example. Trees, bushes or other plants, whether growing alone or in rows with cultivated land or grass surrounding them are accessible as units on which to work, but a 10 -acre field of clover, wheat or any other crop, is a totally different proposition. The former can be reached in all its parts by a spray or other treatment: a wheat plant in the middle of a field may need treatment but to reach it would probably cause a graater amount of injury than would be saved by the treatment.

Field crops and particularly grain crops therefore, present distinct 
problems, and here Economic Entomology and Practical Agriculture have failed to work as closely together as should be the case, and our present methods for controlling field crop insects are less effective than with most others.

The same thing is true with our forests. The shade tree can be sprayed if that is a desirable treatment, but the spraying of forests even if practicable from the standpoint of expense, is frequently impossible because of the nature of the ground on which the forest stands, density of growth and other factors, and other and more indirect methods of insect repression then must be resorted to. 


\section{CHAPTER VII}

\section{INSECTICIDES JN GENERAL: STOMACH POISONS}

Though the farm practices and special methods outlined in the preceding chapter are of great importance for the control of insect pests in many cases, they are ineffective and cannot be made use of in many others. Under these circumstances other methods of attack must be resorted to, and in general, insecticides of various kinds, fitting the particular nature of the injury and of the insect causing it in each case, have proved successful. Insecticides are substances which may be placed upon a plant, or elsewhere, to be eaten by the insect and which when eaten, kill the insect; or materials which on coming in contact with the body of the insect, kill it as a result of that contact. Poisonous gases and vapors would also be included as insecticides, as thus defined.

\section{CLASSES OF INSECTICIDES}

The materials used as insecticides fall into two general groups: (1) Those which are placed upon the food eaten by the insect, swallowed with it, and which upon entering the stomach are dissolved, producing inflammation and finally death. Such poisons can, of course, be used only for insects with chewing mouth parts which bite off and swallow solid food, such as pieces of leaves, stems, etc.; (2) Those which, when they come in contact with the body of an insect either enter the spiracles and penetrate their chitinous lining and kill the tissues beyond; or which corrode the body; deprive it of oxygen; or by softening the coverings over the body (scale insects) cause these to adhere to the plant it is on, killing the insect in any case. The materials of the first group are usually called stomach poisons; those of the second, contact insecticides. The latter could also be used for biting insects but the difficulties in the way of their being successfully applied are such that stomach poisons are used whenever possible.

In reaching the insects concerned, either with stomach poisons or contact insecticides, the methods of conveying the material to where the insect is, and of an even and thorough distribution of it are important. Those substances which are solids in the form of fine powders can be blewn onto the tree or whatever the insect may be on, but some are liquids. Accordingly, "powder guns" for spreading the poisonous dusts have been used with considerable success, and pumps with a fine nozzle at the end of a line of hose are used for the liquids. 
With stomach poisons, however, the poison is not necessarily eaten by the insect as soon as it falls on the plant, but must or should remain there for some time, as the insects may appear during a period of several days or even weeks. During this time much, probably most, of the poisonous dust would be blown off and the treatment be of little value. In spite of this difficulty, much successful work has been done with dry stomach poisons, and they have many advantages over sprays under certain conditions.

It has been found that when stomach poisons are mixed with water and sprayed onto plants in the form of very fine droplets, the spray appearing like a fine mist, each droplet soon dries, leaving behind it the poison it contains, adhering to the leaf, where, unless washed off by rain, it will remain a long time. This has led to the general adoption of spraying, both with stomach poisons and contact insecticides, despite certain difficulties which have developed.

\section{STOMACH POISONS}

Arsenic is the basis of nearly all the commonly used stomach poisons, for though probably more than 50 materials have been tested, only a few have proved at all satisfactory, and with two or three exceptions, useful only under special conditions, they have all been arsenical compounds. It would seem natural under these circumstances to use common white arsenic $\left(\mathrm{As}_{2} \mathrm{O}_{3}\right)$ as the stomach poison, it being, when pure, 100 per cent arsenic (arsenious oxid). But it is found that arsenic dissolves to some extent in water, and that thus dissolved it destroys ("burns") the places on the leaves on which it falls. This result is as bad for the plant as it would be to have the leaves eaten, for the object of spraying is to prevent injury or loss of leaf surface. Because of its solubility in water, therefore, arsenic, as such, is not employed as a spray, but combinations of it with other materials, not, or only very slightly soluble, have been solected for use instead. This produces another difficulty. A combination with lead can be obtained for example, which is almost absolutely insoluble in water and therefore entirely safe for use as a spray. But in this material only about one-quarter of it is arsenic, so that an insect, speaking in a general way, would be obliged to eat about four times as much before being poisoned, as would be the case had the material been arsenic instead. By the use of more or less insoluble combinations of arsenic with other substances, then, reduced injury to the foliage can largely be secured, but a larger leaf surface is consumed by the insect before the poisonous dose is obtained. This is a small matter, however, as compared with the protection of all the foliage on a tree from injury by the spray.

Another difficulty in the use of sprays is the weight of the poison mixed in and carried by the water. It has just been pointed out that 
the poison must not dissolve, or burning of the foliage will result. The poison, instead, must be suspended in the water, which acts merely as a carrier from the pump to the plant over which it distributes the poison. This distribution should be as uniform as possible in order that all parts of the plant may be equally well protected and covered. If the poison be heavy, settling quickly to the bottom of the pump, uneven distribution will result, some parts of the plant receiving too much of the poison while others will get but little. The best stomach poison from this standpoint therefore, is one which is so light that after mixing it with water it will take a long time to settle to the bottom.

The chief stomach poisons now in use in the United States are Paris green, Arsenate of lead, Arsenate of lime, Hellebore, and Sodium fluorid, the last two having only a limited application. Standard formulas for these are given below. Variations from them will be found in connection with the special cases where change from the standard is desirable.

Paris Green.-This was probably the first stomach poison used against insects, having been first employed about 1868 for the treatment of the Colorado potato beetle. Chemically, it is a combination of copper, arsenic and acetic acid, containing when pure, nearly 60 per cent of arsenic, which is high as compared with the other arsenicals in use, and this gives the substance its chief value.

Paris green has three serious disadvantages. One of these is that some of the arsenic will dissolve in the water it is mixed with, causing injury to the foliage. This can in part be avoided by the addition of lime, which combines with any of the arsenic that separates from its combination with the copper and acetic acid and would cause burning, converting it into arsenite of lime which is only slightly soluble under such circumstances. Sometimes though, a slight burning takes place, even under these conditions. By Federal law, not over 3 per cent should be soluble.

A second disadvantage is that Paris green is a heavy substance, settling quickly through the water to the bottom of the pump, which results in an uneven distribution over the plant.

The third disadvantage is that it does not adhere well to foliage, being easily washed off by rains. This means that more frequent sprayings are necessary for the protection of the plants than would otherwise be the case, involving greater cost for material and labor.

A standard formula for Paris green is:

Paris green

Quick lime.

Water.
Per Barrel

1.3 lb.

$1 \mathrm{lb}$.

50 gal.
Pen Gallon

$1 / 2$ teaspoonful (level)

1 teaspoonful (level) 1 gal.

Use fresh stone lime, slaking this in some of the water: work up the Paris green to a paste in a little of the water: add the lime slaked, to the rest of the water, then stir in the Paris green paste. It is not advisable to mix 
this long before it is to be used, nor to mix more than will be used the same day.

Although the addition of lime to the Paris green reduces the danger of injuring foliage, some plants even then, are liable to be burned somewhat. Accordingly, the amount of the poison to use per barrel will vary. Thus, for potatoes the Paris green can usually be increased to $1 / 2 \mathrm{lb}$. per barrel, while for the peach it is not safe to use more than $1 / 6 \mathrm{lb}$. It should not be used on evergreens.

Applied as a dust it is usually thoroughly mixed with flour, plaster or air-slaked lime, in about the proportion of 1 part of the Paris green to from 6 to 10 parts of the other, by weight.

Paris green is unsafe to apply on stone fruit foliage, and because of the danger of burning in general, it is now less used than was once the case, arsenate of lead having largely replaced it as a spray.

Arsenate of Lead.- The value of this material as a spray against insects was discovered about 1892 in the course of the work conducted by the State of Massachusetts on the control of the gypsy moth, and it has now been generally adopted as being, under ordinary conditions, the best stomach poison to use. Two forms of it are available: the basic or neutral (ortho) arsenate, $\mathrm{Pb}_{3}\left(\mathrm{AsO}_{4}\right)_{2}$ and the acid arsenate, $\mathrm{PbHAsO}_{4}$. In pure condition the former is about 25 per cent arsenic oxid and the latter about 33 per cent. The latter is the form in most general use, but on the Pacific Coast, because of local conditions, the former appears to be regarded with more favor.

Arsenate of lead may be obtained both as a paste and as a powder. By law the paste must not be more than half water, but with about this amount present the percentage of arsenic oxid in it is reduced to from 12 or 13 to 19 or 20 per cent. In the powder, water being practically absent, about 32 to 33 per cent is arsenic oxid. As the average in the paste is usually 16 per cent and the price of the powder is about double that of the paste, there is little choice between the two so far as the arsenic is concerned. The Federal law requires that in the paste no more than 0.75 per cent of the arsenic oxid shall be soluble in water.

Either form of arsenate of lead shows well on the foliage, which is useful, enabling the sprayer to see parts he has missed in spraying, and to "touch up" those places. It is also very light, settling slowly in the pump. Under most conditions arsenate of lead does not burn the leaves, being in fact, the safest of the stomach poisons in this regard, and it adheres to the leaves longer than the others (stomach poisons). On the other hand, it acts slowly on insects because of its rather low arsenic content

As a pound of the paste is approximately one-half water, it is necessary in spraying a given area to use twice as much (by weight) as of the powder, in order to supply equal amounts of the poison. 
A standard formula for arsenate of lead is:

\begin{tabular}{|c|c|c|}
\hline & Per Barrel & Per Gallon \\
\hline Arsenate of lead paste. & lb. & teaspoonfuls (level) \\
\hline Water...... & gal. & gal. \\
\hline Arsenate of lead powder........... & $11 / 2 \mathrm{lb}$ & $91 / 2$ teaspoonfuls (level) \\
\hline
\end{tabular}

In mixing the paste it is well to add some water and stir thoroughly before adding the rest of the water, in order to get a more uniform mixture. If it is allowed to dry it will not work up well thereafter by adding water, and it is also injured by freezing.

Arsenate of Lime.-This substance has come into use since about 1914, because of the rapidly increasing cost of arsenate of lead. It is $\mathrm{Ca}_{3}\left(\mathrm{AsO}_{4}\right)_{2}$ and may be obtained, like arsenate of lead, either as a paste or a powder. The former contains about 18 per cent of arsenic oxid, and the latter about 44 per cent, thus being slightly higher in paste form, and considerably higher in powder form, than arsenate of lead. As the costs of the two forms differ correspondingly, there is little choice between them from this standpoint, but convenience and other factors give a slight preference to the powder. Being stronger than arsenate of lead, less needs to be used in order to supply an equal amount of poison to a given area.

Arsenate of lime is not safe for use on foliage, and particularly that of stone fruits, unless an excess of lime is present. Accordingly, as was the case with Paris green, lime must be added to the mixture.

A standard formula for arsenate of lime is:

\begin{tabular}{|c|c|c|c|}
\hline & PER & Barrel & Per Gallon \\
\hline Arsenate of lime past & 2 & lb. & $11 / 2$ teaspoonfuls \\
\hline Quick lime. . & 2 to 3 & $1 \mathrm{~b}$. & 2 teaspoonfuls \\
\hline Water. & 50 & gal. & gal. \\
\hline f lime powder. & $3 / 4$ & lb. & $43 / 4$ teaspoonfuls \\
\hline uick lime.................. & 1 & lb. & teaspoonfuls \\
\hline Tater. . . . . . . . . . . . . . & 50 & gal. & gal. \\
\hline
\end{tabular}

The quick lime, which should be fresh stone lime, is slaked in some of the water, then added to the rest, and the arsenate of lime thoroughly stirred in.

While this material is cheaper than arsenate of lead and perhaps kills a little more quickly, it has not been in use long enough to be certain just what results may be expected in all cases. At least it may at the present time be termed a very promising insecticide.

Poison Baits.-These are included here, as, in most cases at least, they contain an arsenical poison. They are used mainly for the control of cutworms and grasshoppers. There are several formulas proposed, 
but those consisting of bran or horse manure, poisoned with arsenic or Paris green, and made attractive to the insect by adding strong-smelling molasses (syrup) and the juice of citrus fruits, have in general been the most successful. Detailed consideration of them will be given in connection with the insects for which they are used.

Hellebore.-This is the powdered roots of the plants Veratrum album and Veratrum viridis. It is a mild stomach poison and can therefore be usad with safety to man, on plants soon to be gathered for food, as it loses its strength quite quickly on exposure to the air. It is sometimes difficult to obtain fresh.

It may be dusted over the plants, sticking on best if applied while dew is on them, or it may be mixed with from one to three times its bulk of flour or plaster, for this purpose. It may also be used as a spray by steeping an ounce in a quart of water and then adding another quart of water. At the rate of half a pound in 10 gal. of water it is effective against house-fly maggots in manure piles. It is too expensive to use except on a small scale.

Commercial Sodium Fluorid.-This substance has recently been found to be effective for some insects, acting apparently both as a stomach poison and as a contact insecticide. It is applied as a dust, either pure or mixed in about equal parts, with flour or plaster. Details are given in connection with the insects against which it is used. 


\section{CHAPTER VIII}

\section{CONTACT INSECTICIDES}

For insects which do not feed upon solid food, stomach poisons are useless, and sprays which come in contact with, and kill them in one or another of the ways already indieated, must be used. This is unfortunate for it means the most thorough kind of work if all the insects are to be reached by the spray. It is among such insects too, that the greatest difficulties in accomplishing this, occur. Some, though large enough to be almost certainly reached by the spray have a particularly thick outer shell: others are exceedingly small and thus can find protection under buds, in crevices of the bark and in other places where the spray may not reach them: still others form protective coverings (scales) over themselves, which fit tightly to the objects they may be on, so that a successful spray must be very strong and penetrating: and finally, many of the smallest and also of the scale-protected insects have marvelous powers of increase, so that if even a single individual escapes treatment, a few days or a week or two will find the plant again swarming with these insects.

Every insect therefore, which can be killed by a stomach poison is best controlled by such materials. For the others, oils, soaps, nicotine, sulfur compounds and a few other substances of minor importance serve as contact insecticides.

Considering the oils first, there are several which are of use. Among mineral oils, crude petroleum and kerosene are destructive to insect life but so dangerous to plants when of full strength, that some method of dilution becomes necessary.

Kerosene Emulsion: standard formula:

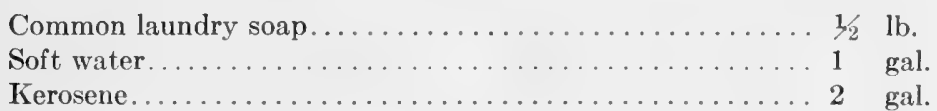

Dissolve the soap in the water (best by shaving it into hot water): then add the kerosene and with a small hand spray pump having a fine nozzle, draw the mixture into the pump and out through the nozzle back into the dish from which it was drawn. In a few minutes it should become creamy and then begin to thicken. When it has become so thick as to go hard through the pump, this process has been completed, 
giving a Stock Solution in which the oil, broken up into very tiny droplets, will not run together again and the water can dilute the mixture. For use against soft-bodied insects, 1 part of the Stock Solution is mixed with about 9 parts of water to spray, while for tougher insects, 1 part is diluted with 4 or 5 parts of water, though this strength may sometimes injure the plants somewhat. The Stock Solution, if well prepared, should keep before breaking down (shown by a film of oil appearing on the surface) for at least a month or two. If the materials fail to thicken in the pump it is probably because the water is "hard water." In that case add a little borax or soda to soften it.

Crude Petroleum can be used in place of kerosene in preparing this emulsion, provided the right grade can be obtained, but this is often difficult, and so is not frequently done.

Miscible Oils.-These are stronger than kerosene emulsion. They contain mineral oils, a small amount of vegetable oil, naphthaline in some cases, some alkali, and water. Properly made they dilute readily with water.

A number of brands of miscible oils are on the market, prepared mainly as sprays for the control of scale insects. For winter use against scales they are generally diluted at the rate of 1 part of the oil to 12 to 14 parts of water. When used in summer against plant lice the dilution should be about 1 part to 35 to 40 parts of water.

The material should not be used if free oil stands on it, as this shows that it has broken down and is not safe on the plants. If sprayed on trees in freezing weather it may gather and freeze in cracks of the trees, injuring them. It is easy to handle and spreads readily from where it strikes, covering more than would otherwise be the case, but it has been claimed, with considerable evidence to support it, that repeated treatments with miscible oils cause a cumulative injurious effect on trees.

Among soaps, common laundry soap and whale-oil (generally fish-oil now) soap are the usual materials used as insecticides.

Whale-oil Soap.-This is a soap made by combining fish oil with an alkali, preferably potash. It is usually diluted at the rate of $1 \mathrm{lb}$. to 5 or 6 gal. of water to apply against plant lice and similar soft-bodied insects in summer, but is also a fair winter application for scale insects, at the rate of $2 \mathrm{lb}$. per gallon of water, though more costly than other, equally good materials.

Common Soap.- This is a fairly good material at the rate of $1 \mathrm{lb}$. in 3 to 5 gal. of water for summer use against plant lice and other softbodied insects but is not as effective as whale-oil soap and is mentioned only because the latter cannot always be obtained.

Nicotine.-This is an alkaloid which occurs in tobacco. It can be obtained by soaking tobacco stems in warm water till a dark brown liquid containing nicotine is obtained, and this is of some value as an insecticide. 
The Lime-sulfur wash is used both as a strong spray against insects during their dormant season, and as a weaker one for general purposes during the summer. In the latter case, besides being a contact insecticide, it has a little value as a stomach poison. It cannot safely be used on stone fruits or potatoes, however.

This material must be kept in air-tight containers as it decomposes on standing when exposed to the air. A film of some vegetable oil over it, for partly filled containers, will give this protection. It should not be allowed to freeze.

For stone fruits where a summer treatment seems necessary, selfboiled lime-sulfur may be used. This is prepared by slaking $8 \mathrm{lb}$. of fresh stone lime in a barrel, in enough water to nearly cover it. Eight pounds of fine sulfur should be gradually added to this, as soon as the lime begins to slake, running the sulfur in through a sieve to break up any lumps. This mixture should be constantly stirred and more water added to form first a thick paste, then gradually a thin one. The heat produced by the lime in slaking will cause the mixture to boil for several minutes. When slaking is at an end, cool the mixture rapidly by adding considerable water, then strain into the pump to remove lumps of lime, but working any lumps of sulfur through the strainer; then dilute with water to a total of 50 gal.

Dry Sulfur Compounds.-These substances have recently appeared in competition with the lime-sulfur wash, the advantages claimed for them being ease of handling, reduction of shipping charges, no deterioration on standing, and equal efficiency at lower cost.

These substances are sulfid combinations with either potassium, sodium, barium or calcium. The amount of sulfur present varies greatly in different brands. They do not contain as much of the polysulfids which appear to be the actual insecticides of the lime-sulfur wash as the liquid wash, and even the amount of sulfur present in them, after the addition of water according to directions, is less than in an equal quantity of the wash, so that basing efficiency on the amount of sulfur, regardless of its form, the amounts of these dry materials would have to be greatly increased to equal that of the wash, and would therefore seriously increase their cost. At the present time their value cannot be considered as having been finally settled though in many cases field tests of them have given good results. Continued studies and tests of these materials are needed to determine their real value.

Sulfur.-This substance in the form of a very fine powder, can be dusted over plants for the destruction of red spiders and other mites, or it may be made into a paste with soapy water, using $10 \mathrm{lb}$. of sulfur and $2 \mathrm{lb}$. of soap in 50 gal. of water, and applier as a spray. Its use is rather limited and its actual value somewhat questionable in many cases. 
Pyrethrum, Insect Powder or Buhach.--This is made by grinding up the blossoms of certain plants, which contain an essential (and volatile) oil effective against insects but not injurious to man. Its use is mainly limited to small areas, and best, those which can be tightly closed. Various other materials will be considered in connection with the particular insects, for the control of which they are used. 


\section{CHAPTER IX}

\section{INSECTICIDES AND FUNGICIDES: FUMIGATION}

\section{COMBINATIONS OF SPRAY MATERIALS}

The greater part of the cost of spraying comes from the time and wages of the workers, the materials used being rather inexpensive in comparison. Wherever it is possible therefore, to make two or three applications at once by using combined sprays, the cost is much reduced.

Frequently there are cases where the application of a stomach poison for chewing insects and of a contact insecticide for sucking forms, can be made at about the same time. Treatment for fungous diseases may also be desirable, and a satisfactory mixed spray for all three purposes can often be given. Certain precautions must be taken in mixing sprays, however, as in some instances the materials of two or more sprays, when combined, will undergo changes, producing substances injurious to the plant or affecting the value of the spray for the purpose for which it was intended.

No spray material containing soap should be combined with one containing lime, as when these materials are brought together, a calcareous and insoluble soap is formed. Thus, when nicotine sulfate is used with lime-sulfur or Bordeaux mixture, the soap usually added to the former must never be put in. Arsenate of lead and compounds containing sodium or potassium sulfid, when mixed, produce sodium or potassium arsenate which is very soluble and will injure foliage, so this combination should also be avoided.

Bordeaux mixture, a fungicide, combines well with most of the insecticides except those containing soap, but as it contains lime, an insecticide with soap is not safe for this combination. In most eases the Bordeaux mixture ready for spraying can be regarded as an equivalent amount of water, to which to add the insecticide. For example, in combining Bordeaux and arsenate of lead, simply add $3 \mathrm{lb}$. of the paste to 50 gal. of the Bordeaux.

Bordeaux mixture will safely combine with any of the arsenical poisons given in this book, and also with nicotine sulfate if the soap be omitted. Lime-sulfur at summer strength may be used with arsenate of lead or nicotine sulfate, leaving out the soap, though in the former case a decomposition is liable to take place which reduces the value of the material. Lime-sulfur at winter strength when added to the 
arsenate of lead brings about a decomposition, as a result of which considerable soluble arsenic is formed, and the efficiency of the lime-sulfur is also reduced about one-third. This may be avoided, however, by slaking $5 \mathrm{lb}$. of quick lime and adding this to the lime-sulfur before putting in the arsenate of lead.

Lead arsenate can be combined with nicotine sulfate, and in some cases at least, with kerosene emulsion. With soap, acid lead arsenate decomposes to some extent forming a soluble arsenate which is dangerous on foliage. Small amounts of soap added as a "sticker," however, are often advantageous even in spite of this decomposition and are frequently recommended, the gain by the addition of the soap being greater than a small injury by burning.

\section{FUMIGATION}

In theory, fumigation is the best method for the control of insects. A gas will reach every portion of a room or a plant, penetrating where no spray can reach, so that insects no matter how well concealed in crevices, under bark or in other locations, will be reached. Still, practical difficulties in the use of poisonous gases are numerous and result in a restricted use of this method of treatment.

The gases used for the destruction of insects act either as actual poisons which enter the body through the tracheal system and directly attack the tissues, or combine with the oxygen of the air and thus remove it from availability by the insect, which suffocates in consequence. In either case, successful fumigation depends upon the liberation of a sufficient quantity of the gas or vapor to make it strong enough to kill the insect.

This at once eliminates trees, bushes and crops growing out of doors from consideration, unless they or their products are so valuable as to make the use of gas-tight tents to cover them during treatment worth the expense, which is considerable. Accordingly, fumigation is generally made use of only with citrus trees, and in houses, greenhouses or other places capable of being tightly closed. Under the conditions mentioned, however, it is an excellent method for insect control, though where plants are to be fumigated, it is usually done at night as the gases or vapors are less liable to cause injury then.

The fumigants most often used are carbon disulfid, nicotine, sulfur and hydrocyanic acid gas.

Carbon Disulfid $\left(\mathrm{CS}_{2}\right)$. - This is obtained in liquid form but becomes a gas on exposure to the air. Impure grades are as good for fumigation as the purified article. The number of cubic feet in the space to be fumigated is calculated, and in general from 10 to $20 \mathrm{lb}$. of the disulfid are used for each 1,000 cu. ft., though if the place is very tight, less than this will be needed. As the gas is considerably heavier than air, the usual 
practice is to put the liquid in rather flat dishes close to the top of the place to be fumigated, as the gas will develop more rapidly in such dishes and work downward from its source. All openings into this place must then be tightly closed at once and everything be left undisturbed for from 24 to $48 \mathrm{hr}$. Ventilate well from outside before entering.

The chief disadvantage in the use of this gas is that it is quite inflammable and cannot be used near where there is a fire or highly heated pipes of any kind. In such quantities as the operator is likely to inhale while using it, a headache is generally the most serious result, though persons with heart trouble of any kind should not work with it as it has some effect on that organ.

Carbon disulfid is used chiefly against clothes moths, carpet beetles, stored grain pests, pea, bean, and other seed pests, ants, and borers in trees. It cannot safely be used in greenhouses or with plants. Details of its uses in different cases will be given in connection with the different insects concerned.

Nicotine.-Nicotine as a vapor may be obtained by evaporating the decoction of it mentioned in the last chapter, in a dish over a lamp, but the uncertainty as to its strength makes treatment in this way liable to prove unsatisfactory.

Nicotine 40 per cent, both in liquid form and as paper rolls saturated with it, are on the market and supply a material of known strength with which to work. It is of value as a treatment for plant lice and other delicate insects. A fluid ounce added to a little water, and this evaporated by heat will be sufficient for about $1,000 \mathrm{cu}$. $\mathrm{ft}$. of space, provided the place is quite tight; or four or five sheets of the paper are usually enough. Upon lighting, the paper smolders, giving off the nicotine vapor. The length of time necessary for nicotine treatment varies with different insects, but is generally begun in the evening, continued all night, and the place opened and aired the next morning.

Sulfur.-The value of sulfur as a fumigant is probably due both to its combination on burning with the oxygen of the air, eliminating this and suffocating the insect, and to the formation in this way of a poisonous gas. It is prepared by burning powdered sulfur in the place to be fumigated, and is used for household pests and also in greenhouses between crops. It cannot be safely used with living plants. From 1 to $2 \mathrm{lb}$. of sulfur per $1,000 \mathrm{cu}$. ft. of space is the usual quantity used. Polished metal surfaces in the place to be fumigated will become tarnished by the gas, and these should be removed, as well as colored goods which are bleached by it. Metal can be protected by covering it with vaseline.

The general practice is to place a large iron kettle on bricks to keep it off the floor, which in that place should be covered for a distance of several feet with something which will not be injured or burned if the sulfur spatters over. In the kettle place the sulfur and add to it a little 
denatured alcohol to insure burning: then light the sulfur and keep the place tightly closed for 24 to $48 \mathrm{hr}$.; then air thoroughly.

Hydrocyanic-acid Gas (HCN).-This is one of the most powerful and dangerous gases known, and persons having had no training in its use are advised not to try it. It is produced by the addition of sodium or potassium cyanid to sulfuric acid which has been diluted with water. Formerly, potassium cyanid was used almost entirely but now the sodium cyanid has taken its place. Care should be taken that the cyanid is of good quality and (at least for use with plants) contains no chlorine. If potassium cyanid is used it should contain 38 per cent of cyanogen: if sodium cyanid, 51 to 52 per cent. The sulfuric acid should have a specific gravity of 1.83 and be free of any nitric acid.

Hydrocyanic-acid gas can be used to advantage in the following ways:

(a) For household and storehouse pests and for fumigating bales of imported cotton.

(b) For greenhouse insects.

(c) For insects on dormant nursery stock.

(d) For insects on citrus trees.

For the first class, an ounce of sodium cyanid for every $100 \mathrm{cu}$. ft. of space is used, and at least $2 \mathrm{hr}$. of fumigation is necessary.

For greenhouse insects the dose is $1 / 2$ to $3 / 4 \mathrm{oz}$. of sodium cyanid for every $1,000 \mathrm{cu}$. ft., with a fumigation period of $3 / 4$ to $1 \mathrm{hr}$. This treatment, at a temperature of about $65^{\circ} \mathrm{F}$. and a low percentage of atmospheric moisture, should be given only after dark. Some of the more delicate varieties of plants may be somewhat injured by this, but in all probability much less than by the continued attacks of the insects. The plants should be dry (not watered recently) at the time of treatment.

Dormant nursery stock should be treated with $3 / 4$ to $1 \mathrm{oz}$. of sodium cyanid for every $100 \mathrm{cu}$. ft., for $1 \mathrm{hr}$. The stock should not be wet nor very closely packed.

For the fumigation of citrus trees during their dormant or most nearly dormant season (October to January) $3 / 4$ to $1 \frac{1}{4}$ oz. of sodium cyanid should be used for every $100 \mathrm{cu}$. ft. of space for a period of $3 / 4$ to $1 \mathrm{hr}$. The value of good citrus trees is such that gas-tight tents are made and used for fumigating them.

In using potassium cyanid, one-fourth more should be taken as the dose than indicated above.

Before treating any place to be fumigated, determine the number of cubic feet in the place and weigh out the proper amount of cyanid. Taking this quantity as the unit from which to determine the amounts of sulfuric acid and water for this dose, measure out $1 \frac{1}{2}$ times as much of the acid in fluid ounces and twice as much water, also in fluid ounces. Thus if the space to be fumigated calls for $4 \frac{1}{2} \mathrm{oz}$. (by weight) of the cyanid, $63 / 4 \mathrm{fl}$. oz. of the acid, and $9 \mathrm{fl}$. oz. of water will constitute the 
dose. With potassium cyanid the proportions of the materials differ somewhat from this, being 1 part of the cyanid, 1 part of the acid and 3 parts of water.

Granite-ware dishes, without flaws exposing the metal, are excellent containers for this work. They should be considerably larger than are needed to hold the dose, and for large areas it is often desirable to divide this among several containers. First, place the proper amount of water in the container; then add the acid slowly to avoid spattering and the production of too much heat; lastly, drop in the cyanid, which it is desirable to have loosely wrapped up in tissue paper in order to gain a moment's time in getting out before the gas begins to be given off freely.

Great care must be taken to leave the place instantly after adding the cyanid to the acid and water, and at the end of the fumigation period there should be a thorough airing for at least a quarter of an hour before entering. If there are windows, these should be opened from the outside only, and under no circumstances should the operator enter too soon. 


\section{CHAPTER X}

\section{THE RELATIONSHIPS OF INSECTS}

Classification may be defined as the orderly arrangement of different objects into groups. Any articles can be classified in one way or another: chairs for example, can be brought into groups according to the kinds of wood of which they are made; or whether they are upholstered or not; or according to their price, and any of these might be equally useful. With living things, however, the problem becomes one of a "natural" as opposed to an "artificial" classification.

It is now the general belief that the first animals were extremely simple in structure, and that in the course of generations (and centuries) variation in their descendants led to the production of different forms, and finally to all the multitudes of kinds now in existence. This development has often been pictured as a tree, the trunk representing the original animals, which, varying as individuals of the same kind always do, began after a time to show several distinct lines along which the variation took place. This would be represented in the tree by the lowest branching of the trunk. Each main limb under the influence of the same conditions would fork in its turn, perhaps into two, perhaps more, and this process repeated again and again would finally produce the terminal twigs - the present animals. Thus each twig would represent all the individuals of the same kind; i.e., a single species; those nearest it the other species most closely related to it; and those on another part of the tree, though species and also related, would only be distantly so, and of course, quite different.

A natural classification of animals therefore, is an attempt to express the actual relationships of the animals, placing nearest each other those most closely related. To do this, the total of their differences and resemblances must be taken into account. Classification based on a single character then, is almost always unreliable. The division of insects into three main groups based on their metamorphosis, is an example of this, for.while it is entirely correct as a statement of facts, a classification using this character would bring near together many insects which in reality are only distantly related.

The largest limb of the animal tree represents the original insects, not because they were so numerous at first, but because they now form such a large part of animal life. This limb is usually called a Class, while the still more comprehensive groups considered in Chapter I are called Phyla. These are the main divisions of the tree. In this case the Hexapoda is the name given to the insect class.

From all the evidence available, the original insects were at least 
comparatively small, wingless, and with practically no metamorphosis. After a time many of their descendants began to develop wings, and a fork of the Class was produced, one branch (or Subclass), the Apterygota, apparently retaining much of its former character, while the other subclass became the Pterygota or winged insects. These have increased greatly in abundance, and their variations have resulted in the production of many branches passing outward toward the twigs, named in sequence, Orders, Families, Genera and Species. Intermediate branchings between these often also need recognition and are called Suborders,

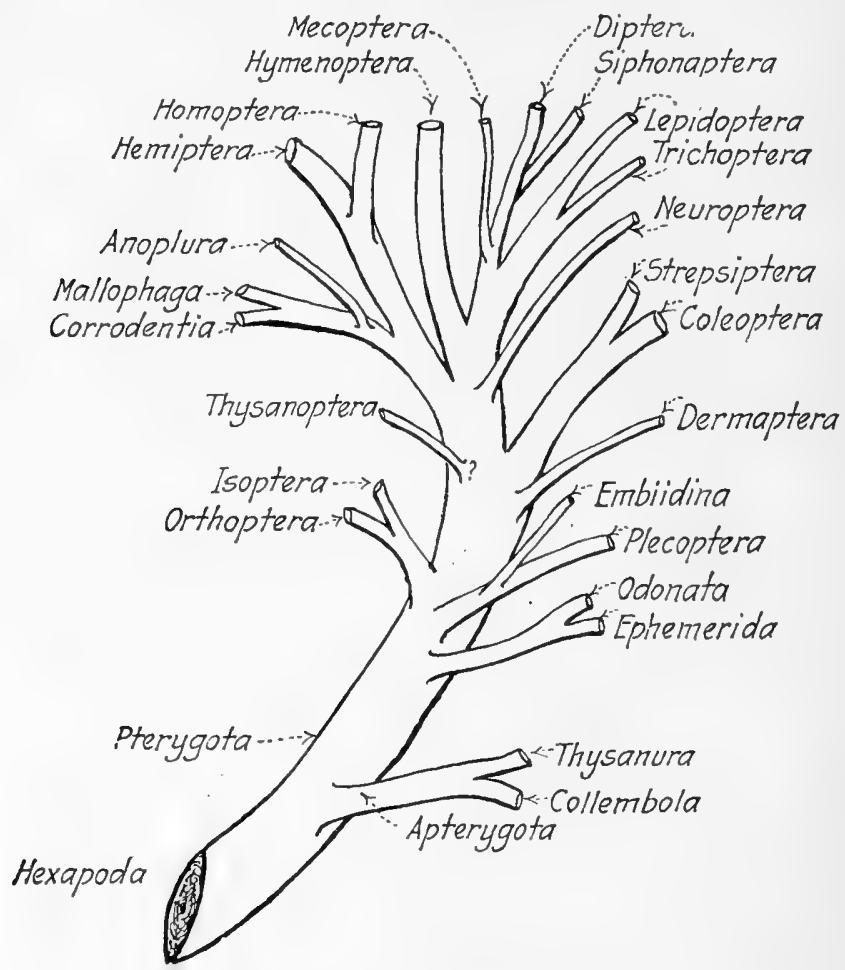

FIG. 34.-Diagram suggesting possible relations of the orders of insects to each other, expressed in a tree-like way: the Hexapod limb.

Superfamilies, etc., as may be necessary. The twigs each represent a single species, but here we may recognize subspecies, varieties, races, etc., among which the individuals which together constitute the species, are distributed.

In any consideration of the different groups of insects one must necessarily follow after another through the book, and when four groups for example, are equally near relatives, the first and fourth treated may thereby appear more distant than is really the case.

Between the fork of the insect limb which produced the Apterygota and the Pterygota, and the twigs representing the species, the actual 
divisions of the branches are more or less uncertain. The species in general, group themselves quite easily into different genera and these into families; but while these last can in most cases be definitely placed in their orders, their correct relation to each other is often debatable. The relation of the orders to each other is far from settled, and while some are evidently more closely allied than others, within certain limits one order could follow another in almost any sequence without any serious loss to the expression of relationships. Where orders appear to be closely allied to each other, this will be indicated in connection with their consideration.

With the relations between the orders and also the families within the orders, still uncertain in many cases, a tree showing these must of necessity express only the views of the individual who drew it. Such a tree carried to the species would be entirely too large for these pages (there are about 80 families of beetles, and many of the other orders have large numbers also), but one carried to the orders is given here (Fig. 34) to illustrate the general idea of a tree-like classification.

Expressed in tabular form, the classification followed in this book is given below.

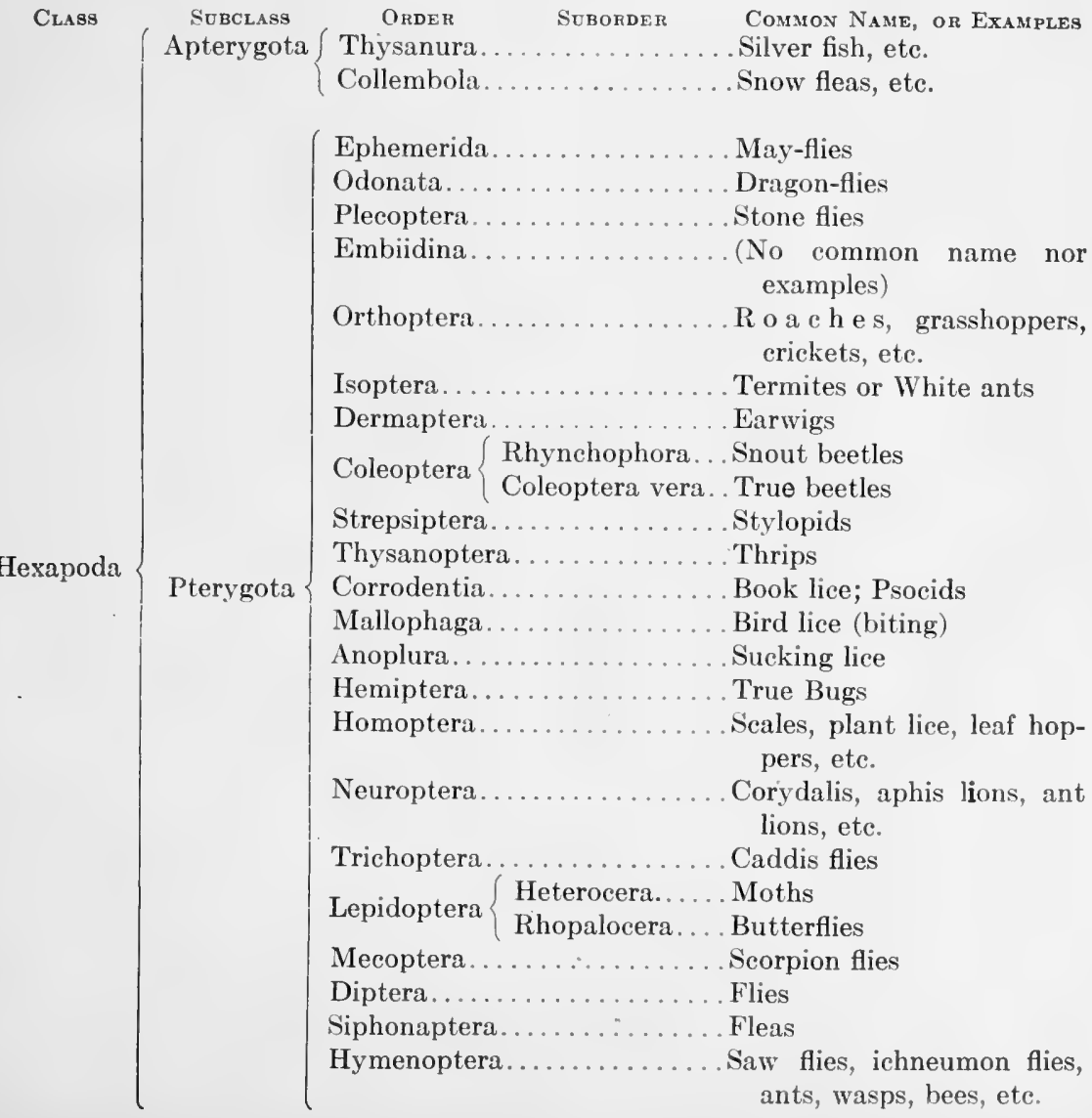




\section{CHAPTER XI}

\section{THE APTERYGOTA}

These are all relatively small insects, some being nearly microscopic in size, while the largest are seldom more than an inch in length. They are all land animals though a few live near the ocean and are occasionally found in tide pools. They are widely distributed over the earth, some living in arctic conditions while others occur in the tropics, but nearly all at least, require a somewhat humid atmosphere.

In this group the mouth parts seem to be typically of the chewing type. In many cases they are as much exposed as in most insects, but in some they appear to have been drawn into the head so that when not in use they are almost entirely concealed. Under such conditions they are often so slender as to be no longer of value for chewing, and are possibly used for rasping and sucking food.

Some Apterygota have traces of abdominal legs ("vestigial legs"). Spine-like appendages, attached to the hinder margins of some of the abdominal segments beneath and called styli, may also occur. A ventral tube present in some Apterygota on the underside of the first abdominal segment may be simply a small projection partially divided into two, or it may be highly developed into two slender but delicate tubes which can be extended to a considerable distance. Its use is not known.

Bringing together these facts, the Apterygota may be characterized as:

Wingless insects having the mouth parts either exposed and of the chewing type, or drawn into a cavity within the head where they are sometimes so slender as to be of no value for chewing but could possibly be used for sucking. In those with exposed mouth parts, more then one pair of styli is present on the back margins of the hinder abdominal segments: in those with mouth parts drawn into the head, styli, a ventral tube or traces of abdominal legs are present.

Very few of the Apterygota are of any importance from an economic standpoint, but they are of much interest, being the simplest insects known and throwing some light upon the subject of the ancestry of the insect group.

Two subdivisions, the orders Thysanura and Collembola, are generally recognized in the Apterygota. The Thysanura have styli present, while in the Collembola they are absent. Cerci, which are segmented, 
antenna-like projections backward from the end of the abdomen, occur in the Thysanura. Here they are two in number, rather long and consisting of many segments, except in a few cases where they have been transformed into a pair of good sized, unsegmented forceps. In the Collembola, cerci are either entirely absent or very small and consist. of only one segment.

\section{THE THYSANURA}

The Thysanura average much larger than the Collembola. They are characterized as:

Apterygota with styli on the underside of the abdomen, and with usually long, many-segmented cerci at the end of the body, except in a feu species where these have become a pair of forceps.

Only one Thysanuran is of particular economic importance in the United States; the Silver Fish or "Slicker" (Fig. 35).

The Silver Fish (Lepisma saccharina L.).This little household pest is found both in Europe and this country. It is silvery gray in color, usually less than half an inch long, and very active and hard to catch. Besides the two long cerci at the hinder end of the body it has a similar "caudal filament" giving the insect the appearance of having three "tails." It prefers dark places and feeds on book bindings, starched clothing, or anything containing starch, and often loosens wall paper by feeding on the starch used to paste it to the wall.

It may be controlled by placing on pieces of

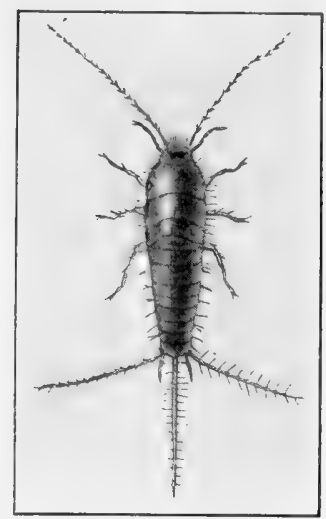

FIG. 35.-Silver $\mathrm{Fish}$ (Lepisma saccharina L.) about twire natural size. (After 14th Rept. Minn. State Entomologist.) card, starch paste made as follows: Flour 1 pint; Arsenic $1 / 2$ to $3 / 4$ oz.; water enough to make a thin paste after boiling. Spread this on the cards and place near where the insects are found, for them to feed upon. Do not place the cards where young children can get at them. The Silver Fish prefers moist to dry places, so clothing should not be stored where it is damp. Sometimes Insect Powder dusted in the haunts of this pest is helpful.

\section{THE COLLEMBOLA}

The Collembola are usually very small inseets, and being dark colored, in most cases are not often noticed. Most of this group have a "spring" attached near the hinder end of the body beneath. This consists of a single piece to which a pair of others are joined and the whole is carried pointing forward when not in use (Fig. 36). When the spring is suddenly pressed against the ground, the entire body of the insect is thrown into the air and a peculiar hopping or leaping motion results. 
The Collembola may be characterized as:

Apterygota without styli on the underside of the abdomen: cerci either absent or very small and consisting of only one segment. Usually much smaller than Thysanura and most of them with a ventral "spring."

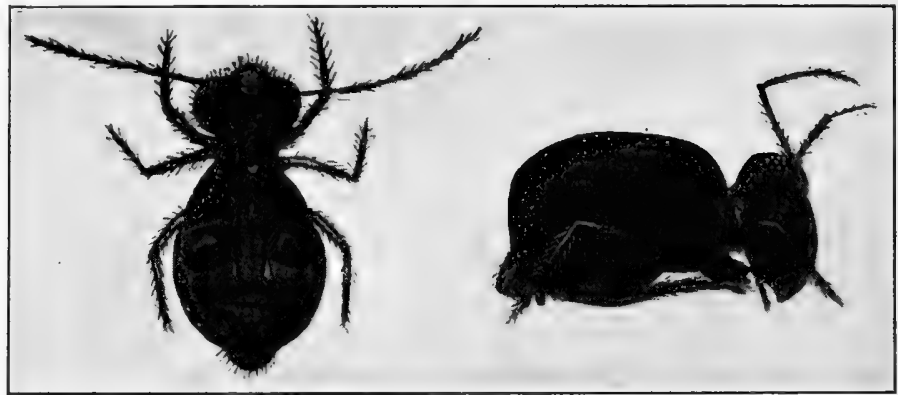

FIG. 36.-Springtail (Papirius fuscus Lucas) showing forked "spring" projecting forward toward the head beneath the body. Greatly enlarged. From Lubbock.)

The most familiar members of this order are probably the Snow Fleas, which are sometimes seen in enormous numbers on snow, where their dark color and their hopping movements make them noticeable (Fig. 37). Some of the group often become a nuisance by gathering

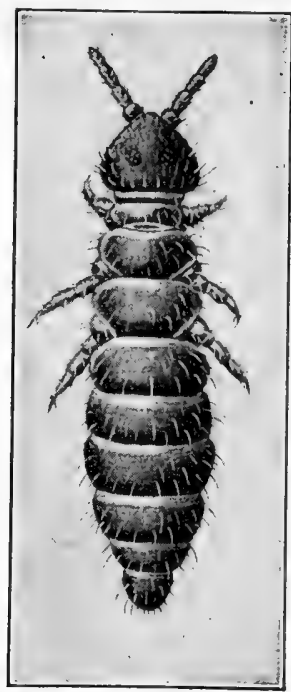

FIG. 37.-Snow Flea (Achorutes niricola Fitch) greatly enlarged. Real length $1 / 12$ inch (From Folsom.)

in maple-sap buckets on trees being tapped. Some also, feed on the leaves of plants making tiny holes, which though of themselves unimportant being small, still afford the spores of fungous diseases excellent opportunities for entrance to the plant tissues. In cases where work of this nature by Collembola is sufficient to warrant it, spraying the leaves as soon as the injury appears, with arsenate of lead, standard formula, is effective. 


\section{CHAPTER XII}

\section{THE PTERYGOTA. THE EPHEMERIDA}

The group Pterygota includes practically all our common insects and is the main branch of the class Hexapoda, the Apterygota though of equal rank, being a mere twig in size, in comparison.

As a whole the Pterygota are characterized by the presence of wings, though as already indicated, many of them for one reason or another have lost these structures.

Almost all characters present in insects may be found in this section without referring to the Apterygota: practically all the pests and all the beneficial forms belong here; and their differences are so great that 22 orders have been established as subdivisions for them.

The 'earliest writers on insects did not regard these differences as of great importance, and called the groups families or gave them even lower rank. More recent workers, however, have regarded them as of greater significance, some students of the subject being inclined to recognize more, rather than fewer orders, and it is not at all unlikely that time will finally bring a general acceptance of 26 or 28 such groups instead of the first seven established by Linné, or the 22 here treated.

\section{THE EPHEMERIDA}

The Ephemerida, May-flies or shad-flies as they are often called (Fig. 38), are insects of medium or small size. The adults have delicate bodies and gauzy, fragile wings, the latter usually with many cross-veins. The fore wings are much larger than the hind ones, which in some cases are absent, and the former are in general, rather strongly triangular in outline. When at rest they are held vertically above the body. At the end of the abdomen two or three long threads, each composed of many segments and often called caudal filaments, are usually present, the lateral ones being cerci corresponding to those in the Thysanura.

The mouth parts of the adult May-fly are of the chewing type, but so poorly developed that it is doubtful if they are ever made use of. In some cases they are even rudimentary. The reproductive organs differ from those in all the other groups, the ducts being not united on the middle line below, but opening separately to the outside-apparently the retention of a very primitive condition. The early stages are passed in the water, the nymphs breathing - at least after the first few moltsby tracheal gills. These are delicate, usually wing-like in form, and are 
outgrowths of the body wall. Into them pass tracheal trunks which - branch again and again so that only their own walls and those of the gill itself separate the air in the tracheæ from that in the water outside, and so thin are these layers that the oxygen in the water can pass through them into the tracheæ, and carbonic acid gas pass out.

These insects add to their list of peculiarities also, the fact that after becoming full grown and being able to fly, they molt once more, even a thin layer over the final wings being shed.

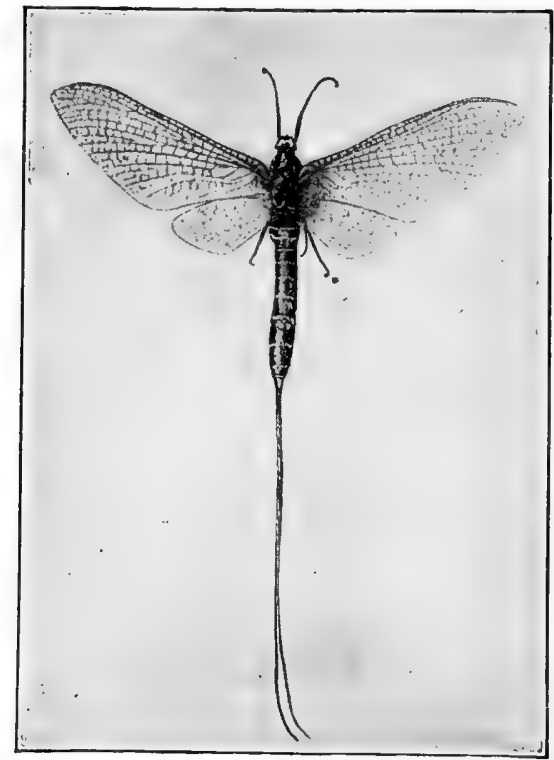

FIG. 38.-Adult May-fly (Hexagenia variabilis Eaton) showing the long cerci. Natural size. (From Folsom.)

From these statements the group may be characterized thus:

Inserts having as adults delicate bodies and usually four wings, the front pair much laryer than the others (which are sometimes absent), and generally with many cross-veins: end of the abdomen with two or three long, caudal filaments composed of many segments: reproductive organs with two openings to the exterior: mouth parts of the chewing type but practically rudimentary: nymphs living in water and with an incomplete metamorphosis, the final molt coming after the wings have become fully developed.

May-flies are most abundant near streams and lakes, as their nymphs live in the water. The fully mature nymphs leave the water, usually in greatest numbers about sunset, and suddenly molting, extend their wings and fly off, but as above stated usually molt again within a few hours. As their flight generally begins about dusk and as they are strongly attracted to lights, they are often seen in multitudes around street lights during the evenings. 
The adults live only a few hours-not more than a day or two at most-but during this time the eggs are dropped into the water. The nymphs which hatch from them feed, probably mainly on vegetable matter at the bottom, though some are doubtless partly carnivorous. They live for one, two or three years, according to the species concerned (some have two generations each year), feeding, and molting with unusual frequency for insects (Lubbock observed 21 molts in one species), until they are full-grown. During this time the mouth parts are well developed and of the chewing type, but in the adult they become practically useless.

These insects are of no economic importance except perhaps to a very slight degree as scavengers in the water, feeding on matter that might otherwise decay and become objectionable, but their value for this is probably small at best. They are fed upon as larvæ and to some extent as adults, by fish and some carnivorous insects of other groups, and for this reason also may be rated as slightly beneficial. At present about 500 kinds are known, but the group has not been very thoroughly studied. Many fossil Ephemerids have been found, which suggests that the insects are possibly less abundant now than was once the case. 


\section{CHAPTER XIII}

\section{THE ODONATA}

The Odonata are such large and noticeable insects that they have received many common names, such as dragon-flies, snake-doctors, devil's darning needles, snake-feeders, etc. They are most plentiful near water, as in this they spend their early lives, though the larger and more powerful members of the group are frequently seen flying high in the air and at some distance from their more usual habitat.

The dragon-flies have rather long, slender bodies, the abdomen being less shortened by the fusion and telescoping of its segments than in most insects. The head is large, generally rather spherical, though concave behind, and a great part of its surface is occupied by two very large compound eyes, each of which in some species, contains more than 30,000 facets. As these insects are carnivorous and capture their prey as it is flying, the advantage of large eyes which are also because of the curvature of the surface of the head, capable of seeing in almost every direction, is evident. There are also three ocelli. The antennæ are short and not very noticeable.

The mouth parts, which are of the chewing type, are large and well developed. The food appears to be captured by the legs and held by them while it is being eaten.

Four wings are present, all of about equal size, though the hinder pair are somewhat larger except in the section known as the Damselflies. The main veins are stout and are connected by many cross-veins. Near the middle of the costa of each wing is a slight notch called the nodus, at which point there is a particularly stout cross-vein. When at rest the wings are held either nearly vertical over the body (damsel-flies) or extended laterally, much as in flight. The metamorphosis is by progressive changes at times of molting, and though the nymph can hardly be said to ever greatly resemble the adult, development may be considered as being by an incomplete metamorphosis.

The Odonata may then be characterized as:

Insects which as adults usually have long, slender bodies, large heads and large eyes: wings four, membranous, the hinder pair as large or larger than the front pair, and each has near the middle of its front margin a notch, somewhat resembling a joint, called the nodus: mouth parts for chewing and well developed. Metamorphosis incomplete.

There are two groups of dragon-flies. In one the insect is slender, the two pairs of wings are of about equal size, and when not in use are 
held almost vertically above the body (Fig. 39). These insects are often called damsel-flies. In the other group the body is stouter and propor-

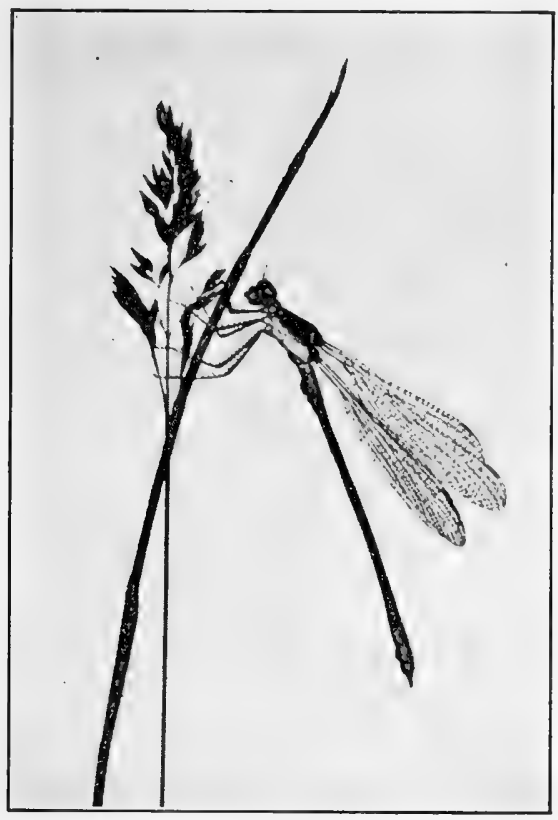

FIG. 39.-Damsel-fly (Lestes uncata Kirby) showing position of wings when at rest. (After Needham, N.Y. State Mus. Bull. 68.)

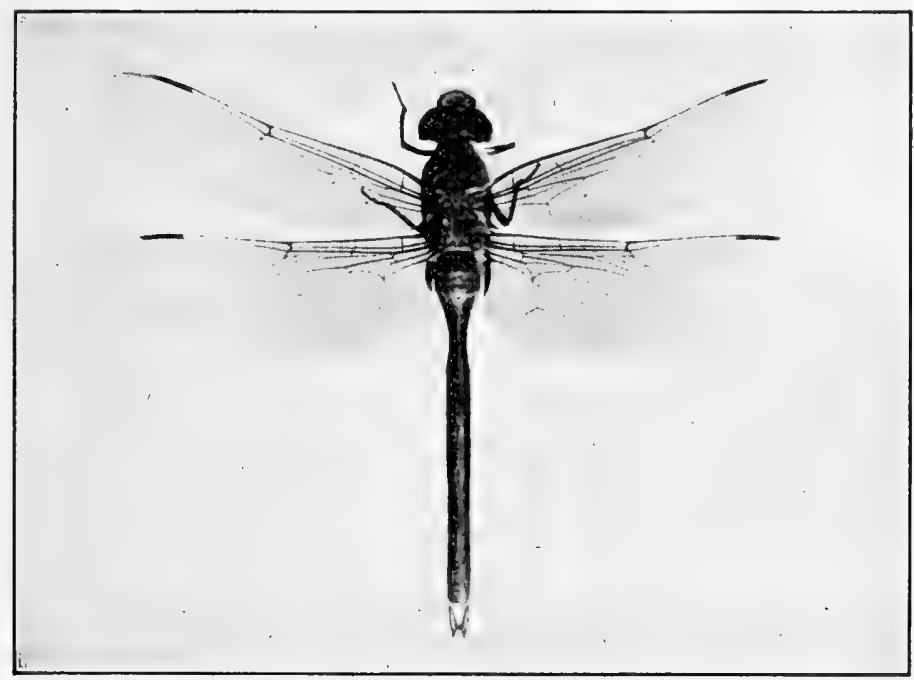

FIG. 40.-Dragon-fly (Anax junius Dru.). Natural size. (Original.) tionally shorter, and the wings when at rest extend out horizontally at the sides of the body (Fig. 40). 
The bodies of dragron-tlies are often brilliantly colored, and in some cases corered with a "bloom," giving them a whitish appearance (Fig. 41). The adults feed on practically almost any flying insects smaller than themselves which they may capture during their Hight. Flies and

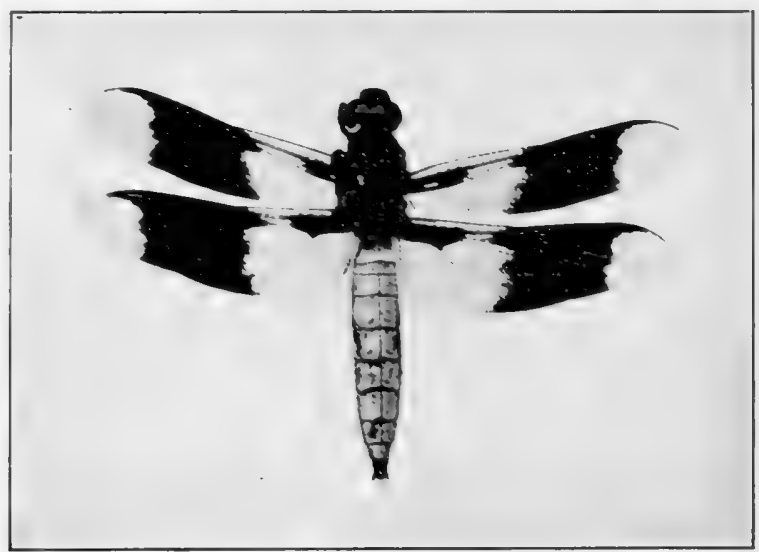

FIG. 41.-Dragon-1ly (Plathemis lydia Dru.) showing "bloom" on abulomen. About natural size. (Original.)

mosquitoes form a farorite foot. and the attempt has heen made to "tame" (lragon-flies and keep them in houses on this aceount. but without suecess. They are very roracious, one specimen having been known to consume to house-flies in less than two hours.

Many dragon-tlies fly very swiftly cither in direct lines or making sudden changes of direction while hunting their prey, and are perhaps

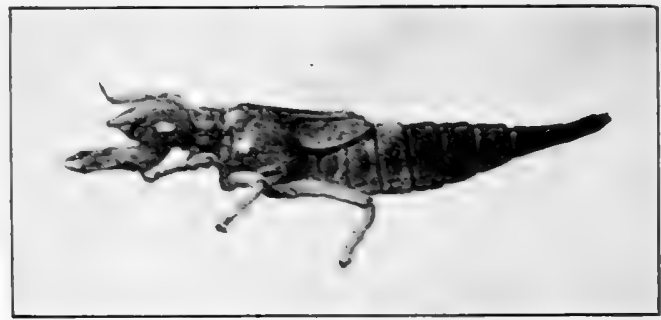

Fici. f2.-Nyuph of a Dragon-fly with mask extended forward. Enlarged ouc-third. (Uriginal.)

uncequalled in this regard by any other insects. They also mate in the air. The curs are laid either in the water, attached to water plants, or in the stems of plants under water. In the latter case they are laid singly but otherwise they are usually in clusters containing either a small or a large number of eggs.

The eqge may hateh after a few days or if laid in the fall, may not produce nymphs until the following spring. The young nymphs stay 
at the bottom of the water and are carnivorous, feeding on larger and larger animals as they grow, individuals of the largest species attacking small fish in some cases, though the bulk of their food is undoubtedly the aquatic larvæ of insects. They lie on the bottom waiting for their prey to come within reach, and when it is near enough they thrust out the under-lip (labium) and seize it (Fig. 42). This labium has been remarkably developed from its usual form, being drawn out into two long pieces with a pair of jaws or claws at the end. When not extended the piece connected at one end with the head is bent backward under the body, while the second piece, hinged to the other end of the first, extends forward so that its front end with the jaws lies near the front of the head, which it somewhat conceals, and this has led to calling the structure a "mask." When this is extended forward it reaches out more than twiee the length of the head, thus enabling the nymph to capture animals which are not very close to it.

Breathing in the nymphs of the damsel-flies appears to be, in part at least, by means of long and rather large, tracheal gills at the end of the abdomen, which are also used for swimming. In the other section of the Order, the gills are found in the rectum, into which water is drawn, bathing the gills there, after which it is expelled, and if this is done quickly the recoil carries the nymph forward, thus providing one means of locomotion.

Molts are frequent, and when full-grown the nymph crawls out of the water and molts for the last time, whereupon the wings grow to full size and the adult insect is produced. Some dragon-flies have two generations a year or possibly even more, while in other cases more than a year is necessary to a generation, but one each season is the usual condition.

Despite tradition and their bad reputation, dragon-flies are in no way injurious to man, not stinging - they have nothing to sting withnor biting to such an extent as to cause the slightest pain, their jaws being too weak to even break the skin. They are beneficial insects both as young and adults, so much of their food consists of injurious insects such as flies, mosquitoes, etc., while the injury they cause by feeding on fish is usually so slight as to be negligible.

Dragon-flies are sun-loving animals, concealing themselves during dark, cloudy weather Between 5,000 and 10,000 kinds are known, and the greatest number of these occur in the warmer regions. Fossil dragonflies or insects resembling them are numerous, and some of them were very large, one measuring more than two feet from wing-tip to wing-tip. 


\section{CHAPTER XIV}

\section{THE PLECOPTERA}

The most usual common name for the Plecoptera is the Stone-flies. They range from small to good-sized insects whose bodies are quite long, flattened and with rather parallel sides. The wings are nearly always well developed and with many cross-veins, though in a few cases they are very small and in some species the cross-veins are few. Considering only the more usual condition, the fore wings extend well behind the end of the body when closed and have a considerably smaller area than the hind wings which are so broad that when they are at rest upon the upper side of the body they must be folded lengthwise into plaits to reduce them to the necessary width (Fig. 43).

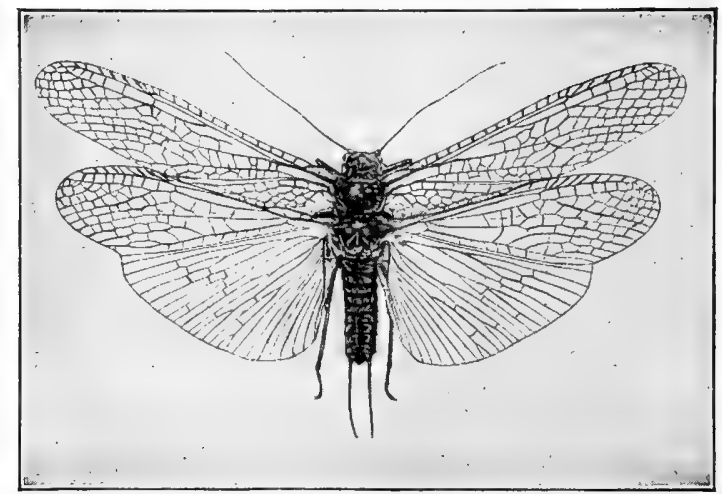

FIG. 43.-Adult Plecopteran (Pteronarcys regalis Newm.). Slightly reduced. (From Folsom.)

The antennæ are long and composed of many segments. In most members of the group a pair of cerei is present at the end of the abdomen. The mouth parts are of the chewing type but are generally so weakly developed as to be practically useless. The larvæ live in water and do not differ greatly in appearance from the adults.

The group may be described as follows:

Insects which as adults have four membranous wings, usually longer than the body, and generally with many cross-veins. Hind wings larger than the front ones and when at rest folded lengthwise and lying, covered by the front pair, on the abdomen. Antennce long: a pair of caudal cerci usually present: mouth parts for chewing but generally poorly developed. Metamorphosis incomplete. 
Adult stone-flies are most numerous near streams and particularly those with a rapid current. The eggs which are often several thousand in number, are laid in the water and the nymphs locate on the underside of stones. Some breathe through the surface of the body. Tracheal gills, when present, are not leaf-like as in the May-flies but are tufts of numerous short, thread-like structures containing tracheæ, a tuft or bundle just behind each leg, on the underside, and also on the first two abdominal segments. When fully grown the nymphs leave the water and molt for the last time on land. They feed on small insects, probably largely May-fly nymphs, and possibly on vegetable matter (diatoms) and are themselves a favorite food for fish.

Some species of stone-flies appear in enormous numbers just as the ice is breaking up in the streams, in the northern United States, and others are found on the snow even earlier in the season, on warm days. In general the group is without economic importance, but a few kinds of adults have recently been observed injuring the buds and foliage of fruit trees as these first develop, in the northwest, and in these species the mouth parts are much more strongly developed than in the others. Only 2,000 to 3,000 species are known. 


\section{CHAPTER XV}

\section{THE EMBIIDINA}

This is a small group of insects, only about 60 species having been described. They live in warm climates either under stones or on plants in crevices of the bark or elsewhere, spinning silken tunnels in which to live. The largest species known is less than an inch long (Fig. 44).

The wings are generally (always?) present in the males and absent in the females. The tunnels appear to be formed at least partly for protection, but perhaps also to aid in preserving moisture, for when dry

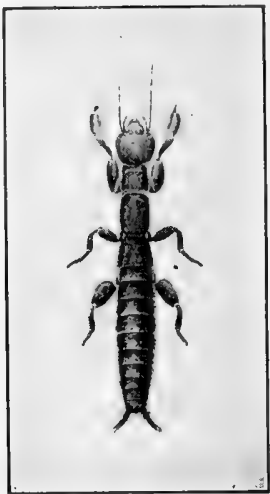

FIG. 44.-Embia major Imms, about $1 \frac{1}{2}$ times natural size. (Reduced from Imms. Trans. Linn. Soc. Lond. 1913.)

weather comes on they are carried deeper into the soil in the groundinhabiting forms. The silk appears to be produced by glands located in the tarsi of the fore legs - something unparalleled elsewhere among insects. The mouth parts are of the chewing type.

The food of these insects is probably vegetable matter, but the injury they do to plants, as thus far reported, is not great. Even where they are most abundant they are seldom seen except by those looking for them. A few fossil specimens belonging to this group have been found preserved in amber. The Embiids appear to be more closely related to the Plecoptera than to any of the other orders of insects. 


\section{CHAPTER XVI}

\section{THE ORTHOPTERA}

The Orthoptera is a large group of insects containing over 10,000 species. Many of them are very large and striking in appearance and common names have been given to different families in the order, but none to it as a whole.

The insects of this order are so diverse in structure, appearance and habits that it is difficult to give distinctive characters, but they all have well-developed chewing mouth parts. The majority of them have four wings, the front pair being slightly thicker than the others, somewhat leathery in texture, and overlapping more or less when folded. The hind wings are almost always larger and fold in plaits. In many of the group, however, the wings are lacking or very small, in which case it is difficult to determine whether the insect is an adult or a nymph, without, or with only partially developed wings.

In some of the families the hind legs are much developed and the insects have the power of jumping: in others this is not the case and walking and running are their methods of locomotion on the ground. On this basis the Order has often been divided into two sections, Cursoria or running Orthoptera, and Saltatoria or leaping Orthoptera.

The Orthoptera may be defined, despite the difficulties above indicated, as:

Insects which when adult have mouth parts for chewing; usually four wings, the front pair thicker than the others; the hind pair larger and folded in plaits when at rest. A pair of cerci is always present. Metamorphosis incomplete.

Many students of the group are of the opinion that the insects included in this order should really be placed in two or three, but at present such a separation seems hardly advisable. Most of the families are quite distinct. The group is frequently divided into eight or ten families, but for the purposes of this book, six will be considered. These are:

\footnotetext{
Cursoria $\left\{\begin{array}{l}\text { Blattidæ, Roaches. } \\ \text { Mantidæ, Mantids. }\end{array}\right.$

( Phasmidæ, Walking Sticks.

Acrididæ, Locusts and Short-horned Grasshoppers.

Saltatoria Tettigoniidæ, Long-horned Grasshoppers and Katydids.

Gryllidæ, Crickets.
} 


\section{Family Blattidæ (The Roaches)}

These insects are known by a variety of common names such as roaches, cockroaches, water-bugs, and black-beetles. The group is primarily one living in warm countries with many kinds living in houses, and many more, some of them several inches in length, occurring wild. In more northern climates only a few are wild and four are household pests; these last when adult ranging from less than an inch to nearly two inches in length. In the north the wild species are found under logs and stones and never enter houses. They are pale brown and the winged adults are an inch or slightly more in length.

Roaches are generally brown or dark colored, though some are green. They are broad and flattened, with the head bent under the body so that the mouth opens backward and the eyes look downward. The antennæ are long, slender and of many segments. Wings are usually developed in the adults and the hinder pair fold once. The mouth parts are strong and the legs are long, and bear many spines. Roaches are active at night, hiding in dark places such as cracks and crevices during daylight, and can run rapidly.

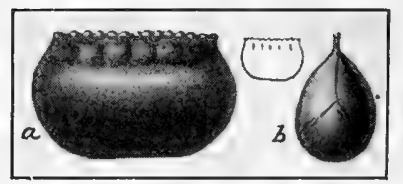

Fig. 45.-Egg case of American Roach: $a$, side; $b$, end view. Both considerably enlarged. (Modified from U.S. D. A. Farm. Bull. 658.)

The household pests of this group consume foods and food materials freely; gnaw woolen goods, leather, and anything which has paste on it, and thus often injure book bindings; in fact they are practically omnivorous. Besides eating, they leave a disagreeable "roachy" odor which spoils food where they have been. When abundant they become very troublesome and vigorous measures must be taken for their control. They lay their eggs in packets, the number per packet varying with the species, and the outside case is horny in nature (Fig. 45). This case may be carried around partly projecting from the body of the parent for several days or even weeks. The young are active, feed freely and molt several times, but it is doubtful if there is more than one generation a year, at least in the northern United States.

\section{House Roaches}

The German Roach (Blatella germanica L.).- This insect, often called the Croton bug, came from Europe and is generally the most common of the house roaches in the eastern United States (Fig. 46). 


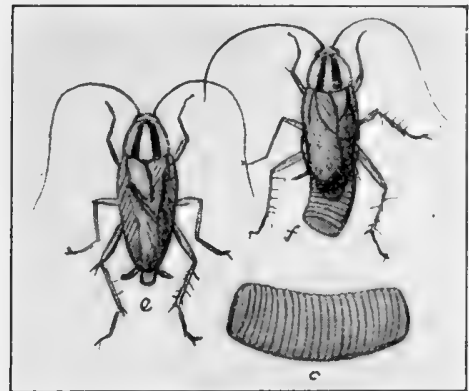

Fig. 46:-German Roach or Croton Bug (Blatella germanica L.). c, egg case much enlarged $e$, adult, natural size; $f$, adult carrying egg case. (From U.S. D. A. Farm. Bull. 658.)

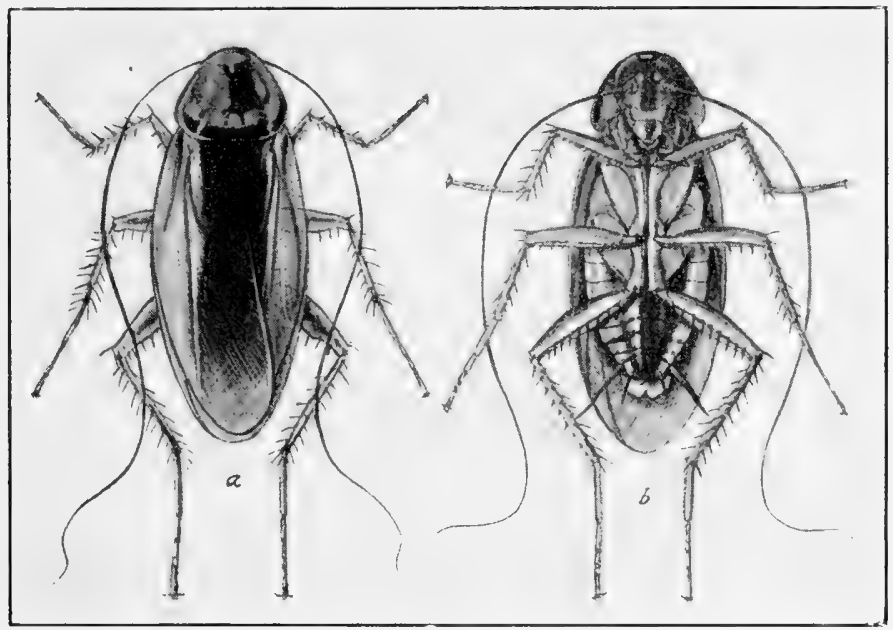

FIG. 47.-American Roach (Periplaneta americana L.) adults: $a$, from above; $b$, from beneath, about natural size. (Modified from U. S. D. A. Farm. Bull. 658.)

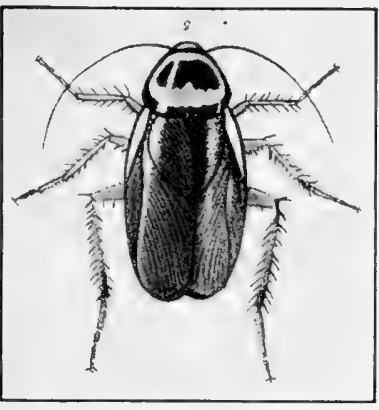

FIG. 48 .

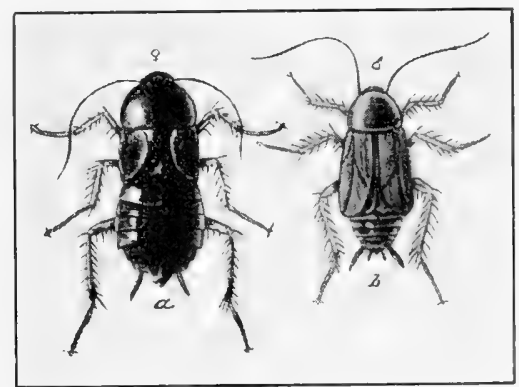

FIG. 49 .

Fig. 48.-Australian Roach (Periplaneta australasice Fub.). Adult, about two-thirds natural size. (Reduced from U.S. D. A. Farm. Bull. 658.)

FIG. 49.- Oriental Roach (Blatta orientalis $L_{\text {. }}$ ) adults about two-thirds natural size: $a$, female; $b$, male. (Reduced from U.S. D. A. Farm. Bull. 658.) 
The adult is from one-half to three-fourths of an inch long, pale brown with two darker brown stripes. It is very active and increases in numbers very rapidly.

The American Roach (Periplaneta americana L.).-This is the largest of the house roaches, being from one and one-fourth to one and one-half inches long when adult. It is brown, darker than the German roach, and has a more or less definite yellow band around the margin of the pronotum (Fig. 47). It is a native of the warmer parts of this country but has spread north and is now abundant everywhere except in the most northerly states.

The Australian Roach (Periplaneta australasice Fab.).- Somewhat smaller and apparently broader than the last, and with the yellow band around the prothorax brighter, and a yellow streak on the costa of the fore wing extending part way toward the tip (Fig. 48). It is particularly common in the Southern States.

The Oriental Roach (Blatta orientalis L.).- This insect is the "blackbeetle" of Europe. It is almost black and the wings in the adult male are considerably shorter than the body, while in the female they are hardly more than stubs. It is a stout-bodied insect, quite generally present in the eastern, southern and central United States as far west as the great plains, and is the most common species in Europe (Fig. 49).

Other kinds of roaches are occasionally found in the Northern States brought there in bunches of bananas or with other southern fruits, but they do not appear to be able to live long in the colder climates.

Control.-Various materials are more or less effective as roach killers, but the best of these is commercial sodium fluorid. It may be mixed with flour or some other inert substance, but nothing is gained by this except a reduction of the cost of treatment and the killing may not be as rapid. The powder is thoroughly dusted where the roaches occur, particularly in their hiding places, using a dust gun or blower. The insects which by crawling or in other ways get the dust on their antennæ or legs, clean these parts by drawing them between their mouth parts so that the powder enters the mouth and probably acts through the alimentary canal.

\section{Family Mantidæ (The Mantids)}

The Mantids are usually quite large insects with bodies much longer than wide, and a broad head which moves very freely upon the thorax. The prothorax, with few exceptions, is very long, and bears legs adapted for grasping the prey and which are well provided with spines, the insects walking on the other four. In nearly all members of the group the wings are well developed, the hinder pair larger and folding in plaits when at rest with the other pair on the back of the abdomen. They are often called Rear-horses, Devil-horses, Soothsayers, Praying Mantids or Mule Killers. 
The Mantids are carnivorous, feeding on flies and other insects and are therefore beneficial. Fifteen to twenty kinds occur in the United States, particularly in the south, but the group is mainly found in tropical countries where it reaches its greatest development and includes some remarkable forms.

Mantid eggs are laid in cases composed of a thick material which quickly dries. They are usually laid in the fall and hatch the following spring. Some of the cases are very noticeable, being an inch or more long. They are usually attached to plant stems (see Fig. 51).

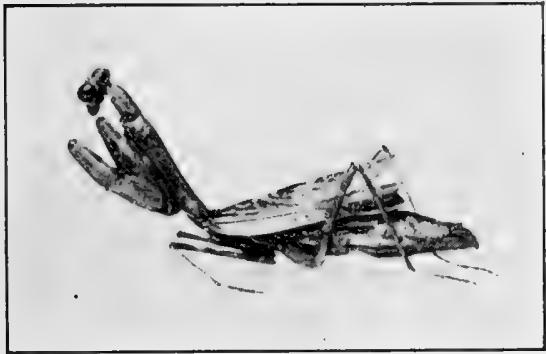

FIG. 50 .

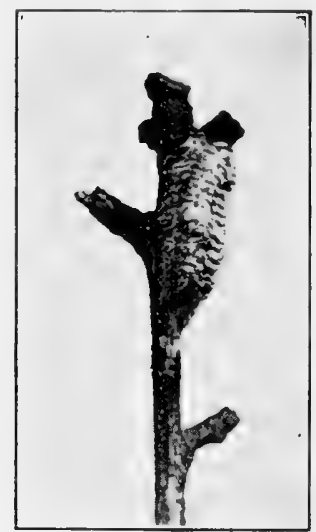

F $1 \mathrm{G} .51$.

Fig. 50.-Common American Mantis (Stagomantis carolina L.) waiting for its prey. Slightly reduced. (Original.)

Fig. 51.- Egg case of common American Mantis, natural size. (Original.)

The most common Mantis (Stagomantis carolina L., Fig. 50) is found as far north as southern New Jersey, Pennsylvania and Ohio. It is about two and one-half inches long when adult, green or brown, or a mixture of the two colors, and is found not only on plants but also often on houses, sheds or in other places where it may obtain its prey. It locates in some spot, then raising its prothorax and head somewhat, with its fore legs partly extended, quietly waits until an unwary insect comes within its reach. When this happens, a quick motion of its fore legs and the prey is seized, the spines aiding in holding the insect, which is then fed upon.

In 1897 a Mantid from China (Paratenodera sinensis Sauss.) was discovered near Philadelphia where it appears to have successfully established itself. It is much larger than the common native Mantis, being about four inches long. In 1899 the common European Mantis (Mantis religiosa L.) was found near Rochester, N. Y., where it appears to be quite common. It much resembles our native form but is slightly larger (Figs. 52 and 53). 
As these insects are beneficial, attempts have been made to establish them in other places, but thus far they do not seem able to withstand severe winters, and in the case of the last named species it has until now

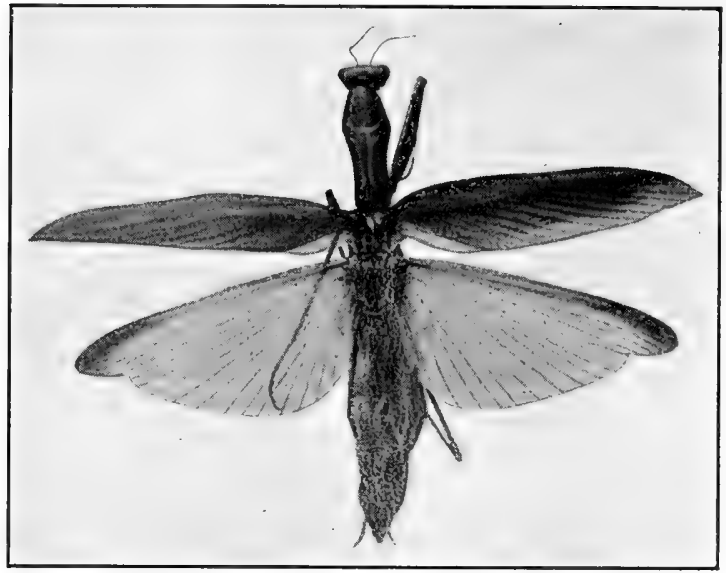

FIG. 52.

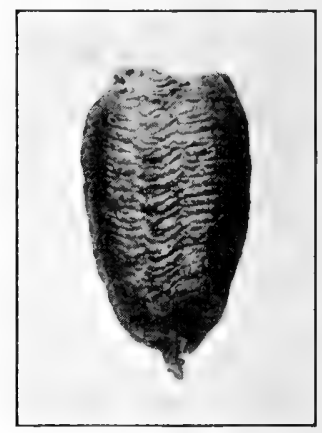

FIG. 53.

FIG. 52.-European Mantis (Mantis religiosa L.), natural size, with wings spread. (Original.)

FIG. 53.-Egg case of European Mantis, natural size. (Original.)

apparently been unable to live north of Ontario, and colonies placed in New England have died out.

\section{Family Phasmidæ (The Walking-Sticks)}

The Phasmids are generally called "walking-sticks." Their bodies are usually long and stick-like, due largely to their very long and slender

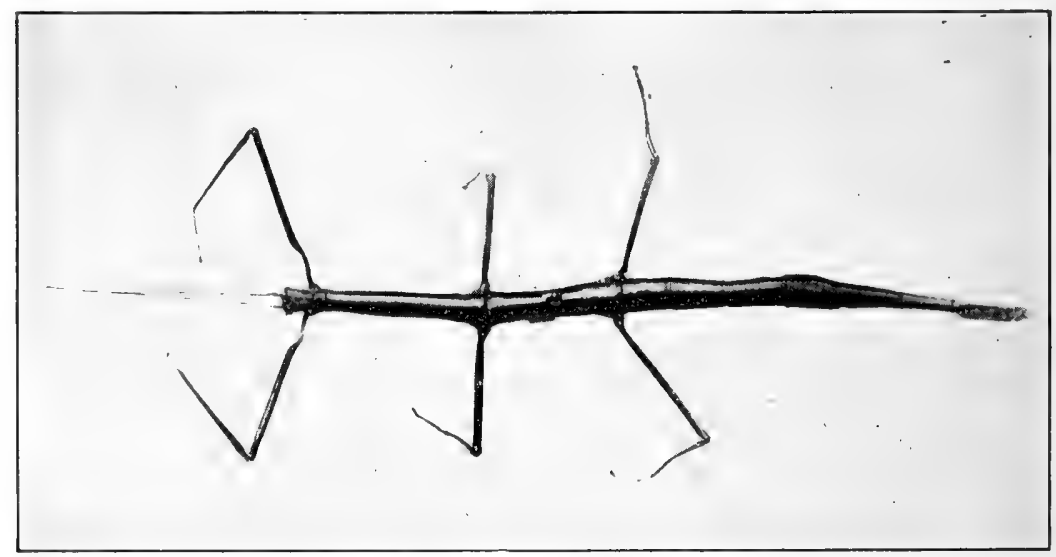

FiG. 54.-Common Walking-stick (Diapheromera femorata Say) natural size. (Original.)

meso- and metathoracic segments. Their legs and antennæ are also generally long, and the 15 to 20 kinds found in the United States 
are wingless, or with only wing stubs, which adds to their stick-like appearance. They are brown or green in color and thus much resemble the twigs on which they rest, or the larger leaf veins. Only one species (Diapheromera femorata Say) is abundant except in the more southern states, but this is quite generally present (Fig. 54).

Walking-sticks feed on foliage and when abundant may entirely strip many acres of forest trees of their leaves, though this does not often happen. Their eggs are laid in the fall, being dropped singly, wherever the insects happen to be, and falling to the ground remain there until the following spring, or in some cases until the second spring, before hatching. Though not laid a number together in a case as in the last two families, each egg has a case or capsule of its own.

Where forest areas are attacked, no entirely satisfactory method of control is known. In the case of a few trees or plants easily accessible, spraying with a stomach poison is sufficient to prevent farther injury.

This group is mainly a tropical one, over 600 kinds being known, very variable in size and appearance. One species has a body nine inches or more in length, and with its front legs extended forward and its hinder ones backward-a position it often assumes-may measure sixteen inches or even more, while its body has a diameter of less than one-quarter of an inch. In the tropical forms wings are

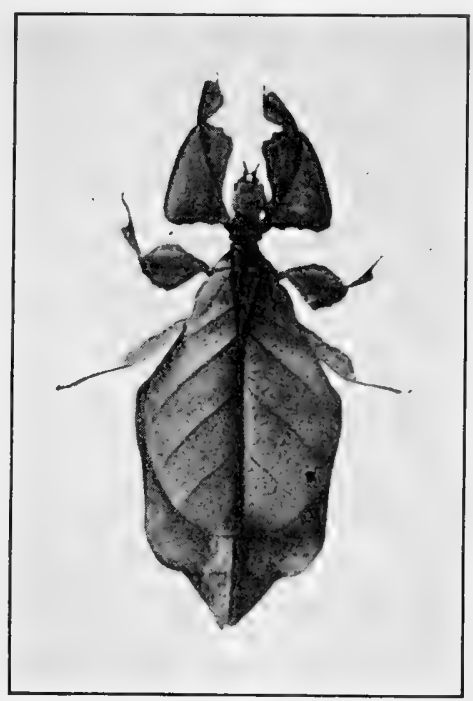

FIG. 55.-A Tropical Leaf-insect (Pulchriphyllium scythe Gray) about half natural size. (Original.) of ten present, and in some cases colored and marked to resemble leaves. This resemblance is increased in Pulchriphyllium scythe Gray (Fig. 55), found in the East Indies, by leaf-like expansions of the femora and tibiæ and of the body itself.

The insects belonging to the three families of this order, treated thus far, are all walkers or runners (Cursoria). Those now to be considered are leaping forms (Saltatoria), the hind legs being longer than the others and provided with powerful muscles. Their heads are generally strongly hypognathous, the mouth being directed downward and in some cases even a little backward. Sounds sometimes called musical are produced by most members of these families.

\section{Family Acrididæ (The Grasshoppers)}

The insects belonging in this group are commonly called grasshoppers. A few kinds when adult migrate, often in such enormous numbers as to 
look like clouds in the sky. These migrating species are sometimes spoken of as locusts.

Grasshoppers are feeders on grass and vegetation in general and are injurious, the amount of injury they cause varying with their abundance. Their antennæ, shorter than the body, and their tarsi, consisting of only three segments, quickly distinguish them from the related family Tettigoniidæ. The pronotum is extended backward somewhat, and down on the sides of the prothorax almost to the base of the fore legs. In the female there is a short, stout ovipositor composed of four parts, and the rather narrow fore wings, usually somewhat leathery in texture, cover the large, delicate hinder pair when these, folded in plaits, are at rest above and along the sides of the body.

Most grasshoppers lay their eggs in the ground, usually in the fall, and these hatch the following spring. The female works its ovipositor into the soil a short distance, then pushes apart its four pieces and deposits its eggs in a cluster containing from twenty-five to perhaps

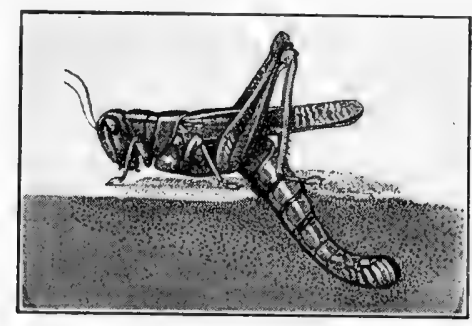

FIG. 56.

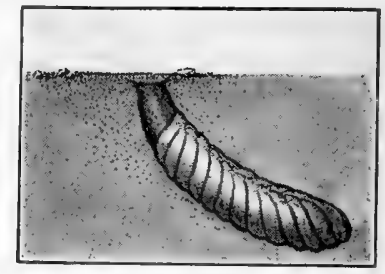

FIG. 57.

FIG. 56.-Two-striped Grasshopper (Mclanoplus bivittatus Say) laying eggs. (Reduccel from U.S. D. A. Farm. Bull. 747.)

FIG. 57. - Sae, or "Egg-pod" of Grasshopper eggs in the ground. About natural size. (Reduced from U.S.D. A. Farm. Bull. 747.)

five times that number of eggs, covered by a fluid which hardens and forms a sort of protecting case (Figs. 56 and 57). The young on hatching, work their way out of the ground and feed, molting several times and becoming adult after 2 or 3 months.

Only a few of the kinds of grasshoppers found in the United States are sufficiently migratory in their nature to deserve the name "locust." During the period between 1860 and 1880, however, and to some extent since, inhabitants of the states west of the Mississippi River have at times suffered the entire, or almost entire loss of their crops by the ravages of swarms of the Rocky Mountain locust (Melanoplus spretus Thom.) which, breeding in immense numbers on the eastern slopes of the Rocky Mountains, upon maturity migrated eastward for food, and stripped everything where they alighted. Settlement of these breeding grounds, and cultivation, destroying the eggs, has largely put an end to these migratory flights, but occasionally grasshoppers occur in destruc- 
tive abundance, not only in the West but in all parts of the country wherever they become so plenty as to lay large numbers of eggs in ground not cultivated, such as pastures. Under such conditions, a sudden, more or less local outbreak of these insects may take place in the spring, the damage being caused in these cases, at first by the feeding of the nymphs, and later, if nothing is done, by the adults.

Aside from plowing, harrowing or disking land in which grasshoppers breed, before the eggs hatch in the spring, the most successful method of control when they appear in sufficient abundance to make treatment necessary, is the use of a poisoned bait. There are various formulas for this, but there is no marked difference in the results in most cases.

One in general use is: wheat bran, $25 \mathrm{lb}$; Paris green or white arsenic, $1 \mathrm{lb}$; oranges or lemons, 6 fruits finely chopped; low-grade molasses, 2 qt. Mix the bran and poison well, dry; then add the chopped fruit and its juice; finally add the molasses and stir thoroughly. Enough water-2 or 3 gal.- should be added to this so that each flake of the bran is sufficiently moist to have some of the poison adhere to it, and also take up the flavor of the fruit and molasses, yet not enough to make the flakes stick and prevent sowing broadeast. This amount of material should be sufficient to spread over two or three acres. In the Eastern States and wherever the air is moist, the best results are obtained by spreading the bait very early in the morning. In arid or semiarid regions, 3 or 4 gal. of water may be needed in the mixture, which should be distributed toward night.

A form of poisoned bait, known as the modified Criddle Mixture, substitutes a half barrel of fresh horse droppings for the bran and omits the molasses. The only advantage with this is that it can be used where bran is too expensive or hard to obtain.

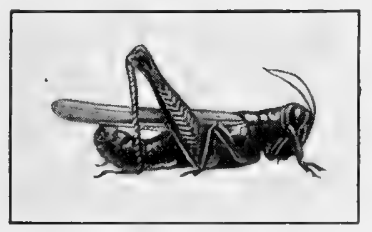

FIG. 58 .

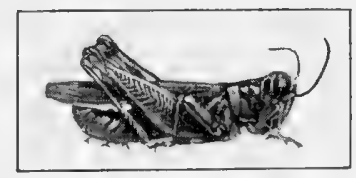

FIG. 59

FIG. 58.-Red-legged Grasshopper (Melanoplus femur-rubrum De G.) about natural size. (Reduced from U.S.D. A. Farm. Bull. 747)

FrG. 59.-California Devastating Grasshopper (Melanoplus devastator Scudd.) about natural size. (Reduced from U.S.D. A. Farm. Bull. 747.)

There are many kinds of grasshoppers in the United States. Among the more abundant and therefore injurious species, may be mentioned the red-legged grasshopper (Melanoplus femur-rubrum De G., Fig. 5s), about an inch long, its hind tibiæ bright red; the California devastating grasshopper (Melanoplus devastator Scudd., Fig. 59), a little smaller, found in the Western States; the differential grasshopper (Melanoplus differentialis Thom.), about an inch and a 
half long, present nearly everywhere, but rare in the East; the two-striped grasshopper (Melanoplus bivittatus Say) about the size of the last, with two yellow stripes along its back, generally distributed except in the South Atlantic States (Fig. 60); the lesser migratory grasshopper (Melanoplus atlanis Riley) about an inch long, found nearly everywhere in the United States and frequently

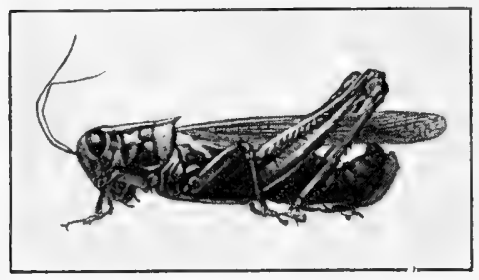

FIG. 60 .

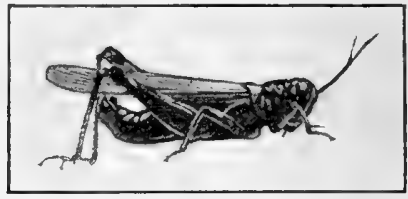

FIG. 61.

F1G. 60.-Two-striped Grasshopper (Melanoplus bivitlatus Say) about natural size. (Reduced from U.S.D. A. Farm. Bull. 747.)

FIG. 61.- - Lesser Migratory Grasshopper (Melanoplus atlanis Riley) about natural size. (Reduced from U. S. D. A. Farm. Bull. 747.)

seriously abundant west of the Mississippi River (Fig. 61); and the clear-winged grasshopper (Camnula pellucida Scudd.) which though small is of ten very injurious. It is found in all the northern United States and has its hind wings clear and almost colorless, while its fore wings are spotted with brown. All of these species attack various cereal and forage crops.

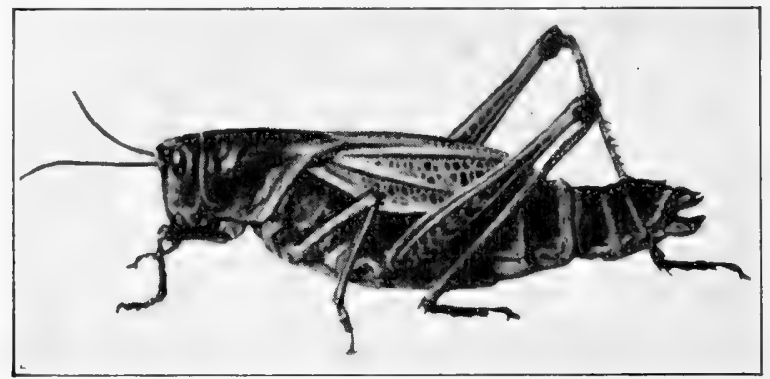

FiG. 62.-Florida Lubber Grasshopper (Dictyophorus reticulatus Thunb:) about natural size. (From U.S. D. A. Farm. Bull. 747.)

In the Southern and Western States are large, short-winged grasshoppers which are very stout, and from their appearance and clumsy movements are called "lubber grasshoppers" (Fig. 62). They attack grass, alfalfa and other crops.

The Carolina grasshopper (Dissosteira carolina L., Fig. 63), one and a half inches or more in length, is gray or brown, varying somewhat with the color of the ground where it lives. It is most noticeable along roads and when startled into flight its black hind wings with yellow margins, and the crackling sound often produced at such times are sufficient to attract attention. It is found throughout the entire United States. 
In one section including the smallest grasshoppers, generally called "grouse locusts," some of which are less than half an inch in length, the pronotum is extended back to, or even beyond the end of the abdomen and the fore wings are reduced to mere stubs. Two common species are shown in Fig. 64.

The hind wings of grasshoppers are often brightly colored, yellow, red, or black. The legs also often show bright colors.

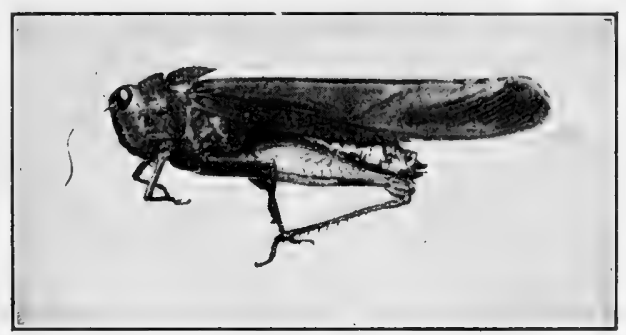

FIG. 63.--Carolina Grasshopper (Dissosteira carolina Say) natura size. (Original.)

The sounds produced by grasshoppers are made in one or the other of two ways. In some species the hind legs are drawn up and down across the fore wings, ridges on the inner face of the femur scratching against a heavy vein on the wing and giving a rasping sound. In others the sound is produced while flying. Here the front edge of the hind wing

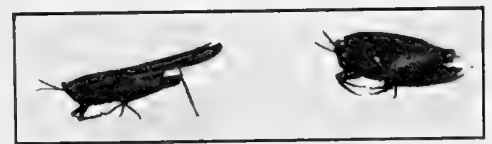

FIG. 64.-Two types of "Grouse Locusts," natural size. (Original.)

is struck against the under surface of the fore wing, making a short, sharp sound, which, quickly repeated, gives a kind of "crackling." Apparently the organs of hearing are located on each side of the body just above the base of the hind leg. Each is a rather large, smooth disk, suggestive of an ear drum membrane, connected by nerve fibers with a small ganglion which in turn connects with the main nervous system.

\section{Family Tettigoniidæ (The Green Grasshoppers and Katydids)}

A part of the insects of this family are called green grasshoppers, long-horned grasshoppers, or meadow grasshoppers, while others are the katydids. Their tarsi consist of four segments. Most of them are green in color, and all have antennæ longer than their bodies. Some of the katydids have broad fore wings and these live among trees and shrubs, feeding on the leaves and even on the more tender twigs (Fig. 65). 
Others have narrow fore wings and appear to prefer bushes or tall weeds and grass as their abiding places (Fig. 66). The meadow grasshoppers resemble the narrow-winged katydids but average smaller and are most

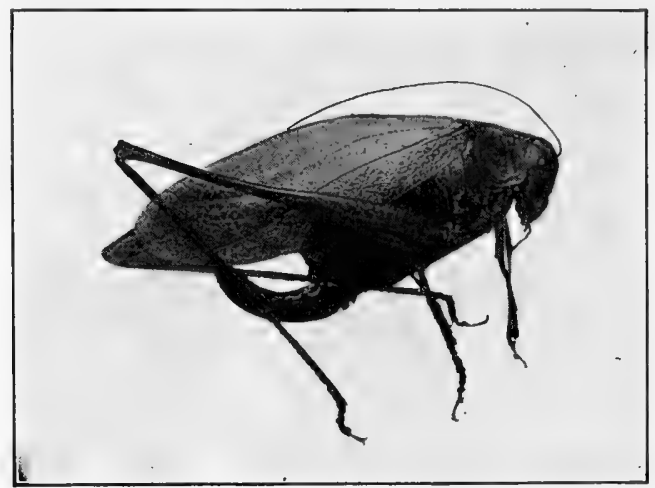

Fia. 65.-Broad-winged Katydid (Amblycorypha rotundifolia Scudd.), natural size. (Original.)

abundant in fields and pastures, particularly where the grass is thick and tall. In most members of the group the ovipositor is long or at least large enough to be quite noticeable.

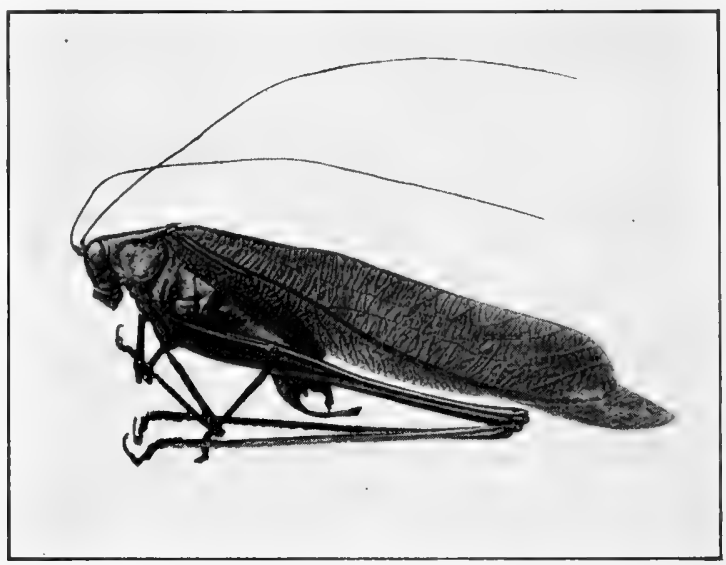

FIG. 66.- Narrow-winged Katydid (Scudderia curvicauda De G.), slightly enlarged. (Original.)

Some of the Tettigoniids are wingless and come out only at night, hiding under logs, stones or in dark places during the day. They are of various shades of brown or gray, and the species found in different parts of the country vary much in appearance (Fig. 67). They are called "wingless grasshoppers," "camel crickets," "shield-backed grasshop- 
pers," "Jerusalem crickets," ete., according to their kind and the local usage.

Sound in this family is produced by the males. The base of the fore wing is modified, not necessarily in the same way in all the species, but in such a manner that rubbing these wings together will produce a sound. The organ of hearing is a small, oval membrane located near

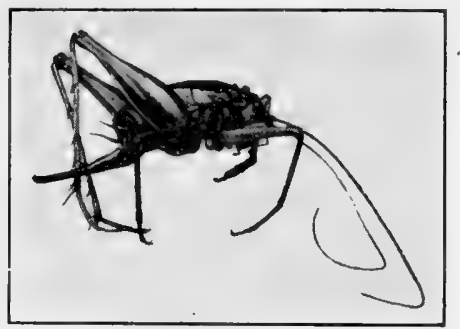

FIG. 67.- "Wingless Grasshopper," natural size. (Original.)

the base of the tibia on each side of the front leg. Inside the membrane is a hollow space or resonance chamber, and a nerve supply. The sounds made by these insects are produced chiefly toward evening and at night, though in dense woods they may sometimes be heard earlier in the day.

The members of this group are rarely serious pests, though katydids have been known to injure orange groves and presumably some forest

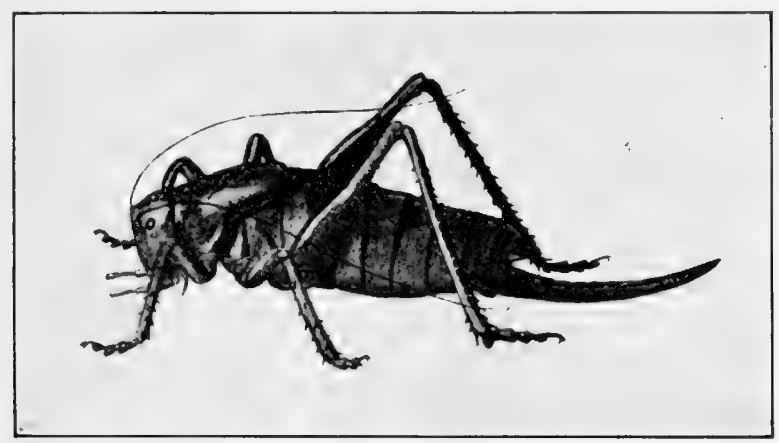

FIG. 68.- "Western Cricket" (Anabrus purpurascens Uhl.), slightly enlarged. (After Gillette.)

trees suffer more than is generally realized, when these insects are abundant. One exception to this general unimportance of the family is met with in the case of the wingless species known as the "western cricket" (Anabrus purpurascens Uhl., Fig. 68), which in some of the Western States may be a serious crop pest. 


\section{Family Gryllidæ (The Crickets)}

The crickets are familiar insects, often seen walking or leaping over the ground.

In this family the wings are frequently reduced or absent, but when present the front pair are so bent that one part lies flat over the back while the other lies against the side of the body when not in use. The antennæ are in most cases, longer than the body. A convenient grouping of these insects is into the field crickets, the mole crickets and the tree crickets.

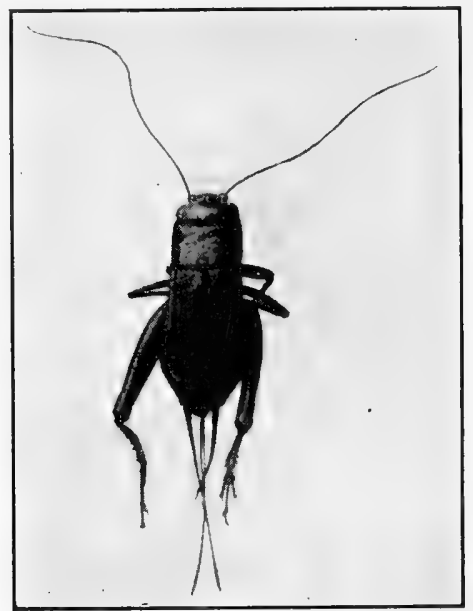

FIG. 69.-Common Black Cricket (Gryllus abbreviatus Serv.), natural size. (Original.)

The sounds are produced by the wings of the males, which are rubbed over each other. On one wing is a strong vein which bears cross ridges, while on the other is a thickened area. These two parts (termed file and scraper by Comstock) when rubbed together cause the sound. Ears in crickets are located as in the last family, on the fore legs, but the two on the same leg differ somewhat in appearance.

The common field crickets (Fig. 69) are black or brown, and a long ovipositor is present in the females. They are rather indiscriminate feeders, consuming either vegetable or animal materials, and may even be cannibals. In houses they will eat foods but are rarely abundant enough to become pests.

The mole crickets are larger and stouter than the common field crickets, and because of their habit of burrowing in the ground are less often seen (Fig. 70). They are brown in color and their fore legs are broad and flat, forming most effective digging organs. The eyes are much reduced and the hind legs not being used for leaping, are not so greatly developed as in the other crickets. They prefer rather moist 


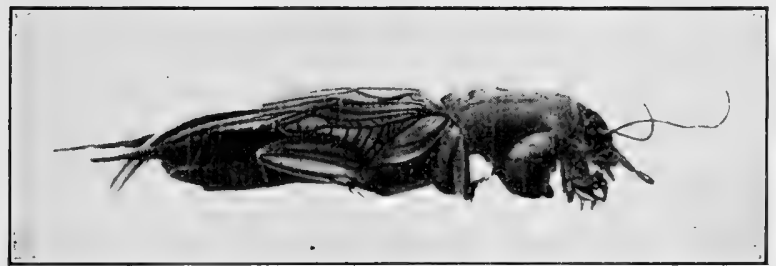

FIG. 70.-Common Mole Cricket (Gryllotalpa borealis Burm.), about natural size. (Original.)

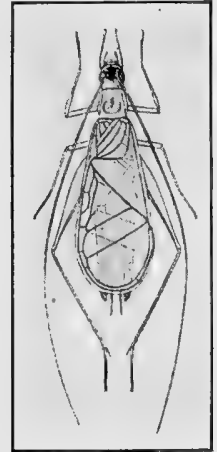

FIG. 71

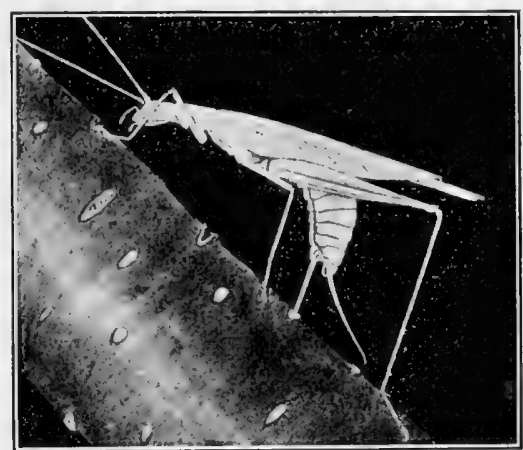

FIG. 72 .

Fig. 71.-Adult Male Tree Cricket (EEcanthus niveus De G.), somewhat enlarged. (Reduced from N.Y. Agr. Exp. Sta. Tech. Bull. 42.)

Fig. 72.-Female Tree Cricket ovipositing in a twig. Enlarged about one-half. (Reduced from N. Y. Agr. Exp. Sta. Tech. Bull. 42.)

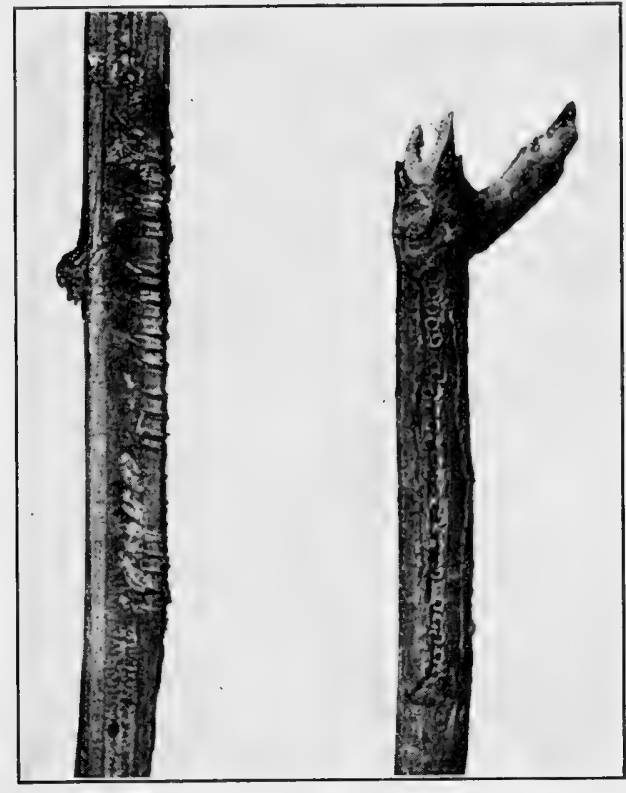

$b$

$a$

FIG. 73.-Raspberry canes showing: $a$, row of egg punctures along the cane, inducing cracking open; $b$, cane split open to show the depth of the punctures. Natural size. (Original.) 
land in which to make their burrows, and feed on plant roots, earth worms and insect larvæ. The "Changa" (Scapteriscus vicinus Scudd.) of Porto Rico attacks the roots of various crops in that island, causing much injury, and has recently been discovered along the sea coast of some of the Southern States where it attacks cotton and may become a serious pest.

The tree crickets differ greatly in appearance from the field and mole crickets, being slender, greenish white and only about half to threequarters of an inch in length (Fig. 71). They occur on trees and bushes and attract attention from July till frost by their shrill, steadily repeated note or song, beginning as it grows dark and continued through the night, the rapidity of the note being so closely related to the temperature that by timing the number of repetitions per minute a close approximation to the thermometer reading can be obtained.

The tree crickets are rather serious pests as during the fall the females make long rows of punctures in the twigs of trees and in berry canes (Fig. 72), laying their eggs in these punctures which usually are nearly as deep as the diameter of the twig or cane (Fig. 73). The general result is the drying and splitting open of the portion of the plant attacked, causing its death, besides providing an opportunity for the spores of fungous diseases to enter and attack the plant. Control of these insects is at present limited to cutting off and destroying the injured parts of the plant, with their contained eggs, before these hatch in the spring.

A few species of crickets live a semiparasitic life in ants' nests and in consequence are so much modified as to show little resemblance to the common forms. 


\section{CHAPTER XVII}

\section{THE ISOPTERA}

These insects are commonly called White Ants or Termites, the former name being used because though not nearly related to ants, they live in colonies and in many of their ways resemble these insects.

The White Ants, as their name suggests, are whitish in color (the winged adults may be brown or blackish). The group is essentially a tropical one but some of them are found as far north as Canada. The

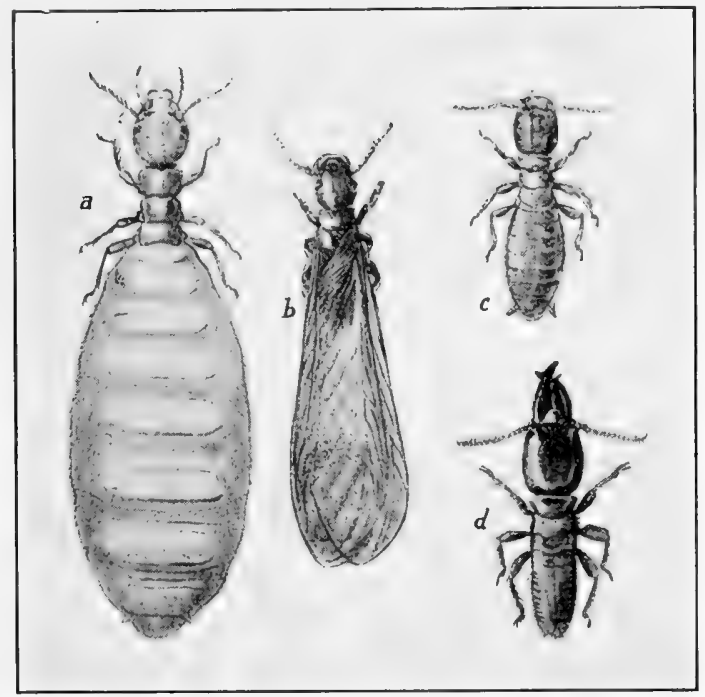

FIG. 74.-Castes of a Termite colony: $a$, queen; $b$, male; $c$, worker; $d$, soldier. (After Jordan and Kellogg, Evolution and Animal Life, D. Appleton and Co.)

tropical species differ so markedly in many of their ways from the northern ones that separate descriptions almost seem necessary. In all, however, there is a colonial life and a division of the insects into several groups or "castes."

A colony normally consists of one or more males or "kings;" one or sometimes several females or "queens" and a variable but generally large number of other individuals, nearly always at least, of two castes, known as workers and soldiers (Fig. 74). These may be individuals of either sex which have not developed to reproductive maturity. During a short period of their lives the kings and queens have fully-developed wings, four in number, long, narrow and quite similar in appearance, 
which when at rest are laid flat upon the back. Near the base of each wing is a line marking where it will easily break off. The part between this point and the body is horny, while the remainder is at most only somewhat leathery. At the end of the abdomen is a pair of short cerci. Development of the young is by an incomplete metamorphosis.

The group may accordingly be characterized as:

Insects living in colonies and of several castes, of which only the kings and queens ever have wings. These are four in number, long, more or less leathery, narrow, similar, laid flat on the back when not in use, and easily broken off near their bases. The bodies of the insects are soft, and usually whitish in color. The abdomen has a pair of cerci at its hinder end. Mouth parts for chewing. The metamorphosis is incomplete.

The food of Termites is mainly dead wood, though living trees and other plants sometimes suffer from their attacks. Their nests in the tropics are made of earth, wood which has been chewed up, and their excrement. They are often prominent objects, sometimes twenty

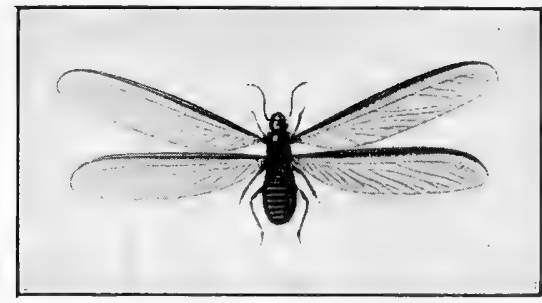

FIG. 75.

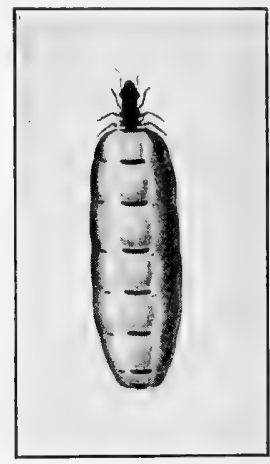

FIG. 76.

Fig. 75.-Adult male of a tropical Termite (Termes spinosus Latr.) about half natural size. (After Desneux.)

FIG. 76.-Laying queen of a tropical Termite (Termes gilvus Hag.). Reduced nearly one-half. (From Desneux.)

feet or more in height, and seem to vary in form to some extent according to the species.

Termites "swarm" at some seasons, enormous numbers of winged kings (Fig. 75) and queens leaving their nest at about the same time and flying off. After alighting the wings are broken off and each pair of individuals turns its attention to the establishment of a new colony. In the tropical species which form large nests and have thousands of individuals in a colony, the abdomen of the queen gradually becomes distended by the developing eggs until this part of the body may become several inches long and an inch or more in diameter, so that the insect is entirely helpless and unable to move (Fig. 76). The workers which are generally blind, provide for the queen, carry away the eggs, feed and care for the young, construct the nest, and indeed do all the work of the colony. The soldiers are generally regarded as a caste produced for the 
protection of the colony, but numerous observations which show the workers to be better fighters, throw doubt upon the real duties of this caste.

Other castes besides those already mentioned have been discovered in different species of Termites, at least 15 having been recognized, though not for any one species. In addition to the royal pair, workers and soldiers, however, a caste consisting of individuals generally called complementary kings and queens or neoteinic members of the colony is generally present, at least in the older colonies. This caste is capable of reproduction, though less abundantly so than the true queen, and appears to be produced to continue the colony after her death.

The most generally common species of Termite in the United States (Reticulitermes flavipes Kol.) except perhaps in the far South and on the Pacific Coast, does not appear to form large colonies (see Fig. 74). Its nests occur under logs and in them, in fence posts, timbers of buildings or other structures, or in tunnels in the ground, though here usually in near proximity to wood. Centering here they go out through tunnels, always protected from the light, mining in woodwork, honeycombing it and leaving only a thin film on the surface to conceal them and shut out the light. If necessary to reach the wood they desire, they may construct small covered passages over the surface of stone, brick or similar materials, through which they pass. They will also attack books and papers, pasteboard, leather, etc., if stored in dark and moist places. In some cases they attack trees, infesting roots and the heartwood near the base. Citrus trees in the South are often seriously injured by them. Field crops are also affected, the roots being fed upon, and plants in gardens and greenhouses are often attacked, the termites sometimes coming up to the benches through covered tubes, in the latter location, and working first in the wooden bench sides, and then passing to the plants themselves. True queens have seldom been found in the nests of this species.

Control.-To check the ravages of these insects in buildings, bridges and other structures, all infested wood should be removed. Foundations should be of stone, brick or concrete, and as far as possible all timbers should be exposed to light and not be so placed as to become moist. As these insects must have moisture where they are, dryness is an effective protection. Where posts must be set in the ground they should be dipped in coal-tar creosote before setting. In general, ventilation and dryness should be secured whenever possible, as the best protection against the ravages of these insects.

The Termites are not a large group, probably numbering less than two thousand species, but the size of their nests in the tropics attracts attention, and their habits and colonial life are of much interest. They appear to be most closely related to the Orthoptera. Fossil species are quite numerous. 
About 1913 a group of insects was discovered, living in Ceylon, Java, Africa and Costa Rica, which seemed to differ so greatly from those already known as to justify placing them in a new order. Those first found were minute, wingless, with only vestiges of eyes at most, and a thorax as long as the abdomen. Cerci are present. The insects average about a twelfth of an inch in length, with legs similar in form and used for running. The tarsus consists of only two segments and the mandibles are well-developed, the mouth parts being of the chewing type. More recent discoveries of these insects in Florida and Texas show that the adult females may have well-developed eyes; wings, at least in some cases, which they shed like the Termites, and that while the head resembles that of the Plecoptera the hinder end of the body resembles that of the Termites. It is also known that these insects are social and generally occur near Termites, though not usually mingled with them. They will probably prove to be rather nearly related to the Isoptera.

The order Zoraptera has been established to include these insects, but so little is as yet known about them that they have not been treated in a separate chapter in this book. 


\section{CHAPTER XVIII}

\section{THE DERMAPTERA}

The insects belonging in this group are commonly called Earwigs, because of a mistaken belief that they crawl into the ear's of sleeping persons. They are most abundant in warm climates, very few being found in the more northern states. Both winged and wingless species are known, the wings always shorter than the body and the front pair tough, leathery and shorter than the hinder pair. The latter are very broad, nearly half-moon shaped, with veins radiating from a point behind the costa and about one-third the distance from the base to the apex. These wings first fold in plaits like a fan, then twice across to reduce their length and thus bring them under the fore wings, the forceps aiding in this. At the end of the abdomen is a pair of prominent, horny cerci, shaped like forceps, differing in form in the two sexes. The mouth parts are well developed and of the chewing type. The order may be characterized as:

Insects which when adult are usually rather long and narrow in form; with chewing mouth parts and a pair of forceps-like cerci at the end of the abdomen. Wings may be absent or present: in the latter case the front wings are leathery and shorter than the others which are broad and fold in plaits from a center, and in addition fold crosswise. The metamorphosis is incomplete.

Earwigs are not generally of great importance as pests in North America, though in the South and on the Pacific Coast, as they generally feed on fruits, blossoms and other vegetable matter, they may occasionally cause some injury. This appears to be more frequently the case in Europe than in this country.

They hide in crevices, among leaves and in the ground in the day time, coming out at night to feed. In the northern states the most common species is the Little Earwig (Labia minor L.), brownish in color and only about a quarter of an inch long. It is sometimes attracted to lights at night. A much larger, dark-brown, wingless species (Anisolabis maritima Bon.), a native of Europe has now reached this country and is found on the sea beaches of the Eastern United States, under seaweed near high-water mark, probably feeding chiefly on decomposing vegetable matter (Fig. 77).

In 1911 the common European Earwig (Forficula auricularia L.), which is about three-quarters of an inch in length when adult, was found 
to have established itself at Newport, R. I., and another colony of this species was discovered at Seattle, Wash. in 1915 (Fig. 78). Both of these colonies are increasing and spreading rapidly. The adults lay their eggs in the ground in the fall and the adult females winter there also.

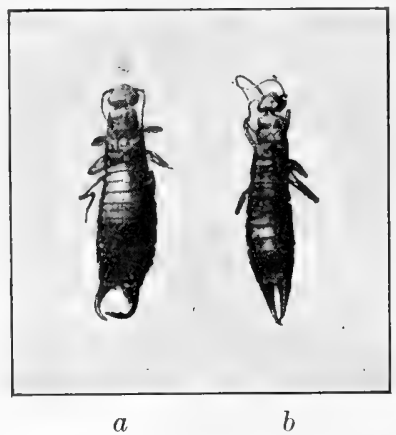

FiG. 77.-Adults of a Wingless Earwig (Anisolabis maritima Bon.), natural size: $a$, male; b, female. (Original.)

The nymphs feed on green plant shoots, injuring garden plants and flowers during the spring, and later in the season turn their attention to blossoms, eating the stamens and bases of the petals. The adults too, feed on these and also on dead flies, larvæ, and even dead or dying individuals

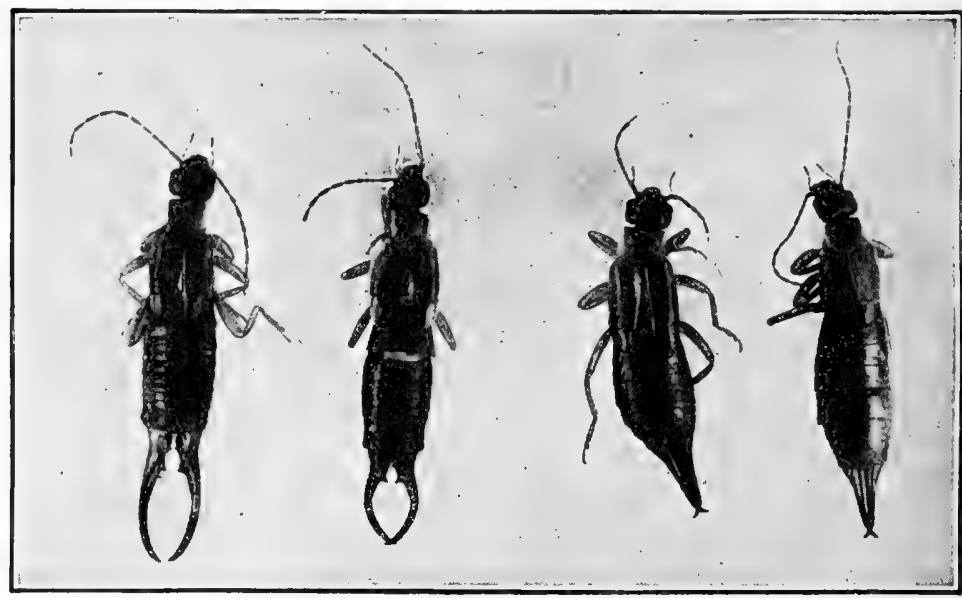

$a$

$b$

FiG. 7 S.-Males (a) and females (b) of the European Earvig (Forficula auricularia L.), ahout twice natural size. (From U.S. D. A. Bull. 566.)

of their own kind. Their actual injuries however, are far less serious than the annoyance caused by their presence in residences, where they crawl over everything at night and hide under chair cushions, dishes, in folds of clothing and in all crevices in and about the houses during the day. 
Control.-During the spring months the nymphs may be destroyed by the use of poisoned bread bait, using $16 \mathrm{lb}$. of stale bread and $1 \mathrm{lb}$. of Paris green or arsenic. Grind the bread fine and thoroughly mix it with the poison; then add water enough to make a mixture which will run through the fingers and which, spread broadcast, will scatter in small particles. Spread this during the evening over lawns or gardens where the insects occur. It may need to be repeated once or twice. After the first of July when the earwigs have taken to feeding on blossoms, the best treatment thus far found is to spray the plants at night with the following contact insecticide:

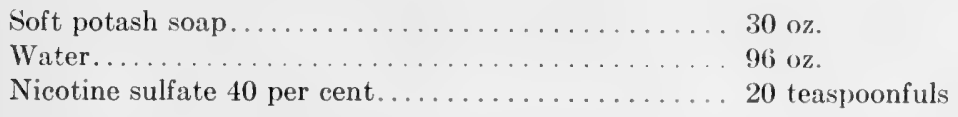

Dissolve the soap in some of the water by heating, then add the rest of the water and the nicotine sulfate, making about a gallon of stock solution. For use, mix 1 part of this with 22 parts of water. The spray should be a fine mist and be thoroughly applied, to be effective.

In Europe this earwig is not a serious pest, perhaps being kept in check by natural enemies not present in this country.

The Dermaptera as a whole cannot be considered as a group of great economic importance. They have sometimes been regarded as a family of the Orthoptera and sometimes as a separate order akin to the latter, but recent studies seem to indicate a closer relationship to the Coleoptera or beetles. Probably not over 500 species of the group are known. 


\section{CHAPTER XIX}

\section{THE COLEOPTERA}

The Coleoptera or beetles is the largest group of insects and members of it are familiar to everyone. Over 175,000 kinds are already known, and more are discovered every year. Beetles usually have wings, though in some cases they are very small and never used. The front pair are hard and horny and are called elytra. They are not used in flight but when closed lie flat on the back, covering and protecting the hind wings and the rather soft external skeleton of the upper side of the abdomen.

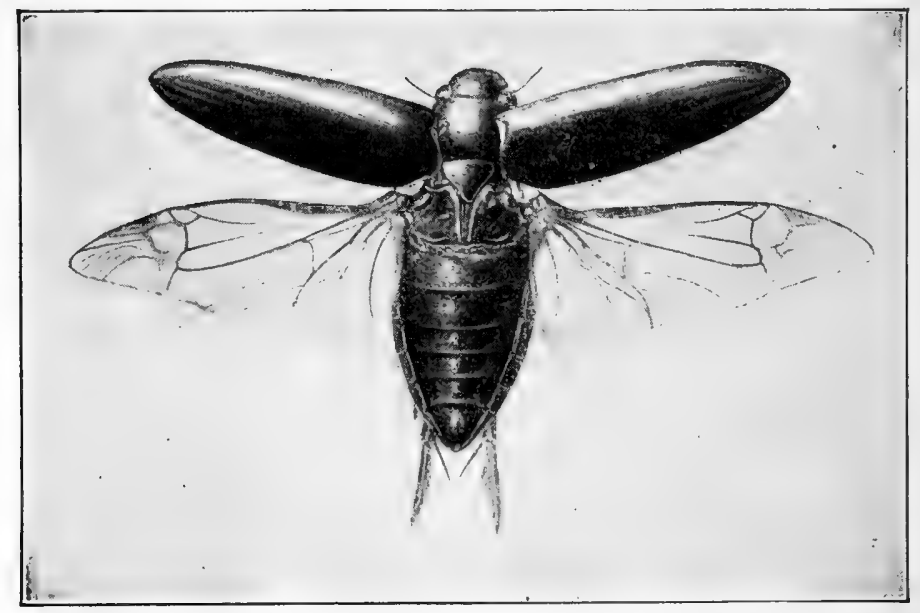

FIG. 79.-Water Beetle with wings spread. (From Folsom.)

In some groups they do not reach the end of the body, and in those insects the unprotected portion of the abdomen is generally of its usual thickness. The hind wings are usually quite large and fold in an irregular peculiar way to reduce their size and bring them under the elytra when they are not in use (Fig. 79).

The external skeleton of the beetles is usually harder and thicker than in most of the other groups. The mouth parts are for chewing, both as larvæ and adults, and the jaws are often very powerful. The early stages are entirely unlike the adult condition, the members of this group undergoing a complete metamorphosis. 
The distinctive characters of the group are:

- Insects which as adults nearly always have four wings, the front pair entirely thickened and horny; the hind pair membranous: mouth parts for chewing: body usually rather stout. Metamorphosis complete.

There is a great diversity in the structure of the antennæ in different beetles, and also in the form of the legs and number of tarsal segments. The arrangement of the skeletal plates around the articulation of the fore coxæ to the body is also variable and of importance in classification.

Eggs of the Coleoptera are laid in many kinds of places-on leaves, in branches, in decaying matter, water, etc. The larvæ which hatch are usually called "grubs" except when they bore in wood. Then, as with larvæ of any order found under such conditions, they are termed "borers." They usually have the three pairs of legs which become those of the adult, though these are sometimes wanting. Some feed upon other animals, some on leaves or wood, some on carrion, and others on various substances. After full larval growth has been attained they pupate. The pupal shell or skeleton generally covers the surface of the body closely, but the wings and legs though lying close to it are covered sepsrately as projecting appendages and not ensheathed by the shell enclosing the body proper. Such a pupa case is called a pupa libera, or free pupa. In some Coleoptera this condition does not obtain, the pupa shell enclosing wings, limbs and body with no projecting appendage sheaths, and such a case is called a pupa obtecta (see Fig. 33).

The beetles are generally divided as a matter of convenience into the true Coleoptera (Coleoptera genuina or Coleoptera vera) and the Snout Beetles (Rhynchophora), though it is at least doubtful if the latter is a natural group. The insects in this section are easily recognized, in most cases, by having the front of the head prolonged into a snout which may be long and slender-in some cases even longer than the body-or short and stout, being sometimes so short as to be hardly noticeable. The antennæ arise from the sides of the snout and in most cases have a bend like an elbow near the middle. The mouth parts are at the end of the snout, but the labrum and both pairs of palpi are absent. The insects of this group are even more firm bodied than the other Coleoptera.

The true beetles (Coleoptera vera) have no snout. The mouth parts are all present and as a group its members average larger than the Rhynchophora: indeed the largest bodied insects known belong here.

THE TRUE COLEOPTERA (Coleoptera vera)

This is by far the larger section of the beetles, more than 75 of the 80 odd families belonging here. They vary greatly in structure, habits and food. Many of the families are of little or no economic importance and have few members, while others include a very large number of species, many of wnich are very destructive. 
Family Lampyridæ (Fire flies, etc.).-In several ways the insects belonging here appear to be among the simplest of the beetles (Fig. 80). Their bodies are quite soft as compared with the others; the abdomen has been little reduced, seven or eight segments being perceptible, and the larvæ are quite simple and feed on small insects and other animals such as snails, either living or dead.

Only a few members of the group are often noticed except by entomologists, but those which attract attention are familiar by the light they

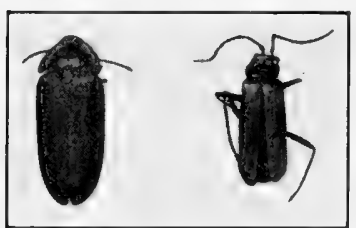

Fig. 80.-Examples of Common Lampyrid Beetles, a bout natural size. (Original.) produce at night, which has given them the names "fire flies," "lightning bugs," etc. The light is produced by specialized areas of the body, frequently at least on the underside of the abdomen near its tip. The light itself is not persistent but comes in flashes and is distinctly yellow in most cases. It is believed to be produced by the oxidation of granules in the outer layer of the luminous organ, the oxygen being supplied by the trachex, and under control of the nervous system. In some species the adult female is wingless so that its light appears as it crawls on the ground, and such individuals are often called "glow-worms."

Other insects and animals also have luminous organs, but the lights they produce are probably less frequently seen than those made by Lampyrids, these being widely distributed and very abundant insects.

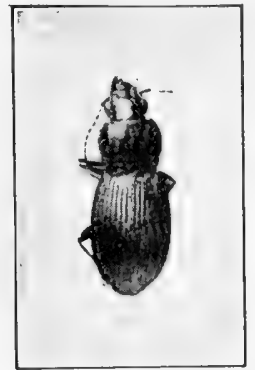

Fig. 81.-Common Ground Beetle (Harpalus caliginosus Fab.), natural size. (Original.)

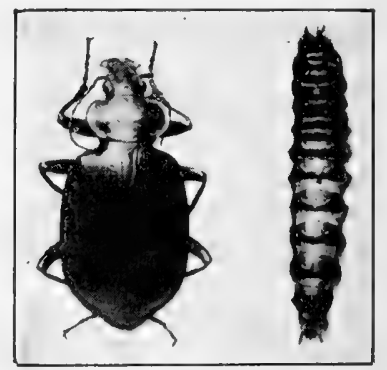

Fig. 82.-European Calosoma Beetle (Calosoma sycophanta L.) and its larva, natural size. (Original.)

F'amily Carabidæ (Ground-beetles).--These insects are active, running quickly over the ground, and the group is a large one containing many different species, over 1,200 of which are found in the United States (Fig. 81). They feed mainly at night, hiding by day, and the majority are dark colored or black, though a few have bright colors. They are predaceous, both as larvæ and adults in most cases, though a few have been known to depart from their usual habits and feed on berries and seeds. One species (Calosoma sycophanta L.) has been brought to this country from Europe as it feeds to quite an extent on the caterpillars of the Gypsy 
Moth, even climbing trees in search of its prey, and it is now fairly common in most of the New England States (Fig. 82). As a whole, the group is distinctly a beneficial one, feeding on injurious insects both above ground and as these enter the ground to pupate.

Family Cicindelidæ (Tiger beetles).- The active flight and bright colors of many of the tiger beetles, though most of them are small insects, only about half an inch long, make the members of this family quite noticeable (Fig. 83). They are sun-loving forms, most common along roadsides and in sandy places. When flushed they fly quickly a few yards, then alight and often turn, facing the intruder as though watching his movements. Both they and their larva feed on other insects, the larva living in a burrow in the ground and placing itself at the mouth of the burrow ready to grasp any unwary insect which may come near. The elytra of the adult are usually metallic brown with light-colored marks suggestive of musical characters or perhaps hieroglyphics, though in some cases bright green, purple, or other colors dominate. In the West the largest insect belonging to this family (Amblychila cylindriformis Say) does its hunting at night, as is also the case with certain related forms of the Pacific Coast.

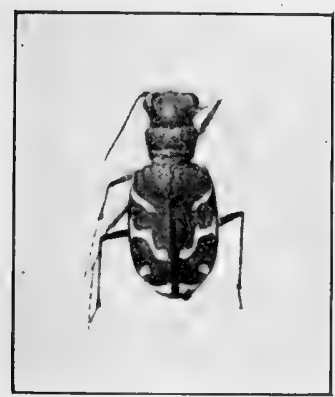

FIG. 83.-Tiger Beetle (Cicindela), slightly enlarged. (Original.)

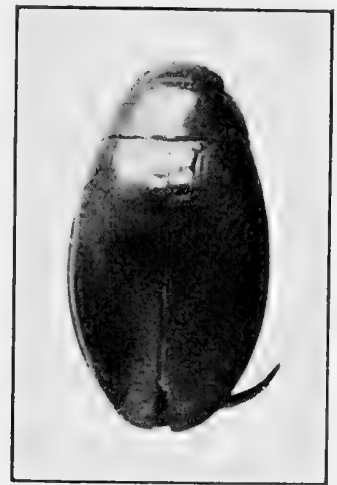

Fig.84.-Dytiseid Beetle (Dytiscus verticalis Say), natural size. (Original.)

Family Dytiscidæ (Carnivorous diving-beetles).--Members of this family are present in almost every quiet stream and pond. They are oval, rather flat beetles, usually black, and good swimmers, the hinder pair of legs being broad and somewhat oar-like and heavily fringed with hairs (Fig. 84). The antennæ are thread-like. Whenever they need air, they float up to the surface of the water and allow the hinder end of the body to project a little out of the water. Then, lifting the elytra slightly, the air enters the space under them and is retained there aided by hairs present. The insect can now stay under water until this air supply has been exhausted. The larvæ, of ten called "water-tigers," they are such voracious creatures, feed, like the adults, on various water insects and other animals, even attacking small fish. Some of this family may be at least an inch and a half long.

Family Gyrinidæ (Whirligig-beetles).--These insects swim on the surface of quiet water, generally in groups, and go around and around in a "whirligig" sort of fashion. They are usually bluish-black, oval in form, and the compound 
eyes are so divided that one part of each is directed upward and the other downward (Fig. 85). They feed on small insects which come within their reach. The larvæ, living in the water, breathe by abdominal tracheal gills, and are also carnivorous. The group does not include many species, but their habit of swimming in companies, and their peculiar "gyrating" over the surface attracts attention, nearly everybody having noticed them on this account.

Family Hydrophilidæ (Water-scavenger beetles).-The water-scavenger beetles occur in the same types of stream and pond as the carnivorous diving beetles, which they greatly resemble (Fig. 86). The outline, however, is usually a little more elongately oval; the antennæ are club-shaped, and in addition to other structural differences, they obtain air by raising the head slightly above

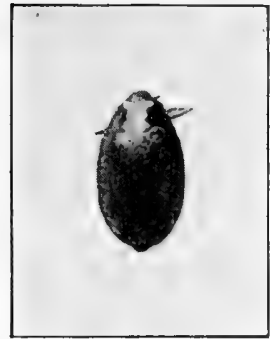

Fig. 85

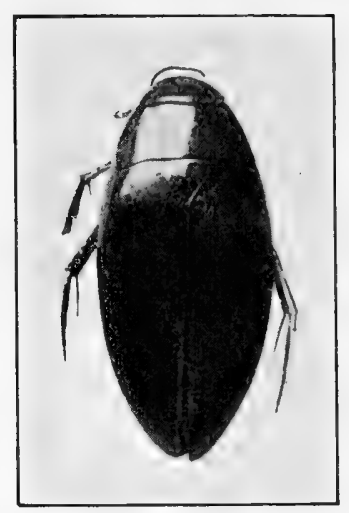

FrG. 86

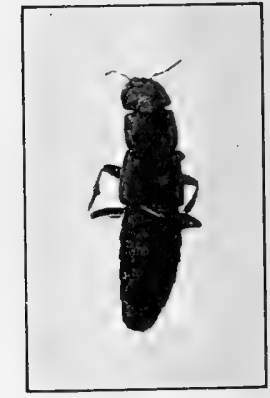

FIG. 87 .

FIG. 85.-Gyrinid or Whirligig Beetle (Dineutes), natural size. (Original.)

FIG. 86.- Water-scavenger Beetle (Hydrous triangularis Say), natural size. (Original.)

FIG. 87.-Rove-beetle (Staphylinus vulpinus Nordm.), slightly enlarged. (Original.)

the surface and collecting a film of it over the under surface of the body, where it is retained by a close coating (pubescence) of fine hairs. They feed on decaying animal and plant material for the most part, though sometimes taking to living plants and insects. Some species may be about two inches in length. They are of little economic importance.

Family Staphylinidæ (Rove-beetles). - This large family in some regards is suggestive of the fire flies as the body of the insect in this group is not as hard and firm as in most beetles and seven or eight abdominal segments are present (Fig. 87). In other ways, however, it differs greatly from the Lampyrids, the body being slender for its length, and the elytra short, not nearly covering the top of the abdomen, the segments of which are very movable. The insects run rapidly, often lifting up the end of the abdomen in a menacing way. Most of the thousand or more species found in this country are small, the larger kinds seldom being more than an inch long. They are land forms, feeding on decaying vegetable and animal materials near which, or under stones and wood, they are found. They must be considered as beneficial insects, acting as scavengers. 
Family Silphidæ (Carrion-beetles).-Most of the members of this family are of good size, ranging from half an inch to three times that length. Two rather distinct types of insect are common in the group, one (Silpha, Fig. 88) having a broad, rather flat body and with the sides of the prothorax very thin. These insects average less than an inch in length and the elytra are usually black. In the other type (Necrophorus, Fig. 89) the insect is larger, stout, with a body more cylindrical, and the elytra generally have dull red markings and are frequently shorter than the abdomen. Both types feed on dead animals in most cases, and their larvæ have the same food, so that the group mav therefore be regarded as beneficial. It is not a very large family, in the United States at least.

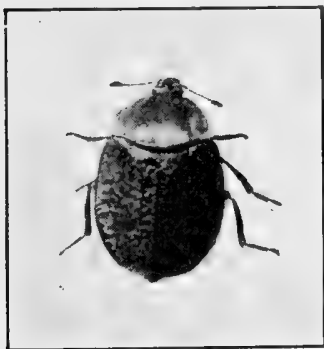

Fig. 88.-Carrion-beetle ( Silpha a mericana L.), about natural size. (Original.)

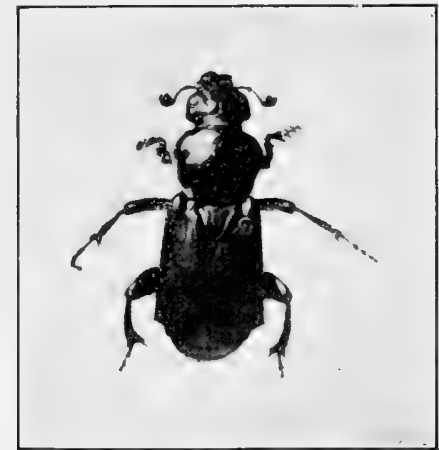

IIG. 89,-Carrion-beetle (Necrophorus marginatus Fab.), slightly enlarged. (Original.)

Family Dermestidæ (Dermestids).-These insects are small, the largest common species in this country being only about one-third of an inch long. Most of them are rather short, thick-set beetles, covered with very small scales which give them a gray or brown color, with o:cesional black, white or red sealy areas in some cases, producing spots or bands of these colors. They feed on decaying substances, but those most important as pests attack wool, furs, feathers and meat, cheese and fats. In some cases the a Jults feed on pollen and only the larvæ are destructive.

The Larder Beetle (Dermestes lardarius L.).-This common insest is frequently found in pantries on foods, particularly of a fatty nature. The adult (Fig. 90) is dark brown, with a pale-yellowish band across the elytra near their bases, in which are a few black dots. The larva (Fig. 91) is longer and more slender than the adult, with numerous, rather long, black hairs; is brown in color, and attacks ham, cheese, beeswax, feathers, and almost any material oily or fatty in its nature.

Control.--Little can be done in the way of controlling this pest, except by sleanliness and close watch of all fatty substances kept in stock, removing and destroying the insects whenever they are discovered. Tightly closed receptacles, giving no opportunity for the insects to enter, should be used in which to keep such substances. 
The Buffalo Carpet Beetle (Anthrenus scrophularice L.).-The adult of this insect is a tiny beetle about three-sixteenths of an inch long, mottled black and white, with a red line having three pairs of side branches or lobes, down the middle of its back (Fig. 92). It is a household pest in the northeastern states and as far west as Iowa and Kansas. In Europe, of which country it is a native, it does not appear to be of much importance. The beetles appear in the fall and may continue to be found in heated houses all winter. The eggs are laid on woolen cloth or clothes, carpets, rugs, furs, feathers or silk, all of these being animal products, and the small hairy larvæ feed on the materials named. After pupation has been completed, the adults appear and are often noticed on windows. In the spring months, probably after laying their eggs, the beetles appear outof-doors and feed on the pollen of various blossoms, the Spirca being a favorite.

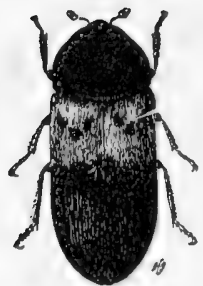

FIG. 90

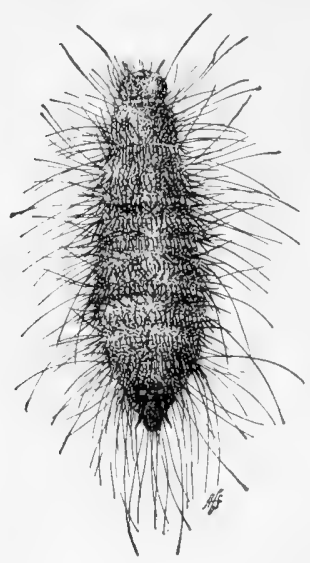

Fig. 91.

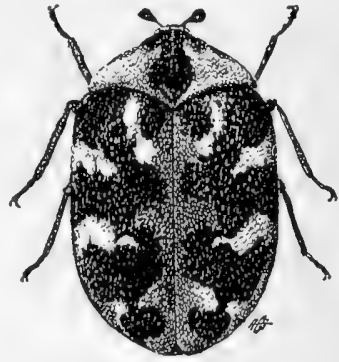

Fig. 92 ,

Fig. 90.-Adult Larder Bectle (Dermestes lardarius L.) four times natural size. (From Herrick's Insects Injurious to the Houschold. By Permission of the Macmillan Company, Publishers.)

FIG. 91.-Larva of the Larder Beetle, three times natural size. (From Herrick's Insects Injurious to the Household. By Permission of the Macmillan Company, Publishers.)

FIG. 92.-Adult Buffalo Carpet Beetle (Anthrenus scrophulariæ L.), nine times natural size. (From Herricli's Insects Injurious to the Household. By Permission of the Macmillan Company, Publishers.)

Whether there is more than one generation a season has not been definitely settled. Many of the larvæ breed in floor cracks under carpets and rugs, on the woolen debris there.

A somewhat similar, closely related beetle, the Black Carpet Beetle (Attagenus piceus Oliv.), also of European origin, and dull black in color (Fig. 93), is likewise an enemy to the same general class of materials as the Buffalo Carpet Beetle. It appears to be a pest farther south than the last-named insect. The larva (Fig. 94) is longer and more slender than that of the Buffalo Carpet Beetle, reddishbrown, and with a tuft of long hairs at the end of its body.

Control of Carpet Beetles.- These insects are repelled by the odors of various substances, and clothing, furs, feathers, etc., when put away, can be protected from their attacks by placing them in tight bags or boxes, together with the repellent. Naphthaline ("moth balls") is the most effective for this purpose, and 
the oil in cedar wood is also of value, hence the use of cedar chests for storage purposes, these giving some protection as long as their odor lasts. Camphor also is a fair repellent. But with all these materials the tendency is to use too little, and in such cases the insects are not driven off. Then too, if the food of these pests be put away with either eggs or larva present, the repellent will not prevent the larvæ from feeding. The best practice therefore, is to fumigate all material likely to be attacked, before packing it away, placing it in a tight box and treating it with Carbon disulfid for $24 \mathrm{hr}$. Then add a liberal supply of moth balls and close tightly. The fumingation will destroy these pests in any stage in which

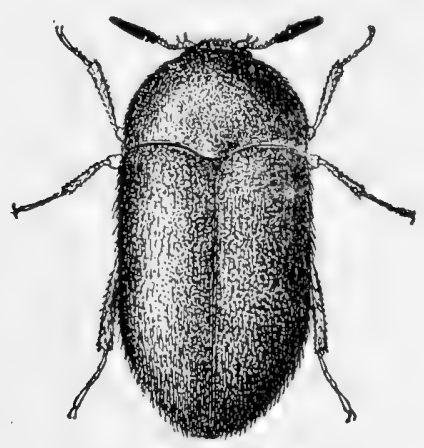

FIG. 93 .

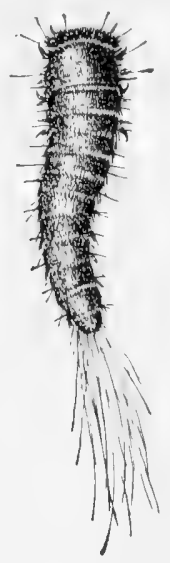

FIG. 94 .

FIs. 93.-Adult Black Carpet Beetle (Attagenus piceus Oliv.), enlarged nine times. (From Herrich's Insects Injurious to the Household. By Permission of the Macmillan Company, Publishers.)

Fig. 94.--Larva of the Black Carpet Beetle, five times natural size. (From Herrick's Insects Injurious to the Household. By Permission of the Macmillan Company, Publishers.)

they may be present, while the naphthaline will keep out adults which might otherwise enter thereafter. Fumigation of a room or an entire house if necessary, with Hydrocyanic acid gas, or sulfur, is also a good treatment, though if the latter substance be used its effect upon metals, and on colors in clothes and wallpapers should be remembered. Carpets may be steam-cleaned, this killing the pest in all stages, and cold storage for furs and feathers at least, if the temperature be kept below $40^{\circ} \mathrm{F}$. will prevent injury, though not necessarily killing any of the insects which may be present. As some of the larva may be in floor cracks when carpets and rugs are infested, these should be treated with kerosene or gasoline. Woolen clothing kept in closets during the warmer seasons of the year should be frequently brushed out and aired in the sunlight.

Family Buprestidæ (Flat-headed Borers).-This group of beetles contains many forms which injure trees by boring in their trunks. Others attack berry canes which often show swellings as a result. A few are leaf miners or gall makers. The adults are generally stout, robust beetles with heads set into the thorax, rather flat backs, and in general dark colored but with a metallic luster, though a few are bright 
green or other colors. The larvæ which bore in trees, are white except for a small, yellowish head, and have a large, flattened prothorax and no legs. Some of these insects attack pines; others, different forest trees, burrowing at first just under the bark in the sap-wood and later in the heart-wood. The average life history requires about a year for its completion, but if the tree be vigorous the larva is liable either to die or be delayed in its development. The adults are fond of the sum and fly freely in the daytime. They are often found on flowers. Several hundred species are known in this country, all of them injurious, the damage they do being largely dependent upon the importance of the tree or plant they attack.

The Flat-headed Apple-tree Borer (Chrysobothris femorata Fab.).This is probably the most injurious of the Buprestids. It attacks more than 30 kinds of trees and shrubs, generally selecting individuals which are not in a healthy condition or are otherwise favorable for their larva.

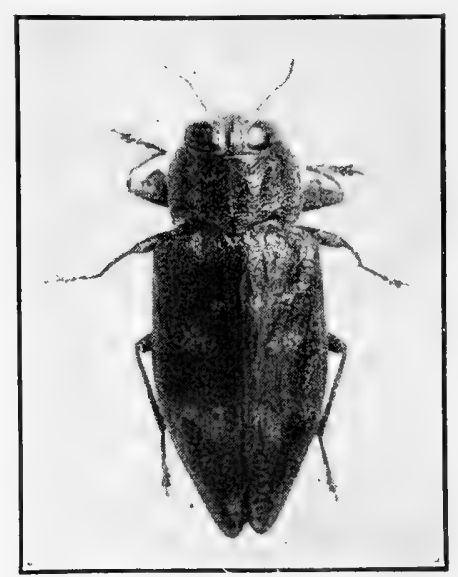

Fig. 95.-Adult Flat-headed Apple-tree Borer (Chrysobothris femorata Fab.), enlarged 31/2 times. (From U.S. D. A. Farm. Bull. 1065.)

The beetle (Fig. 95) is about half an inch long, rather broad, dark brown, faintly marked with bands and indefinite spots of gray, and having a brassy metallic reflection at certain angles. The underside is bronze, and under the wings the abdomen is a metallic greenish-blue. It occurs almost everywhere in the United States and in Southern Canada, and is a serious enemy of fruit trees.

The beeties appear soon after apple-blossom time and live for several weeks. They frequent the sunny side of the trunks and limbs of trees. Here the eggs are laid in fine cracks or under small scales of the bark. They hatch in from 2 to 3 weeks and the tiny larva (Fig. 96) bores into the inner bark, feeding on this and on the sap-wood and grows rapidiy 
unless the tree is vigorous, in which ease such an outpouring of sap-may occur at the wound as to kill (drown?) it or drive it into the outer layers of bark where it may live for a time, later working back into the sap-wood if the flow becomes small enough to permit it. If the larva can feed in the sap-wood it will grow to full size, about an inch long, by fall, at this time burrowing into the wood to form a pupal cavity in which the winter is spent, pupation itself taking place there the following spring and continuing several (three to four) weeks, after which the alult beetle escapes.

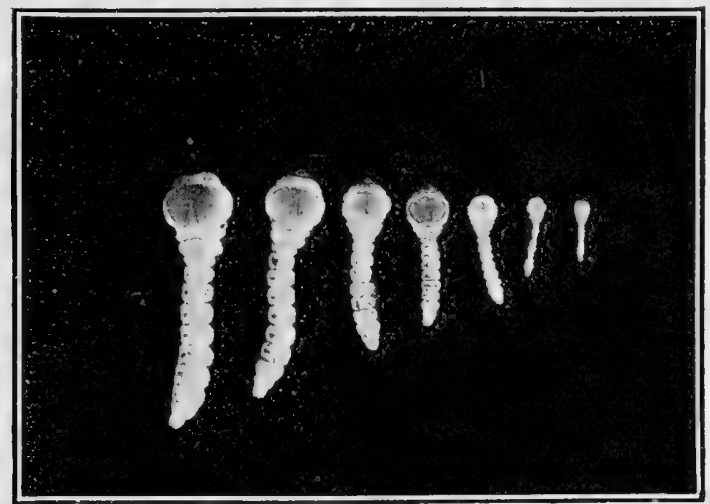

FIG. 96.-Flat-headed Apple-tree Borers (larva) of various sizes. Natural size. (From U. S. D. A. Farm. Bull. 1065.)

Control.-Vigorous, healthy trees are not generally liable to attack, and cultural methods which will insure this condition are important. Trees headed low will shade their trunks and the sun-loving beetles will go to those exposed to sunlight. Shading trunks exposed to the sunlight, by boards cutting off this light, is a protection, as are also poles set in the orchard and covered with sticky material to eatch and hold the beetles visiting them in search of places to lay their eggs. Wrappings of burlap or paper extending from the ground to the limbs will prevent egg-laying, but should be removed when this period is past. Birds and insect enemies aid in controlling this pest.

Family Elateridæ (Snapping beetles; click-beetles; skip-jacks).These insects somewhat resemble the Buprestids when adult but are usually more slender, with their sides more nearly parallel, and the economic species also lack a metallic reflection. The hinder corners of the pronotum are elongated forming sharp points in the majority of the group, and the insects are usually some shade of brown or black, though the pronotum and elytra sometimes differ in color and the latter are spotted in some cases, mottled black and white in our largest common species, and some have rather bright colors or markings (Figs. 97 and 98). When these insects fall on their backs they are able to throw themselves 
into the air by a sudden snap of the body for the purpose of getting onto their feet as they alight again, and if this fails at first the snapping is repeated. The larvæ (Figs. 97 and 98), commonly called wireworms, are nearly all slender, yellow or brown, with very hard shells, often glistening, one sub-family where they are soft-bodied and white forming a notable exception to this. The outline of the hinder end is often made use of in distinguishing the different kinds of wireworms. Their food habits have a wide range: some feed on decaying wood under bark or elsewhere; others on fungi; several groups are carnivorous, and still others feed on roots or seeds in the ground.

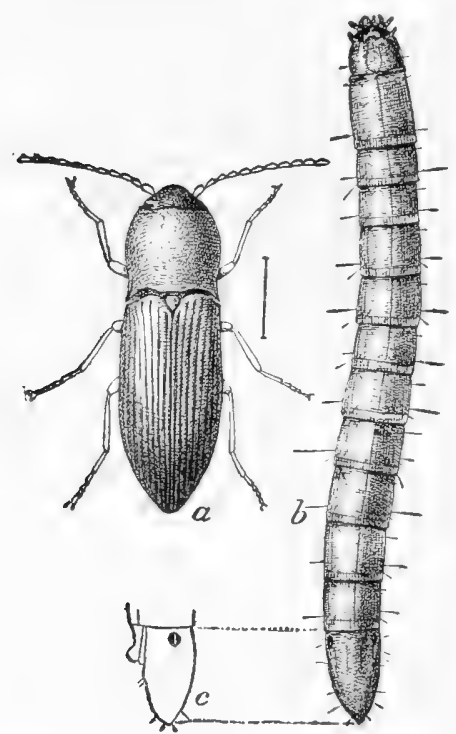

FIG. 97 .

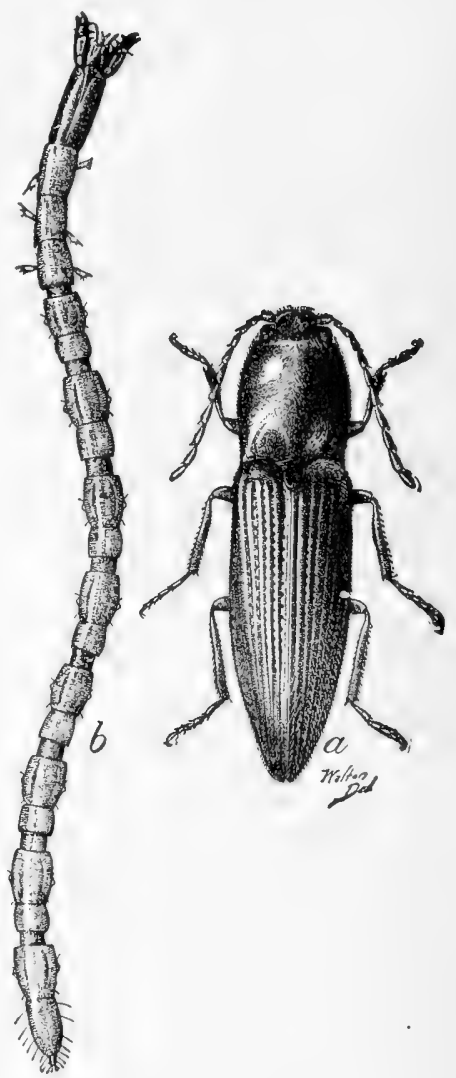

FIG. 98 .

FIG. 97.-Wheat Wireworm (Agriotes mancus Say): a, adult, enlarged about five times; $b$, full-grown larva (Wireworm), enlarged about three times; $c$, side view of last segment of larva. (From $U$. S. D. A. Bull. 156.)

FIG. 98.-Corn and Cotton Wireworm (Horistonotus uhleri Horn): $a$, adult, enlarged about ten times; $b$, full-grown larva (Wireworm), enlarged over four times. (From U.S. D. A. Bull. 156.)

One of the largest insects of this family found in the United States is the Eyed Elater (Alaus oculatus L.), which is about an inch and a half long; the elytra black, finely marked with white dots; and with a pair of large, oval, velvety-black spots rimmed with white on the pronotum (Fig. 99). The larve of this insect feed on insects in decaying wood, often that of the apple, but are of little economic importance. 
In the South and also in the West Indies and Mexico are species of Elaterids (Pyrophorus spp.) which have an oval, yellowish spot near each hinder corner of the pronotum (Fig. 100), and also an area on the underside of the abdomen close to, and partially concealed by the metathorax, which are luminous, producing an intermittent, greenish-yellow, quite brilliant light, making the insects very noticeable at night. They are beneficial, the larvæ feeding on white grubs.

The injurious members of this family are those wireworms which feed on seeds and the roots of plants, and there are many kinds which have

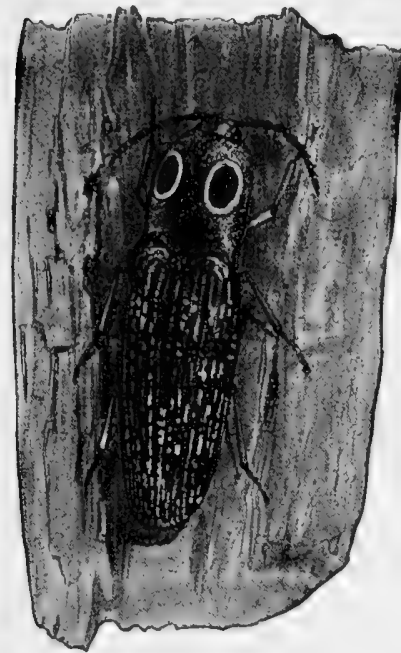

FIG. 99. this habit. Some attack wheat; others corn, and still others feed on cotton, grass, potatoes, sugar-beets and other crops, doing much damage. Some are most abundant in heavy soils containing

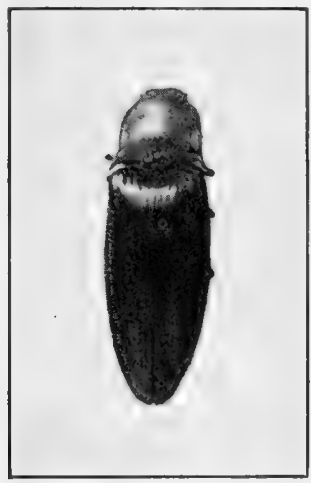

FIG. 100 .

Fig. 99.-Adult Eyed Elater (Alaus oculatus L.), about natural size. (From Linville and Kelly, General Zoölogy, Ginn and Company, Publishers.)

Fig. 100.-A Luminous Elaterid (Pyrophorus sp.) showing luminous spots on sides of pronotum. Natural size. (Original.)

much vegetable matter, while others prefer high, sandy land. So many species of wire-worms are injurious and so unlike are their habits in different parts of the country that each kind seems to require treatment especially adapted to it.

Control.- Some general factors in control may, however, be suggested. When wireworms are abundant in low, poorly drained land, drainage will be of much assistance. When they attack grass roots in great numbers, it is desirable in cultivating such places to substitute field peas, buckwheat, or some crop not closely related to grass, for the first crop, if possible, even though this does violence to the general ideas of crop rotation. When sod land is to be planted, plowing it in July and cultivating often and deeply the rest of the summer will destroy many of the insects. In the South and in arid regions, however, the insects go deeply 
into the ground during hot or dry weather, beyond reach by cultivation. In such cases planting early in the season and forcing the plants ahead by fertilizers and frequent cultivation are helpful. As the underground feeding period of these insects is from 3 to 6 years, proper treatment for a single season will at best give only partial relief, and to obtain the most successful control the special habits of the particular species concerned should be ascertained, and control measures to correspond be adopted. Various methods for the protection of planted seed have been tried but the results have not agreed in all cases and further studies along this line are needed.

The Elateridæ is one of the most important groups of beetles from an economic standpoint, and injurious species occur practically everywhere in the United States. Several hundred kinds are known in this country.

Family Scarabæidæ (Lamellicorn beetles).-This is a very large and important family of beetles, containing many pests. The antennæ

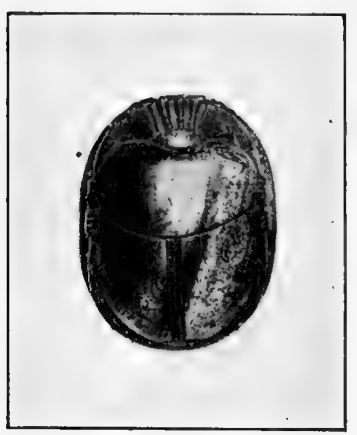

FIG. 101.-Egyptian c a rving of a Secarabæus. (Original.) in this group have several of the terminal segments large, flattened, and broader on one side, movable but generally carried close together. The insects are stout and rather short in most cases, and the elytra usually do not cover the entire abdomen.

Based on their habits, two sections of the family can be distinguished: the scavengers which both as larvæ and adults feed on decaying matter; and the leaf chafers which as adults generally consume leaves or flowers, and whose larvæ occur in the ground feeding on roots, or in decaying wood.

The Scavengers, though they may be considered as beneficial, are not of great importance, but some species because of their peculiar habits have attracted attention for centuries. The habit referred to is that shown by some of the so-called "Tumblebugs" in connection with egg laying. A pair of these beetles will together form a little dung into a ball which they then begin to roll over the ground, often for a long distance. Finally they bury it in the ground after an egg has been laid upon it, thus providing partially decomposed food for the larva. The Sacred beetle or Scarabæus of the Egyptians was one of the insects of this group (Fig. 101) and has been preserved in their drawings and carvings as a symbolic record of their beliefs. The leaf chafers form the larger part of the family. Among them are a number of serious pests.

The June Bugs or May Beetles (Phyllophaga and other genera).This is a group of beetles quite similar both in appearance and habits. The adults are generally dark brown and rather glossy above, from half 
an inch to an inch long, and very stout (Fig. 102). They appear during the spring months, earlier in the South than in the North, flying at night and are attracted by lights, to which they fly in a clumsy, crratic way. They feed at night on the leaves of various trees, often entirely stripping them. Different kinds of June bugs appear to prefer different kinds of trees for their food. Some species seem to select the oak, others the ash, still others the pine. Small birches have been completely stripped of their foliage in a single night. In the South two species appear to prefer the longleaf pine and whatever the species, large areas of timber may be defoliated when the beetles are abundant, Though this seldom appears to be the case in New England. On the Pacific Coast too, though June bugs oceur, they do not seem to be as important as in the interior of the country, particularly in the Mississippi Valley and as far north as the Great Lakes.

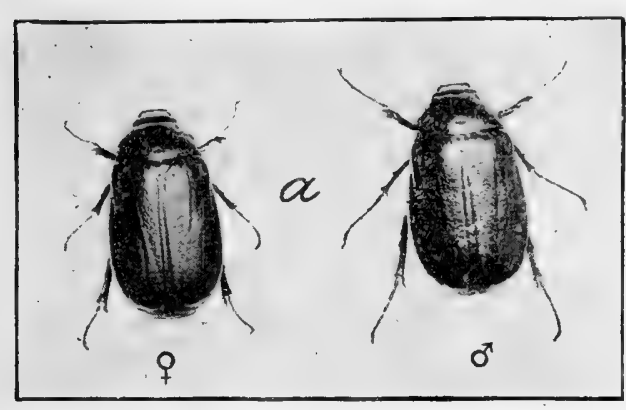

FIG. 102.

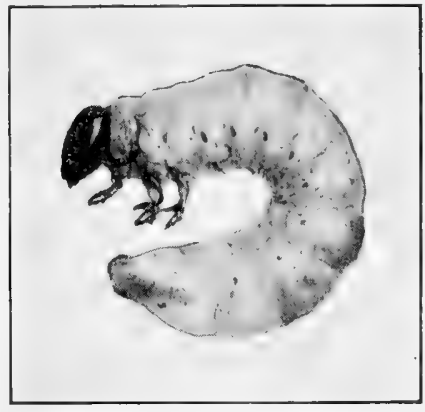

FIG. 103.

FIG. 102.-Adult "June Bugs," female and, male, natural size. (From U.S. D. A. Farm. Bull. 940.)

FIg. 103.-Full-grown larva (white gmb) of "June Bug." natural size. (Original.)

The eggs of the June bugs are laid in the ground and hatch in a fow weeks into tiny "white grubs" with brown heads and legs, and soft, white bodies which increase in size toward the hinder end. The grub (Fig. 103) as usually found when dug up is eurled through the greater part of a circle and this is very characteristic, only a few other beetle larvæ (and those belong in the same family) greatly resembling it. The grubs feed during the summer on decaying vegetation and living plants close to the surface of the ground but on the approach of cold weather go deeper into the ground to pass the winter. The following spring they come up near the surface again and now feed on the plant roots, causing in this, their second season, the largest injury. In the fall of the second season they again go deep into the ground to pass the winter, coming up the third spring to feed on plant roots until June or July, when they go down a little, though not usually much if any below where they may be reached by deep plowing. Here they transform to pupæ which become adult 
after a month or two, but the beetles remain in these underground pupal cells until the next (fourth) spring, when they emerge. The length of a generation as thus outlined therefore is 3 years, but the progeny of any given beetle appearing one spring will appear the spring of the fourth year following, i.e., a generation requires 3 years but is present in parts of 4 calendar years.

This life history holds for most of the injurious species of June bugs in the Central States, through the country east of the Rocky Mountains. In the North, however, the life history in some cases at least, requires 4 years, while in the Southern States 2 years appears to be the normal period. Some appear every year though, indicating the existence of three broods in those regions where the 3-year life-history exists, but the size of these broods is markedly different. Though undoubtedly subject to factors which may increase or decrease the size of these broods as years pass, the most abundant and destructive one at present is that in which the beetles appeared in 1917 and 1920, and which will reappear at 3-year intervals hereafter, the greatest destruction being caused by the grubs the following year. The second brood, the beetles of which appeared in 1918, was not of sufficient size to attract much attention by their injuries in 1919 and probably will not be important in 1922 , while the third brood with the beetles in 1919 and their injuries in 1920 was of importance in only a few areas. How soon favoring conditions may lead to one of these last-named broods becoming large enough to be important, or unfavorable factors reduce the importance of the first-mentioned one, cannot be predicted.

Though white grubs have many natural enemies, including numerous mammals, birds and insects, and also several diseases, both bacterial and fungous, they are not sufficient checks to prevent considerable injury.

Control.-Pasturing hogs in fields considerably infested by white grubs is a good practice, the hogs feeding on other insects they find in the ground, as well. Poultry can be made use of in the same way, but this is most effective when the ground is being cultivated. Rotation of crops is also of value if used intelligently. Corn and clover are crops in which the beetles will not lay eggs freely. Grain fields have many eggs laid in them, but if followed by clover the grubs will do little damage. Fall plowing before the grubs go down to pass the winter will destroy many of them. This should be done as late before the grubs start down as possible. The spring after beetles were abundant the year before, many small grubs should be found in cultivating. In this case seed with small grain or clover. If large grubs are abundant either in the fall or the following spring, plant late if possible, as the grubs finish feeding before July in most cases; or plow as soon after July 15 as possible, to break up and destroy the pupæ. Where beetles are stripping foliage, spraying with a stomach poison, standard, or a little above standard strength, is a good treatment where conditions are such as to make it practicable. 
In general the treatment can be based on the year the beetles are abundant. Sod land broken up that year should be plowed before October and should not be in corn or potatoes, but in clover, small grain or buckwheat the next year, if the farm practice of that region will permit. The following year delay planting till as late as possible. Pasture every season with hogs in the fall as soon as the crop is out.

The Rose Chafer (Macrodactylus subspinosus Fab.).-This insect occurs all over the Eastern United States as far south as Virginia and Tennessee and west to Colorado, being particularly abundant and destructive in sandy localities. The adult beetle is about a third of an inch long, rather stout, though less so in pro-

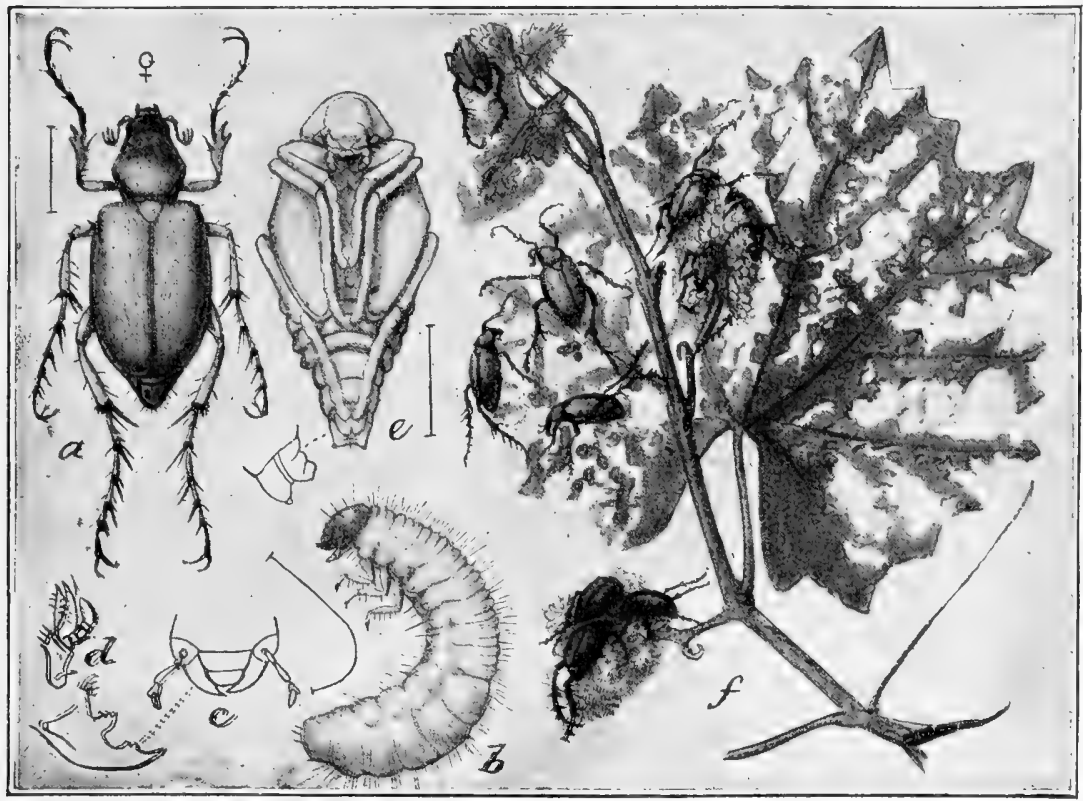

FIG. 104.-Rose Chafer (1Facrodactylus subspinosus Fab.): $a$, adult beetle; $b$, larva (grub); $e$, pupa; $f$, injury to leaves and blossoms of grape with beetles at work. Fine lines beside $a, b$, and $e$, show the true length: $f$, somewhat reduced. (From U.S.D. A. Farm. Bull. 721.)

portion to its length than are the June bugs, dull yellow, with pale, red legs which are long and slender. It appears about the time roses begin to bloom, i.e., in May in the South, and in June in the more northern part of its range, and attacks a large number of plants. It seems originally to have been a rose feeder: later it became a serious pest of the grape and is now destructive to many fruit and shade trees and shrubs, and even to garden fruits and vegetables when abundant, eating blossoms, leaves and any fruit which may be available during its adult condition (Fig. 104).

The eggs, about thirty in number, are laid a little below the surface of the ground, sandy land being apparently somewhat preferred, and these hatch in 2 to 3 weeks into tiny white grubs somewhat resembling those of the June bugs. 
These grubs feed on plant roots, particularly those of grass, until quite late in the fall, then work down in the ground to below the frost line, where each forms a small earthen cell in which to winter. In the spring pupation takes place and from 2 to 4 weeks later the adult beetle is produced and digs its way to the surface. An adult individual lives about 3 weeks.

Control.-Stomach poisons will kill the adults in time but they work too slowly to save the plants, which are seriously injured before the beetles die. In any case, these could hardly be used on flowers as they would at least mar their appearance. On grapes and other fruits, arsenate of lead, using $5 \mathrm{lb}$. of the paste in 50 gal. of water or Bordeaux mixture (better), applied very thoroughly as soon as the beetles appear, or just before the blossoms open in the case of the grape, has given fair results, though a second treatment just after the blossoms fall is sometimes needed. With stone-fruit trees the self-boiled lime-sulfur wash should be used instead of the Bordeaux.

Hand picking, though tedious, is effective with plants growing low enough to make this method of control practicable, but must be repeated every day to get those which fly to the plants from elsewhere, or emerge from the ground later. Bagging the clusters of grapes is often practiced where this plan seems worth while. Harrowing the breeding grounds of the insect to a depth of three or four inches, during the time they are pupæ, i.e., the latter part of May for the central part of their range, destroys many of the pupæ which appear to be very easily killed by any disturbance while in this stage. The difficulty with this is to locate the areas where they are breeding most abundantly. Light, sandy ground will generally prove to be the place for such treatment.

This insect seems to have a poisonous effect when eaten by small chickens, many dying within a day or two after feeding on Rose Chafers.

On the Pacific Coast several species of Hoplia seem to play much the same role as the Rose Chafer does in the East. Their life history does not appear to have been worked out but probably does not differ greatly from that of the Rose Chafer, and the treatments are practically the same. The beetles of all the species range from about one-quarter to one-half an inch in length and are light brown, grayish, mottled, or black with brown, orange-yellow or olive, either in spots or entirely concealing the black. Grape, rose, greasewood, blackberry, etc., are the chief food plants.

The Green Japanese Beetle (Popillia japonica Newst.) has recently been discovered in New Jersey. The beetles attack the foliage of many kinds of plants including fruit trees, small fruits, garden crops and ornamental trees and shrubs: the larvæ feed on the roots of plants and on decaying vegetable matter. The beetle is about half an inch long and somewhat resembles several of our native forms. If, in spite of vigorous measures now being taken to eradicate it, this insect should become widely distributed, it will undoubtedly become a serious pest as it already is in Japan.

Many other Scarabæids are occasionally injuriously abundant in different parts of the country but can hardly be considered as of nationwide importance. The largest beetles found in the United States also belong here and are called rhinoceros beetles. One species, Dynastes 
tityrus L. (Fig. 105), about two and one-half inches long, is greenish-gray with black spots on the elytra. The male has a long horn on the head, projecting forward and upward, and another projecting forward from the pronotum. The female has only a small tubercle on the head. It occurs in the Southern States. In another species found in the West the prothoracic horn is much longer.

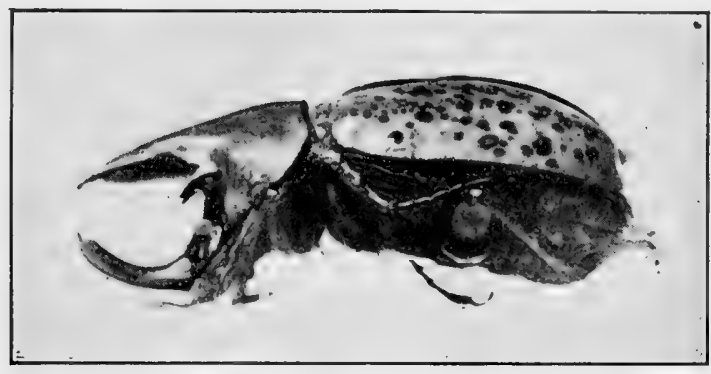

Fig. 105.-Rhinoceros Beetle (Dynastes tityrus L.), about natural size. (Original.)

Family Chrysomelidæ (Leaf beetles).-This is the largest family of beetles but its members are small, not of ten being over half an inch long. Most of them are leaf feeders, though the larvæ of a few are worm-like and attack underground stems or roots. Many are serious pests, and though almost none are found throughout the entire country, allied species working in similar ways, occur.

In the group as a whole, yellowish elytra with black lines or spots seems to be the prevailing color pattern, though of course, with many exceptions. Together with the next two families, from which other characters separate this one, the third segment of the tarsus is generally broad, being drawn out into a lobe on each side, and is covered beneath with minute, closely set hairs (pubescent). The antennæ are at most, of only average length.

The Colorado Potato Beetle (Leptinotarsa decimlineata Say).This well-known insect was discovered about 1823 by Long's exploring expedition to the Rocky Mountains, in the region of the upper Missouri River. Its food there was the Buffalo-bur (Solanum rostratum Dunal) and the insect was apparently not remarkably abundant, and certainly of no economic importance, nor did it become so until civilization, and with this the potato, reached that territory. Then a new and satisfactory food plant, abundant enough to provide all the insects with food became available and the potato beetle increased in numbers and began to spread to the East. At first its rate of spread was only about 50 miles a year but after crossing the Mississippi River this became more rapid and it reached the Atlantic Coast about 1874. Since then it has spread both northward and southward until it is now found practically 
everywhere east of the Rocky Mountains where the potato is grown and it has also reached the Pacific Coast. It does not apparently thrive in the hot climate of the more southerly States.

The adult beetle (Fig. 106b) is somewhat less than half an inch long and about two-thirds this width, its back rather high and rounded. It is clay-yellow and has 10 longitudinal black lines on its elytra. The head has a black spot above, and the pronotum has a number of irregular spots. Winter is spent as the adult in the ground but the insects come out quite early in the spring. As soon as the potatoes are up, they begin. to feed and soon lay their eggs, placing these on the under surface of the leaves

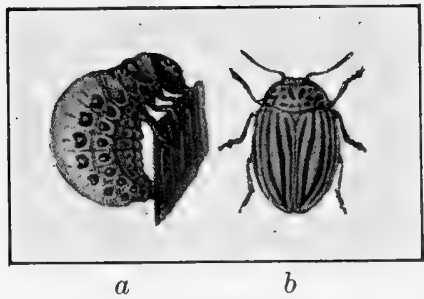

FIG. 106.-Colorado Potato Beetle (Leplinotarsa decimlineata Say), slightly enlarged: $a$, fullgrown larva (Grub); adult Beetle. (From Berlese, After U. S. Bur. Eut. Cire. 87.) in small clusters, an individual laying 500 or more in all. They are small, yellow eggs which hatch in from 4 days to a week or more, according to the temperature. The grubs or "slugs" as they are often called (Fig. 106a) are dull brick-red, soft and with fat bodies. They feed for from 2 to 3 weeks, then go into the ground where they pupate for a week or two, after which the adults emerge and lay eggs for a second generation, the adults of which appear early in the fall. This second generation of beetles feeds for a time, then in

September or October enters the ground to pass the winter.

As the eggs of this insect are not all laid at one time, different ages and different stages even, may be found together in the same field. And as the adults feed in the spring during their egg-laying period, as do the two generations of adults produced during the season, in addition to the two generations of grubs which also consume the leaves, the plants are being attacked much of the time.

While the potato appears to be the preferred food of this insect, other members of the nightshade family are sometimes attacked, particularly the tomato and eggplant.

Control.-This pest is easily controlled by spraying with either of the stomach poisons and as the potato is quite resistant to poisons, the strength of the mixture can with safety be somewhat increased above that of the standard formula. The chief difficulty in control is that as the beetles attack the rapidly-growing plant as soon as it appears above ground, the spray should be applied then, while a week later a large amount of new growth which has no poison on it will have developed, upon which the insects can feed. To avoid this, spraying during the period of rapid growth needs to be done more frequently than is the case with most plants. Two or three treatments, however, will generally be sufficient, and a combination with Bordeaux mixture is advantageous where arsenate of lead is the stomach poison used. 
On small areas, Paris green dry, mixed with 10 to 20 parts of some inert material, dusted over the plants, preferably while the dew is on them, is a fair treatment, and this poison as a spray can also be used. Arsenate of lead is at present the preferred poison for this pest, however.

Various birds, skunks, snakes and toads feed on the Colorado Potato Beetle to some extent, and it also has numerous insect enemies.

The history of the development of the Colorado Potato Beetle, from an unimportant, even probably a rather uncommon insect, feeding upon a plant of no value to man, into one of the most abundant and widely distributed of our pests, attacking and seriously injuring an important crop, is a suggestive one. In a division of the insects of the United States into those which are injurious as regards man and his various interests; those which are beneficial, and those which are of little or no economic importance either way, we shall find that the last group is by no means a small one. How many species in this group are there which are potential pests? It is true that the making available of a new food plant to which the Colorado Potato Beetle could turn, was probably the chief factor in this particular case, but any insect which for some reason changes from an unimportant food plant to a crop plant may at once become a pest. Thus another Chrysomelid only a little smaller than the Colorado Potato Beetle and closely related to it, the Three-spotted Doryphora (Doryphora clivicollis Kirby), which feeds on milkweed, is now of practically no importance. But if it should change its food to some valuable crop plant it would at once become an important addition to the list of insect foes man has to combat. Several such cases are already known. How many others may appear as the changing conditions which always accompany an increasing population and the consequent changes in plant population take place, no one can predict. Some species of plants once common are rapidly disappearing. As they go, will the insects feeding on them go too, or will they be able to find another food plant, and will this one be of value to man? The appearance of new pests in such ways may come at any time, and the fact that an insect is not now a pest should not lead to its being ignored, for it may have great potential importance. The Murky Ground Beetle (Harpalus caliginosus Fab.) is now mainly a carnivorous beetle, but sometimes, though rarely, attacks the strawberry. If it should turn to this latter plant entirely for its food, another important pest would be added to our list and lost from among our friends.

Such facts call for as complete a knowledge as possible of the life and habits of all insects whether now beneficial or only of no economic importance, in order that we may have the knowledge of them and their ways which is necessary in case they should become injurious. 
The Striped Cucumber Beetle (Diabrotica vittata Fab.).--The common Cucumber beetle is found everywhere in this country (of which it is a native) east of the Rocky Mountains. It is a small beetle about a fifth of an inch long, with a black head, yellow pronotum and three black stripes along its yellow elytra (Fig. 107). The insect passes the winter as the adult beetle in protected places, probably among dense weed growth. It leaves its winter quarters early in the spring, before any of its cultivated food plants are available, and feeds on blossoms of various kinds until cucumbers, squashes and the other cucurbits which are its favorite food plants are available. It then attacks these and may also seriously injure peas, beans, apples, and later in the season, corn. It lays its

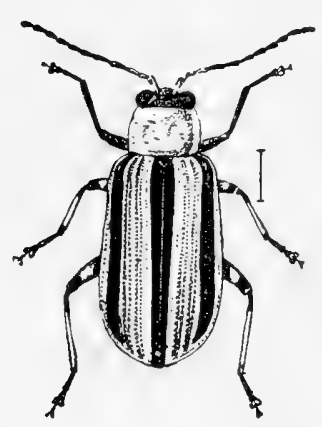

FIG. $107 .-\mathrm{Adult}$ Striped Cucumber Beetle (Diabrotica vittata Fab.) enlarged about six times (see hair line for true length). (From U. S. D. A. Farm. Bull. 1038.) eggs either singly or in clusters, in the ground near the stems and roots of the cucurbits, often in crevices of the soil, the total number of eggs per beetle varying from a few hundred to over a thousand. The eggs hatch in a week or two, according to the temperature at that time, and the grubs feed on the stems and roots. They are tiny, white, slender, and resemble maggots more than the usual forms of beetle larvæ, and when full grown, after 2 to 5 or more weeks, according to the temperature, are only about three-tenths of an inch long. They then soon change to pupæ, still in the ground, in which stage they remain for about a week before the beetles emerge. The life cycle therefore varies in length according to the temperature, it being perhaps not over 4 weeks in the South and 8 in the more northern States. This gives time for several generations each season, and though in the North there is apparently but one, this number increases farther south until in Texas there may be four.

The destruction caused by these insects when they are abundant is often very great. Their first attacks come just when the young plants are struggling to establish themselves and the feeding of the adult beetles is often sufficient to kill them. Later in the season the beetles continue feeding on the leaves and stems, reducing the vigor of the plant and its productiveness, and they may also feed on the outer surface of the fruit, making it more or less unsalable. They also frequently enter greenhouses and attack cucurbits there. The larvæ affect the vitality of the plant by attacking the underground stems and roots but are less injurious than the adults.

The beetles are also injurious by carrying the "bacterial wilt" disease and "cucurbit mosaic" disease, not only from plant to plant, but also from one season to the next. As these diseases are serious ones, 
often destroying plants, this adds to the importance of the insect as a pest.

On the Pacific Coast is a slightly larger species known as the Western Striped Cucumber beetle (Diabrotica trivittata Mannerh.) which has much the same habits as the eastern form. In the more southerly portion of this region the adults are more or less active during the cold months. There appear to be at least two generations a year, and the methods given below for the control of the eastern species also apply for this one.

Control.-This is a difficult insect to control, particularly where large areas are planted to any of the cucurbits and small garden methods will not pay. Protective methods, practicable in gardens, enable the plants to get well started, after which they are able to grow and produce the crop to quite an extent, despite the insect. Screening the plants before they come up, using fine-mesh wire or thin cheese-cloth stretched over a frame, works well for this purpose, provided the edge of the frame fits tightly into the earth everywhere, so that the beetles cannot burrow under it. Sometimes an excess of seed is planted with the idea of giving the insects enough food so that few or none of the plants will be too thickly infested to be able to live, and the poorest ones can be thinned out later. Gathering all but a few of the plants as soon as the crop has been harvested, and burning them will leave the others for the beetles to gather on. These can then be sprayed with a strong stomach poison or a strong contact insecticide. Early cucurbits such as gourds, can be planted near later cucumbers and will act as trap plants, attracting the beetles.

Spraying with a stomach poison, either alone or with Bordeaux mixture, is a good treatment if both sides of the leaves and the stems are well covered. Arsenate of lead $6 \mathrm{lb}$. of paste in 50 gal. of water seems generally to give the best results. The addition of $3 \mathrm{lb}$. of soap to each 50 gal. of spray makes the latter adhere better to the plant. Arsenate of lime gives fair results. Dusting the plants with the dry poison mixed with air-slaked lime or plaster, at the rate of $1 \mathrm{lb}$. of the poison to anywhere from 25 to $50 \mathrm{lb}$. of the inert material, sometimes works well. Its weakness as a treatment is mainly that it is difficult to get it onto the under side of the leaves and have it stay there.

Whatever spray material is used, give the first treatment as soon as the plants show above ground and repeat two or three times at about weekly intervals, or oftener if rain makes it necessary.

Several other minor remedies such as dusting the plants while the ground is moist, with tobacco dust, lime, or a mixture of the two; and hastening the growth and increasing the vigor of the plants by fertilizers and frequent cultivation, have some merit. If any or all the above-suggested treatments have been used, however, some of the insects will generally be present, none of these methods giving absolute freedom from the pest. 
The Corn-root Worms.-There are several species of the genus Diabrotica which as larve appear to make a specialty of feeding either upon the base of the stem or the roots of corn.

The Southern Corn-root worm or Twelve-spotted Cucumber beetle (Diabrotica duodecimpunctata Oliv.) is found practically everywhere in the United States east of the Rocky Mountains, but is usually a serious pest only from Maryland to Florida and as far west as southern Ohio, Indiana and Illinois, Alabama, Louisiana and Texas. The insect generally winters as the adult beetle (Fig. 108) under rubbish or in other protected places, except in the far South where it is

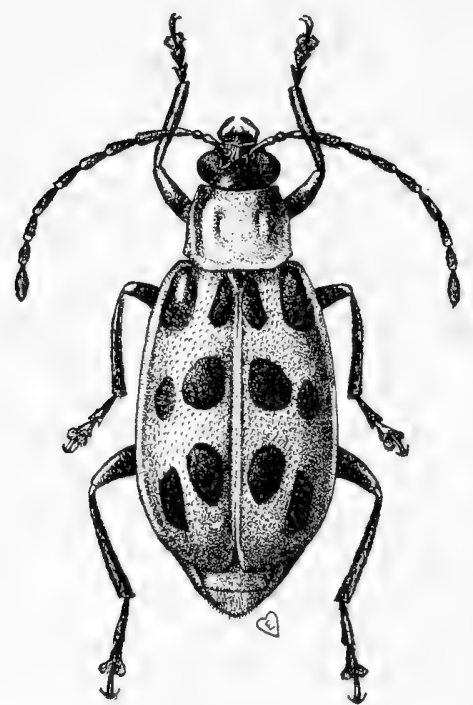

FIG. 108.

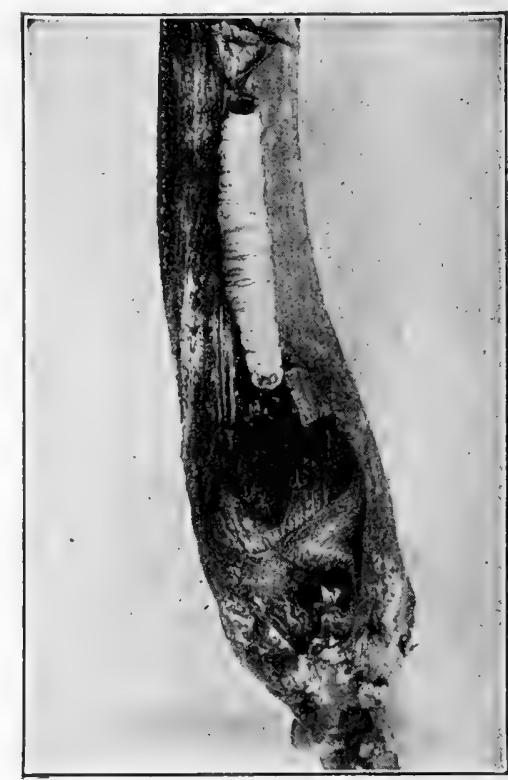

FIG. 109

FIG. 108.-Adult Southern Corn-root Worm (Diabrotica duodecimpunctata Oliv.), enlarged about eight times. (From U.S. D. A. Farm. Bull. 950.)

FIG. 109.-Grub of Southern Corn-root Worm and its burrow in corn. Much enlarged. (From U.S. D. A. Farm. Bull. 950.)

more or less active during this period. In spring it lays its eggs just below ground, on or near the young corn plants, and the tiny grubs which hatch, attack the corn, feeding on the roots and drilling into the stem just above them, boring out the crown and killing the bud (Fig. 109). From this habit the insect is often called the "budworm" or "drillworm." Small plants injured in this way break off at the crowns when pulled, and larger ones become dwarfed and yellowish. Other plants such as wheat, millet, alfalfa, etc., are also attacked by the larvæ. The adult beetle is about a quarter of an inch long, yellowish-green with black head and legs and twelve black spots on its back. It feeds on squashes, cucumbers and many other plants. There appear to be two generations each year in the North and three in the South, but most of the injury is caused by the first generation. Burning over waste places where there is rubbish, during the cold months or on cold days will destroy many of the beetles which are seeking protection 
there. A careful crop rotation, never planting corn twice in succession on the same land is also of value. Cotton, not being attacked by this pest is a safe crop to follow corn and a legume is desirable in the rotation. The insect is most serious in wet seasons and on low land. Corn is often more thickly planted on low places on this account, to increase the chance of getting a stand. Fertilization and cultivation increase the vigor and resistance of the plants to attack. In the far South corn planted during April is more likely to be injured than that planted before this time or after the tenth of May.

The Western Corn-root worm (Diabrotica longicornis Say) occurs from Nova Scotia to the Gulf of Mexico and west to Minnesota, Nebaska and New Mexico, but is most injurious from Ohio to Tennessee and from South Dakota through Nebraska, lowa and Missouri. The winter is spent in the egg in the ground and the grubs (Fig. 110) hatch in the spring and attack the corn roots (Fig. 111) but never the stem. After

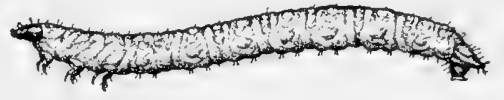

Fig. 110.-Grub of Western Corn-root worm (Diabrotica longicornis Say), much enlarged. (From U.S. D. A. Bull. 8.)

feeding until full-grown they pupate in the ground and the adult beetles emerge in July and August and lay their eggs. There is therefore, but one generation a year. The adult beetles (Fig. 112) are about one-fifth of an inch long and, except for their black eyes, are entirely greenish or yellowish-green. They feed on the pollen and silk of corn and on the

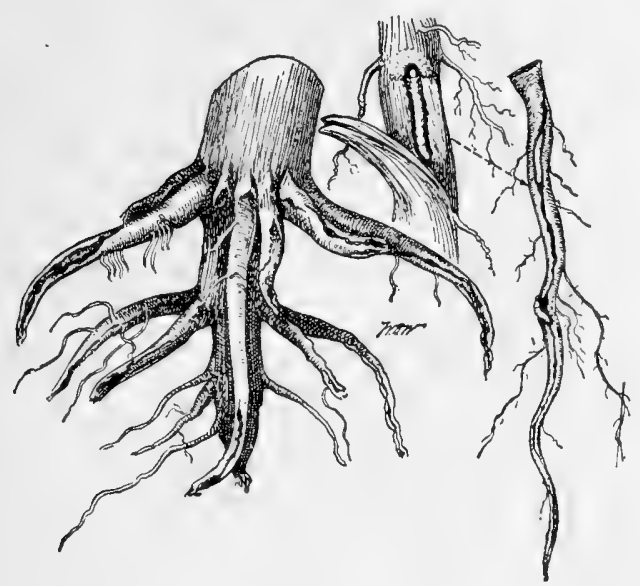

FIG. 111.

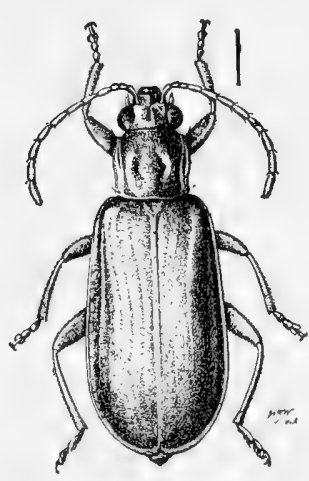

FIG. 112 .

Fig. 111.- Work of Western Corn-root worm in corn roots: (From U. S. D. A. Bull. 8.)

Fig. 112.-Adult Western Corn-root worm, enlarged. Hair line at right shows real length. (From U.S.D. A. Bull. 8.)

blossoms and leaves of other plants, in August and September and if abundant then in a corn field, one may be certain that that field will be well stocked with eggs and therefore that corn should not be planted there again the following spring Corn attacked by the grubs at first produces shortened ears with kernels lacking at the tips: later it fails to produce the ears, and dwarfing of the plants 
occurs. Rotation of crops has proved a successful control for this insect in practically every case where it has been tried.

Another species (Diabrotica vergifera Lec.) having similar habits and similarly controlled, is of ten destructively abundant in Colorado.

On the Pacific Coast a different species, the Western Twelve-spotted Cucumber Beetle or Flower Beetle (Diabrotica soror Lec.), appears to have the same general habits as its eastern relatives, but observations thus far indicate that the grubs are injurious mainly to alfalfa, beet, pea and peanut roots, while the adults do much damage to many plant leaves, buds and flowers. The winter appears to be spent in the adult stage and the eggs are laid from March to May in different latitudes. There are probably two generations each year. The adult is one-fifth to one-fourth of an inch long. The head, antennæ, legs and body are black; the pronotum and elytra green or yellowish, the latter with twelve black spots often partly fused. Control thus far has been directed mainly against the beetles, spraying plants on which they are feeding with arsenate of lead (neutral) at the standard formula, using either water or Bordeaux mixture.

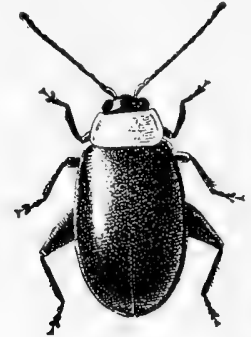

$a$

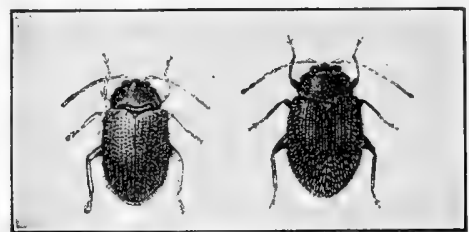

$b$

$c$

FIG. 113.-Adult Flea Beetles: $a$, spinach Flea Beetle, enlarged nearly five times; $b$, Potato Flea Beetle, enlarged about seven times; $c$, Egg-plant Flea Beetle, enlarged about seven times. (From U.S.D. A. Bulletins.)

Flea Beetles.-Many tiny beetles belonging in the Chrysomelidæ are known as Flea beetles because when disturbed they hop away like fleas. The economic forms vary in size from about a fifth to a fifteenth of an inch in length (Fig. 113). Most of them are blackish or steelblue, though some have portions of the body yellow, whitish, red or other colors. The hind femora are very large, enabling the insects to make vigorous leaps. The adults feed on the leaves, eating tiny holes, while in most cases the larvæ are root feeders, generally on the same plants which their adults attack, though in some cases they also attack the leaves. Many attack garden crops such as the potato, turnip, beet, spinach, rhubarb and radish, while other species feed on the strawberry, grape, tobacco, hop, clover, apple, Virginia creeper, willow, alder, etc. In most cases there are two generations a year, the first appearing early in the season and the second in mid-summer or early fall, though some species have but one generation and some have several.

Control.-These insects which are often serious pests, appear to be repelled by Bordeaux mixture, but it is better to combine this with 
arsenate of lead, standard formula. Dusting with Paris green and land plaster may also be used with some success as a control method. Where the larvæ mine in the leaves, as certain species do to some extent, treatment must be directed toward the destruction of the adults which indeed, should be the case with all the species. Where plants are started in seed beds and are attacked there, screening the beds with cheese-cloth is practicable. When plants from seed beds are set out they may be protected by dipping them in $1 \mathrm{lb}$. of arsenate of lead paste in $10 \mathrm{gal}$. of water before setting them.

It is believed that the Cucumber Flea-beetle like the Three-lined Cucumber Beetle may inoculate plants with the cucurbit wilt already referred to. Certainly the tiny holes made in the leaves by their feeding provide excellent places for the spores of fungi to establish themselves and produce disease.

The Common Asparagus Beetle (Crioceris asparagi L.).- This insect reached this country from Europe about 1856 and is now present in the Eastern States as far south as North Carolina and westward to the Mississippi River. Farther west it has been reported from several scattered localities, including California, and it may be assumed that it will in time become generally distributed.
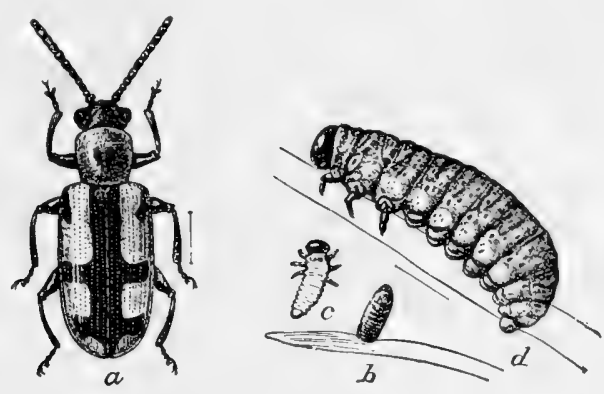

Fig. 114.-Common Asparagus beetle (Crioceris asparagi L.): $a$, Adult; $b$, Egg; $c$, larva, just hatched; $d$, full-grown larva. Greatly enlarged: hair lines beside $a$ and $b$ show 'real length. (From U.S.D. A. Farm. Bull.837.)

The adult beetle (Fig. 114) is a little less than a quarter of an inch long. It is dark blue or bluish black, with a red thorax, and its elytra are dark blue and yellow, the former present as a band along the middle, with two lateral extensions toward the sides into the yellow, while the outer border is reddish. The distribution and amount of the blue and yellow varies considerably according to the locality, the blue often so encroaching on the yellow as to leave only six spots of the latter color.

The insect winters in the beetle stage in any protected place it can find, and as the asparagus plants begin to come up in spring, leaves its winter quarters to feed and lay its eggs (Fig. 115a). The beetles at this 
time feed on the stems and when abundant do considerable harm. The eggs are laid on the stems, singly, attached by one end, are dark brown in color, and hatch in from 3 to 8 days according to the temperature. The grubs (Fig. 114d), often called "slugs" are gray with black heads. They feed from 10 days to 2 weeks, gnawing the stems and thus aid the beetles in making these unfit for sale. Then they enter the ground and pupate for about a week which is followed by the emergence of the adults. The life cycle therefore is from about 4 weeks during hot weather to 6 or

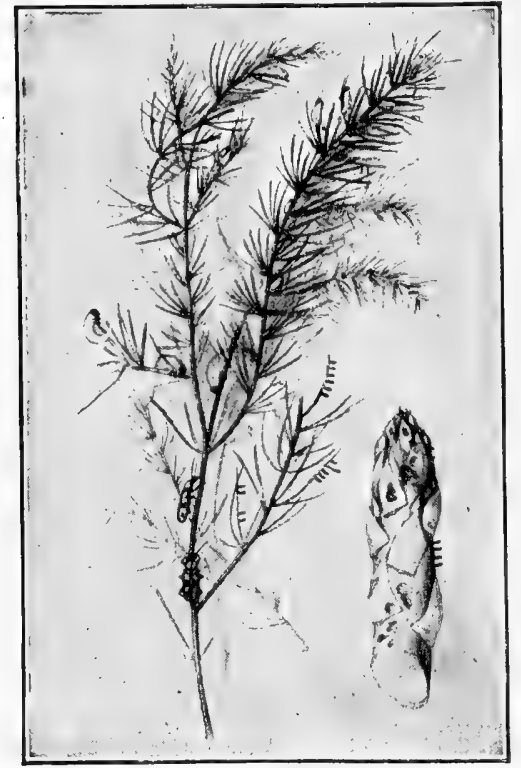

FIG. 115.--Eggs, larvæ and adults of Common Asparagus Beetle on the plant. Natural size. (From U.S.D. A. Farm. Bull. 837.) 7 weeks in spring or fall. There are at least two generations in the North and probably three or four in the South each year.

The later generations feed on the leafy growth and in the case of young plants may seriously weaken them. Eggs when abundant on the stems cut for market are objectionable, and a black fluid poured out by the grubs when disturbed, often stains the stems also. Fortunately, excessive heat appears to kill many of the grubs, and the alternation of severe cold with much warmer periods in winter, has a similar effect on hibernating adults. Several parasites and other enemies also reduce the numbers of this pest.

Control.-Fresh air-slaked lime dusted over the plants while these are wet with dew is an excellent control measure for small areas. Fowls feed freely on the insects and are therefore of value when allowed to run through the asparagus beds. For larger areas a frequent practice is to keep the plants as closely cut as possible, leaving a few stems here and there as traps on which the beetles can lay their eggs. These plants should be cut once a week and destroyed, others being then allowed to grow to take their places. Where cutting is not being done, spraying with arsenate of lead a little stronger than the standard formula is a very satisfactory treatment, the number of treatments required being generally not more than two or three at most during an entire summer.

The Twelve-spotted Asparagus Beetle (Crioceris duodecimpunctata L.).This insect arrived in this country from Europe about 1881 and was first discovered near Baltimore, Md. Though beginning its work here more than 20 years later than the other species, it has already nearly everywhere overtaken the latter and is now widely distributed. 
The adult beetle (Fig. 116) is slightly larger and broader in proportion to its length than the Common Asparagus Beetle. It is orange-red or brick-red above except for twelve black dots on the elytra. The life history and habits do not seem to differ much from those of the other species exrept in the following features. The beetle appears to depend upon flight rather than upon dodging around the stems to escape its enemies: the egg is not attached by one end but by a side, to the plant; the larva feeds inside the berries and is orange to yellowish in color. The hibernating insects feed on the young plants like the other species but the beetles of later generations feed on the berries. Control is

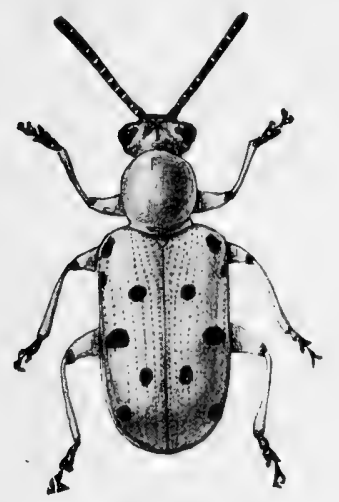

FIG. 116. similar to that for the Common Asparagus Beetle except that dusting with air-slaked lime will not reach the larvæ.

The Grape-root Worm (Fidia viticida Walsh). -The Grape-root Worm appears to be a native

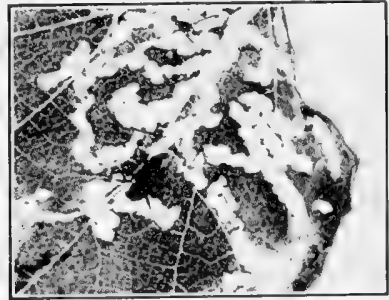

FIG. 117 .

FIG. 116.-Adult Twelve-spotted Asparagus Bectle (Crioceris duodecimpunctata L.) nearly six times natural size. (From U.S.D. A. Farm. Bull. 837.)

FIG. 117.-Adult Grape-root Worm (Fidia viticida Walsh), about natural size, and its work on a grape leaf. (Modified from Cornell Exp. Sta. Bull. 208.)

of this country and is found from New York to North Carolina (and Florida?) and west to Dakota, Missouri and Texas. There is also a California record for it but it appears to be largely replaced there, by the California Grape-root worm (Bromius obscurus L.). The insect passes the winter as the nearly- or full-grown larva, a number of inches deep in the ground, but in spring it comes nearer the surface and feeds on the roots of the grape until full grown. Pupation usually occurs two or three inches below the surface and the adult beetles begin to emerge about the time blossoming of the grape ends, most of them appearing during a period of 4 or 5 weeks. The beetles (Fig. 117) are brown, covered with whitish hairs; are rather stout, about a quarter of an inch long and have long legs. They feed on the grape leaves, making irregular holes, often so connected as to form narrow, crooked slits. The eggs are laid, several hundred in all, placed in clusters of about 30 or 40, mainly under loose strips of bark. These hatch in about 10 days and the tiny grubs drop to the ground and work down to the roots consuming the smaller ones entirely and burrowing in the larger ones, until winter, when they are full grown or nearly so.

When these insects are abundant the grape vines may be killed in a year or two but the usual result of their presence is to so check the growth of the plants that little or no crop is obtained. The grape-raising territory of western New York, Pennsylvania and Ohio appears to suffer most from the attacks of this pest. 
Control.-The adult beetles can be killed by spraying the leaves with arsenate of lead using 3 or $4 \mathrm{lb}$. of the paste in 50 gal. of Bordeaux mixture, just before or as soon as the first signs of feeding appear, and again after 10 days. Great care must be taken, however, to do this work thoroughly, as the beetles avoid sprayed foliage. The beetles may also be jarred off the vines, particularly on warm days, onto sticky boards, fly paper, or sheets or some other type of catcher placed beneath the plants, whence they can be gathered and destroyed. The pupæ are located within a few inches of the top of the ground and are mostly within two or three feet of the vine. In this state of their existence they are easily destroyed by any thorough breaking up of the soil where they are, and this is taken advantage of by throwing up the earth on each side of the vines in the fall to form a ridge. Most of the larvæ work up into this to pupate, the following spring, and while the insects are in the pupa stage there this ridge should be hoed away by a horse-hoe and by hand, or by the latter alone for small areas. Later cultivation will reach some of those escaping the first treatment which in the grape belt named is usually about the middle of June.

The Californian species is a little smaller than the one just described, and jetblack or brown. Its habits and methods for controlling it are about the same as with the eastern pest.

The Elm Leaf Beetle (Galerucella luteola Muls.).-This European insect appears to have reached this country at Baltimore about 1834 and has now spread through most of the New England and Middle Atlantic States and westward nearly to the Mississippi River, though not everywhere present within these limits.

The adult beetle (Fig. 118) is about a quarter of an inch long, dull yellow in color, with black spots on the head and pronotum, a black band near the outside of each elytron, and a short streak at the base of each, nearer the middle. The beetles winter over in protected places and in the spring the dull yellow has changed to an olive-green (Fig. 118). They fly to the elm trees when the foliage develops, and feed, eating irregular holes in the leaves and from time to time laying yellow eggs on the underside of the leaves, usually about 25 in number and nearly always in two rows, side by side (Fig. 118). The eggs hatch after about a week and the tiny yellow and black grubs feed for about 3 weeks, working on the under surface and leaving the upper epidermis of the leaf unbroken. When fullgrown (Fig. 118) and about half an inch long they crawl down the tree to the trunk and pupate for from 1 to over 3 weeks according to the temperature, either in crevices of the bark on the lower part of the trunk or on the ground near the foot of the tree (Fig. 118). In the more northerly states the larvæ feed during June. Farther south they begin in May and a second generation feeds during the late summer or early fall. The European elms are most severely injured by this insect but other species often suffer greatly.

Control.--Spraying the trees about the time the eggs are laid, i.e., soon after the leaves are fully grown, with arsenate of lead is the usual method of control. The strength of the material should be increased above the standard to $5 \mathrm{lb}$. of the paste, to obtain good results, and it should be kept in mind that as the grubs do not feed on nor reach the upper surface of the leaves, the spray should be directed as far as possible onto the under surfaces. 


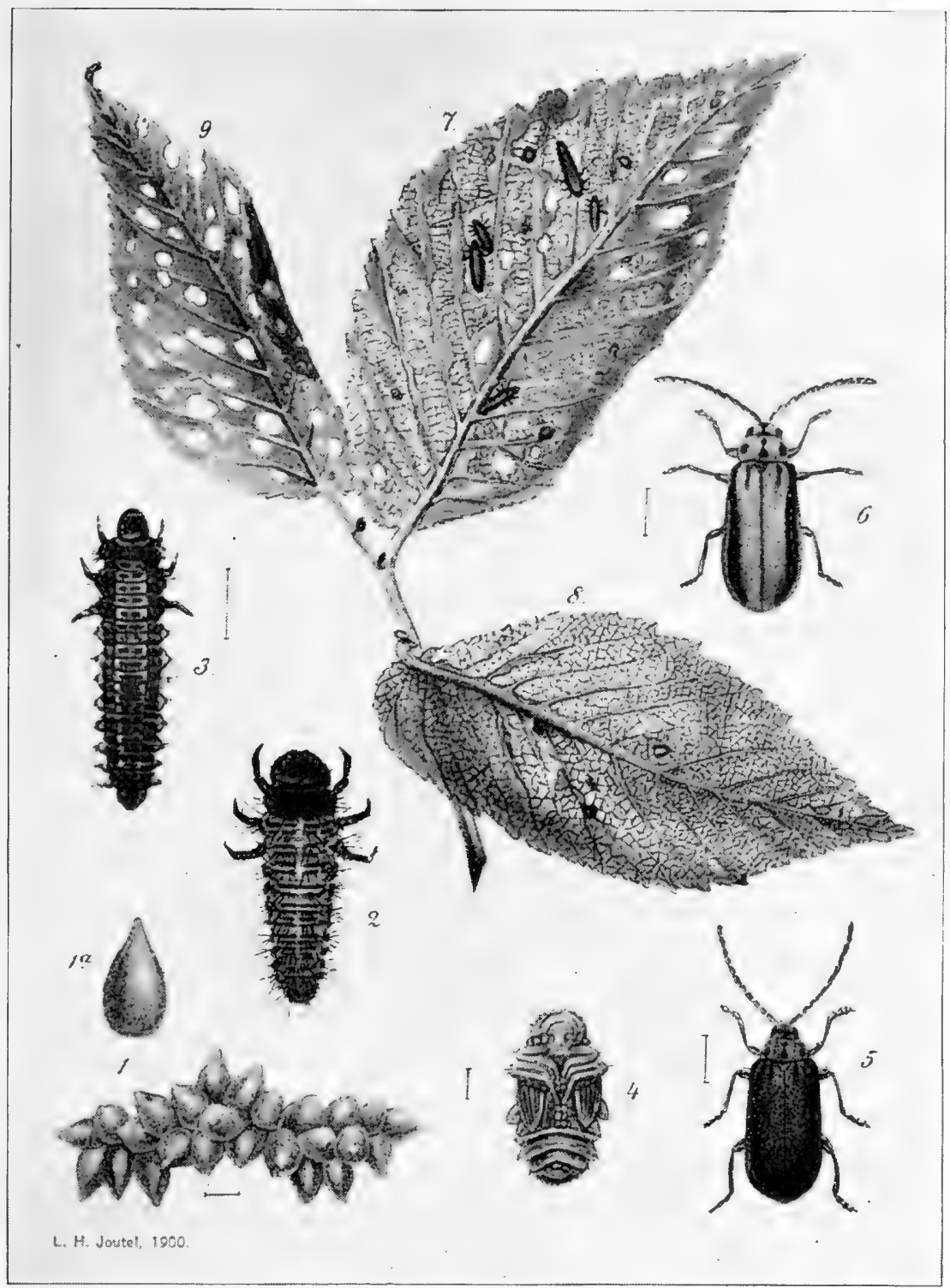

FIG. 118.-The Elm Leaf Beetle (Galerucella luteola Muls.): 1, egg cluster; 1a, single egg greatly enlarged; 2 , recently hatched larva (grub); 3, full-grown larva; 4 , pupa; 5 , beetles after wintering over; 6 , freshly emerged beetles; 7 , under surface of leaf showing grubs, their work and a few holes eaten by adult beetles; 8 , leaf nearly skeletonized by the larvæ; 9, leaf eaten by adults. Hair lines by Figs, 1 to 6 show natural size: 7,8 and 9 natural size. (From Bull. 332 Ohio Agr. Exp. Sta. After Felt.) 
Destroying the descending larvæ and the pupæ on the lower part of the trunk and on the ground, with a strong kerosene emulsion spray is an auxiliary treatment, but as these individuals have completed their feeding, this affects only the abundance of the next generation. Power sprayers are a necessity for spraying tall trees in the way here described.

The Tortoise Beetles are interesting members of the Chrysomelidx (Fig. 119) because of their resemblance in form to tortoises and in most

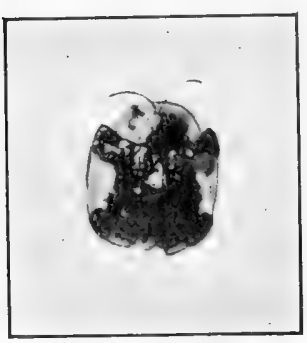

FI G. 119.-Tortoise Beetle (Deloyala clarata Fab.) about $2 \frac{1}{2}$ times natural size. (Original.) cases, on account of their golden color, which is lost after death. Some species attack the sweet potato but are not usually serious pests. They are small insects, usually not over a quarter of an inch long, nearly as wide, and often with black markings. If they become injuriously abundant, spraying the leaves on which the larvæ feed, with arsenate of lead will control them.

Family Bruchidæ (Pea and Bean Weevils).-In this group of small beetles the head is extended downward into a broad but short snout. The elytra are shorter than the body leaving the hinder end of the abdomen exposed above. The larvæ feed in the seeds of leguminous plants such as peas and beans, and frequently cause a great amount of damage. Several kinds are abundant in the United States, the pea weevil and the common bean weevil being perhaps the most important.

The Pea Weevil (Bruchus pisorum L.).-This pest of field and garden peas winters as the adult beetle (Fig. 120a) either in peas or in protected places, and after the pea pods begin to form, lays its eggs on them. It is about one-fifth of an inch long, brownish, with black and white spots. The larvæ (Fig. 120b) bore their way into the peas, the holes they make either closing up or being too small to be noticed, and feed on the contents of the pea until full-grown. They then pupate (Fig. 120c) and upon the pro-

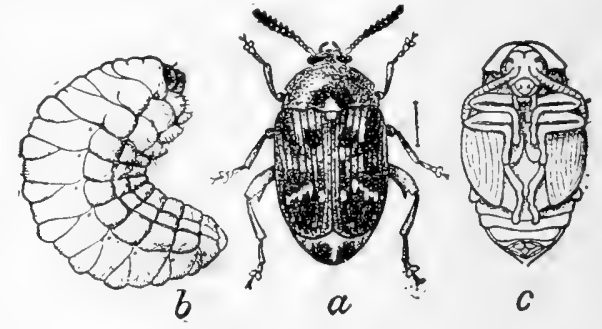

FIg. 120.-Pea Weevil (Bruchus pisorum L.): $a$, adult beetle; $b$, larva (grub); $c$, pupa. Greatly enlarged. (From U.S. D. A. Farm. Bull. 983.)

duction of the adult, those in the South leave the peas, while in the North they remain, in them over winter. Only one weevil usually feeds in a pea and the insect cannot reproduce in dried peas. There is therefore only one generation a year except where spring and fall crops of peas are grown. 
The Common Bean Weevil (Bruchus obtectus Say).- This insect is now found in nearly all parts of the world. The beetle is smaller than the Pea Weevil and is brownish-gray in color, its clytra slightly mottled (Fig. 121). The beetle lays its eggs on or in the pods of the beans growing in the field, either in holes made, or in cracks caused by the pods splitting. In the case of shelled beans the eggs are placed on the beans themselves. The larvæ gnaw their way to and into the beans, and unlike the Pea Weevil, a number may enter the same seed and feed upon its substance. Development from the egg to the adult occurs within the bean and the adult finally escapes through a circular hole it has cut in the skin after having spent from 3 weeks to nearly 3 months there, according to the tempera-

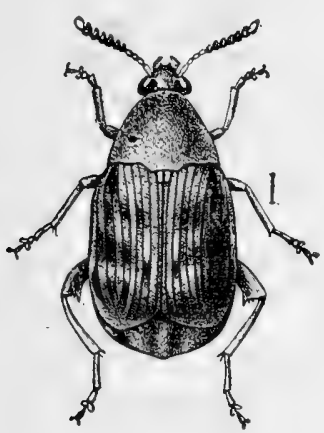

Fig. 121 . ture where the beans are kept. When infested beans gathered in the field are brought in, their infestation may not be apparent, but after being kept a while, the adult beetles will escape

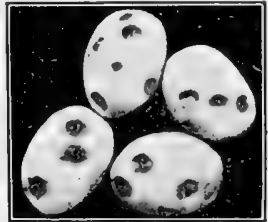

FIG. 122 .

Frg. 121.-Adult Common Bean Weevil (Bruchus obtectus Say), greatly enlarged: hair line at right shows real length. (From U. S. D. A. Farm. Bull. 983.)

FIG. 122.-Work of Bean Weevils, natural size. (Original.)

and lay their eggs for another generation which will develop in the same seeds if these are kept where it is fairly warm (Fig. 122), and thus by spring there may be practically no beans left to plant. Six generations may be produced in a year in the South and if the beans are kept where it is warm during the colder months, as many may occur in northern localities, though in the field it is doubtful if there are more than one or two.

Another species, the Cowpea Weevil (Bruchus chinensis L.) which feeds on the cowpea, and other peas, and beans, is more abundant in the South, and a fourth, the Four-spotted Bean or Cowpea Weevil (Bruchus quadrimaculatus Fab.) has a wide distribution, probably wherever cowpeas are grown. Both of these species breed generation after generation in stored cowpeas, and in warm temperatures there may be a number of generations each year.

The Broad Bean Weevil (Bruchus rufimanus Boh.) in its life and habits more nearly resembles the Pea Weevil than the other species above considered. It is injurious in Europe and Northern Africa and has now established itself in California. The beetles resemble the Pea Weevil but seem to prefer broad beans or horse beans. They appear in the fields in March and lay numbers of eggs on the bean pods and the grubs on hatching make their way to the young beans, several 
of ten entering one bean. Feeding is completed by early August and the adults are produced later in the fall. They generally winter in the beans but do not breed in dried beans, there being therefore only one generation a year.

Injuries. - The damage caused by the attacks of pea and bean weevils is of two kinds: injury by consuming the bulk of the seed and leaving the remainder unfit for food; and injury by so reducing the stored material or the germ itself that the seed cannot germinate and grow.

Control of Pea and Bean Weevils.-The original attacks of these insects are upon growing plants out-of-doors. Here no control seems possible. When the crop is gathered, however, treatment can easily be given by shelling at once, placing the seed in gas-tight receptacles, and fumigating it with carbon disulfid, using this at the rate of at least 8 or $10 \mathrm{lb}$. for every $1,000 \mathrm{cu}$. ft. of space in the container, and continuing the treatment for at least 1 - better 2 -days. The disulfid may be poured directly onto the top of the seeds. For best results this should be done in a place where the temperature is at least $75^{\circ} \mathrm{F}$. Then the seed should be packed in weevil-tight boxes, but it would be wise to examine it again after a time and if living weevils are still present, give it another treatment. Where the seed is not to be used for food, packing it in air-slaked lime at the rate of 1 part by weight of lime to 2 or 3 parts by weight of seed has proved satisfactory. Even where use as food is intended, this method can be used if the seed is thoroughly washed before cooking. Cold storage below $34^{\circ} \mathrm{F}$. will prevent development of the insects. Heat will destroy the weevils and if seed is raised to $131^{\circ} \mathrm{F}$. and kept at that temperature for an hour, this will kill all the weevils present. Apparently, treatment in this way and for this length of time will not prevent germination. None of these methods will prevent reinfestation if the seeds are afterwards exposed to attack by insects from outside, where the temperature is such that they are active. In general then, give the first treatment immediately after gathering, and store in tight containers and preferably in a cold place.

The shorter seasons and cold winters of the North give the pea and bean weevils less opportunity to increase through a number of generations than in the South, and many of the adults are killed by the cold. Northern climates for these reasons are therefore better for the extensive production of seeds of these plants.

Family Cerambycidæ (Round-headed Borers or Longicorn Beetles).The insects of this family are for the most part of fair size, a number being several inches in length. Their antennæ are usually long-sometimes longer than the body - and the beetles are frequently bright-colored and strikingly marked (Fig. 123).

The larvæ are chiefly wood-borers, living in burrows in the trunks or roots of trees, or the pith of plant stems, and are termed round-headed 
borers because the thoracic segments are circular in outline and the tunnels they produce are therefore also of this shape. The larvæ themselves are soft, whitish or yellowish grubs, with.strong jaws, and most of them have no legs. The eggs are usually laid on the bark of the tree and the larvæ live on the wood they tunnel out, for a varying period, usually 2 or 3 years, and pupate in the tunnels just beneath the bark, through which the emerging beetle finally gnaws its way and escapes.

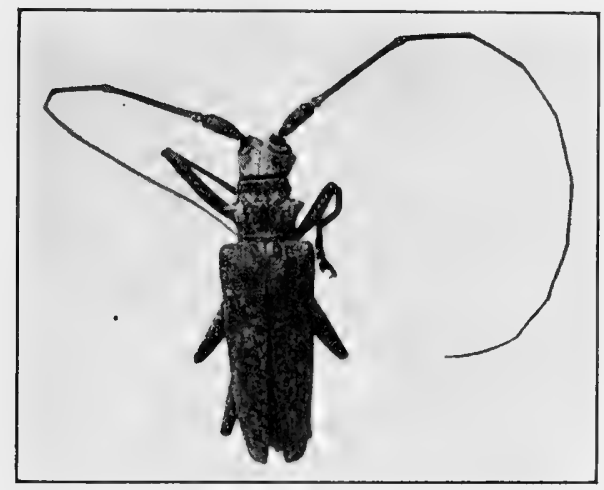

FIG. 123.-Cerambycid (Monohammus), natural size, showing long antennæ.

(Original.)

Some species cut the stem in which they live, nearly through, and when it breaks off, fall with it to the ground, thus pruning the tree. Those which tunnel in the heart-wood of timber trees often greatly reduce the value of the timber by their holes. Some species attack sound wood and apparently vigorous trees, while others seem to prefer trees already unhealthy, for their food. The family is a large one and contains many forms injurious to shade and forest trees.

The Round-headed Apple-tree Borer (Saperda candida Fab.).-This serious enemy of the apple tree is found practically everywhere in the eastern United States except in the extreme South, and westward into Minnesota, Iowa, New Mexico and Texas. It also attacks the service tree, pear, quince, thorns, mountain ash, and a few other Rosacex. The adult beetle (Fig. 124) is a little less than an inch long, pale brown above, with a pair of white stripes extending backward from the head across the pronotum and along the elytra to their tips at the hinder end of the body. Beneath, it is silvery white. It appears during the late spring and summer months and lays its eggs singly here and there in small slits it cuts in the bark near the base of the tree, laying about 15 to 30 in all. On hatching, 2 to 3 weeks later, the larva burrows through the bark to the sap-wood, and there makes broad, rather shallow galleries just under the bark and in general working downward. The bark over these galleries frequently dries and cracks, or the borer makes holes in it, letting 
out the borings and castings, often called "sawdust" which shows the location of the burrows. After hibernating during the winter the borer (Fig. 124) resumes its work the following spring, still feeding on the sapwood, and if the tree is small or if several borers are present, girdling may result. After a second winter in hibernation the borer turns its attention to the heart-wood, boring into this, and finally as it approaches full growth, working its way out toward the surface, being now about threequarters of an inch long. After a third winter of rest the larva pupates in its tunnel in the spring, having previously carried the tunnel out to the bark, and the adult beetle emerges after about 3 weeks. One generation

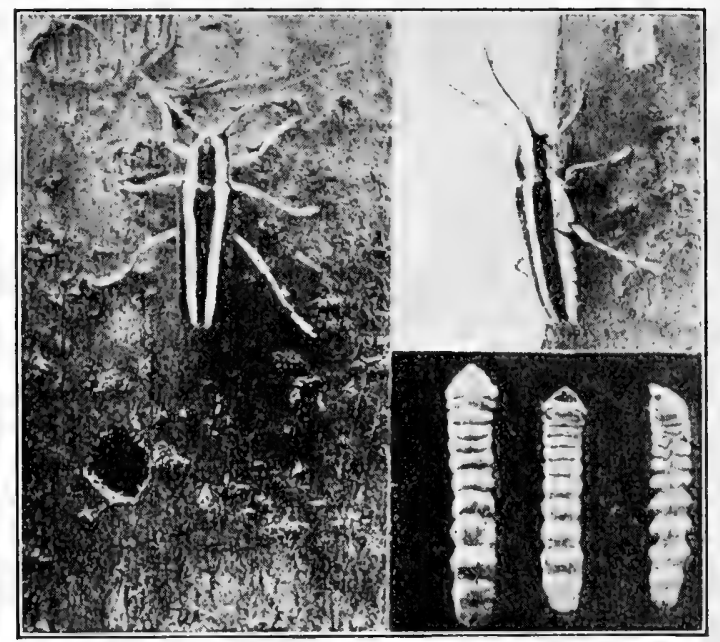

FIG. 124.-Round-headed Apple-tree Borer (Saperda candida Fab.): back and side views of adult beetle on bark and exit hole; full-grown larvæ (borers). (After Rumsey and Brooks.)

accordingly requires 3 years in which to complete its life history but this comes in parts of 4 calendar years. In the southern part of its range this is shortened to 2 years and in intermediate regions some may require 2 , and some 3 years.

Small trees suffer most severely by the attacks of this pest, a single borer often entirely girdling a tree: larger ones are weakened and become unhealthy and if strongly infested may also be killed.

Control.-Various methods of control have some value. "Worming" the trees, i.e., cutting out the young borers early in the fall is a good practice if it is thoroughly done and if the cutting is carried on carefully. Litter should be carefully scraped away from the trunk to expose any sawdust present, and from this the burrows can be located and the dead bark cut out and the borer killed, either in place under the bark or by running a flexibie wire into its burrow if it has gone deeper into the tree. In cases where the borer cannot be reached by the wire, a little carbon 
disulfid on cotton placed in the burrow, the opening then being closed with mud, will serve the same purpose. Worming should be done in early fall; the work should be thorough, and host trees of every kind within several hundred feet of the orchard should be worked at the same time for the beetles do not usually fly far and if the immediate neighborhood is cleared of them, reinfestation from a distance does not occur very frequently.

Thick paints are sometimes used as repellents. These are applied beginning a few inches below ground, the earth being removed for the purpose, and extending about a foot up the trunk, just before the egglaying period begins. The paint should be thick and be thoroughly applied and should be pure white lead in raw linseed oil, as other materials have been known to injure the trees.

Protectors, such as newspaper wrappings (several layers thick), building paper, cloth, wire netting, etc., may be used, being placed around the trunks before egg-laying begins. In all cases, however, these must enter the ground at the bottom and be tightly fitted around the trunk at the top and be without holes or cracks through which the beetle can crawl. Asphaltum has given fair results in some cases, but appears to be liable to injure the tree.

As the beetle feeds somewhat on twigs and leaves, the usual sprayings with a stomach poison for other apple pests are liable to kill some of the beetles also. Woodpeckers feed freely on the borers.

Family Coccinellidæ (Lady Beetles, Lady Bugs or Lady Birds).The lady beetles are nearly all carnivorous, feeding both as larvæ and adults on scale insects, plant lice and other important pests. They are generally small beetles, nearly circular or oval in outline, strongly convex, often resembling in size and form a split pea. Their colors are usually black and red or reddish-yellow, sometimes the spots or markings being black on a red ground, sometimes the reverse. In a number of species the beetle is entirely black (Figs. 125 and 126).

The larvæ (Fig. 126) are active and crawl around over leaves, twigs, etc., searching for their food. They are dark colored, but frequently have a few spots of yellow or blue on the side of the body, and their general appearance has suggested to some persons, a resemblance to alligators.

The family is quite a large one, and its species are abundant and well distributed over this country. Among the more useful or noticeable of the family is the Two-spotted Lady beetle (Adalia bipunctata L.), one of the smaller species averaging about a sixth of an inch in length (Fig. 125b). The head is black, sometimes with two yellow spots; the pronotum black with yellow side margins, and the elytra are red with a black dot in the center of each. This insect frequently winters in houses and may be found on the windows in spring trying to escape. It is often mistaken for some 
injurious household pest on this account. This species feeds mainly on plant lice, but to some extent also on the pear psylla. Another species of about the same size is known as the Twice-stabbed Lady beetle (Chilocorus bivulnerus Muls.). Here the head and pronotum are black, as are also the elytra, except for a red spot in the center of each, thus just reversing the elytral color pattern of the last described species. It feeds on scale insects and also on plant lice and the Colorado Potato Beetle.

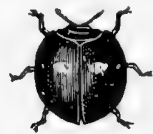

$a$

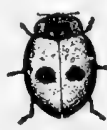

$b$

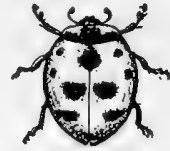

c

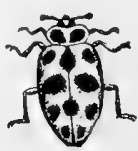

$d$

F1G. 125.-Examples of Lady Beetles: $a$, Twice-stabbed Lady Beetle (Chilocorus bivulnerus Muls.): $b$, Two-spotted Lady Beetle (Adalia bipunclata L.); $c$, Nine-spotted LadyBeetle (Coccinella novemnotata Hbst.): $d$, Spotted Lady Beetle (Coleomegilla fuscilabris Muls.): all about twice natural size. (From Conn. Agr. Exp. Sta. Bull. 181.)

Other common species are the Nine-spotted Lady beetle (Coccinella 9-notata Herbst.) with nine black spots on its red elytra; the Fifteen-spotted Lady beetle (Anatis 15-punctata Oliv.), the largest species in the Northeastern States, which has 15 black spots on its red elytra; the Pitiful Lady beetle (Pentilia misclla Lec.), a very tiny black species which feeds on scale insects and aphids, and the Spotted Lady beetle (Coleomegilla fuscilabris Muls.) about a fifth of an inch long, usually bright pink with black spots and with its body rather oval in outline, somewhat pointed behind. This species feeds on many kinds of plant lice and other small insects and tends to hibernate in clusters, of ten several hundred together, under leaves at the bases of treetrunks.

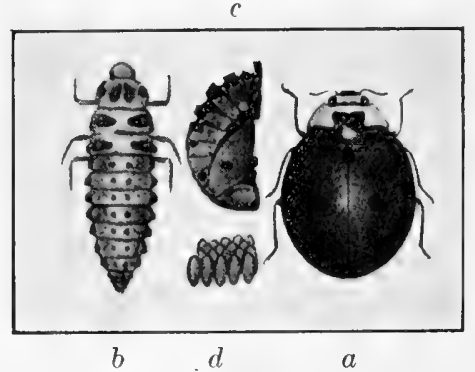

FIG. 126.-Different stages of the Nine-spotted Lady Beetle: $a$, adult; $b$, larva; $c$, pupa; $d$, eggs. All much enlarged. (Modified from Palmer, Ann. Fnt. Soc. Am., vii, 1914.)

The Convergent Lady beetle (Hippodamia convergens Guer.) is about a quarter of an inch long, with two converging yellow marks on the pronotum and six black spots on each elytron. This widely distributed species has been found feeding on a number of kinds of plant lice and in addition, on asparagus beetle larvæ, eggs of the Colorado Potato beetle and of the Grape-root worm, red spiders, the Bean Thrips, Alfalfa Weevil and Chinch Bug. On the Pacific Coast it gathers in enormous numbers 
in the high mountains to hibernate and while thus collected in quantities they are gathered and in sping distributed through the truck-growing regions to attack the plant lice, about 30,000 being regarded as enough to protect the plants growing on 10 acres. Several tons are often collected for distribution for this purpose. It takes nearly 1,500 of these beetles to weigh an ounce.

Because of their efficiency as feeders on insect pests, a number of kinds have been introduced into this country to attack the special insects of their native lands which have reached the United States and have become pests here. Among these are the Vedalia (Novius cardinalis Muls.) (See Fig. 216), imported from Australia to attack the Cottony-cushion or Fluted Scale; the Mealy-bug Destroyer (Cryptolomus montrouzieri Muls.), brought also from Australia to attack several kinds of Mealy-bugs found in California; the Steel-blue Lady beetle (Orcus chalybeus Boisd.) which feeds on a number of kinds of Armored Scales; and the Black Lady beetle (Rhizobius ventralis Erichs.) which is an active enemy of the Black Scale (Saissetia olece Bern.); besides numerous other species. Many of these imported forms have done valiant work in their attacks upon their ancient foes in the country to which both have come, but in some cases this attempt to aid nature in the control of insect pests has been less successful, and it is evident that the success of each experiment of this kind can rarely be determined beforehand. (See Cottony Cushion Scale, Chapter XXVI).

Family Tenebrionidæ (Darkling Beetles).-This rather large family of beetles contains many forms found on the ground and superficially resembling the Carabidæ. They are usually rather slow of movement, however, feed on vegetable instead of animal food, and while their fore and middle tarsi are each composed of five segments as in the Carabids, their hind tarsi each have only four. They are particularly abundant in the Southwest and West, though a number are present practically everywhere.

The Yellow Meal-Worm (Tenebrio molitor L.) about three-quarters of an inch long (Fig. 127), is often found around stores of grain, in pantries, stables etc., and its larva which closely resembles a wireworm, feeds upon meal and similar materials. It is often raised as food for cage birds. Where abundant, a thorough cleaning out of infested places, followed by sprinkling air-slaked lime around, or fumigation of the infested material with Carbon disulfid, is all that is necessary.

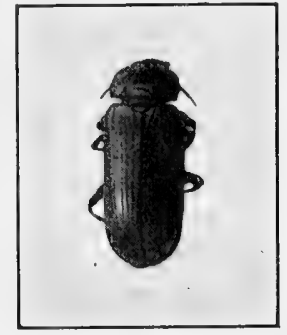

FIG. 127.-Yellow Meal-worm (Tenebrio molitor L.), about natural size. (Original.)

Family Meloidæ (Blister Beetles).-The insects of this family also have but four segments to each hind tarsus. The body is quite cylindrical and rather soft, and the head joins the thorax by a distinct neck (Fig. 128). Many of the members of this family contain a substance 
called cantharidin, which when applied to the skin, produces blisters. The bodies of these species, powdered, are used in medicine under the name "cantharides" or "Spanish flies," for blistering purposes.

A dozen or twenty kinds of Blister beetles, averaging from half an inch to over an inch in length are more or less serious pests as adults, feeding during the summer or fall on foliage and blossoms, various vege-

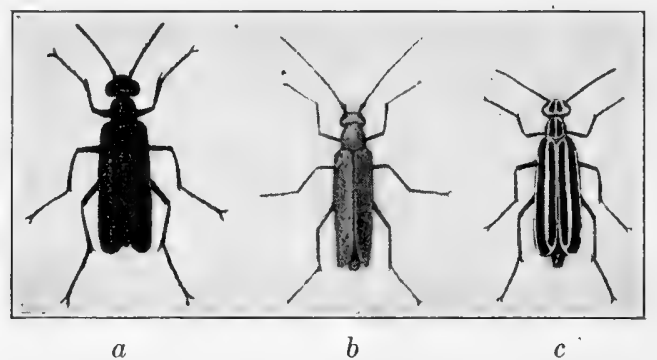

FIG. 128.-Adult Blister Beetles: a, Black Blister Beetle (Epicauta pennsylvanica De G.); $b$, Ash-gray Blister Beetle (Macrobasis unicolor Kby.); $c$, Striped Blister Beetle (Enicauta vittata Fab.); all about natural size. (Modified from U. S. D. A. Bulletins.)

tables and ornamental plants being attacked. Vegetable crops are sometimes seriously affected. The larvæ on the other hand, feed on the eggs of various species of grasshoppers and are therefore beneficial. The adults are not easily controlled as they are rather resistant to arsenical poisons, and as they fly freely, it is difficult to reach them with contact insecticides. In cases where stomach poisons can be applied, arsenate

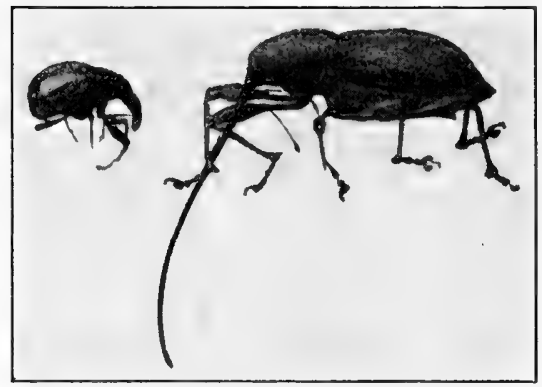

FIG. 129.--Examples of adult Snout Beetles showing differences in the development of the snout. About twice natural size. (Original.) of lead, taking about $4 \mathrm{lb}$. (if the paste be used) to $50 \mathrm{gal}$. of water, has proved the best treatment. Where this cannot be done, handpicking, and screening valuable plants with netting, may be resorted to.

\section{RHYNCHOPHORA (Snout Beetles)}

The snout beetles are included in several families. Some are called curculios, weevils, and billbugs, and those of one family, the larvæ of which work in the bark and wood of trees, are called Engraver beetles and also bark borers. Over twenty-five thousand species of Rhynchophora are known (Fig. 129).

Except for this last named family, most snout beetles feed on fruits, nuts, etc., though a few attack stems and leaves. The white, nearly always footless larvæ, also feed for the most part on such materials, and a number are very destructive and therefore important pests. 
The Plum Curculio (Conotrachelus nenuphar Herbst). - This insect is a native of the United States and formerly fed upon the wild plum and thorn fruits, but now also attacks cultivated plums, prunes, cherries, nectarines, apricots, apples and peaches. It is found practically everywhere east of the Rocky Mountains, though in

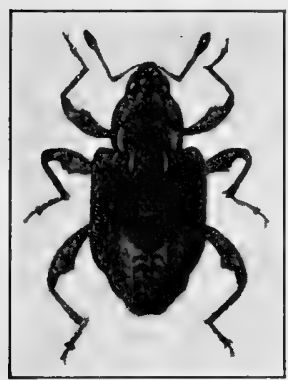

FIG. 130. the western portion of this area it seems to be of less importance than elsewhere. The adult beetle (Figs. 130 and 131) is small, being only about a

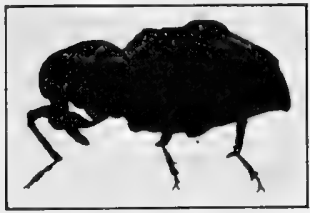

FIG. 131.

FIG. 130.-Adult Plum Curculio (Conotrachelus nenuphar Hbst.), view from above. About five times natural size. (Modified from U. S. D. A. Bur. Ent. Bull. 103.)

FIG. 131.- Side view of adult Plum Curculio showing humps on the back. Enlarged about five times. (Modificd from U.S.D. A. Bur. Ent, Bull. 103.)

fifth of an inch long, dark colored as a whole but mottled with gray and brown. Its elytra are rough and on each is a black, shining hump a little behind the middle.

This pest spends the winter, or the colder months in the South, hiding in any protected place it can find, particularly in the woods, in stone walls or under leaves. It appears about the time the plum buds open in spring and feeds more or less on the developing leaves. When the fruit begins to develop, the beetles turn their attention to it, feeding by cutting a circular hole through the skin and consuming the flesh beneath to a depth about equal to the length of the snout of the insect. They also begin now to lay their eggs in the young plums, cutting a hole in the skin and then running the snout obliquely into the flesh beneath. In this cavity the egg is placed and it is then pushed farther in by the snout. The beetle next cuts a crescent-shaped slit through the skin close to the

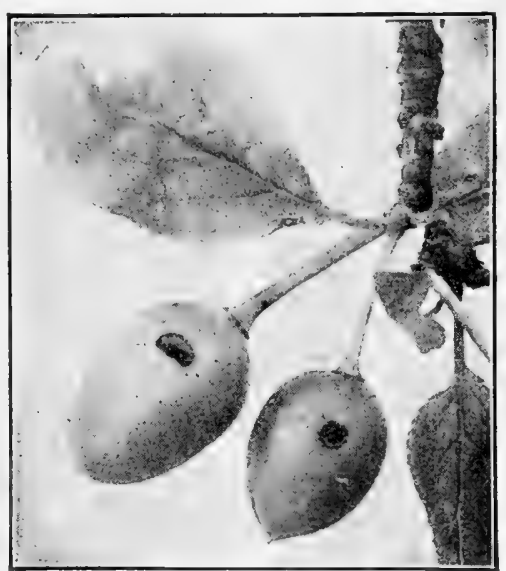

FIG. 132.-Egg puncture and feeding puncture of Plum Curculio in young plums. (From U.S. D. A. Farm. Bull. 908.) egg (Fig. 132) and carries this down through the flesh beneath the egg which thus comes to lie in a sort of flap which wilts and remains soft, and the crushing of the egg by the growth of firm tissue there is prevented. 
Several hundred eggs are laid in this way and the "spot and crescent" marks of the insect on small plums are familiar to plum growers. The fruit often pours out gum at these places, probably in an attempt to repair the injury.

The eggs hatch in a week or less and the tiny whitish grub bores through the flesh, and in stone fruits passes to the stone, around which it feeds for about two weeks or until full-grown. It then leaves the fruit, and as this in most cases has fallen before this time because of the injury, the larva finds itself on escaping, on the ground. Into this it now burrows an inch or two and pupates. About a month later the adult beetle emerges, comes to the surface of the ground and attacks fruit for food, egglaying rarely if ever taking place at this season, and when cold weather comes on it locates in some protected place for the winter. There is accordingly, but one generation a season.

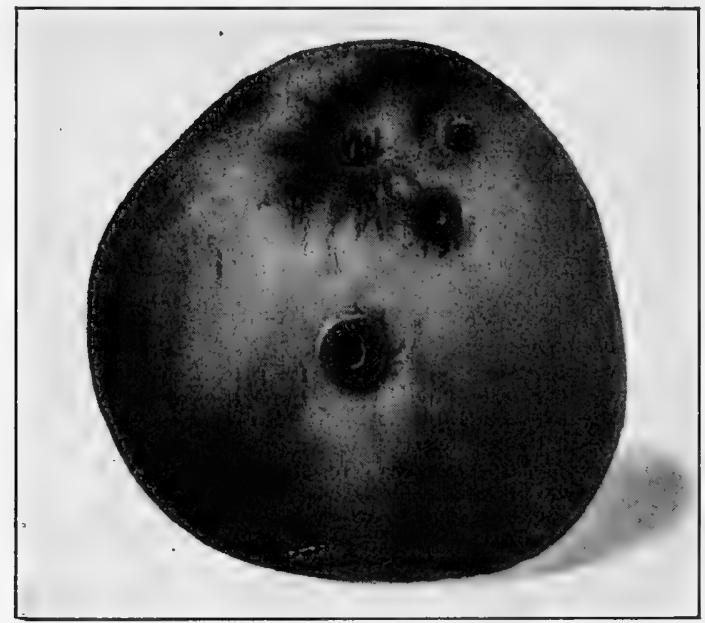

Fıg. 133.-Apple showing injury by Plum Curculio in fall. (Modified from Ill. Agr. Exp. Sta. Bull. 98.)

This insect, both by its feeding and egg-laying punctures, affects the value of the fruit not entirely destroyed, not only in appearance but by the opportunity these cuts afford for the entrance of the spores of disease-producing fungi, and the destruction in the United States which it causes has been estimated at over eight million dollars annually. While the insect rarely succeeds in developing in the apple, the punctures cause dropping of the fruit or its malformation, and the production of hard, woody places in the pulp. In the fall its feeding holes in apples also cause much injury (Fig. 133).

Control.-No one method nor even all the methods of control taken together will give entire freedom from this pest. A combination of 
treatments, however, will accomplish considerable in this line. The usual measures taken are as follows:

(1) Remove all opportunities for the successful wintering of the adults, as far as possible. Rubbish, stone walls, and trash of all sorts should be removed. Plum orchards near woodland are poorly located from this standpoint. (2) The curculio prefers shade in which to work, and larvæ even inside fallen fruit are unable to survive any long exposure to direct sunlight. The trees therefore should be so pruned as to let the sunlight through all parts, and fallen fruit should be exposed to the sun by proper treatment of the ground under the tree. (3) Fowls and hogs will eat many of the larvæ in the fallen fruit and larvæ or pupæ in the ground, and should be allowed to run under the trees; or thorough, shallow cultivation under the trees should be given from the time the larvæ begin to leave the fruit until at least 6 weeks later, to destroy the insects there. (4) Spraying with arsenate of lead either alone or combined with the self-boiled lime-sulfur has been fairly successful if the applications be thorough and at the right times. For plums spraying with $2 \frac{1}{2} \mathrm{lb}$. of lead arsenate paste $\left(1 \frac{1}{4} \mathrm{lb}\right.$. of the powder) in 50 gal. of water or limesulfur as soon after the blossoms fall as leaves begin to develop, and the treatment repeated 8 or 10 days later has proved the best method. Cherries can be treated in the same way. With peaches, $2 \mathrm{lb}$. of the arsenate in 50 gal. of water, to which the milk of lime obtained by slaking $2 \mathrm{lb}$. of quick lime has been added, is sprayed as soon as the "shucks" are beginning to shed from the blossoms. About 3 weeks later a spray of $2 \mathrm{lb}$. of the arsenate in $50 \mathrm{gal}$. of the self-boiled lime-sulfur is made. A third treatment about a month before the fruit begins to ripen, using the lime-sulfur only, is also often given. For apples the precautions necessary in spraying stone fruits with arsenate of lead need not be taken. Here the treatments commonly given for the Codling Moth (see Chapter XXIX) are also effective at those times for the Curculio, though later similar applications may also be necessary if the insects are abundant. (5) Where only a few stone-fruit trees are involved, jarring them early in the morning, after spreading white cloth under them, is a good treatment. The beetles at that time of day are sluggish and drop onto the cloth when the tree is given a sudden blow, and they can then be gathered and destroyed. This should be begun as soon as the blossoms have all fallen and continued until the beetles no longer appear.

The Plum Gouger (Coccotorus scutellaris Lec.).--This plum pest like the last, is a native of this country and is found from New York west to the Rocky Mountains and south to Texas. It appears to be destructive, however, mainly west of the Mississippi River. The adult (Fig. 134) is somewhat larger than the Plum Curculio. The head and thorax are dull yellow and the elytra are lead-gray in color, and the surface is without any humps or other irregularities. In many regards the habits of the Gouger are like those of the Plum Curculio, but it leaves 
its winter quarters earlier than the last named insect and feeds for a time on the opening buds and leaves, gouging holes in the blossoms (Fig. 134b) and thus causing them to drop off. Feeding holes and egg punctures in the young plums (Fig. 134c) are holes into the flesh in some of which the eggs are placed, but many more holes are made than eggs deposited. The grubs work their way to and into the stone or pit and feed on the flesh (seed) within until full grown. Each then gnaws a hole through the stone, after which it pupates inside the stone, the adult appearing in late August and September. There appears to be but one insect in a fruit.

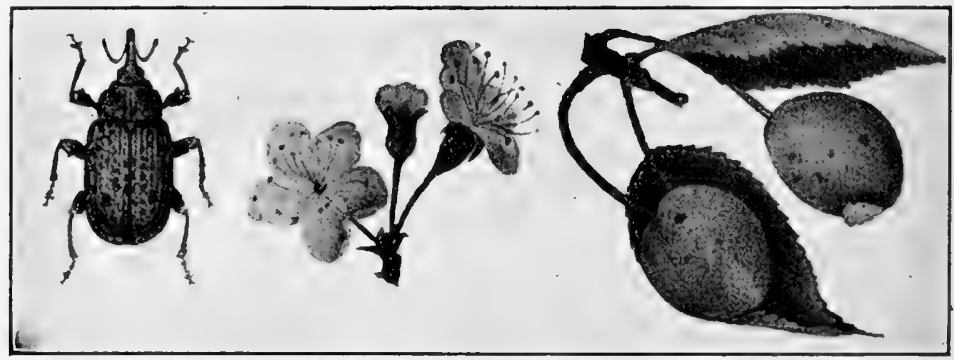

$a$

$b$

$c$

FIG. 134.-Plum Gouger (Coccotorus scutellaris I.ec.): $a$, adult beetle about three times natural size; $b$, plum blossoms attacked at their bases by the beetle; $c$, young plums punctured by the beetle. (Modified from Minn. Agr. Exp. Sta. Bull.66.)

Plums attacked by the Plum Gouger do not drop, but mature on the tree, but such plums are worthless for market because of the injured spots and because of the deformed fruit produced.

Control.-Picking off the injured plums before the beetles emerge in the fall has been recommended as a method of control for this insect, and jarring in spring has also been advised; though the beetles do not drop as freely as in the case of the Plum Curculio. It is possible that spraying with arsenate of lead as for the Curculio, making the first application as soon as the buds are open enough to provide any surface for the poison to adhere to, may prove of some value.

The Cotton Boll Weevil (Anthonomus grandis Boh.).-This is at the present time the most serious insect pest of cotton which we have. Recent estimates place the destruction by the boll weevil at about 400,000 bales per year, which at average prices for the cotton not thus destroyed would be many millions of dollars. Diversification of crops has come into practice, however, where the cotton crop has suffered, so that in a number of the affected States the total value of all crops after the appearance of the weevil, has been greater than before. In some cases then, the loss to cotton has been more than made up by turning to other crops, but the reduction in the amount of cotton needed for use in the world is important.

The cotton boll weevil is a native of tropical America, whence it spread northward through Mexico, and about 1892 entered Texas. Since that time it has extended its area of infestation, reaching the Atlantic 
Coast in Georgia in 1916 and in time it will probably be present everywhere in the cotton belt, except perhaps in the more arid portions and in places where it can find little protection during cold weather.

The adult boll weevil (Fig. 135) varies considerably in size but averages about a quarter of an inch in length. When it first emerges from the pupa it is light brown, but it soon becomes gray or almost black. It winters as the adult, hiding under rubbish, in cracks in the ground, in Spanish moss growing on the trees, or in fact in any protected place, though those which winter in the cotton fields appear to be least protected and hence least liable to survive, while those in wooded areas winter more successfully.

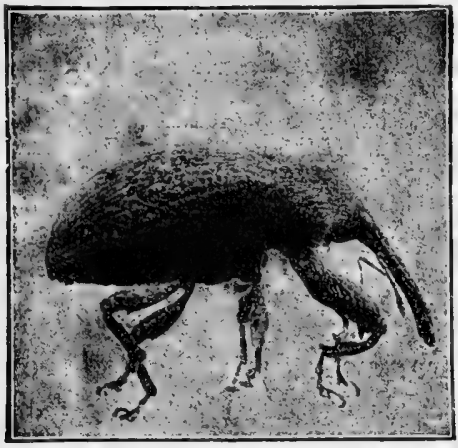

$a$

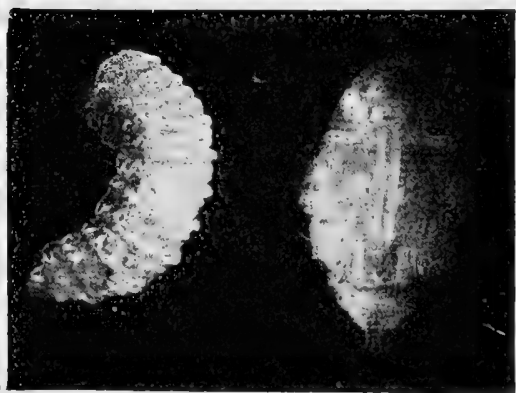

$b$

c

FIG. 135.-Cotton Boll Weevil (Anthonomus grandis Boh.); $a$, side view of adult beetle enlarged about six times; $b$, larva (grub); $c$, pupa; both much enlarged. (From Sanderson: Insects Injurious to Farm, Garden and Orchard.)

In spring the beetles leave their winter quarters, the time generally varying from March to the last of June. "In the spring and throughout the fruiting season of cotton the eggs are deposited by the female weevils in cavities formed by eating into the fruit of the plant. An egg hatches under normal conditions in about three days, and the grub immediately begins to feed. In from 7 to 12 days the larva or grub passes into its pupa stage, corresponding to the cocoon of butterflies and moths. This stage lasts from 3 to 5 days. Then the adult issues, and in about 5 days begins the production of another generation. Climatic conditions cause considerable variation in the duration of the stages, but on an average it requires from 2 to 3 weeks for the weevil to develop from the egg to the adult. Males and females are produced in about equal numbers. The males feed upon the squares and bolls without moving until the food begins to deteriorate. The females refrain from depositing in squares visited by other females. This applies throughout most of the season, but late in the fall, when all the fruit has become infested, several eggs may be placed in a single square or boll. As many as 15 larvæ have been found in a boll. The squares are greatly preferred as food and as places 
for depositing eggs. As long as a large supply of squares is present, the bolls are not damaged to any serious extent. The bolls, therefore, have a fair chance to develop as long as squares are being formed." (Marlatt, Farmers' Bulletin 848, U. S. D. A., 1917).

These insects are extremely prolific. It has been calculated that from a single pair of the beetles in spring there might be $12,755,100$ progeny by the end of the season, but many factors prevent this from actually being the case. Infested squares soon drop off the plant and on the ground generally become so heated as to kill the larvæ in them. Parasites and other enemies, particularly ants, attack the insect, and other minor factors are of some value. All of these combined, however, only prevent a bad condition from becoming worse, and control measures must be resorted to.

Control.-There are several control measures which seem to give partially satisfactory results. One of these is to destroy all infested plants in the fall, particularly in the southern part of the area where the weevil is found. This kills great numbers of adults about ready to hibernate, many more still in early stages in the plants, leaves no food for those escaping, and prevents the production of the latest beetles, thus reducing the number to hibernate. It also permits fall or winter plowing which is good farm practice in cotton growing. Generally this destruction of the plants should occur in October, even though a little cotton is lost in this way. The destruction of any hibernating weevils wherever possible is advantageous. Crop rotation is also desirable, as many of the weevils winter near the cotton fields and do not fly far in the spring. Any methods which will hasten crop production, such as fertilizers, the use of early maturing varieties and early planting, are desirable. Dusting the young plants with arsenate of lead or arsenate of lime blown directly onto them has frequently given good res!lts. The use of all these methods together gives considerable relief from the attacks of this pest, and the problem how far to go in carrying them out is largely one of their cost as compared with the value of the cotton which will be saved by the treatments. Hand picking of the weevils and of infested squares has not generally proved successful. As the insect has thus far been known to feed only on cotton and the wild cotton of Arizona (where it probably does not yet occur), the danger of its increasing on other food plants does not at present seem to exist.

The White Pine Weevil (Pissodes strobi Peck).-This native enemy of the pine occurs practically wherever the white pine is found, viz., from New Brunswick and Canada west to Minnesota, and south to North Carolina. It also attacks our other native pines and the spruces somewhat.

The adults (Fig. 136) pass the winter in protected places, possibly in the ground, and in spring gather on the terminal shoots (leaders) of the pines, generally on the trunk leader in preference to those of the branches. Here, near the tip, 
they feed on the bark and soon cut tiny holes in it, placing their eggs in the holes. The borers which hatch from these eggs tunnel downward through the leader (Fig. 137) and by August have finished feeding and pupate in the tunnels. After transformation to the beetle has been completed, these escape to the outside by making round holes through the stems they are in. Later they hibernate for the winter.

The adult beetle is about a quarter of an inch long, reddish-brown or somewhat darker, with a white spot on each elytron not far from its outer end, which when the elytra are at rest brings these spots not far from the end of the body. There are also several irregular areas on the elytra somewhat lighter than the ground color.

Control.- Spraying the leaders before the beetles gather on them in the spring, with arsenate of lead, using one pound more than the standard formula for the paste, is one method of control. Collecting the beetles after they have begun to gather on the leaders is also practiced, jarring them off into

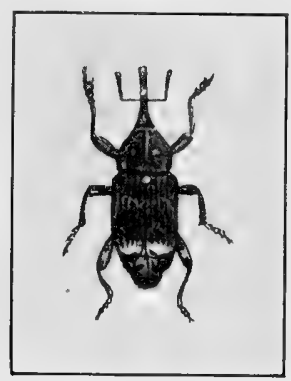

FIG. 136.

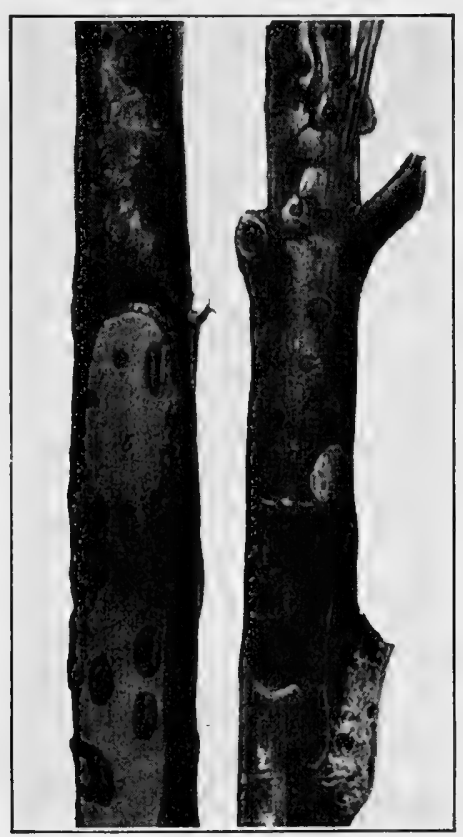

FIG. 137.

FIG. 136.-Adult White Pine Weevil (Pissodes strobi Peck); enlarged nearly three times. (After Felt: N. Y. State Mus, Mem. 8.)

FIg. 137.-Work of White Pine Weevil in terminal twigs of pine. (After Felt: N. Y. State Mus. Mem. 8.)

a net held beneath, as they generally drop instead of flying when disturbed then. This treatment should be repeated several times at 4 or 5 -day intervals. It can hardly be done except on small trees.

The injury caused by these insects aside from their feeding, is the killing of the leader which stunts the growth of the tree. Usually a side branch grows up to replace the lost leader and makes the tree deformed, or when two do this, a fork is produced. In either case the value of the tree either for timber or as an ornament is largely lost. The work of the weevil is most serious and also most frequent on young trees, making its injuries more serious on this account.

The Alfalfa Weevil (Phytonomus posticus Gyll.).-This European insect was discovered in this country about 1904 and is now found in parts of Utah, Idaho and Wyoming, and is gradually spreading. The adult (Fig. 138) is a snout beetle only about three-sixteenths of an inch long, brown when fresh but almost 
black after a time. It winters as the adult close to the ground or in crevices there, and in some cases under rubbish, and in severe winters many are killed by the cold. As soon as warm days come the weevils become active and lay eggs in the dry alfalfa stems, before the regular laying season, and the larva from these eggis attack the young plants, often causing serious injury. The weevils also feed on the plants quite freely at this season. After a few weeks the true egg-laying period begins and the adults now puncture the living alfalfa stems and lay their eggs in them, this process usually being finished by the tenth of June, though a few eggs are laid much later. The eggs hatch in about ten days and the larvas (Fig. 139) consume the alfalfa leaves, those from the ones laid early beginning to

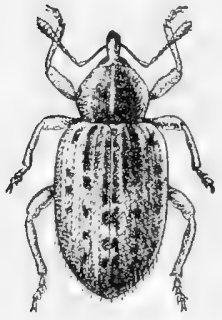

FIG. 138

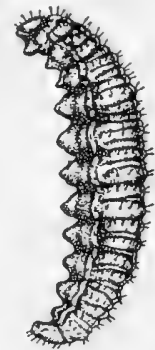

FIG. 139

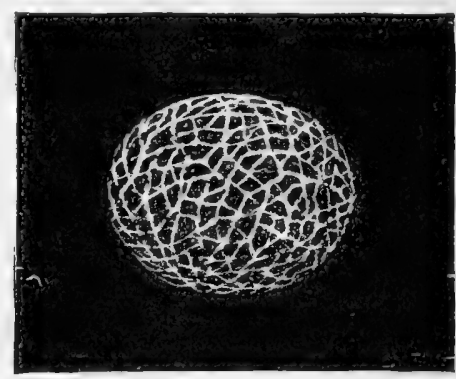

FIG. 140

Fig. 138.-Adult Alfalfa Weevil (Phylonomus posticus Gyll.) much enlarged. (From U. S. D. A. Bur. Ent. Bull. 112.)

FIG. 139.-Side view of larva of Alfalfa Weevil, greatly enlarged. (From U. S. D. A. Bur. Ent. Bull. 112.

FIG. 140.-Cocoon of the Alfalfa Weevil, greatly enlarged. (From U. S. D. A. Bur. Ent. Bull. 112.)

feed in May, while later individuals are feeding until into July or even August, with some stragglers later. The larval period varies greatly, but an average length of time in this stage would be perhaps a month. When full-grown the larva goes to some protected place such as a dry, curled leaf or dead vegetation near the ground and spins a cocoon (Fig. 140) in the form of a loose network, in which it pupates. This stage lasts about 10 days before the appearance of the beetle. In late summer these beetles begin to look for winter shelter and in this search may spread some distance. In spring a somewhat similar flight in search of food, also increases their spread. This insect feeds on various species of clover in addition to alfalfa, and as it seems to be persistently spreading, it must be considered a menace to nearly all parts of the country.

Control.-The most serious injury to the crop is that caused by the spring feeding before the first cutting, and this also delays the production of the second crop. Any treatment of the field, such as disking it with a harrow, which will hasten growth at that time will be a gain. Spraying these fields with arsenate of lead, $1 \mathrm{lb}$. of the paste in $50 \mathrm{gal}$. of water, appears to reach many of the insects and be quite effective. Pasturing during the spring months, dividing the fields so that each piece may be grazed close about once every 2 weeks, and continuing this until most of the eggs of the weevil have been laid, has also given good results, as has cutting and feeding the crop before the eggs hatch. Spraying 
the stubble after the first cutting, or treating such fields by going over them once or twice with a disk or spring-tooth harrow, followed by dragging with a brush drag, to give a dust mulch, will protect the second crop but is probably less valuable than the earlier spring methods.

The Potato Stalk Weevil (Trichobaris trinotata Say).-This pest of the potato is widely distributed over the United States east of the Rocky Mountains except in the more northerly States. It has also been reported from California. The beetle is gray with a black head and three black spots at the base of the elytra and is about a fifth of an inch long. It winters in the old potato stalks and when the young potato plants are large enough it makes small holes in the stalks and sometimes in the branches, in which the eggs are deposited. The eggs hatch in a week or 10 days and the grubs burrow downward toward the roots and after reaching them turn upward again, enlarging the burrows. This tunnelling weakens the stalks and causes the plant to wilt and die. Pupation takes place in the stalks, usually near the ground, and the adults are produced in from 1 to 2 weeks, but generally do not leave the stalks until the following spring. A number of individuals may be present in a single stalk. Other food plants are Jamestown weed, horse nettle, eggplant and other plants of the family Solanacer.

Control.-Where the plants have wilted and dying leaves, and an examination of the stem shows borers to be present, pulling up and burning infested stalks is desirable. Practically the same result may be obtained by collecting and burning all the stalks as soon as the crop has been dug, thus destroying the weevils in them. The destruction of all weeds around, which are liable to be infested by the insects, this work being done after the egg-laying season is over, is also desirable.

The Sweet Potato Weevil (Cylas formicarius Fab.).This is a tropical insect which was first reported in the United States about 1875. It now occurs in the most southerly States from Georgia to Texas, attacking the

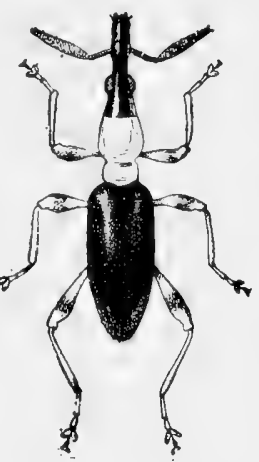

FIG. 141.-Adult Sweet Potato Weevil (Cylas formicarius Fab.) enlarged over five times. (From U. S. D. A. Farm. Bull. 856.) sweet potato. The adult (Fig. 141) unlike the other snout beetles here considered, is very slender, about a quarter of an inch long, with a black head, reddish prothorax and legs, and dark blue elytra. The prothorax is strongly narrowed, forming a noticeable "waist" for the insect.

The eggs of this pest are laid singly in small holes eaten in the stem or any exposed potato. They hatch in a few days and the grubs in the stems burrow through them down to the potato, then tunnel irregularly about, becoming fullgrown in 2 or 3 weeks. The grub now forms a cavity and in this it pupates for about a week and then a few days later eats its way out and may leave the potato, or may remain there and lay eggs for another generation in the same potato in which it itself developed, and this process may continue until the entire potato is destroyed. As long as food is available, one generation after another is thus produced, but when no more can be found the adult insects live along for a considerable time without feeding, attacking the plants and laying their eggs in them whenever more appear. Adult beetles feed on the leaves and stems somewhat. 
As soon as tunnels in the potato are formed, the tissues around them change color and decay soon follows, so that an attack quickly ruins the value of the crop.

Control.-Sweet potatoes found infested ever so slightly should immediately be destroyed, either by feeding to stock or in some other way. If any area becomes infested no sweet potatoes should be planted there for several years, and as it is probable that the insect can also breed in the wild morning glory, all plants of this species should also be destroyed as far as possible within the area. Spraying the plants with arsenate of lead or other stomach poison, applied as soon as the beetles appear has recently given encouraging results. Following sprays at about ten-day intervals may be given if necessary.

Family Ipidæ (formerly Scolytidæ) (Bark beetles or Engraver beetles). The members of this family are borers and nearly all attack the inner bark or wood of trees. They are small insects, from one twenty-fifth to two-fifths of an inch long, brownish or blackish in color, and usually with cylindrical bodies (Fig. 142). In habits they form two chief groups. In the so-called Ambrosia-beetles the tunnels extend through the wood and the young develop there: in the True Bark-beetles the tunnels are formed either in the inner bark or between this and the wood. The adult in

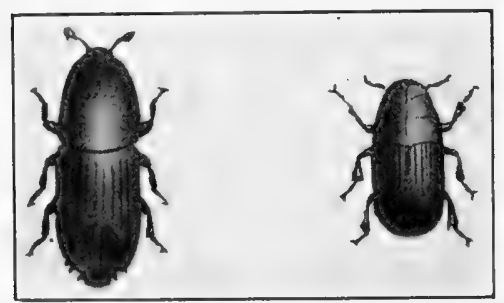

FIG. 142 .

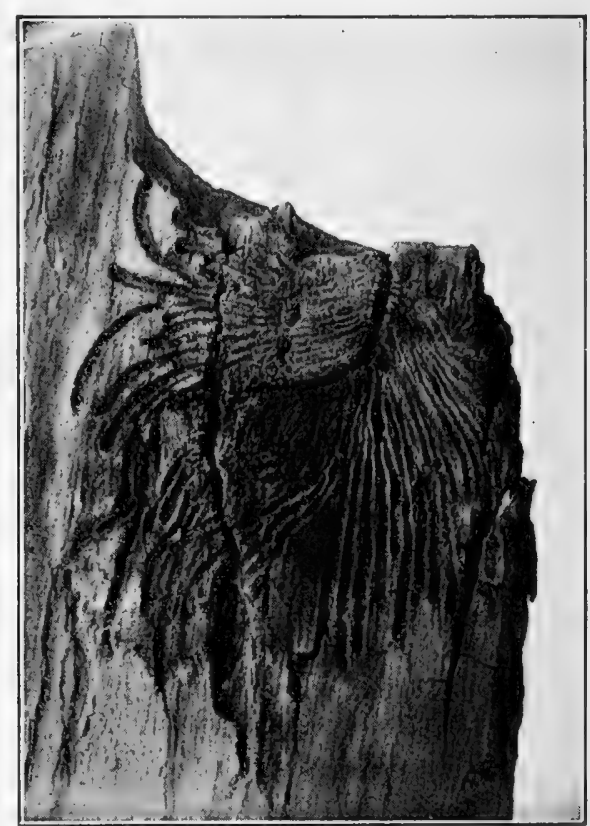

FIG. 143.

FiG. 142.-Adult Bark Beetles, greatly enlarged. (Modified From Felt: N. Y. State Mus. Mem. 8.)

FIG. 143. -W ork of Bark Beetles on inside of bark, slightly reduced. (Original.)

either case cuts a tunnel slightly larger than itself in to the inner bark or through this, but the Ambrosia-beetles continue it on, into the wood. The Bark-beetles having arrived at the desired depth, turn and excavate one or more channels between the bark and the wood, which become the egg tunnels. Along the sides of these the eggs are deposited, either singly in little hollows, several together in larger excavations, or 
many in grooves of the tunnel. The larvæ, on hatching, excavate tunnels for themselves, leading away from the egg tunnel (Fig. 143) and becoming larger with the growth of the larvæ. Pupation is at the end of the larval tunnel in a somewhat wider portion and after transformation the adult bores its way to the outside. In the case of the Ambrosiabeetles a fungus used as food by the insects, grows on the walls of the tunnels and generally turns these walls black.

Destruction by these insects is mainly of forest and shade trees. As nearly all the bark-beetles appear to prefer dying bark in which to live, the refuse of cutting operations, commonly termed "slash," will provide much of this, and most of the insects will work there. When slash comes to an end, however, by operations ceasing in that area, the increased abundance of the insects due to abundant slash often forces them for lack of other material, to turn to the healthy trees, themselves changing thereby from "secondary" to "primary" foes. Slash should therefore be destroyed before beetles in it can develop to the adult condition. Fire in forests produces many dead and weakened trees also, frequently leading to insect attacks, and epidemics, either local or quite widespread, may thus result. Many trees when the beetles bore into them, pour out their sap or resin, and some of the insects may easily be drowned in this. If attacked by multitudes, however, the supply of sap becomes so reduced that the insects coming later can accomplish their purpose.

Removing "beetle trees" before the adults escape, and either removing and burning the bark, floating the logs, or sawing the same winter and burning the slabs and trimmings, are some of the measures used for the protection of our forests against these insects.

One species of Ipid, the Clover Root-borer, tunnels in the main roots of clover. Several other species attack fruit trees, usually those not healthy.

The Fruit-tree Bark-beetle or Shot-hole Borer (Eccoptogaster rugulosus Ratz.).-This European fruit-tree pest has now been in the United States about 50 years and is present nearly everywhere east of and in many localities west of the Mississippi River, and has been reported from California. It breeds in most of the cultivated deciduous fruit trees as well as in several kinds of wild ones. The beetle (Fig. 144) is about a tenth of an inch long, almost black, except the tips of the elytra and the legs, which are dull red.

In the spring the beetles enter the trees and dig out egg channels one or two inches long, about parallel to the grain of the wood, partly in this, partly in the inner bark. Here, in little niches or hollows along the sides, the eggs are laid. These hatch in a few days and the grubs burrow, first directly away from the egg channel, then turning in various directions, extend these larval tunnel sseveral inches, and pupate at their ends. 
When the beetles have been formed there, they bore out to the surface of the tree (Fig. 145) and soon begin to tunnel in again, to lay eggs for a second generation which in the North becomes adult before winter, thus giving two generations a year. In the South with its longer warm
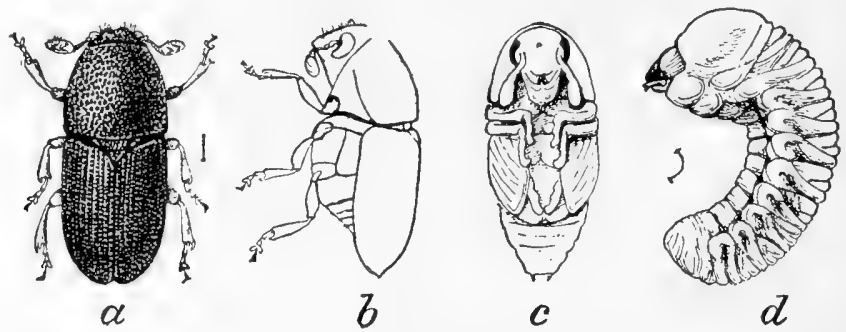

FIG. 144.-Fruit-tree Bark-Beetle (Eccoptogaster rugulosus Ratz.); $a$, Adult Beetle; $b$, side view of same; $c$, pupa; $d$, larva. Hair lines show true length. (From U.S.D. A. Farm. Bull. 763.)

season, three or perhaps four generations may be produced each year, the adult beetle in some cases at least, wintering in the tree, while in others this season may be passed in the egg stage.

Healthy trees are not of ten attacked except when the beetles become so abundant that a sufficient supply of weak or dying ones is not available.

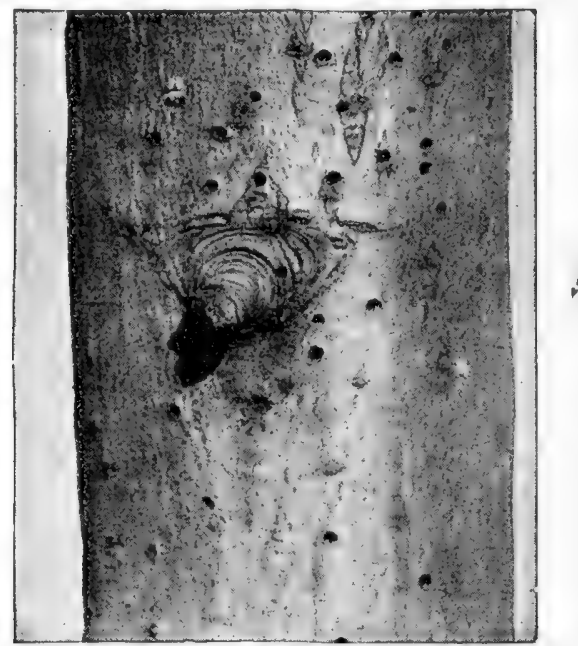

FIG. 145.-Exit holes of the Fruit-tree Bark-Beetle in bark of a young tree, about natural size. (From U. S. D. A. Farm. Bull. 763.)

In healthy trees the flow of gum sometimes prevents the development of larve but in time this becomes less and the insects then have a weakened tree to attack. Trunk, branches and twigs are perhaps equally liable to be injured. The burrows extending in all directions, partly in the outer 
surface of the wood, partly in the inner bark, destroy the cambium or growing layer, often entirely girdling the twig, branch or trunk as the case may be, and causing its death.

Control.-This must largely be accomplished by measures to keep the trees as vigorous and healthy as possible. Any injured, broken or otherwise affected limbs should be removed or so treated if possible, as to restore them, and close watch of trees outside the orchard, liable to infestation, should also be given. Infested trees which are still pouring out gum can sometimes be saved by cutting back strongly and then cultivating and fertilizing freely. In some cases a thick coat of whitewash mixed with a little table salt can be applied as a repellent for the beetles. This treatment sometimes needs to be applied three times-once in spring, again in midsummer, and once again in the fall. Washes of soap and carbolic acid have occasionally been used with some success, and it is claimed that the larvæ can be killed in their burrows by using a carbolineum spray material. This is made by dissolving $3 \mathrm{lb}$. of naphtha soap in 3 gal. of hot water; adding a gallon of carbolineum, stirring thoroughly and then diluting for use at the rate of 1 part of this to 4 of water.

These methods should work equally well for any of the barkbettles where the bark is no thicker than at the places where these insects attack the fruit trees. 


\section{CHAPTER XX}

\section{THE STREPSIPTERA}

These tiny insects are seldom seen except by entomologists, and their parasitic habits aid in their concealment. For a long time opinions were divided as to where they belonged, some regarding them as a family of aberrant Coleoptera, while others considered them as forming an order. Recent studies seem to confirm the latter view and the group is now generally rated as a separate order, though its closest relations are probably with the beetles.

The Strepsiptera, from the meaning of this name, may be called the Twisted-wing Parasites, though the words stylops and stylopid are frequently used in referring to them. The males on reaching the adult condition (Fig. 146), become free and can fly. The females on the other

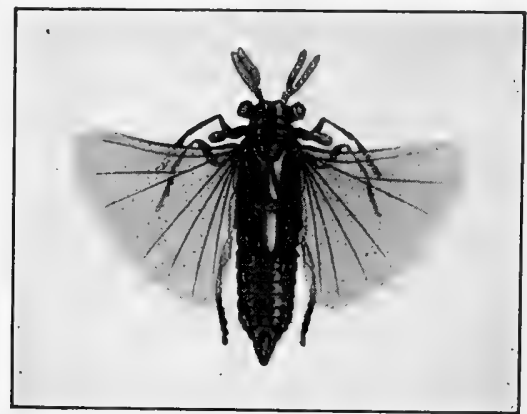

FIG. 146.--Male Strepsipteron (Xenos vesparum Rossi), rather more than six times natural size. (After Pierce.)

hand, remain partly within the bodies of their host insects and are wormlike or grub-like (Fig. 147) in appearance. The males are very small, soft-bodied animals, ranging from about one to perhaps four twentyfifths of an inch in length. The eyes are more or less stalked and the antennæ have one or more segments elongated on one side. The mouth parts are greatly modified but appear to be of the chewing type, though the adult does not feed. On the mesothorax is a pair of tiny clubs, sometimes rather flattened, which represent the front pair of wings. The metathorax forms nearly half the entire length of the body. It bears a pair of well developed wings which are broad and fold lengthwise when at rest. The abdomen is composed of ten segments. The females are soft and resemble a rather long sack bearing traces of segmentation, and at one end a constriction, beyond which is a sort of knob, believed to be a 
combination of the head and thorax; a cephalothorax in fact. This portion of the body is pushed out between two of the body segments of the host during the latter part of the metamorphosis, thus becoming external (Fig. 147) and the body of the host is distorted in this way.

The members of this order may be characterized as follows:

Tiny insects which from the first larval instar to the adult, are internal parasites in other insects. The male adult has stalked eyes, mouth parts of the chewing type, but little or not at all developed; antenna with one or more segments prolonged laterally; pro- and mesothorax small, the latter with a pair of small clubs corresponding to the fore wings of most insects; metathorax long, forming at least half the length of the body and bearing a pair of

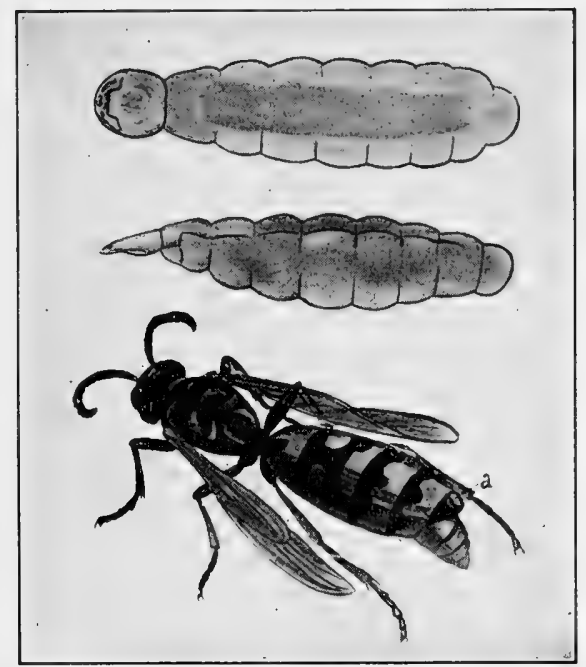

Frg. 147.-Female Strepsipteron, top and side views and a Stylopized Wasp: $a$, end of the parasite projecting hetween the abdominal segments of the Wasp. All greatly enlarged. (After Leuckart's Wandtafein.)

broad wings which fold longitudinally. The female adult is worm-like, without feet, and located within the body of its host except for a cephalothorax which protrudes between two abdominal plates of the latter. It is enclosed by its pupa skin. Metamorphosis complete.

These insects, often called "stylops," are parasitic only in some Orthoptera, Homoptera, Hemiptera and Hymenoptera, as far as known, and at the present time only Gryllotalpa in the Orthoptera and Chrysocoris in the Hemiptera are known as hosts in those groups. Most of the parasitism is of leaf-hoppers, wasps and the solitary bees, and these are so disabled by the removal of their body fluids by the parasites that "stylopized" individuals are unable to reproduce and are greatly lacking in vitality. Their bodies are often distorted also and other changes are produced. 
The eggs of the stylops appear to hatch within the body of the mother and the young escape by passing from the body out into the space between this and the pupa case of the parent in which it remains, and then through an opening in this at the cephalothorax, thus reaching the open air. They are now on the body of the parental host and this insect may carry them to its nest, where if it is a colonial form, the stylops may find young to attack there. It is generally probable though, that they leave the parental host at some place (possibly a blossom) where other insects of the host species will be liable to visit. Transferring onto such individuals as chance may permit, the stylopids finally arrive where larvæ of the proper species are available, and at once attack them. Thus far they have been active little six-legged larvæ, but after burrowing into the body of their host larvæ they change greatly, becoming worm-like and legless. The males finally enter a pupa stage, after which the adults escape, but the females remain throughout the rest of their life in the bodies of their hosts.

Where stylopids are abundant and attack injurious species of insects, such as are most at least of the Homoptera, the stylopized individuals, being unable to reproduce, become of lessened importance and their parasites must be considered as beneficial. Most of the Hymenoptera they attack, however, are beneficial and parasitism in such cases can hardly be considered helpful to man. The group is not sufficiently abundant though, to be an important factor under ordinary conditions, as only about a hundred species are known, but these are widely distributed over the globe. 


\section{CHAPTER XXI}

\section{THE THYSANOPTERA}

The Thysanoptera-sometimes called Physapoda-are very small insects, peculiar in many ways. The common name for members of this group is Thrips, unchanged in spelling whether one or many are referred to.

As a whole these insects appear to have some affinities with the hemipteroid groups (Anoplura, Hemiptera and Homoptera) yet to be considered, but are generally looked upon as forming an order by themselves, though in some regards they seem to have certain relations to the Corrodentia and Mallophaga. It is not improbable that they form a group originating not far from the common trunk of all the above-named orders.

Thrips vary from one-fiftieth to one-third of an inch or more in length. Their mouth parts (Fig. 148) form in part a short, stout cone attached far back on the underside of the head, composed of the labrum, a portion of the maxillæ, and the labium. Within this cone are three bristles consisting of the lobes of the maxillæ and one mandible, the other not being developed. The animals are sucking insects. Four wings are usually present, rather long and narrow, with few veins, and fringed behind and generally in front also, with slender hairs, longer than the

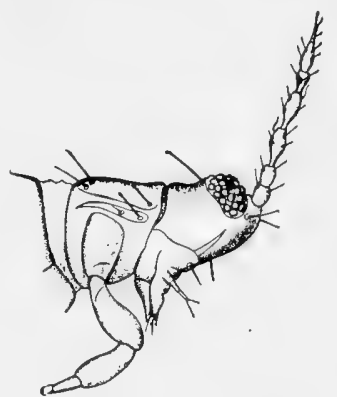

FIG. 148.- - Side view of the head and prothorax of a Thrips to show the mouth parts. (From U.S.D.A. Bur. Ent. Bull. 68 Part 2.) breadth of the wing itself. When at rest the wings lie flat on the top of the abdomen. In some cases they are greatly reduced in size or may even be wanting entirely. The tarsi are composed either of one or two segments, usually the latter: at the tip is a bladder-like portion which can be drawn into the segment or pushed out. The abdomen consists of ten segments, the last either conical or tubular in form.

Summarizing these facts, the adult Thysanoptera may be described as:

Small insects with greatly modified mouth parts forming a cone attached to the back part of the head beneath and used for sucking. Wings four, generally present, long, narrow, with few veins, and fringed behind (usually in front also) with long hairs. Tarsi of one or two segments, the tip with a bladder-like swelling capable of being drawn into the tarsus. Abdomen of ten segments, the last either conical or tubular. Metamorphosis incomplete but approaching completeness. 
Thrips feed on plant juices, puncturing the tissues and extracting the sap, leaving white marks or streaks where the cells without their juices have dried. They attack stems, leaves and blossoms, in the last case often blighting them and preventing the setting of fruit. On leaves of plants the under surface appears in most cases to be the preferred place of attack and the insects do not move about much. With grasses and cereals the stems as well as the leaves suffer, thus checking the growth of the top, and in some cases the kernels of growing grain are also fed upon. Some species live under loose bark and a few have been reported as feeding upon other insects. In many cases the injury caused by these insects is very serious.

In one section (Suborder Terebrantia) the female has an ovipositor with which she saws slits in the epidermis of plants, placing an egg in each slit. In the other section (Suborder Tubulifera) there is no ovipositor and the eggs are laid upon the surface of the food material. The larvæ considerably resemble the adult. After from two to four molts they leave their food to find some more protected place and there molt again, at which time wing stubs appear and other changes can be seen. Another molt and now the insect becomes quiet unless disturbed, not feeding, and marked changes become evident, bringing it more nearly like the adult, and the completion of these changes is followed by a molt which produces the adult itself. This is more than a typical incomplete metamorphosis, yet not entirely comparable with a complete one. It may be regarded therefore as intermediate between the two.

In some cases parthenogenesis, i.e., the production of the next generation by unfertilized females, occurs. This is perhaps to some extent determined by weather conditions, in this group. Parthenogenesis is frequently present here and there among insects and will be considered more fully elsewhere. Driving rains are very destructive to all kinds of Thrips. Lady beetles and other insects of several species feed freely upon them.

The Wheat or Strawberry Thrips (Frankliniella tritici Fitch).-This is probably the most widely distributed species of the group in this country. It feeds on wheat, strawberry, apple and many other plants and where the blossom is attacked as in the case of the strawberry, it is blighted, preventing the formation of the fruit and producing the stunted structures known as "buttons," instead. Leaves attacked often curl and become malformed, the particular parts injured soon turning brown and dying. In California it is a particular pest of alfalfa.

The adult is about a twentieth of an inch long, yellowish in color. In the warmer parts of the South it is more or less active at all seasons of the year, but in the North it winters in protected places, many probably, like other species, in grass fields close to the ground.

The life history in the South requires about 12 days but is probably 
longer in the cooler temperatures of the northern states, and several generations are produced in a season.

Control.-In general, spraying with nicotine sulfate 40 per cent, standard formula, or with kerosene emulsion, 1 part in 4 parts of water, is a good treatment. Success with these materials, however, depends largely upon the thoroughness of the application and the number which are killed. A favorite formula in California consists of $1 \frac{1}{4}$ gal. of commercial lime-sulfur, and $3 \frac{1}{2} \mathrm{fl}$. oz. of nicotine sulfate 40 per cent in 50 gal. of water, applied as a spray. Where the adults are wintering in grass fields and it is practicable, burning these over will destroy many.

The Onion Thrips (Thrıps taoac Linde.).-This pest is present practically everywhere in Europe and the United States, having first been noticed here about 1872 (Fig. 149). The adult is about a twenty-fifth of an inch long, rather light yellow, but turning brown as it becomes older. It feeds on a great variety of plants but being the species which is particularly injurious to growing onions, is generally known as the Onion Thrips. The onion leaves are whitened by the removal of their juices, and soon begin to bend sharply downward, and later they may curl or twist and even die, an area much affected in a field being noticeably pale colored and the plants stunted, while the bulbs make little growth.

Winter in the North is spent as the adult in protected situations such as in dead grass close to the ground or in rubbish left on the field. In

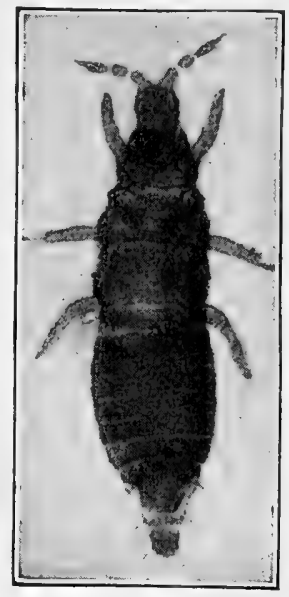

FIG. 149.- Nymph of the Onion Thrips (Thrips tabaci Linde.), greatly enlarged. (From Britton: Third Rept. Conn. State Entomologist.) spring the young onion plants are attacked soon after they come up, first in the bud, later on the leaves, in which the eggs are laid. The life cycle from egg to adult is influenced by the temperature, varying from a little less than 3 weeks to over a month, and in the most southerly states the generations overlap so that practically all stages may be found at the same time. Sometimes in the North this insect becomes a greenhouse pest on roses, carnations, cucumbers and tomatoes, though the Green-house Thrips (Heliothrips homorrhoidalis Bouché) is most often responsible for this injury.

Control.-Any methods of farming which will reduce the opportunities for this insect to pass the winter successfully, are of value. The destruction of all refuse on the field after the crop has been gathered: fall plowing of such fields, and burning over grass lands adjacent to them, at the proper time in the spring, are all beneficial. Cultivation and fertilization to push the crop ahead early to "keep it ahead of the thrips" is 
also helpful. Spraying the plants with nicotine sulfate 40 per cent, $3 / 8$ pint., $4 \mathrm{lb}$. more or less of soap, and 50 gal. of water is a fairly effective treatment. Fish-oil soap is better than laundry soap when obtainable, and the amount to use is determined by spraying a leaf with the mixture. If the spray gathers together into larger drops, leaving parts of the leaves dry, more soap is needed, for its use is mainly as a "spreader" over the leaf surface. This treatment should be repeated every 8 or 10 days as long as the Thrips are present in any abundance, until within a month of harvesting. Use a fine, misty spray with conderable pump pressure. Only thorough spraying will give effective results.

The Pear Thrips (Toniothrips inconsequens Uzel).-This insect was first discovered in the United States in the central part of California,

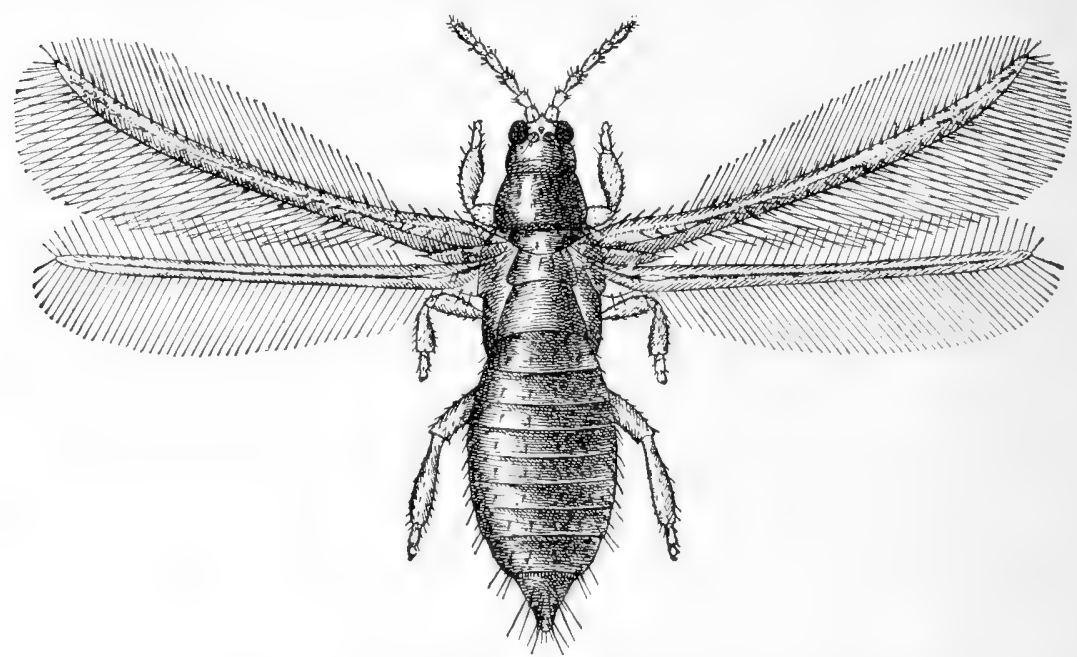

FIG. 150.-Adult Pear Thrips (Taniothrips inconsequens Uzel), greatly enlarged. (From U.S.D. A. Bull. 173.)

attacking deciduous fruit trees, particularly pears, prunes and uherries, blighting the blossoms by the abstraction of their sap. Later it was found in British Columbia, in the Hudson River Valley in New York, and still later in Pennsylvania, Maryland, and in England. Recently it has been learned that the insect was first discovered in Bohemia, feeding in blossoms.

The destruction caused by this pest in California has been very great some years. The crop of prunes in the Santa Clara Valley alone has been estimated as having been reduced in the 7 years, 1905 to 1911 , $141,000,000 \mathrm{lb}$. The injury is caused by the feeding of the young and adults on leaves, buds, flowers and fruit, and by laying eggs in the leaves and fruit stems and also in the small fruit. 
The dark brown-almost black-adults (Fig. 150) appear carly in spring, coming out of the ground about the time the fruit buds are swelling and opening, and as soon as these have opened slightly the insects work their way into them and feed on the most delicate parts. The eggs are laid mainly in the young leaf and fruit stems and young fruit and hatch on an average after about 8 days. The nymphs (Fig. 151) feed on the leaves and young fruit forming a sort of "scab" on the surface of the latter, and remain on the tree for 2 or 3 weeks, though from the first young to appear to the last young to disappear, may be more than 2 months. When through feeding they fall to the ground, which they enter for a varying distance, and there, after from 2 to 5 or 6 months, they transform to the last stage before the adult, having previously molted once underground. Late in the fall or winter the final molt produces the adults which remain in the ground till early spring.

This remarkable life history, quite unlike anything known for any other Thysanoptera, permits but one generation a year, with active injury during only a rather short period in the spring.

Control.-These insects can be destroyed by spraying with Nicotine sulfate 40 per cent used at the rate of 1 part to 800 parts of water, standard formula. Success with this treatment, however, is entirely dependent upon the thoroughness of the application. The first treatment should at once follow the discovery of the Thrips upon the swelling buds and should be repeated at least every 2 or 3 days until the buds are open or the Thrips have become very few. No spraying

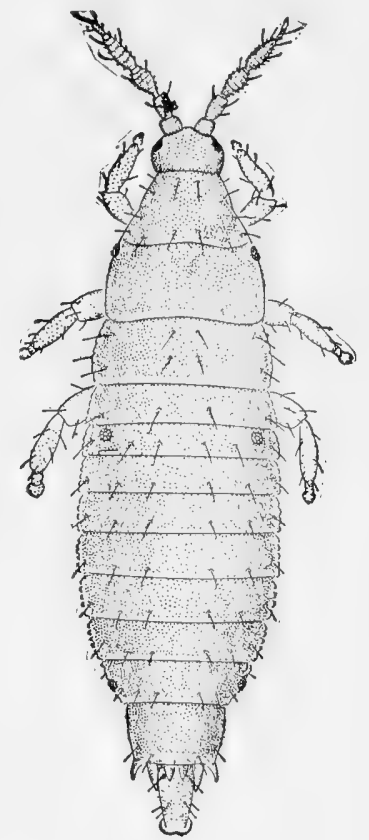

Fig. 151.-Nymph of Pear Thrips, greatly enlarged. (From U.S.DA. Bur. Ent. Bull. 68, Part 1.) should be done from the time the blossoms open until the petals fall. Then, if Thrips are abundant on the remains of the blossoms, another treatment should be given.

The Citrus Thrips (Scirtothrips citri Moult.) is a rather serious pest in California and Arizona. It feeds upon the tender stems, leaves and fruit of citrus trees, and occasionally also attacks the grape, apricot and other plants. With seedling plants the leaves and buds are injured and growth is checked. The fruit is injured by scars and scabs caused by the feeding, and greatly reduced in value, and some drops to the ground.

The adult is one of the smallest of the Thysanoptera, varying from one-fiftieth to one-twentieth of an inch in length, and is orange-yellow in color. The young appear in April and May and gather on the leaves 
and fruit where they remain until the midsummer hardening of these parts leads most of them to leave for various other food plants, until August and September when they return to the citrus trees again and lay their eggs in the leaves and stems of the plant. These winter over and hatch the following spring. Following the production of adults from the hatching and development of these eggs, there may be six to eight generations during the season and all stages may be present at once on a tree as late as December, though these die with colder weather, leaving only the eggs to hatch in the spring. The last stage before the adult, during which the insect is quiet, is passed in crevices of the trunks or in rubbish under the trees, but not in the ground.

Control.-Spraying, either with lime-sulfur wash using 1 part (if of a density of $33^{\circ} \mathrm{Bé}$.) in 50 parts of water, or with more water than this if the wash reads higher; or with Nicotine sulfate 40 per cent, at the rate of 1 part in 800 parts of water, have given excellent results. The first application should be made as soon as four-fifths or more of the blossoms have fallen, and a second 10 days to 2 weeks later. If these two treatments have been well-timed and thorough, the third can be delayed until about 3 weeks after the second. A fourth treatment late in August or early in September, if the returning insects are very abundant on new shoots, will aid much in checking their increase. In all treatments the spplication should be very thorough and with a pressure of at least $125 \mathrm{lb}$. Particular attention should be given at the second application to completely drenching the fruit and any tender leaves.

In addition to the species of Thrips given separate consideration above, nu nerous other species are frequently of some importance. Among these the Grass Thrips which sucks the sap from the stems of the lighter grasses, turning them white and killing them, thus causing "silver top" as it is called; the Greenhouse Thrips which attacks tomatoes, cucumbers and many other plants in greenhouses in the North and outof-doors in the South, and the Camphor Thrips which is a serious pest of the Camphor tree in Florida, are perhaps the most important. 


\section{CHAPTER XXII}

\section{THE CORRODENTIA}

Most of the Corrodentia are very small, even tiny insects, though a few giants of the group found in South America have a wing-spread of about an inch. Some of the group are wingless and are most often noticed as small, whitish, gray or brown specks running over the leaves of old books. These are generally called Book-lice. The winged forms (frequently called Psocids, though this name really applies to the entire group) when adult are somewhat larger and are found on tree trunks, weathered fences and other places where lichens grow, and furnish them with their food. 'In general the members of the group eat animal or vegetable refuse, mould, fungi and similar materials. Several hundred kinds are known.

The body in the Corrodentia though quite soft, is well developed, but the prothorax is small and concealed in some cases between the head and the mesothorax. In others it is distinct, but as the meso- and metathorax are grown together in those cases, only two of the three thoracic segments are evident. The antennæ are rather long and slender, and the mouth parts are for chewing but considerably different in some details from the typical structure. The wings when present are four in

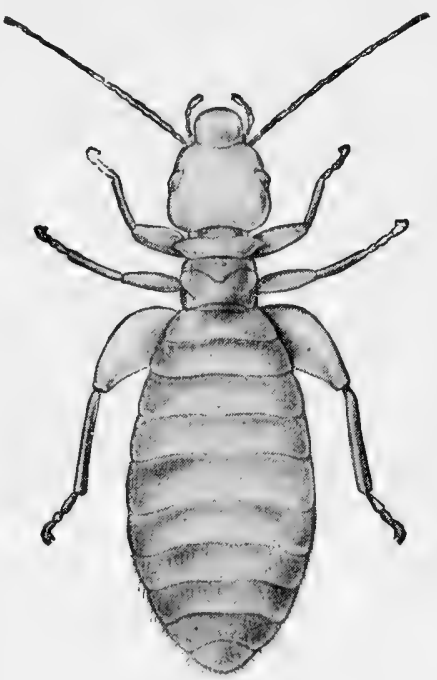

FIG. $152 .-$ Adult Booklouse about fifty times natural size. (From U. S. D. A. Farm. Bull. 1104.) number, with very noticeable veins, few of which are cross-veins. When at rest the hinder margins of the wings of the opposite sides are brought together over the back of the insect with their upper surfaces sloping down at the sides, thus assuming the position of a steep house roof. They are often more or less dusky or mottled. The tarsi consist of only two or three segments. Ocelli may be present in the adults but not in the nymphs. These are quite similar to the adults otherwise, and develop through a series of molts into the adult condition.

The group may be characterized as follows:

Small, soft-bodied insects with or without wings when adult. In those having wings there are two pairs, with prominent veins: when at rest they 
are held at a sharp angle over the body, hinder margins uppermost. Antennce long and slender. Tarsi of two or three segments. Ocelli sometimes present in the adult condition. Metamorphosis incomplete.

This little order contains few species of much economic importance. The wingless forms-book-lice (Fig. 152)-found in buildings, eat the paste and paper of old books and are also found in birds' nests where they find in feathers and other organic debris their food. The winged forms, frequently called Psocids, are found in various places, but perhaps most frequently on the trunks of trees, generally in clusters and of ten in various stages of their development. They have the power of produring silk and sometimes the clusters appear to be covered, at least partly, by a web of this.

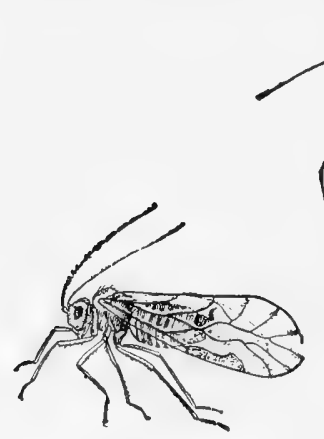

a

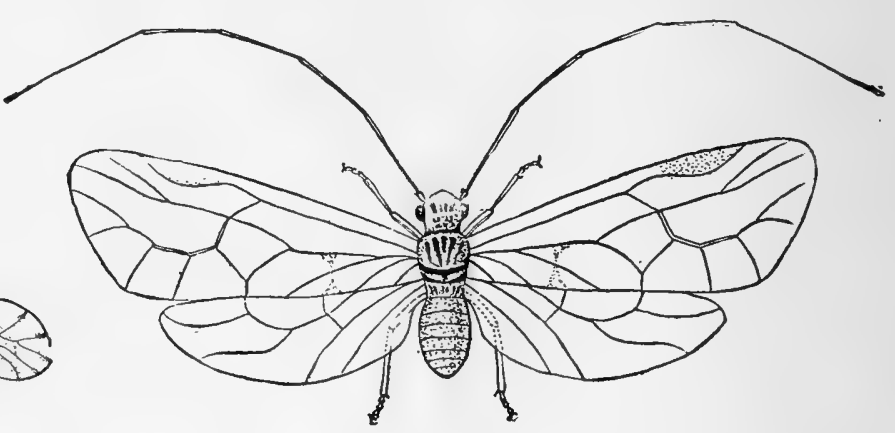

$b$

Frg, 153.-Adult Psocids: $a$, side view showing position of wings at rest; $b$, Psocid (Psocus lineatus) with wings spread. Both greatly enlarged. (From Sanderson and Jackson, Elementary Entmology: a, after Kellogg: b, after J. B. Smith.)

Some of the book-lice are claimed to be able to make a ticking sound something like that of a watch, and this sound is often called the "death watch." Such a sound is certainly produced by a small beetle, and the possibility of the book-lice also being able to make it has been questioned. The weight of evidence thus far, however, seems to favor this possibility. It is heard chiefly in old houses at night or when everything is quiet, as a faint, rapidly repeated tick-tick-tick, and is in all probability, the call of an insect to its mate.

The winged Corrodentia (Psocids, Fig. 153) are not known to be of any economic importance. Where the wingless forms (book-lice) become extremely abundant in buildings, relief may be obtained by a thorough cleaning of the infested places. Light and air, particularly dry air, are unfavorable to them, and heating a room to quite a high temperature for a few hours and the exposure of all the furniture to sunlight for a time on a bright day will generally free the place from these insects. All stages except the egg appear to die at the beginning of winter. 


\section{CHAPTER XXIII}

\section{THE MALLOPHAGA}

The Mallophaga are generally called bird-lice but as they feed by biting off particles of feathers, hairs and scales of the skin, from the animals on which they live, the name biting-lice would be better as it would distinguish them more accurately from a large number of very similar insects found in many cases on the same animals, which feed by sucking the blood of their hosts, and which are called sucking-lice.

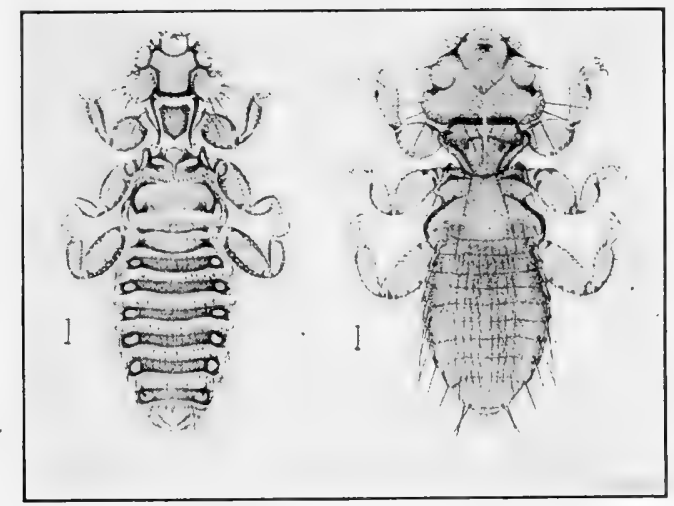

FIG. 154.- Samples of Mallophaga or Biting Lice, greatly enlarged: hair lines show actual length. (After Kellogg.)

The bird-lice or biting-lice (Fig. 154) are very small insects ranging from about one-twenty-fifth to one-tenth of an inch in length, rather whitish in color, much flattened and with an external shell which is unusually hard for such small insects. They are wingless and are rarely found off the bodies of the birds and mammals on which they live. Development from the egg is gradual, through a series of molts which finally produces the adult.

The group may be described thus:

Small, wingless insects, usually with a large head; mouth parts for biting. Body quite hard, flattened. Parasitic on the bodies of birds and some mammals. Metamorphosis incomplete.

About fifteen hundred kinds of Mallophaga are known, most of them living on birds, where they feed on fathers and skin scales. On mammals, hairs replace the feathers as their food. When abundant, bare areas on the bodies of birds appear where the feathers have been eaten or 
have dropped out as a result of the feeding of these insects. Birds normally dust themselves, working the dust in among their feathers, where it is claimed it gets into the spiracles of the lice and suffocates them. Apparently the greatest injury to the fowls does not come from the feeding on the feathers and scales, but from the irritation produced by the scratching of the skin caused by the tarsal claws of the parasites as they move about, and this must be quite severe, for birds considerably infested become dull and act sick, and are certainly less able to resist disease than usual.

The eggs of the lice are attached separately to the feathers or hairs of the host, and hatch into nymphs, which on the whole considerably resemble their adults. They feed, molt, grow and become adult in a few weeks.

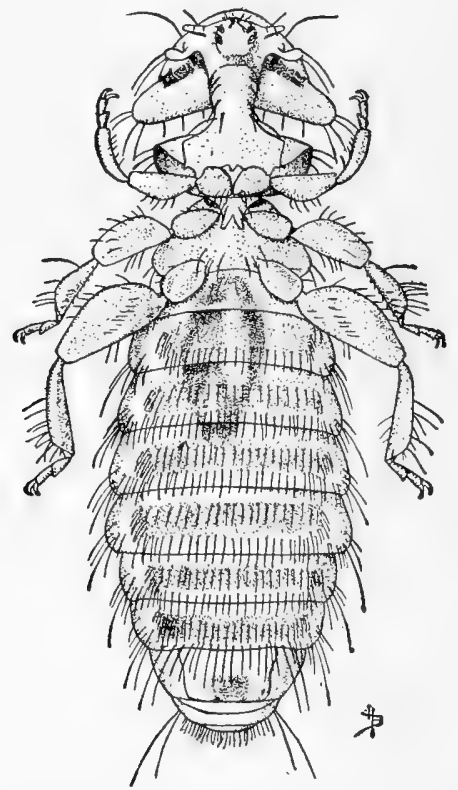

FIG. 155.-Female Chicken Body Louse (Menopon biserialum Piag.), greatly enlarged. (From U. S. D. A. Farm. Bull. 801.)

Though these insects are widely distributed on many kinds of birds and on a number of mammals, they are of importance from an economic standpoint mainly on the domesticated birds such as chickens, turkeys, geese, ducks and pigeons, though occasionally dogs, cattle and horses become infested.

Seven different kinds of biting-lice are fairly common on domestic fowls. Of these, some prefer the head for their location, others the body (Fig. 155), etc., though not found exclusively in those locations. Four kinds are often present on turkeys and quite a number occur on geese and ducks. Pigeons and guinea fowls have several species. 
Control of Lice on Poultry.-Various methods of control for poultry lice are in use, but in most cases at least, the best one is the use of sodium fluorid, dry or dissolved in water. Either the commercial or the chemically pure grade can be used but the commercial is somewhat easier to work with, particularly for dusting the fowls.

The first step in treatment is to shut up all the fowls. Then each bird is taken and while being held either by the wings or legs with one hand, pinches of the powder are placed in among the feathers, "one on the head, one on the neck, two on the back, one on the breast, one below the vent, one on the tail, one on each thigh, and one scattered on the underside of each wing when spread." For young birds dusting rather than dipping is advisable.

If dipping is preferred for the older birds, use warm water in a tub, measuring the water put into the tub and adding from $3 / 4$ to $1 \mathrm{oz}$. of the commercial fluorid (or $2 / 3 \mathrm{oz}$. of the chemically pure fluorid) to each gallon of water. Dip the birds in this, holding the wings over the back with one hand and ruffling the feathers with the other, below the surface of the water. Then duck the head of the bird once or twice, take it out of the water, let it drain for a moment and then let it go. After a little experience, three-quarters of a minute per bird will be an ample amount of time for this treatment.

The water in the tub will be reduced in quantity of course, by use, and more, having the proper amount of fluorid dissolved in it should be at hand to add from time to time.

Whether the sodium fluorid treatment, which has only recently been discovered, will give satisfaction for the treatment of biting lice on mammals cannot be stated. Heretofore, washing an infested animal with kerosene emulsion has been advised.

Boxes of road dust, available in poultry houses during the winter months for the birds to dust themselves in, are desirable. Formerly used to actually aid the birds in freeing themselves of lice, they now act as indicators that lice are present and that treatment should be given 


\section{CHAPTER XXIV}

\section{THE ANOPLURA}

These insects are the sucking lice which attack mammals, and mammals only. They are small, wingless insects from about one twenty-fifth to one-fourth of an inch in length, and with mouth parts for sucking. The head is usually rather pointed in front and is of ten joined to the thorax by a distinct neck which permits its free movement. The distinction between thorax and abdomen is less evident, the constriction there being practically non-existent. The legs, which join the thorax well out on its sides, are constructed for climbing and grasping, and each ends in a single claw, so placed with reference to the rest of the leg that it can tightly grasp a hair, the claw on one side and the tibia on the other. The eyes are rudimentary or absent in some cases.

The group may be defined as:

Small, wingless insects with sucking mouth parts, feeding on the blood of mammals. Eyes present or absent. Tarsi each with one claw. Metamorphosis incomplete.

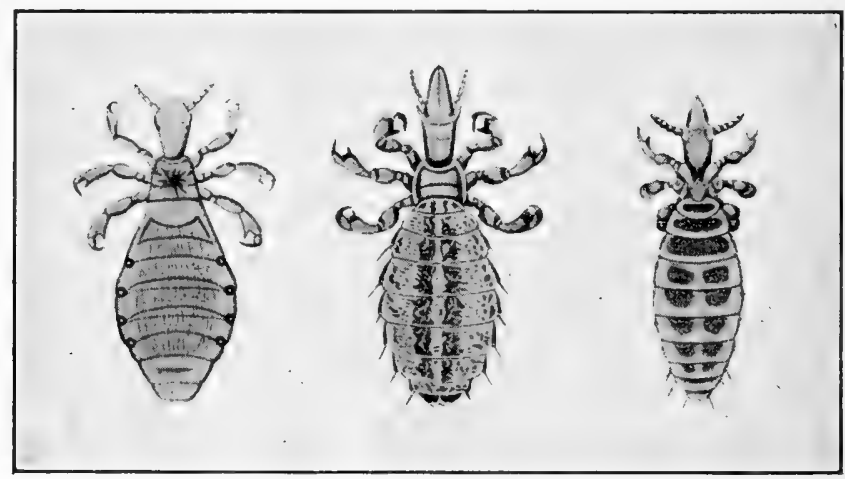

FIG. 156.--Samples of Anoplura or Sucking Lice, greatly enlarged. (After Dalla Torre.)

Anoplura (Fig. 156) occur on man, monkeys, domestic animals, rats, mice, rabbits, squirrels, the elephant, etc., and one genus is found on the seal. The mouth consists of a flexible proboscis which may be drawn in or pushed out, turning inside out as it goes and exposing some chitinous hooks which attach themselves to the skin of the host. Lodged in the head are two long, slender, sharp-pointed structures called stabbers, one, possibly both, apparently double in nature but more or less fused, and so placed as to form a canal between them through which saliva may 
be injected into the wound they make. These stabbers are forced through the skin within the area encircled by the proboscis, saliva is forced into the wound and after a few moments feeding begins, the blood of the host being pumped into the body of the louse.

Eggs or "nits" are laid singly, attached to the hairs of the host or in some species, to the fibres of the clothing. They hatch in from 1 to 2 weeks, according to the species and the temperature, but when the latter remains low, as where the eggs do not feel the effects of the warmth of the host, they will not hatch (at least with the lice infesting man). The nymph stage probably requires 8 to 10 days, though practically nothing is known of the development except with the lice attacking man. Several hundred eggs are usually laid by each female during a period of nearly a month, so that a heavy infestation becomes possible in quite a brief time.

The Anoplura is a small group of insects, probably only about a hundred species being known. They were formerly considered degenerate Hemiptera, but with the division of the old Order Hemiptera into separate orders-the Hemiptera in a more restricted sense and the Homoptera - it has seemed more logical to regard the Anoplura as also an Order, most closely related to these, but still sufficiently different to entitle it to ordinal rank.

The Human Body Louse (Pediculus humanus L.).-This pest (Fig. 157), which during the European war also received the common name "cootie," is now generally regarded as being of two races, the head louse (formerly called Pediculus capitis) which is found chiefly on the head, and the body louse (formerly Pediculus vestimenti or $P$. corporis) found mainly on the clothing, rather than different species, but the races differ

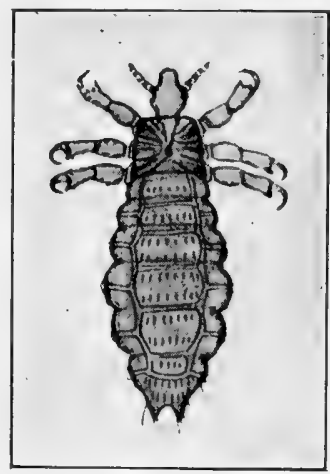

FIg. 157.- Human Body Louse (Pediculus humanus L.) about eight times natural size. (From Berlese.) somewhat because of different conditions under which they live. This insect under ordinary conditions of cleanliness can be easily controlled, but in camp life finds an opportunity to increase, often almost without possibility of being checked.

Under ordinary conditions a simple treatment for the race living on the head is to wash thoroughly with tincture of larkspur, which can be obtained of a druggist, and repeat this two or three times at intervals of about a week. For the race living on the body, treatment is somewhat different, as the pests are largely on the clothing, reaching across from this to the skin to feed. Here boiling all clothing which can be so treated, dry heating the rest to $130^{\circ} \mathrm{F}$. for $1 / 2 \mathrm{hr}$. and taking a hot bath will usually be sufficient. 
Rather recently it has been discovered that the lice of man are concerned in the transmission of Relapsing fever, Trench fever, and that terrible disease Typhus fever. It does not at present seem that the causal agents of the first two of these are actually transferred to man by the feeding of the infested lice, but rather that these agents are present in their bodies and feces, and that by scratching parts irritated, fluids from crushed lice or the feces get rubbed into the irritated areas, are able to enter the body, reach the blood and begin the disease. This also appears to be true in the case of Typhus fever, but here inoculation by the feeding of the lice also seems probable. In some cases where scratching does not occur but where Relapsing or Trench fever nevertheless develops, it is probable that the feces get into the feeding wounds and in that way cause the disease.

The Crab Louse (Phthirus pubis L.).-This louse is quite different in appearance from the last, being smaller, shorter, broader, and with its legs projecting outwardly near together

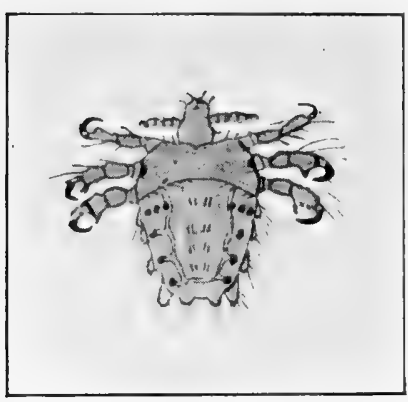

FIG. 158.-Human Crab Louse (Phthirus pubis L.) about twelve times natural size. (From Berlese.) (Fig. 158). The fore legs are slender but the others are stout and each has a powerful serrated claw which shuts against a projection of the preceding segment of the leg in such a way as to give a very firm grip on a hair. This insect is found primarily on the hairy parts of the body except the head, but in exceptional cases it may be found there also. It holds onto the hairs while feeding and in moving about always holds tightly to hairs on one side until it has obtained a grasp on others on the other side. This gives it a sideways movement which is responsible for its common name. Its life history is much the same as in the other species.

Washing thoroughly with tincture of larkspur as for the head louse is usually an effective treatment. An ointment made of 4 parts of crude naphthaline mixed with 1 part of soft soap rubbed on the underclothing in the infested region has also been found to be a very successful treatment.

Lice on Domestic Animals. - These are sometimes serious in their attacks, weakening the animal greatly if they are abundant. In the treatment of these pests it should be borne in mind that poisonous materials cannot be used because of the danger coming from the animals' licking themselves. Various substances have been used for live stock, such as 15 per cent kerosene emulsion scrubbed on the skin; washing with potassium sulfid, using from 2 to $4 \mathrm{oz}$. per gallon of water according to the size and vigor of the animal; the application of a mixture of sulfur 
1 part, lard 4 parts, rubbed over the body, or washing with dilute carbolic acid using 1 part of the acid in 30 parts of water. The most usual treatment for cattle lice, however, is by the use of stavesacre (Delphinium) seeds. Four ounces of these seeds and $1 \mathrm{oz}$. of white hellebore are boiled in a gallon of water until only 2 qt. remain. This is then applied with a brush to the animals. It may need to be repeated if more lice appear, showing that eggs or some of the lice escaped the first application. Raw linseed oil, applied with a brush has recently been recommended as an alternative treatment, the material for one animal costing about five cents.

The relation of insects to disease as has been brought out above, where lice serve to convey the germs or parasites causing illness to man, is one of the newer subjects in Entomology but one which has been shown to be of great importance. Medical Entomology is already a large field upon which much has been written, and yet one about which little is probably known in comparison with its actual size. 


\section{CHAPTER XXV}

\section{THE HEMIPTERA}

The Hemiptera is a large group containing many insects which are always injuriously active, and many more which occasionally become so. They vary greatly in size, some being minute while others may attain a length of four or five inches. They are most numerous in species in the warmer portions of the globe, but an abundance of individuals in colder regions results in making them extremely common everywhere.

Most Hemiptera have the dorsal surface of the body rather flattened, though there are many exceptions to this statement, and the wings when not in use rest upon this surface. The wings are nearly always present, four in number, and the basal half, or sometimes more, of the front pair is thickened and horny, resembling the elytra of beetles. The outer end, however, is membranous and veins traverse this portion, so that the fore wings are appropriately called hemielytra. The membranous part of one wing largely overlaps that of the other when they are at rest. In a few families the difference in the texture of the two portions is not very perceptible but in most cases it is plainly evident. The hinder wings are entirely membranous and when not in use are concealed beneath the others.

The body of the Hemipteron with few exceptions, shows no constriction at the junction of thorax and abdomen and is usually widest at the hinder end of the prothorax. The attachments of the wings behind this do not occupy anywhere near all of the width of the body, and directly behind the pronotum, between the wings, the space is taken up by a rather large, usually quite triangular plate called the scutellum. In some families this becomes greatly enlarged, covering more or less of the dorsal surface of the body from the pronotum back, and in such cases the wings in closing slip under this so that little besides their costas show.

Hemiptera are sucking insects (Fig. 159), obtaining their food by piercing the surfaces of plants or animals and drawing into their own bodies the sap or blood. The mouth parts in the group have been identified with those of chewing insects, but they have been greatly modified to form a beak or rostrum which is attached to the front of the underside of the head. The details of structure of the rostrum differ in different Hemiptera but agree in general plan (Fig. 160). The outside of the 
rostrum is a sheath which appears in the main to be derived from the labium or hinder lip of the chewing insect, being much elongated, and its sides rolled forward to meet or almost meet in front, forming a tube. The front part of this tube, however, near the head, seems not to be formed by the labium, leaving open a somewhat triangular place and the labrum or front lip appears to have grown downward to more or less completely close up this portion of the sheath. Within the tube

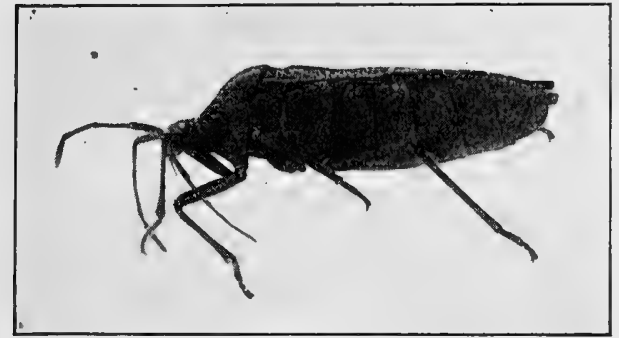

FIG. 159.

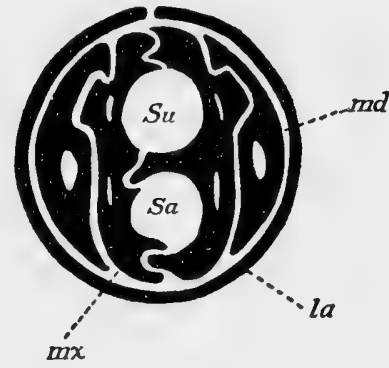

Fig. 160 .

FIG. 159.- Side view of a Squash Bug (Anasa tristis De G.) showing the rostrum, and its attachment to the front of the head. Some of the mouth parts usually within the sheath have been pulled out and show in front of it. Rather more than twice natural size. (Original.)

FIG. 160.-Diagram of a cross-section of rostrum of a Squash Bug: la, labium; $m d$, mandible; $m x$, maxilla; $S a$, tube carrying saliva to the wound; $s u$, tube through which the food is drawn into the body. (Modified from Tower, Am. Ent. Soc. Am. VI, 1913.)

thus formed lie the mandibles and maxillæ which have become transformed into long and slender bristles with pointed tips. The surfaces of the maxillæ which face each other have so changed their outline as to form two gutters or troughs and when the maxillæ are pressed together as is the case in the living insect, each gutter of one side coincides with the corresponding one of the other to form two tubes, half of each being contributed by each maxilla. The more anterior of the tubes is for sucking the nourishment obtained, into the bug, while the other is for injecting saliva into the wound. The mandibles lie beside the maxillæ and seem to function chiefly as piercing organs.

In feeding, the tip of the rostrum is brought into contact with the surface of the object to be fed upon and the tips of the mandibles and maxillæ are then driven into it until sap or blood as the case may be, is reached. Then saliva is forced into the wound and this seems to be irritating or even poisonous in its nature and its presence in the wound causes (in animals at least) an increased flow of the body fluids to that point. Assured thus of a sufficient supply of food, sucking it into the body of the insect is then begun.

The eggs of Hemiptera are laid under greatly differing conditions. Some are inserted in twigs or stems; others are laid either singly or in 
clusters on leaves, twigs or in other places. The eggs themselves vary much in appearance, some being provided with circlets of spines, some with long filaments and some being smooth but of unusual form or color. They hatch into nymphs (Fig. 161) more or less closely resembling the adult, which stage they reach by a series of molts, changing with each molt.

The Order Hemiptera may be characterized as:

Insects which when adult nearly always have four wings, the front pair in most cases partly horny, partly membranous: with a plate located between the bases of the wings, usually triangular in outline, in some cases covering more or less of the abdomen above: mouth parts for sucking, and attached to the front end of the underside of the head. Metamorphosis incomplete.
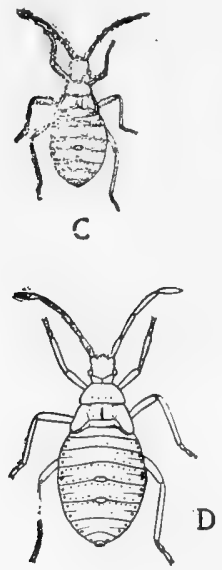

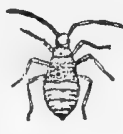

B
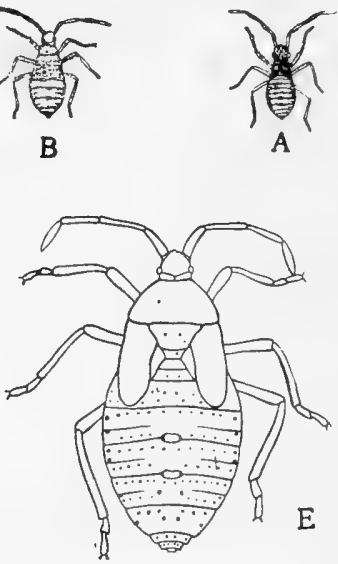

A

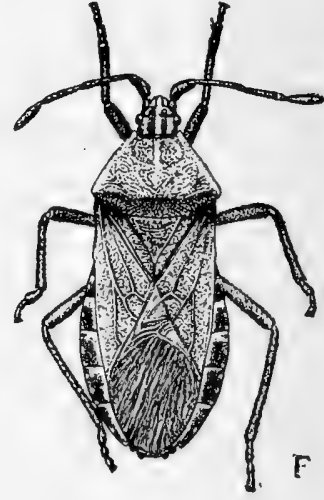

FIG. 161.-Metamorphosis of the Squash Bug (Anasa tristis De G.): adult and nymphs of different ages, all twice natural size. (From Folsom.)

Hemiptera occur under almost every conceivable condition of life. Some live in water, coming to the surface only to obtain air: some are found on the surface of the water and some are found on the ocean hundreds of miles from land. Most of the group are terrestrial, however, and in many cases are widely distributed. Probably fifteen thousand species are already known but the group has been little studied as compared with some of the more attractively colored and marked orders. Those living in water are at least for the most part, feeders on insects and other animals small enough for them to capture: those which live on the surface are also predaceous, while of the land forms some consume other insects but probably the larger number are plant feeders. The Hemiptera are the true bugs, the general use of the term "bug" as applied to all insects being incorrect. 
Family Pentatomidæ.-This group consists of land forms, many of them producing a disagreeable odor which has resulted in applying to these insects the common name "stink bugs" (Fig. 162). Most of them suck the sap from various plants, leaving behind the odor so often noticeable on berries. Others are carnivorous, attacking caterpillars and sucking their juices. Many of them are minor pests and potentially important ones, and their fair size-often half an inch or more in lengthtogether with considerable width, giving them a broad surface, makes them fairly familiar objects.

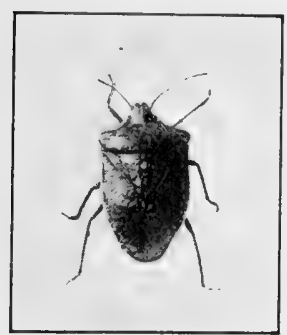

FIG. 162 .

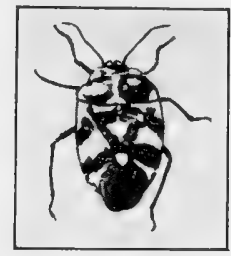

FIG. 163.

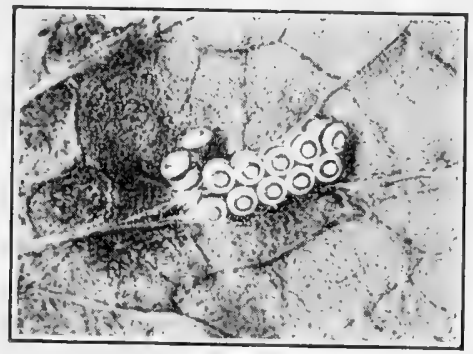

Fig. 164 .

FIG. 162.-Pentatomid Bug (Euschistus), naturai size. (Original.)

FIG. 163.-Adult Harlequin Bug (Murgantia histrionica Hahn.), slightly enlarged (Original.)

FIG. 164.-Eggs of Harlequin Bug, slightly enlarged. (Modified from Essig. Inj. and Benef. Ins. Cal.)

The Harlequin Bug (Murgantia histrionica Hahn).-This pest, native to Mexico and Central America, has gradually spread northward, feeding on cabbage, kale, mustard, turnip, radish and other eruciferous plants, and its present northern limits are now in New Jersey and Long Island, Ohio, Indiana, Wisconsin, Iowa, Nebraska, Colorado, Arizona, Nevada and Washington, though the insect rarely does much injury so far north.

The adults (Fig. 163) are about half an inch long, black or dark blue with bright red or orange marks, the brilliancy of the colors making the insects very noticeable and resulting in the common names "calicoback," "terrapin-bug" and perhaps "fire-bug" as well. They winter in the adult stage under rubbish or wherever they can find protection, though in the far South they are more or less active nearly all the time and there the nymphs are also present then.

Farther north the bugs become active during the early spring and attack various wild cruciferous plants and lay their eggs (Fig. 164). These are usually placed in clusters of about 12 , in two rows, and are somewhat barrel-shaped, white, with two black rings around each, and a third ring on the upper end, being both very noticeable and distinctive. They hatch in from 3 to 11 days according to the temperature and the nymphs suck the sap from the plants for 1 to 2 months, again according 
to the temperature, before becoming adult. When cabbage, cauliflower, kale, turnip, radish, etc., become available, the bugs go to these and thereafter devote their attention to these plants until late in the fall when various other kinds, such as egg plant, asparagus, tomato, beans, beets, etc., may be attacked.

Control.-Insecticides which do not injure the plants the bugs are on, are not usually effective against this pest and preventive methods have thus far given the best results. Planting a very early crop of kale, mustard or rape, to which the bugs when they first become active in spring may be attracted, is a good practice, for the insects seem to prefer these to the other plants. Here the bugs may be killed by spraying with kerosene, collected in nets and destroyed, or may be burned with a torch. The few that may escape this treatment can be picked by hand wherever found, but if the trapping method above is followed, few usually escape.

Clean culture is also helpful. As soon as the crops are gathered all the stalks and leaves of the plants on which the Harlequin bug feeds should be gathered and destroyed, both to leave them no food and to remove possible places where they might winter. Rubbish which might provide wintering quarters should also be carefully removed. Recent tests with contact insecticides show some possibility that control by these materials may be obtained, but this subject has not yet been sufficiently investigated to warrant definite recommendations.

Family Cydnidæ.-The bugs of this family are usually of little economic importance. Some of them are interesting, however, as in them the scutellum, usually quite small, becomes greatly enlarged, covering nearly all of the thorax and abdomen behind the pronotum. In one genus the insects are nearly circular in outline, very convex, having much the form of lady beetles, and are generally glistening black, in a ferw cases with a narrow line of white. These are often called "negro-bugs" and one species feeds on small fruits and leaves a disagreeable odor.

Family Coreidæ.-Many of the members of this large family are of considerable size for bugs, some being over an inch long, but their bodies are much more narrow in proportion to their length than in the Pentatomidx. Some of the southern species have broad, flat expansions of the tibiæ, giving them a curious appearance. The insects of this group suck plant juices and a number are frequently more or less injurious to various plants.

The Squash Bug (Anasa tristis De G.).-The Squash Bug is common almost everywhere in the United States feeding on squash and pumpkin and sometimes on cucumber and melon plants (see Fig. 161). The adult is a dark brown bug, very finely mottled with gray or lighter brown in many cases, about three-quarters of an inch long. It winters as the adult under rubbish or in other protected places, and appears in spring, ready for its food plants when these come up. When the leaves of the 
plants develop the bugs lay their eggs on their under surface in clusters which vary greatly in the number of eggs composing them. The eggs themselves are oval in outline, very convex, and being resin-brown in color are very conspicuous against the green background of the leaf. In a cluster the eggs are not usually so laid that they touch, but somewhat spaced apart in most cases. At intervals before and during the egglaying period the adults feed on the plants and when they are very abundant may seriously injure or in some cases even kill them.

The eggs hatch on an average in about 10 days and the tiny nymphs, green and reddish in color, begin to suck the sap from the under side of the leaves, at first together, but scattering later. The reddish color of the nymph quickly changes to black and the green gradually becomes more of a gray. Feeding and molting five times results in the production of the adult after a period of from 4 to 5 weeks from the time the eggs hatch, and in the North the adults feed on the plants until fall; then go into winter quarters. In the South the longer seasons which permit an earlier start in the spring and the higher temperature which causes the eggs to hatch more quickly, permit the production, in some cases at least, of two generations each season.

The injury to the plants caused by the spring feeding of the adult is continued by the sucking of the young. Where these are plenty, growth is checked and the crop reduced. If the plants are killed by frost before the nymphs are mature, they often attack the fruits in order to obtain the nourishment they need to become adult.

Control.-Contact insecticides are not effective for the adult Squash bug, which has an unusually thick shell. The usual methods for control are the removal as far as possible of all rubbish and places where the insects can obtain protection during the winter; stimulation of growth of the plants by fertilizers and cultivation; protection of the young plants by fine netting until they are so well started that they can thrive despite the bugs; traps of bark or shingles placed close to the plants, under which the bugs gather at night and whence they can be gathered and destroyed early in the morning (this can be begun even before the plants are up); egg-masses being easily seen can be quickly found and crushed; and while the nymphs are small, spraying. with Nicotine sulfate 40 per cent, 1 part in 400 of water will destroy them. The difficulty in reaching the nymphs on the under side of the leaves with the spray, can in part be obviated by attaching the nozzle of the spray pump to a piece of tubing connecting at its other end with the hose, and bent in a loop so as to give an upward spray.

In the South one or two very closely allied species also attack the squashes and cucurbits and may be controlled in the same ways.

Family Pyrrhocoridæ.-The insects of this family superficially resemble the Coreids and are of medium size. Only one is of any economic 
importance in the United States, and that in only a few of the Southern States though it is also injurious in some of the West India Islands. The Cotton Stainer (Dysdercus suturellus H.-S.) as it is called (Fig. 165), feeds on cotton, and occasionally the egg plant and orange among cultivated crops. On oranges it attacks the fruit about the time it is ripening, puncturing the skin and thus hastening decay. On cotton the insect punctures the partly developed bolls and if the attack is severe these may be destroyed. If not, the fiber is more or less stained, apparently from the punctures in the seeds, reducing the value of the cotton anywhere from 5 to 50 per cent. As the bugs develop in colonies and remain close together for some time and in their early stages are red, they

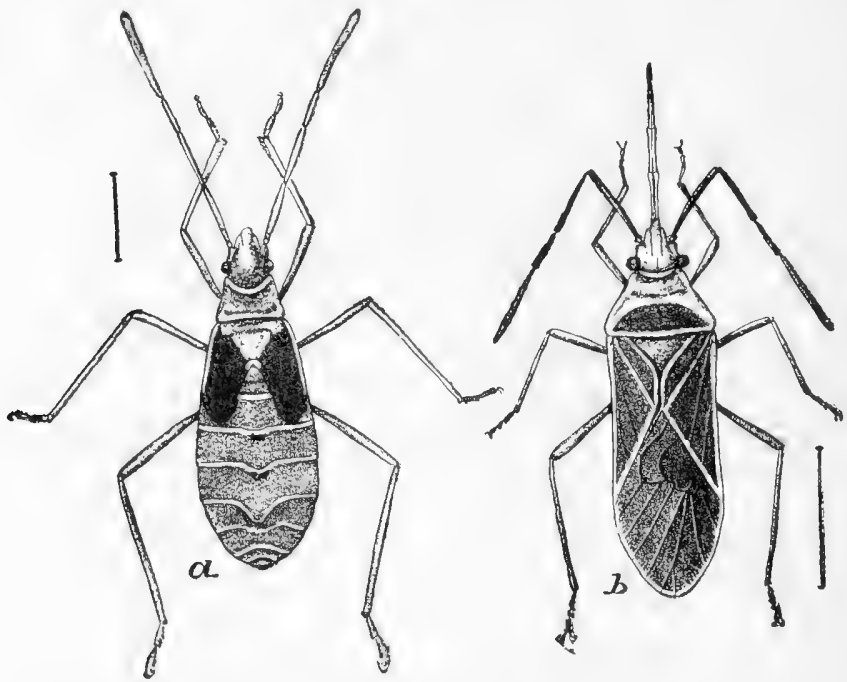

FIg. 165.-The Cotton Stainer (Dysdercus suturellus H.-S.): $a$, nymph; $b$, adult. Enlarged about three times. (From U.S.D. A. Farm. Bull. 890.)

are easily located and knocked off into dishes containing kerosene. In fall and spring they are attracted to baits, either of cottonseed or sugar cane, where they can be killed with kerosene. The bugs also feed and breed freely on Hibiscus and the Spanish. Cocklebur, and the destruction of these plants near cotton fields will prevent their breeding there and spreading in larger numbers to the cotton.

Family Lygæidæ.- There are many kinds of insects in this family but nearly all are small, being in most cases less than a third of an inch long. A number occasionally injure various plants, and one-the Chinch Bug-is one of the worst half-dozen pests in the United States.

The Chinch Bug (Blissus leucopterus Say).- This little bug, less than a quarter of an inch long, feeds on all the grasses and cereal crops. It is apparently a native of tropical America which has migrated northward, 
up the Atlantic Coast, the Mississippi Valley and the Pacific Coast, and is now found everywhere south of the St. Lawrence River and the Great Lakes and also in southern Ontario, Minnesota, Manitoba, the Dakotas and along the eastern slope of the Rocky Mountains to Texas. It has also been found in Arizona, California and Washington. It is not a serious pest usually in the northeastern states and many of the others, but in the Mississippi Valley it often destroys crops valued at a hundred million dollars, in one season.

The adult bug (Fig. 166) is a tiny insect seemingly incapable of causing so much injury, but its enormous numbers make up for its small size.

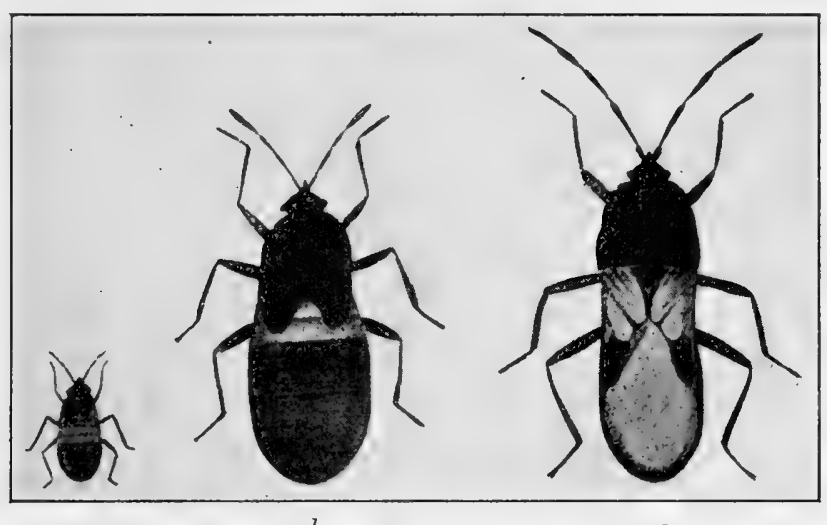

$a$

$b$

$c$

Fig. 166.-Different stages of the Chinch Bug (Blissus leucopterus Say): a, nymph in first instar; $b$, fourth instar nymph; $c$, adult. All enlarged about nine times. (Modified from Ill. Agr. Exp. Sta. Bull. 95.)

Its body is black or dark gray, with white and therefore conspicuous wings, each having a single black spot. There are two forms of adult, however, one with long, full-sized wings; the other with short wings only partially covering the top of the abdomen. The former occurs in the Mississippi Valley while the latter is met with, together with the longwinged form, in the Atlantic States and to some extent inland from there along the more southern of the Great Lakes to fllinois.

The long-winged form passes the winter as the adult in grass tufts, under fallen leaves or in other places giving it protection. Corn shocks left out over winter often harbor enormous numbers. In spring the bugs leave their winter quarters and fly to the grain fields. Here they lay their eggs, several hundred in number, on the ground at the base of the plants or on the roots just below the surface, this process lasting about a month. The average length of the egg stage is about 2 weeks and the young which hatch, suck the sap from the plants for about 40 days before becoming adult. The nymphs are yellow with an orange tinge about in the middle of the abdomen. This soon spreads over the greater part 
of the body. In later stages the red becomes vermilion, with a pale band across the front of the abdomen, the head and prothorax dusky and before becoming adult the red becomes quite dark.

Development, at least for the individuals coming from the later eggs, is not complete before harvesting time, and to finish their growth they are obliged to migrate and find more food. They accordingly march in armies, often travelling some little distance on foot, and many which have already become adults, able to fly, march with them. In new feeding grounds development is completed and the eggs for a second generation are laid. This generation appears to feed more particularly on corn, kafir corn, millet and other, similar crops, and its members become adult before winter, and go into hiding until the following spring.

With the short-winged form, hibernation at a distance from its food plant is impossible because of its inability to fly. This form therefore winters in grass-land and begins its work there in the spring. It is a question whether there is more than one generation a year for this form. Migrations when they occur, are of course on foot, and corn is no more liable to be attacked than timothy or any other grass crop.

The Chinch Bug is particularly affected by weather conditions, dry weather being favorable, and wet seasons unfavorable. Dry weather appears to induce migration, and a succession of several dry years favors a large increase in their numbers and consequently of the injury they cause. Rains during the hatching periods of the eggs are very destructive to the insect, and the suppression of a Chinch Bug attack, anticipated because of the great abundance of the wintering bugs, by heavy rains at the right time in the spring is one reason why these pests are not even more serious than is the case.

A fungus (Sporotrichum globuliferum Speg.) generally called the "Chinch-bug Fungus" frequently attacks this insect, particularly during periods of wet, cool, cloudy weather, and then kills enormous numbers of them. In dry seasons it seems to have little effect, and attempts to control the Chinch Bug by placing individuals inoculated with the fungus in infested fields, while successful from the experimental standpoint, have on the whole, hardly produced the results hoped for. It is most valuable in seasons which are dry during the egg-hatching period but wet thereafter.

In seasons then, when rains occur during the egg-hatching periods of the bugs, these and the fungus present will usually prevent serious outbreaks. In dry seasons, and particularly where there are several in succession, artificial methods of control must be resorted to.

Control.-Numerous methods of control have been tested, with varying degrees of success. Destruction of the adult bugs while wintering, has proved to be an efficient treatment when conditions are such as to make it reasonably complete. Burning over fields where the bugs are 
hidden in the grass has destroyed from about 50 to 75 per cent of them in cases where counts of the bugs could be made, including as well, however, areas covered with weeds, fallen leaves and other rubbish. The difficulty with this treatment is to get weather conditions such that the burning can be well done and without injury to the grass. Where thickets, hedges and other excellent hibernating places which cannot be burned out are plenty, this treatment, while of value for the bugs in the areas where this method can be used, will of course fail to reach those in the other locations and thus leave many to appear in the spring.

Where Chinch Bugs leave one field for another, an old practice has been to plow a furrow across their line of march and dig an occasional hole in the furrow into which the bugs, diverted from their first direction of march, might fall and be destroyed with oil or other material. Bands of tar or of road oil across their line of march have also been used with some success, the difficulty with this plan being in most cases that the band must be placed on firm, hard ground or it will soak in and need frequent renewal, besides forming (with some materials) a surface film on which the bugs can cross.

Crude creosote similarly applied, has recently been found to work well. Though it soaks into the ground it appears to repel by its odor, and the bugs reaching the band turn away from it. Renewal is necessary only when the odor becomes so slight that it no longer acts as a repellent. In 1914 the average cost for material of maintaining a mile of this band during the migrating period of the bugs was only $\$ 16.50$ at the then prevailing price of the creosote.

When the Chinch Bugs are entering fields (usually corn) at this season, spraying the plants with kerosene emulsion, Nicotine sulfate 40 per cent and soap solutions has been tested. The former is liable to injure the plants if great care is not given to its application, but the tobacco extracts have proved satisfactory. Soap alone, used at the rate of $3 \mathrm{oz}$. per gallon of water has given excellent results, and while the Nicotine sulfate, using $1 / 2 \mathrm{H}$. oz. in 1 gal. of water in which $1 / 2 \mathrm{oz}$. of soap has been dissolved, may be the most effective, soap alone is likely to prove very satisfactory and is less costly. As the bugs enter corn fields from elsewhere, the spray need be applied only to the outer rows if the invasion is observed in time.

The advice has also been given to cease planting corn in years when the Chinch Bugs are liable to be abundant, raising instead cowpeas, buckwheat, stock beets or soy beans, on which the bugs do not feed.

In the case of the short-winged form there is little migration, and plowing and the rotation of crops where the insects appear, seems to be about the only treatment available, and probably all that will be necessary. 
That insects like other animals suffer from the attacks of various diseases, is perhaps not generally realized. Yet the list of these diseases is not a small one and our knowledge of them is still extremely limited. Some of them are caused by bacteria and are just as truly germ diseases as are those from which man suffers. Others are caused by parasitic plants which in one way or another enter the body of the insect and grow, consuming the nourishment they find there and finally kill the animal, usually making its body hard and firm, or "mummifying" it. A third type of disease is that known as the "wilt disease," in which neither bacteria nor fungi have been discovered, where the insect "wilts" after a time, becomes soft, and gradually decays. The producing cause of this class of diseases is still unknown, but they are infectious, spreading from one individual to another, and where the insects are abundant and weather conditions are favorable they cause a high mortality.

Attempts have been made to utilize diseases for the control of insect pests. The Chinch Bug has been the subject of one of the most thorough of these experiments, the fungus already referred to having been cultivated for the purpose. It was found that by the use of appropriate methods, cultures of the fungus obtained in the fall could be grown during the winter, and bugs inoculated with it in the spring could be sent out to fields where the insects were abundant, and liberated there to spread the disease. To some extent this was a success, but it was soon found that if the inoculated bugs were set free during dry weather the disease failed to spread rapidly enough to prevent great injury, while if the weather was wet the fungus was in most cases already present and the addition of more diseased bugs at best only hastened its spread somewhat. As a business proposition then, the artificial cultivation and distribution of the fungus has been given up.

In the case of a bacterial disease of grasshoppers which has at times been observed greatly to reduce the numbers of this insect, somewhat similar results have been obtained. In a few instances some degree of success has been secured by spreading the germs, but here the factor of cannibalism seems to enter into the problem. With species of grasshoppers which feed considerably on dead or dying individuals, there is some probability of successful treatment in this way, but such species are not numerous, and there also appears to be more or less immunity to the germ in some species.

The whole problem of control by disease appears to hinge on satisfactory answers to three questions: Can the disease be cultivated so that a supply can be obtained and continued? Can it be introduced successfully into regions where it is needed but not present? Will the disease establish itself there and become effective?

The answers to the first two of these questions are liable to be affirmative ones, though this is not always the case. The third is the most 
difficult to determine. It may be that the disease is not already present where it is desired to introduce it because conditions there are such that it will not thrive. Fungous diseases at least are influenced to a very large degree by the weather, most of them thriving best in warm, moist weather and if these conditions are not present they will amount to little.

At the present time it would appear that the success of artificially introducing diseases to control insect attacks is so dependent upon weather conditions that man can do little more than supply the disease and trust that the needed kind of weather may follow. Unfortunately the very conditions under which injurious abundance of the insect takes place, appears in too many instances to be those distinctly unfavorable to the spread of the disease.

Family Tingididæ.-The insects (Fig. 167) of this family are delicate little bugs, usually having the pronotum broadly expanded and, with the

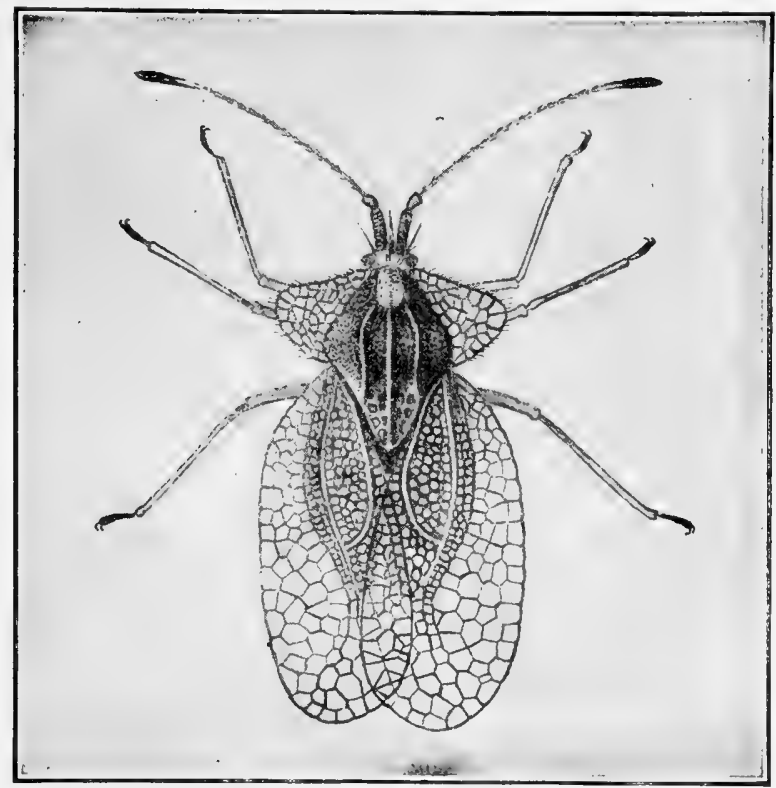

FIG. 167.--Example of a Tingidid Bug (Gargaphia solani Heid.), enlarged alout ten times (From U. S. D. A. Farm. Bull. 856.)

hemielytra, covered with reticulated marks, giving them something the appearance of a bit of lace and this has been responsible for their common name-lace-bugs. They are rarely more than an eighth of an inch Jong, usually whitish in color, and suck the sap from various plants, being generally found on the under side of the leaves. Their eggs are placed on the leaves, generally at the tops of small, brown, rather conical projections produced by the bugs, and which somewhat resemble places 
where fungi project from the leaf surface. Several species are occasionally rather injurious.

Family Miridæ.-This family until recently was called the Capsidæ. It contains a very large number of species, perhaps more than any other family of bugs, all small, and all feeding on plant juices. Some feed on grass; others on succulent stems; some make a specialty, at least at certain seasons, of sucking the sap from leaf and flower buds, distorting them or even preventing their development. Sometimes they are present in great numbers and do much injury. Fruit is attacked by some species, while it is small and rapidly growing, and such attacks produce "dimples" or small depressed areas, or they may even deform and thus greatly reduce the value of the fruit. Many secondary and potential pests belong in this family.

Some of the adults are bright red; others red and black, yellow and black or other colors. In those feeding on grass, grayish-yellow or

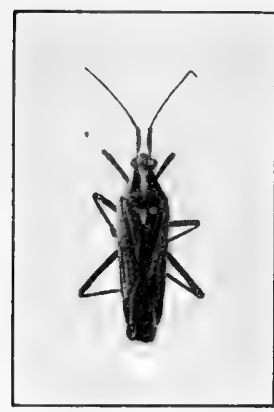

Fig. 168.-Meadow Plant-bug (Miris dolobratus L.), nearly twice natural size. (Original.) greenish-yellow is a frequent color. In many cases it scems that this is in some way connected with the color of their food, as for example, some species found on the stems of the red dogwood are themselves largely red, though in other cases it is difficult to discover any such correspondence of color between the insect and its food plant.

The Meadow Plant-bug (Miris dolobratus L.).This is apparently a species introduced from Europe about a hundred years ago and now found over the eastern United States and as far west and south as Minnesota and Kentucky. It attacks cultivated grasses and is often extremely abundant. The adult (Fig. 168) is a rather slender bug about two-fifths of an inch long, with quite narrow wings. It is gray or yellowish-gray with darker markings and has long, black antennæ.

The eggs are laid in late summer and fall in grass stems, for the most part below the cutting level. They hatch the following spring and the nymphs feed on the sap of the plant stems for a little over a month before becoming adult. Many of the adults have short wings, a similar condition to that found in the chinch bug, but here the two forms mingle everywhere, though the short-winged individuals may make up as much as 90 per cent of the total number.

Control.-Wintering in the egg stage in grass stems suggests the possibility of destroying many of the insects by burning over grass fields and particularly places where the grass was not cut, during the winter season. Early and close cutting of the fields might leave the insects little to feed on. Fall pasturing of the fields and the cultivation of sod 
land found heavily infested may be of assistance, but so far, little or nothing has been done to combat this pest.

The Tarnished Plant-bug (Lygus pratensis L.).- The Tarnished Plantbug is widely distributed, both in Europe and this country. It is about a quarter of an inch long (Fig. 169), shorter and broader in proportion than the Meadow Plant-bug, and varies greatly in its coloration. The general color, however, is brown, variegated with shades of yellowish and brownish and with black spots in some places.

This pest feeds on over 50 different kinds of plants which are of value to man. The adults attack apple, pear, peach, and in fact all fruit tree buds, destroying or at least seriously injuring them: small fruits are often stunted or "buttoned" by them: flower buds of such plants as the chrysanthemum, dahlia, peony and aster are punctured and destroyed or malformed: potato leaves are often injured, causing tip-burn, and beets, particularly sugar beets, have their leaves curled and injured. Corn, wheat, oats and other grain and grass crops are also injured by this omnivorous feeder. With young peach trees in nurseries it causes the

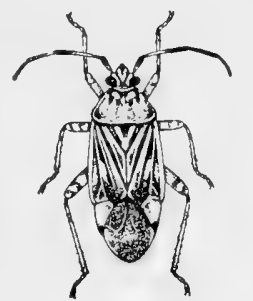

$a$

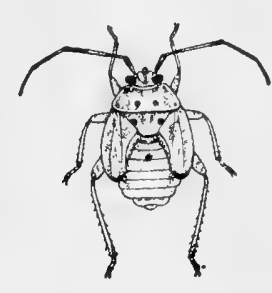

$b$

Fig. 169.-Tarnished Plant-bug (Lygus pratensis L.): $a$, adult; $b$, nearly full-grown nymph. Nearly four times natural size. (From U.S. D. A. Farm. Bull. 856.) trouble called "stop-back" by killing the terminal buds, and it is a carrier of the fire-blight of the pear, conveying the bacteria causing this disease from infected to healthy trees. It is therefore a serious pest.

The insect passes the winter as the adult and possibly as the nearly full-grown nymph also, in protected places, and appears with the first warm spring days and attacks the buds of fruit trees and other plants. Its eggs are inserted in leaf veins and stems, flowers and similar places, and they hatch in about 10 days. The nymphs feed on the juices of the plants and become adult in from 3 weeks to a month. There is therefore, time for several generations in a season, though the actual number of these does not appear to have been worked out and probably varies somewhat according to the length of the season in different parts of the country.

Control.-No effective method of control has as yet been discovered for this pest, though many have been tried. Spraying the plants infested, with kerosene emulsion, Nicotine sulfate or soaps, early in the morning has been found to kill some of them. Shields covered with sticky flypaper, placed beside and over the plants which are then jarred, captures some: the destruction of all wild plants such as asters and goldenrod on which they feed and breed has been advocated; and growing plants under cheese-cloth; driving the insects down the wind, and other methods have been suggested, but no really efficient conirol is yet known. 
Family Phymatidæ.-The Ambush-bugs (Fig. 170) as members of this family are called are carnivorous bugs which usually hide in blossoms to capture insects visiting there. They are rather short and stout, generally less than half an inch long, and have colors so combined on their bodies as to render them very inconspicuous in the flowers. Their prey is generally any insect they can grasp with their stout fore legs, whether it be injurious or otherwise.

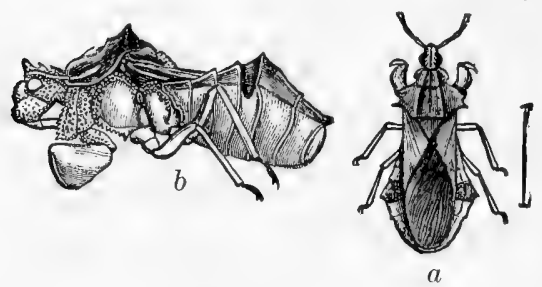

Fig. 170 .

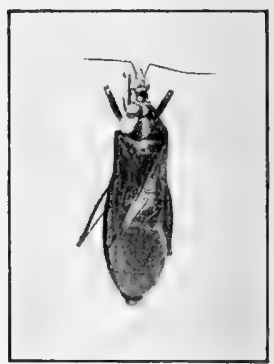

FIG. 171.

FIG. 170.-Ambush-bur (Phymata erosa wolffi Stal.): $a$, from above; $b$, from the side, showing the grasping front leg. Enlarged: true length shown by hair line. (Modified from Sanderson and Jackson, Elementary Entomology, after Riley, U. S. D. A.)

FIG. 171.-Reduviid Bug, about natural size. (Original.)

F'amily Reduviidæ.-This large family consists of carnivorous insects some of which are small while others are considerably more than an inch long (Fig. 171). Though generally feeding on the blood of other insects they may occasionally attack man and in such cases produce rather painful wounds. One species, most common in the Southern States, often enters houses and feeds upon the bedbug, and from this habit has been called the Masked Bedbug Hunter, the mask referring to dust which adheres to its rather sticky body before it becomes adult. Another species in the West and South is occasionally found in beds where it imitates the habits of the true bedbug. A similar but different species occurs in California.

The group as a whole, preying as its members do upon other insects almost entirely, must be regarded as a beneficial one. The family is most abundant in the warmer climates.

Family Cimicidæ.-The Cimicidæ is a very small group but well known through one of its members, the Bedbug. All of the insects belonging here are small, rather oval in outline, very flat, and rather reddish in color. Birds, poultry and bats are attacked by species similar to but smaller than the Bedbug and some of these under unusual conditions, may enter houses and attack man.

The Bedbug (Cimex lectularius L.).-This universally distributed and well-known pest (Fig. 172) appears to have originated in Asia and has now spread wherever man is found. It is a small, flat insect, reddishbrown in color, about a fifth of an inch long when adult, and wingless, 
only tiny stubs of wings remaining to show that it has been derived from winged ancestors. It produces a very noticeable odor.

It is a nocturnal animal, hiding during the day in any cracks and crevices it may find, either in the bedstead, behind loose wall paper or elsewhere. In these places it lays its eggs, probably about 200 in number, these hatching in from a week to a much longer period dependent upon the temperature. The nymphs are yellowish-white at first, turning brown gradually with increasing age. Nymphal life varies greatly in its length, being affected by the temperature and food supply, but when these are favorable, about 7 weeks is required to produce the adult bug. Under less favoring circumstances the nymphs may remain unchanged but alive, for a long period. The number of generations in a year may therefore differ greatly under different conditions but in warmed houses there are probably at least four.

Where human blood is not obtainable for food, that of mice, rats or other animals where available, may be taken instead, and living bedbugs in empty houses may perhaps be accounted for in this way. Without food, however, death within a year is a practical certainty.

The "bite" of the bedbug is quite poison-

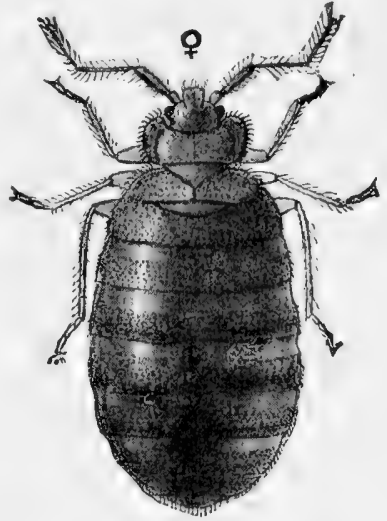

F I G. 172 .- Adult female Bedbug (Cimex lectularius L.) gorged with blood. Greatly enlarged. (From $l$. S. D. A. Furm. Bull. 754.) ous to some persons but not to others and in some cases a sort of immunity is obtained by individuals continuously exposed to attacks.

Bedbugs are known to be carriers of contagious diseases of man, such as the African relapsing fever, Kala-azar, plague, and possibly leprosy also, but of course the insect must first become itself infected with the causal agent of the disease which is very rarely the case, at least in the United States. It does not appear to transmit the diseases except as the agents of them by accident get on the mouth parts of the insect.

Control.-Where sulfur can be burned in a room, using a pound for each 1,000 cu. ft. of space for $24 \mathrm{hr}$. the fumes will destroy all stages of the bedbug if the room is reasonably tight. A thorough treatment of all places where the insects can hide and lay their eggs, with gasoline, benzine or kerosene is also successful if the material penetrates all parts of the cracks. Corrosive sublimate at least as strong as a 6 per cent water solution, can be used in the same way. Heating a room or house to from 120 to $130^{\circ} \mathrm{F}$. in summer for an hour or even less has proved effective, as has a temperature below $32^{\circ} \mathrm{F}$. continued for 3 or 4 weeks. Persons obliged to stop at infested places can usually obtain protection by dusting insect powder (Pyrethrum) between the sheets of the bed. 
Family Gerridæ.--These insects, the Water Skaters or Water Striders (Fig. 173) as they are commonly called, are often noticed during the summer, skating over the surface of quiet pools of water. Their bodies are slender in most cases, less than half an inch long, usually black or brown, and their long, slender legs project some distance from the body. A few are shorter and broader bodied. They feed on any small insects they are able to capture and winter either under sticks or stones under water, or in mud near the edge, under leaves and rubbish. A few live on the surface of the ocean in warm climates. They are interesting insects to watch but are of little if any economic importance.

Family Notonectidæ.-The Backswimmers (Fig. 174) as they are termed, live in fresh water. They

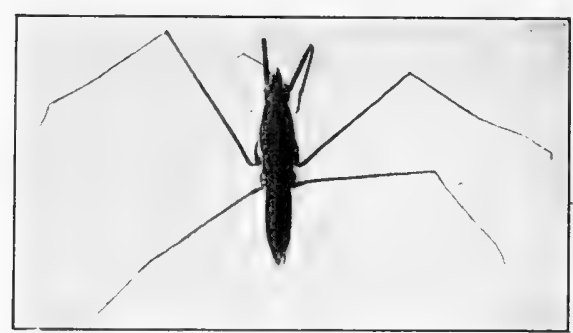

FIG. 173.

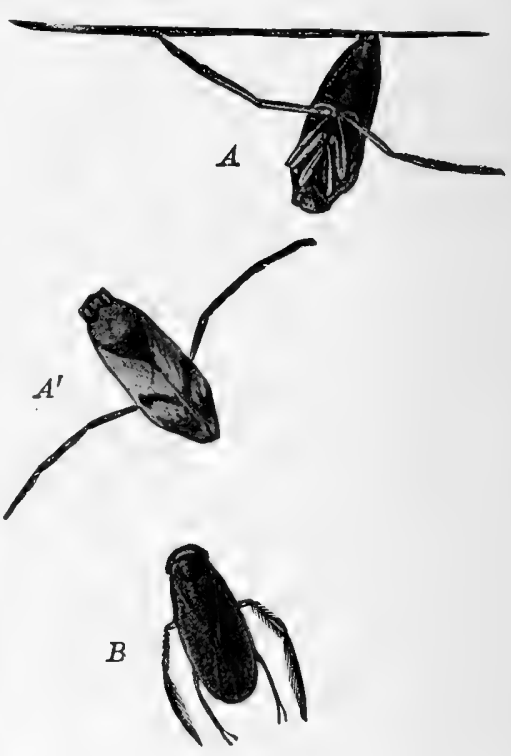

FIG. 174.

FIG. 173.-Water Skater (Gerris conformis Uhl.) about natural size. (Original.)

FIG. 174.-Notonectids and Corixid: $A$, Notonectid at the surface of the water showing under surface; $A^{\prime}$, swimming showing upper surface; $B$, Corixid swimming. Somewhat enlarged. (From Linville and Kelly, Text-book in General Zoology.)

are small, rarely more than half an inch in length and generally black and cream-colored. The back has sloping sides something like the bottom of a boat and they swim on their backs, propelling themselves by their long legs which are fringed with hairs. They occasionally come to the surface for air, a supply of which they carry down with them under their wings and between the fine hairs covering the under side of the body. They are carnivorous, feeding on other small insects but are of little importance.

Family Corixidæ.-Living in the same places and with similar habits to the Back-swimmers are small, greenish and blackish mottled insects, rather oval in outline with heads somewhat flattened in front, and known as Water-boatmen (Fig. 174B). They have long, fringed, oar-like legs but do not swim on their backs and in some way are able to remain under water without coming up for air for a much longer time than the back- 
swimmers. Like the latter group they often leave the water and fly at night and are frequently attracted to lights.

Family Nepidæ.-The water-scorpions as these insects are called, live in fresh-water ponds and pools. Two types of form are included,

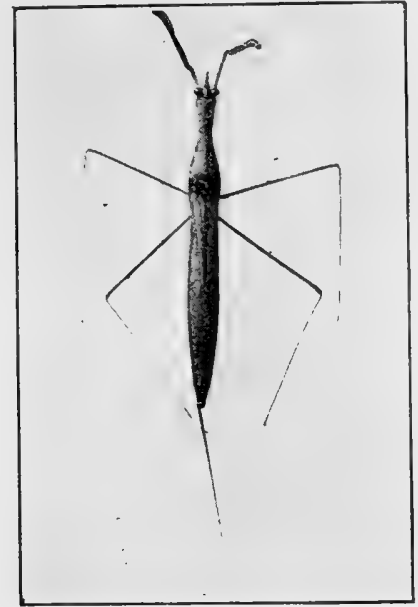

FIG. 175

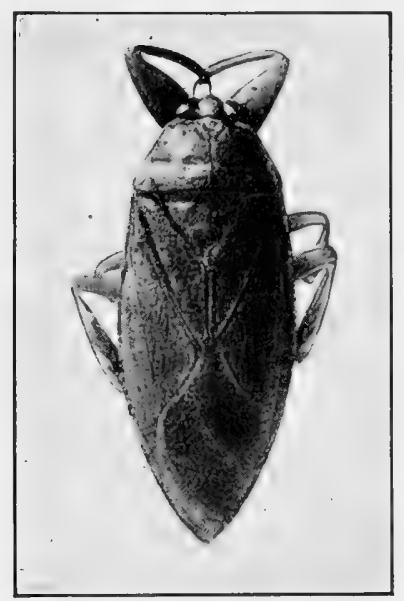

FIG. 176

FIG. 175.-Water-scorpion (Ranatra americana Montd.) about natural size. (Original.) FIG. 176.-Giant Water-bug (Lethocerus americanus Leidy), natural size. (Original.)

one having a long, slender body and long legs (Fig. 175), the front pair of which, unusually long, are constructed for grasping their prey which consists of small insects. In the other type the body is short, rather broad, and flat. In both a long tube consisting of two pieces which can be pressed together to form the tube, joins the hinder end of the body and while the insect is an inch under water in some cases, this tube is pointed upward until its tip is out of water and through it the insect obtains air. The slender forms lying quiet on the bottom of pools resemble dead twigs and thus obtain the concealment needed to enable them to get within reach of their food.

Family Belostomidæ.-These insects are generally termed the giant water-bugs. Some of them are the largest members of the Hemiptera, being two, three or more incheslong, broad, flat and brown in color (Fig. 176). They live in fresh water and feed on insects and even small fish and are thus

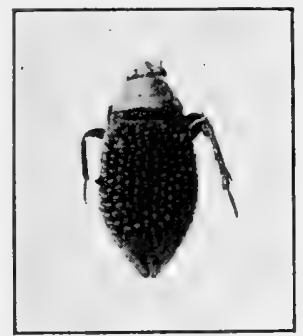

FI G. 177 - Male Belostomid (Belostoma flumineum Say) carrying eggs on its back. Natural size. (Original.) sometimes injurious in the production of food fishes. They fly by night and are frequently attracted to electric lights, which has led to the larger species being sometimes called "electric-light bugs." In some of the smaller species (Fig. 177) the eggs are laid on the back of the male who is thus obliged to carry them around until they hatch. 


\section{CHAPTER XXVI}

\section{THE HOMOPTERA}

The Homoptera is a large group containing insects of many forms, often showing little resemblance to one another. They suck sap from plants through a beak, apparently very similar in structure to that already described for the Hemiptera, but it is attached, not to the front but to the hinder part of the under surface of the head which is very closely joined to the prothorax so that the beak frequently appears to arise between the front legs. In some instances where the adults do not feed, this structure is lacking. The wings are often absent but when present are usually held, while at rest, sloping over the body like a house roof. They are of the same thickness and usually, though not always, transparent. In this group (except the male scale insects) the metamorphosis is incomplete. These facts may be summarized as follows:

The Homoptera are sucking insects with the beak (when present) arising from the back part of the under side of the head which is very closely joined to the prothorax. The wings (frequently absent) are of uniform thickness throughout and when not in use are held sloping over the body. The metamorphosis (except in male scale insects) is incomplete.

Few groups of insects show as great differences in their members as are found here. The cicadas, of ten two or three inches in length and with a wing spread of four inches or more, are among the giants of the order, while some of the white flies and scale insects are hardly more than just visible to the eye. Most of the group move about freely, though some locate in one place soon after they hatch and remain there the rest of their lives. In one section the insect produces a protective scale which covers it, and beneath this, degeneration of some parts of the body occurs.

Many Homoptera secrete a sweet, sticky fluid called honey-dew, often in such quantities when the insects are in abundance, that in falling it makes a noise like fine rain. Striking on leaves, fruit or bark, it adheres and dries, and a blackish fungus grows in it, giving to such places a sooty appearance. This secretion appears to be produced most abundantly by the soft scales, white flies, plant lice, jumping plant lice and some of the tree hoppers. Ants and honey bees feed on the honey-dew and frequently visit the insects producing it, for this food.

Nine families of Homoptera are generally recognized, but four of 
these may, for convenience, be combined here. The six to be considered therefore are:

Order Homoptera $\left\{\begin{array}{l}\text { Cicadas (Cicadidx). } \\ \text { Leaf Hoppers and Tree Hoppers (four families). } \\ \text { Jumping Plant Lice (Chermidæ). } \\ \text { Plant Lice (Aphididæ). } \\ \text { White Flies (Aleyrodidæ). } \\ \text { Scale Insects (Coccidæ). }\end{array}\right.$

Family Cicadidæ (The Cicadas).-Most of the members of this family are rather large insects, with bodies often two or three inches or even more in length and quite stout as well. Their wings are correspondingly large, and in some species have a spread of more than six inches. Though usually transparent and with prominent veins they sometimes have pigmented areas of various colors.

The adults place their eggs in slits they make with their ovipositors in twigs. On hatching the nymphs drop to the ground and make their way to the roots where they feed on the sap. Metamorphosis is more nearly a complete one than in the other families of Homoptera (except the scales), the nymph having but little resemblance to the adult, and the last two nymphal stages are rather transitional in appearance between the two.

The adult males have vocal organs located on the under side of the basal segments of the abdomen and covered by extensions backward of the metathorax. The sound produced is often so loud, especially when the insects are abundant, as to be very noticeable and even unpleasant. No auditory organ has as yet been discovered with certainty, in either sex.

Cicadas are particularly inhabitants of warm countries, though some species are abundant quite far from these regions. In North America they occur in Canada and probably in all the States farther south, and are found as far north as England in the Old World. They are often wrongly called locusts.

The Periodical Cicada or Seventeenyear Locust (Tibicina septendecim Say). - This remarkable insect is a native of North America. It is found from Massachusetts to Northern Florida and west to Wisconsin, Iowa, Kansas, Oklahoma

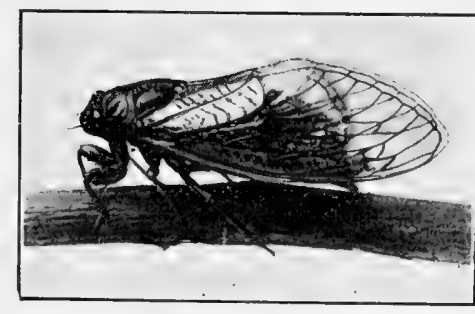

Fig. 178.-Adult Periodical Cicada (Tibicina septendecim L.), natural size. (Original.)

and Texas, but is much less important near its northern limits than near the center of its range.

The adult (Fig. 178) is about an inch long, with a stout, black body, orange eyes, legs and wing veins. The wings when at rest extend consid- 
erably behind the body. In the far South it appears early in May while near its northern limits it may be as late as early June. The insects are usually in evidence for 5 or 6 weeks and are particularly noticeable in and near wooded areas. They suck the sap from various trees but do little injury in this way. The females lay their eggs in the smaller twigs of trees, shrubs and even in herbaceous plants, the oak and hickory, and in the case of fruit trees the apple seeming to be preferred for this purpose, though more than 75 kinds are attacked. The eggs are placed in slits made in rows by the ovipositor and a twig thus punctured is liable to break off either entirely or in part. The eggs hatch in 6 or 7 weeks and the nymphs drop to the ground and burrow to the roots where they feed until the seventeenth spring from the one when they entered the ground, most of them being between six and eighteen inches below the surface.

During the seventeenth spring the nymphs burrow upward, nearly to the surface of the ground but do not usually come out until ready for the final molt producing the adult. In some cases, however, upon reaching the surface they construct earthen cones or chimneys sometimes six or eight inches high, within which the burrow is continued. It is supposed that these are constructed where the cicadas are in moist places and these structures will bring the insects out above the moisture, or that a shallow soil enables them to reach the surface before the normal time, or unusually warm conditions hasten their start, and on their arrival they are not ready for their final molt. Recent work indicates that length of day is a factor. Probably the last word on this subject has not yet been said.

Arrived at the surface of the ground and ready to molt for the last time the nymphs crawl out of their burrows, the greater number of them in the afternoon and evening, and make their way to any objects such as a tree, stick or anything at hand, and on these molt for the last time and become the adults which are ready for flight the next morning.

In the course of nearly 17 years of underground feeding it is only natural that some finding an abundant food supply should be able to gain a little time and appear during the sixteenth year as "forerunners" of the main brood, and that others with scanty food should be delayed until the eighteenth season. These are few in number, however. In the South is a race with a 13-year life, the origin of which as related to the other race is not as yet explained.

Though a cicada's life is (except for the race just mentioned) 17 years, they occur in one place or another every year, showing that in some way in the past these insects have diverged so that there are now 17 broods. Some places are so unfortunate as to have several of these broods but though the cicada may appear there every 4 or 5 years, the descendants of any one of these will not be found until 17 years have elapsed. 
Some of the broods are more abundant and widely distributed than others. Four are of sufficient importance to be mentioned. These are Brood II, due in 1928 from Connecticut into North Carolina and at a few scattered points to the west; the insects are quite abundant: Brood VI, due in 1933, widely scattered over the country but not very abundant: Brood X, due in 1936 from New York to Georgia and west to Michigan and Illinois and at scattered points elsewhere, this being the most abundant brood: and Brood XIV, due in 1923, from Massachusetts to Georgia and west to Illinois; also an abundant brood. The important thirteenyear broods are: XIX, due in 1924, from Iowa to Louisiana and eastward to the Carolinas and Virginia, the largest of these broods: and Brood XXIII, due 1928, from Missouri, Illinois and Indiana down the Mississippi Valley with scattered colonies here and there to the east as far as Georgia. This is also a large brood.

Numerous enemies of the Periodical Cicada are known, many of them being parasites. Some birds feed on them and a fungus causes disease of the adults. Various mammals feed on them as they are coming out of the ground.

Control.--In forests nothing can be done to control these insects, but when they appear in sufficient numbers in parks and orchards to make treatment desirable, certain methods for preventing injury or for the destruction of the insects are feasible. In some cases collection of the adults by hand has paid. In others, spraying the tree-trunks and other objects on which they rest while molting after leaving the ground, aiming to hit as many of the insects as possible, and using a strong kerosene emulsion for the spray material has proved quite effective, for where the cicadas are not killed they are crippled by the action of the particles of the spray which strike them. This treatment, however, to be successful must be repeated every evening about sunset or very early in the morning before the insects begin to fly, as long as they continue to come out of the ground.

In the case of fruit trees anywhere, pruning is not advisable the spring cicadas are due in that locality, until after the eggs are laid. Then, pruning and burning the punctured twigs before the eggs hatch is desirable. In some cases young trees suffer so severely that it is not advisable to set out nursery stock the year before cicadas are due. Apple "whips" however, can usually be safely planted the same spring that the cicadas come, being generally too small to suffer much by the attacks of these insects. Hogs allowed to run under trees known to have cicadas at their roots will kill many of these pests as they come to the surface to become adult in May and June of their seventeenth year.

Various species of cicadas are common in nearly all parts of the United States. In the East the Dog-day Harvest-flies (Tibicen linnei Sm. \& Grsb., and others) are often noticeable (Fig. 179), singing in the trees 
during late July and August. Most of these species are somewhat larger than the Periodical Cicada and generally black and olive-green, with a white powder or "bloom" on the under side of the body. They are supposed to have about a 2-year life history and'as individuals occur every year, two distinct broods. A few of these species greatly resemble the Seventeen-year Cicada in color but are smaller, and as they appear more than a month after the latter have disappeared, no confusion should lead to the belief that the Seventeen-year Cicada has appeared at that season.

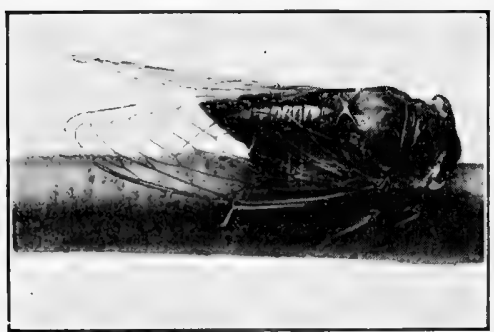

FIG. 179 .

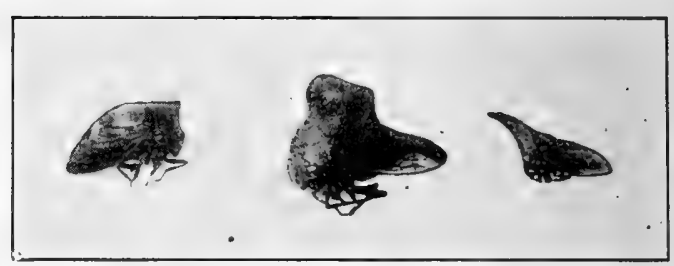

FIG. 180

FIG. 179.-Adult Dog-day Cicada (Tibicen linnci Sm. and Grsb.), natural size. (Original.)

FIG. 180.-Tree-hoppers showing remarkable forms of the pronotum. Enlarged about twice. (Original.)

Leafhoppers and Treehoppers.-The four or more families included under this heading contain a large number of kinds of insects, many of which are extremely numerous. Among them are the lantern-flies of South America and the candle-flies of China and India which are quite large insects, a number of which at least are luminous. Some of the insects here included are highly colored and some secrete quantities of wax which is often used for candles and other purposes.

In one of the families - the Treehoppers-the pronotum is largely and often remarkably developed, sometimes giving these insects a very grotesque appearance. In this country, however, such forms are not usual, the development of this section of the body being mainly in the line of horns or humps and the enlargement of this plate in width or height and in its extension backward until it covers most or all of the body (Fig. 180). The Treehoppers of the United States are all small insects, less than half an inch long, and as they sit on twigs their peculiar forms seem to give them resemblances to buds, swellings or other characters, which suggests that their odd outlines may be for resemblance to these structures and thus secure the protection from their enemies which this would give.

In general the Treehoppers puncture the twigs of plants and are injurious, though only a few kinds are ever so abundant and attack plants of such importance as to need consideration.

Among these the most common is the Buffalo Treehopper (Ceresa bubalus Fab., Fig. 181) found practically everywhere in the United States except perhaps 
in the most southerly portions, which injures the twigs of fruit trees by its egg punctures made in the fall. Two rows of punctures are made, nearly parallel to each other, the two rather resembling parenthesis marks, and in each a number of eggs is laid which hatch the following spring. Injury caused by the feeding of the nymphs and adults is slight, and in fact most of the young feed mainly on weeds, but the egg punctures (Fig. 182) cause distorted growth and weaken the twig. Spraying with a fairly strong contact insecticide to destroy the nymphs wherever these are found, and the destruction of all weeds like burdock, thistles, etc., near the fruit trees appear to be the only methods of control, and the former is rarely practicable.

The Leafhoppers (Fig. 183) are extremely abundant insects and some of them must do much injury to the grass crop as it has been estimated that there

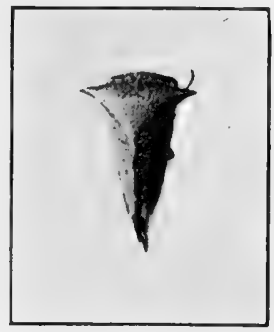

FIG. 181.-Adult Buffalo Tree-hopper; view from above. Enlarged about twice. (Original.) are frequently as many as one to two millions of them per acre. Most of them are very small.

Some leafhoppers have one generation a year, others more, and

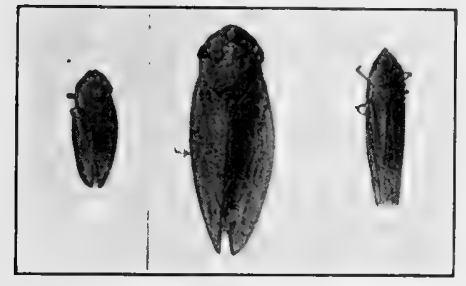

FIG. 183.- Three kinds of Leafhoppers enlarged about twice. The left hand figure is of a "spittle insect." (Original.) different species appear to hibernate in different stages. In addition to various grasses, grain, alfalfa, clover, sugar beets, grape, and rose, the apple, elm, willow and other trees have their juices extracted by the feeding of these insects.

A group of tiny leafhoppers known as froghoppers or spittle insects (See Fig. 183) is also included here. They are common on grasses and other herbaceous plants and also on some trees such as the pine, etc. The nymphs produce a fluid and liberate air in this in such a way as to form a sort of froth or "spittle" in which they live. They are very abundant in the northern states practically across the entire continent, and one species, the Grass-feeding Froghopper (Philanus lineatus L.) is often so common as to wet the shoes of a person who walks through the grass in June. The nymphs suck the sap from the grass stems, withering and turning white the upper parts of the stems and the blossoms, much as does the grass thrips. Burning over old grass fields where these insects are most abundant, in early spring will destroy many of these insects in their winter quarters close to the ground.

The Apple Leafhoppers (Empoasca mali Le B. and others), tiny insects about a twelfth of an inch long, attack over fifty different kinds of plants being generally most abundant on the apple, Norway maple, and some kinds of oaks among the list of trees, and on alfalfa, clover, potato and beets. They appear to occur in almost every part of the United States and in some sections of Canada. The adults are generally pale green with white markings on the pronotum. Other similar insects are often present along with these species, but treatment for all would be identical. 
The apple leafhoppers winter as the adults under rubbish and in spring after mating the eggs are laid in the veins of the leaves. Some observers claim that at least a part of the nymphs in spring hatch from eggs laid in apple bark in the fall. The eggs hatch in about a week and the nymphs feed for about 3 weeks, and the adults of these nymphs lay eggs for another generation. In the middle Atlantic States there are three generations each year, but this number may be reduced near the northern limits of their range or increased farther south.

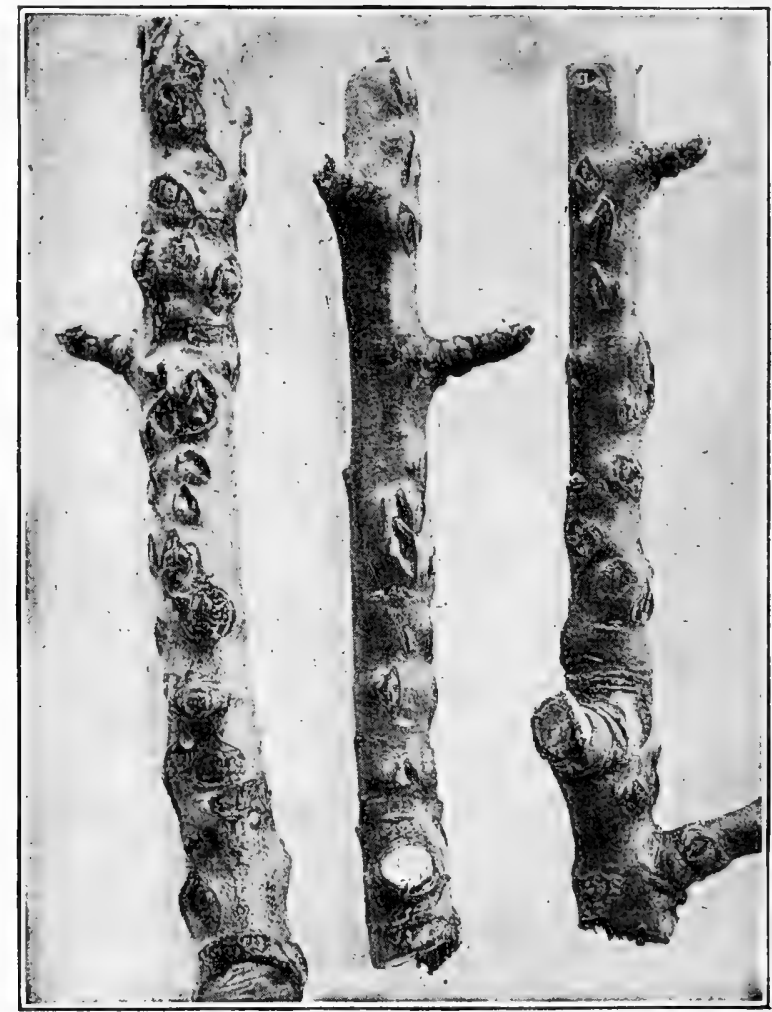

FIG. 182.- Twigs showing injuries caused by the Buffalo Tree-hopper in laying its eggs. About natural size. (From Britton, Fifteenth Rept. Conn. Agr. Exp. Sta. 1915.)

The injury caused by these insects appears to be a curling and checking of the growth of the leaves in some cases, particularly those near the tips of the shoots in the case of young apple trees. Older trees suffer less than nursery stock.

Control.--Spraying thoroughly with nicotine sulfate 40 per cent, 1 part in 1,400 or 1,500 parts of water, with the addition of soap, is a successful treatment to use for these insects if applied soon after the nymphs appear in the spring, or at least before the leaves have curled. Good results have also been obtained by dipping nursery stock in a 
solution of whale-oil soap $1 \mathrm{lb}$. in 8 gal. of water, or dissolving a bar of common laundry soap in 6 to 8 gal. of water for the purpose.

The Rose Leafhopper (Empoa rosæ L.).-This European insect is now present practically everywhere in the United States and is also found in Nova Scotia, Ontario and British Columbia. It is a general feeder and will probably attack most plants of the family Rosaceæ, but appears to be particularly injurious to the rose and apple. The adult is almost as large as the apple leafhopper and is creamy white to light yellow. It lays its eggs during the fall in the bark of rose bushes, apple trees, berry canes and other plants and there they remain until spring, when they hatch. The nymphs suck the sap from the under side of the leaves of the plants, producing a mottled appearance, and as the injury increases the leaves may turn yellow and dry up, but they do not curl. There are two generations of this insect a year, the eggs for the second generation being laid in July. Most of the wintering eggs are deposited in rose stems.

Control.-This insect is rarely of importance as an apple pest but rose bushes often suffer by the loss of sap and the impossibility of their injured leaves performing their proper functions. Spraying infested plants with nicotine sulfate as for the apple leafhoppers, as soon as the nymphs are observed, is usually sufficient to prevent further injury.

Many other leafhoppers are at times serious pests. The beet leafhopper in the Western States in addition to its injury to the plants by feeding, transmits a "curly leaf disease" and the grape leafhopper is sometimes so abundant that grape leaves in vineyards are turned brown and much injured. The six-spotted leafhopper attacks some grains and grasses, and other species generally of slight importance, at times assume prominence. In general, nicotine sulfate prepared as indicated above, is an effective control material for these insects wherever conditions permit its use.

Family Chermidæ.-The Jumping Plant-lice as the members of this family are usually called, are very small insects which feed on various plants but are rarely abundant enough to become of economic importance. One exception to this occurs and a consideration of that species will also give something of a general idea of the insects of the group as a whole.

The Pear Psylla (Psyllia pyricola Först.).--The Pear Psylla is a European pear pest which seems to have reached this country about 1832 and is now present everywhere in the eastern United States at least as far south as Virginia and west to the Mississippi River, and has also been reported (perhaps erroneously) from California. Where it is abundant it is very injurious, seriously checking the growth of the tree, so that many of the leaves turn yellow and drop off, as does much of the young fruit, while the entire vitality of the tree is reduced and it makes little or no growth.

The adult (Fig. 184) is about a tenth of an inch long, the body black with reddish markings, and long antennæ are present. Except for this last feature 
it greatly resembles a tiny cicada. The insects pass the winter as adults hiding in crevices of the bark or similar protected places and in spring lay their eggs on the twigs, and particularly around the bases of the buds. These eggs hatch in from 2 to 3 weeks according to the temperature. The nymphs (Fig. 185) suck the sap from the axils of the leaves and fruit stems and if abundant gather around the bases of leaves and fruit stems and spread to the under surface of the leaves themselves. They move about but little and secrete large amounts of honey-dew, sometimes so much when they are very numerous, as to cover the leaves and branches. They are broadly oval, flat creatures, yellowish at first but blackish with reddish marks later and with bright red eyes. They become adult in about a month and lay their eggs, this time on the under side of the leaves or on the leaf petioles. These eggs hatch in a week to 10 days and adults are produced in about a month. There are three or four generations a year in New England and more in the South.

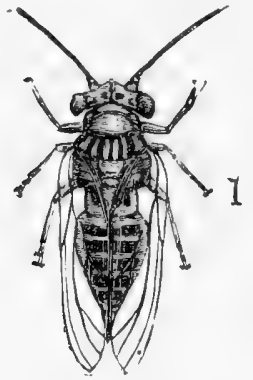

FIG. 184.

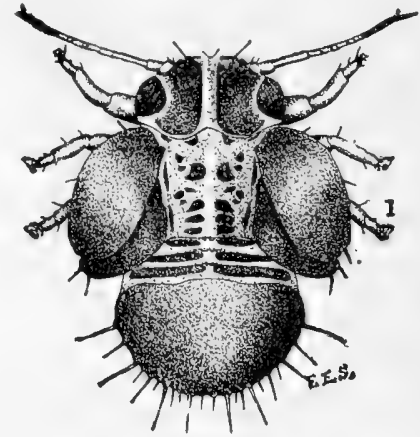

FIG. 185.

Fig. 184.-Adult Pear Psylla (Psyllia pyricola Först.) about ten times natural size. (From Britton, Third Rept. Ent. Conn. Agr. Exp. Sta. 1903, after Slingerland.)

Fig. 185.- Nymph of Pear Psylla, greatly enlarged. (From Britton, Third Rept. Ent. Conn. Agr. Exp. Sta. 1903, after Slingerland.)

Control.-Methods for checking the injuries caused by these insects center around their control in winter and early spring. Most of the adults winter under the loose bark of the trees or in tufts of grass and rubbish near the trees. s'craping off all loose bark and removal of the rubbish, followed during any warm days in November or December by a thorough spraying of these places with nicotine sulfate, standard formula, will kill large numbers. It should not be cold enough for the spray to freeze on the trees. In spring, just as the clusters of blossom buds begin to separate from each other, but before the blossoms open, the lime-sulfur wash diluted at the rate of 1 part of the wash to 8 or 9 parts of water will kill the eggs and any newly-hatched nymphs. The fruit spurs and the under sides of the twigs should receive particular attention with this treatment.

Family Aphididæ (Plant Lice or Aphids).-This is one of the most important groups of insects from an economic standpoint, as all its memhers are injurious, of ten very abundant, and a species usually doing little harm may at any time become a serious pest. 
Aphids are tiny, soft bodied insects, the largest being less than a third of an inch long, generally with long legs and antennæ, and are of various colors, green, black, various shades of red and brown, white and gray being the most usual ones. Some are more or less completely concealed (Fig. 186) beneath long, white waxy threads, giving them a "woolly"

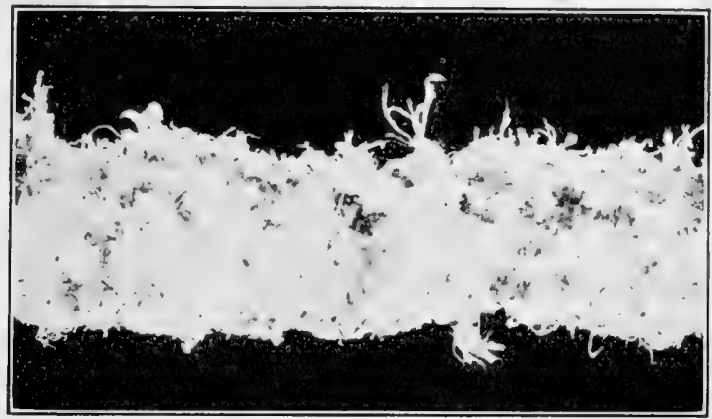

FIG. 186.-Alder twig covered by woolly plant lice, the "wool" entirely concealing their bodie Somewhat enlarged. (Original.)

appearance; others have a sort of dust or "bloom" like that on a plum, coating their bodies; but the majority (Fig. 187) are without any covering. Many species of aphids have a pair of tubes called cornicles, projecting upward from the top of the abdomen. These were formerly believed to

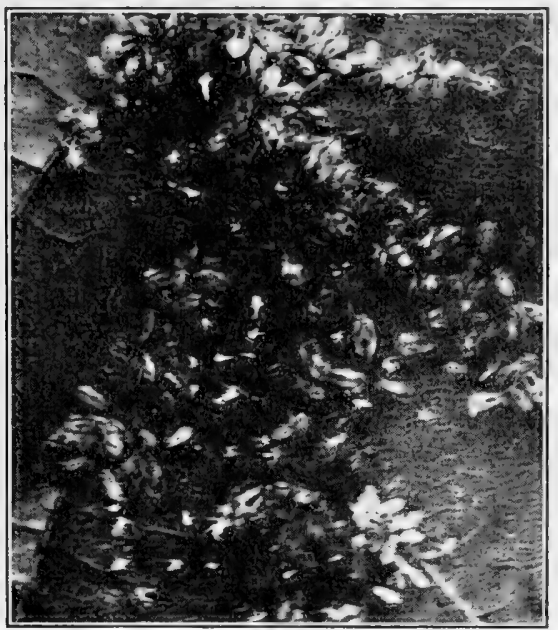

FIG. 187.-Portion of leaf showing plant lice clustered together. Somewhat enlarged. (Original.)

be the exit ducts through which honey dew, abundantly produced by the insects, escapes, but it is now known that this substance is expelled through the anus, often in such quantities that when the insects are abundant it forms a sort of fine rain which can be heard falling on the leaves 
and ground. This fluid which is sweet and sticky is eagerly fed upon by ants. Falling on twigs and leaves it dries there and a fungus grows in it turning it black, and plants where aphids have been abundant of ten show this by their black appearance. Some plant lice produce galls within which they live for at least a part of their lives but most of them are not thus enclosed, living on leaves, twigs, succulent plant stems or roots.

Though there are great variations in the life histories of different aphids, certain general facts hold for most of the group. In general, eggs are laid in the fall, on a food plant of the species concerned, and these hatch the following spring. The nymphs soon become full-grown and are known as "stem-mothers" and without fertilization (there are no males) produce eggs, or in most cases living young which like the stem-mother are all females and on reaching maturity produce young in a similar way. The production of young without fertilization of the parent is not uncommon in insects and is called parthenogenesis or agamic reproduction. In this case the production of these young alive rather than from deposited eggs introduces the additional fact that these insects are also viviparous except in (generally) one generation. The number of young produced by each parent varies but will perhaps average about ten, a few being born every few days, and the number of generations is variable but is also likely to be about 10 , though the first born young in each generation, being a week or two older than the last born young, will gain enough time during the season to produce more generations than the others. In fact, in some species a range from 8 to 21 generations for late and early born individuals has been observed, and an average number of 28 young produced per parent, so that the figures given above may be regarded as conservative. But even with this moderate estimate, allowing only 10 young to a generation and 10 generations a season, the total product from a single egg hatching in the spring and itself counted as the first generation, would be $1,111,111,111$, and this would be far below the actual number in most cases, were it not for the enormous destruction of these insects by their enemies and by unfavorable weather conditions.

In many species instead of 10 young being produced per female as an average, the number is likely to be nearer a hundred, and in those species which also have more than 10 generations the total number of individuals which would theoretically be produced in a season "would be sufficient to completely cover the entire world with a continuous layer of plant lice."

With such a marvelous reproductive power as this it becomes evident that despite natural checks to their increase, plants infested are liable after a few weeks to be entirely unable to provide food for the hordes of plant lice upon them. Accordingly we find that in most of the generations winged individuals may be produced so that they can migrate to other plants. Winged and wingless forms may therefore be found at 
almost any time during the summer, and a wide distribution of the insect is obtained in this way.

When cold weather approaches in the fall a generation appears, consisting of both sexes, and the females of this generation lay fertilized eggs which winter over and hatch the following spring. In some cases this does not happen until the second fall and in a few species at least, sexual individuals have not been discovered and may occur only at long intervals, if at all.

Many aphids do not feed entirely on one kind of plant but spend a part of the year on one species, and the rest on another. One of the species which is injurious to the apple remains on this tree from fall until May or June when it migrates to grain and spends the summer months there. Another species, living on the elm during the fall, winter and spring, passes to the apple for its summer residence, and a long list of aphids having alternating food plants is now known.

Plant lice suck the sap from plants and often produce curling or malformation and even wilting of the leaves, frequently accompanied by discoloration. Root-attacking forms produce knots and deformities affecting the health of the plant, and young fruit becomes hard at the attacked spots and remains small. The punctures aphids make often enable the spores of fungi and bacteria causing plant diseases to enter the plants, and they may even transfer these from one plant to another. Among the diseases transferred thus are an oat blight, fire blight of the pear and cucurbit wilt. Indirectly by the honey dew in which spores can live for several days, it is probable that the diseases can also be widely distributed through the agency of other insects which visit and feed on honey-dew. In general a year when plant lice are abundant over a large part of the country is certain to result in great injury to plants of all kinds affected by these insects.

Ants not only gather the honey dew the Aphids produce, but in some cases the relation is closer, particularly with root feeding species. The eggs of the corn-root louse for example, are gathered by ants in the fall and kept in their underground chambers during the winter. In the spring the ants place the insects on the roots of certain weeds but after the corn has begun to grow well, they transfer them to the corn roots where they visit them during the summer to collect honey dew. (See page 203.)

Plant lice have many enemies which destroy great numbers of them. They are also affected by the weather, cloudy, wet periods being favorable, though driving rains destroy many.

In general the best control of plant lice is obtained by the use of nicotine sulfate 40 per cent used at a dilution of from 1 to 800 to 1 to 1,000 parts of water. Where this cannot be obtained, kerosene emulsion or fish-oil soap solutions rank next as control. 
The Apple Aphids.-There are three species of plant lice which attack the apple more or less generally throughout the United States, and a fourth is injurious in some parts of the country. In addition, a woolly species feeding both on the twigs and roots is of importance and will be treated later.

The three species referred to are the Green Apple Aphis (Aphis pomi DeG.), the Rosy Apple Aphis (Anuraphis roseus Bak. and Turn.) and the Apple Grain Aphis (Rhopalosiphum prunifolix Fitch), the latter until recently believed to be the same as a European species and generally known therefore, as the European Grain Aphis. All three lay their eggs in the fall on the twigs of the apple. In the spring the eggs of the Apple Grain Aphic hatch a week or 10 days before those of the other two. The young of all three kinds feed on the buds and become stem mothers which when full-grown, differ in appearance.

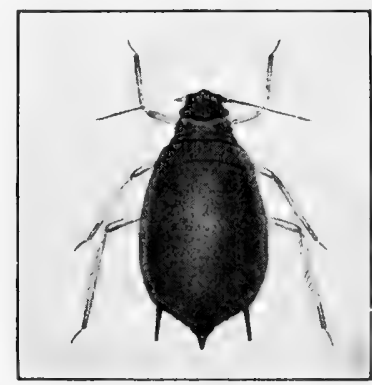

FIG. 188.

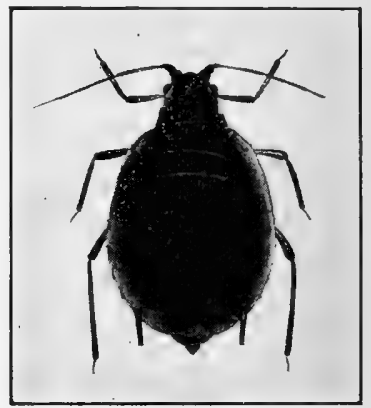

Fig. 189

Fig. 188.-Green Apple Aphis (Aphis pomi De G.), stem mother, about eight times natural size. (Modified from Cornell Agr. Exp. Sta. Mem. 24.)

Fig. 189.- Rosy Apple Aphis (Anuraphis roseus Bak. and Turn.), stem mother, greatly enlarged. (Modified from Cornell Agr. Exp. Sta. Mem. 24.)

The Green Apple Aphis stem mother (Fig. 188) has a uniformly green body, brown head and long, dark cornicles: the Rosy Apple Aphis stem mother (Fig. 189) is greenish but blended with purplish brown, and the cornicles are long, slender and dark; the body in this case is so dark as to be often described as blue: the Apple Grain Aphis stem mothers (Fig. 190) are yellowish-green, with a broad darker green stripe along the middle above, from which several side branches pass off, and with rather short, stout, yellowish cornicles.

As the leaves develop the lice feed on them and in the case of the Rosy Apple Aphis produce much curling. This is usually less pronounced with the Green Apple Aphis and does not occur with the Apple Grain Aphis.

After a generation or two on the apple, winged forms (Fig. 191) begin to appear and these migrate to summer food plants, except with the Green Apple Aphis which remains an apple feeder throughout the year. The 
Rosy Apple Aphis migrates to species of plantain, particularly the narrow-leaved plantain and it is noticeable that the spread of this plant louse over the country has closely followed that of this introduced weed. The Apple Grain Aphis migrates to small grains such as wheat and oats. On these summer food plants generation after generation is produced but in the fall a migration back to the apple occurs and here a sexual generation appears and eggs are laid which hatch the following spring. In some cases the Apple Grain Aphis may winter over close to the ground on the grain, not returning to the apple. The winged form of the Rosy Apple Aphis during the summer months has a pinkish or reddish body which has led to its being given its common name.

In the middle West the Clover Aphis (Aphis bakeri Cowan) has a similar life history to those just outlined, but during the summer lives on clovers.

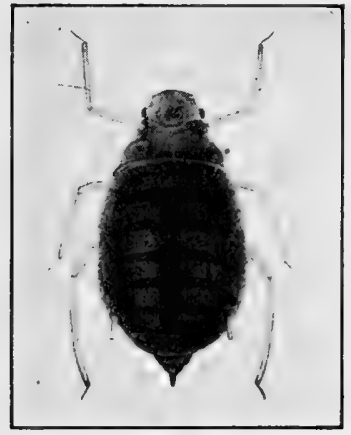

FIG. 190.

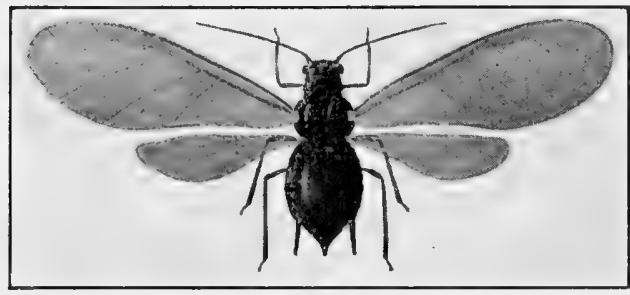

FIG. 191.

FIG. 190.-Apple Grain Aphis (Rhopalosiphum prunifolia Fiteh), stem mother, greatly enlarged. (Modified from Cornell Agr. Exp. Sta. Mem. 24.)

Fig. 191.- Winged Migrant of Green Apple Aphis, greatly enlarged. (Modified from Cornell Agr. Exp. Sta. Mem. 24.)

The chief injury to the apple caused by these insects is that their feeding on the buds checks their growth. The leaves are also curled and growth is reduced.

Control of Apple Plant Lice.-Destruction of the winter eggs by sprays has not thus far been very successful. The best control known at present is to very thoroughly spray the trees just as the buds are beginning to open and the eggs hatch, with the standard formula of nicotine sulfate 40 per cent. If an application of lime-sulfur is desired the nicotine sulfate can be added to that, provided the soap be left out. A second application about 2 weeks later, is sometimes desirable. In case nicotine sulfate cannot be obtained, kerosene emulsion, 1 part to 9 of water, or fish-oil soap, $1 \mathrm{lb}$. in 5 to 7 gal. of water may be used instead.

The Woolly Apple Aphis (Eriosoma lanigera Hausm.).-This European pest has been in the United States for many years and is widely dis- 
tributed. The adult is a small insect more or less completely covered by white, cottony or woolly threads of wax which practically conceal the louse beneath. Recent studies have shown that in most cases at least, the winter is spent in the egg stage in crevices in the bark of the elm. The eggs hatch in spring and the young lice pass to the buds and attack the leaves when these develop, causing them to become deformed, curled and clustered together forming "rosettes." Several generations participate in this work.

During the later spring months winged migrants are produced and these pass to the apple, hawthorn and a few other related trees where

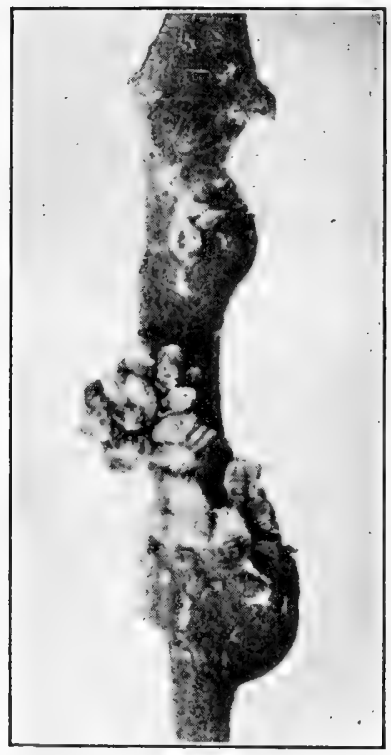

Fig. 192.-Apple twig showing Woolly Apple Aphis (Eriosoma lanigera Hausm.) and swellings of the twig produced by their attacks. About twice natural size. (Original.) they locate on the under side of the leaves and produce young which crawl to thin places, wounds or water shoots and there locate and reproduce during the summer and fall (Fig. 192) until cold weather comes on, when migrating forms are produced which return to the elm where the eggs are laid.

This life history is complicated by the fact that during the summer some of the plant lice migrate from the branches of the apple tree to its roots and feed there, producing knots and swellings which interfere with the nutrition of the plant, and if sufficiently abundant may cause its death. These lice are believed to remain on the roots the year around, generation after generation, but with their ranks recruited from time to time by migrants from the aerial members. Some of the latter also, are believed to remain on the apple all winter as hibernating nymphs.

The amount of injury to the apple caused by this insect above ground is not very great except perhaps on nursery trees. Woolly spots at scars and wounds on the branches, noticeable chiefly in the fall, are not abundant enough to affect the trees much, usually. The root form, however, is sometimes quite injurious, particularly south of the latitude of Washington, and young orchards may suffer severely.

Control.-The waxy "woolly" threads covering the bodies of these insects make control more difficult by spraying than would otherwise be the case, as the threads repel the spray. Nicotine sulfate 40 per cent, standard formula, or kerosene emulsion 1 part to 9 of water, driven with much force are about the only treatments for the aerial forms which have given much success. It is evident that elms growing near apple trees 
directly favor the successful migration of this pest, and as far as possible therefore, no elms should be allowed to grow near apple orchards.

For the root form, when sufficiently injurious to make it pay, removing the earth to a depth of six or eight inches over the root area and pouring kerosene emulsion or nicotine sulfate diluted as above, over this exposed surface, using enough to thoroughly wet the ground, has given good results.

Nursery stock affected can be dipped in the lime-sulfur wash or in these materials, when dug either for transplanting or sale, and as the Northern Spy seems to be rather free from this pest, using trees grown on stocks of that variety is desirable.

The Grape Phylloxera (Phylloxera vitifolice Fitch).-This aphid is a native of America and attacks the grape. Native Ameriean vines, however, are resistant to its work to a considerable degree, so that injury to them is not serious.

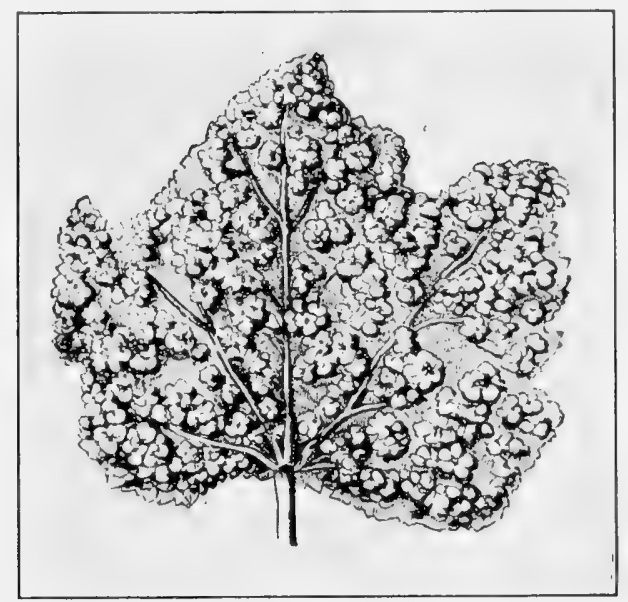

FIG. 193.- Under surface of Grape ieaf showing galls produced by the Grape Phylloxera (Phylloxera vitifolia Fitch). Somowhat reduced from natural size. (From Riley, U. S. D. A.)

The European grape (Vitis vinifera) on the other hand, is very susceptible to its attacks and when the Phylloxera reached Europe about 1860, it became very destructive, causing the loss of over two million acres of vineyards before any successful checks to the insect were discovered. In this country it reached California where the European grape is also grown, about 1874 and has been the cause of great injury there also.

The insect lays its eggs, one per female, on old wood of the grape in the fall, and these eggs hatch the following spring into tiny lice which locate on the upper surface of the young leaves and begin to suck the sap. This causes the leaf to become depressed at each place where a louse is at work, so that galls (Fig. 193) projecting from the under surface are soon produced, in which the insects live. Upon becoming full-grown these lice lay eggs in the galls and the young which hatch from them pass to other parts of the leaves and produce galls of their 
own. This process continues through the summer but in the fall the young desert the leaves (Fig. 194) and work down to the roots and rest until the follow-

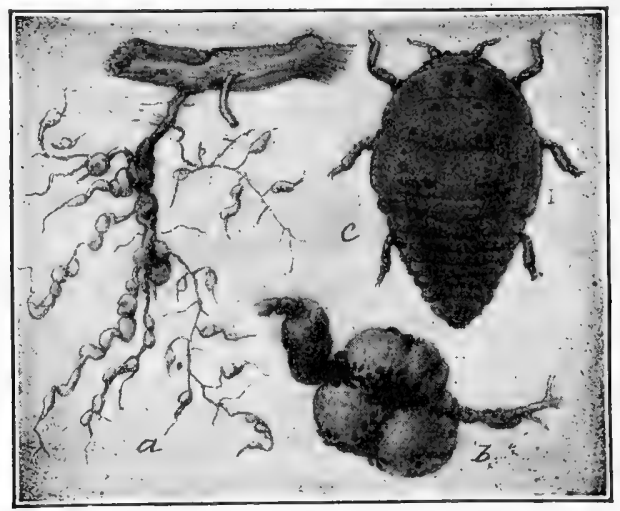

FIG. 194.-Grape Phylloxera: $a$, galls on grape roots; $b$, galls enlarged, showing the insects; $c$, Phylloxera from a root gall: $b$ and $c$ enlarged. (From Sanderson, Insects Injurious to Farm, Garden and Orchard; after Marlatt, U.S. D. A.)

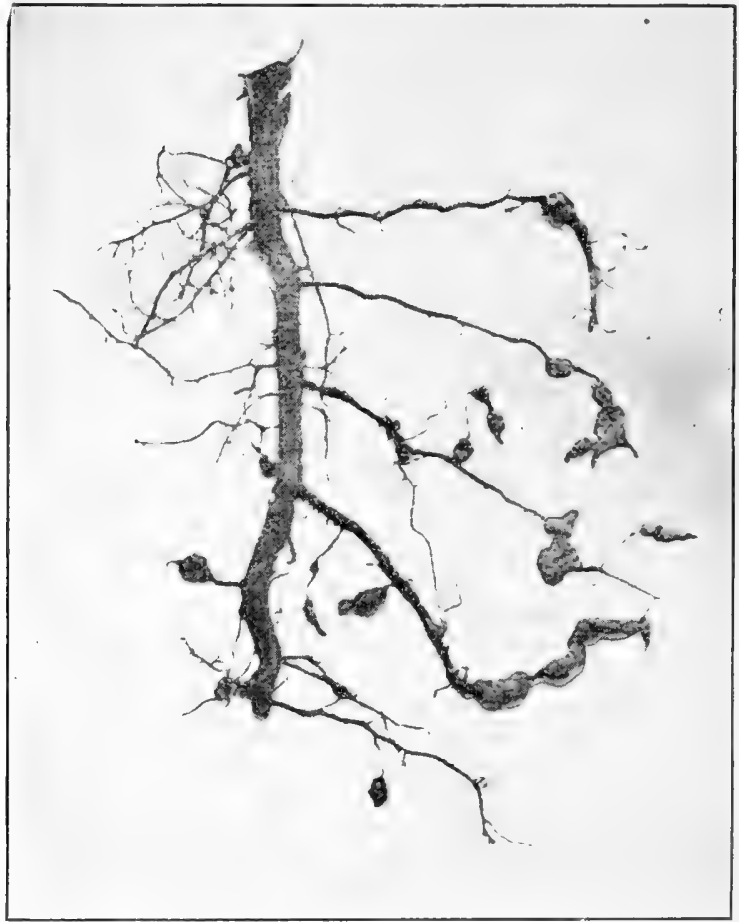

FIG. 195.-Grape root showing galls caused by Phylloxera. (From Berlese.)

ing spring. Then they attack the roots, forming swellings (Fig. 195) which on young rootlets stop their growth, and on the larger ones cause decay which spreads around the root and kills it beyond that point. 
During the latter part of this second season some winged forms (Fig. 194) are produced and these make their way up to the surface of the ground and migrate to other vines where they lay eggs. These produce both male and female plant lice and each female lays a single fertilized egg which winters over.

This 2-year life and the production of leaf galls is not always necessary to the continued existence of the insect however. The root form generally goes on, brood after brood, particularly on the European grape, without the formation of leaf galls, and while young from the leaves may probably pass to the roots at any time during the summer, the migration of root forms to the leaves is unknown. Apparently then, the life history just outlined applies to American varieties of the vine, but in the case of the European species, while the lice may pass to the roots they do not usually, at least, seem to migrate in the reverse direction, the insects coming from fertilized eggs passing directly to the roots. Root forms may spread to other plants through the soil.

Control.-Four methods of control have been made use of for this pest, viz., the injection of Carbon disulfid into the soil close to the roots; flooding the vineyard with water; planting in very sandy soils; and the selection of resistant varieties. The first of these has given fair results where the soil is loose, deep and rich, but is most successful in cooler locations, and here the insect is least abundant. It is also rather expensive and has therefore largely been replaced by other treatments.

Submersion of the ground under water is a better method, but obviously cannot be made use of in most cases. The vineyard must be kept covered with at least six inches of water in order to drown the lice and unfortunately the best time to do this is during the summer when the vines are most liable to be injured by this treatment. The time chosen therefore, is after the vines have stopped active growth but before the lice have become dormant. In California this is generally some time in October. Flooding then should last from a week to 10 days: later in the season it must be extended and in the winter months 35 to 40 days of treatment is necessary.

Planting in sandy soil is, for some reason not understood, a protection of the vines against Phylloxera, particularly where it contains a high percentage of siliceous sand. It is not always possible to locate vineyards on such soil however.

The selection of resistant varieties of the grape is now the favored method of control. With such varieties the insects when present on the roots do not increase rapidly and the diseased tissue of the swellings on the roots does not go deeper than the bark, leaving the roots proper quite healthy. At the present time the grafting of vinifera varieties on resistant stalks which preserves the resistant properties of the roots while producing the vinifera quality of grapes so much desired, seems to give the best results in vineyards, though the proper combination of different varieties of the two calls for a detailed knowledge of the subject in actual practice.

The Corn Root Aphis (Aphis maidi-radicis Forbes).- This insect, though it ${ }^{*}$ can hardly be regarded as universally distributed through the United States, is both a serious pest of corn over a large area and because of its interesting relation with ants, an interesting species. It appears to occur throughout the eastern United States as far west as South Dakota and Colorado and south to South Carolina, Louisiana and Texas, but its destructive work mainly covers the territory from New Jersey to South Carolina and west to the Mississippi River. 
The eggs of this aphid hateh early in spring and from 10 to 22 generations (Figs. 196 and 197) are produced during the season. As cool fall weather appears, a generation of sexual individuals (Fig. 198) appears and these lay eggs which pass the winter. During this season they may be found in the

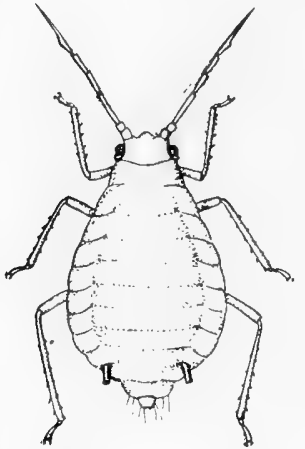

FIG. 196.-Corn Root A phis (Aphis maidiradicis Forbes); wingless, viviparous female. Greatly enlarged. (From U. S. D. A. Bur. Ent: Bull. 85, Part VI.) ground in nests of several kinds of ants but most frequently in those of the little brown ant, Lasius niger americanus. They are oval, black and glistening and are sometimes found in small piles in the nests of the ants. In cold weather the ants carry the eggs down below the frost and on warm days bring them up to warmer levels. In spring, when various weeds such as smartweed, begin to grow, the ants tunnel along the roots of these weeds and place the young lice as they hatch, on them to feed. Later, when corn roots become available the ants transfer the lice to them, where they and their descendants feed during the rest of the season. Winged migrants are produced after a generation or two and these individuals spreading, are taken to corn roots by ants which may find them. All summer and fall the ants care for the lice, taking them from one plant to another and collecting from them the honey-dew upon which the ants feed. In the fall when the eggs are laid these are gathered by the ants and stored in their nests over winter.

Where the Corn Root Aphid is abundant it becomes a serious corn pest, dwarfing the corn and turning the leaves yellow or reddish and sometimes destroying the plants, particularly when weather conditions are also unfavorable.

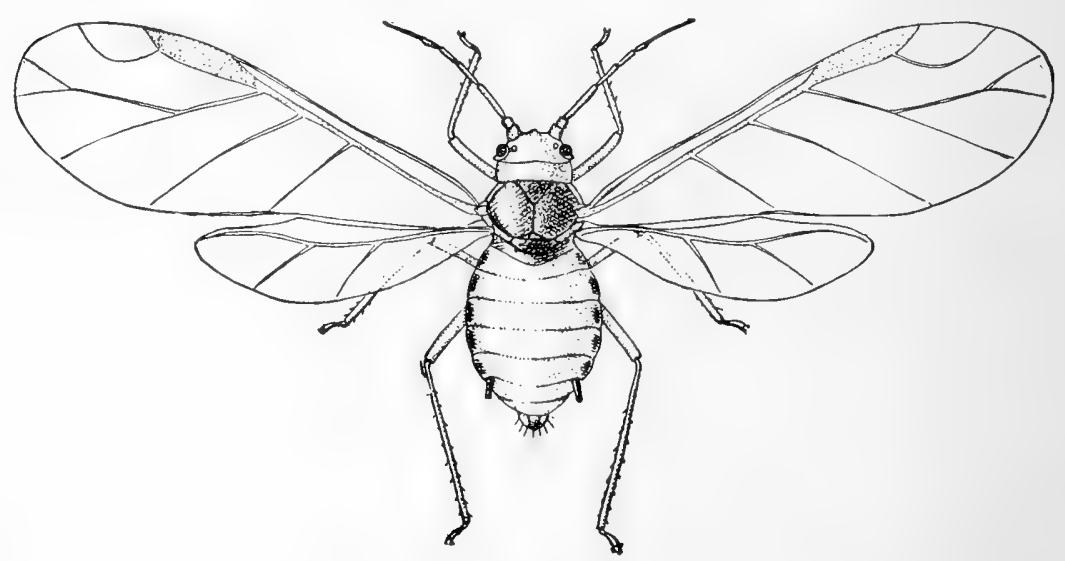

FIG. 197.-Winged, viviparous female of the Corn Root Aphis, greatly enlarged. (From U. S. D. A. Bur. Ent. Bull. 85, Part VI.)

Control.-Rotation of crops is of much value as a control, for as the lice cannot migrate until their second generation, corn planted on land where they are not already present will get well started. Fertilization and frequent cultiva- 
tion to produce vigorous growth will aid in this. The worst injuries are usually where corn is planted to follow corn and therefore where this pest is already present in the field from the preceding year. Any method which will destroy the nests of the ants which care for the lice will also be helpful, and deep plowing and harrowing both in late fall and early spring has proved of value for this purpose.

Some plant lice attack evergreens and produce rather soft, fleshy galls, generally at the bases of the outer shoots. These appear during the spring months and are of full size by midsummer. They then dry and crack open, showing little cavities occupied by the plant lice which now leave the galls for other parts, either of the same or some other kind of tree, according to the species concerned. The gall formation interferes with the growth of the tree by preventing wholly or in part, the circulation of the sap in the shoot at the

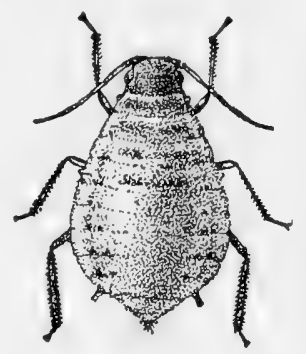

Fig. 198.-Oviparous female of the ('orn Root Aphis, greatly enlarged. (From I'. S. D. A. Bur. Ent. Bull. 85, Part VI.) base of which the gall is located, and this results, by the death or checking of the growth, in trees which look thin rather than dense, and in some cases they may become worthless as lawn ornaments. In the East the spruce is often seriously injured in this way.

Many kinds of plant lice often become seriously abundant for periods of 2 or 3 years, then disappear for a time. The Potato Plant louse, the Pea louse, the Beet-root louse, Cherry plant lice and others have all been destructive for a year or two at a time within the last decade, and similar outbreaks of these or others may be expected any year. Wherever it is possible, spraying thoroughly upon the first appearance of the lice, with

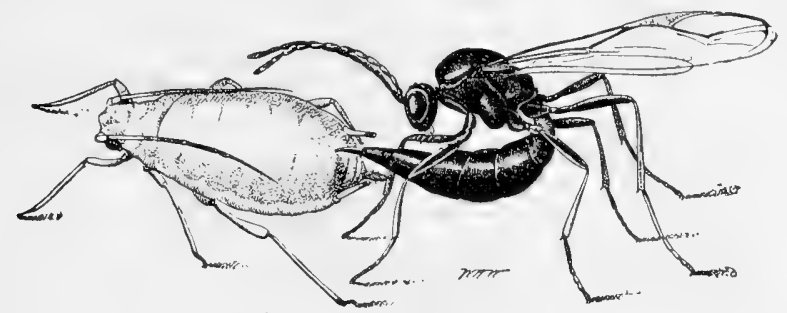

FIG. 199.-Aphid parasite (Lysiphlebus testaceipes Cress.) ovipositing in the body of a Spring Grain Aphis. Greatly enlarged. (From U.S.D. A. Bur. Ent. Bull. 110.

nicotine sulfate, kerosene emulsion or fish-oil soap should be resorted to as measures of relief. If for any reason this cannot be done and no special method of control seems available, dependence must be placed upon climatic influences and insect enemies to check these pests, and this will occur within 2 or 3 years in nearly every case.

Among their many enemies is one group of tiny insects which makes a specialty of attacking plant lice. An insect of this group will select a 
louse (Fig. 199) and, facing it, will thrust its abdomen forward beneath its body and drive its ovipositor into the louse. The young parasite

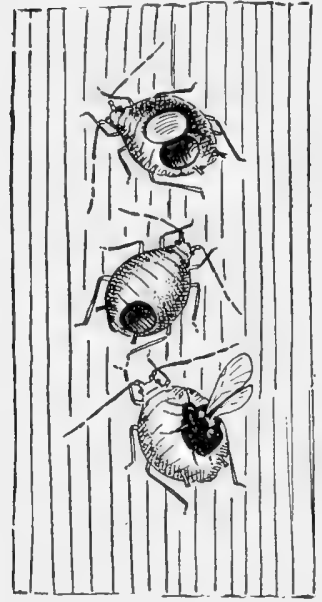

FIG. 200.-Plant Lice killed by parasites. Upper figure shows the circular piece of chitin cut by the parasite in escaping, but still attached. Lower figure shows the parasite just escaping. Much enlarged. (From U.S.D. A. Bur. Ent. Bull. 110.)

hatching from an egg thus deposited, will feed upon the aphid whose body becomes distended and generally changes color after a time and finally dies adhering to the plant on which it was. When the parasite has completed its development within the body of the louse it escapes by cutting a circular, lid-like opening through the skin (Fig. 200), and lice attacked and killed in this way are often very plentiful during and particularly toward the end of a period of destructive abundance of these insects (see page 344).

Family Aleyrodidæ.-The adults of the insects belonging in this family (Fig. 201) are very small and have four wings which are broadly rounded and have a white dust covering them, which has led to calling the group the White Flies. Occasionally the wings have dark spots or streaks. The eyes are often constricted in the middle or even divided into two parts. The body is generally yellowish, though in some species it may be of other colors.

The nymph on hatching, crawls around for a short time before settling down on a leaf, then inserts its rostrum in the tissues and begins to feed. After molting the insect becomes quiet, with its legs and antennæ much reduced, and thereafter does not move from its location until it becomes

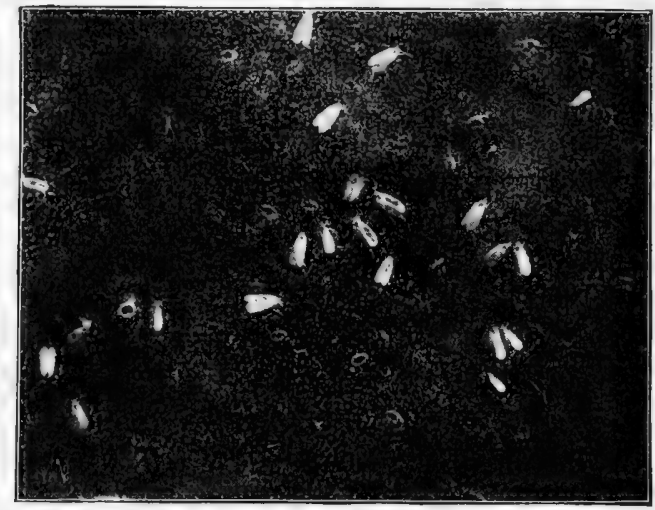

Frg. 201.-Adult White Flies twice natural size. (From Britton, Second Report Ent. Conn. Agr. Exp. Sia. 1902.)

adult, and wax which may have been produced before the first molt, now becomes more noticeable. This wax may take the form of a fringe 
around the sides and may more or less cover the body. The animal after its third molt differs so from its former appearance that this stage is often called a pupa, and as the following molt produces the adult there is evidently quite a metamorphosis to justify the use of this term in the group. Honey-dew is produced by these insects.

White Flies are essentially tropical though a few species live in the northern United States. In greenhouses everywhere the Greenhouse White Fly (Aleyrodes vaporariorum Westw.) is too often a serious pest, for it multiplies rapidly and the tiny nymphs (Fig. 202) are not generally noticed in time to check their increase before the plants have suffered

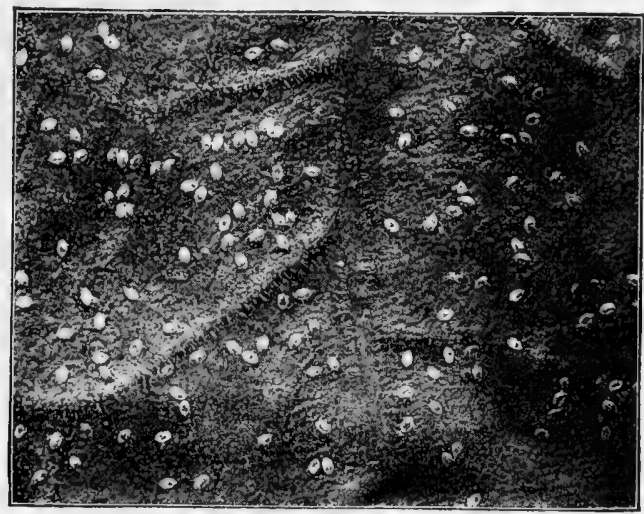

FIG. 202.-Nymphs of the White Fly on underside of a leaf, enlarged twice. (From Britton, Second Rept. Ent. Conn. Agr. Exp. Sta. 1902.)

greatly. When they are abundant, fumigation for $3 \mathrm{hr}$. at night, using between $1 / 5$ and $1 / 6 \mathrm{oz}$. of sodium cyanid to each $1,000 \mathrm{cu}$. ft. of space in the greenhouse should kill all but the eggs and some of the pupæ, and repeating this treatment twice afterwards at intervals of 2 weeks should destroy the others in the stages to which they will have then progressed. If for any reason this treatment is not desirable, syringing the plants with fish-oil soap using from 1 to $1 \frac{1}{2} \mathrm{oz}$. per gallon of water, giving particular attention to the under surface of the leaves will give some relief.

In the Southern States and in California, white flies attack citrus fruits and cause much injury. Several species are more or less concerned, the most important one being the Citrus White Fly (Dialeurodes citri Ashm.). These insects usually check the growth of the tree and fruit, reducing the yield and its size, and also by the production of honey-dew, induce the growth in this of a fungus called "sooty mould" which interferes with the ripening of the fruit and is also believed to affect its flavor, besides making it look objectionable, so that fruit partly covered with the mould must be cleaned before shipping. The reduction of the vitality of the tree by these insects also favors the more active development of other citrus insects and of diseases. 
Certain fungi live on the white flies, however, and are of assistance in their control, but as they need certain weather conditions for their best growth during about 3 months, they can rarely accomplish more than a third of the amount of control necessary.

Spraying with paraffin-oil emulsion prepared according to special directions has proved to be a successful method of control for citrus white flies, and miscible oil has also given good results. In either case the material as applied should contain about 1 per cent of oil.

Family Coccidæ (Scale Insects).-These are remarkable insects having been much modified and changed in appearance from the more ordinary forms. Without attempting an accurate classification, they may be grouped under three heads: the armored scales, the soft scales, and the mealy bugs.

The mealy bugs are the least degenerate of the three groups. In them the females preserve their body segments, eyes, antennæ and legs, and can move about. They secrete a waxy material, usually as long cottony threads or plates, more or less covering their bodies and sometimes forming a large egg sac at the hinder end. In the female soft scales the antennæ and legs are not lost but they become reduced to such an extent that though the adult can move about somewhat, it seldom does so. Wax when secreted, is usually to form a sac at the hinder end of the body enclosing the eggs, and the skeleton on the back of the insect becomes very much thickened, forming a scale, often very convex, strong and protective, though seemingly softer than in the armored scales. In this last-named group the female loses antennæ, eyes, and legs, and secretes a waxy scale, with which the molted skins from the bolly are felted together, forming generally a rather flat and very tough scale. The metamorphosis in the females of all three groups is incomplete. In some cases the females are fertilized before they have attained full size and grow considerably afterwards.

The males develop much as do the females, at first, though not losing any of their parts by degeneration. After reaching full size, however, they pupate and emerge from the pupa as very tiny insects with only one pair of wings and no mouth parts. Thus in the scale insects we have the remarkable fact that while in the males there is a complete metamorphosis, in the females it is incomplete. Whether the former was the original condition in the group, and the females through the degeneration connected with their mode of life have changed to an incomplete metamorphosis, or whether this was the primitive condition and complete metamorphosis has been developed in the males, is unknown, though the other Homoptera all have an incomplete metamorphosis.

About 2,000 species of scale insects are known, attacking nearly all kinds of trees and shrubs, and sometimes other plants as well. Many have an almost incredible rapidity of increase, and when under favorable 
conditions, this results in the death of the plant they are on. A few are beneficial to man. Thus the bodies of a scale feeding upon cactus, when dried and prepared, furnish the dye known as Cochineal. Shellac is obtained from the excretions produced by another scale, and China wax, used as furniture polish, comes from a third species. Most scale insects, however, are injurious and fail to compensate for the injury they cause by producing anything of value.

Among so many serious pests, only a few can be considered in detail here. Taking the armored scales first, these are the Oyster shell, the Scurfy and the San José Scales, with brief reference to a few others.

\section{Armored Scales}

The Oyster-shell Scale (Lepidosaphes ulmi L.).-This insect, native to Europe, has been so long in this country that it is now very generally distributed. It is chiefly an enemy of the apple, pear, poplar, willow, ash and lilac, but is often found on other plants. It feeds on all parts covered by bark, and the male scales are also often found on the leaves.

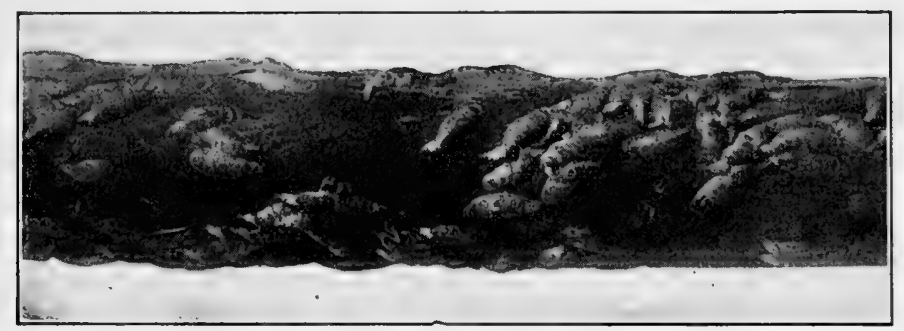

FIG. 203.-Female scales of the Oyster-shell Scale (Lepidosaphes ulmi L.) on a twig, albout twice natural size. (Original.)

The full-grown female scale (Fig. 203) is about one-eighth of an inch long and has much the form of an oyster shell, one end narrowly rounded, the other rather more broadly so, and the shell as a whole usually bent somewhat to one side. It is brown to gray in color, varying with age, and to some extent, the plant it is on. During the winter examination of the scale will show beneath it at the narrower end, the dead body of the insect, and behind it from 15 to 100 tiny whitish eggs. These hatch the following May or June, according to the advancement of the season, into very small whitish nymphs or "crawling young," which are extremely delicate and with no scale. These young crawl out from beneath the parent scale and wander about for a few hours or even a day or so, seeking for places where they may settle: then each thrusts its beak through the bark and begins feeding, and degeneration of eyes, antennæ and limbs, and the secretion of wax over the body begins. To this secretion the molted skin is added at each molt, making a very tough, hard, cover- 
ing scale. The insect beneath this becomes adult after a time and following the laying of its eggs, dies. In the northern states the eggs are laid in August or September, but in the middle states and farther south, the earlier seasons permit hatching enough earlier in the season for the adult condition to be reached and the eggs laid by midsummer, and these eggs soon hatch and produce egg-laying adults before the following winter. Thus, this insect though having but one generation each year in the more northern states, has two from about the latitude of New Jersey southward, except at such altitudes as to produce northern conditions.

Many of the male crawling young go to the leaves to settle and the scales they form are smaller and somewhat different in shape from those of the females. Beneath them they attain their growth, then pupate, still under their scales, and at the end of this process emerge as very small two-winged adults without any mouths or mouth parts, having undergone a complete metamorphosis.

Control.-These insects are least protected while crawling young, and as they are sucking forms, a contact insecticide should be applied while they are moving about or at least before they have had time to produce scales covering themselves. The usual treatment therefore is to spray with 1 part of kerosene emulsion to 9 of water, or with Nicotine sulfate 40 per cent, 1 part, water 800 to 1,000 parts, as soon as the young appear. They are so small, however, that it is very difficult to reach them all with the spray, and as all do not hatch at the same time, a second application about 10 days after the first, is desirable. Winter spraying with lime-sulfur wash is also a fairly good treatment. Where neither of these methods proves effective (as is sometimes the case), spraying in spring, shortly before the eggs hatch, with linseed oil emulsion, has worked well. This is prepared as follows:

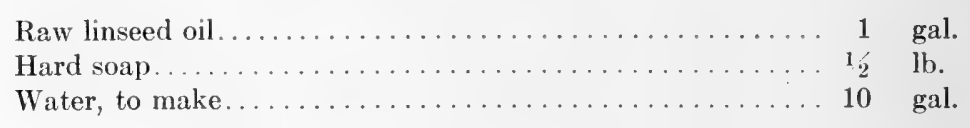

Dissolve the soap in the water; add the oil and churn through a pump as for kerosene emulsion until thoroughly mixed (it does not thicken up like the latter) and spray.

The Scurfy Scale (Chionaspis furfura Fitch).- This insect is a native of America and is usually less abundant in the more northern states than elsewhere, attacking the apple, pear, mountain asn, currant, gooseberry, hawthorn, Japanese quince and other plants. The full-grown female scale (Fig. 204) is shorter and broader than the Oyster-shell scale, and when perfect in outline, rather pear-shaped, and dirty white in color. Its life and habits are much the same as those of the Oyster-shell scale, 
but the eggs are fewer in number and dark purple in color, as are also the crawling young which usually hatch a few days later in the season than the other species. Control methods are the same as for the Oyster-shell scale.

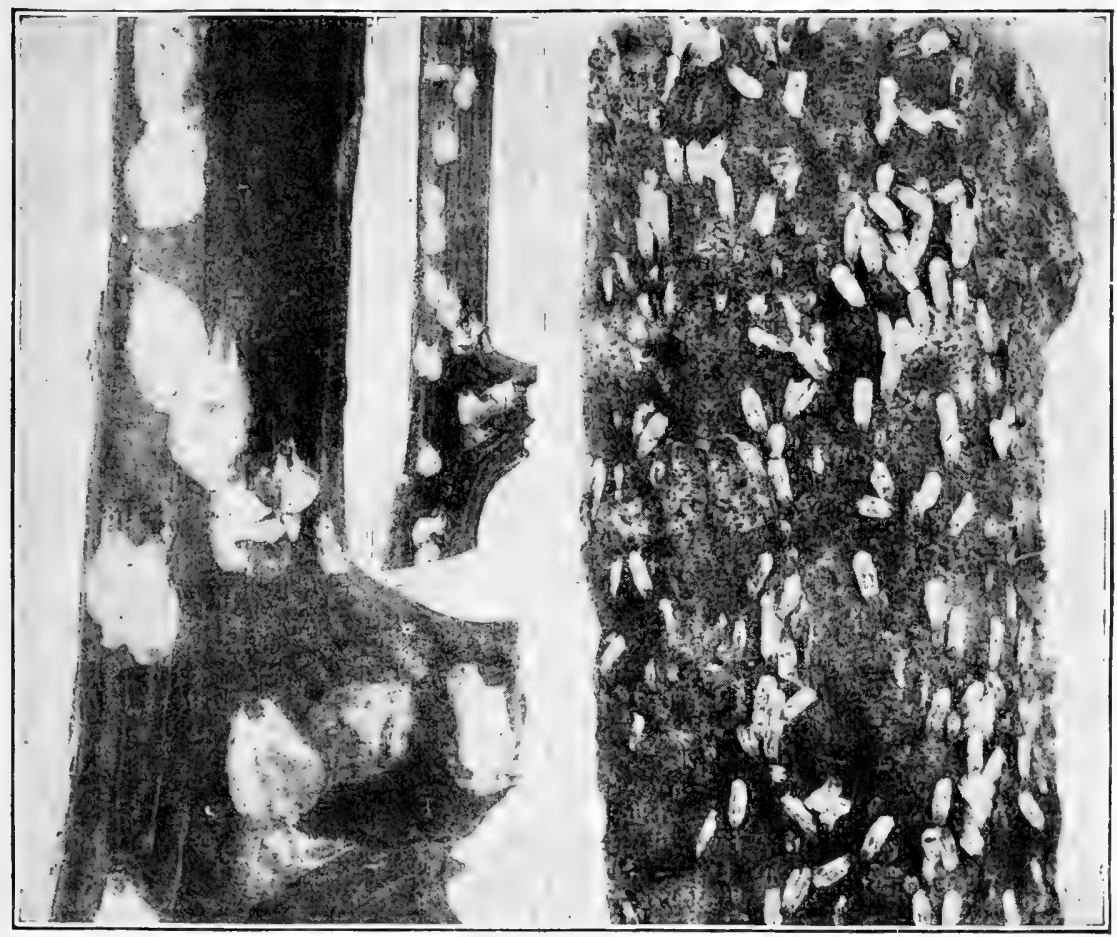

FIG. 204.-Scurfy Scales (Chionaspis furfura Fitch). Male scales at right, female scales at left. Left hand figure greatly enlarged; the other two somewhat enlarged. (From U.S. D. A. Farm. Bull. 723.)

The San José Scale (Aspidiotus perniciosus Comst.).-This is one of the most serious pests among the scale insects. Its original home was probably China, but it appears to have reached California about 1870 and since then has spread practically all over this country. It has a wide range of food plants, on many of which it thrives sufficiently to quickly kill them. The plants which suffer most from its attacks are the fruit trees and currants, the dog-woods, thorns, poplars, ornamental cherries and plums, hardy roses, willows, lilacs and lindens; and even maples and elms are sometimes attacked, the total list of plants upon which it has been found numbering over a hundred. It feeds on all parts of the plant above ground, even including the fruit.

The full-grown female scale (Fig. 205) is about the size of a pin head, nearly circular in outline and rather flat, sloping gradually upward from 
its edge to near the center where a slight circular depression surrounds the raised center or "nipple" itself. It is brownish-gray in color when adult, but in earlier stages may vary from this. The adult male scale is somewhat smaller, more oval in outline, and with the nipple not centrally placed but nearer one end.

At the beginning of the winter season specimens of this scale of practically all ages occur, but probably only those from about one-third to one-half or two-thirds grown survive the winter. In the spring these

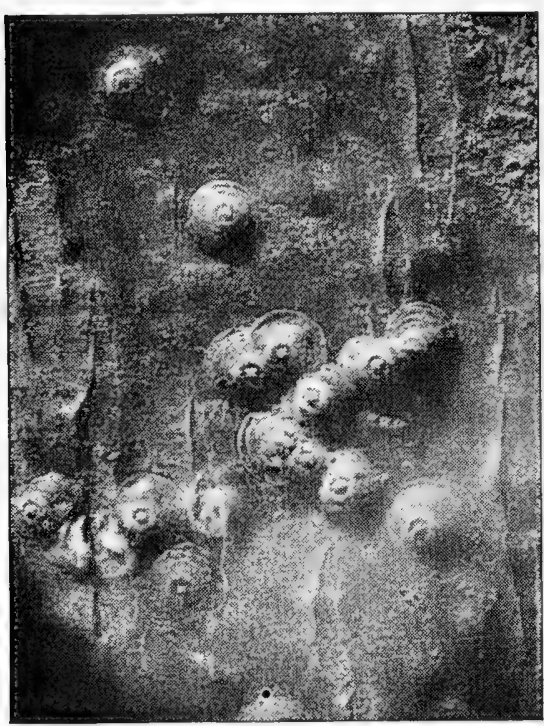

Fig. 205.-San José Scale (Aspidiotus perniciosus (Comst.): adult female scales enlarged about five times. (From Houser, Ohio Agr. Exp. Sta. Bull. 332.) individuals resume their feeding on the sap and after a time the males appear. In the northern states this condition is hardly reached before the middle of May, but at Washington, D. C. it comes early in April, and farther south still earlier. After mating, the females continue to grow and about a month later the first young appear. These do not, in the San José Scale, hatch from eggs laid by the parent but the young are born alive; i.e., this insect is viviparous. These young are produced, a few every day or two, and the parent lives for a month or more, producing an average total of about 400 young. These resemble the crawling young of the scales already considered, except that they are lemon yellow in color, and they crawl about and settle down to feed in the same way. The scale now begins to appear, at first as white waxy threads over the back, which soon mat together to form a pure white covering. As the nymph beneath molts, the molted skins are added to this and variations in color of the scale appear. Sometimes the scale of the partly grown insect may show white, black and gray, varying in arrangement according to the completeness with which the different parts have combined, but before maturity it becomes a quite uniform grayish-brown. The young become adult in a little over a month and then themselves begin to produce young, and in the northern states there are usually at least three generations in a season, while in the south there are four or even more. The generations overlap, the earliest young produced by the second generation for example, sometimes appearing before the last born of the preceding one, which results in the almost constant presence of 
crawling young on an infested tree, from the time the first one appears until reproduction is stopped by cold weather. Assuming the production of four full generations in a season, equally divided between the sexes, and with no loss in number from death by accident or other causes to reduce the number produced, we have a total of $3,216,080,400$ in individuals as the descendants during one season from a single pair. Fortunately, many never reach maturity, or an infested tree would often be sucked dry before winter.

The San José Scale has a number of parasites which are sometimes quite effective, destroying a large per cent of the scales in some localities, but with such an enormous power of increase of the pest, even a high degree of parasitism fails to give the relief needed. A few predaceous insects are also known, which feed upon the scale. Most noticeable among these is the Twice-stabbed Lady Beetle (Chilocorus bivulnerus Muls.), a small black beetle (Fig. 206) with two red spots. It is nearly circular in outline, very convex and is about one-eighth of an inch long. A fungous disease also attacks the scale, particularly in the South, but parasites, predaceous foes and diseases together, generally fail to hold it entirely in check.

A lady beetle closely resembling the Twicestabbed Lady Beetle is an enemy of the scale in China, the native home of the pest, and this insect has been brought to the United States

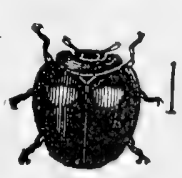

(

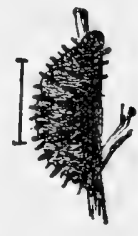

b

FIG. 206.-Twice-stabbed Lady Beetle (Chilocorus bivulnerus Muls.): $a$, adult; $b$, larva enlarged: real length shown by the hair lines. (From Sanderson and Jackson, Elementary Entomology: after Riley.) with the hope that it might do effective work here, but thus far, for various reasons, it has failed to accomplish much.

Control.-Spraying as for the Oyster-shell Scale is useless, for that treatment is based upon the destruction of the delicate, crawling young, by one or at most two applications. With the San José Scale, however, the young do not all appear at about the same time, but are present practically from May or June according to the latitude of the locality, until winter. To use this method successfully therefore would require spraying about every 2 weeks or so for a period of at least 5 monthsa treatment manifestly impracticable.

Stronger materials are therefore used, during the dormant season, when the tree is least liable to injury by the spray, and when a more thorough application can be made, the leaves having fallen. For this purpose the lime-sulfur wash and miscible oils are generally used (see Chapter VIII). At times injury to the trees has been observed following the use of miscible oils, but on the other hand these materials spread better over the tree than the lime-sulfur. Many persons now make a practice of spraying every third winter with miscible oil, but using the lime-sulfur at other times. 
In some cases summer treatment may be desirable where the seale is increasing rapilly, to preserve the tree until winter gives an opporfunity for the regular applieation. In such cases a greater dilution of the lime-sulfur becomes necessary, and with stone-fruit trees the self-boiled material should be used.

Fumigation with Hydrocyanic acid gas is the most effective treatment. for the san José siale, hut the cost of the tents large enough to rovere all but the smallest treese is so great that this method is made use of only for fumigating nursery stock after it has been dure, in houses built for that purpose.

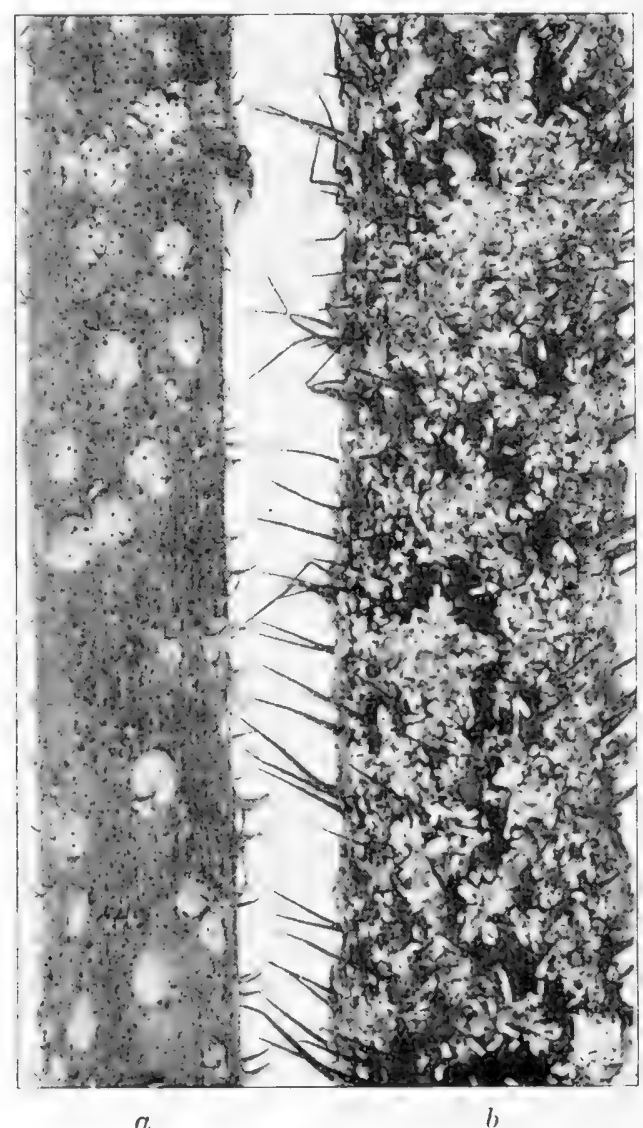

FIG. 207.-Rose Scales (Aulacaspis rosa Bouché): $a$, female scales; $b$, male scales. Considerably enlarged. (From Houser, Ohio Agr. Exp. Sta. Bull. 332.)

The Rose Scale (Aulucrapis rosce Bouche).-Generally distributed in the United states on ratipberry, blackberry, dewherry, rose, pear and some other plants. Female sales (rig. 207) white with more or less yellow at margin; nearly circular, about one-tenth of an inch in diameter. Male soales white, narrow, very small. Plants thickly infested appear as though sprayed with white- 
wash. Winters in various stages, so all may be present at almost any time. Two or three generations per year. Control by cutting out the worst infested stems during the winter, and spraying with lime-sulfur as for San José Scale in early spring. Whale-oil soap ( $1 \mathrm{lb}$. in 1 gal. water) may also be used. .

The Pine-leaf Scale (Chionaspis pinifolice Fitch).-Occurs generally in the United States on leaves of pine, and sometimes other evergreens. Female scale (Fig. 208) white, narrower than Scurfy Scale but varying to fit the width of the leaf: male scale much smaller. When abundant, whole branches may appear

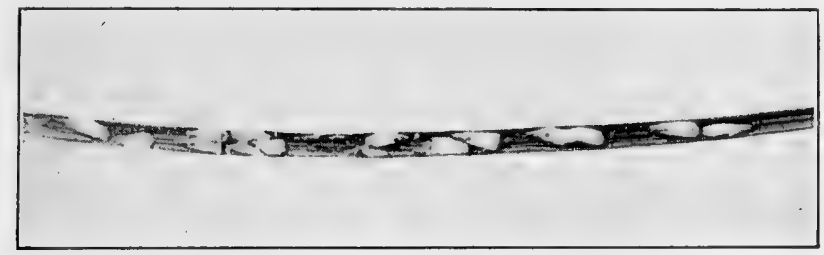

FIg. 208.-Pine-leaf Scale (Chionaspis pinifoliœ Fitch). Female scales on pine leaf, about twice natural size. (Original.)

as though their leaves had been sprayed with whitewash. Two generations a year, purplish crawling young appearing in the northern states about the middle of May and the first of September, at which times spray with either kerosene emulsion or the linseed oil emulsion as advised for the Oyster-shell Scale.

The Purple Scale (Lepidosaphes beckii Newm.).-In the South and on the Pacific Coast this insect is very injurious to citrus plants, even on the fruit of which it is often seen. It greatly resembles the Oyster-shell Scale in appearance (Fig. 209) and size There are three or four generations each year. Control is usually by fumigation with Hydrocyanic acid gas during the colder months.

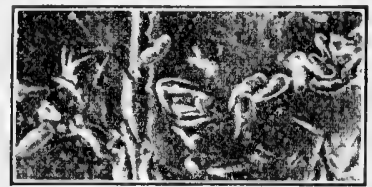

FIG. 209.

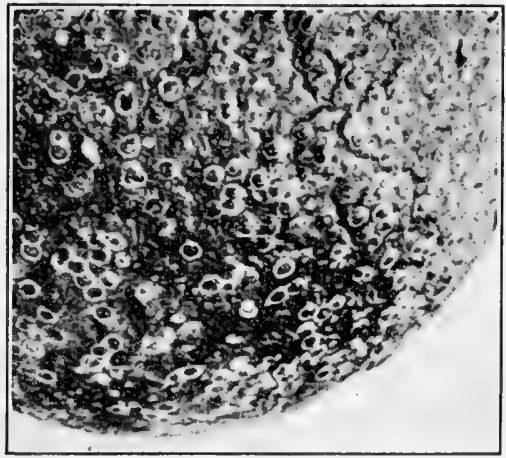

FIG. 210

FIG. 209.-Purple Scale (Lepidosaphes beckii Newm.), about natural size. (Modificd from Cal. Agr. Exp. Sta. Bull. 226.)

FIG. 210.-Red Scale (Chrysomphalus aurantii Mask.) on a portion of a grape fruit. About natural size. (From Cal. Agr. Exp. Sta. Bull. 214.)

The Red Scale (Chrysomphalus aurantii Mask.).-A serious pest of citrus trees in California. The female scale resembles the San José Scale in outline, but averages larger (Fig. 210) and the scale is transparent enough to allow the red body (yellow in a variety) of the insect to show through. The male scales are smaller and rather elongate. The life history is similar to that of the San 
José Scale, the young being born alive during the summer months. Control on citrus trees appears to be best obtained by fumigation with Hydrocyanic acid gas, but with deciduous fruit trees the lime-sulfur wash may be used.

Occasionally the lenticels or breathing pores through the bark of plant twigs resemble armored scales, particularly the more circular ones. To determine in any case whether a debatable structure on bark is a scale or only a lenticel, it may be scraped with the finger nail. If it can be removed without breaking the bark (it may leave a whitish mark) the object is a scale, but if the bark is neces-

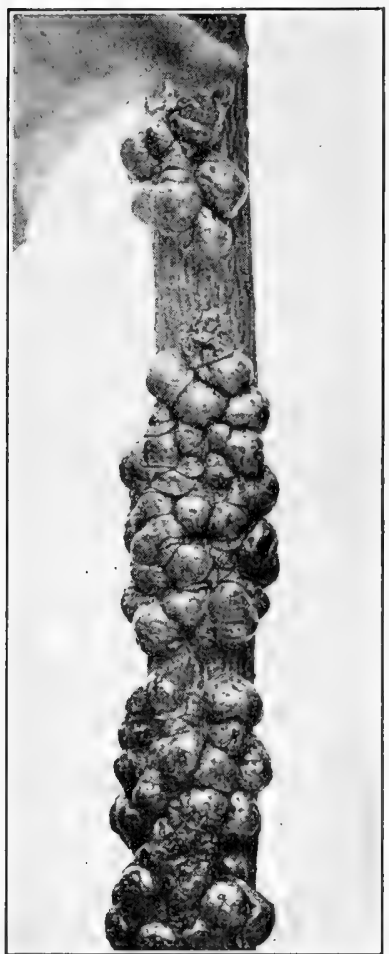

FIG. 211. sarily torn or broken to get it off, it may be assumed that it was a lenticel.

\section{Soft Scales}

As a group the soft scales are less injurious than the armored scales. Their rate of increase is less, their covering less protective, and their larger size renders them more cer-

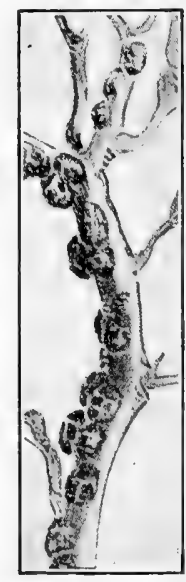

FIG. 212.

Fig. 211.-Tulip Tree Scale (Eulecanium tulipiferæ) Cook), about natural size. (Original.)

Fig. 212.-Black Scale (Saisettia oleœ Bern.), about natural size. (From Cal. Agr. Exp. Sta. Bull. 22:3.)

tain to be reached by sprays. The largest one found in the United States is the Tulip Tree Scale, the adult female scale being about one-third of an inch in diameter (Fig. 211). An African soft scale is known which is about an inch long.

The Black Scale (Saissetia olece Bern.).-This scale is found in nearly all parts of the world. It has a long list of food plants but is chiefly a pest on citrus trees and the olive, oleander, apricot and prune. In the United States it is therefore chiefly important in the South and West. The adult female scale is 
from one-eighth to one-fourth of an inch in diameter and almost hemispherical in form, black in color and with ridges forming an " $\mathrm{H}$ " on the back (Fig. 212). The male scales are much smaller, long, narrow and flat. The eggs, from 50 to 3,000, are for the most part, laid in May, June and early July, and the adult condition is reached early the next year, though variation from this is frequent. The young scales attack the leaves generally, but later pass to the twigs. The injury they cause by removing the sap from the tree is increased by the honey-dew they secrete, which falling in large amounts on fruit and leaves, forms an excellent material in. which a sooty fungus grows, and more or less cuts off light from the leaf surface, thus affecting the growth, and may also clog the stomata or breathing pores on the leaves, besides causing the fruit to look objectionable and need cleaning before its sale. Control of this pest is by Hydrocyanic acid fumigation between September 1st and January 1st. Several parasites and enemies are known. One parasite, imported from South Africa, has at times done excellent control work, but has not been continuously effective.

The Terrapin Scale (Eulecanium nigrofasciatum Perg.).- This is a native insect attacking various shade and fruit trees. The scale of the female is nearly hemispherical in form, about one-sixth of an inch in diameter, reddish, mottled and streaked with black (Fig. 213). This insect is viviparous, the young appearing in June and July and becoming adult the following spring. The young spend a part of their life on the leaves before migrating to the stems. Control, when necessary, is by spraying just before the buds open in spring with miscible oil, using 5 parts of this and 3 parts of gasoline thoroughly emulsified, and 92 parts of water.

The Cottony Maple Scale (Pulvinaria vitis L.). This insect attacks maple, linden, and other shade trees and plants. The scale of the adult female is rather flat, about one-fourth of an inch in diameter, and by midsummer generally lifted

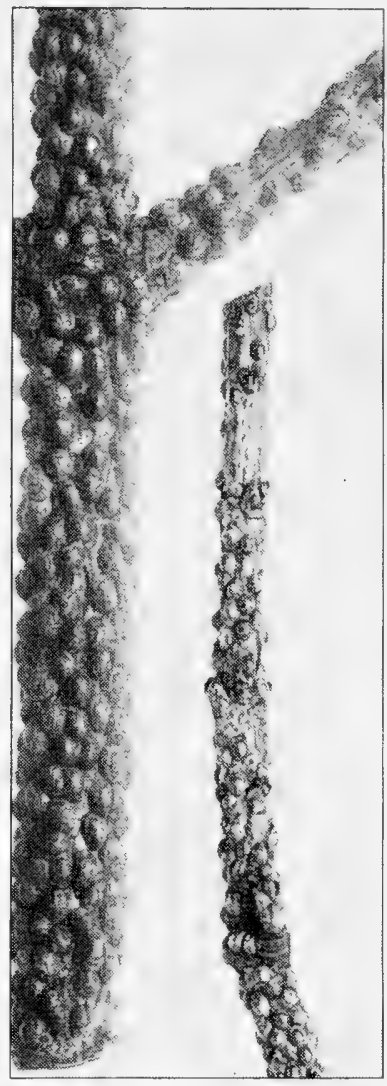

FIG. 213.-Terrapin Scale (Eulecanium nigrofasciatum Targ.), reduced somewhat (right hand figure), and somewhat enlarged (left hand figure). (From Houser, Ohio Agr. Exp. Sta. Bull. 332.) at one end from the twig it is on, by a projecting mass of cotton-like threads which surround 2,000 to 3,000 eggs (Fig. 214). These soon hatch and the young crawl to the leaves and cover themselves with a thin waxy coating. In fall they migrate to the twigs for the winter and become adult the following spring. When abundant the large, white, cotton-like masses make this a very noticeable insect. Contro is by spraying with a miscible oil, 1 part, water 15 parts, just before the buds open in the spring, or with kerosene emulsion, stock 1 part, water 3 parts. 
The Hemispherical Scale (Saissetia hemisyherica Targ.).-This scale is usually found in greenhouses and on house plants, such as ferns, palms, ornamental asparagus, etc., and also out of doors in the South. It is very convex, but rather oval than hemispherical, about one-eighth of an inch long, brown in color. The partly grown young are very flat and with a notch at the hinder end. The eggs are laid during about a 3-month period in late spring, thus resulting in the ap-

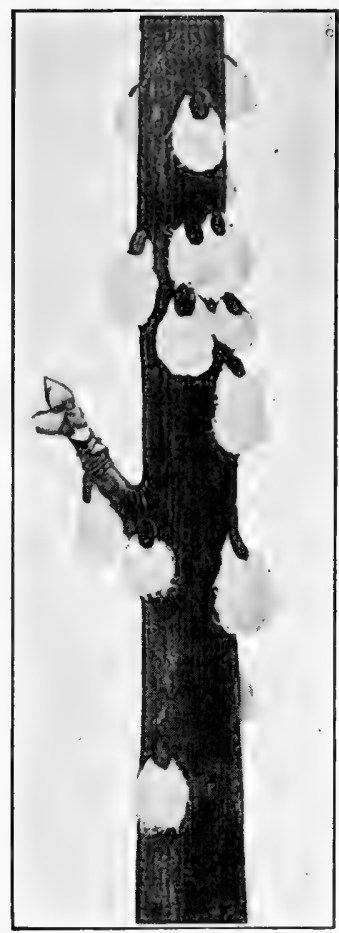

FIG. 214.

pearance of young during a long time. Fumigation as for the Black Scale, or dipping the plant in whaleoil soap $1 \mathrm{lb}$., water 2 gal., and after an hour rinsing the plant by dipping it in water, are fairly effective treatments.

\section{Mealy Bugs}

Mealy Bugs move about more or less freely during their life, as their limbs are not lost to any extent by degeneration. Nor is a scale present, the body being generally well covered by long, waxy threads, though in some cases waxy secretions forming plates connected with the body are produced.

These insects are inhabitants of warm climates and in the North are found only in greenhouses and on house plants.

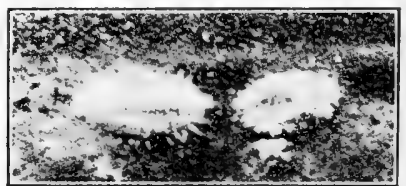

H'IG. 215.

Fig. 214.-Cottony Maple Scale (Pulvinaria vitis L.), about half natural size. (Modified from Felt, N. Y. State Mus. Mem. 8.)

Fig. 215.-Citrus Mealy Bug (Pseudococcus citri Risso.), enlarged.

The Citrus Mealy Bug (Pseudococcus citri Risso).- - This insect attacks many plants and is a serious pest on citrus plants, feeding on the roots, stems, leaves and fruit, gathering in large clusters on the last. It produces a large amount of honey-dew, on which the sooty fungus already referred to grows. The adult females, pale yellow in color and well covered by a th ck waxy secretion (Fig. 215), are one-fourth of an inch long. The 300 to $500 \mathrm{eggs}$ are laid in loose, white cottonlike masses, chiefly during fall and winter, and young and adults move about freely, the former becoming adult before the following summer. The cottony wax covering the insects renders them particularly difficult to reach with sprays. The best spray thus far found is a carbolic acid emulsion. To prepare this take 8 gal. of water and boil, adding $8 \mathrm{lb}$. of soap. After this has dissolved, add $1 \mathrm{lb}$. crude carbolic acid and boil 15 to $20 \mathrm{~min}$., which will give a thick, creamy emulsion. To spray, dilute 1 gal. of this with 20 gal. of water. Spray between 
October and March. Hydrocyanic acid fumigation has also given satisfactory results, especially with light doses frequently repeated. A number of natural cnemies are of some value against this insect.

The Long-tailed Mealy Bug (Pseudococcus longispinus Targ.).-This is of ten found in greenhouses attacking many kinds of plants. The bodies of adult females vary from yellow to gray, and the young are born alive, there being apparently several generations each year. Hydrocyanic acid fumigation seems to be the most successful treatment for these insects. Nicotine sulfate may also be used.

The Cottony Cushion Scale or Fluted Scale (Icerya purchasi Mask.).-This serious pest of citrus and many other plants, apparently reached California from Australia about 1868 and by 1880 had spread all over the citrus-growing regions of the State and was threatening the destruction of the entire citrus fruit industry.
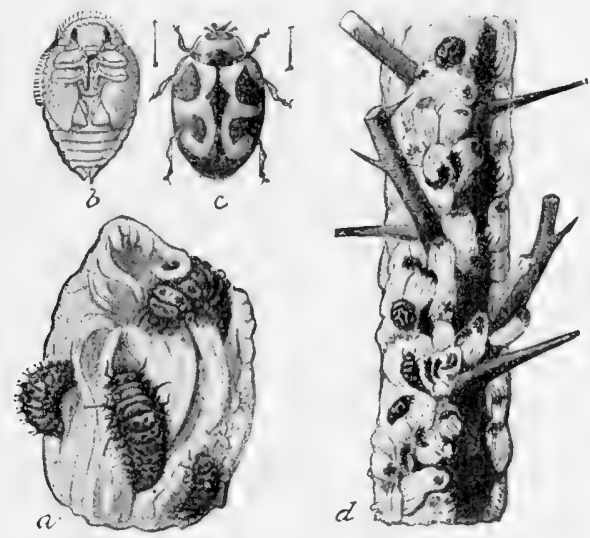

FIG. 216.-Cottony Cushion Seale (Icerya purchasi Mask.) and its lady beetle enemy, the Vedalia (Novius cardinalis Muls.): $a$, larvæ of the Vedalia feeding on a Seale; $b$, pupa of the Vedalia; $c$, adult Vedalia; $d$, twig with the Scales and lady beetles. $a$, greatly enlarged; real length of $b$ and $c$ shown by hair lines; $d$ about natural size. (From Sanderson and Jackson, Elementary Entmology: after Marlatt, U.S. D. A.)

Investigation showed that in Australia it had an enemy known as the Vedalia (Novius cardinalis Muls.), a lady beetle, and these were finally brought to California and colonized in the orange groves, where they attacked the scales so effectively that in the course of a few ycars these were brought under control, and now only an occasional local outbreak makes the scale of importance. When this happens, the introduction of the lady beetles to that region is soon sufficient to check all injury. In later years the scale has appeared in Portugal, South Africa and elsewhere, and when the introduction of the Vedalia into those regions has successfully followed, the scale has soon become relatively unimportant.

The female scale has a red, yellow or brown body. It lays its 400 
to 1,000 eggs in a large cottony mass formed at the hinder end of the body, the upper surface of the mass being grooved or fluted (Fig. 216). There are several generations in a season.

Several of the scale insects treated in this chapter furnish good illustrations of the way in which nature works to preserve a balance in the insect world. In the first place it should be noticed that our native scales are often found with tiny circular holes in them showing where parasites after having fed on the insect beneath, have made their escape. Other scales, long in this country, such as the Oyster-shell Scale, now have numerous parasites, some of which are also enemies of other kinds of scales, and in fact may be considered as scale enemies in general, or at least of most scales of the same section. New parasites also appear from time to time as enemies of scales, such as a tiny insect, Prospaltella perniciosi Tower, first discovered about 1912, which at times has done remarkably good work against the San José Scale. But when a new scale or other insect native elsewhere, establishes itself in this country, one of the factors at least in its success here, must be that none of its parasites in the locality whence it came, accompanied it in its transfer. If under these circumstances, climatic and other conditions prove satisfactory, we have a case of an insect set free from all restraint, to work its destruction with no check, at least until. some insect already present shall select it as a new and satisfactory food. This was evidently the case with Prospaltella and the San José Scale, already mentioned. In the meantime, however, years of destruction may elapse before any such check will appear, and the possibility of obtaining its special enemies from its native country appears to offer much in the way of quick relief. This "bug $v s$. bug" idea as it has been called, has a strong appeal to those suffering losses from the attacks of a newly introduced pest, and it has therefore been widely exploited.

Probably the first attempt to carry out this idea was the introduction of the Vedalia for the Cottony Cushion Scale, and in this case an unqualified success resulted. On the other hand, the attempt to establish the Chinese Lady Beetle in this country to control the San José Scale has thus far been a failure, and the introduction of the parasite Scutellista cyanea Motsch. to work on the Black Scale cannot be regarded as more than partially effective.

The danger of introducing along with the parasite, its own parasites (secondary parasites) at such a time is great, and therefore this work should be attempted only by those especially trained for it.

All in all, the "bug $v s$. bug" idea is one which, though always having many possibilities of success, is also one which will often fail, and therefor cannot be relied upon as a certain panacea for troubles caused by introduced pests. 


\section{CHAPTER XXVII}

\section{THE NEUROPTERA}

The insects placed in this group, though quite similar in structure, differ markedly in appearance in many cases. They vary much in size, ranging from less than a quarter of an inch to several inches in length, and their wings may be small or large.

The mouth parts are for chewing or biting, and most of the group feed upon insects and other small animals. The wings are four in number, well supplied with both longitudinal and (with a few exceptions) cross-veins. The larvæ in general are active, moving about in search of their prey. A few though, live in the egg sacs of spiders, feeding on the young spiders, and in one or two cases, fresh-water sponges appear to be their food. There is a quiet pupa stage.

The group may be characterized as:

Insects which when adult have two pairs of wings usually large as compared with the body and with numerous longitudinal and (in most cases) cross-neins. Mouth parts for chewing. Metamorphosis complete.

So far as is known, none of the Neuroptera are injurious insects and some at least are decidedly beneficial. About half a dozen families are usually recognized and some of these are here considered, either because of their economic importance or because they are large and common enough to frequently attract attention.

In the family Sialidæ belongs the largest member of the order (Fig. 217) found in the United States. This is commonly called the Corydalis or Hellgrammite (Corydalis cornuta L.) which is quite common throughout the country except in arid regions. The mandibles of the male are nearly an inch long, slender and somewhat curved; those of the female are short. The distance from tip to tip of the wings when these are extended, may be over five inches, and the size of the insect and the long jaws of the male have led to the mistaken belief that this really harmless animal is dangerous. The egg are laid in large masses on objects which hang over the water, into which the larvæ enter on hatching, making their way under stones where they feed for nearly 3 years on the nymphs of May-flies, and other insects. Here they are searched for by fishermen to use as bait, and are usually called "Dobsons." When full-grown the larva makes a cell under some stone close to the stream and pupates for about a month, after which the adult escapes . 
Smaller species, some with gray, black, or black wings spotted with white, belong here. They are often quite common around streams and ponds during the summer months and are frequently called "Fish-flies."
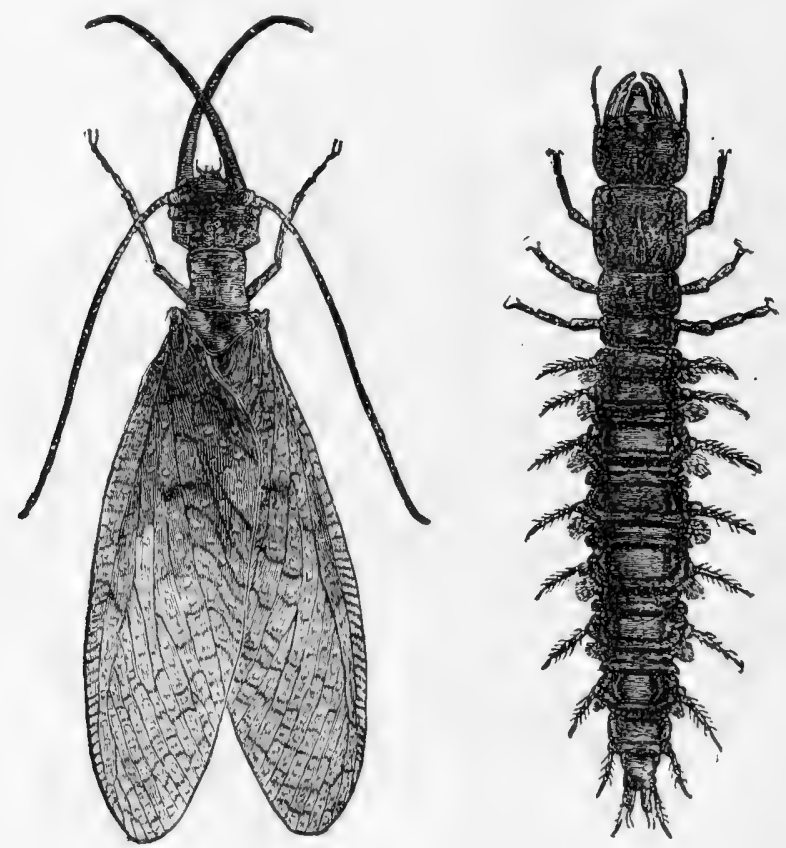

Fig. 217.-Adult Corydalis, about natural size and its larva. (From Sanderson and Jackson, Elementary Entmology; after Comstock.)

The members of the family Chrysopidæ are of great economic importance as the larvæ feed freely on injurious insects, particularly aphids, and are so voracious that they are often called Aphis-lions. The adults (Fig. 218) are rather small, slender-bodied insects averaging less than an

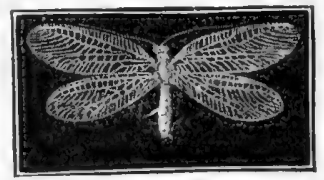

Fig. 218.-Adult Lacewing (Chrysopa plorabunda Fitch), slightly reduced. (From Folsom.)

inch long, with long antennæ and large, finely-veined, green wings, which when not in use are carried sloping over the body. These adults are sometimes called "Golden-eyes" because of their shining, golden-yellow eyes, but perhaps more frequently "Lace-wings" from the delicacy and beauty of these structures. 
The Lace-wings are found practically everywhere in this country and are usually quite abundant. They lay their eggs on the stems, branches, and leaves of plants, first constructing a slender but quite stiff stalk of silk about half an inch long, to the end of which the egg itself is attached (Fig. 219). These eggs are usually placed in groups and it is believed that were the eggs not raised on stalks out of rach, the first larva to hatch would at once proceed to eat the eggs as its first meal.

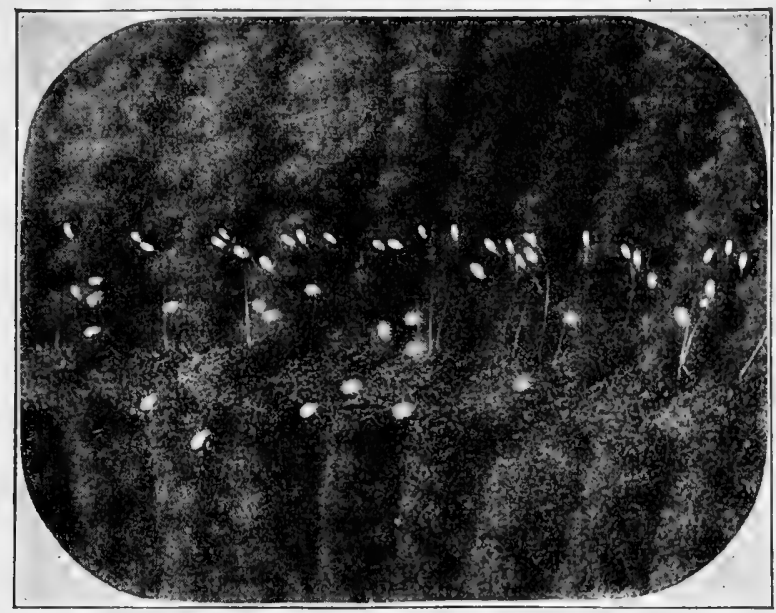

FIG. 219.-Eggs of a Lacewing, greatly enlarged. (From Sanderson and Jackson, Elementary Entmology; after S. G. Hunter.)

These larvæ are rather short, somewhat oval in outline, and have long mandibles with which they grasp their prey. The lower side of each mandible is grooved and the maxilla of the same side is so modified as to fit into this groove and convert it into a tube. An insect attacked by an Aphis-lion is seized by the tips of the jaws and its blood is drawn through the tubes into the body of its captor.

Aphis-lions are often found in colonies of plant lice which have by their - feeding caused leaves to curl, and with an abundant food supply thus provided, the insect is both protected by the leaf and insured of the food it needs for its development.

When full-grown the Aphis-lion forms around its body a white, shining, spherical silken cocoon in which it pupates. When this process is complete the adult cuts out a circular piece of the cocoon, forming a hole through which it escapes.

The importance of Lace-wings as friends of man is such that they should be protected and not destroyed under the impression that being among known pests they must also be for that reason injurious. 
In the Western States are a few insects belonging to the Neuroptera, and family Raphidiidæ. They are small, less than an inch in length, but with an unusually long prothorax (Fig. 220). The larvæ feed on other insects and, among others, on codling moth larvæ. They occur chiefly under loose bark in this stage, and while not as abundant as could be desired, do good work by attacking many injurious species. They have been introduced into Australia in the hope that they may become effective enemies of the codling moth there.

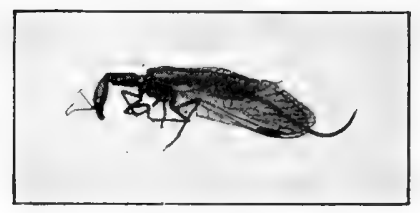

FIG. 220.

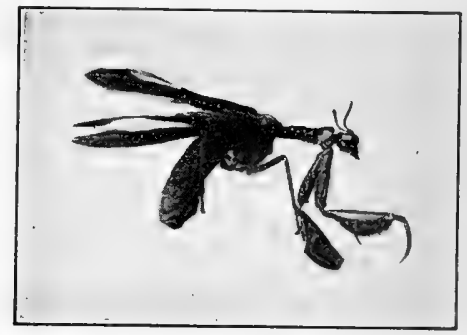

FIG. 221.

FIG. 220.-Adult Raphidian (Raphidia oblita Hagen), about twice natural size. (Original.)

FIG. 221.-Adult Mantispa (Mantispa brunnsa Say) showing grasping front legs. Somewhat enlarged. (Original.)

Another family, the Mantispidæ, though few in numbers, has its members quite widely distributed. The Mantispas (Fig. 221) as they are called, like the Raphidians, have a greatly elongated prothorax and their fore legs are also long and adapted to grasping their prey. The adults are larger than the Raphidians, being about an inch in length and with long wings. Though feeding on other insects, most of which are likely to be injurious, the Mantispas are not numerous enough to be of any great importance.

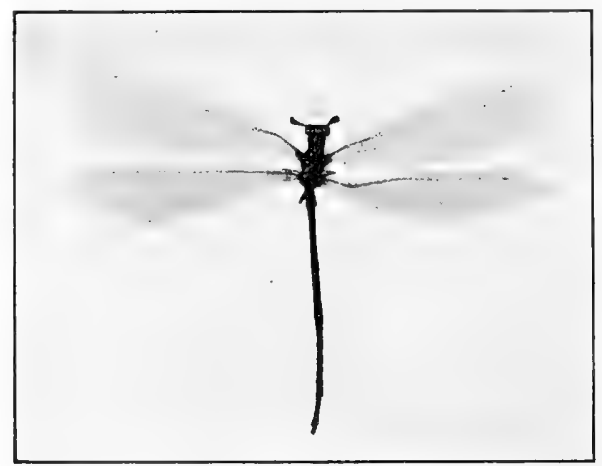

FIG. 222.

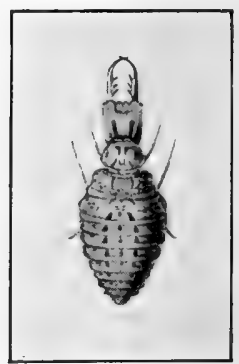

Fig. 223.

FIG. 222.-Adult Ant-lion about natural size. (Original.) FIG. 223.-Larva of an Ant-lion, about twice natural size.

(After Meinert.)

The insects belonging to the Family Myrmeleonidæ are generally spoken of as the Ant-lions, though the name "Doodle-bug" is sometimes applied to their larvæ. They are widely distributed over the United States, particularly in sandy places, but are most abundant in the South. 
Many kinds of the adults (Fig. 222) superficially greatly resemble the "damsel-fly" section of the Dragon-flies (Odonata), their long, slender bodies, large, gauzy wings and their general size causing the resemblance. Their antennæ, however, instead of being very small and not noticeable, are of fair size and knobbed at the tip, which provides an easy way by which to distinguish the two groups. Other characters and their life history also prove that the resemblance is only superficial.

The larvæ of the ant-lions (Fig. 223) greatly resemble those of the lace-wings in general form and in the possession of long jaws grooved for sucking the blood of their victims. They excavate little conical pits in soft, dry, preferably sandy ground, an inch or two across and as deep as possible for the sandy sides to hold. At the bottom of the pit thus dug the young ant-lion buries itself except for its head, and waits for an unwary insect to fall in. Sliding down the slope of loose earth the victim literally falls into the jaws of the waiting enemy and is killed and devoured. It has been stated that sometimes the insect on its way down the side of the pit is able to check itself and start to climb out, and that then the ant-lion shovels a load of sand onto the top of its flat head, with its leg, and snaps the sand up the side of the pit, where falling, it sweeps the prey down to the bottom within reach of the ant-lion!

The process of excavating the pit is also one of extreme interest. The insect first traces out a circle of the desired size, loading its head with sand from inside the circle and snapping it out, and on completing the circle, repeats the process but in the reverse direction, and this is continued until the pit has been completed. In doing this the larva always moves backward.

After becoming full-grown the ant-lion larva forms a spherical cocoon of sand and silk in the ground, within which it transforms to the adult.

The ant-lions, though feeding on other insects, are of little if any economic importance as the forms they are most liable to capture are not of ten probably, serious pests. Their habits and manner of life, however, are so interesting that much attention has been given to them and what has been published about them forms one of the most interesting chapters of Entomology.

The Neuroptera, though widely distributed over the world, do not constitute a large group. Less than two hundred kinds are known in this country, and probably not more than a thousand kinds in all have thus far been discovered. Fossil specimens of several of the families have been recognized. 


\section{CHAPTER XXVIII}

\section{THE TRICHOPTERA}

The Caddice (sometimes spelled Caddis) Flies, as the members of this order are usually called, are rather soft-bodied insects ranging in size from less than an eighth of an inch to an inch or more in length.

The wings, though much reduced in a few cases, are almost always large and well developed, with numerous longitudinal, but few cross-veins. They are membranous, the front pair somewhat leathery, and all are more or less densely covered with hairs which in some species are rather scale-like in form. The hind wings are usually broader than the front pair and when not in use are sometimes folded lengthwise. The position of all the wings when at rest is with their hinder margins together over the back of the insect and their costas down at the sides of the body, upper faces sloping downward and outward like a house roof (Fig. 224).

The mouth parts of the adult are poorly developed though evidently modified from the chewing type and it is probable that little if any food is taken in this stage. The antennæ are generally well developed, and in some species they may be several times as long as the body. The legs are quite long and slender.

The larvæ (Fig. 225) somewhat resemble small caterpillars in form. They are nearly all found in water, chiefly that of ponds or slow-running streams, though a few inhabit rapid currents. The abdomen is soft, the chitinous skin being delicate, and the larva therefore construct cases of various materials as a protection for this portion of the body.

The Trichoptera may be defined as:

Insects which as adults have rather soft bodies: four membranous wings with numerous longitudinal and few cross-veins, and more or less closely covered by hairs, folded over the body like a house roof when at rest: mouth parts rather rudimentary: antennce and legs quite long, the former sometimes exceptionally so. Larve living in cases, nearly always in the water. Metamorphosis complete.

The adult Caddice-fly, though having well-developed wings, is not a strong flier and these insects are therefore most frequently found near water.

The eggs are, at least usually, laid in clusters in a mass of jelly, and are probably dropped into the water. On hatching, the larvæ begin the construction of cases in which to live. The materials of which these are 
made differ according to the species of Caddice-fly concerned and vary greatly (Fig. 226). Some take pieces of leaves which have fallen into the water; others select veins of the leaves and similar sized straws and put them together cris-cross, something like the logs of a log house; some species use the finest sand for this purpose;

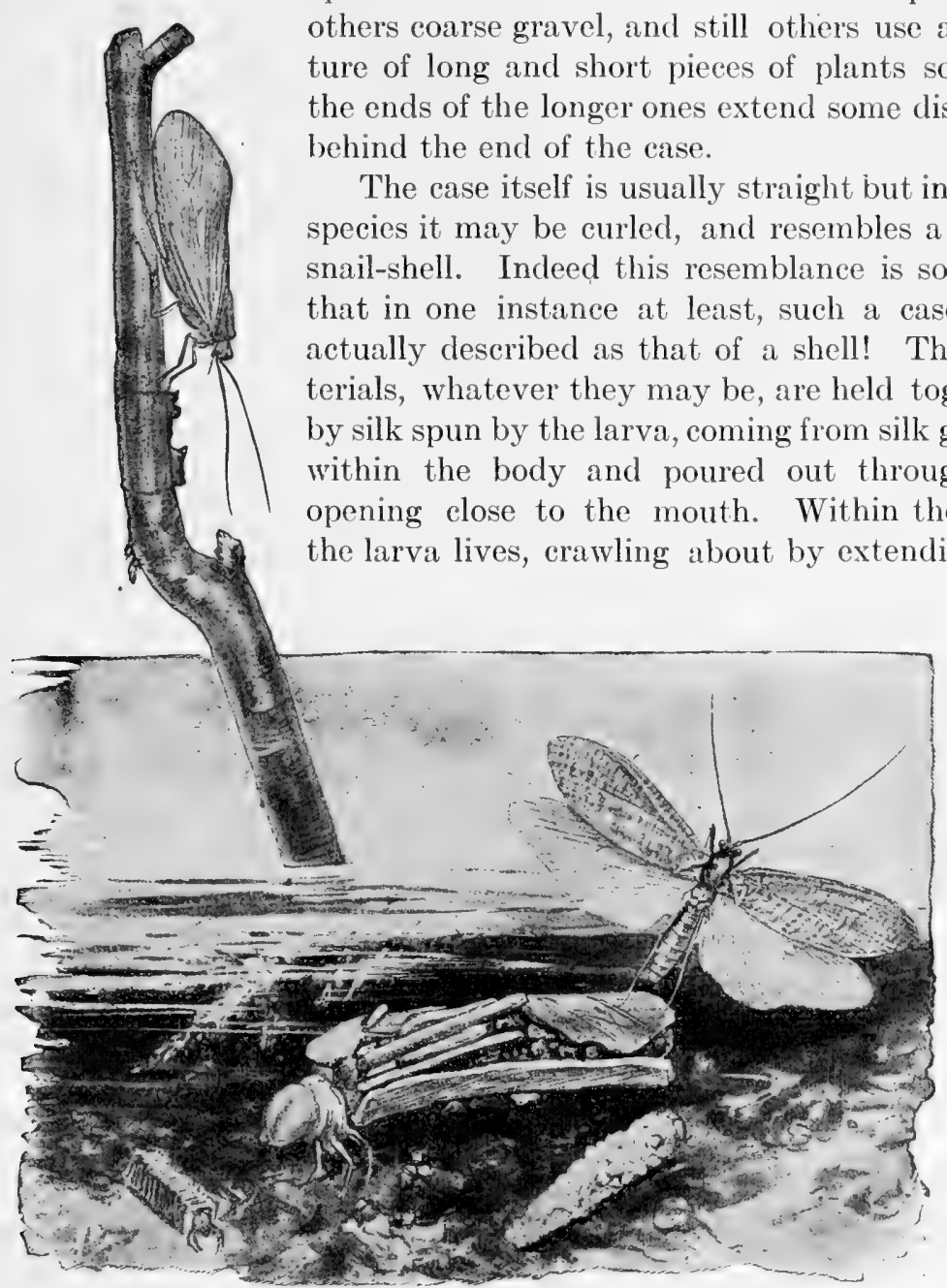

FIG. 224.-Caddice-flies: adult at rest, above; with wings spread, below. Larvæ showing three kinds of cases, crawling. (From Linville and Kelly, General Zoology.)

head and thorax out of the front end so that its feet can be used, and dragging the ease along.

Some caddice-fly larvæ make simpler houses than these. Such species live in rapid water and there fasten a few tiny stones under rocks by their 
silk, and between these spin a silken tube in which to live. Close to this they spin more or less funnel-shaped webs, the mouth up-stream and so arranged that tiny animals swept down by the current within the outer limits of the funnel come within reach of the larva lying in its tube. While the food of these larvæ is carnivorous, in most of the species plant materials are consumed.

The larvæ, in most cases, breathe by tracheal gills which are slender filaments, frequently grouped in clusters, and attached to the abdominal segments. Other structures present in some species are also suspected of being concerned with respiration.

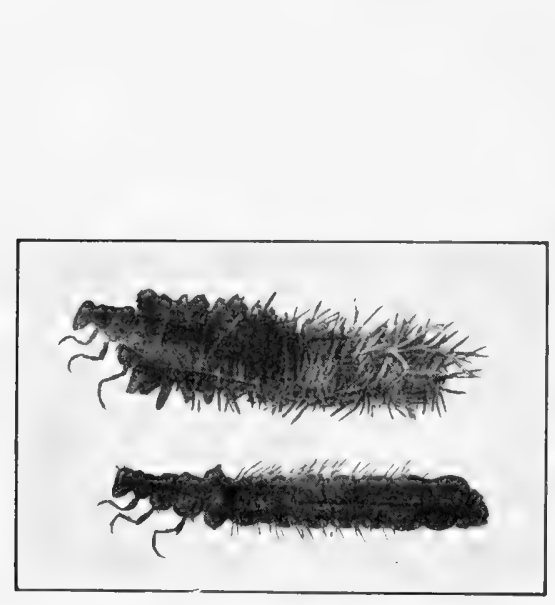

FIG. 225.
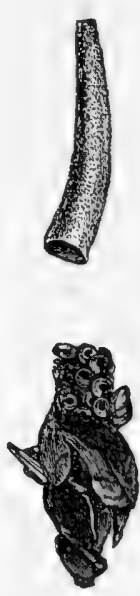

FIC. 225 - Ceddice-fly lar above; larva removed from its case, below, showing tracheal gills. About twice natural size. (Modified from Leuckart's Wandtafeln.)

FIG. 226.--Examples of different types of cases formed by Caddice-fly larvæ. (From Sanderson and Jackson, Elementary Entomology: after Furneaux.)

When full-grown the Caddice-worm forms a sort of lid or door grating across the front opening of its case, though not complete enough to prevent water from entering and supplying the insect with the oxygen it needs. After pupation in its case the adult swims to the surface and grasps some object, from which it takes its flight. In some species it is apparently the pupa which when ready to become the adult, comes to the surface and passes its final molt there.

The Trichoptera is quite a large group of insects and representatives of it are found in almost all parts of the world. Probably not many more than a thousand species have been described, as they do not appear to be of any economic importance unless their consumption of decaying vegetable matter in pools can be considered as desirable, but it is very likely that there are from five to ten thousand kinds in existence. Their cases have been found as fossils and adults have also been preserved in this way. 
The Trichoptera are evidently closely related to the Lepidoptera in many ways and are undoubtedly with the last-named order, divergent descendants from common ancestors. Some Lepidoptera so closely resemble Trichoptera in fact, that they have been placed in the latter group. They also have many resemblances to the Neuroptera, but their connection with this order is plainly more remote, and sufficient time has elapsed since the divergence of the present Neuroptera and Trichoptera from their common ancestors, to permit the development of many differences. 


\section{CHAPTER XXIX}

\section{THE LEPIDOPTERA}

The Lepidoptera are the moths and butterflies, which form one of the largest and most noticeable groups of inscets. Its members are found in all countries and their large size in many cases, their brilliant colors and the habits of their larvæ as well as the injuries they cause, have attracted much attention.

The adults have four, large, membranous wings in most cases (a few have lost their wings), more or less completely covered by overlapping scales making the wings opaque where these are present. Colors of the

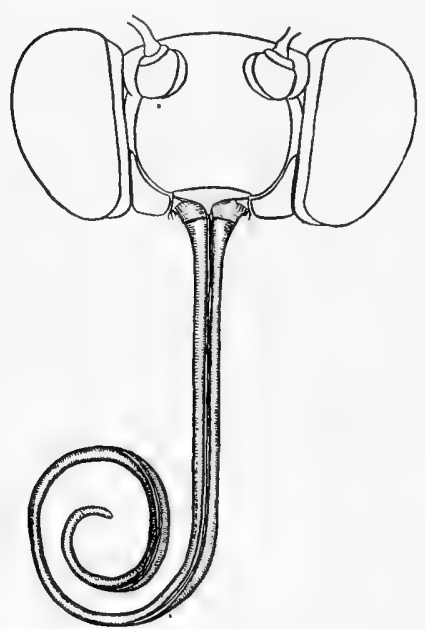

FIG. 227.-Diagram of head of a Lepidopterous insect, showing the tongue. (From a drawing by M. F. Webster.) wings are due either to the presence of pigments in the scales: to optical colors caused by the surfaces of the scales breaking up the light striking them; or by both factors together.

The mouth parts of the adult are greatly modified from those of chewing insects, though enough remains to show that the ancestors of the group must have fed by chewing. The development of the parts varies in different species, some of the lower forms having as a whole, a much closer resemblance to the condition in chewing insects than is the case with most of them. In one group, the mouth parts are sufficiently of the mandibulate type to enable the insects to feed on pollen.

In general a labrum or front lip is evident, but the mandibles are practically lost. The maxillæ are extremely modified, a portion of each contributing its half to the formation of a proboscis or tongue (Fig. 227). This is a flexible organ varying greatly in length, its two halves so interlocking as to form a tube between them, through which, when completely developed, fluids may be drawn into the mouth. The degree of development of the proboscis differs greatly in different Lepidoptera, and while it is functional in perhaps the majority of the group it is only partly developed or even rudimentary and useless in others. Such Lepidoptera evidently do not feed while adult. 
In some cases the maxillary palpus is developed: in others it is nearly or wholly lacking. The labium or hinder lip is also practically absent except for the labial palpi which are usually large, thickly covered by hairs or scales, and project forward at the sides of the head, often turning upward somewhat, and partially or wholly concealing the proboscis when this is coiled up under the head, the place where it is carried when not in use.

The mouth parts of the larva (or caterpillar as it is usually called) are entirely different. In this stage they are chewing structures, similar to those of a grasshopper in a general way, and no special description is needed. In the center of the end of the labium, however, is a slender projection called the spinneret, which at its tip has the external opening of the duct leading to the silk glands.

The antennæ of adult Lepidoptera are usually quite long but vary greatly in their form in different species. In the butterflies they are slender but enlarged near the tip forming a club (Figs. 309 to 317), or with this enlarged part bent into a sort of hook (Fig. 308). These forms of antennæ are almost never found in the moths, where they may be simple and thread-like; with small hair-like projections at the side; bristles in place of the hairs; clusters of the bristles; with tooth-like or saw-like side projections; with long projections on one or both sides, in the latter case giving the antennæ a feather-like appearance; and other forms also occur. (Compare Figs. 228 to 305).

The eyes are large, though in some cases partly concealed by hairs or scales, which as a rule thickly clothe the entire body. Ocelli are also sometimes present. On the top of the prothorax a pair of projections or lobes often occurs, called patagiæ, sometimes very large and capable of some movement; in others, smaller or even reduced to mere traces. On the large mesothorax is a somewhat similar pair of structures called the tegulæ which extend backward over the point where each fore wing articulates with the body. The abdomen may be long or short, stout or slender, connected with the thorax either by a broad or a rather constricted attachment. 'The legs are quite long and slender.

Characters by which the members of this group may be distinguished are:

Insects which as adults have (with a few exceptions) four membranous wings more or less completely covered by overlapping scales: mouth parts for sucking. The larvo have chewing mouth parts. Metamorphosis complete.

The Lepidoptera is such a large order that great differences in its members are very common. The smallest ones are almost microscopic while the largest one known may measure about a foot between the tips of its expanded wings. The wings of each side, to obtain their greatest efficiency, are more or less completely coordinated for flight by one 
of three methods. In the butterflies and some of the moths, the basal portion of the costal region of the hind wing is enlarged, forming a sort of shoulder over which the hind margin of the fore wing lies, thus enabling the two to a large extent, to function as a single wing. In most moths, however, instead of a shoulder, a rather long, curved bristle or cluster of bristles, called a frenulum, arises near the base of the hind wing and runs forward and outward, passing under a small flap or through a tuft of scales on the under side of the fore wing, so that as the two wings move in flight, this frenulum slides backward and forward in its track under the fore wing and holds the two together. A third type of connection, found in only a few moths, is a small lobe near the base of the hind margin of the fore wing, which extends backward toward the hind wing. This lobe is called a jugum and is also probably more or less effective in producing coordination in the use of the wings.

The number and arrangement of the wing veins is of great importance in the Lepidoptera, much of the classification in this order being based upon these structures. The main veins (see Fig. 20) are of course, longitudinal, starting at the point of attachment of the wing to the body and diverging toward its outer margin, some of them branching several times. Cross-veins are very few, however, and consequently there are only a few closed cells (see page 13), and some at least (perhaps all) of these are produced by the fusion of branches of longitudinal veins, rather than by true cross-veins.

Various ways of designating the veins and their branches have been offered, but these are best comprehended in connection with laboratory work on the insects themselves, and are therefore not given here.

The eggs of Lepidoptera vary greatly in form and also in color. They may be elongate, spherical, flattened, scale-like, or of other forms, and the shell or chorion may be smooth or sculptured with ridges and reticulations. The eggs may be laid singly or in clusters and may or may not be covered with hairs from the body of the parent moth, or with a secretion which conceals them from view. They may hatch in a few days or after longer periods, in some cases many months. The adults have no ovipositor so the eggs are always laid on the surface of the place of deposition, though if the abdomen of the insect be small, this may be in a small crack or other opening.

The larvæ produced by the hatching of the eggs are called caterpillars and have no resemblance whatever to the adults they are to become. They are usually rather worm-like animals, with a generally recognizable head and a body consisting of a series of rather similar segments, the first three of which correspond to the thorax of the adult and almost always bear six legs. Some of the following segments will also have legs but these are totally different in structure from the others and are merely temporary in their nature, designed to support this portion of the body. 
The internal structures of the caterpillar do not differ greatly in their arrangement from those of an adult insect, except that the reproductive organs are only slightly developed at this time, and in the presence along each side of the body of a silk gland, large in those which will later need large quantities of silk, but present in all. A duct from each gland runs forward to the mouth where the two unite and open to the exterior through the spinneret already referred to.

Most caterpillars feed on plants or vegetable material. Their work is noticed chiefly by their stripping plants of their leaves, though some bore in stems, roots, fruit, seeds or other parts. A few attack feathers, silk, etc., but this is not the general habit. The larval stage may last only a few days for some species but is generally a month or more, and some feed during the fall, become quiet during the winter, and complete their feeding the following spring.

A large majority of the caterpillars are termed naked, having only a few tiny spines or hairs, not large enough to be noticeable. From this condition every grade of density of covering occurs, to species entirely covered by long, thickly placed hairs which give the animal a hairy or "woolly" appearance. Some have large warts or horns on the thorax or a sort of horn above, near the hinder end of the body.

Their colors also vary greatly, some being brightly colored while others, green, either with or without white streaks, appear to seek concealment by their resemblance to the leaves on which they feed. Those living in protected situations, such as in plant stalks, are nearly white: cutworms which pass the day in the ground are dark as a rule, with rather faint markings.

When the caterpillar has become full-grown it generally leaves the place where it was feeding and in some satisfactory location, spins a cocoon around itself, using for this purpose the silk produced by its silk glands. In some species the cocoon is very complete, thick, tough, and entirely conceals the larva within. On the other hand, there are cocoons where only sufficient silk is used to attach the insect and hold it in place; and between these extremes all degrees of cocoon construction occur. Sometimes leaves, hairs from the body of the caterpillar, or dirt when the insect enters the ground at this stage, are incorporated in the cocoon.

Within the cocoon the caterpillar molts, leaving its cast-off skin at one end. The result of this molt is a pupa, its form showing through its new skin which is generally brown, the outlines of the adult body and its appendages including the wings being evident, these last, however, very small as there would be no room for the full-sized wings of the adult within the cocoon. Internal changes and the completion of such external ones as are necessary, now proceed until the adult insect has been entirely formed, and is ready to escape. When this happens another molt re- 
leases the insect from the brown outer pupa skin, and either before or after this, an opening in the cocoon is made and the adult emerges. It then crawls up on something and remains quiet for a while; its wings being free to expand, increase rapidly till of their full size; the surplus fluids in the body are expelled, and after an hour or two the insect is ready for flight.

While for most Lepidoptera this outline of development is in general correct, in the butterflies we find that cocoon making is limited to attaching the hinder end of the body by silk, to the object on which it is to pupate, and the formation of a silken loop around its body to hold it up. Such a pupa, producing a butterfly, is usually given the special name "chrysalis." (See Fig. 317f).

Besides the names "butterflies" (Rhopalocera), and "moths" (Heterocera) used to distinguish different sections of the Lepidoptera, we also have the terms "Microlepidoptera" or small moths, and "Macrolepidoptera" or large ones. These are wholly relative and rather indefinite, but are nevertheless convenient in spite of the fact that it would be cloubtful under which head to designate many species of the order.

The latest list of the insects of this order found in North America places them in about 70 families, but there are more of these divisions in other parts of the world. Some of the families include many species and insects of much economic importance, while others have only a very few. Only the more important families, either in size or because of the pests they contain, are included here.

Family Cossidæ (Carpenter Moths).-The larvæ of the moths belonging in this family bore in trees and are sometimes quite injurious. There are several native species, the most common being the Carpenter Worm or Goat Moth (Prionoxystus rolinice Peck) which lays its eggs in the crevices of the bark of various trees. The larvæ bore in the limbs injuring or killing them, and the entire life history is believed to take 3 years. The adults which appear in June and July are quite large, the wings of the female spreading about three, and those of the male about two inches. The wings are mottled light and dark gray, except the hind wings of the male which are yellow. The Leopard Moth (Zeuzera myrina L.), a European pest belonging in this family, reached this country before 1879 and now occurs along the Atlantic Coast from New Hampshire to Delaware and a rather short distance inland. The wings of the moths (Fig. 228) spread from one to about two inches and are white with numerous black spots. The thorax has seven black spots above. The moths appear from May till September and lay their eggs on the bark, several hundred in all, but usually only a few at a place. The caterpillars (Fig. 229) are liable to enter the small twigs, but may enter elsewhere, and bore through the wood. Small twigs are killed and larger ones weakened and in time may also be destroyed by this boring, and if the branch becomes too small at any time for the larva, it will leave it for a larger one. Injured limbs are often so weakened as to break off during storms. The borer feeds during parts of three seasons, pupating in its burrow the third spring. It is more abundant in and near cities and towns than in the open country 
The work of borers of this group is often evidenced by fine chips, excrement or frass pushed out of the entrances to the tunnels; by wilted leaves; by tunnels

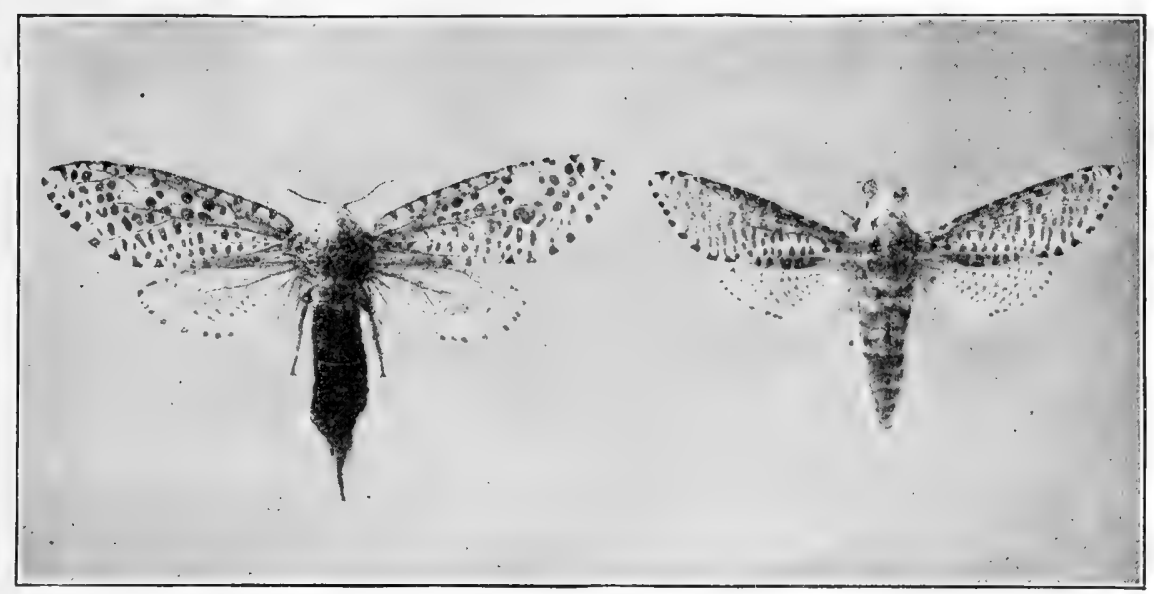

FIG. 228.-Adult female (left) and male (right) of the Leopard Moth (Zeuzera pyrina L.) about natural size. (From Britton, Eleventh Rept.Ent. Conn. Agr. Exp. Sta. 1911.)

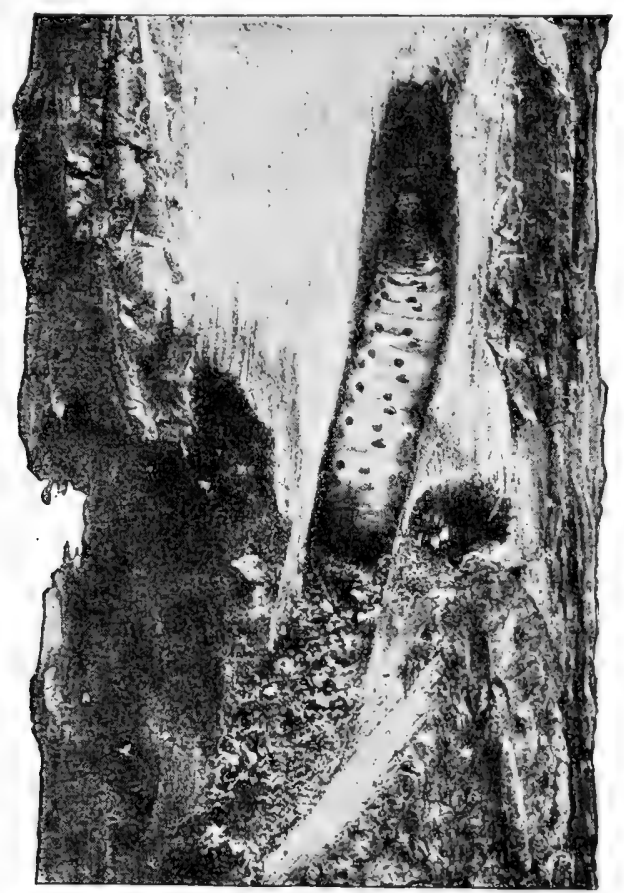

Fig. 229.- I Iarva of Leopard Moth in its burrow. Natural size. (From Britton, Eleventh Rept. Ent. Conn. Agr. Exp. Sta. 1911.)

in fallen branches, and by splits and breaks in the bark when the larvæ work just beneath it. 
Control for the Leopard Moth and for Carpenter Moths in general is to locate the entrance holes of the larvæ and inject a little carbon disulfid into them, then stopping the opening with putty, mud or wax. Thoroughly infested trees should be cut and burned during the cold months, to destroy the caterpillars in them, as such trees are doomed in any case.

Family Tineidæ (Tineids).-The insects belonging in this family are all Microlepidoptera, the distance between the tips of their wings when spread being generally much less than an inch. They are not noticeable insects and only a few are of great importance. Three, however, are serious household pests and cause much injury, being the species commonly called Clothes Moths, all natives of Europe but for many years now, present in this country.

The Case-making Clothes Moth (Tinea pellionella L.).-This is the most generally distributed of the three species and is the most common one in the North. The moth flies at night and may frequently be seen in

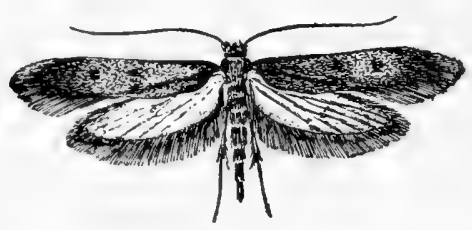

FIG. 230 .

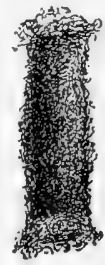

FIG. 231

FIG. 230.-Adult of Case-making Clothes Moth (Tinea pellionella L.) four times natural size. (From Herrick's Insects Injurious to the Household. By Permission of the Macmillan Company, Publishers.)

FIG. 231.-Case of the Case-making Clothes Moth, three times natural size. (From Herrick's Insects Injurious to the Household. By Permission of the Macmillan Company, Publishers.)

infested houses flying about the rooms but not attracted to any light there may be present. In fact, if during June, July or August any tiny moth flies to the light in a room at night, that fact is of itself evidence that the insect is not a clothes moth.

The adult (Fig. 230) is grayish-yellow with faint spots, its hind wings more nearly a silvery gray. It spreads about half an inch. The eggs are generally laid on woolen goods of any kind, furs or feathers. They hatch in about 10 days and each larva constructs a case (Fig. 231) made of particles of the materials on which it feeds, lined with silk, and with its body in the case, crawls about, feeding as it goes. As it grows and the case becomes too small, the caterpillar enlarges it and when full-grown attaches it to some object and pupates in it, the moth emerging about 3 weeks later. In the North there usually seems to be but one generation a year but in the South there are two and possibly more.

The Webbing Clothes Moth (Tineola biselliella Hum.).-This species, though found in the North, is most common in the South. The adult 
(Fig. 232) is of about the same size as that of the last-described species, but its fore wings are uniformly yellowish. There are two generations each year. The caterpillar feeds on the same materials as that of the Case-making Clothes Moth and has also been known to eat cobwebs, dried specimens of insects and beef meal. It does not form a case but spins a sort of web of silk as it moves about. When ready to pupate it forms a cocoon of silk to which particles of wool or whatever it has been feeding on, are added.

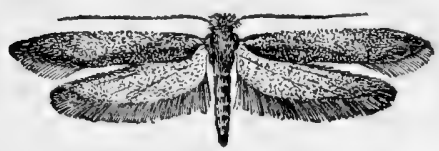

FIG. 232 .

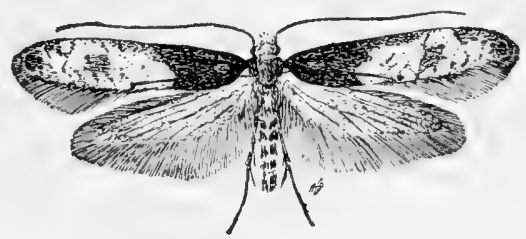

FIG. 233.

Fig. 232. - Adult of the Webbing Clothes Moth (Tineola biselliella Hum.), four times natural size. (From Herrick's Insects Injurious to the Household. By Permission of the Macmillan Company, Publishers.)

Frg. 233.- Adult of the Tapestry Moth (Trichophaga tapetzella L.), three times natural size. (From Herrick's Insects Injurious to the Household. By Permision of the Macmillan Company, Publishers.)

The Tapestry Moth (Trichophaga tapetzella L.).-The Tapestry Moth is not as common in this country as the other two clothes moths, and is a larger insect (Fig. 233), spreading about three-quarters of an inch. It seems to prefer to attack heavier and coarser cloths than the other species, as well as felts, skins, etc., and is found in carriage upholstering and similar places, as often as in houses. The caterpillar tunnels in its food, lining the galleries somewhat with silk, and in these galleries it also pupates.

Control for Clothes Moths.-All woolen goods, furs, feathers, rugs and similar materials not in regular use during the summer should be carefully aired in the sun as long as possible, and brushed, beaten or shaken thoroughly before being put away in the spring. They should then be placed in tight trunks, boxes or bags either of cloth or paper. After being thus treated they should be safe for the summer, provided no eggs nor larvæ have escaped and are still present in the materials. But a surer method is to thoroughly fumigate the articles when they are packed away, using carbon disulfid. Thus an ordinary trunk filled with such articles can be fumigated for from 24 to $48 \mathrm{hr}$., then opened and a liberal supply of moth balls (naphthaline) or flake naphthaline be added and the trunk finally closed.

Repellents are of some value to keep clothes moths away from materials liable to injury, but their value is largely dependent upon the amount used and on whether the insects are already present. It appears that while clothes moths will not usually, at least, lay their eggs on materials stored with an abundant supply of naphthaline, this substance 
in any such amounts as are usually added will not keep eggs already present from hatching, nor the larvæ from feeding. Therefore, fumigation first, to kill any of these insects which may be present in any stage, followed by an abundant supply of naphthaline to keep them away thereafter would seem to be the best method of procedure.

Other repellents often used are cedar-wood chests, sprigs or chips of cedar, camphor, tarred paper, and tobacco. They are all repellents, but apparently less effective than naphthaline. In the case of cedar it is the oil present which gives the protection, and as this is volatile it is lost after a time and then a cedar chest is of no more value for storage than one of any other kind of wood.

Closets of ten become infested by clothes moths and even after taking out and treating the clothing the moths may appear. It is probable that in such cases the larvæ find particles of wool or other edible materials in the cracks of the floor or e! sewhere on which to live. In such cases the free use of gasoline or kerosene on the walls and floors, paying particular attention to all cracks, followed after a few hours by a thorough airing, should give relief. If not, fumigation of the closet, being careful that cracks around the doors or other openings are tightly sealed, will exterminate the insects there.

Rugs and carpets infested should be thoroughly cleaned and can then either be baked to $125^{\circ} \mathrm{F}$., fumigated as above, or sprayed with benzine. Furniture attacked may be saturated with benzine or fumigated. Where an entire house is infested, no one place apparently more than another, fumigating with hydrocyanic acid gas at the rate of $1 \mathrm{oz}$. of sodium cyanid to every $100 \mathrm{cu}$. ft. of space has given good results.

Rugs, furs and woolens valuable enough to place in cold storage may be protected during the summer by cold. It has been found that exposing infested goods to very low temperatures for a few days, followed by another short period in a fairly warm place, then returning them to the cold room for a short time will kill the insects present, these being unable to live through such severe temperature changes. After this the articles can be stored during the rest of the season in a temperature of about $40^{\circ} \mathrm{F}$. with safety.

Family Eucosmidæ.-In this family are a number of pests of fruit trees and other plants. All of them are small moths, rarely spreading over three-quarters of an inch. One of the worst pests of the apple-the apple-worm or codling moth-belongs here.

The Codling-moth (Laspeyresia pomonella L.).-This pest of apples, pears and occasionally of other fruits is a native of Southeastern Europe but is now found almost everywhere and is present in all the apple-growing sections of this country. 
The adult moth (Fig. 234) has its fore-wings brown, crossed by irregular gray and brown lines. It spreads about three-quarters of an inch and is not of ten seen as it flies only at night and is not attracted by lights.

Winter is passed in the full-grown caterpillar stage in some protected place, usually under a piece of bark of the tree where the insect fed (Fig. 235). Under the bark the caterpillar digs out an oval cavity and lines it with silk in which to winter. In the spring it pupates here and the adult moth escapes a week or two after the petals fall at the blossoming season in the

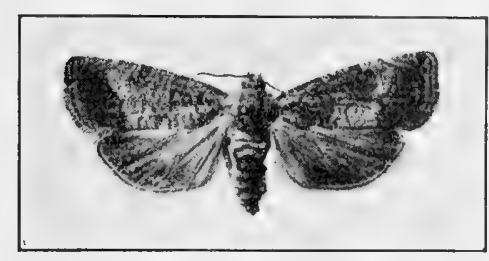

FIG. 234 ,

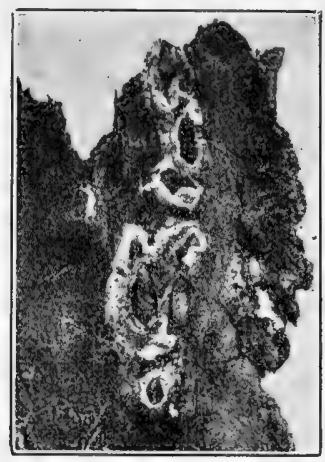

FIG. 235.

FIG. 234.-Adult Codling Moth (Laspeyresia pomonella L.), twice natural size. (Original.)

Fig. 235.- Piece of bark showing Codling Moth cocoons and pupre on its under surface. About one-third less than natural size. (Modified from Cornell Agr. Exp. Sta. Bull. 142.)

spring. Tiny, white, flattened eggs, 50 to 75 in number, are now laid singly on leaves, twigs or on the small fruit, but mainly on the leaves. The eggs hatch in about a week and the little caterpillars feed for a short time on the foliage, but soon leave this and crawl to the fruit, where from 60 to 80 per cent enter at the blossom end, often burrowing their way through between the closed calyx lobes or sepals to reach the cup-shaped cavity within. From the bottom of this cavity they tunnel into the fruit to the core, in and around which they feed until full-grown; a period of nearly a month in most cases. The other 20 to 40 per cent enter the fruit at any point, but appear to prefer a place where a leaf or some other object lies against the fruit.

When its growth has been completed the caterpillar (Fig. 236) is

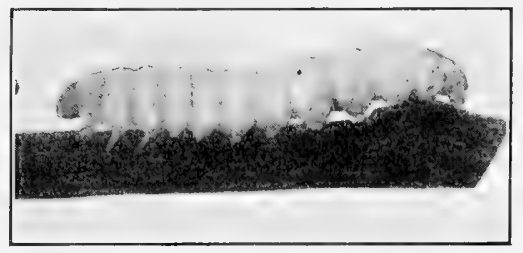

FIG. 236.-Full-grown larva of Codling Moth, about twice natural size. (Modified from Corncll Agr. Exp. Sta. Bull. 142.) about three-quarters of an inch long, pinkish or whitish, with its head and a patch above, just behind the head, and another at the hinder end of the body, brown. It now leaves the fruit, generally burrowing out through the side and makes its way down the tree until it finds some piece of bark loose enough to permit it to gnaw its way under, and here it forms an oval cavity as already described. 
Over the greater part of the United States there are two generations of the Codling-moth each year. Where this is the case the larva pupates in this cavity for about 2 weeks before it escapes as an adult. Eggs are now laid for the second generation and on hatching the larvæ attack the fruit, which is quite well grown by this time, entering it at any point and showing no preference for the blossom end. The feeding of this generation of caterpillars proceeds as with the spring generation, but in many cases has not been completed when the fruit is gathered. In this way a number of the larvæ may be carried to the bins or barrels in which the fruit is stored. Later, they leave the fruit and make their wintering cases on the sides of the bins or elsewhere.

In the Northern States there is only a partial second generation, most of the caterpillars feeding during late June and July, failing to transform into moths that season, so that the work of the insects in fruit during the fall is comparatively unimportant. From Southern New England south, however, two complete generations are the rule and in the more southern States with long growing seasons, there may be three generations. In the West, even as far north as Washington, two generations occur. Cold and drought have a considerable effect everywhere, however, late springs reducing the number of moths which appear the same season.

The injury caused by this insect places it among our most important pests. Small apples attacked, drop in many cases, resulting in the entire loss of some of the fruit early in the season. In years of an abundant crop, this is of less importance, but in "off years" it is a serious matter. Fruit infested which remains upon the tree is reduced in value and thus another loss is produced. It has been estimated that a few years ago the State of New York alone lost apples and pears forming a third of the entire crop, which valued at $\$ 1.50$ per barrel, would amount to about $\$ 3,000,000$ per year.

Control.-There appear to be two chief ways by which the habits of this insect aid in control measures. The number which enter the fruit at its blossom end is large, and poison placed there for them to eat as they bore their way through it into the apple, has proved effective. The fact that the caterpillars feed for a time on the leaves before going to the fruit also indicates a place for successful treatment.

Accordingly, spraying with arsenate of lead, standard formula, within 10 days after the petals fall, directing the spray so that as far as possible it will fall into the cup surrounded by the calyx lobes (sepals) is the most usual method of control. In applying this spray, however, it should be remembered that in the case of the apple these calyx lobes which at first stand widely open around the edges of the cup, soon draw together and close up the cup mouth, after which no spray can be placed where it is of use (Fig. 237). This closing comes about 10 days after the petals fall 
(Fig. 238) and thus limits the effective spray period to that time. Fortunately, different varieties of apples do not bloom at quite the same time, so that spraying where large orchards are involved should begin with those

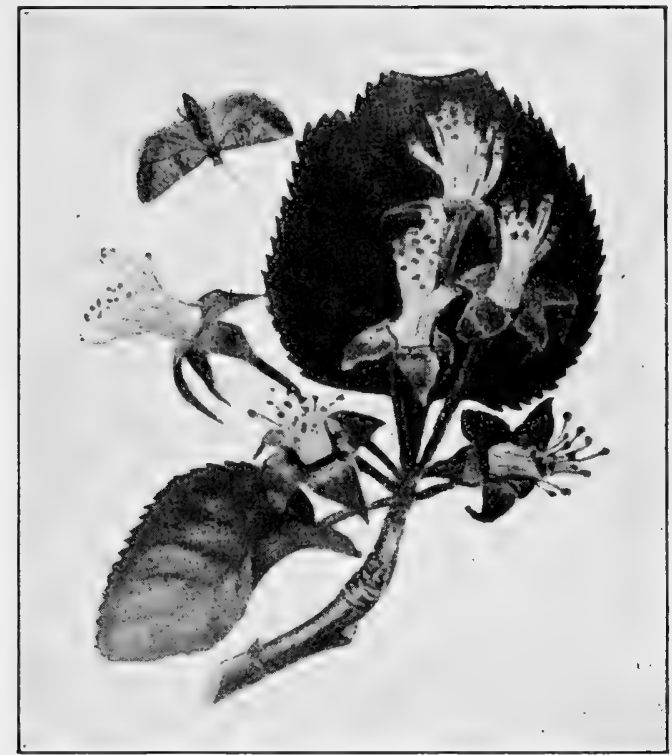

FIG. 237.-Apple blossoms in proper condition for receiving the calyx spray. Adult Codling Moth, natural size, above. (From Felt, 27th. Rept. N. Y. State Ent., 1911.)

trees which lose their petals first, taking the later-blooming varieties afterwards. When the sepals close this helps to hold the poison in the cup ready to be consumed whenever the caterpillars reach it. Where

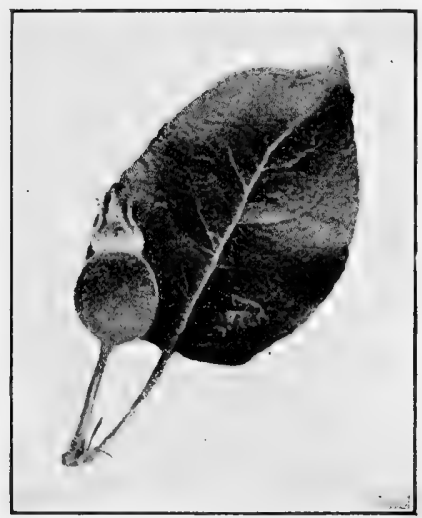

FIG. 238.- Small apple showing calyx lobes practically closed. Too late for successful spraying. (Modified from Cornell Agr. Exp. Sta. Bull. 142.)

pears are to be sprayed, their treatment can be postponed until the work on the apples has been completed, as in the pear the calyx lobes do not 
close and the spray can be successfully applied more than 10 days after the petals fall.

About 3 weeks after the petals have fallen, or perhaps a few days later, a second spray of arsenate of lead, placed upon the leaves, poisons these just before the young caterpillars of the Codling-moth hatch and begin to feed. Many of these larvæ will thus be poisoned before they reach the fruit.

Another application of arsenate of lead 8 or 9 weeks after the petals fall will poison the leaves just before the second generation of caterpillars begins feeding, which seems to be the chief protection available against these insects at this time.

Minor methods for reducing the numbers of this pest are also made use of. Some of the caterpillars may escape death from feeding on the poisoned leaves and in the first, as well as in the second generation, enter the fruit through the side. These larvæ cannot themselves be reached, but, the pupæ or adults they become, if destroyed, will reduce the number of the next generation. To accomplish this all loose bark on the trees is removed about the first of July (earlier in the South) and a loose band of cloth or burlap is placed around the trunk. The larvæ on leaving the fruit, seek for a place in which to transform to adults, and finding no bark under which to make their cocoons, crawl down the tree till they find the band which provides the opportunity they desire, and under which they therefore go. Turning over this band frequently during the summer and fall and destroying the insects found under it will therefore eliminate them from any further consideration.

Cleaning out bins, barrels and all other places where fruit has been stored, early in the spring, destroying all the insects found there is also a good practice and is a desirable treatment for the Codling moths located in such places.

In spraying for the codling-moth there has been a considerable difference of opinion as to the most successful method. Some western workers have advised a rather coarse spray driven with great force, such as by a pressure of $200 \mathrm{lb}$. or more at the pump, just after the petals fall, claiming that in this way the spray is driven to the bottom of the cup and that later sprayings are unnecessary. Others, mainly in the East, have advised a misty spray driven by a pressure of about $100 \mathrm{lb}$., and giving a second (and where there are two full generations a third) spray. These opposing views may have an explanation in the different conditions in apples at the calyx end during and after the closing of the calyx lobes in different parts of the country, but in general a compromise between the two methods, resulting in the use of a medium spray driven with considerable force, followed by the other sprays as they may be needed, seems to be the usual practice at the present time. 
Family Ægeriidæ (The Clear-winged Moths).-This family, sometimes called the Sesiidæ, includes a number of moths whose wings are only partially covered by scales. They are not large insects, spreading on an average, about an inch and are often brilliantly colored. They fly during the day and particularly during its warmest portion, and are very rapid in their flight. The larvæ are whitish in color and are all borers, either in stems, roots or under bark. They are therefore, all injurious, their importance to man depending on the value of the plant attacked.

The Peach Borer (Synanthedon exitiosa Say).-This insect which is a native of North America is a serious pest of the peach wherever these trees occur east of the Rocky Mountains. West of this a very closely related species, the Pacific Peach Borer (Synanthedon opalescens Hy. Edw.) has a similar life history, habits and control methods.

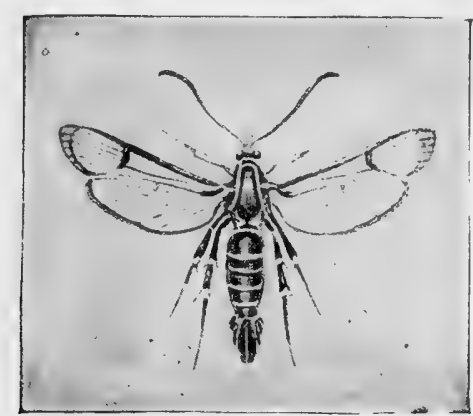

$a$

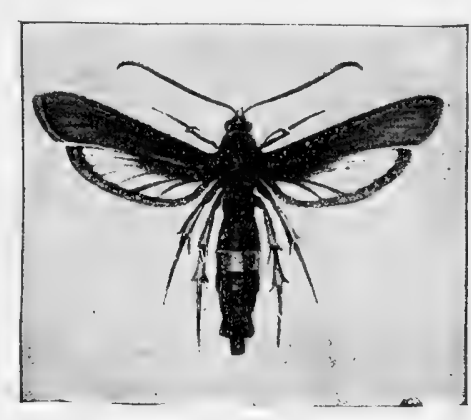

$b$

Fig. 239.-Adult Moths of the Peach Borer (Synanthedon exitiosa Say), twice natural size: $a$, male; b, female. (From Britton, Ninth Rept. Ent. Conn. Agr. Exp. Sta. 1909: after Beutenmuller.)

The adult insect (Fig. 239) is a little larger than the average, usually spreading a little more than an inch. The male has a dark blue body and its transparent wings are bordered with blue. In the female the fore wings are entirely blue, the hind wings transparent and an orange band crosses the blue body at about the middle of the abdomen. The moths may often be noticed darting about in peach orchards during the middle of the day, anywhere between early May and October (even earlier in the Gulf States), but are most abundant during June and July in the Southern States, and July and August in the North. The eggs, several hundred in number, are laid singly or a few together on the trunk of the tree near the ground, and the larvæ on hatching bore into the sap-wood close to the ground and feed in that region until winter, at which time most of them are about one-third grown. In the spring they resume their feeding (Fig. 240) and upon reaching full size work their way to the surface and pupate, forming their cocoons of their excrement 
and particles of bark, and lined with silk. These cocoons may be at the openings of the burrows but are more frequently fastened to the bark just about at the level of the ground. After 3 to 4 weeks in the pupa stage, the transformation to the adult is completed and the pupa breaks

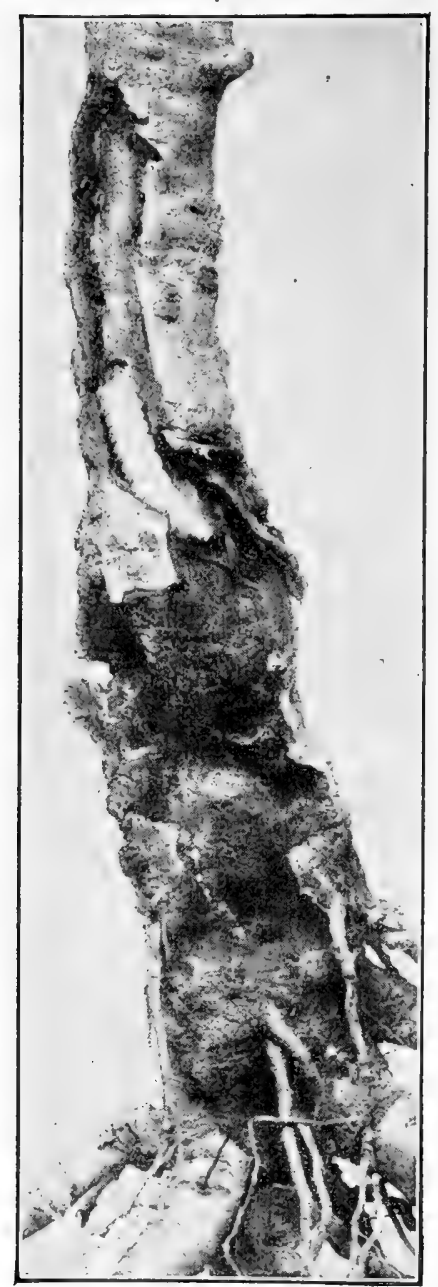

Fig. 240.-Larva of Peach Borer Moth and its work on a young peach tree. (From U.S. D. A. Farm. Bull. 908.) its way through the cocoon until it is about halfway out. Then the pupa skin splits and liberates the moth.

The injury caused by this insect when it is abundant is often serious. The feeding of the borers is in the eambium layer which is tunneled through in an irregular way, interfering with the growth of the trees, and where these are small they are often girdled. The weakened trees also become more liable to injury and destruction by bark borers and other insects.

Where the tunnels are formed, a flow of sap results in the pouring out of gum and this substance on the bark near the ground is usually a good indication of the presence of the borers.

Control.-Of the many methods which have been tried, only two appear to have given at all valuable results. These are "worming" and "mounding." Worming is the removal of the borers late in the fall and again in the spring, the date for the spring treatment varying with the locality but before the borers have completed their feeding. A day or two before this treatment the earth around the trunk should be removed to a depth of several inches, so that fresh gum and sawdust produced thereafter by the borers, or below the level of the ground, will show. With these as guides where to work, the borers can be located and removed with a sharp knife, and a light, pointed wire, care being taken to cut as little as possible and to leave clean-cut edges. Then replace the earth. In the spring, following the "worming," mound up the earth six or eight inches high around the trunk and leave it there until after the moths are done flying, but remove it in time for the bark to harden before winter. This mounding forces the moth to lay its eggs further up where the bark is tough 
and harder than at and below the ground level, and fewer of the borers are able to penetrate it to the cambium layer.

Probably more kinds of materials have been tested for the control of this insect than of any other, but it is still without an entirely satisfactory treatment, though Paradichlorobenzine pulverized to the fineness of coarse salt, has given fair success recently. The ground close to the tree is somewhat loosened, an inch or two deep; the material is then evenly sprinkled around the trunk in a band an inch or two wide; then two or three shovels of earth are placed over it and compacted with the back of the shovel. Three-fourths of an ounce to an ounce of the material is enough for trees 6 to 15 years old. It is not entirely safe for use with younger trees. The base of a tree treated thus, should be uncovered a month or so later and left exposed for a day or two before recovering with the earth.

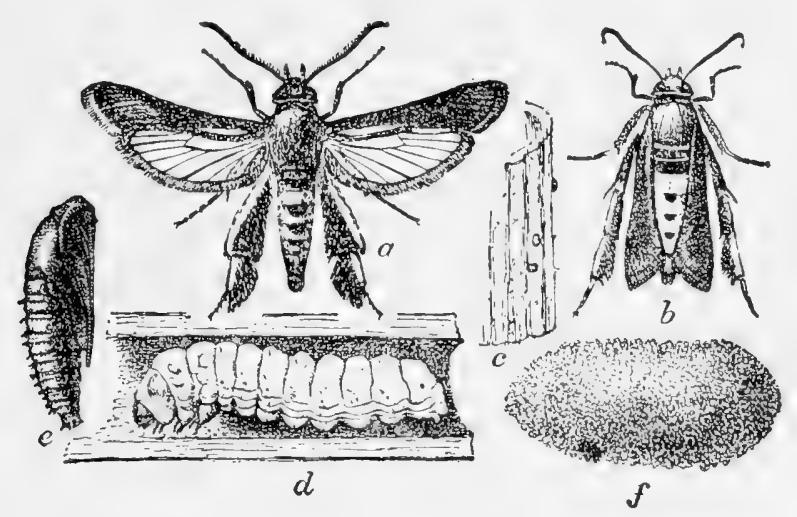

Fig. 241.-Squash-vine Borer (Mellitia satyriniformis Hbn.); $a$, male moth; $b$, female, wings folded; $c$, eggs on a piece of squash stem; $d$, full-grown larva in squash stem; $e$, pupa; $f$, pupal case, found in the ground. All one-third larger than natural size. (From U.S. D. A. Farm. Bull. 856.)

The Squash-vine Borer (Melittia satyriniformis Hbn.).-This pest is also a native of the New World, and is found from Canada southward to Brazil and west practically to the Rocky Mountains. It attacks the squash, pumpkin and occasionally the gourd, melon and cucumber, but does not usually, at least, infest the last two plants when the others are at hand. The adult moth (Fig. $241 a$ and $b$ ) is about the same size as, but a little stouter than the Peach Borer. Its fore wings are a dark, metallic green, its hind wings transparent, its abdomen orange and black and its hind legs heavily fringed with long, black, orange and a few white hairs, making these legs look very large. It appears about the time the plants are large enough for egg-laying and feeding upon-in April or May in the South; in June in the Middle Atlantic States and in July in New England - and lays its eggs at first near the base of the plant on the 
stem but later almost anywhere on it. About 200 eggs (Fig. 241c) are laid singly, and these hatch in from 1 to 2 weeks. The larvæ now bore into the stem and feed, generally working toward the base of the plant, making holes through it to the outside here and there, through which some of the excrement is expelled. They become full-grown (Fig. $241 d$ ) in about 4 weeks and then go a few inches into the ground to pupate, making dark-colored silken cocoons (Fig. 241f) mixed with dirt. Some soon pupate (Fig. 241e) while others remain as larvæ in their cocoons until the following spring. After the pupal stage has been completed the pupa works through the cocoon and to the surface of the ground and the moth then emerges from its pupal skin.

In the South there are two generations a year of this insect: farther north there is a partial second generation, and in the northern part of its range there is only one, winter in any case being passed in the ground.

The injury caused by these insects when they are abundant is serious. The burrows become wet and slimy, hastening decay and thus separating much of the plant from its roots. The feeding also interferes with the circulation of the sap to some extent. A sudden wilting of the leaves is generally an indication of the presence of the borers, and coarse yellowish excrement beneath the stems is also evidence of their activity. In some cases entire fields of the plants have been killed by the work of this pest.

Control.-Sprays tried thus far have proved ineffective. As the winter is spent in the ground of the field where the insects fed, it is evident that their food plants should not be planted 2 years in succession on the same land. Light harrowing of infested fields in the fall to bring up the cocoons and expose them to winter surface conditions, followed by spring plowing to a depth of at least six inches has given good results. Planting a few plants of very early varieties of summer squash as a trap crop on which the insects may lay their eggs before the real crop is available for them, followed by the destruction of the trap plants before the larvæ are full-grown is helpful. Covering the stems with earth to induce the production of roots from the nodes along the stem will often enable an attacked plant to continue to grow even after its connection with its original roots has been destroyed. Finally, when borers are found in the stems they may be cut out, using a sharp knife and splitting the stem lengthwise where the borer is and removing it, then covering the stem thus treated with moist earth to aid it in healing the wound.

Many other injurious insects belong in this family, among which the Imported Currant Borer boring in currant stems and killing them; the Blackberry Crown Borer which bores in the roots and crown of the blackberry and raspberry and has a 2-year life history; and the Maple Sesian which bores in the trunks of maples, may be mentioned. 
Family Gelechiidæ.-Some of the small insects which compose this group are leaf-miners; others feed on buds and others skeletonize leaves or attack plants in various ways. Many are injurious at times, the amount of injury done depending on their abundance which varies from year to year.

The Angoumois Grain Moth (Sitotroga cerealella Oliv.).-This little insect, a native of Europe where it was extremely injurious in the French province of Angoumois, whence its name, has been known in the United States since about 1730 and is widely distributed but is not often important in the more northerly states. The larva attacks wheat, barley, oats and corn, both in the fields and in storage, often destroying a large part of the grain.

The adult moth (Fig. 242a) is small, spreading about half an inch, yellowish in color, slightly speckled with black. Winter is spent as the caterpillar in the grain wherever it may be stored, and pupation occurs in the spring, also in the grain, followed by the emergence of the adult which flies to the fields and lays its eggs,

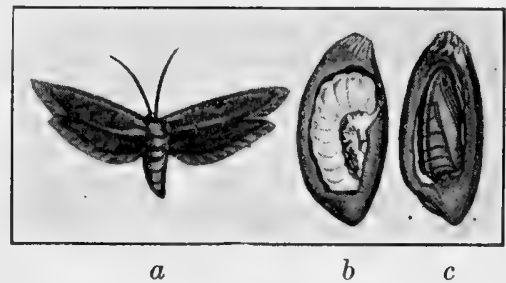

FIG. 242.-Angoumois Grain Moth (Sitotroga cerealella Oliv.): $a$, adult moth, ahout twice natural size; $b$, larva in a grain of wheat; $c$, pupa in another grain. $b$ and $c$ about three times natural size. (Modified from Sander.) about a hundred in all, in the young grain heads. The eggs hatch in about a week and each tiny caterpillar attacks a kernel, gnawing into it (Fig. 242b) and consuming its contents. After about 3 weeks the larva becomes full-grown and pupates in the kernel (Fig. 242c) where it fed, escaping a little later as the adult moth. Eggs are now laid on grain ready to harvest and either in the harvested grain or in corn after it has been husked and is therefore accessible to the insects, there now follow later generations, until cold stops their further development which is resumed the following spring.

Small grains and corn thus attacked are badly injured, not only by consumption of the contents of the kernels but also because of the presence of the bodies of the insects themselves and of their excrement which gives a disagreeable taste to the flour, which lacks adhesiveness and breaks up when stirred in water.

Control.-When this insect is present, destroy or feed all waste grain and screenings and clean up all grain and refuse from places where grain has been stored, in early spring. Good grain should be fumigated at this time also, if the caterpillars are present. The purpose of this is to destroy the insects before they pass to the growing food plants out of doors. Threshing the grain soon after harvest, not keeping it in the mow long, is also important. Fumigation of the threshed grain for $24 \mathrm{hr}$., with Carbon disulfid, using $1 \mathrm{lb}$. for each $100 \mathrm{bu}$., if it is infested or heats, 
which is due to infestation, is an important control which should not be omitted. If the insect is present the sooner fumigation is given the sooner the loss by feeding will be stopped.

Family Pterophoridæ. - The insects of this family, though rather small, are of much interest, the wings being cleft for a part of the distance in from the outer margin toward the base (Fig. 243). In most cases the fore wing is divided into two such parts and the hind wing into three. A single species found in this country and placed in a separate family (Orneodidæ, Fig. 244), has each of its wings divided into six parts.

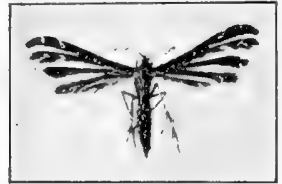

FIG. 243.

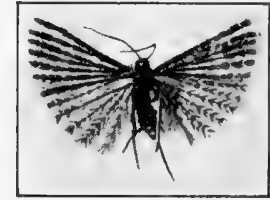

FIG. 244

Frg. 243.-Adult Pterophorid Moth showing the cleft wings, nearly twice natural size. (Original.)

FIG. 244.-Orneodid Moth showing the cleft wings. Twice natural size. (Original.)

Most of the Pterophoridæ are not of great economic importance. One species, however, causes some injury to the grape by webbing together the leaves, usually the terminal ones, and feeding within the web. As this frequently involves a cluster of buds which may also be fed upon, the crop may be somewhat reduced in this way. The only control known is to remove the webs by hand and crush the little caterpillars.

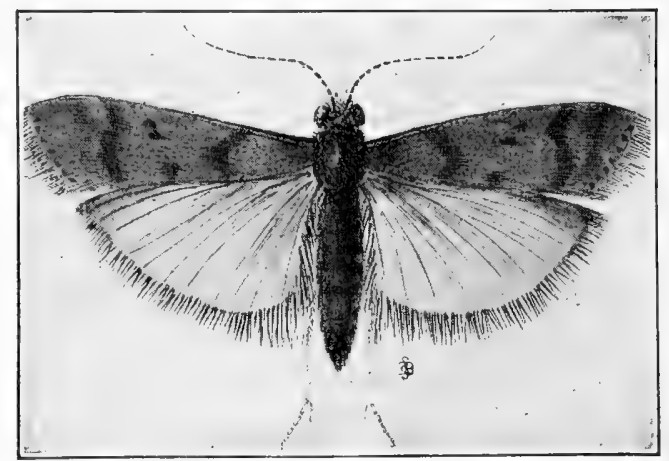

FIG. 245.-Adult Mediterranean Flour Moth (Ephestia kuhniella Zell.), three times natural size. (From Herrick's Insects Injurious to the Household. By Permission of the Macmillan Company, Publishers.)

Family Pyralidæ.-This is a large family but most of the moths belonging here are small. The members of the group have very varied habits. Some fold or roll leaves; some bore in plant stems; some feed on stored cereals or dried fruit; one or two feed on wax and are pests in bee hives; others attack foliage, grass or various materials. Many are injurious but few can be rated as serious pests over the entire country. 
The little white or brown and white moths which are so numerous in grass fields during the summer months, belong here. On alighting on a grass stalk they place their bodies parallel to the stems and fold their wings closely about them. Their larvæ feed on grass and are sometimes quite injurious, corn and oats suffering severely. Early fall plowing and replowing early the following spring are helpful under such conditions.

Three species are often found in houses attacking flour, meal, cereals and dried fruits. One species, the Mediterranean Flour Moth (Fig. 245) (Ephestia kuhniella Zell.) spins a web which causes flour to stick in loose masses, and in mills and storage houses this becomes serious. The other two species are more liable to be found in dried seeds, fruits, etc., and often cause considerable injury. In storage houses and mills fumigation with Hydrocyanic acid gas is often used as a control, and if the place can be heated to $125^{\circ} \mathrm{F}$. for about $6 \mathrm{hr}$., this also has proved effective.

The Bee Moth (Galleria mellonella L.) also belongs here (Fig. 246). It is an enemy of the bee-keeper living in the bee hives where it feeds on wax and spoils the honey. Strong colonies of bees can usually protect themselves from this

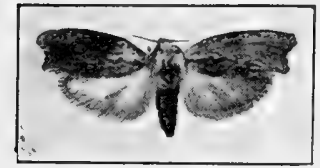

FIG. 246.

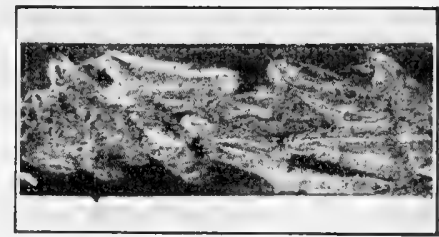

FIG. 247.

FIG. 246.-Adult Bee Moth (Galleria mellonella L.), natural size. (Original.)

FIG. 247.-Cocoons of the Bee Moth from the inside of a hive. Natural size. (Original.)

pest, particularly the Italian races. Where necessary, the bees can be transferred to another hive and the infested one fumigated with Carbon disulfid (Fig. 247).

The European Corn Borer (Pyrausta nubilalis Hbn.).-- This pest of corn and many other plants has only recently been discovered in this country, and in $\mathbf{1 9 2 0}$ was found only in parts of New Hampshire, Massachusetts, New York, Pennsylvania and Ontario. It is a borer in plant stems, in which it winters as a partly grown larva (Fig. 248), finishing its feeding and pupating (Fig. 249) in its burrow in the spring. The moths appear in Jume and lay 300 or 400 eggs in small clusters on the leaves of their food plants and the larvæ tunnel in the stems (Fig. 250), becoming full-grown in about 6 weeks and the moths these produce appear in July. Eggs for another generation are now laid and the larvæ feed until winter, when they hibernate in their burrows. In some places, instead of two generations each year there is only one.

The moths spread from about an inch to an inch and a quarter. The male is rather dull purplish or reddish-brown with yellow spots or a band on the fore wings and grayish hind wings. The female has dull yellow fore wings more or less marked with brown, and grayish-brown hind wings. The moths fly most. freely about dusk and are only slightly attracted to lights. 
Corn, and particularly sweet corn, appears to be a favorite food of this insect, and where it is abundant a large part of the crop may be destroyed. Largestemmed weeds such as barnyard grass, pigweed, etc., are also attacked, as well as dahlias, gladiolus and other cultivated plants, which complicates the problem of control.

Control.-The best method for checking the ravages of this pest is the destruction of all corn stalks to below the ground level, either by burning during the winter or by using as ensilage.

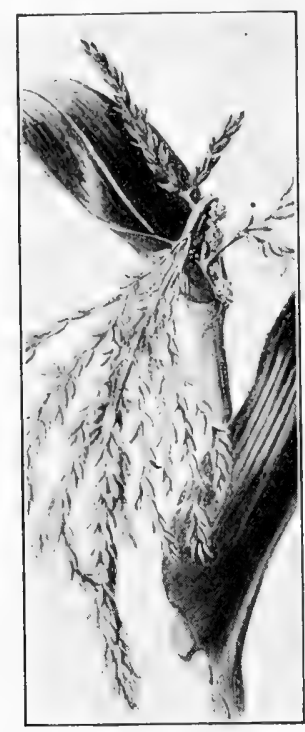

FIG. 248 .

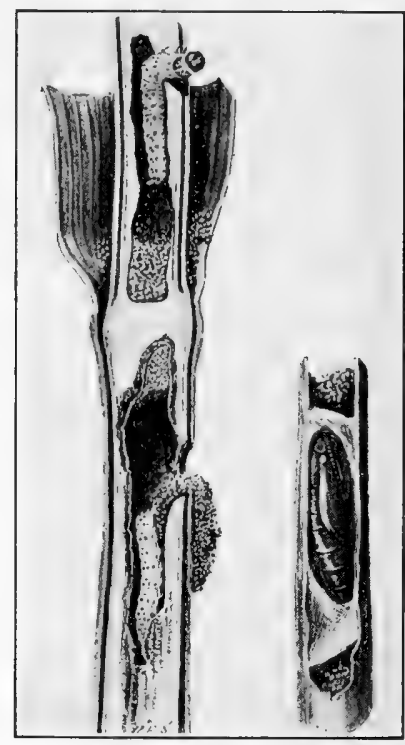

FIG. 249.

FIG. 250 .

FiG. 248.-Part of a corn plant showing effect on the tassels of the work of the European Corn Borer (Pyrausta nubilalis Hbn.). (From a drawing by Snodgrass, U. S. D. A. Bur. Ent.)

FIG. 249.-Corn stalk split, showing the larvæ of the European Corn Borer and their tunnels. About natural size.

FIG. 250.-Corn stalk cut into to show the pupa of the European Corn Borer Slightly enlarged. (Both figures from drawings by Snodgrass, U. S. D. A. Bur. Ent.)

Family Limacodidæ (Slug Caterpillars).-The insects belonging to this family are of little importance from an economic standpoint, but their larvæ are curious in appearance, having little resemblance to ordinary caterpillars. Instead, they are slug-like, short and rather stout, quite flat beneath, and appear to slide along rather than crawl. Many have spines and rather showy, colored markings, in some cases with soft, fleshy projections sometimes partly or entirely covered with hairs. The Oriental Moth (Cnidocampa flavescens Walk.) several times imported into this country from Asia by accident, has established itself in Eastern Massachusetts but is not apparently of much importance, though the spines on the caterpillar cause a nettling of the skin of a person where the insect has been touched.

Family Psychidæ (Bag Worms).-The caterpillars of a few species of moths in this country construct silken bags around their bodies, partly covered with 


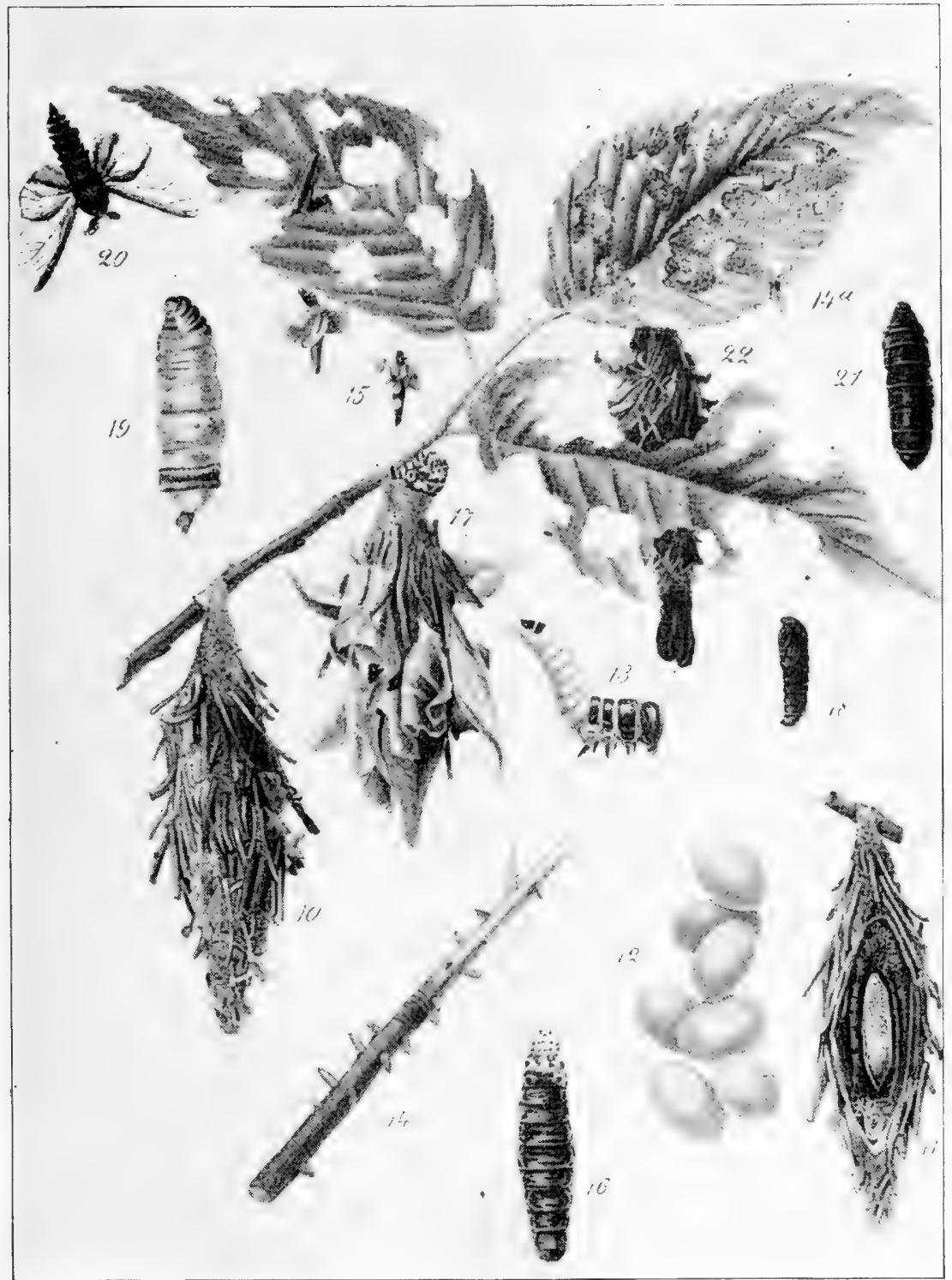

Fig. 251.-Common Bag Worm (Thyridopteryx ephemerceformis Haw.): 10, bag, as seen in winter; 11, same, cut open, showing pupa case and eggs; 12, eggs; 13, young larva; 14, cases of young larvæ on a twig; 15, older larvæ in their bags, one hanging by a thread it has spun; 16, full-grown larva removed from its case; 17, full-grown larva, crawling; 19, adult (wingless) female Moth; 20, adult male Moth; 22, bag of male with empty pupa case protruding from its lower end. All natural size except 12 and 13 which are greatly enlarged. (From Houser, Ohio Agr. Exp. Sta. Bull. 332: After Felt.) 
twigs or other parts of the plant on which they feed. The female is wingless and lays its eggs within the pupa case or skin she vacated on becoming adult. Only one species, the Common Bag-worm (Thyridopteryx ephemerceformis Haw.) is of

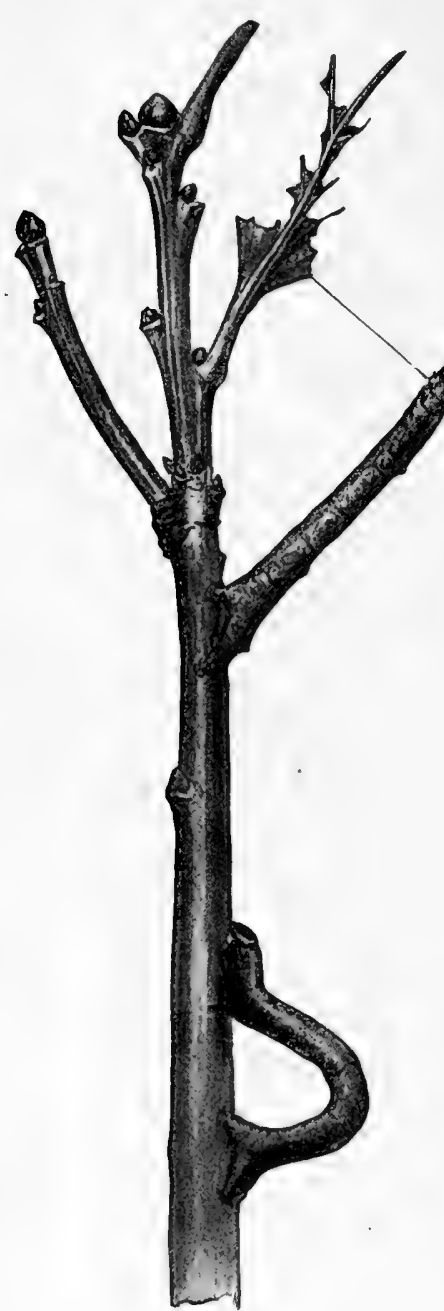

Fig. 252.-Two "Inch Worm" larvæ, the lower one crawling, the upper one hanging outward like a twig. Compare with real twig just above, on opposite side. (From Linville and Kelly, General Zoology.) much importance, but where this is plentiful the plants on which it feeds may suffer considerably (Fig. 251). It occurs from Massachusetts west to Nebraska and south to North Carolina, Tennessee and Texas. Spraying infested trees as soon as the eggs hatch in the spring, with arsenate of lead, standard formula, is usually a sufficient control without a second application later.

\section{Family Geometridæ (Inch worms,} Span worms or Measuring worms).-This is a large family in this country and the moths vary greatly in size, some being very small while others may spread nearly two and one-half inches. They nearly all have rather delicate wings and are fragile creatures.

The larvæ (Fig. 252) have a peculiar appearance when moving, as the feet which are usually present near the middle of the body in most caterpillars, are lacking in this group, leaving only the three regular pairs.near the front end and two pairs at the hinder end. In consequence, walking is accomplished by bringing the hinder end up as closely as possible to the front end, the body forming at this time a loop. Then the front legs let go their hold and the body is straightened out to find a place where the front legs can grasp and hold on. This striking method of locomotion has led to the common names given to the caterpillars in this family.

Another feature of interest about these larvæ is that many of them are colored and formed so as to resemble twigs. When disturbed the caterpillar releases the grasp of its front feet and straightens out, standing at an oblique angle to the twig it is holding on to, and resembles a dead twig of the plant. Some have markings which make them resemble twigs having buds, leaf-scars or scales of the bark, thus increasing their deceptive similarity. 
The food plants of the insects in this family are very numerous. Trees and shrubs of many kinds including fruit trees, currant and gooseberry bushes, cranberries and other plants of value to man, suffer from the attacks of these insects, though few are regularly injured, the pests in most cases being destructive only for a year or two, then disappearing, at least for the most part, during quite a period.

Canker Worms.-There are two species of Geometers which are widely distributed over this country and which at times do serious damage to fruit and shade trees. They are known as Canker Worms, and while they differ in certain features, have much in common. In both species the pupal stage is passed in the ground: in both, the female is wingless: in both, the eggs are laid on the twigs of the trees, and in both the caterpillars feed at about the same time in the spring.

The Fall Canker Worm (Alsophila pometaria Harr.) occurs in nearly all parts of the Northern United States as far west as Wisconsin, and south at least through the Middle Atlantic States. It has also been re-

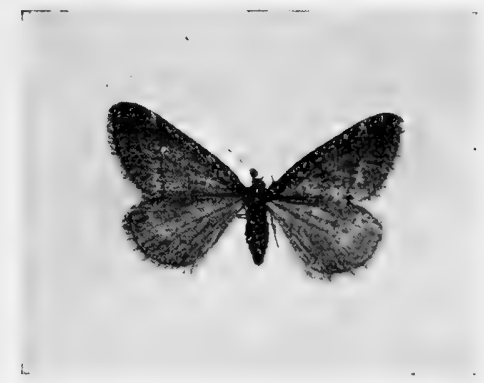

FIG. 253.

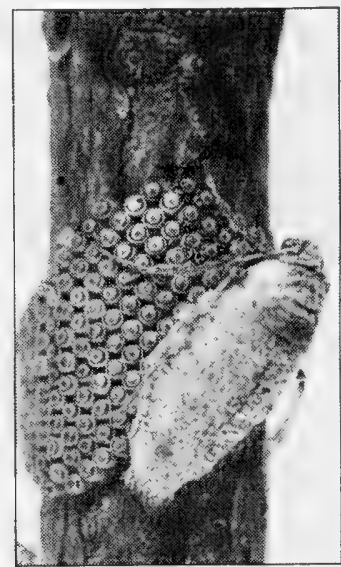

FiG. 254 ,

Fig. 253.-Male Fall Canker Worm (Alsophila pometaria Harr.), about natural size. (From Britton, Eighth Rept. Ent. Conn. Agr. Exp. Sta. 1908.)

Fig. 254.-Adult Female Fall Canker Worm on a cluster of eggs. About 21/2 times natural size. (From Houser, Ohio Agr. Exp. Sta. Bull. 332.)

ported from Colorado and California. The adult male moth (Fig. 253) spreads about an inch and a quarter, its wings light gray with faint markings. The female (Fig. 254) is light gray, and wingless. The moths usually appear late in the fall, escaping from their pupæ in the ground, and the females crawl up the tree trunks to the twigs where they lay their eggs (Fig. 254) in clusters. These eggs hatch the following spring, as the leaves develop, and the caterpillars (Fig. 255) feed on the foliage until full-grown some time in June in the Northern States, and earlier farther south. During this time they often drop from the leaves 
some distance, spinning a thread as they go, and up which they return to resume their feeding. A sudden jar of an infested tree will cause great numbers to drop or "spin down" several feet in this way. When feeding has been completed the larvæ enter the ground and pupate a few inches below the surface in a silken cocoon, from which the moths escape late in the fall.

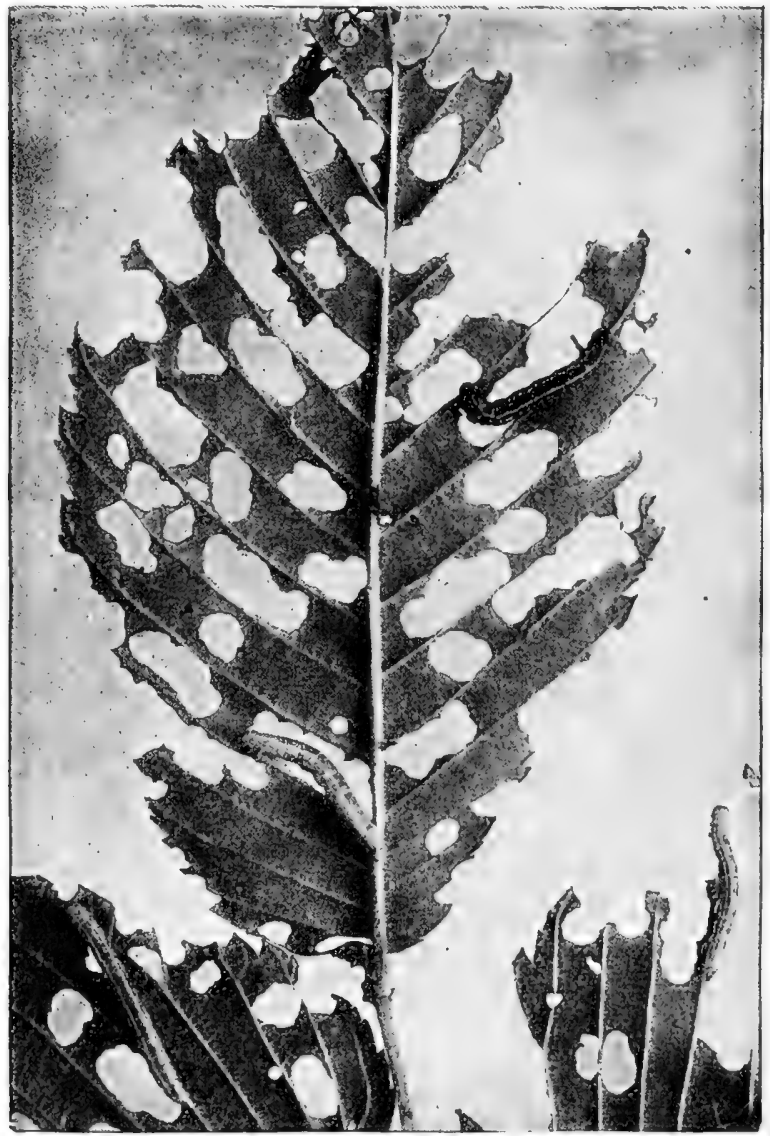

Frg. 255.-Fall Canker Worm caterpillars feeding on Elm. Natural size. (From Britton, Eighth Ropt. Ent. Conn. Agr. Exp. Sta. 1908.)

The Spring Canker Worm (Paleacrita vernata Peck).-The adult male of this species averages slightly less in its wing-spread than the Fall Canker Worm and its wings are somewhat lighter in color. It occurs throughout the Eastern United States except in the South and has also been taken in Texas and California. It is particularly injurious at times in the Mississippi Valley. This pest escapes from its pupa in the ground, as the adult, very early in the spring, and the females crawl up the trees on which they lay their clusters of eggs, frequently under 
loose bark or in crevices. These eggs hatch about the time the leaves open and the larvæ feed during about the same period as the other species, and enter the ground to pupate at nearly the same time. This insect also has the habit of spinning down on a thread when disturbed.

Control of Canker Worms.-The wingless condition of the females which necessitates their crawling up the trunks of the trees in order to reach the places where their eggs are laid, offers an opportunity for control by banding the trunks, in the fall for the Fall Canker Worm, and at the first warm days after winter has broken (even in February in New England, in some seasons) for the spring species, either with sticky bands which the insects are unable to cross, or with loose fluffy cotton in which they become entangled. Care should be taken to keep the bands fresh or in order so that no gaps through which they can crawl, or bridges of their dead bodies over which they can cross, are formed. If the caterpillars are already feeding when their presence is discovered, spray with arsenate of lead, standard formula.

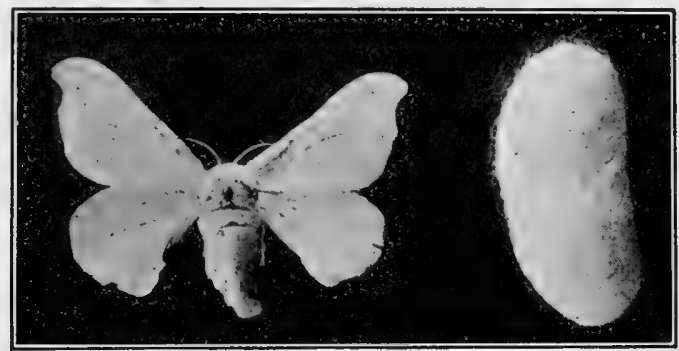

FIG. 256.-Silk Worm (Bombyx mori L.): adult moth and its cocoon. About natural size. (Original.)

Family Bombycidæ (True Silk Worms).-The only representative of this family in North America is the Silk Worm (Bombyx mori L.) introduced many years ago because of the silk obtained from its cocoon. It does not appear to have established itself anywhere in this country and silk-raising has not proved profitable here because of the cost of the labor required, as compared with that in the Orient.

The adult moth (Fig. 256) spreads about an inch and three-quarters and is creamy-white in color, with two or three faint lines across the fore wings. The larvæ feed on the leaves of the mulberry and Osage orange trees, and when full-grown leave their food and spin their cocoons (Fig. 256). When spinning has been completed these are gathered and the insects within are killed by heat or fumigation. Now the loose silk of the outside is removed and the cocoons are ready to market. Nearly $73,000,000 \mathrm{lb}$. of raw silk were produced in the world in 1918, and the importance of the industry is enormous. 
Family Lasiocampidæ (The Lasiocampids).-This small family includes several species which are common and at times quite important pests. The moths are of only medium size, with rather stout bodies, antennæ fringed on one side (pectinate) and with a large shoulder at the base of the hind wing, instead of a frenulum. The larvæ feed on the leaves of trees.

The Apple-tree Tent-caterpillar (Malacosoma americana Fab.).This native insect is at times a pest for several years in succession, after which it practically disappears for some time. It is found almost everywhere from Canada to Florida and west to the Rocky Mountains. From

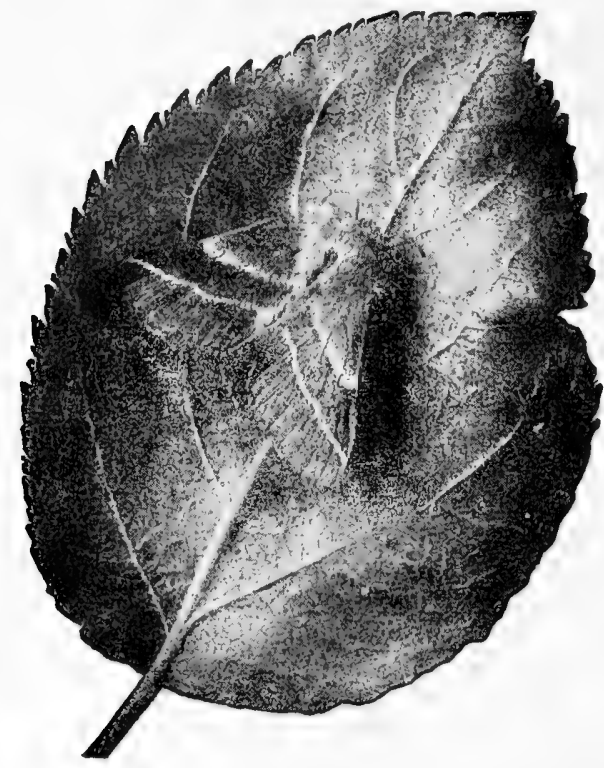

FIG. 257 there to the Sierra Nevada Mountains another species having similar habits occurs, while on the Pacific Slope several others are present.

The adult moth (Fig. 257) is rather stout, with a reddishbrown body and wings, the front

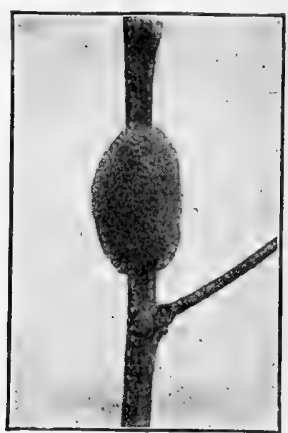

FIG. 258.

FIG. 257.-Adult Apple-tree Tent-caterpillar (Malacosoma americana Fab.), about natural size. (From Sanderson, Insects Injurious to Farm, Garden and Orchard; after Lowe.)

Fig. 258.-Egg belt of the Apple-tree Tent-caterpillar, encircling a twig. Natural size. (From Britton, Thirteenth Rept. Ent. Conn. Agr. Exp. Sta. 1913.)

pair of which have two whitish lines crossing them. The male spreads about an inch and a quarter and the female about half an inch more. They fly at night and do not feed as adults. The wild cherry and apple appear to be the preferred food plants of the caterpillar, but other fruit and shade-trees are sometimes fed upon.

The moths appear during the early part of the summer and lay their eggs (Fig. 258), 200 or 300 in number, in belts around small twigs, one belt probably being all that is laid by one insect. These belts more or less completely surround the twig, and after depositing a belt, the insect covers the eggs with a layer of a brown, sticky substance, beveled 
down to the twig at each end, which soon hardens and glistens. Within the eggs the larvæ develop and are ready to hatch by winter, but remain within the egg-shells until spring. They then leave the eggs and may feed first on the material covering the eggs, but soon crawl together to some near-by fork of the tree and there spin a web (Fig. 259) in which to live. From this they go out during the day to feed, spinning a thread

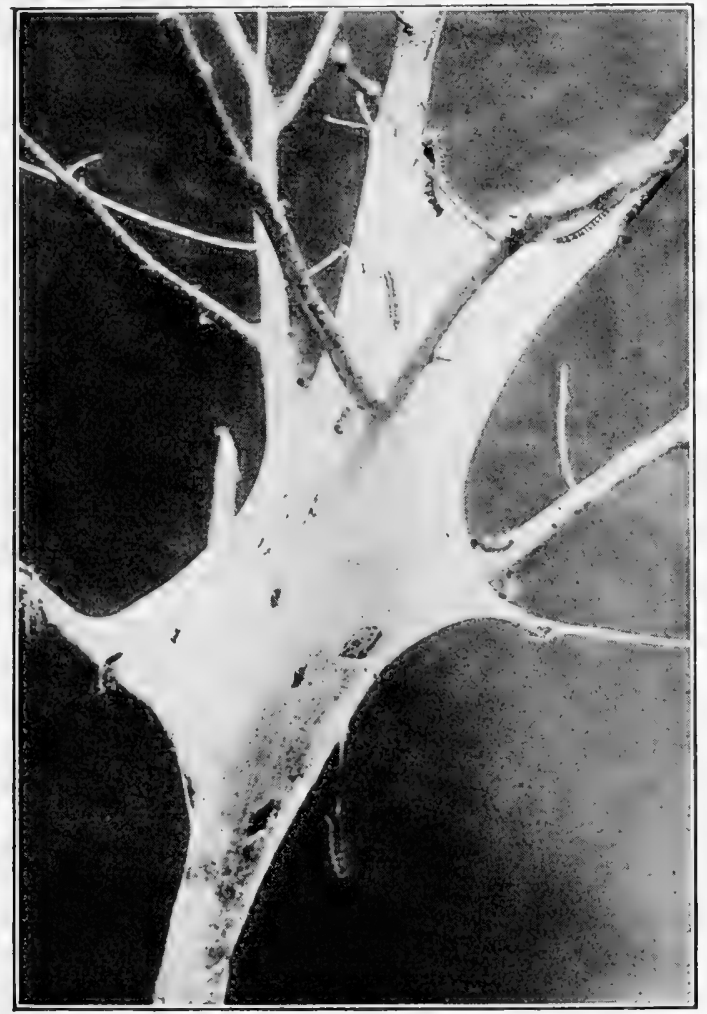

Fig. 259.-Tent of the Apple-tree Tent-caterpillar, about half natural size. (Original.)

as they go, perhaps to aid them in finding their way back. As they grow the tent or web is enlarged by the addition of outer layers and may be nearly a foot long and seven or eight inches across before the larvæ are full-grown, the feeding period being about 6 weeks.

Though at first very small, the larvæ grow rapidly and when of full size are about two inches long, black with a white stripe along the middle of the back and a row of pale-blue spots on each side, with a velvety-black spot in front of each blue one (Fig. 260). Fine yellowish hairs are also present.

When about through feeding the caterpillars scatter and finally spin rather large, quite thick, white cocoons in any protected places 
they may find, and within these they pupate, taking about 3 weeks in this stage before the moth appears.

An unusual feature in this life history is the long period spent in the egg, which may be almost 10 months.

Control.-Although this insect has numerous enemies both among birds and insects, there are periods during which these are unable to prevent trees being stripped by the pest. In general, the calyx spray used on apples and pears for the Codling Moth is sufficient to destroy

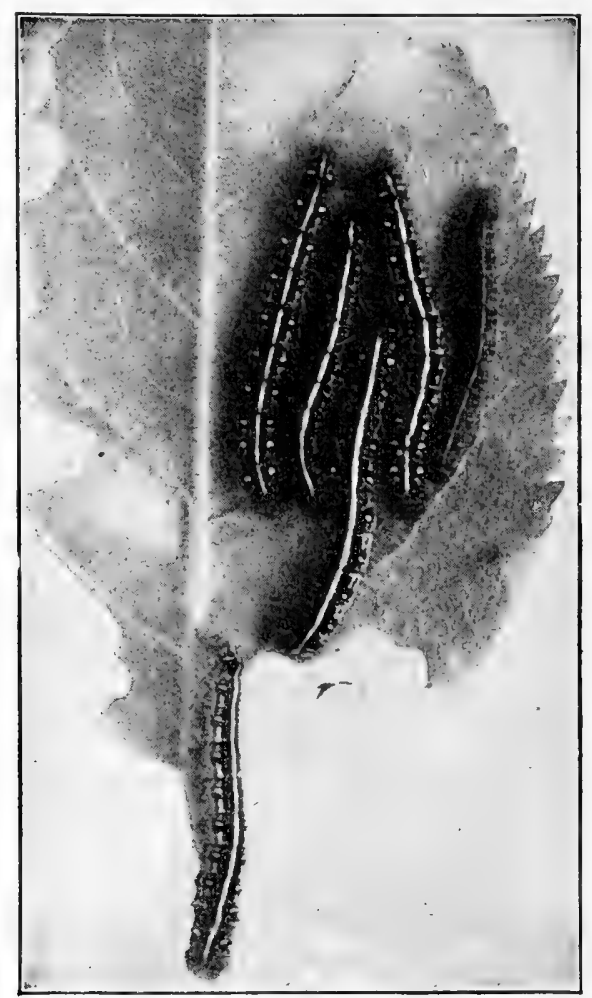

FIG. 260.-Larvæ of the Apple-tree Tent-caterpillar, natural size. (From Britton, Thirteenth Rept. Ent. Conn. Agr. Exp. Sta. 1913.)

this caterpillar also. On wild cherry and other trees not usually sprayed, however, it finds a breeding place from which the fruit trees may be restocked, and such trees should also be cared for, to prevent this. Examination of such trees any time between August and March, to find, cut off, and burn the eggs, and the destruction of the caterpillars while in their tents on rainy days or at night, either by crushing or by burning with a torch, are desirable auxiliary treatments in addition to spraying. The torch method should not be used on young fruit trees, however, as holding the torch at a fork a moment too long is liable to injure this 
place, and in later years the injury will show as the fork becomes an important one, in the form of a splitting at that point under the weight of the branches and fruit beyond.

The Forest Tent-caterpillar (Malacosoma disstria Hbn.) is also a native of North America. It greatly resembles the last species, both in appearance and in some of its habits, but though occasionally found feeding on some of the same food-plants, it appears to prefer the oak, maple and other forest and shade-trees.

The adult (Fig. 261) is of about the same size and general appearance as the Apple-tree Tent-caterpillar, but the general color is lighter brown and the lines or bands across the fore wings are darker, instead of lighter

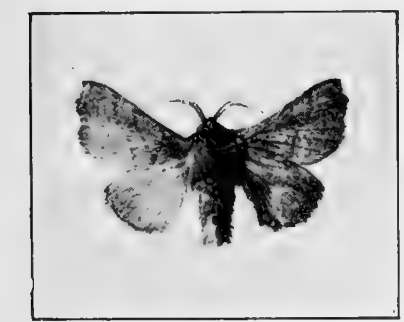

FIG. 261.

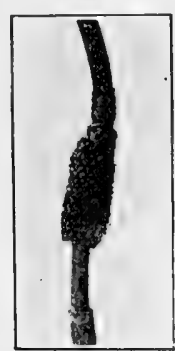

FIG. 262.

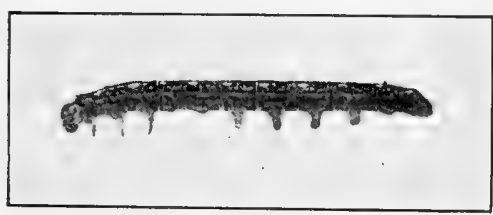

FIG. 263.

Fig. 261.-Adult Forest Tent-caterpillar (Malacosoma disstria Hbn.), natural size. (Original.)

FIG. 262.-Egg belt of Forest Tent-caterpillar, natural size. (Original.)

Fig. 263.-Full-grown larva of the Forest Tent-caterpillar. About two-thirds natural size. (Original.)

than the ground color. The egg belts (Fig. 262) are similar but quite squarely cut off at their ends instead of being rounded down to the twig: the caterpillar (Fig. 263) has a row of rather oval white spots instead of a white stripe along its back, and its sides are noticeably light blue, with two broken, longitudinal, yellow lines. The caterpillars make no tents but scatter after hatching. Otherwise the life history, time spent in the different stages and the periods of the year during which these occur are the same in both species.

Control.-Where the caterpillars can be reached by sprays, control is comparatively simple; as with the Apple-tree Tent-caterpillar. In forests, however, where large trees are stripped of their foliage, this method is rarely practicable. Destruction of the egg-belts is of value, but these can seldom be reached in any numbers, being usually high up on the small twigs. Jarring the trees where these are small enough for this, will cause many of the caterpillars to drop to the ground, and by the use of sticky or cotton bands they may be prevented from crawling back again. The caterpillars frequently cluster in large numbers on the trunks of the trees and at such times, spraying these clusters with any 
strong contact insecticide is an effective treatment. For the most part, however, little can be done and in "sugar bushes" extensive defoliation with a consequent reduction of the vitality of the tree and of the sap flow will follow, only relieved after a year or two by an increase in the enemies of this insect to such an abundance as to reduce it to unimportance.

Some of the western species of Tent-caterpillars make tents, while others do not. Occasionally one species or another may become so abundant as to strip everything in one place, and in such cases the larvæ crawl off in enormous numbers seeking for more food. In one instance their line of march was across a railroad, where they were crushed by the car wheels until the rails became so slippery that trains were unable to run except by sweeping the caterpillars off or by blowing them off the track ahead of the engine by jets of steam!

Family Lymantriidæ (The Tussock Moths).-This family, though small in numbers in this country, includes some serious pests. The moths are of medium size, and the females in some cases are either wingless or nearly so. The legs are rather thickly clothed with hairs. The group as a whole is one of night-flying insects but a few fly freely in the day time.

The larvæ are often highly, even brilliantly colored, and are thickly covered with hairs. These may be quite uniformly distributed, but in some cases there are also bunches or "tussocks" of them projecting some distance from the skin, and long, slender "pencils," composed of a few hairs which may be a quarter as long as the body of the caterpillar. Most of them feed on the foliage of trees but some have a wide range of food plants.

The White-marked Tussock Moth (Hemerocampa leucostigma A. \& S.).- This common species is found along the entire Atlantic Coast

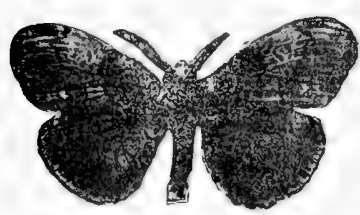

FIG. 264.-Adult male of the White-marked Tussock Moth (Hemerocampa leucostigma A. and S.), about natural size. (From Britton, Fifth Rept. Ent. Conn. Agr. Sta. 1905.)

from Nova Scotia to Florida and westward at least to Nebraska, and has also been reported from Oregon. It is mainly a pest of shadetrees, and most injurious in and near cities and towns, but at times attacks fruit-trees and eauses much injury.

The adult male moth (Fig. 264) spreads about an inch, and its wings are gray with wavy dark bands and light marks. Its antennæ are heavily fringed. The female (Fig. 265) is wingless, with a gray body.

The winter is spent in the egg stage, the larvæ hatching in the spring, feeding until full-grown, on foliage, then crawling away to pupate, sometimes on the twigs but usually either on the bark of the trunk or lower limbs, or on other objects near-by. The cocoons are composed of silk 
mixed with hairs from the body of the caterpillar and are gray in color. The female on emerging from the pupa stage crawls to the surface of the cocoon and later lays there from 300 to 500 eggs (Fig. 265) which she then covers with a white froth which soon hardens and forms a crust covering and hiding the eggs. This white crust on the gray background of the cocoon and the generally dark bark of the tree makes the eggs very conspicuous objects.

The eggs soon hatch and the caterpillars thus produced feed on the leaves until full-grown (Fig. 266) then pupate as in the preceding generation and the moths appearing later, also lay their eggs on their cocoons and cover them with white froth. It is probable that throughout the

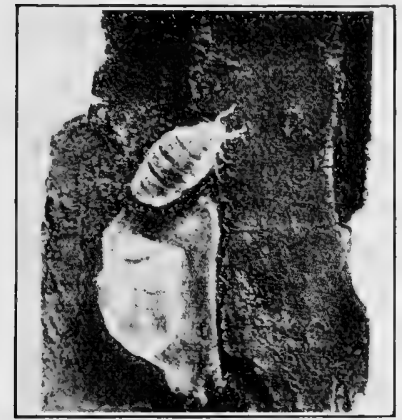

FIG. 265.

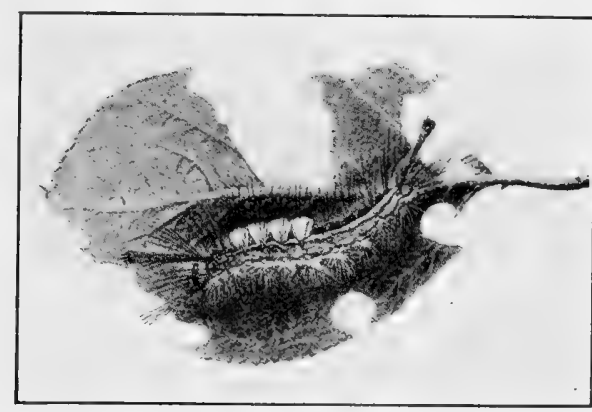

FIG. 266.

Fig. 265.-Adult female of the White-marked Tussock Moth with an egg mass covered by a white crust, resting on her cocoon. About natural size. (IIodified from N. Y. Agr. Exp. Sta. Bull. 312.)

FIG. 266.-Caterpillar of White-marked Tussock Moth. Note the four "tussocks" of hairs. Slightly reduced. (IIodified from N.Y.Agr. Exp. Sta. Bull. 312.)

northern part of the territory inhabited by this insect, these eggs will be laid so late in the season that they will not hatch until the following spring and the white crusts covering them will therefore be prominent objects during the winter. We accordingly find two generations of this insect in the Middle States; one in the North, and there are probably three in the South, corresponding to some extent at least, with the length of time during which food is available.

The moths are seldom seen, though the males fly somewhat during the day. The egg clusters, however, are objects which attract attention and the caterpillars are highly colored and so peculiar in appearance as to be very noticeable. A full-grown caterpillar is nearly an inch and a half long, with a bright red head and also two red humps above, near the hinder end. Between the head and the middle of the body is a row of four large cream-colored tufts or "tussocks" of hairs standing up some distance above the surface of the body. The side is gravish with a yellow band above and below. Projecting upward, forward and outward from just behind the head are two slender clusters of black hairs or "pencils" 
about half an inch long, and a single similar but gray pencil of hairs projects upward and backward from near the hinder end of the body. These characters make the caterpillar of this insect a very striking and noticeable animal.

Control.-Gathering and destroying the egg clusters or applying creosote to them freely enough to penetrate the crust and reach all the eggs beneath are methods which can be made use of whenever the clusters are observed. Spraying for the caterpillars, using arsenate of lead, standard formula, is also effective. Trees not infested, whose branches do not touch those of other and infested trees, can be protected by the use of sticky or cotton batting bands around their trunks during the periods when the caterpillars are crawling.

The Antique or Rusty Tussock Moth (Notolophus antiqua L.).-This is a European insect but widely distributed in North America. The male moth averages about as large as the White-marked Tussock Moth and has rusty-brown wings, each fore wing with a small white spot. The female is wingless. The eggs are laid on the cocoon of the parent moth but without any white crust to conceal them, and the caterpillar has a black head. Of the four tussocks on the back, the first two are black at first but become whitish later, like the others. The pencils of hairs just behind the head and at the end of the abdomen resemble those of the other species and an additional pair is also present, one on each side of the body a short distance behind the head.

The life history of this insect is probably similar to that of the last species, though the number of generations in different parts of the country does not appear to have been worked out. In the Northern States there is one each year. Control measures are the same for both species.

The Gypsy Moth (Porthetric dispar L.).-This European insect was introduced into this country near Boston, Mass., by accident, about 1869 and has gradually spread until it now covers the greater part of the New England States. It has also appeared in other localities but these places were discovered early and the insects exterminated.

The adult male moth (Fig. 267) is brown with some yellowish markings, and spreads about an inch and a half. It flies freely during the day. The female has nearly white wings, with dark markings; a stout, heavy body covered behind with buff hairs: its wings spread about two inches, and though having well-developed wings, this sex does not fly.

Winter is passed in the egg stage, the caterpillars hatching in the spring and feeding on many kinds of leaves, though the apple, oak, willow, alder and birch appear to be favorites, and shrubs and herbaceous plants do not escape. Ash is not fed upon, nor is pine during the first two instars.

Feeding until early in July the caterpillars become full-grown (Fig. 268) and may then be nearly three inches long and as large as a lead pencil. They are brown, partially hairy, the hairs being somewhat clustered, and on the back bear five pairs of blue spots, followed behind by six pairs of red ones. At the end of 
the feeding period the caterpillar crawls to any satisfactory place, usually the underside of some limb or on the trunk, and there spins a few threads to hold it

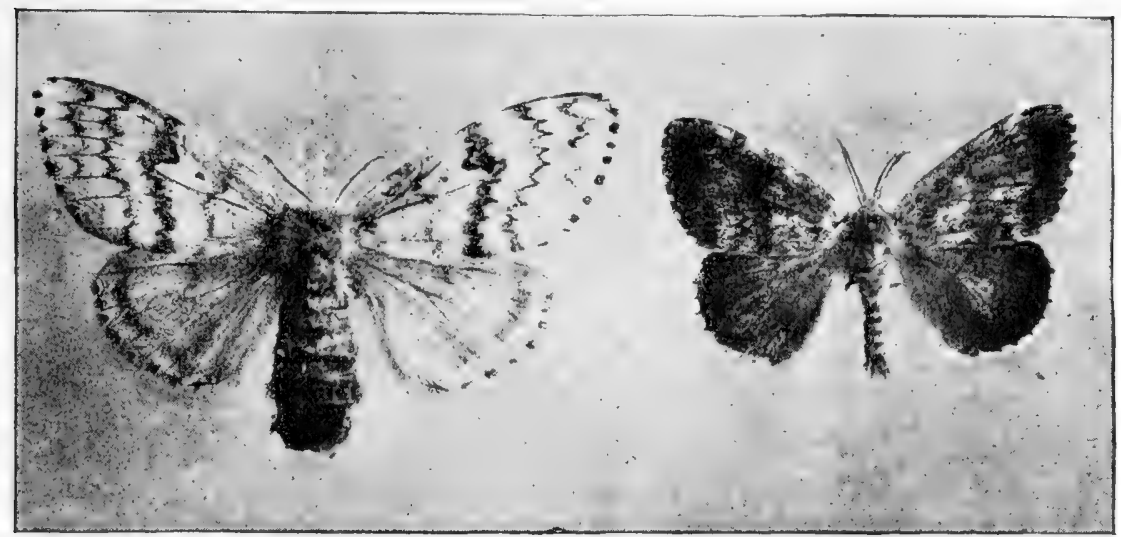

FIG. 267.-Adults of the Gypsy Moth (Porthetria dispar L.); female on left; male on right. Natural size. (From Britton, Fifth Rept. Ent.Conn.Agr.Exp.Sta. 1905.)

body in place rather than for concealment or protection, and in this exceedingly scanty cocoon it pupates (Fig. 268) and after a period of from a week to 17 or 18 days, the moth emerges.

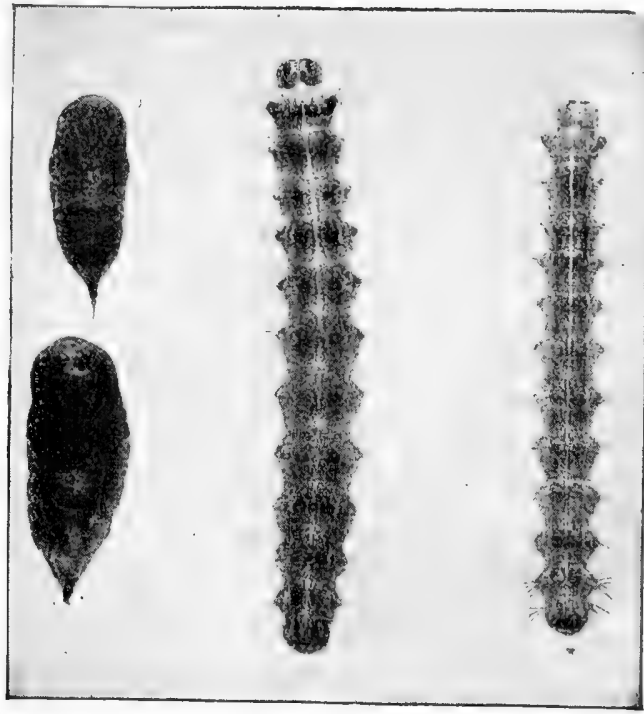

FrG. 268.-Pupæ and larvæ of the Gypsy Moth, natural size. (From Britton, Fifth Rept. Ent. Conn. Agr. Exp. Sta. 1905.)

The eggs are now laid in oval clusters throughly covered by buff hairs from the abdomen of the moth, and each cluster may contain from four to five hundred. There seems to be little choice where the clusters are placed, many being on the 
trunks and limbs of the trees, but others are found in cavities in the trunks, on the stones of stone walls, even in the middle of the wall, in tin cans, and in fact, anywhere the female may crawl to. They hatch the following spring.

Distribution appears to be accomplished by the crawling of the caterpillars; by carrying to other places objects on which egg-clusters have been deposited; by caterpillars spinning down on threads from the trees onto passing vehicles; and by the wind.

The injury caused by this insect is often very serious. The caterpillars have voracious appetites and eat large amounts and their abundance has often resulted in the stripping of large areas, which repeated several years in succession usually causes the death of the trees. With evergreens, a single defoliation is usually sufficient to kill the trees, and in many parts of Eastern Massachusetts the thinning of woodland areas in consequence of the work of these insects, is very evident.

Parasites and other enemies of the Gypsy Moth have been introduced in large numbers by the Federal Government, and where these have become abundant they have done good work, though of course nothing like extermination of the pest has been accomplished. A wilt disease present in favorable seasons, kills many of the larvæ at such times. In general though, outbreaks of this insect in any locality are not repressed by their natural enemies for several years, and in the meantime the damage is great. This condition therefore calls for the use of control methods.

Control.-The egg clusters constitute one place where control measures can be applied. It is much easier to kill 400 or 500 insects concentrated in a space an inch square or less, than the same number in the larval stage, scattered over a tree. Soaking the egg clusters at any time after they are laid until they hatch the following spring, with creosote to which a little lampblack has been added (to show by its color which clusters have been treated and which have not) is a good treatment. Care must be taken, however, in using this material, to take enough to reach all the eggs in the cluster. Usually a swab on the end of a stick, soaked in the creosote, is used for this work. The difficulty with this method is that of finding all the egg clusters in their varied places of concealment.

While the caterpillars are very small, spraying infested trees and other plants with arsenate of lead, using about $5 \mathrm{lb}$. of the paste $\left(2 \frac{1}{2} \mathrm{lb}\right.$. of the powder) in 50 gal. of water, is a good treatment, but as the larvæ become larger they seem to develop a greater resistance to poisons and spraying becomes less effective.

As the larvæ feed largely at night and seek concealment during the day, put loose bands of burlap around the trunks of infested trees, where they may hide in the daytime. Success with this method of control is dependent upon daily visits to the bands and the destruction of the caterpillars found under them.

Sticky bands around the trunks of non-infested trees will keep the caterpillars off such trees as long as the bands remain fresh and in good order.

As the caterpillars do not feed on the pine until after they have passed their second instar, pure stands of pine may be protected by removing all undergrowth other than pine and banding the trees as above, to prevent older larvæ from crawling to them from places outside where they have obtained their earlier food. 
The Brown-tail Moth (Euproctis chrysorrhoea L., Fig. 269).-This is another European pest which was accidentally introduced into this country near Boston,

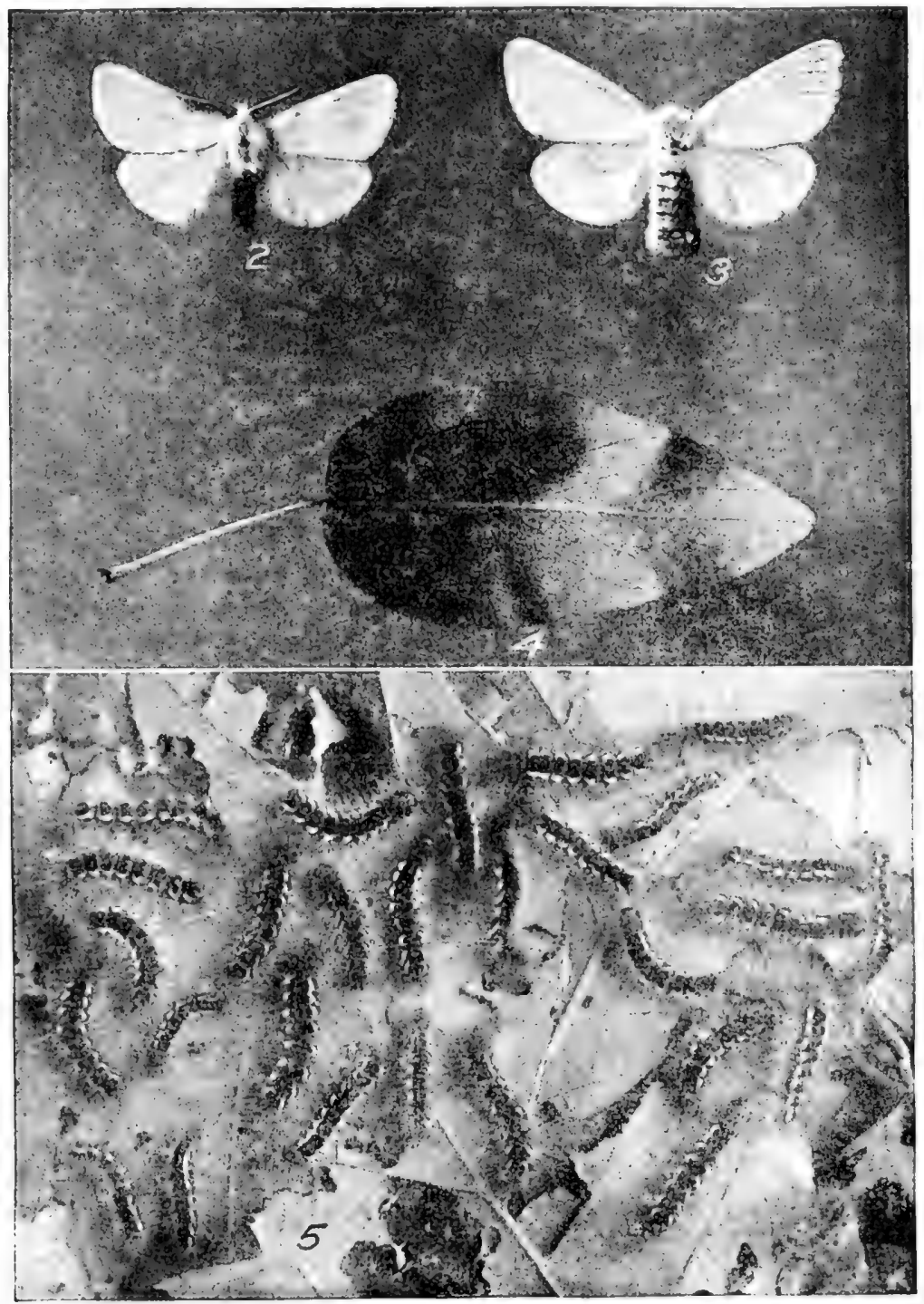

FIG. 269.-Brown-tail Moth (Euprocis chrysorrhoca L.): 2, adult male; 3, adult female moth; 4 , egg cluster on leaf, covered with hairs from body of parent; 5 , caterpillars feeding. About natural size. (From U.S. D. A. Bur. Ent. Bull. E7.)

reaching there about 1592. Since that time it has spread as far as Nova Scotia and New Brunswick, and also practically covers all of New England.

The moths are white except for the abdomen which has a few brown hairs, and the tip is covered by a tuft, large in the female, of golden brown hairs- 
the character which has given this insect its common name. The moths spread about an inch and both sexes are strong fliers, appearing early in July. They are somewhat attracted to lights but in most cases the females found thus attracted, appear to have already laid their eggs. The moths lay 200 or 300 eggs in a cluster, usually on the leaves, and cover them with brown hairs from the tip of the abdomen. They hatch in from 2 to 3 weeks and the little caterpillars feed on the foliage in company during the early fall, leaving the veins, and thus skeletonizing the leaves. Early in September they go together to the tip of some twig and there spin a very tough, dense, silvery tent incorporating some of the leaves in it, to use as their resting place for the winter. The size and form of this tent will vary with the number of caterpillars contributing to its formation, but it is usually three or four inches long and an inch or two in diameter at its widest p lace. After the leaves fall these tents at the tips of the twigs are very conspicuous objects during the winter. At the time of the formation of the tent the caterpillars are about one-third of an inch long.

In the spring as soon as the leaf-buds begin to open, the caterpillars leave their tents and scatter, feeding until June when they become fully grown and are about an inch and a half long, brown, slightly mixed with orange, fairly well covered with fine reddish-brown hairs, and with two bright red tubercles, one behind the other, on the middle line of the body above, near the hinder end. These red tubercles are very distinctive and give a positive recognition of this caterpillar.

The hairs just mentioned are delicate, brittle, barbed in some cases, and secrete a poisonous fluid very irritating to the skin. As the caterpillars molt these hairs are liable to be broken off and carried through the air to persons or onto their clothing, and a painful rash somewhat resembling that caused by poison ivy is produced, known as the "brown-tail rash."

Pupation usually occurs among the leaves and after about 20 days is followed by the emergence of the adult moths. The cocoon, though more developed than with the Gypsy Moth, is not very thick or dense, and the pupa can generally be seen through its walls.

Control.-Cutting off and burning the winter tents at any time between September and April is an effective method of control where the size of the tree is such that the tents can easily be reached. Spraying with arsenate of lead, standard formula, either in the fall if no fruit is involved, or when the larvæ first resume feeding in the spring, is also a good treatment.

Many of the parasites imported by the Federal Government to destroy the Gypsy Moth, attack this species also and appear to have done good work. For the last few years this insect has been rather less abundant than was previously the case. Whether this condition will continue, or outbreaks will recur from time to time cannot now be determined, but probably the latter will be true.

Family Notodontidæ (The Prominents).-The Prominents as the insects of this family are often called, are of medium size as adults and usually not at all brilliantly colored. Few of them are serious pests, and then generally only for a year or two at a time. The caterpillars of the different species differ greatly in appearance, some having dorsal humps or projections, others a much elongated end of the body, or other modification of the typical form of caterpillar. 
One part of this family consists of moths known as the Datanas. The larvæ of these insects feed on orchard, shade and forest trees, keeping together in groups, and when resting or disturbed they bend the ends of the body nearly at right angles to the middle part, in a very characteristic attitude. They feed during July and August and when full-grown are about two inches long. One species is common on the apple (Figs. 270, 271): others occur on the oak, walnut, hickory and other plants. The presence of 100 or 200 caterpillars feeding together on a single branch, and of considerable size as they get older, often disturbs the owners of infested trees who unnecessarily fear serious injury to their trees.

The fact that the caterpillars feed in groups renders control easy, however, either by removing the groups by hand or by spraying the region attacked, with a stomach poison, which is very effective for these insects.

Another Notodontid having similar habits and found at the same season is the Red-humped Apple-tree Caterpillar (Schizura concinna S. \& A., Fig. 272). The larva (Fig. 273) has a red head; a red hump a short distance behind; a double row of black spine ${ }_{\mathrm{S}}$

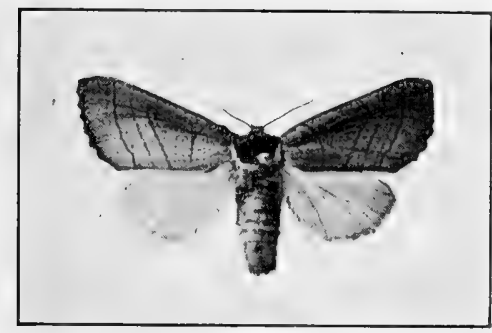

FIG. 270.

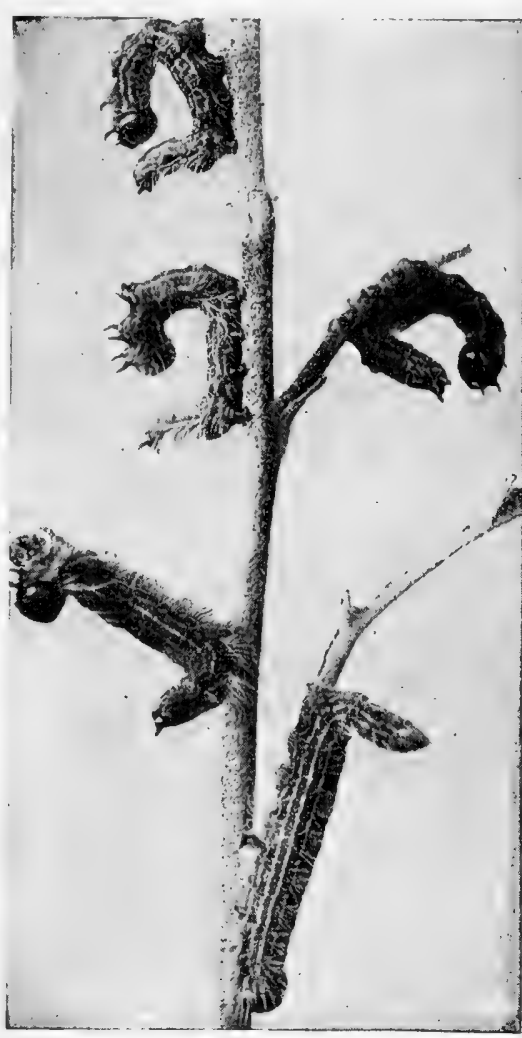

FIG. 271.

FIG. 270--Adult Moth of Yellow-necked Apple-tree Caterpillar (Datana ministra Dru.), slightly less than natural size. (Original.)

FIG. 271.- Yellow-necked Apple-tıee Caterpillars on a branch, showing characteristic attitudes assumed when disturbed. Natural size. (From Britton, Eighteenth Rept. Ent. Conn. Agr. Exp. Sta. 1918.)

along its back; and its body is narrowly striped with yellow, black and white. Control is the same as for the Datanas.

Family Dioptidæ.-This family appears to have but one North American representative, found only on the Pacific Slope. It is known as the California Oak Worm (Phryganidia californica Pack.), and the caterpillar feeds upon the leaves of the live oak and deciduous oaks. The adult moth (Fig. 274) is light brown with darker veins and a wing-spread of about an inch and a quarter. The eggs are laid on the leaves of the oaks and various other plants in October 
and November, and hatch during the 5 months following. Those on the deciduous oaks fall with the leaves, and larvæ from them rarely find anything to feed upon and therefore die. The eggs laid on the live oak, eucalyptus and chestnut, however, produce caterpillars (Fig. 275) which can generally obtain food and they become full-grown in May and June and pupate in any protected place, spinning no cocoon. The moths from these pupæ emerge after about 2 or 3 weeks and lay their eggs for a second generation, the larvæ of which feed during the last of July, August and September. Pupation follows, after which the moths appear and lay their eggs as already indicated.

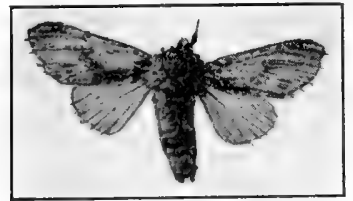

FIG. 272.

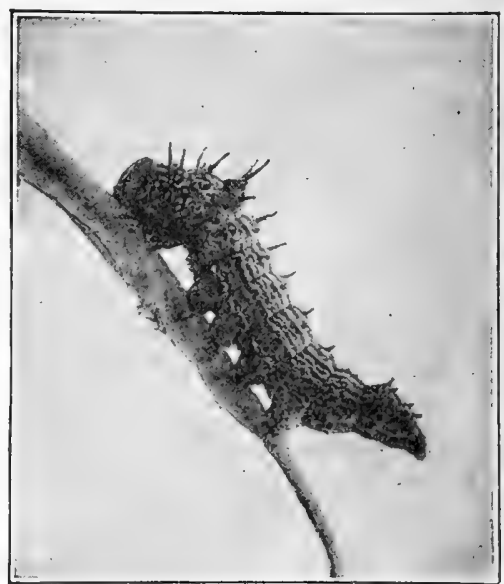

FIG. 273.

FIG. 272.-Adult Moth of Red-humped Apple-tree Caterpillar (Schizura concinna S. and A.), natural size. (Original.)

FIx. 273.-Red-humped Apple-tree Caterpillar in feeding position. Somewhat enlarged. (From Britton, First Ript. Ext. Conn. Agr. Exp. Sta. 1901.)

When abundant, the trees upon which these insects feed are liable to be entirely stripped of their foliage and this sometimes happens over large areas.

Control.- Spraying the trees when the caterpillars are abundant, as they begin to feed, with Arsenate of lead, 4 or $5 \mathrm{lb}$. of the paste ( 2 or $2 \frac{1}{2} \mathrm{lb}$. of the

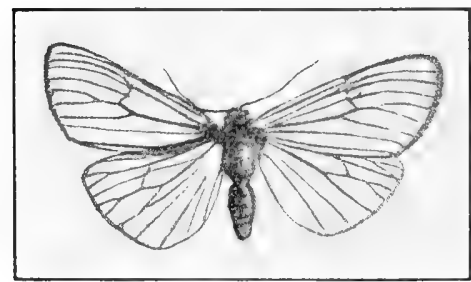

FIG. 274 .

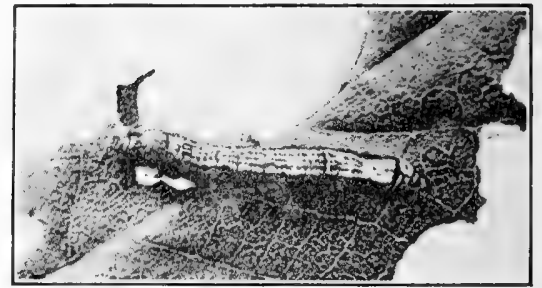

FIG. 275.

FIG. 274.-California Oak Worm Moth (Phryganidia californica Pack.), about natural size. (After Essig, Inj. and Benef. Ins. of Cal.)

FIG. 275.-Caterpillar of the California Oak Worm, natural size. (Modified from Essig, Inj. and Benef. Ins. of Cal.)

powder) in 50 gal. of water is effective where the size of the trees permits this treatment. Power sprayers and nozzles giving a fine mist are the most effective for this purpose.

Family Noctuidæ (The Owlet Moths).--The Noctuids form the largest family of moths in this country and are everywhere abundant. Within 
the group there are great differences in the appearance of the moths and in the habits of their larvæ. Lochhead has divided the family into nine sections, based mainly on differences of larval habits.

Some members of the Noctuidæ are known as the Catocalas or "Underwings." Some of these are quite large, spreading three inches or more, the fore wings with quiet colors and marked so that they resemble the bark of trees (Fig. 276). One has fore wings similar to the bark of the white birch: another resembles the bark of the beech, and many kinds of trees are thus imitated in color and markings. The hind wings are brightly, often brilliantly colored and it appears to be the habit of the moths, which fly at night, to rest during the day on the tree trunks whose bark their fore wings resemble, folding these over their gaudy hind wings, in this way obtaining through concealment, protection from their enemies. How far in the course of thousands of generations, the weeding out by these enemies of these least closely resembling the bark, leaving behind to continue

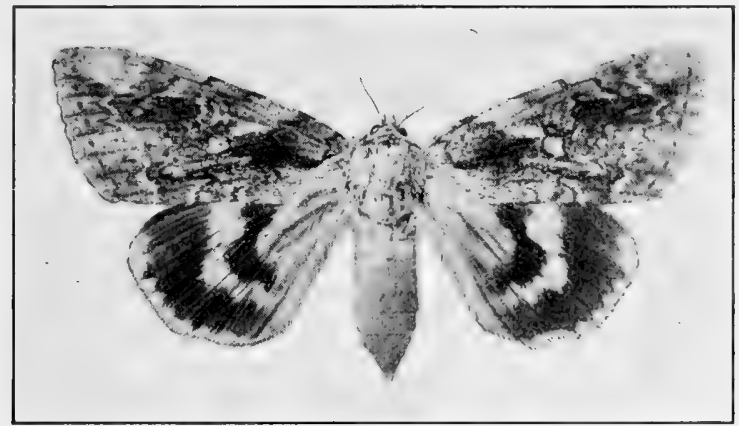

FIG. 276.-Catocala Moth, natural size. (Original.)

the race the closest imitators of the bark, has resulted in giving to the present members of the group a closer resemblance than their ancestors, is a question for speculation. The larve of the Catocalas feed on foliage but are rarely if ever injurious enough to be of importance.

The largest Noctuid found in this country is known as the Black Witch (Erebus odorata L.). It does not live in the United States, being an inhabitant of the tropics, but its size and powerful wings which of ten spread six inches, enable it to fly long distances and it is often captured in the late summer and fall in the Northern United States. It has dark wings of various shades of brown, and a small "eye" spot in each fore wing.

The Cotton Worm (Alabama argillacea Hbn.).-The Cotton Worm is not a native of this country but of more tropical countries, from which it frequently comes and attacks cotton in the Southern States. The moths (Fig. 277) are of a nearly uniform reddish-brown or tawny color, and spread a little over an inch. They lay their eggs singly on the cotton leaves and these eggs hatch in from 3 to more than 20 days, according to the temperature. The caterpillars are at first yellowish-green with pale yellow heads. Later they vary much in color and markings, some changing little, while others acquire a black stripe along the middle of the back, with a fine central yellow line, and each segment has four 
black dots above. 'The full-grown larva webs a leaf or two together and pupates in this place, remaining there a varying length of time before the adult emerges.

Fall flights northward of Cotton worm moths occur frequently and may extend into the Northern States and Canada, where these insects are sometimes found abundantly in September and October.

Control.-Dry arsenate of lead dusted over the plants when these insects first appear, using from 2 to $4 \mathrm{lb}$. per acre, according to the size of the plants, appears to be a satisfactory treatment.

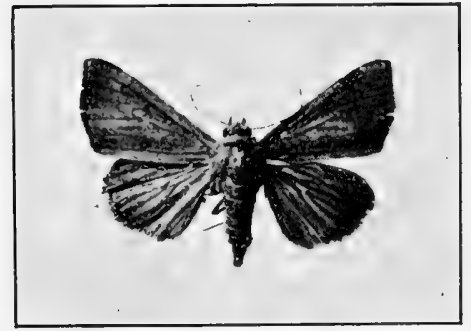

FIG. 277.-Adult moth of the Cotton Worm (Alabama argillacea Hbn.), about natural size. (Original.) It is usually applied while the dew is on the plants.

The Dagger. Moths are leaf feeders on various shrubs and trees in their larval stages. The fore wings of the moths are various shades of gray in most cases, and the larvæ are usually quite well covered by rather uniformly distributed gray hairs.

Several species are known as Green Fruit worms, the caterpillars being greenish, without hairs, and feeding on the leaves and small fruit of apple and other trees during the later spring months. They are not often seriously abundant.

Some of the Noctuids are Stalk Borers, tunneling in the stems of cultivated and other plants, among the plants affected in this way being corn, tomatoes, potatoes, asters, dahlias, etc. The larva feeds during the summer months and as a rule pupates in the lower part of its tunnel. Accordingly, all wilted plants should be examined, and if a borer is present the plant should be destroyed with the borer either as larva or pupa, within it.

The Corn Ear Worm (Chloridea obsoleta Fab.).-This widely distributed pest is known by several common names, such as the Cotton bollworm, tomato fruitworm and false budworm of tobacco, in addition to the one first given. In the South it attacks cotton bolls and tobacco seed pods, as well as tomatoes and corn which are its usual food in the North. It is present practically everywhere in the world between the parallels of $50^{\circ}$ north and south latitude, and its original home is problematical.

The adult insect (Fig. 278a) spreads about an inch and three-quarters and is extremely variable in color, so that several varieties have been recognized. It ranges from a pale reddish-brown to olive, with a greenish tinge toward the outer margin of the fore wings, with darker bands and spots, and the hind wings are lighter, with dark veins and a blackish shade crossing from one outer angle to the other, leaving more or less of a lighter color between this and the outer margin.

The insect appears to pass the winter as a pupa in the ground, the adult emerging in the spring, earlier in the South and later farther North. The eggs, varying in number from less than 500 to nearly 3,000 are now laid on different parts of the food plants and on weeds or even on the ground. They hatch in a week or less, according to the temperature, and 
the larvæ (Fig. 278b) begin feeding, at first on the surface of the plant but soon boring into it at some tender place.

With cotton, injury is caused by eating out the squares and the more tender bolls. In the case of corn the first attack is by boring into the bud and eating down into the developing leaves. Later, the tassels are often injured before they open, and after the silk appears eggs are laid on this and the caterpillars which hatch from them bore into the ears of corn to varying distances, often entirely destroying the ears, particularly in the case of sweet corn. Tomatoes are injured mairly by the larvæ boring
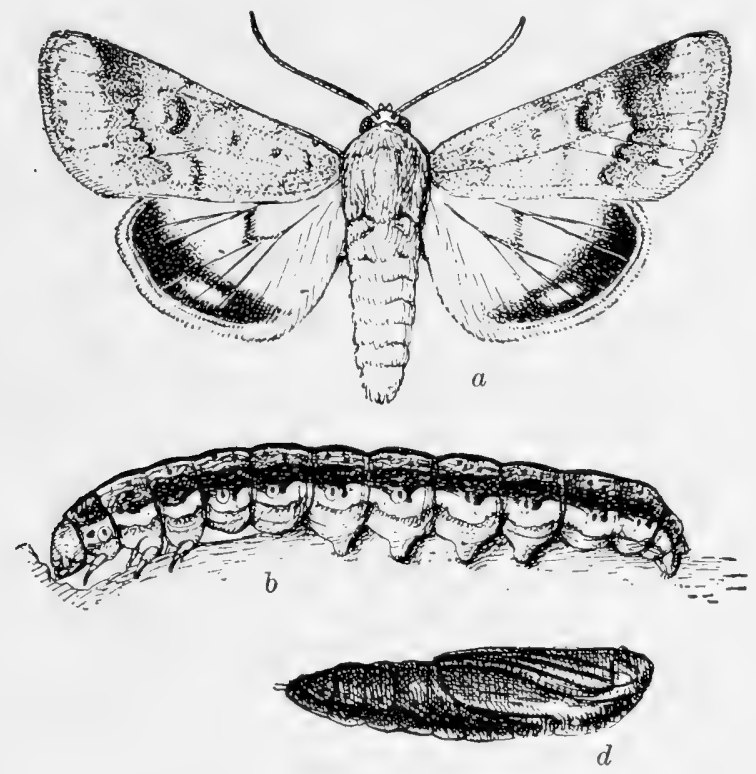

FIG. 278.-Corn Ear Worm (Chloridea obsoleta Fab.) : $a$, adult moth; $b$, larva; $d$, pupa: all enlarged. (From U.S.D. A. Farm. Bull. 890.)

into the green or partially ripened fruit, and in some cases by boring into the tips of the plants or eating the blossoms. With tobacco the larvæ attack the bud leaves at the tip of the plant and later bore into the pods. Peaches, peas, beans, etc., are also sometimes injured and the average annual loss by the ravages of this pest in the United States has been estimated as over eighteen million dollars.

There are several generations of this insect each year, four or five being produced in the far South and this number reducing northward until in the Northern States and Canada there is but one. The larvæ vary greatly in color and markings and are most easily recognized by the nature of their work. When full-grown they are about an inch and a half long. 
Control.-Late fall plowing to break up the earthen cells in the ground where the insects winter as pupæ, provided the plowing is rather deep, is a helpful procedure. As the larvæ feed for a short time on the surface of the plants before boring into them, the application of arsenate of lead at or just before this time, is advantageous. With the increasing numbers in the later generations of the insect, fertilization, culture and any methods possible for hastening the maturity of the crop are desirable. Green corn is the preferred food plant of this insect and rows of corn planted in and near cotton fields, if in tassel and silk about the first of August will attract most of the moths, leaving the cotton much more free than otherwise. On corn itself, dusting powdered arsenate of lead onto the silks, as soon as these appear, seems to reduce the damage to quite an extent if applied at 3 or 4 -day intervals while the silk is developing.

In the Noctuidæ are a number of species where some of the abdominal feet of the caterpillars are not functional or are absent, as a result of which these larvæ travel like those of the Geometers or "inch worms" already described. Several of these species are occasionally injurious to cultivated plants. In most cases at least, such larvæ can be controlled by the application of arsenate of lead.

The Army Worms also are members of the Noctuidæ, this name being given to the insects because of their habit of marching from place to place all together, like armies. They are periodically injurious insects, appear-

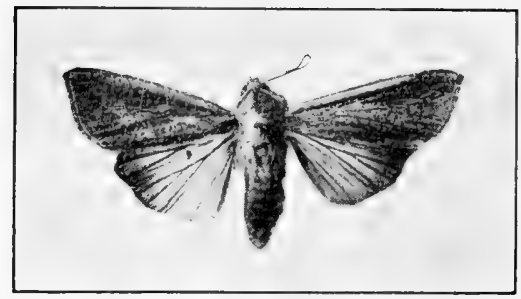

FIG. 279.-Adult Moth of the Army Worm (Cirphis unipuncta Haw.), slightly reduced. (Original.) ing in great abundance at times, but rarely troublesome for more than one season at a time in the same place.

The Army Worm (Cirphis unipuncta Haw.).-This pest is probably a native of North America. It occurs over the entire eastern United States as far west as Kansas and Nebraska, and has been reported from the Southwestern States and California.

The adult moth (Fig. 279) spreads about an inch and a half, and is quite uniformly brownish-gray with a tiny white spot near the middle of each front wing and a rather dusky outer margin on the hind wings. The moths fly at night and are often attracted to lights.

In what stage this insect passes the winter does not appear to have been conclusively proved, but it is probably as the partly grown caterpillar hiding in rank, dense weedy growth. In late spring, at least, the nearly full-grown larvæ have been found feeding on grasses primarily and then on small grain. The larvæ mature quite rapidly, pupate in the ground and produce the moths in June, at least in the North. Eggs are now laid on grass and similar plants and hatch in 8 or 10 days 
and the larva feeds for 3 or 4 weeks until about an inch and a half long. It is now a nearly naked caterpillar (Fig. 280), somewhat variable in color but generally rather greenish, with a broad dark stripe along its back with a fine, broken, white line along its middle, and a dark stripe along each side.

Before this size has been attained all the food where these insects are, may have been consumed if the larvæ are abundant, and in this case they march off in armies to find new feeding grounds, and it is these marching armies which usually attract attention in July or August. When feeding has been completed they pupate in the ground and the moths emerge in September or October and probably lay eggs which soon hatch, the caterpillars thus produced, feeding to some extent before winter. The spring-feeding generation appears to be little noticed, the destruction seen being by the summer generation.

When the caterpillars are abundant numerous flies resembling, but larger than house-flies, and called "tachina flies," are usually noticed flying about the army. These are, nearly always at least, parasites laying their eggs on the caterpillars. The maggots which hatch from these eggs bore into the caterpillars and feed upon and

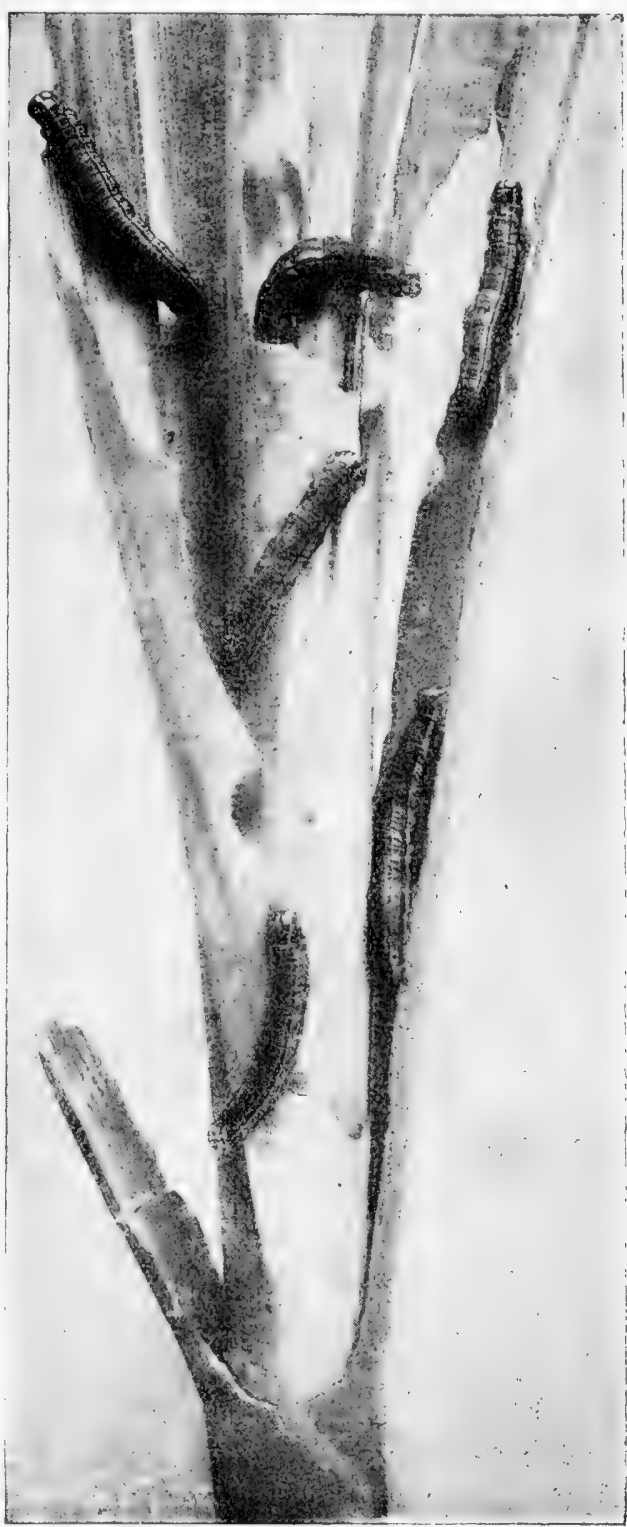

FIG. 280.-Army Worm Caterpillars feeding on corn. Natural size. (From Britton, Fourtecnth Rept. Ent. Conn. Agr. Exp. Sta. 1914.)

finally kill them. There are also several other insect enemies of the Army Worm. 
Control.-If Army Worms are discovered before they begin their march, spraying all the plants where they are with a stomach poison is an effective treatment, or if the infested area is small, straw can be spread over it and burned. Once on the march, protection of any crops towards which the caterpillars are marching, either by destroying the insects or by preventing their reaching the crops, is the aim of any treatment. Poisoned baits (see under "Cutworms," page 276) may be used for this purpose, or where the ground over which the insects are marching is fairly smooth and firm, the use of a heavy roller is possible. A ditch dug across their line of march or around an infested area is often used, and a log dragged along in the ditch as the caterpillars become thick in it will kill multitudes. Food in a strip ahead of their line of march, sprayed with a stomach poison will result in the poisoning of those which feed there, and in some cases the caterpillars while marching can be reached and killed by a strong contact insecticide.

The Fall Army Worm (Laphygma frugiperda S. \& A.).-This insect in many ways resembles the true Army Worm. It has numerous common names such as the "grassworm," "overflow worm," "alfalfa worm," etc., and it is called the Fall Army Worm only in the Middle and Northern States, as it does not appear there before fall.

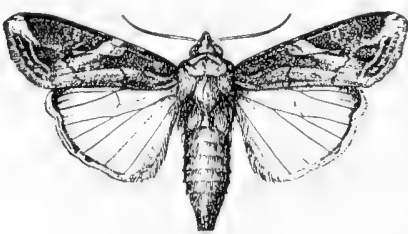

FIG. 281.

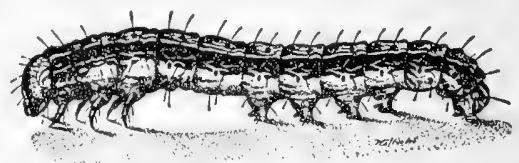

FIG. 282 .

FIG. 281.-Moth of Fall Army Worm (Laphygma frugiperda S. and A.), about natural size. (Modified from U.S. D. A. Farm. Bull. 75.2.)

Frg. 282.-Full-grown Caterpillar of Fall Army Worm, somewhat enlarged. (Modified from U. S. D. A. Farm. Bull. 752.)

This insect is probably a native of this country. While most destructive in the South it may spread during the season far to the North, reaching the New England States, southern Wisconsin and southeastern Montana, and extending westward to the Rocky Mountains.

The moth (Fig. 281) spreads about an inch and a quarter. Its front wings are mottled gray, usually with a light spot near the tip, and the hind wings pearly white, edged with a rather narrow, dark line. It does not seem to be able to live over winter north of the southern parts of the Gulf States. The caterpillar (Fig. 282) feeds upon native grasses primarily, but when these are not sufficiently abundant it may attack grains, sorghum, alfalfa, clover, cotton and other crops.

In what stage this insect spends the winter does not seem to have been positively determined, but it is probably the pupa. The eggs, 
from 50 to several. hundred in number, are laid preferably on grass blades and in the South hatch in a few days. The caterpillars feed 2 or 3 weeks before reaching full size and are then very similar to those of the Army Worm. They then pupate for 10 to 14 days in the ground, after which the adult moths emerge. Many of these moths now fly northward, of ten several hundred miles, before laying their eggs, and in this new location another generation is produced, the adults of this generation also flying northward to lay their eggs. In this way the northern part of the country becomes infested in the fall but frost puts an end to the development of these insects near their northern limits before more than one generation can be produced. Going southward, more are possible, and in the Gulf States there may be six in the course of a season.

Where corn and cotton are grown the destruction caused by this insect is often

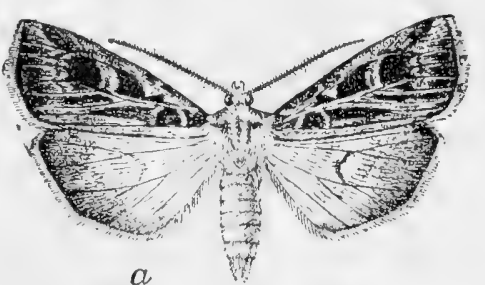

a
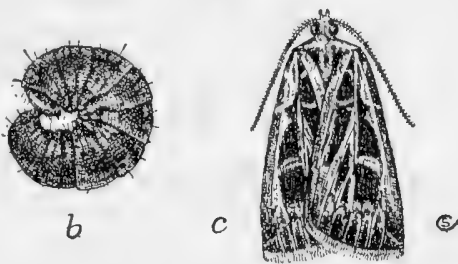

FIG. 283.-Dingy Cutworm (Fellia subgothica Haw.): $a$, moth, wings spread; $b$, larva (Cutworm); $c$, Moth, wings folded. All somewhat enlarged. (From U.S. D. A. Farm. Bull. 856.) very great, the caterpillars as they get large having voracious appetites. They usually feed more at night than during the daytime, and like the

Army Worm, march to
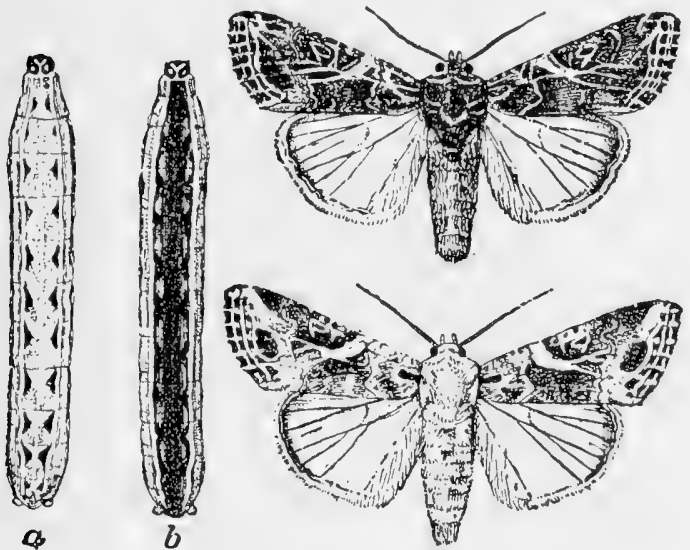

FIG. 284.-Cotton-boll Cutworm (Prodenia ornithogalli Guen.): $a$, light form of Cutworm; $b$, dark form; dark form of Moth above; pale form below. All somewhat enlarged. (From U.S.D. A. Farm. Bull.890.)

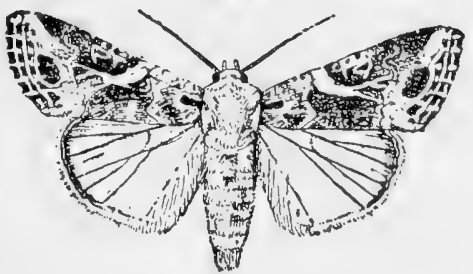

other places to find food when the supply where they are becomes exhausted.

In general the methods used for controlling the Army Worm apply to this insect also.

A number of other species of Noctuids have the habit of marching in armies when their food becomes searce. Their life histories and habits are for the most part quite similar to those of the two species already described, and control methods for them are generally the same.

Still another section of this family occurs, widely distributed, and causing much injury. The insects of this division are called Cutworms (Figs. 283 and 284) because of the habit of the larvæ of feeding on the 
stems of succulent plants at about the level of the ground and thereby either partially or entirely cutting them off at this point. Several hundred species have this habit and many kinds of garden and field crops suffer in this manner during the spring and early summer months. A few have the habit of climbing up the plants at night and feeding there, some distance above the ground.

The moths are usually of medium size, spreading from an inch to about two inches, and are generally quiet colored, gray, brown or blackish, more or less mottled, streaked or banded on the fore wings while the hinder pair are nearly white and unmarked except for darker margins in some cases. Some species are more strongly marked, however, and have brighter colors.

Most of these insects winter either as pupæ or partly grown caterpillars. In the spring the latter pass the day in the ground, coming up at night to feed. They are generally dull colored with rather faint spots and lines and without a hairy covering, and when full-grown will average an inch to an inch and a half in length. When feeding has been completed they pupate a few inches deep in the ground. Some species have one generation each year; others two.

Control.-Late fall plowing to bring up and expose the insects to the fluctuating temperatures of the cold season and its rains, is a useful treatment, but other measures are also necessary. When Cutworm work is seen the use of a poison bait is desirable. For this purpose one good formula is: LARGE
QUANTITY For SMALI

Bran. $50 \mathrm{lb}$.

Paris green

$2 \mathrm{lb}$.

Cheap molasses.

2 qt.

Oranges or lemons.

Water.

3 fruits

3 to $7 \mathrm{gal}$. or 4 to $6 \mathrm{qt}$.

The second formula is for use where only a small quantity is desired.

Mix the bran and Paris green together thoroughly, dry: add the juice of the fruit to some of the water and chop up the rest of the fruit finely and add this and the molasses. Now combine this mixture with the bran and Paris green and stir thoroughly, adding enough more water to finally produce a rather stiff dough. This can be used in gardens, placing about a teaspoonful close to the base of each plant liable to attack, but should be put on toward night so that it will not dry up in the sun and lose its attractiveness to the Cutworms. Fowls should be shut up while this treatment is being used, to prevent their feeding on the bait and being poisoned.

Where large fields are to be treated, a modification of this formula is desirable, reducing the amount of water to a point where the mixture is dry enough to spread broadcast, yet wet enough so that each flake of 
bran has been moistened by the molasses and fruit juice sufficiently to make it attractive, and also bears a little of the poison. The amount of water to add to obtain this condition must be determined by testing the mixture at intervals to see that the bran is dry enough to spread, and also that it has been able to take up the other materials. In any case the mixture should stand for several hours before use, to allow the bran time to take up the other constituents. The larger quantity given above is sufficient to spread broadcast over several acres.

The size of the family Noctuidæ and the abundance of its members in all parts of the country, as well as the various methods of feeding present in the group make it one of the most destructively important families of Lepidoptera in the United States.

Family Arctiidæ (The Tiger Moths),- The Arctiids are mainly medium-sized moths, of ten brilliantly colored. Most of the group are not serious pests, but individuals, particularly in their larval stage, are often seen. Many of these caterpillars are quite densely and uniformly covered with long hairs and are sometimes called "woolly bears." One of them often seen crawling about in the

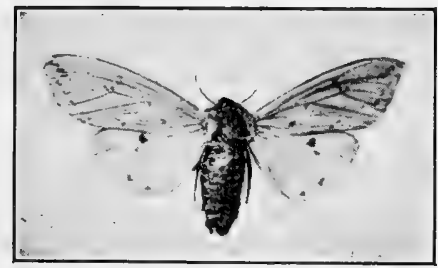

Fig. 285.

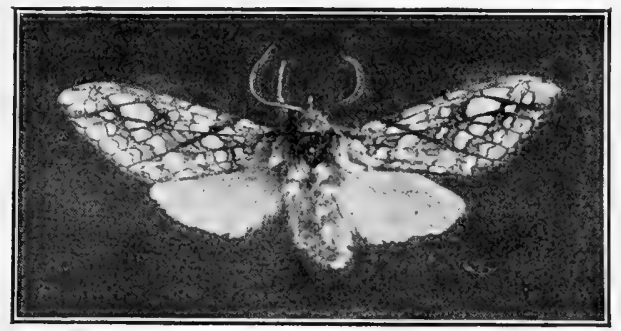

FIG. 286.

F1G. 285.-Isabella Tiger Moth (Isia isabella S. and A.), slightly reduced. (Original.)

FIG. 286.-Hickory Tiger Moth (Halisidota carya Harr.), natural size. (From Britton, Seventh Rept. Ent. Conn. Agr. Exp. Sta. 1907.)

fall is covered with reddish-brown hairs at each end, and black ones in the middle, and is sometimes given the particular name "hedgehog caterpillar." The adult (Fig. 285), not often seen, is an orange-buff moth, its hind wings tinged with pinkish, and spreads a little over two inches. It is called the Isabella Tiger Moth (Isia isabella S. \& A.). Another caterpillar, the "salt-marsh caterpillar" (Estigmene acree $a$ Dru.) has a blackish head and body, well covered with long, tufted, brownish hairs. The adult is about the size of the Isabella Tiger Moth, the male having white fore wings spotted here and there with black, while the female has all its wings white and spotted. The abdomen of both sexes is orange. The Hickory Tiger Moth (Halisidota caryee Harr., Fig. 286) is quite common in the northeastern United States and Canada, west to Minnesota and south to North Carolina and Ohio. The larvæ, which occur in the summer and fall, feed on many kinds of trees and are sometimes rather injurious. At first they feed in company but during the latter part of their larval life they scatter. The full- 
grown larva (Fig. 287) is an inch and a quarter or more in length, covered with grayish-white and black hairs. Along the middle of the back is a row of tufts of black hairs and there may also be longer, slender black tufts or "pencils." The insect winters as the pupa under rubbish on the ground, and the moths emerge in late spring and early summer and are yellowish in color, the fore wings sprinkled with brown dots and two brownish streaks. These wings are rather narrow for their length, and somewhat pointed. The hind wings are nearly

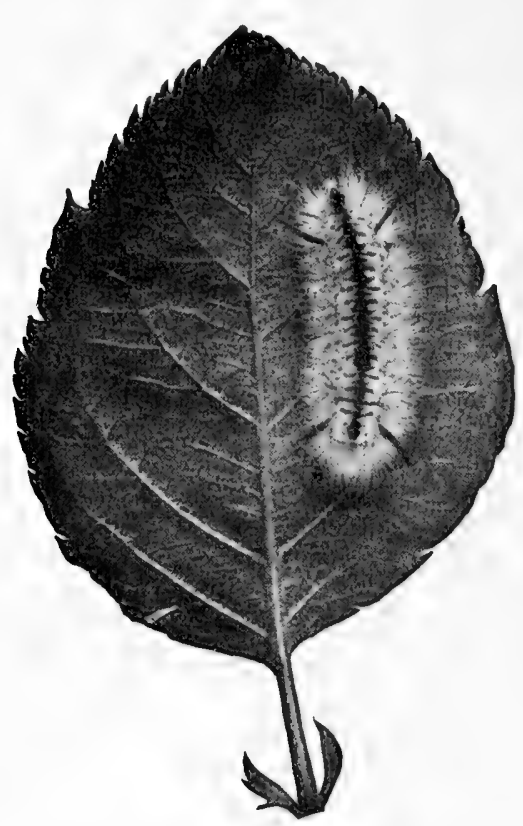

FIG. 287. transparent and almost white. The moths spread about two inches. Control is by spraying with a stomach poison as soon as the work of the caterpillars is noticed.

The Fall Webworm (Hyphantria cunea Dru.).- This insect is a pest on shade, fruit, and ornamental trees. It is found everywhere in the eastern United States and as far west as Montana and Texas. In the South and northward about to New York there are two generations each year and a correspondingly greater amount of injury than where one is the rule.

Fig. 287.-Full-grown Caterpillar of the Hickory Tiger Moth, natural size. (From Britton, Seventh Rept. Ent. Conn. Agr. Exp. Sta. 1907.)

FIG. 288.-Fall Webworm (Hyphantria cunea Dru.), about natural size. (Original.)

The adult moth (Fig. 288) spreads about an inch, and in the north has pure white wings. Farther south black spots are present on them and this difference has led to the belief, still held by some persons, that there are really two species concerned. The winter is spent as the pupa in the ground, the moths emerging in the late spring and laying their eggs in clusters, often 200 or 300 in number, on the under side of the leaves. These hatch in about 10 days and the larvæ pass together to the outer foliage of some branch, where they form a thin white web over the surface, feeding on the leaves enclosed within the web (Fig. 289). As the caterpillars grow and consume this foliage, the web is extended to cover more leaves and by the time full size has been attained by the caterpillars, the web may be as large as a bushel basket. The full-grown larva (Fig. 290) is over an inch long, quite hairy but not 
sufficiently so to conceal the body which is generally "pale-yellowish or greenish, with a broad, dusky stripe along the back and a yellow stripe along the sides; they are covered with whitish hairs which spring from

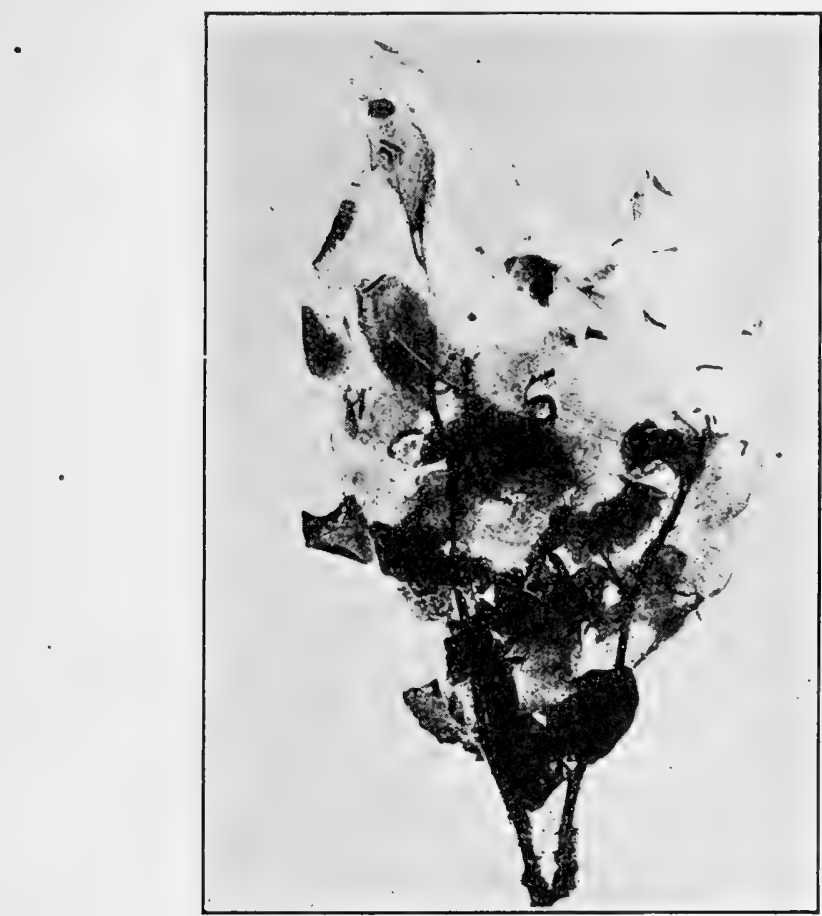

Fig. 289.-Branch covered by web of the Fall Webworm. (From N.H. Agr. Exp. Sta. Bull. 139.)

black and orange-yellow warts" (Packard). The head is black. The larvæ pupate in the ground:

Where there are two generations the moths appear in June or even earlier and the second generation moths develop early enough in the fall for the larvæ from their eggs to become fullgrown before the leaves drop. Where there is but one generation the webs appear the last of July and in August, and reach full size in September.

Control.-There are several ways by which to check the ravages of this insect. When the

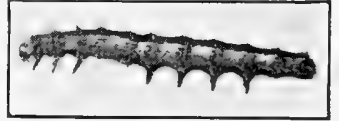

FI G. 290 .-Full-grown larva of the Fall Webworm, natural size. (Original.) webs first appear they may be stripped off by hand and the then small larvæ crushed. Branches attacked may be cut off if the tree is of sufficient size not to be marred in this way. Spraying all around the tent with a stomach poison, standard formula, will poison the leaves next to be brought within the web by its further enlargement, and thus provide the caterpillars with poisoned food. 
Family Ceratocampidæ (The Royal Moths).-In this family are included several very large moths and a few smaller ones. The Regal Walnut Moth (Citheronia regalis Fab.) may have a wing-spread of six or seven inches (Fig. 291). Its fore wings are rather dusky but the veins are lined with orange-red and there are numerous yellow spots. The hind wings are lighter, with some yellowish areas, and veins lined as in the other pair. The stout body is brownish-orange with

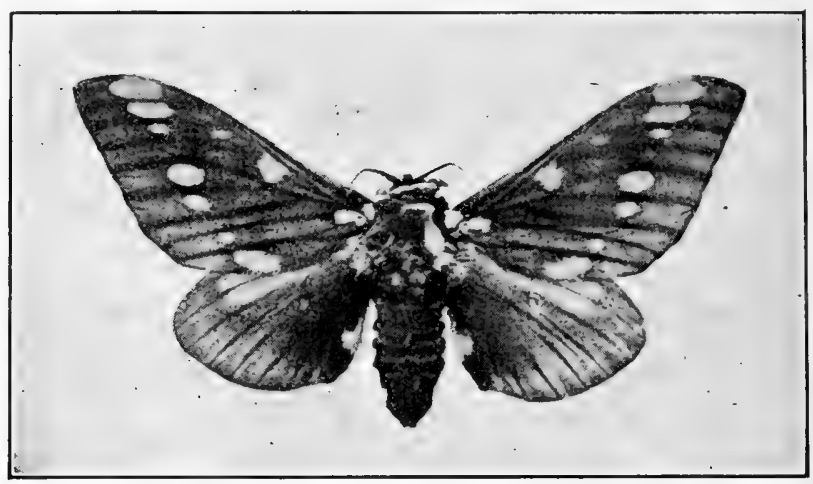

FIG. 291.-Regal Walnut Moth (Citheronia regalis Fab.), about half natural size. (From Felt, N.Y. State Mus. Mem. 8.)

narrow yellowish cross lines. The caterpillar (Fig. 292) which feeds upon various trees, is four or five inches long when full-grown and has a green body bearing numerous black spines and, just back of the head, a number of very long reddish spines bending backward and tipped with black. The head is red. The terrifying appearance of this caterpillar has probably been the reason for calling it

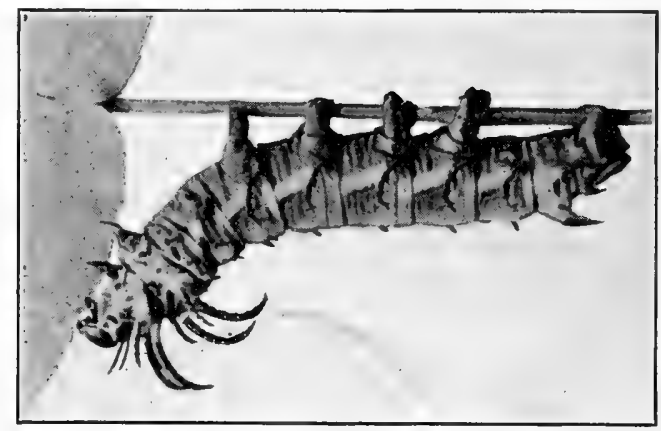

.Fig. 292.-Full-grown larva of the Regal Walnut Moth, slightly less than half natural size. (From Packard, Mem. Nat. Acad. Sci., IX, Part II.)

"The Hickory Horned Devil." The insect is found from Massachusetts to Louisiana, Texas and Missouri, but is not very abundant and therefore does little injury. It feeds on the black walnut, butternut, hickory and a number of other trees, and has once or twice caused some damage to cotton. It winters as a pupa in the ground. 
Another large moth belonging here is the Imperial Moth (Basilona imperialis Dru., Fig. 293) which has about the same distribution as the Regal Walnut Moth. The adult often spreads six inches and is yellow, with lilac or purplish-brown

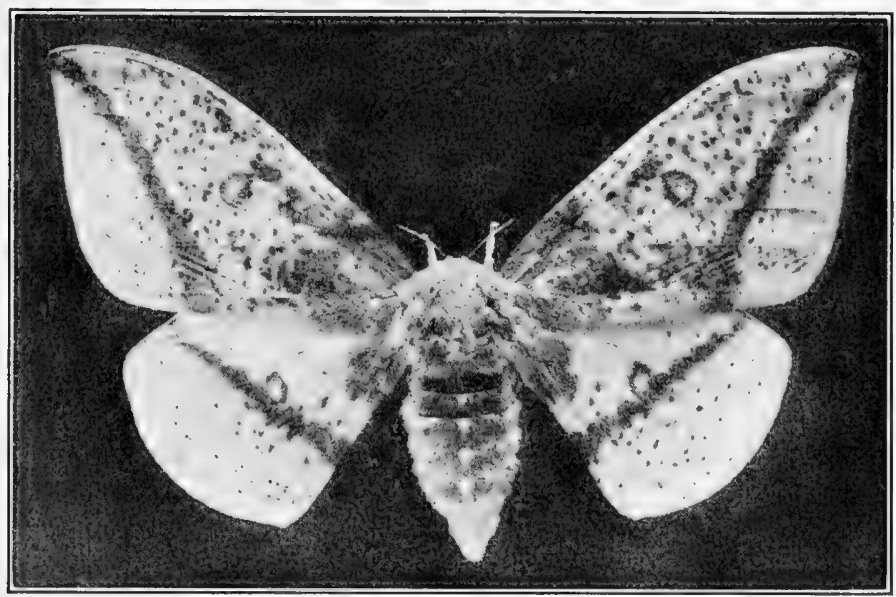

FIG. 293.--Imperial Moth (Basilona imperialis Dru.), slightly more than half natural size. (From Felt, N. Y. State Mus. Mem. 8.)

areas or bands and spots. The caterpillar (Fig. 294) is green (or brown sometimes), from three to four inches long when full-grown, rather well covered with long, white hairs, and has two pairs of rather stout, upward projecting tubercles or horns behind the head. It feeds on quite a list of trees including some of the

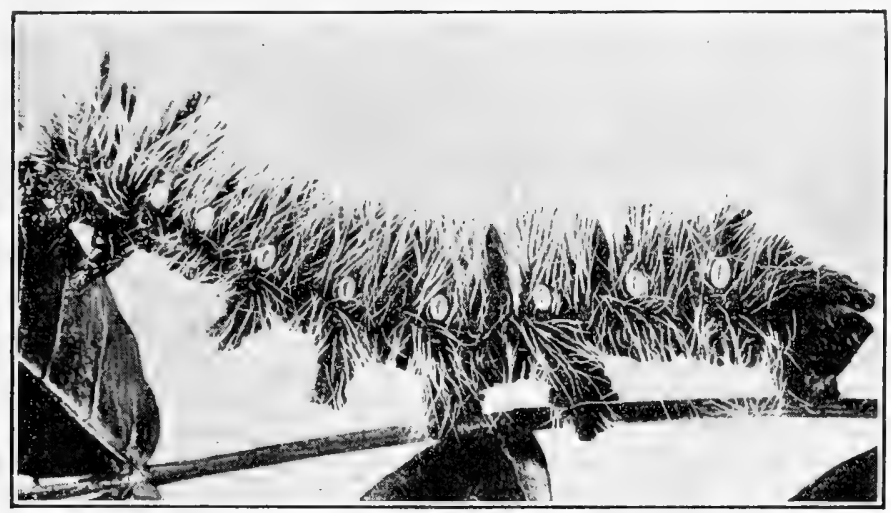

FIG. 294.-Full-grown larva of Imperial Moth, somewhat reduced. (Reduced from Packard, Mem. Nat. Acad. Sci. IX, Part II.)

evergreens, and pupates in the ground during the winter. Like the last species it is rarely if ever abundant enough to be of economic importance.

Several insects in this family are quite common at times and locally may be numerous enough to cause some injury to oaks, maples and other trees they feed upon, but their presence is noticed for only a year or two at a time. 


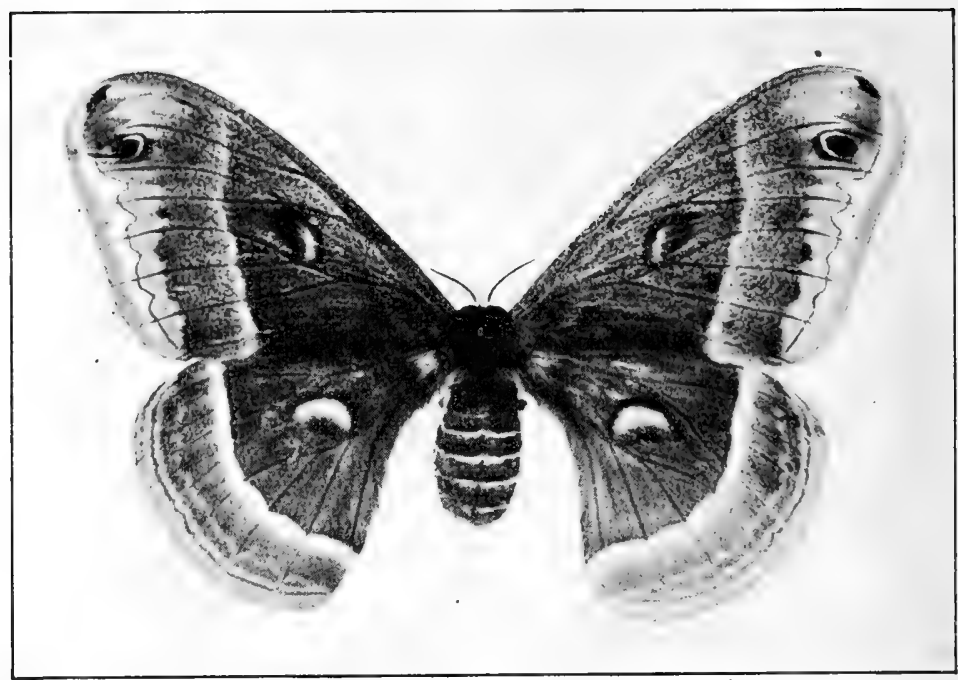

FIG. 295.-Cecropia Moth (Samia cecropia L.), slightly over half natural size. (Original.)

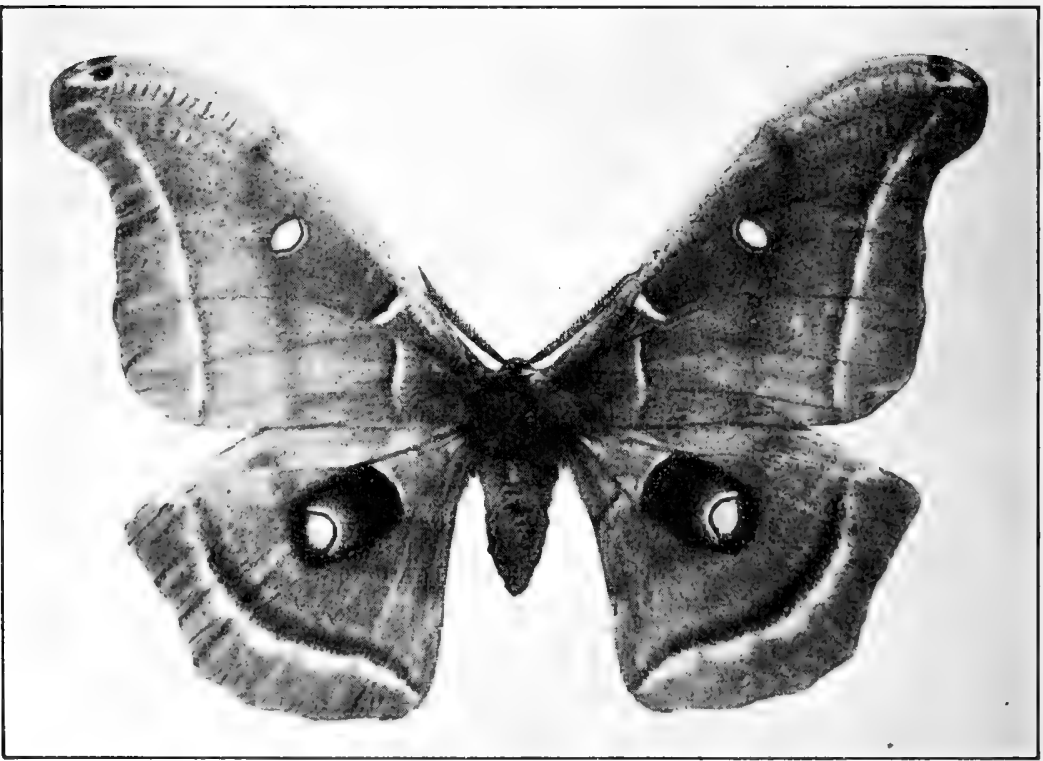

FIG. 296.-Polyphemus Moth (Telea polyphemus Cram.), about three-quarters natural size. (Original.) 
Family Saturniidæ (The Giant Silkworms).--In this family belong most of the common, very large moths found in North America. Though their size and that of their caterpillars attracts attention, these insects are of little economic importance as the number of eggs laid by an individual is not very large and they are generally well scattered so that few larvæ are often found on any one tree. If the silk of their cocoons could be utilized they would become industrially important, but the thread is frequently broken so that reeling it is difficult and expensive.

One of the more common species in this family is the Cecropia Moth (Samia cecropia L.), a very large, brownish-gray insect (Fig. 295) with a whitish, crescent- . shaped spot partly shaded with brown, near the center of each wing. Outside this spot a whitish line crosses the wing and the outer margin is more or less broken by black spots on a whitish ground. The abdomen is brown with white crossbands. The caterpillar (See Fig. 21), which when full-grown is from three

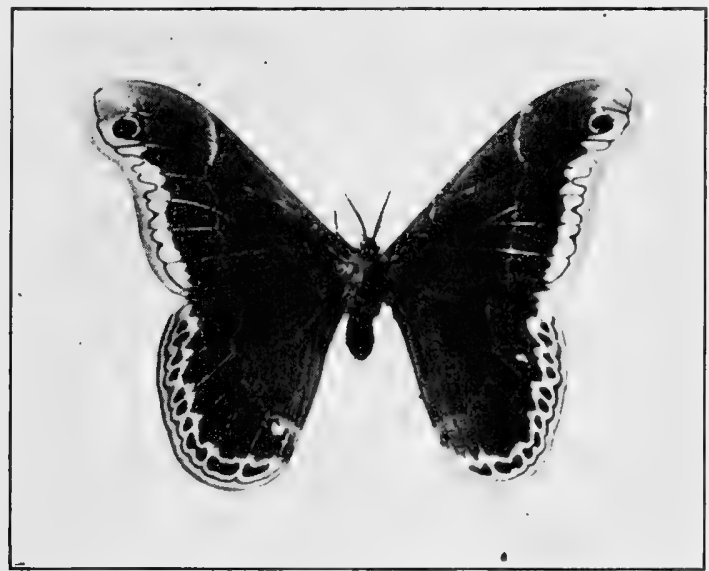

Fig. 297.--Male Promethea Moth (Callosamia promethea Dru.), about two-thirds natural size. (Original.)

to four inches long, is green with tubercles along its back, two pairs near the head being coral red and the others yellow except the first and last pair which are blue. The insect feeds on many kinds of plants, including some fruit and shadetrees. The moths appear in late spring, the larvæ feed during the summer, and in the fall spin rather dense cocoons on the twigs of the trees, in which they pupate and pass the winter

A rather similar moth, though usually a little smaller, is the Polyphemus Moth (Telea polyphemus Cram.), with brown wings crossed near the outer margin by a blackish band (Fig. 296). The front wing has a transparent "eye" spot with a yellow margin, around which is a black line. The hind wing has a somewhat similar spot, but the black around it covers quite an area, particularly toward the base of the wing. The caterpillar is green with a yellow, oblique line on the side of most of the segments of the abdomen and it feeds on many fruit and forest trees. The cocoon is spun among leaves on the ground.

Somewhat smaller, spreading about four inches, is the Promethea Moth (Callosamia promethea Dru.). The male moth (Fig. 297) is dark brown except toward 
the outer margin of the wing where the color lightens somewhat outside a whitish cross line, and the outer margin is light-grayish with fine brown lines. Near the apex of the front wing is a black "eye" spot, margined on the inner side with blue. The female (Fig. 298) is brown with a triangular, white spot near the center of each wing, a short distance outside of which the brown ends abruptly in a very irregular edge against white which shades off into brown again. The outer margin is as in the male and the eye spot is also present on the fore wing.

The caterpillar is pale green with very small black tubercles in pairs above, except two pairs not far behind the head, which are coral-red and larger than the others, and a yellow one above, near the hinder end. The larvæ feed on many kinds of trees and shrubs, appearing to prefer the sassafras, wild cherry and ash, and when through feeding, each selects a leaf, the petiole of which it spins around, fastening it in this way to the twig on which it grew, so that it cannot drop off in the fall. It then

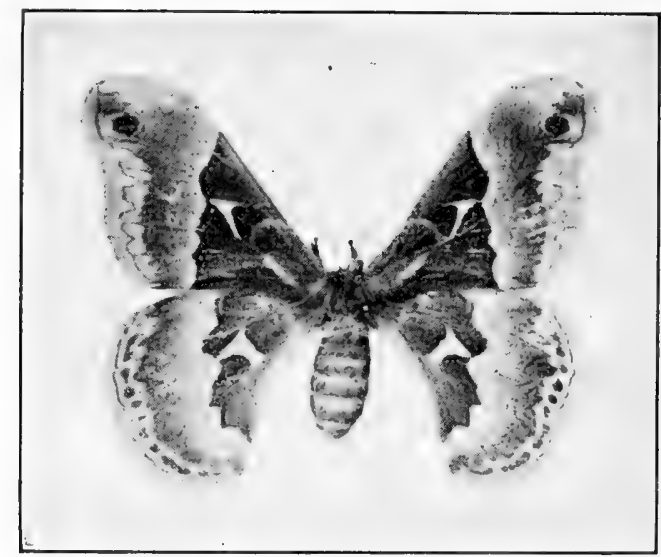

FIG. 298.

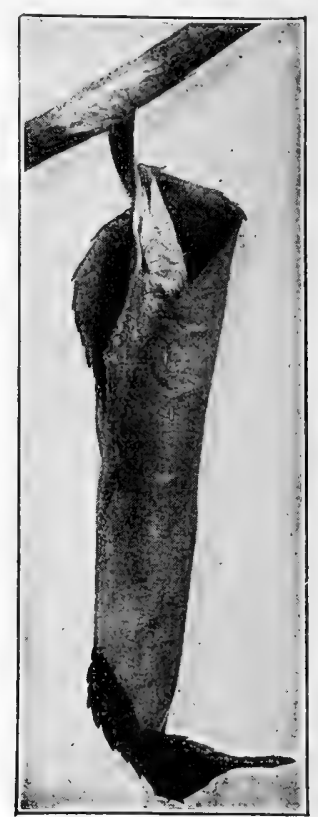

FIG. 299.

FIG. 298.-Female Promethea Moth, about two-thirds natural size. (Original.)

Fig. 299.-Cocoon of the Promethea Moth, natural size. (From Britton, Thirteenth Rept. Ent. Conn. Agr. Exp. Sta. 1913.)

forms its cocoon with the leaf as a partial wrapping, drawing the edges around the cocoon (Fig. 299). Here, in this hanging cocoon, swaying in the winds, the insect passes the winter.

The Japanese Silkworm Moth (Philosamia cynthia Dru.) was introduced into the United States in a futile attempt to use its cocoons for silk. Some of the insects escaped and this species is now occasionally captured in Southern New England and the Middle Atlantic States. The moth (Fig. 300) spreads about six inches and is of a rather rich shade of brown. On each wing is a large white crescentic spot, edged in front by a black line, and a white band, shading on its outer side into lilac, then into brown, crossing the wing, touches the outer angle of the crescentic spot. On the front wing a white band runs from the inner angle of this spot to the body and another to the costa or front margin of the wing. On the hind wing a similar band curves across about halfway between 
the crescent spot and the base of the wing. The caterpillar feeds on the leaves of the Ailanthus tree and has tufts of white hairs on its body. The cocoon is made within a partly rolled leaf as in the case of the Promethea Moth.

One of the largest insects in this family is known as the Luna Moth (Tropoea luna L.). Its body is densely covered with white hairs giving it a woolly appearance, and its wings are pale green, with more or less complete purplish margins, particularly strong along the costa of the fore wing (Fig. 301). In the front wing is a rather oval "eye" spot connected by a purplish band with the costa. The hind wing also has an "eye" spot, more circular in outline, shaded with darker on the side nearest the body, and the wing itself extends backward into a long, narrow tail. The green caterpillars, between two and three inches long when

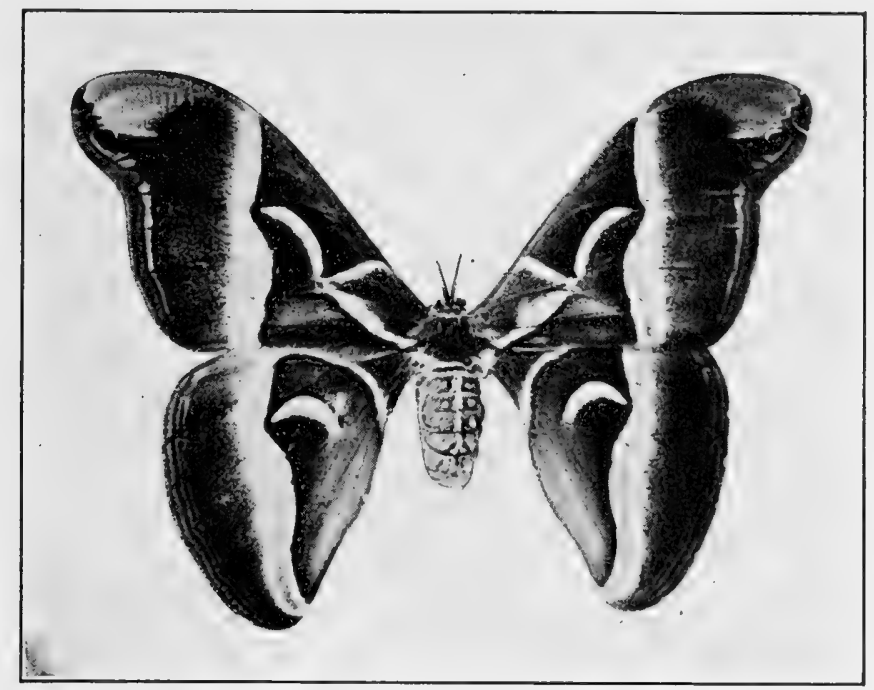

Fig 300.-Japanese Silkworm Moth (Philosamia cynthia Dru.), about two-thirds natural size. (Original.)

full-grown, feed upon a number of kinds of trees and pupate among leaves on the ground in the fall. The insect is found from Canada southward throughout the United States east of the Rocky Mountains.

One of the smaller, very common moths of this group is the Io Moth (Automeris io Fab.) which spreads between three and four inches (Fig. 302). The two sexes differ in color, the ground color in the male being yellow, while in the female that of the fore wings is purplish-red. The yellow of the male fore wing has irregular spots and a wavy line of brownish: in the female the ground color is broken by irregular shadings and a lighter wavy line. The striking feature of the hind wing in both sexes is a large, circular, bluish "eye" spot with a white dot forward of its center. The bluish shades into black outside, and is surrounded by the yellow ground color. Between the eye spot and the outer margins are a black line and a dull-rose band, and the base and hinder margin are dull rose. 
The caterpillar is about two inches long when full-grown, with a rather wide reddish-brown stripe edged with white below, on each side of the body. It has many spines which branch, the branches being tipped with black. Touçhing

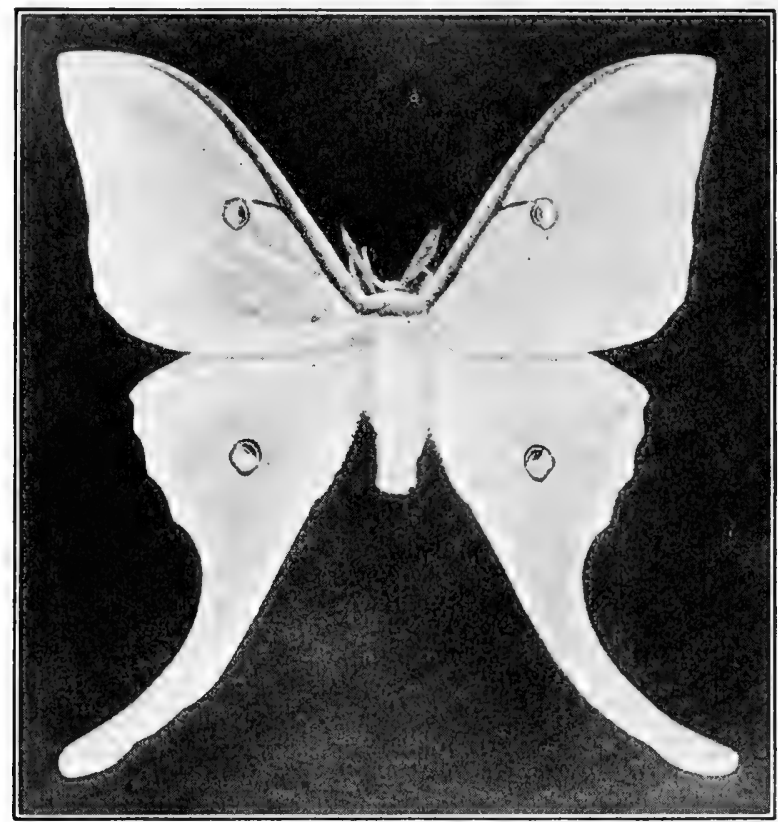

Fig. 301.-Luna Moth (Tropæea luna L.), slightly over half natural size. (From Felt, N. Y. State Mus. Mem. 8.)

the caterpillars produces a nettling of the skin, due to poison conveyed through the tips of the spines. The larvæ feed on fruit, forest and shade-trees and usually make their cocoons among leaves on the ground.

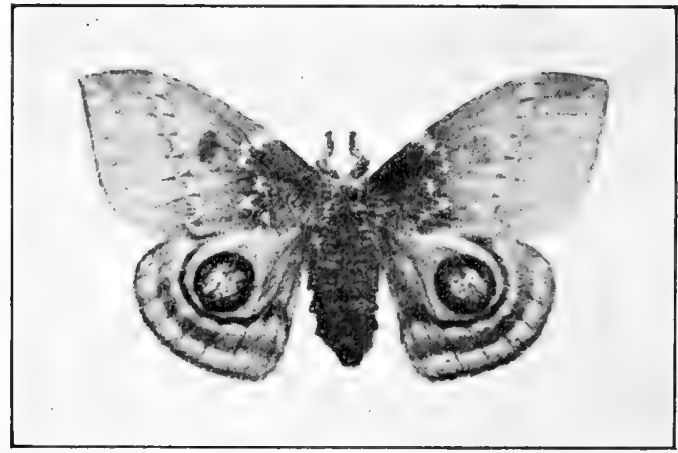

Fig. 302.-Female Io Moth (Automeris io Fab.), about two-thirds natural size. (From Felt, N. Y. State Mus. M.em. 8.)

There are quite a number of kinds of Giant Silkworms, the family being represented in all parts of the country. One generation a. year; the moths appearing earlier or later in the spring according to the length of the season; the larvæ 
feeding during the summer; and pupation in the fall, with the winter spent in this stage, appears to be the general rule, though with some exceptions, for most if not all of the species.

Family Sphingidæ (The Hawk Moths).-This large and widespread group of insects has long and rather narrow fore wings and its members have a strong flight. Most of them are of quite large size (Fig. 303) and fly chiefly at dusk, visiting flowers for the nectar, upon which they feed. They do not alight on the flower but hover over it, running the tongue, which is often much longer than the body, into the nectary. The body

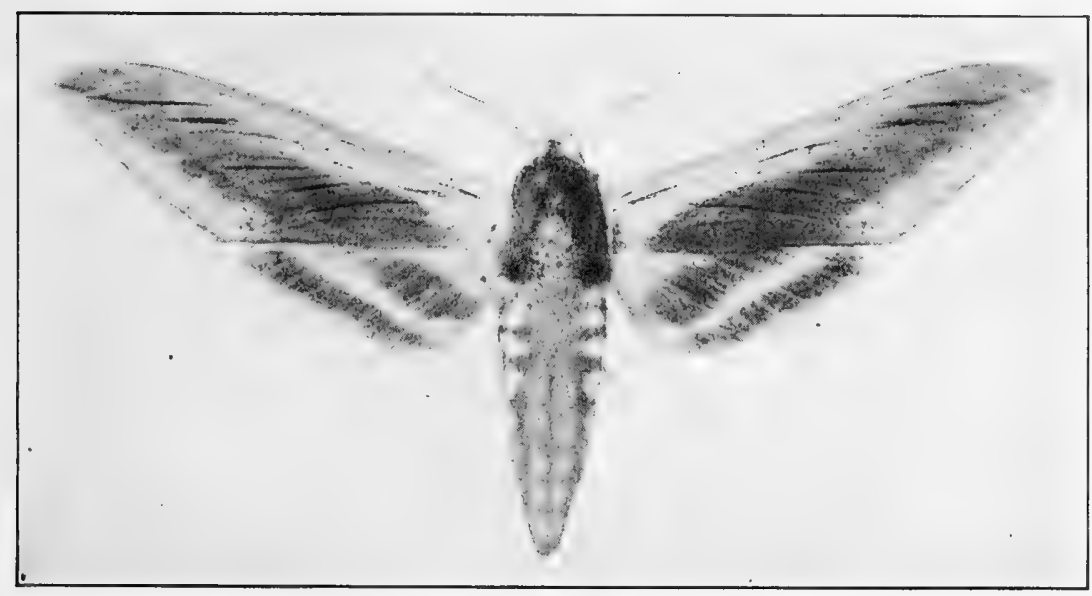

Fig. 303.-Hawk Moth (Sphinx chersis Hbn.), natural size. (Original.)

is usually rather stout, spindle-shaped, and it and the wings are often beautifully colored with combinations of black, gray, olive, tan and rose or pink. The antennæ are large, usually somewhat thickened near the middle, and the end is in some cases curved a little, like a hook.

The larvæ feed upon the leaves of various trees and other plants. They are naked; generally green, though frequently of other colors, and in the former case often have oblique white streaks on the sides of the body and a long horn projecting upward and backward from the upper side near the hinder end. Some when full-grown, may be two or three inches long. Pupation is usually in earthen cells underground, though some form partial cocoons of leaves and silk on the surface. In some species the tongue at the time of pupation is not enclosed by that part of the pupal skin which covers the body, but by a separate portion which joins the remainder at the front of the head and touches the body about halfway back, which makes it resemble the handle of a pitcher or jug in its relation to the pupa as a whole. 
A few species have their wings only partially covered by scales. These are among the smaller species and they fly during the day (Fig. $304)$.

Of the various species of Hawk, or Humming Bird Moths as they are sometimes called, only two or three are usually of any great economic importance.

The Tobacco and Tomato Worms.-There

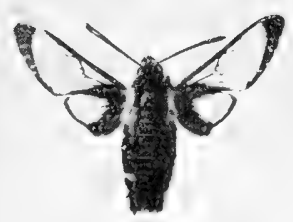
are two closely related Hawk Moths whose larvæ feed on tobacco and tomato leaves. One of these is known as the Northern Tobacco (or Tomato) Worm (Phlegethontius quinquemaculata Haw.) and the other as the Southern Tobacco Worm (Phlegethontius sexta Johan.). The former is present nearly every-

FIG. 304.-Day-flying Hawk Moth (Hemaris diffinis Bdv.), about natural size. (Original.)

where in the United States: the latter from Massachusetts southward, and westward to the Pacific Coast.

The adult is a moth (Fig. 305) spreading from four to five inches, but in the Northern Tobacco Worm the color of the fore wings is ashygray and the abdomen has a row of yellow spots, usually five in number

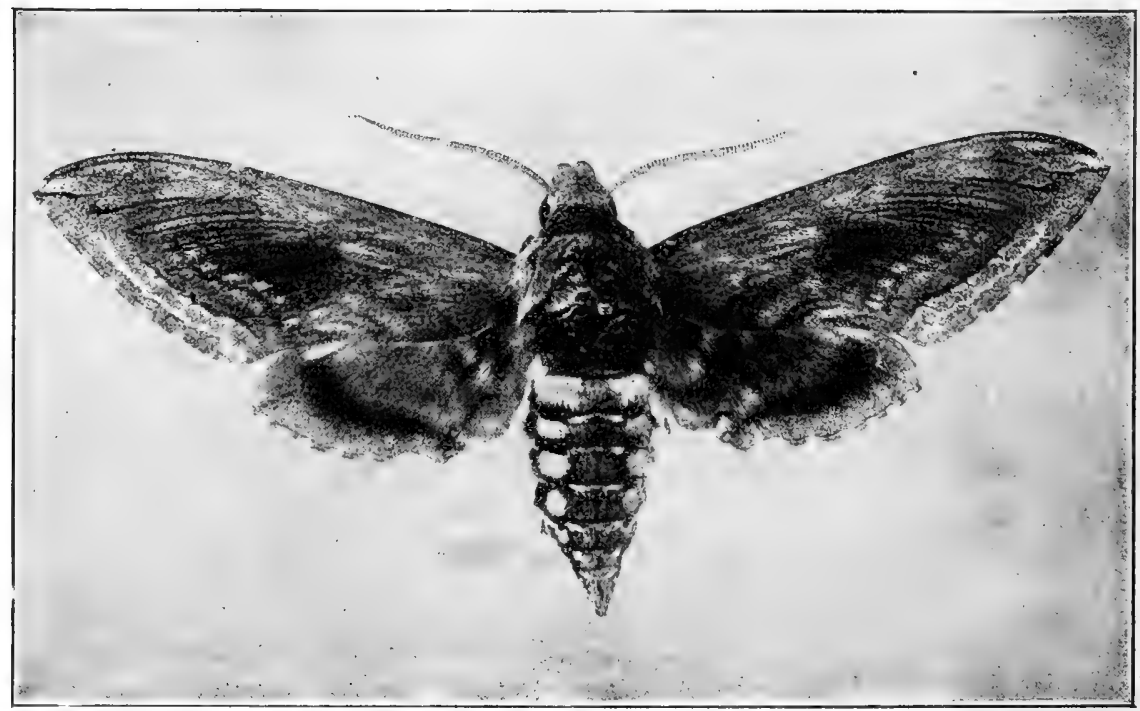

FIG. 305.-Northern Tobacco Worm Moth (Phlegethontius quinquenaculata Haw.), natural size. (From Britton, Sixth Rept. Ent. Conn. Agr. Exp. Sta. 1906.)

on each side, while in the Southern Tobacco Worm the fore wings are brownish-gray and there are usually six yellow spots on each side of the abdomen. 
The life history in both species is quite similar. Winter is passed as a pupa (Fig. 306) in the ground and in these insects the tongue

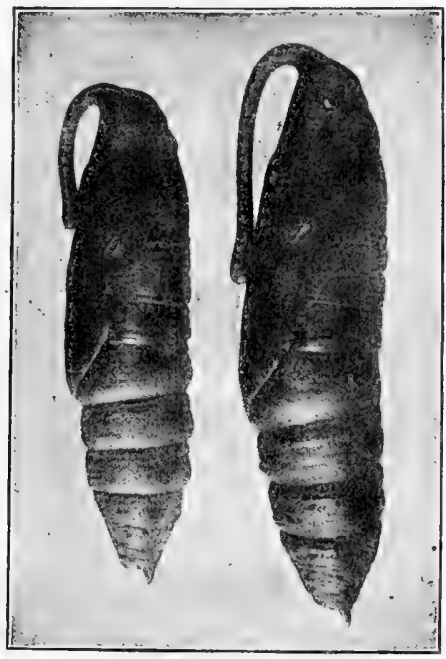

Fig. 306.-Pupa of the Southern Tobacco Worm (left) and of the Northern Tobacco Worm (right), natural size. Note difference in length of the tongue case. (From Britton, Sixth Rept. Ent. Conn. Agr. Exp. Sta. 1906.)

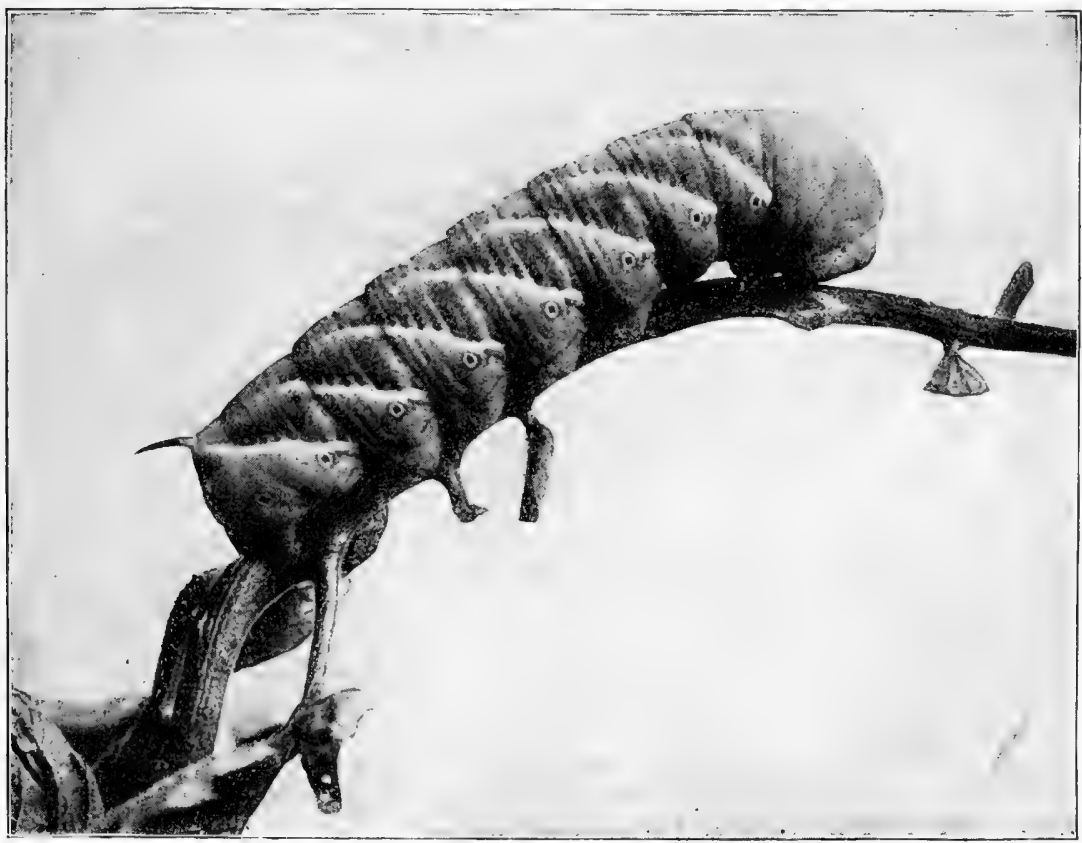

FIG. 307.-Full-grown larva of Southern Tobacco Worm, natural size. (From Britton; Sixth Rept. Ent. Conn. Agr. Exp. Sta. 1906.)

has a separate case in the pupa. The moths appear in the spring and lay their eggs singly on the leaves of their food plants, and the 
caterpillars feed for 3 or 4 weeks, becoming three or four inches long, green or sometimes brown in color. In the Northern Tobacco Worm each abdominal segment is marked on the side by an oblique greenish-white stripe joining a similar horizontal one at its lower end, forming a series of whitish Vs. On the hinder end of the body above, is a projecting green horn with black sides. The larva of the Southern Tobacco Worm (Fig. 307) has only the oblique bands and the horn is usually reddish. In the northern part of the range of these species there is one generation a year. Farther south, two seems to be the rule, while in the Gulf States three or four are claimed to occur.

Control.-Hand picking is a frequent method of control where the larvæ are not abundant. Spraying when the caterpillars are first seen, with arsenate of lead, standard formula, has proved effective. Applied as a dust it has also given good results, but this material either as a spray or as a powder should not be used on tomatoes after the fruit is half grown.

The remaining families of Lepidoptera to consider are those of the suborder Rhopalocera, or butterflies. Most of the insects in this section are rarely of much economic importance, their larvæ feeding chiefly on plants not utilized in any way as food. Occasionally some species may cause local injury, but only a few need special consideration from this standpoint.

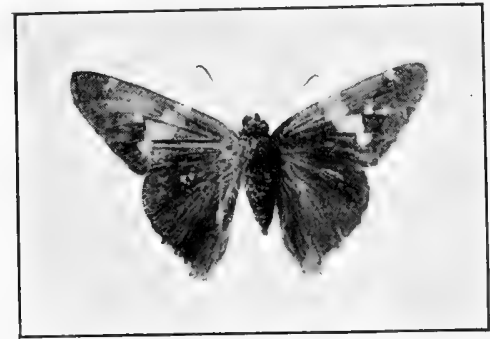

Fig. 308.

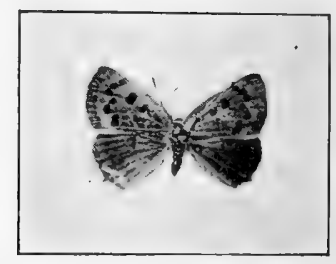

FIG. 309 .

FiG. 308.-Skipper Butterfly (Epargyreus tityrus Fab.), natural size. (Original.)

FIG. 309.-Little Copper Butterfly (Heodes hypophleas Bdv.), about natural size. (Original.)

Family Hesperiidæ (The Skippers).-These are rather small butterflies which have a curious "skipping" style of flight. They are most frequently black, or yellow and black in color, often with silvery spots or streaks (Fig. 308). The larve in this family have heads much larger than the part of the body next behind, making them easy to recognize. One of the larger members of this group, found in the South feeds as a caterpillar on the bean, and is known as the Bean Leaf-roller.

Family Lycænidæ.-- In this group belong the little blue butterflies spreading in most cases at least, less than an inch; similar sized dark-brown butterflies; and others which are of a red or coppery color (Fig. 309), with black spots. Many 
of these insects are very common but are of no importance economically. One species here departs from the general rule as to the food of Lepidoptera, its larva being carnivorous and feeding on plant lice. Unfortunately it is not common enough to be very beneficial.

Some of the species in this family have more than one generation each year and the adults of the two generations are so different that until one kind was bred from eggs laid by the other they were supposed to be different species. Difference in color, markings or both, may therefore be correlated with the season of the year, and insects having two different forms according to the season, present cases of what is called seasonal dimorphism.

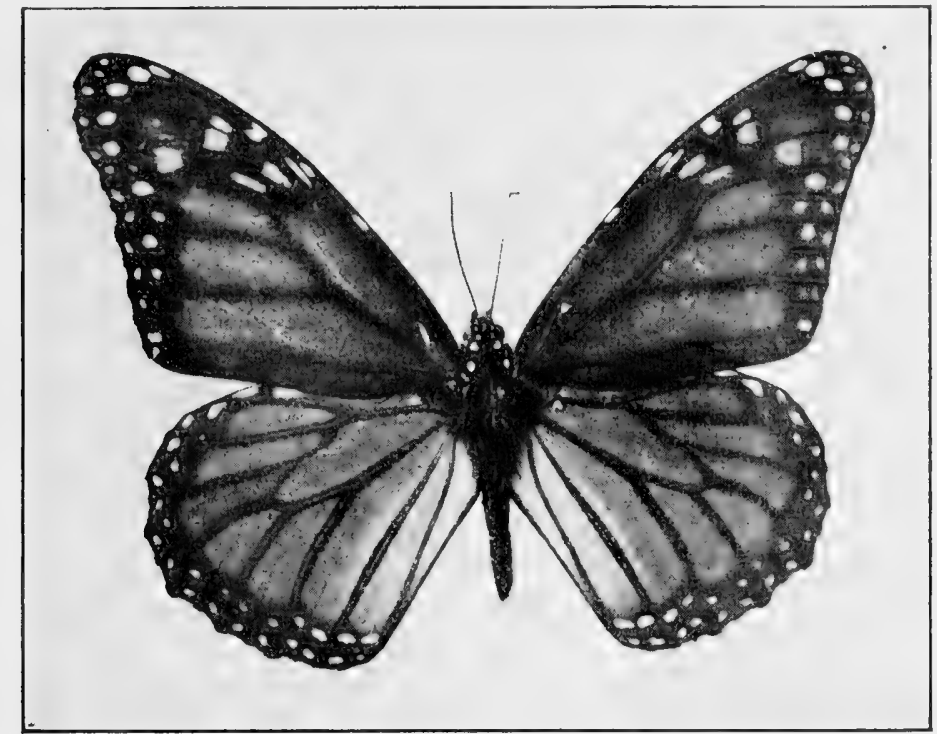

Fig. 310.-The Monarch (Danaus archippus Fab.), natural size. (Original.)

Family Danaidæ.-This small family is of interest in the United States mainly because it includes one of our largest and widely distributed butterflies, the Monarch (Danaus archippus Fab.). This is common in nearly all parts of the country and has a striking way of sailing about in the air. The ground color of the wings is tawny brown marked with black lines along the veins, and broad black borders containing white spots (Fig. 310). The caterpillars feed upon milkweed and are greenish-yellow with black cross-bands and a pair of soft, fleshy projections on the back a little behind the head, and another pair not far from the hinder end of the body. The pupa (chrysalis) is usually attached to the plant and is about an inch long, stout, bright green with golden dots.

Though the Monarch breeds in the Northern States during the summer, it appears to come from the South each spring, and in the fall multitudes often gather and fly southward together. Whether they 
succeed in reaching climates where they can successfully winter is perhaps questionable, but if not, others at least, make their way North each spring.

This insect is practically free from attack by birds, probably because it is able to produce a disagreeable odor.

Family Nymphalidæ.-This large family includes many familiar forms, most of them large or of at least fair size. Their fore legs have been reduced so much they they are no longer used but are carried folded up against the thorax.

Several of the common species in this group are found in Europe as well as in this country and a few occur nearly everywhere in the world where food and temperature permit their existence. The larvæ of some species feed on the currant, gooseberry and hop in the list of cultivated plants, but are not often important pests.

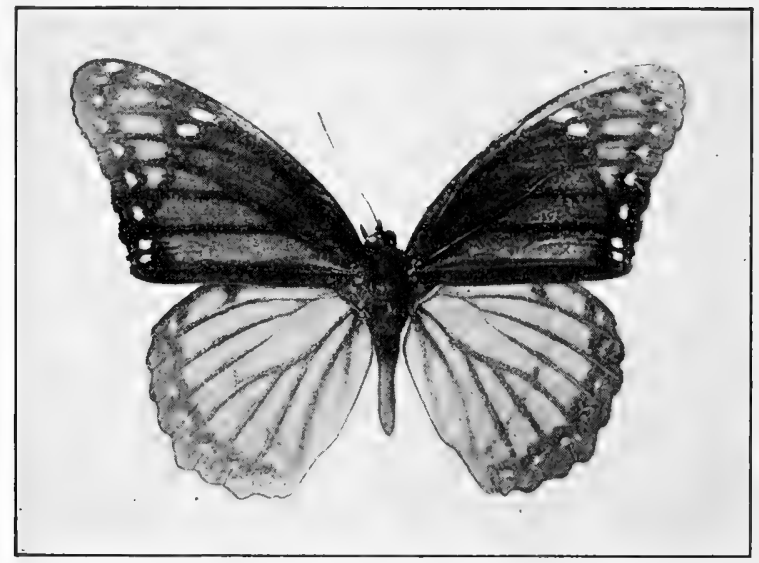

FIG. 311.-The Viceroy (Basilarchia archippus Cram.), natural size. (Original.)

In one section of the family the insects are usually black with blue or green, and occasionally red spots, and one or two species have a white band across the wings. One of this group, however, differs greatly in color from all the rest of its relatives, being reddish-brown with blacklined veins, black wing borders enclosing white spots, and so closely resembling the Monarch that it has been called the Viceroy (Fig. 311) It differs from the Monarch, to the eye, however, by the presence of a narrow black band across the hind wings and by its somewhat smaller size.

This radical departure in color and pattern of this insect from that of all its near relatives is believed to be because this group is one freely attacked by birds for food, while the Monarch, perhaps because of a disagreeable odor, escapes. Any imitation which would deceive the birds, would accordingly protect insects possessing it and enable them 
to avoid destruction. How such a change could be rapidly developed, however, to such a degree as to enable its possessors to benefit by it, has not been satisfactorily explained, and if it were not so developed the individuals in which the change began could hardly differ enough from their former condition to escape. Here remains one of the unsolved problems of insect life.

Family Satyridæ (The Satyrs).-The insects belonging in this family are of medium size, and nearly all have gray or brown wings with spots more or less resembling eye spots (Fig. 312). They are common near the edges of woods and sometimes drift out into the fields. One species is found only on the tops of the White Mountains in New Hampshire and on the higher Rocky Mountains. How these colonies became so widely separated is a question, though explanations for it have been suggested.

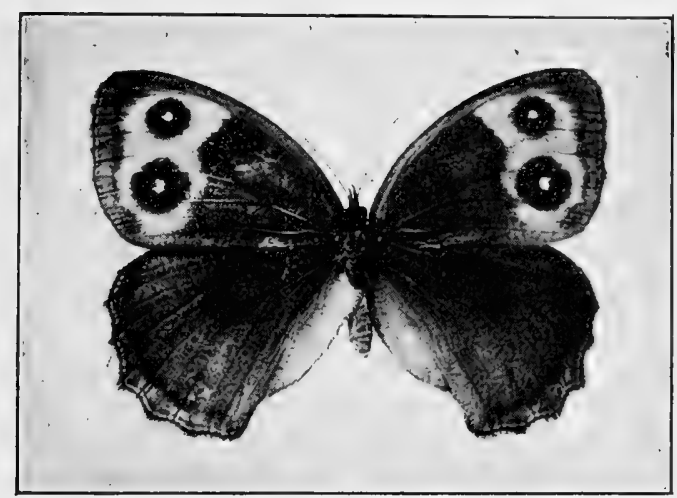

FIG. 312.-Satyr Butterfly (Cercyonis alope Fab.), natural size. (Original.)

Family Pieridæ.-In this family belong the medium sized or small yellow butterflies of various shades and the white ones, common in all parts of the country. About 50 kinds occur in the United States and some of them are occasionally, and others almost always, injuriously abundant in one place or another.

The Imported Cabbage Butterfly (Pontia rapce L.).-This insect, a native of Europe, appears to have reached Quebec about 1859. It spread rapidly and ten years later had reached Massachusetts. Other specimens arriving at New York and Charleston, N. C., also established centers from which the insect spread in all directions, and it is now found nearly everywhere in the United States.

The adult (Fig. $313 a$ ) spreads a little less than two inches. Its wings are white, the tip of the front wing grayish. In the male there is a black spot near the center of the front wing and one on the front margin of the hind wing, while in the female the front wing has a second black spot behind the other. 
The insect passes the winter as a pale brown chrysalis (Fig. 313d) about three-quarters of an inch long, attached in some protected place. The adults emerge in the spring and lay their eggs singly (Fig. 313b) on the leaves of cabbage, cauliflower, mustard, nasturtium and other plants of the family Cruciferæ, and about a week later the caterpillar hatches and begins to feed. At first it is pale green, but when fullgrown, after about 2 or 3 weeks, is a soft, velvety-green, and about an inch long (Fig. 313c). At first it feeds on the under surface of the

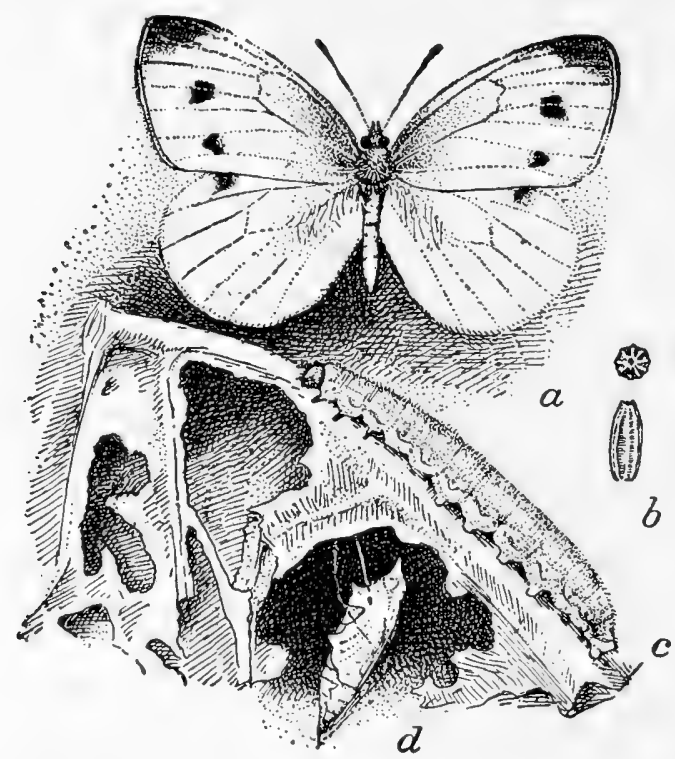

FIG. 313.-Cabbage Butterfly (Pontia rapce L.): $a$, adult, slightly enlarged; $b$, egg, from side and from above, considerably enlarged; $c$, caterpillar, somewhat enlarged; $d$, chrysalis, somewhat enlarged. (From U. S. D. A. Farm. Bull. 856.)

leaf, but after growing, eats holes through and may leave only the veins. It of ten bores into the forming heads also, in search of more tender food. It feeds for from 2 to 3 weeks, then pupates for a rather shorter period, at the end of which time the adult emerges and lays eggs for a second generation. There are usually two or three generations in the Northern States and as many as five or six in the South.

Where these insects are abundant they cause considerable injury, not only to the leaves but by boring into the heads, reducing their value.

Control.-Spraying with a stomach poison, preferably arsenate of lead, a little stronger than the standard formula, as soon as the caterpillars appear in the spring, is a successful treatment, but as the spray tends to run off the smooth leaves of the plants, the addition of a little soap as a "sticker" is desirable. If the larvæ of the first generation are killed for the most part by this, later applications will generally prove unnecessary. In some cases the poison is dusted on instead of sprayed. 
If treatment is needed after the heads are half grown, they may be dusted with pyrethrum, though the danger of poisoning them by the use of arsenate of lead is practically none.

A native cabbage butterfly closely resembling the last, was formerly common in the North, but appears to have suffered from competition with its imported rival. A southern native specics has also become somewhat reduced in abundance, but less so than the northern one.

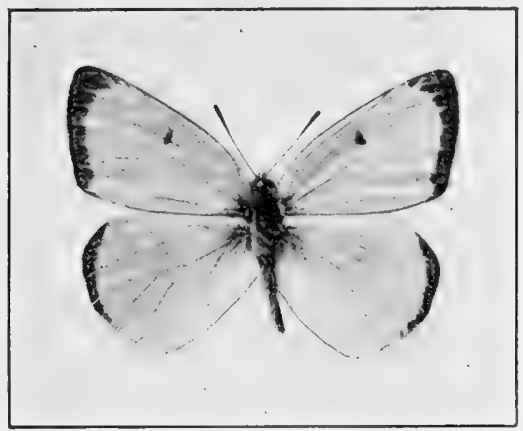

FIG. 314.-Male Sulfur or Yellow Butterfly (Eurymus philodice Godt.), natural size. (Original.)

The common sulfur-yellow butterflies (Fig. 314) with more or less of black markings on their wings are for the most part, feeders on clover in their larval stages. One of them, the Alfalfa Caterpillar (Eurymus eurytheme Boisd.) is frequently a pest on alfalfa. It occurs everywhere in the United States west of

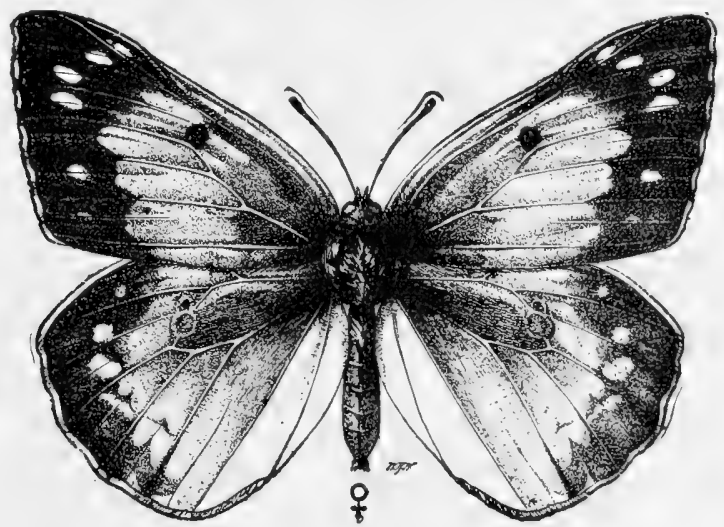

Fig. 315.-Alfalfa Butterfly (Eurymus eurytheme Boisd.), ahout 11/2 times natural size. (From U. S. D. A. Bull. 124.)

the Allegheny Mountains and has been taken occasionally along the Atlantic Coast, but is chiefly of importance in the Southwest.

The adult (Fig. 315) spreads about two inches and its wings are orangeyellow with black outer borders; a black spot in front of the center of the fore wing and two reddish-orange spots which touch each other, near the center of 
each hind wing. In the female the black wing border has yellow spots in it. Sometimes the orange color in the female is replaced by whitish. The caterpillar is brown at first but later becomes dark-green with a white stripe on each side (Fig. 316). Alfalfa, clovers, vetches and other legumes are fed upon. The number of generations seems to vary in different parts of the country from two in the North to six or possibly more, in the far South. The colder, or

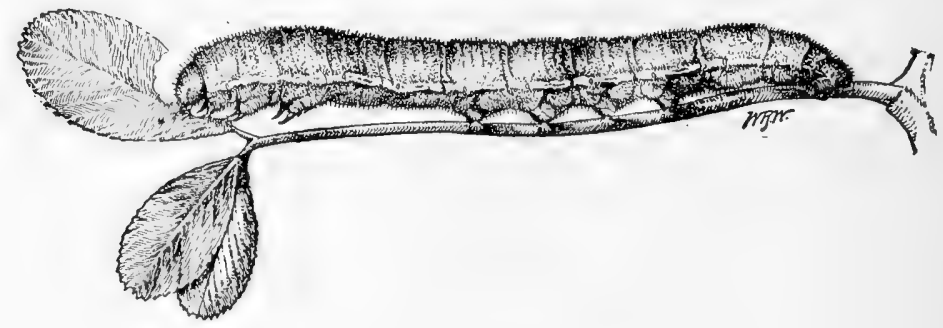

FIG. 316.-Caterpillar of the Alfalfa Butterfly, about three times natural size. (From $U$. S. D. A. Bull. 124.)

in the Southwest, the dry months may be passed either as larva, pupa or adult. Treatment is by cultural methods such as pasturage, or early and close cutting of the crop, followed if necessary by rolling or brush dragging.

The spreading of an insect introduced into a country is always of interest, even if no financial factor is involved, and several of the species considered in this chapter supply good examples of this. Its method of introduction; its establishment; the rapidity with which it spreads, and the final limits of its distribution, are all topics for investigation.

In the case of the Gypsy Moth its introduction was apparently intentional, though it was far from the plan of the scientist who brought it to this country that it should escape. It is stated that this scientist had in mind testing the silk-producing possibilities of various Lepidoptera and imported a number of species for that purpose. Unfortunately in some way, some of the Gypsy Moth specimens escaped and as he could not find them, he issued a notice calling attention to the fact, and warning the public of the possible menace they might become.

The Brown-tail Moth appears to have been brought to this country as a winter tent containing young caterpillars, on an importation of roses from Europe. This occured before the inspection of nursery stock imported into this country was required by law. How the Cabbage Butterfly arrived, is not known, but it was probably the chrysalis on - some material brought as freight.

It is evident that in any case, either an adult female able to deposit fertile eggs, or else several individuals at least, in some early stage, must be imported at about the same time, if the species is to obtain a start. Then with an individual ready to lay its eggs, suitable food 
plants for its young must be found. There can be no doubt, in theory at least, that there have been many cases in the past where failure to succeed in this has resulted in the failure to establish themselves, of many species which would have been serious pests.

Once started, however, even in a small way, an increase in numbers and in distribution becomes possible. If some of the insects, however, were parasitized and the parasites escaped, as well as those not so affected, the spread might be checked because of the small number of the pests which would not be found by the parasites.

The spreading of a species from the point where it starts, has been aptly compared to that of a ripple caused by throwing a stone into water, which passes out in every direction on its surface. Such a spread will extend as far as the insect can find food on which it can live and a temperature and humidity under which it can survive. It follows that for many insects adapted to northern climatic conditions, a point will be reached in its southward spread where the temperature and humidity are such as to prevent its going farther. A lofty and continuous mountain range may, by producing such conditions, also prove a barrier to farther extension in that direction, even though beyond the range a favorable climate may again be found. Absence of any food upon which an insect can live will also put an end to distribution in that direction, and a pest adapted to the moist climate of the Eastern States may find itself unable to establish itself in arid regions. The rapidity with which it spreads appears to be determined by its fecundity, power of flight in many cases, and food supply, at least generally; an insect having a high rate of increase, abundant food, and strong in flight sometimes spreading several hundred miles in a year. The much larger area to the north and northeast of Boston than to the south and west, now occupied by the Browntail Moth appears to be due, in part at least, to strong southwesterly winds while the moths are flying.

Study of these and other factors involved, shows that northern insects as they spread southward are found chiefly at least, on higher land. One living at near the sea level in the Northern States will generally be found in the mountains in the South, and if it extends into Mexico it will there occur only on the higher Cordilleras, gaining by its elevation the lower temperature it has lost by its change of latitude.

Thus we find that with sufficient information at hand, the distribution of many insects can be mapped, and that there is a division of the country into regions, the insects of one region rarely spreading far beyond its limits, and then only forming outposts of the species.

It is true that some species are less affected than others by these conditions. The Monarch Butterfly, the House Fly and many others appear to be able to live under wide differences of temperature, humidity and the other factors concerned. As a whole though, an insect will 
spread within certain limits, but only within these, and this applies to other animals and to plants as well.

Family Papilionidx (The Swallow-tails).-The butterflies of this group are nearly all large, and with a backward-projecting lobe or tail on the hind wing. One species or another may be seen in ălmost every part of the country but they rarely do much injury, feeding for the most part on plants of little importance. The Black Swallow-tail Butterfly (Papilio polyxenes Fab.) is probably the most important species, as it occurs all over the United States and feeds on celery, carrots, parsnips and other plants.

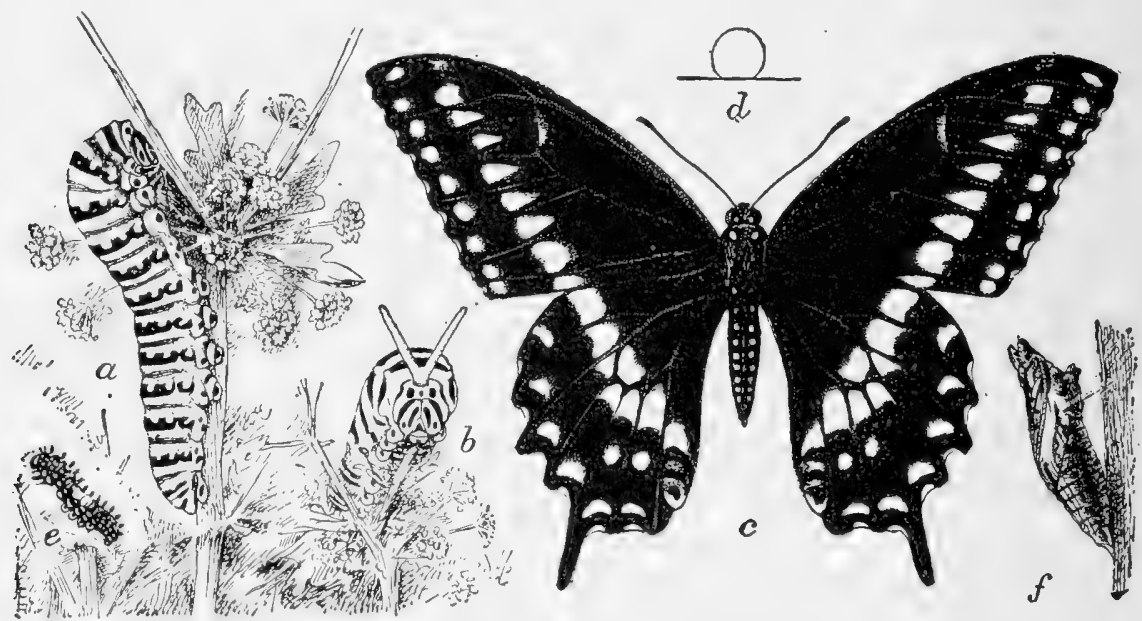

FIG. 317.-Celery Butterfly (Papilio polyxenes Fab.): $a$, full-grown caterpillar; $b$, head of same showing osmaterium extended; $c$, male butterfly; $d$, outline of egg; $e$, young larva; $f$, chrysalis. All about natural size except $d$, which is much enlarged. (From $U$. S. D. A. Farm. Bull. 856.)

The butterfly (Fig. 317c) spreads between three and four inches, and its wings are black with two rows of yellow spots crossing each wing, with blue shadings between the two rows on the hind pair. There is also a black spot surrounded by orange on the outer part of the hinder margin of the hind pair. In the male the inner row of yellow spots becomes a band on the hind wing.

In the South the butterflies winter over, but in the North this period is spent as the pupa. Eggs are laid singly on the leaves of the food plants, and hatch in about 10 days. The caterpillars feed for from 10 days to several weeks, then form their chrysalids (pupæ) on some part of the plant (Fig. $317 f$ ) and in from ten days to 2 weeks more the adult butterflies emerge. There are two generations in the North and more in the South. 
The caterpillar when full-grown (Fig. $317 a$ and $b$ ) is about two inches long, green with a black cross band on each segment, which may enclose six yellow spots or may fail to close these in on the front side of the band. Just back of the head is an opening out of which a soft, widely forked horn can be protruded when the insect is distributed. Such structures are called osmeteria and give off a disagreeable, pungent odor, and are probably to drive away enemies which may attack them.

This insect is rarely if ever important enough to call for any control other than destroying the larvæ by hand, though in most cases spraying with a stomach poison would be entirely effective if such a treatment were needed.

A similar species present on the Pacific Coast, has the same habits. 


\section{CHAPTER XXX}

\section{THE MECOPTERA}

The Mecoptera is a small order of insects, both in numbers and in the size of its members. The adults usually have wings which are membranous, long, and generally narrow, with numerous veins. In a few cases, however, they are reduced or even rudimentary. The head is elongated on its underside, forming a sort of beak or rostrum, at the end of which are the chewing mouth parts (Fig. 318). In the males of one genus the terminal segments of the abdomen are drawn out and curl upward, suggesting the position of the end of the body in the scorpion, and from this the common name "Scorpion Flies" has been applied to the

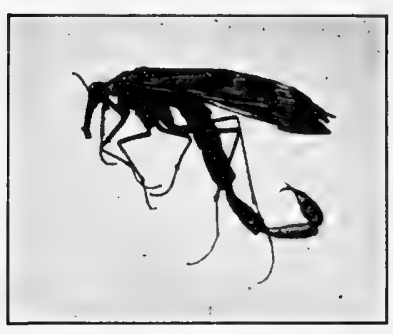

FIG. 318.-Adult Meeopteron (Panorpa nuptialis Gerst.) natural size, showing beak projecting downward from the head, on the end of which are the mouth parts. (Original.) order, though some of its members do not have this character. The larvæ considerably rusemble small caterpillars.

The distinctive characters of the order are:

Insects which when adult nearly always have four membranous wings, long and narrow and with numerous veins: head prolonged downward forming a beak, bearing chewing mouth parts at its end. Larve more or less caterpillar-like. Metamorphosis complete.

Mecoptera occur in nearly all parts of the world but nowhere appear to be very abundant. They seem to prefer to live in places having rank growth, and in low, damp woods, and are apparently carnivorous both as larvæ and adults. A few species are found on snow during the winter months and are wingless or nearly so, but most of the group have wings longer than their bodies and fly quite well. The eggs are usually laid in masses in the ground and the larvæ live in burrows in the ground, coming out to feed. They have legs supporting the abdomen and these are more numerous than in caterpillars. As far as known they pupate in earthen cells in the ground.

The adults certainly feed upon other insects: larvæ in confinement can be fed upon meat, but their natural food is probably any animal material they can obtain. Under such circumstances, these insects must be regarded as being, at best, of little economic importance. Fossil forms belonging to the Mecoptera have been discovered in different parts of the world.

In a general way this order appears to have the Diptera, Trichoptera and Lepidoptera as its nearest relatives. 


\section{CHAPTER XXXI}

\section{THE DIPTERA}

The Diptera or Flies are small insects, the largest species known being slightly more than two inches long, but the majority are much smaller, and many are almost microscopic. The flies as a group are distinguished from other insects by the presence of only one-the front-pair of wings, attached to the mesothorax. Sometimes these are absent, the insect being entirely wingless, but there are only a few such cases. The hind wings have been transformed into a pair of curious structures known as halteres. They are small and each resembles a sort of knob joined to the body by a stalk, usually slender, and variable in length. They are believed to have special functions but what these are is far from settled.

The wings are usually transparent though sometimes smoky or otherwise colored, and in some instances scales are present either along the veins or elsewhere, and in one family they entirely cover both the body and wings. The veins are usually quite numerous but often show a tendency to unite toward the outer margin of the wing, forming closed cells in this way as well as by the more usual method with cross veins. In some families, the veins are very few and sometimes several appear only as faint traces. The hinder margin of the wing not far from its attachment to the body frequently has a notch called the axillary incision or sinus, and the membrane from here to the base may form one lobe, or by other incisions consist of two or even three lobes. The one nearest the base in some instances appears to become enlarged and lie over the base of the halter, often partly or entirely concealing this structure from above.

The head of the fly is connected with the thorax by a small neek which permits considerable rotation. Much of its surface is occupied by the very large compound eyes which frequently meet above, particularly in the males. Between the two eyes, or behind their point of meeting, are usually three ocelli on the top of the head.

The antennæ vary greatly. They may consist of as many as 16 segments or as few as three, in the latter case a bristle, frequently feathered, being often present, joined to the outer segment.

In one section, a crescent-shaped cleft occurs above the attachment of the antennæ to the head, curving downward on each side. This slit is called the lunula, and at the time when the fly escapes from its pupa case a large, bladder-shaped structure is pushed out through this from the inside of the head, and pressing against the end of the case, forces it off, enabling the fly to escape. Later, this structure which is called the ptilinum is drawn back into the head. 
The mouth parts of flies are for sucking, and in some cases for piercing, also. True "biting flies" do not exist, the "bite" being really caused by the plunging of the sharp-ended, piercing mouth parts into the object attacked. There seems to be little doubt that the mouth parts of flies have been derived from ancestors with chewing structures, but the changes have been so great that to identify the different pieces with the corresponding ones of chewing insects is very difficult, and different views on this have been advanced by students of the subject.

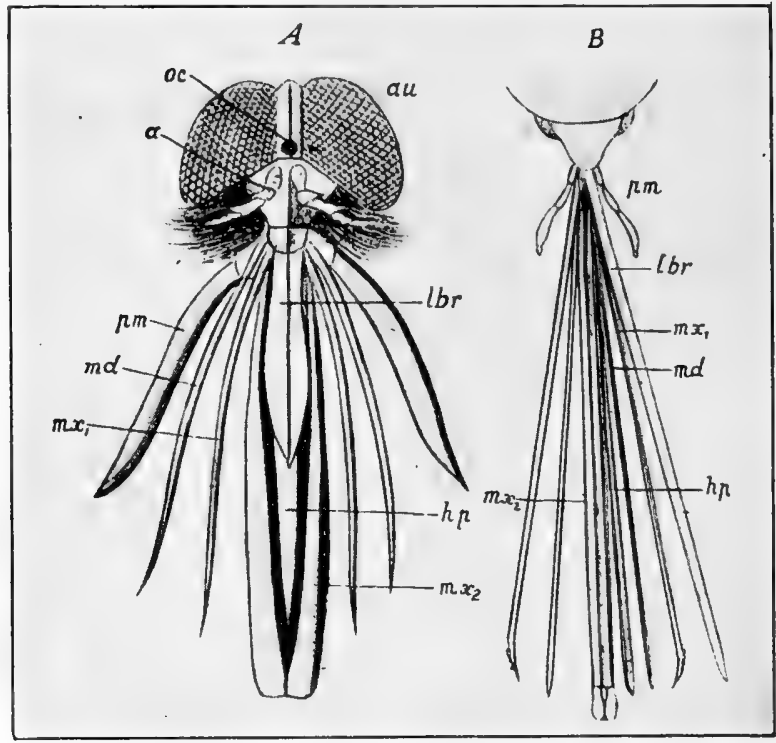

FIG. 319.- Mouth parts of $A$, a Tabanid; $B$, a mosquito: $a$, antenna; $a u$, compound eye; $h p$, hypopharynx; $l b r$, labrum; $m d$, mandible; $m x$, maxilla; $m x_{2}$, labium; oc, ocellus; pm, maxillary palpus. (Modified from Laug's Lehrbuch.)

Without going into details, it may be stated that in the more typical fly mouth parts there are six bristle-shaped structures enclosed by a sheath, and one pair of segmented palpi (Fig. 319). The sheath is generally regarded as representing the labium or hinder lip, while the bristles represent the front lip or labrum, the tongue or hypopharynx, the two mandibles and the two maxillæ. At the outer end of the sheath is a pair of lobes, often large, and these are considered as the labial palpi, leaving the segmented pair to represent the maxillary palpi. In some cases, the surfaces of the lobes regarded as labial palpi are roughened and adapted to the rasping of surfaces. Bringing together certain of the bristle-like mouth parts forms two tubes, or, in some cases, grooves more or less completely closed, through which fluids can be drawn into the body, and saliva be led into the wound made by the tips of the bristles. Solid food is utilized only by first dissolving it in saliva. 
The thorax, though composed of three segments as usual, has these very closely and firmly united. In the abdomen, the number of visible segments varies from nine to five, or even four in some instances. The legs, usually at least, are well developed, with a pair of claws at the tip and a pulvillus at the base of each claw. Between the claws there is often an membranous pad, similar to a pulvillus, or it may be a bristle. In either case, this centrally placed structure is called an empodium.

On the surface of the body, bristles are often present which have definite positions and are of aid in identifying the species.

Fly larvæ are usually called maggots. Some have well developed heads while in others no structure of this nature can be recognized. True legs appear to be absent, though projections of the body which can be utilized in moving about are common and often bear circlets of hooks. These vary in their position in different species. The larvæ breathe through spiracles, but the location of these differs greatly. In some they are found along the sides of the body as usual; in others there is a pair near each end of the body; in still others there is only one pair at the hinder end, and these may occur at the tip of a very extensible tube which, when fully stretched out, may be several inches long. Nourishment is sometimes obtained by osmosis directly through the body wall of the larva but it is generally taken into the mouth. The mouth parts in the least modified forms are of the chewing type but in most members of the order they are greatly modified. In some cases, a pair of claws or hooks appear to be the only structures, while in others a chitinous "rake" consisting of a cross-bar bearing a row of teeth and connected with a single rod running backward, serves to rasp and break open the vegetable cell walls and expose their fluid or semifluid contents of which the larva avails itself.

Some flies construct regular cocoons but the pupa is usually either naked or located in a puparium which is the last larval skin. In this case, the larva, when ready to pupate, shrinks away from its skin and pupates within it, using this skin or puparium as a protection instead of making a cocoon. Escape from the puparium may be either through a T-shaped split on the back near the front end; a transverse split between the eighth and ninth abdominal segments in a few cases; or through a circular opening in the front end.

The chief distinctive characters of the Diptera are:

Insects which when adult have, with a few wingless exceptions, only two wings, these attached to the mesothorax; the hind wings greatly modified, each consisting of a small knob attached to the metathorax by a stalk, these structures being called halteres; mouth parts for sucking, and sometimes for piercing also. The larve are called maggots and are without true legs. Metamorphosis complete.

This is one of the large orders of insects and members of the group 
are found in all parts of the world. They differ greatly in their habits, food, and general modes of life. Some are serious pests either of crops or of man, while others are among the most beneficial insects known, acting as parasites. A number of species function as carriers of diseaseproducing organisms and are of importance in that way.

About fifty families of Diptera are recognized, many of them very large while others contain few species.

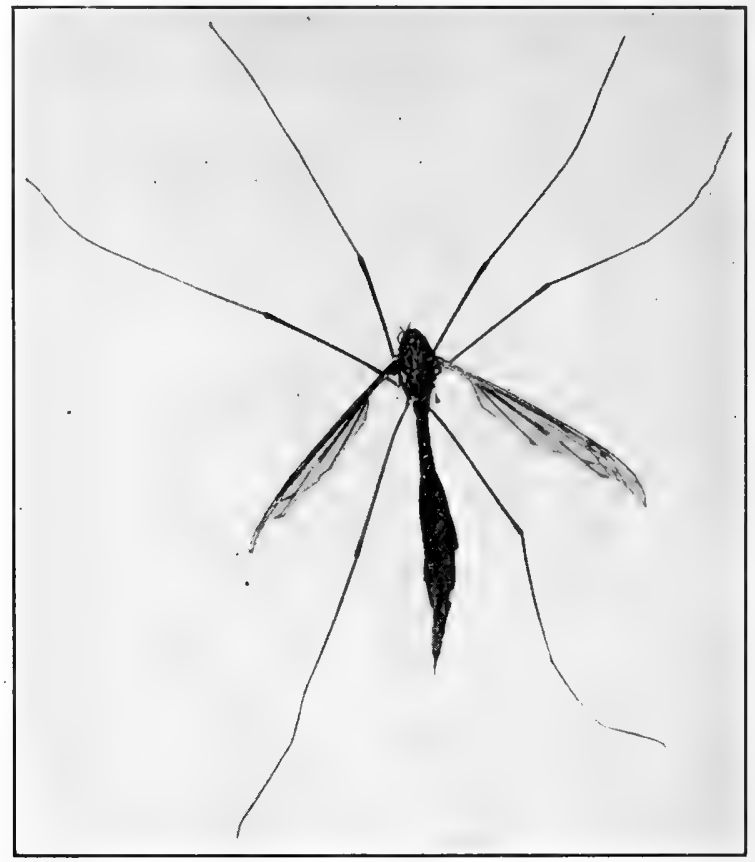

FIG. 320.-Large Crane-fly (Tipulid), head bent downward and almost wholly concealed; halter of right side showing plainly. Natural size. (Original.)

Family Tipulidæ (The Crane-flies).-This is a large and widely distributed family composed of Diptera having long and rather slender bodies and very long legs; in fact resembling enormous mosquitoes in appearance though a few are very small (Fig. 320). The antennæ are generally thread-like and there is a broad $\mathrm{V}$-shaped groove or suture on the top of the thorax.

The larvæ of crane-flies in most cases live in the ground and feed on the roots of grasses and grain and at times cause much injury in this way. Some exceptions live in decaying wood, on leaves, in water or elsewhere. There seem to be two generations each year, adults appearing in the spring and fall, and winter is passed as the partly-grown maggot. Injury is most of ten noticed on low or poorly drained land or where a field has been left in grass for a number of years. Control of these insects, when they are sufficiently injurious to make it pay, is by draining, rotation of crops and plowing early in the fall, when the insects are in the pupa stage just below the surface of the ground, to crush them there. 
Family Culicidæ (The Mosquitoes).--These are small insects, familiar to everyone as they attack man and other animals, and in most species the females feed upon blood. A few species appear to consume plant juices. The mouth parts of the males are much reduced and the members of this sex rarely, if ever, feed. There are many kinds of mosquitoes but the larvæ of all live in water and generally not in large ponds but in more or less stagnant water, and the most abundant species develop in temporary pools.

The adults have scales fringing their wings and also along the veins. The antennæ of the males are plumose (feather-like) and very noticeable. The winter is passed either as the egg, larva or adult, according to the species concerned.

The eggs may be laid either singly, in small clusters, or in masses often called "rafts" on the surface of standing water or even on the ground, hatching in the latter case after rains or the melting of the snow in spring. The number of eggs laid by one insect varies in different species but probably averages several hundred.

The larvæ or "wigglers" live in water and move with a motion which has given them their common name. The head and thorax are large and distinct, while the abdomen is slender, and projecting from next to the last segment of this section of the body is a respiratory tube which is usually

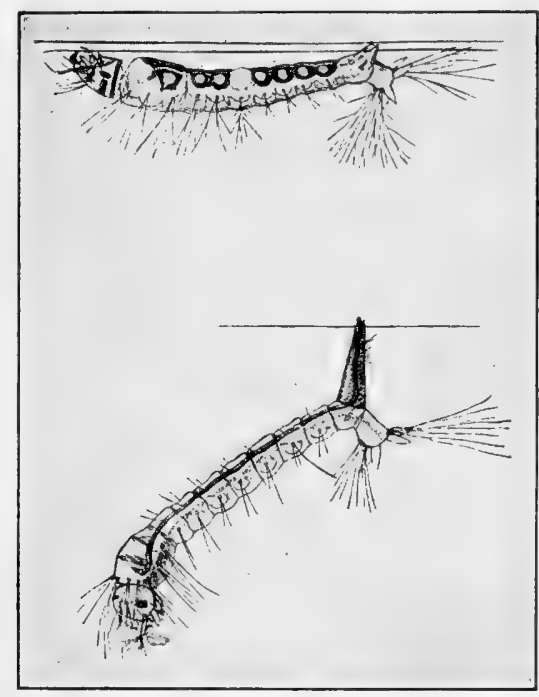

Fig. 321.-Breathing position of larva of Culex (below), and feeding and breathing position of Anopheles (above). Much enlarged. (Modified from U. S. D. A. Div. Ent. Bull. 25, n. s.)

rather long and near the end of which the breathing organs open by a sort of spiracle. When air is desired, the larva floats to the surface and projects the tip of the respiratory tube just above the water level, to renew its supply (Fig. 321).

The larvæ have mouth parts of the chewing type, and some are plant feeders. Most of them, however, are predaceous, feeding on tiny water animals and even on other mosquito larvæ, a pair of small brushes at the mouth being used to cause currents in the water and bring food within their reach. They molt four times and, after a varying length of time (a week or 10 days in many cases) in different species and at different seasons of the year, transform into pupæ. These are quite different in appearance from the larvæ, the head and thorax forming a 
large, rounded mass, joined by a slender abdomen. Differing from most insect pupæ, the pupal mosquito is active, moving through the water by a curious tumbling end over end. On the top of the thorax in this stage are two breathing tubes (Fig. 322), and when air is desired the tips of these are pushed above the surface of the water. The animal swims by making use of a pair of leaf-like appendages at the end of the abdomen.

After a brief pupal stage, usually lasting only a few days, the animal comes to the surface of the water and a split of the pupal skin along the middle of the back of the thorax appears, through which the adult mosquito escapes, balancing itself on this skin until it is ready for flight.
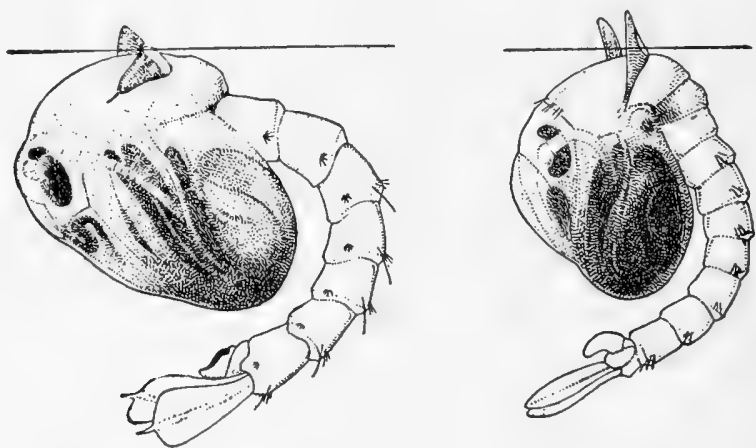

Fig. 322.-Pupa of Anopheles (left) and of Culex (right) showing position when breathing. Difference of form, position in the water and in the breathing tubes are shown. Greatly enlarged. (Modified from U.S.D. A. Div. Ent. Bull. 25, n. s.)

Of the many kinds of mosquitoes known, a small number are of particular importance aside from their habit of attacking man, being disease-carriers.

The House Mosquito (Culex pipiens L.).-This is a very common species almost everywhere in the Northern United States east of the Mississippi River and north of North Carolina. It is probably a native of the Old World where it is also abundant. Though as far as known it is not a carrier of any human disease yet it is a most irritating pest, and its control is important on that account.

Winter is passed as the adult (Fig. 323) in protected places and, in spring, egg clusters containing from 100 to about 300 eggs are laid on the surface of water. These eggs hatch in from 1 to 4 or 5 days and the larval stage usually continues for a week or two (Fig. 324). During this period, the larvæ spend much of their time at the surface, the respiratory tube projecting slightly above the water-line and the body hanging downward. Pupation for a few days follows, after which the adult appears. There are a number of generations each season. The adult 
has unspotted wings and, when at rest, its body is parallel to the object on which it has alighted (Fig. 325).

A number of other species not concerned in carrying disease are also liable to be pests. Near salt marshes of the eastern and southern

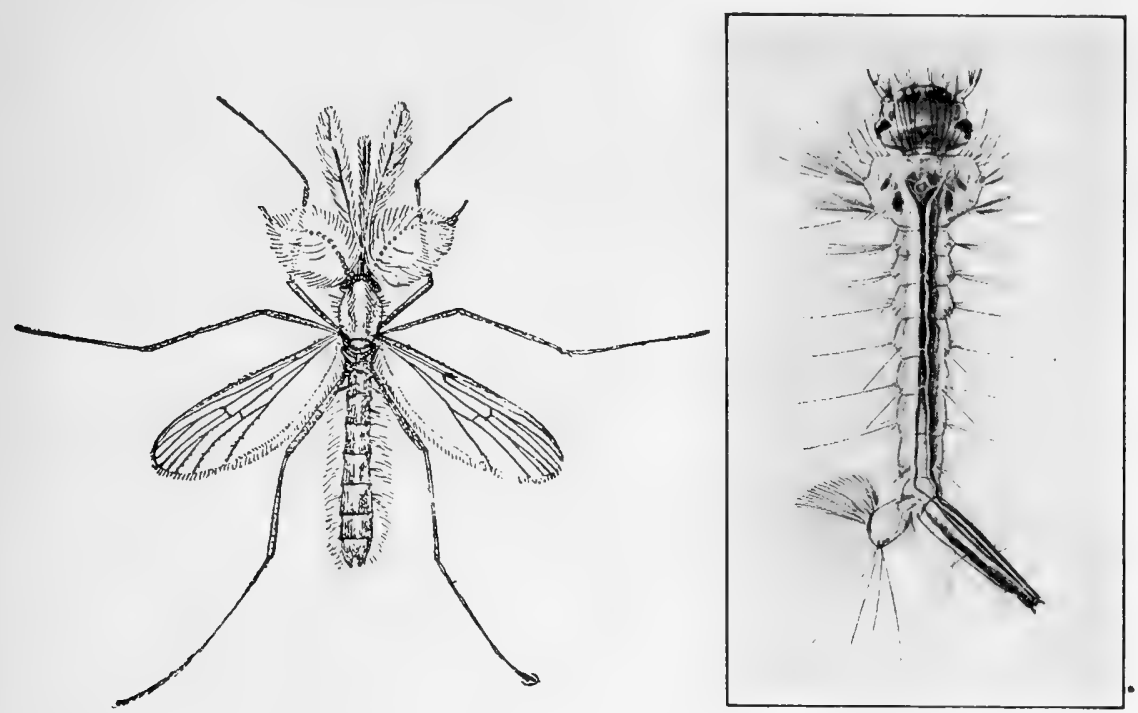

FIG. 323.

Frg. 324.

Fig. 323.-Male House Mosquito (Culex pipiens L.), greatly enlarged. Note the large feathery autennæ of this sex. (From U.S.D. A. Div. Ent. Bull. 25, u. s.)

Fig. 324.-Larva of House Mosquito, greatly enlarged. (After Howard, Dyar and Knab.)

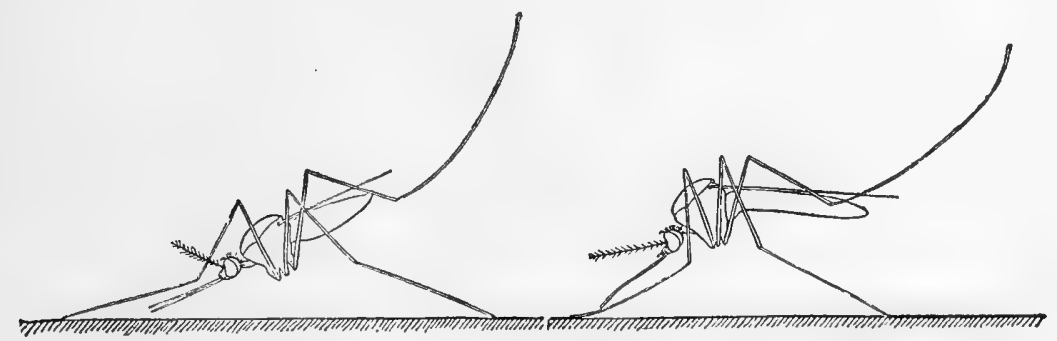

FIG. 325.-Alighting positions of Anopheles (left) and Culex (right) Mosquitoes. (From U.S. D. A. Div. Ent. Bull. 25, n. s.)

United States, the Salt Marsh Mosquito (Aëdes sollicitans Walk.) is very troublesome, and this species may fly quite a long distance inland. In the West, other species are abundant.

The Malarial Mosquitoes (Anopheles quadrimaculatus Say and others).-The species of Anopheles are carriers of malaria. The adults (Fig. 326) are larger than those of the House Mosquito and their wings 
are marked with dark spots. In alighting on an object, the body is tipped at quite an angle to the object on which it rests (Fig. 325) and these two differences will at once serve to distinguish the malarial mosquitoes from other species. Another distinction is in the length of the palpi of the female which in the House Mosquito are short, while in the Malarial Mosquito they are as long as the beak and therefore quite noticeable.

The species of Anopheles named above is found from Canada to Mexico, east of the Rocky Mountains.

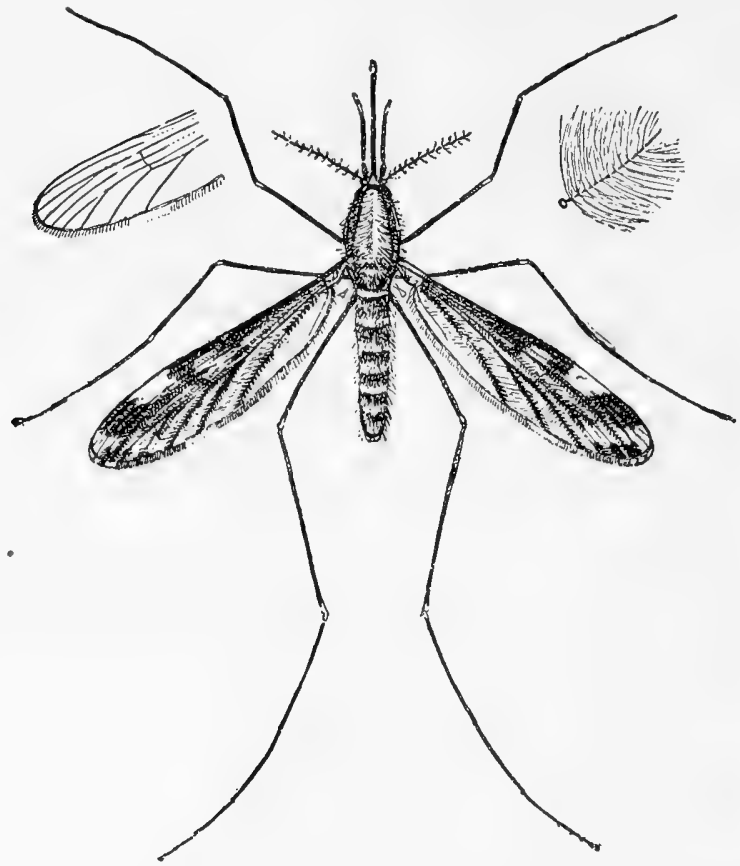

FIG. 326.

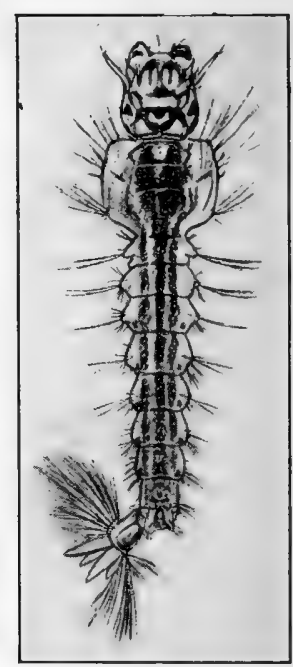

FIG. 327.

FIG. 326.-Female Malarial Mosquito (Anopheles punctipennis Say) much enlarged. Antenna of male at right. (From U.S. D. A. Div. Ent. Bull. 25, n. s.)

Fig. 327.-Larva of Malarial Mosquito, greatly enlarged. (After Howard, Dyar and Knab.)

Winter is passed as the adult, and the eggs are laid singly on the surface of water and hatch 2 or 3 days later. The larvæ (Fig. 327) resemble those of the House Mosquito but have a shorter respiratory tube and lie horizontally just below the surface instead of hanging head downward. (Fig. 321). The larval period is about 2 weeks, followed by a pupal stage lasting 2 or 3 days. Accordingly, a.new generation of these mosquitoes may appear about every 3 weeks.

Most species of Anopheles attack man chiefly during the twilight and early morning hours. The various species of Culex seek their food at night though often beginning their work late in the afternoon. 
Different species of Anopheles appear to be connected with different types of malaria. Anopheles quadrimaculatus has been proved to carry the organisms causing both the tertian and quartan forms while Anopheles crucians is a carrier of the organisms producing the rstivo-autumnal type of the disease, and, in other parts of the world, other species play similar roles in relation to these forms.

The animals causing malaria are believed to be of three closely related kinds, belonging to the Protozoa. In its form when introduced into the blood of man, the animal is a rather long and slender spindle with pointed ends. It now assumes an amœboid form and attacks a red blood corpuscle, working into it, feeding on its hæmoglobin contents and producing black granules. It feeds on the hæmoglobin in the corpuscle until this has all been consumed and grows until it nearly fills the corpuscle. It now divides into many parts, each similar to the one which first entered the corpuscle, and these proceed to attack other corpuscles in a similar way. This breaking up of the animal into parts coincides with the "chill" of the disease and the interval of time between successive chills determines which type of malaria is present, a period of 2 days indicating the tertian type; 3 days the quartan type, while a varying period indicates the rstivo-autumnal type. As the parasites increase in abundance and consume more of the corpuscles, the patient becomes anæmic and weaker.

Some of the products of division in the corpuscle, however, do not proceed to attack other corpuscles and increase in numbers but are of two different kinds which are the sexual stages. When these are taken into the stomach of an Anopheles which attacks a person having malaria, the two kinds fuse and the resulting animal penetrates the cells of the stomach wall of the mosquito and there remains, forming a cyst. Division of the animal here results finally in the production of cells like those which enter human blood, and these now escape into the body cavity of the mosquito and gradually gather in its salivary glands whence, they are expelled into the wounds caused by the feeding of the mosquito thereafter. The time which must elapse after a mosquito has received the malarial parasites before it can transmit these to man varies, but is usually at least 10 or 12 days and may in some cases be more than this.

The Yellow Fever Mosquito (Aëdes rogyti L.).- This insect, formerly known as Stegomyia fasciata, is the carrier of Yellow Fever. It occurs in the tropics throughout both hemispheres and, during warm weather, may extend to the temperate regions, but can survive there only while the temperature is fairly high.

The adult (Fig. 328) is a small mosquito with silvery lines along the back of the thorax and its legs are banded with white. It flies in the daytime and occurs mainly in towns and cities, being only rarely found in the country. Its eggs are laid singly or in small clusters on, or close 
to, water in houses or near by, it having apparently become a "wholly domesticated" species. The eggs hatch in from $10 \mathrm{hr}$. to about 3 days, and the larvæ hang downward from the surface. After a week or 10 days in this stage, they pupate for 2 or 3 days before the emergence of the adult. Feeding by the adult appears to be mainly during the warmer hours of sunny days though extending somewhat into the evening.

Repeated investigations show that the unknown germ or organism producing Yellow Fever is conveyed to man only by the attacks of this insect. Apparently about 12 days is required after feeding on a Yellow Fever patient before the mosquito is able to transmit the organism caus-

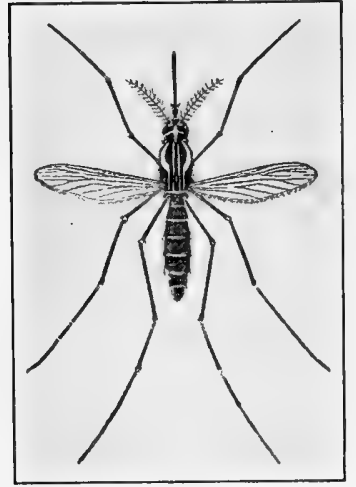

FIG. 328.-Adult Yellow Fever Mosquito (Aëdes agypti L.), considerably enlarged. Note black and white banding of the legs. (After $U$. S. D. A. Farm. Bull. 547.)

various substances have proved of value for this purpose. Among these are spirits of camphor, oil of pennyroyal and oil of citronella which seem to be the favorite substances used in this way. Smudges will keep away mosquitoes where the smoke is, and burning insect powder in a room stupifies the insects so that they fall to the floor and can be swept up. Other materials for use in a similar way are also available.

Destruction of the larvæ, pupæ and eggs is the most direct way in which to control mosquitoes in large numbers, and many methods for accomplishing this have been tried. As mosquitoes develop only in water, the removal of the places where they can breed, such as the drainage of marsh land, filling up small pools, hollows in trees containing standing water, and all such situations will accomplish a great deal. The drainage of the salt marshes of the New Jersey coast and elsewhere has resulted in a marked relief from the attacks of mosquitoes in those localities. Where the water can not be drained off, covering it with a film of kerosene will suffice to destroy the eggs on the surface, larvæ and 
pupæ at or coming to the surface for air, and any adults which may alight on the water to lay their eggs. Rain water barrels and cisterns for storing water for use can be screened, and ponds where the use of oil is undesirable may be stocked with small fish (sun-fish or top minnows) which feed voraciously on these insects. Recent experiments indicate that where the water must be used for drinking purposes, making the use of oil objectionable, sprinkling powdered formalin on its surface will kill mosquito larvæ but not fish present, without making the water impossible to drink!

The catch-basins of sewer openings are usually favorite breeding places for mosquitoes and these must be given attention, along with cess-pools and any tin cans or other receptacles containing rain water which can be found.

Oil used should be sprayed on the water, working preferably along its windward side and using about $1 \mathrm{fl}$. oz. to every $15 \mathrm{sq}$. ft. of surface. The oil will spread if simply poured onto the water, but rather more of it will be required by that method. It is important to be sure that little detached pools along the shore receive their film of oil also. This treatment should be repeated every 10 to 15 days unless heavy rains carry off the oil soon after a treatment, in which case the oil should be renewed sooner. Sawdust soaked in kerosene has been found to give up the oil slowly and thereby preserve the film on the surface longer, when this material is scattered along the edge of the water.

Family Itonididæ (The Gall Midges).-These tiny flies are very numerous. Most of them produce galls on plants, living in these galls, but some suck plant juices without producing galls, and a few live in decaying wood or fungi, or even feed on Aphids. The adults have long antennæ with, in the majority of the species, a whorl of hairs on each segment. All parts of the plant are attacked by one species or another, and the galls produced are typical for the species in each case.

The gall appears to be the result of the irritation caused by the larva feeding, and to some extent its size is dependent upon the number of larvæ present. Winter is frequently spent as the larva inside the gall and, in many cases, there is but one generation each year though, on the other hand, some species have several generations.

The larvæ are small, of ten brightly colored maggots. The method of pupation varies in different species, some forming true cocoons while others have a puparium and others are without any covering:

Among the species not producing galls is the Clover-flower Midge (Dasyneura leguminicola Lint.) which lays its eggs in the flower heads of mammoth, red, crimson and white clover and is probably present everywhere in America where these clovers occur. There are two generations each year. The larvæ feed on the flowers and prevent their forming seed. As the insects do not affect other parts of the plant, they are not of serious importance except where seed is grown, 
but in those localities they are very injurious pests. The usual methods of control are to pasture the fields before starting a seed crop, to destroy all the midges present in the heads then available: by early cutting, to dry up the heads before the maggots in them have finished feeding, which in the northern districts would mean cutting early in June. Sometimes, cutting the clover back between the fifteenth and twenty-fifth of May will prove advantageous as the new blossoms will not develop until after the adults of the first generation are gone, and will have progressed beyond danger of injury by the time the adults of the second generation appear. Clover so cut can be fed green to stock.

The Hessian Fly (Phytophaga destructor Say).-This insect, which like the last is one of the non-gall-making Itonididæ, is a native of Europe and was first noticed in this country about 1779 on Long Island, N. Y. Since that time, it has spread over a large part of the United States and Canada and is now one of the most

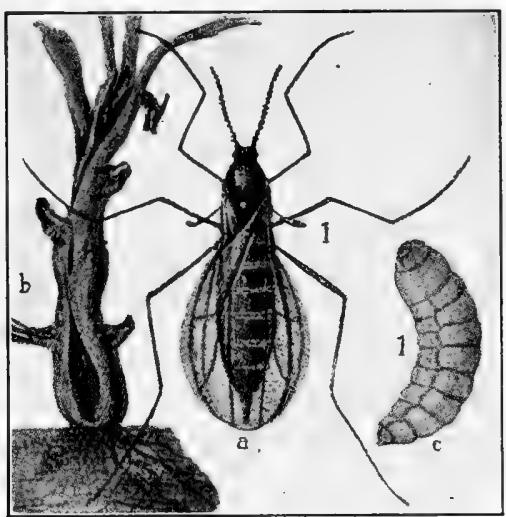

FIG. 329.-Hessian Fly (Phytophaga destructor Say): $a$, adult fly; $b$, wheat plant affected; $c$, maggot. Hair lines show true length of $a$ and $c$. (From Berlese.) injurious insect pests in the country, often destroying wheat valued at millions of dollars. It feeds on wheat, barley, rye, and several other species of grasses.

Its life history differs somewhat in different places, apparently being modified by the different methods of wheat growing. Where wheat is planted in the fall, the eggs are laid on the leaves of the plants soon after they come up, the time varying with the latitude from late August and September in Michigan, to the last of November or early December in Georgia. The eggs are placed in irregular rows of about half a dozen, generally on the upper surface of the leaf, and each fly lays 100 to 150 in all. They hatch after a few days, and the tiny pinkish or reddish maggots work their way down between the leaf and the stem to a point just above the joint (Fig. 329). Here they remain, sucking the sap until the approach of cold weather, turning more nearly white in color. Their presence at this time is at first indicated by the dark color of the leaves, missing stems which would otherwise begin to show, and later, the yellowing and death of the plants. After feeding about a month, the larva pupates within its larval skin which therefore becomes a puparium and so greatly resembles a flax-seed that in this condition the insect is generally spoken of as being in the "flax-seed" stage. In this condition, it spends the winter and the adult flies (Fig. 329) emerge in the spring; early in the South; later in the North. These now lay their eggs on the wheat and, 
as by this time the plants may be a number of inches high, the eggs can be laid at different heights on the plant, and the larvæ will pass down to the joints immediately below the leaves on which the different eggs are laid. Feeding at these joints continues during the spring and the flax-seed stage is reached at or before harvesting time. Some of the flax-seeds will be in the straw cut and harvested while many more will remain in the stubble and the flies emerge from the flax-seeds during the early fall as already indicated, ready to attack the fall-planted wheat as soon as it comes up.

In regions where the wheat is planted in the spring, the insect winters in the flax-seed stage in stubble and volunteer wheat, and the adults appear in May. The second generation quickly follows the first, particularly in wet seasons, and there seems to be no period of delay such as occurs during midsummer in the fall-wheat regions.

Control.-The Hessian Fly has numerous parasites which are undoubtedly of much value, as where great loss occurs these insects are few in number. It is so often the case, though, that the fly is abundant, that parasites can not be relied upon and other measures, largely preventive in their nature, must be taken.

It is evident that, if fall planting can be delayed until the adults which appear at that time are gone, the crop will be protected from attack. To carry out this plan, however, latitude, elevation and humidity perhaps, as well, must be taken into consideration. Investigations along this line, though far from complete, now indicate that it is generally safe to plant wheat in northern Michigan after the first of September: in southern Michigan and northern Ohio, about the twentieth of that month: in southern Ohio, after October 7: in Kentucky, after October 15: and in Georgia, from the last week in October to the middle of November. Thus in general, the farther south, the later the planting date should be, though very high land in any region can probably be planted earlier than low land if the area and elevation are sufficient to give it the more northern conditions.

The rotation of crops is also of advantage, driving the flies elsewhere to lay their eggs and making them more liable to destruction while en route.

Many of the flax-seeds are left in the stubble at harvesting and any method of destroying these is beneficial. Where the grain is cut rather high and a mowing machine is then run over the field, cutting the stubble as close as possible, burning this cut stubble after a few days' drying is effective. Unfortunately, however, the general custom of planting grass and clover in such fields, to come up as the grain progresses toward harvesting, too often makes this control impracticable.

Volunteer wheat as it is called, coming from grain scattered through and around the wheat fields by accident, starts early and provides plants 
for the Hessian Fly to lay its eggs on before the main planting is available. This will produce an abundance of the insects to attack the crop the following spring. All such plants should be destroyed before the maggots in them have reached the flax-seed stage.

The use of good seed, planted in soil that has been thoroughly cultivated to break up all the lumps of dirt and thus provide a compact, fine soil, is very helpful, and the addition of plenty of fertilizer is also of importance.

One writer has summarized control methods for the Hessian Fly as follows: "Sow the best of seed in thoroughly prepared, fertile soil after the major portion of the fall brood has . . . passed out of existence, and, if possible, sow on ground not devoted to wheat the preceding year. In the spring-wheat section late seeding will not apply. It seems likely, on the contrary, that the earlier it is sown in spring the less it will suffer from the Hessian Fly," (Webster).

Another Itonidid attacking wheat, and also barley, rye and oats occasionally is the Wheat Midge (Contarinia tritici Kirby), a native of Europe, first noticed near Quebec about 1819, and which has now spread over the wheat-growing regions of the East, and through the Mississippi Valley. The adults are very small, yellow or orange colored, and appear in June. They lay their eggs in the chaff covering the growing kernels of grain, and the reddish maggots suck the juice from the kernels causing them to shrivel, blighting the heads. When fullgrown, the maggots pupate in the ground, usually passing the winter in this stage. There is generally only one generation each year.

For many years, this was a very serious enemy of wheat, the loss in New York being estimated at $\$ 15,000,000$ in 1854 , but since about 1860 it has been less destructive and only local in its attacks. Plowing infested land deeply in the fall so that the insects wintering there will be buried too deeply for them to escape the following spring: burning the chaff and screenings after threshing the grain from infested fields, and rotation of crops are the control methods used for this pest.

Family Tabanidæ (The Horse Flies or Gad Flies).-These pests of cattle, horses, and occasionally of man also (Figs. 330 and 331) are in many cases quite large insects, with bodies an inch long though most of them average a third to half an inch in length. The head of the adult is large and fits onto the thorax somewhat like a cap. Only the females feed on blood, the males lacking some of the mouth parts necessary with which to pierce the skin. They therefore feed on such plant juices as they may be able to obtain, honey dew and other similar materials.

The eggs are laid in masses on plants over water or marshes, and the larvæ live in water, damp places, or in the earth when it is soft, and are carnivorous, feeding on snails, small insect larvæ, etc.

The family is a large one, both in this country and elsewhere. The larger species, (one has a black body and smoky wings), are often noticed 
around domestic animals because of their size. Many of the smaller kinds have wings banded with dark. Some of these are called"Green-heads" because of the bright green color of their eyes (Fig. 331). Their attacks irritate and disturb the animals and, in the case of milch cattle, this may reduce the amount of milk produced.

As these insects attack domestic animals only for their blood, any repellent measures which prevent this are sufficient. Fly-nets covering the greater part of the animals are sometimes used for this purpose: and smearing the ears and legs with substances having an odor objectionable to the flies is also practiced. One of several materials often applied is fish oil, either alone or mixed with tar. The following mixture has proved

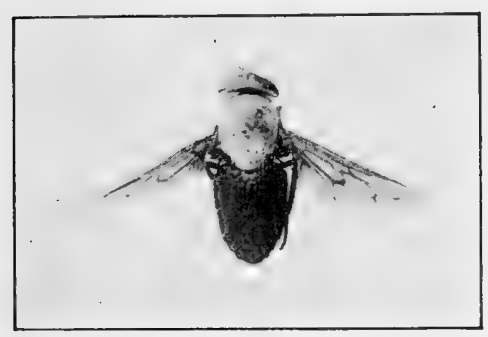

FIG. 330.

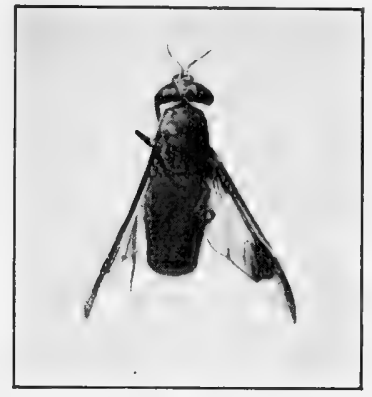

Fig. 331.

Fig. 330.-Large Horse Fly (Tabanus stygius Say), slightly reduced. (Original.)

Fig. 331.- Small Horse Fly (Chrysops vittatus Wied.), over twice natural size. (Original.)

effective against those Tabanids which preferably attack the ears and the region around the eyes of the animals: pine tar, 1 gal.; fish oil or crude carbolic acid, 1 qt.; powdered sulfur, 2 lb. These materials are thoroughly mixed and rubbed on the parts most liable to be attacked. As so many Tabanids pass their early stages in stagnant water, the treatment of such breeding places with kerosene will destroy the larvæ as they hatch and enter the pools.

Family Simulidæ (The Black Flies or Buffalo Gnats).-The small flies which compose this family feed upon the blood of man and other animals, attacking them at all exposed places. As in the Tabanidx, only the females are concerned and these are active only during the daytime. The eggs are laid in such places that the larve can enter water, and in most cases, swiftly running streams where they feed on small animals. They usually anchor themselves to some object in the water and have a pair of fan-shaped structures at the mouth which are used to produce currents toward the mouth. In the South, all domestic animals suffer severely from the attacks of these insects, and many are even killed by them. There are usually two or three generations each year, particularly in the South. The best control methods known are the use of repellent materials on the animals, such as fish oil three parts, kerosene one part, applied about twice a day. Animals kept in dark stables are not attacked while there. 
Family Asilidæ (The Robber Flies).-These insects as adults prey upon other insects, attacking any species they are able to overcome (Fig. 332 ), but using little discrimination as to the importance to man of their captures. They can hardly be regarded as more than accidentally beneficial to man. Some species (Fig. 333) so closely resemble bumblebees that a careful examination of the number of wings present is necessary to determine what the insect is. The larvæ are found chiefly under bark, in decaying wood or in the ground where decaying vegetable matter occurs, and feed upon insect larvæ present in such places.

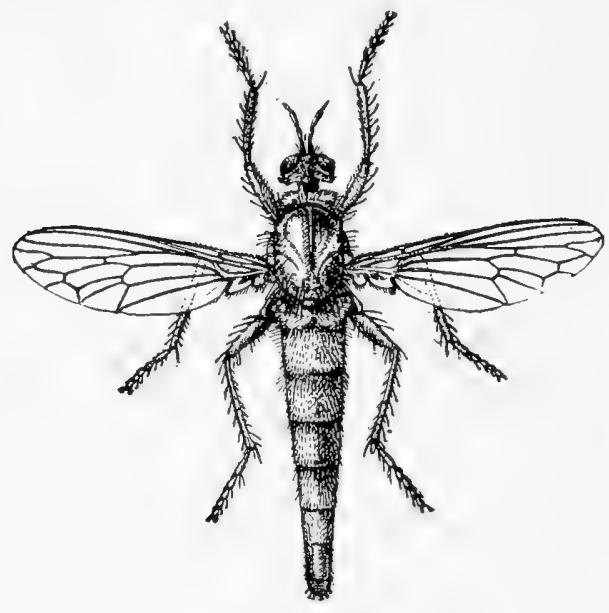

FIG. 332 .

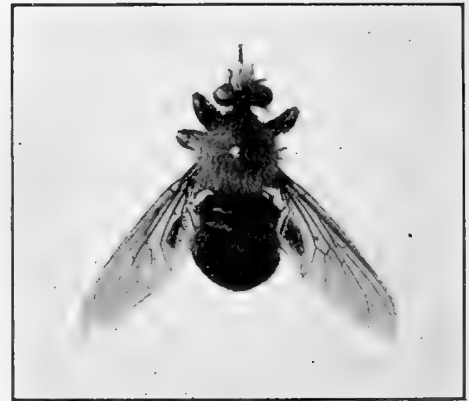

FIG. 333.

Fig. 332.--Robber Fly (Scleropogon picticornis Loew), about twice natural size. (From U. S. D. A. Bull. 124.)

FIG. 333.-Bee-like Robber Fly (Dasyllis grossa Fab.), slightly reduced. (Original.)

This family is one of the largest in the order and its members average large, ranging from a length of about a fifth of an inch to nearly two inches:

Family Syrphidæ (The Syrphus Flies).-This is one of the largest families of Diptera. The adults range from quite small to rather large insects which visit flowers, feeding on the pollen and nectar, and are most noticeably abundant in bright, sunny weather. They are usually rather brightly colored.

The larvæ of these insects vary greatly in their appearance, five types of them having been recognized. Some are rather flattened, elongate, often green with white spots, and are found with clusters of plant lice on which they feed. Others have nearly cylindrical bodies and bore into the bulbs of various plants. Others live and feed in filth and have short extensible tubes for respiration. Another class which also inhabits filth has extensible respiratory tubes which, when extended to their limit, may be several times the length of the body. Still another group are short, broadly rounded, flattened beneath and high above, somewhat hemispher- 


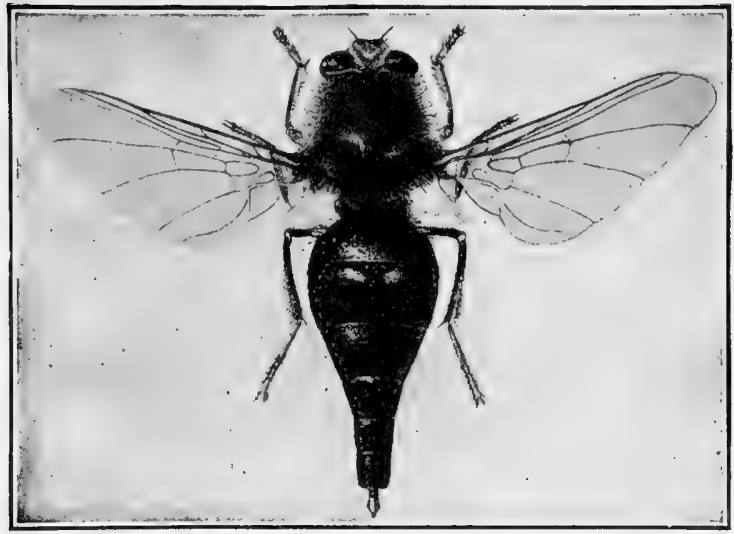

FrG. 334.-Adult female Bot Fly (Gastrophilus nasalis L.), nearly twice natural size. (From U.S. D. A. Bull. 597.)

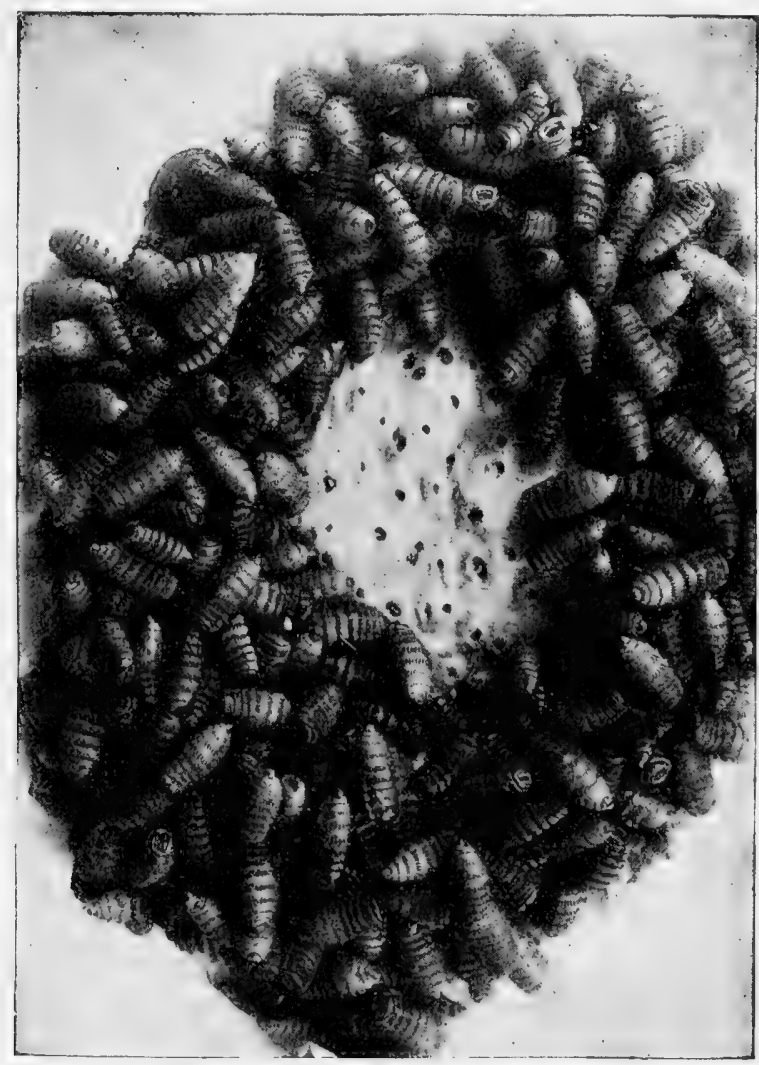

FIG. 335. - Nearly full-grown larvæ (bots) of a Horse Bot Fly attached to the inside wall of the stomach. (From U.S. D. A. Bull. 597.) 
ical in form. These are usually found under logs and in ants' nests and may easily be mistaken for rather peculiar snails.

Though the adults consume pollen, their visits to flowers are valuable to man for the cross-pollination and the resulting "setting" of seed. The insect-eating larvæ often destroy enormous numbers of insect pests, and the filth-inhabiting forms are at least cleaning up decaying matter, which is generally considered desirable. On the other hand, some are injurious by boring into the bulbs of cultivated plants, and several species cause myiasis in man and some of the domestic animals, these insects in one way or another entering the body and passing through their larval development there.

Family Estridæ (The Bot Flies).--The bot flies in their early stages are parasites on mammals. The adults are of medium to large size, with rather stout, thick-set bodies and frequently with reduced mouthparts, not feeding in this stage (Fig. 334). Though the group is not a large one, its members are included among the more important pests of domestic as well as of other animals. The parasitic part of the life of these insects is in some species spent in the stomach (Fig. 335) or intestines, in others in the pharynx or nasal cavities and frontal sinus, while others live under the skin.

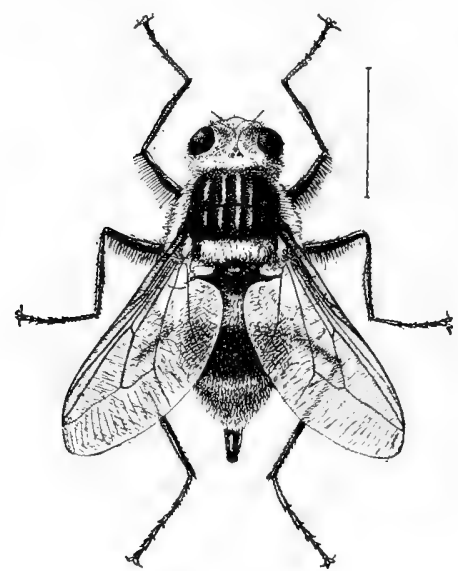

Fig. 336 .

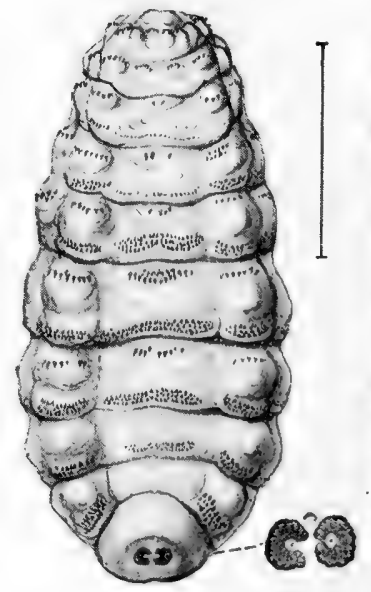

FIG. 337.

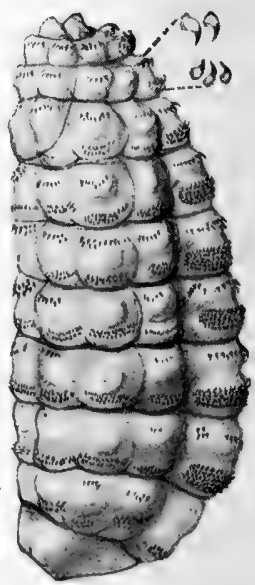
Fig. 336.-Ox Warble Fly (Hypoderma lineata Vill.). Real length shown by hair
Fig. 337. - Full-grown Warble (larva), dorsal view (left) and side view (right). FIG. 337.-Full-grown Warble (larva), dorsal view (left) and s
Real length shown by hair line. (From U.S.D. A. Div. Ent. Circ. 25.)

The Ox Warbles (Hypoderma lineatum Vill. and Hypoderma bovis De G.).- These two insects, both natives of Europe, are present in this ocuntry, the former widely distributed, the latter most abundant in Canada and a few of the Northern States. The adult fly (Fig. 336) is about half an inch long. The eggs of both species are laid on the hairs of 
cattle on almost any part of the body during the late spring or summer months, and the larvæ bore through the skin into the connective tissue and then wander through the body in the connective tissues until late fall or winter when they locate along the back, a few inches from the backbone. Here each makes a hole through the skin through which to escape but remains inside, feeding on the pus and bloody matter produced by its presence there, and the swelling caused by the insect is called a "warble." Finally the maggot, now nearly an inch long (Fig. 337) and grayish-white in color, works its way out through the hole and drops to the ground which it enters for an inch or two, and forms a pupa within a brown puparium from which the adult fly appears from 3 to 6 weeks later, the larval period within the cattle being 9 or 10 months.

The presence of the maggots of the ox warbles in the cattle is shown by a loss of flesh, reduction of the milk in the case of milch cattle, and by the presence, during late fall and winter, of the sores on the back.

Control.-The chief control method in general use is squeezing out the larvæ in the back whenever they are observed there. With a little practice, pressing with the thumbs on the skin at the sides of the opening will result in the expulsion of the maggots. During the egg-laying season, cattle in the field may be protected to a considerable extent by the application of repellents such as are used to keep off Tabanids.

Various other bot flies attack different animals. Among them are the Horse Bot Flies (Gastrophilus of several species), the larvæ of which live in the stomach of the horse during the fall, winter and spring and the Sheep Bot Fly (Estrus ovis L.) which in the larval stage inhabits the nasal cavities and frontal sinuses of sheep during the same period.

Family Trypetidæ (The Fruit Flies). - Some of these small flies attack various fruits in which their maggots tunnel, ruining the fruits. Others mine the leaves of plants, occur in blossoms or form galls in the stems or roots of plants. Those which live in fruit are of economic importance. Most of the flies belonging here have dark bands, or dark markings enclosing transparent spots on their wings. Two species attack cherries; one feeds in currants and gooseberries; one in the apple, thorn, blueberry and huckleberry, and other species injure citrus fruits.

The Apple Maggot or Railroad Worm (Rhagoletis pomonella Walsh).--This insect is apparently a native of this country and its original food seems to have been the berries of the thorn and possibly the blueberry. It has been found in various parts of Canada and the eastern United States as far south as North Carolina and west to Minnesota, South Dakota and Colorado, but is most serious in the northern and eastern portion of this territory.

The adult (Fig. 338) is about a fifth of an inch long and has a wing spread of about half an inch. Its body is black with light marks on the upper side of the abdomen, and the wings have heavy dark bands. The flies first appear in the orchards early in July in New England (somewhat earlier farther south) and 
attack the early varieties of apples. Later appearing flies may sometimes be found until into September, and these select fall and winter fruit for egg laying. Some varieties of apples are much more subject to the attacks of this insect than are others.

Egg laying begins about 20 days after the fly emerges and probably continues for 2 or 3 weeks, the total number of eggs laid being several hundred. These are inserted singly under the skin of the apple and preferably where the surface is not exposed to sunlight. They hatch in 4 or 5 days and the little whitish maggots tunnel through the pulp of the fruit in all directions. At first, the rapid growth of the fruit may fill up these tunnels, but after a time the walls around the tunnels instead of filling in, turn brown and the fruit softens, decay may follow, and the entire apple is spoiled for sale. The maggot (Fig. 339) has no real jaws with which to tunnel but has a pair of small hooks at the mouth opening with which the pulp is rasped and torn, freeing the juice upon which the insect feeds.

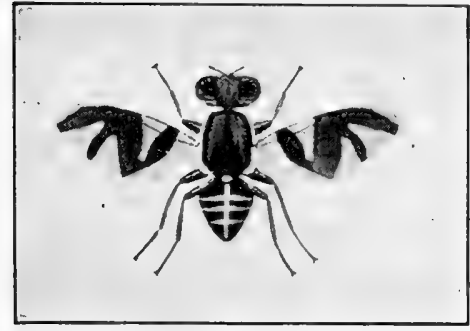

FIG. 338 .

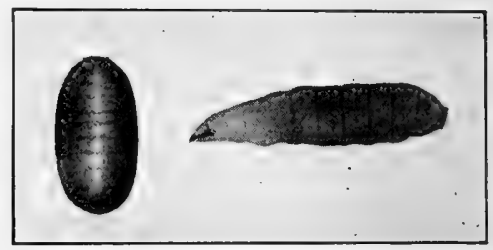

FIG. 339.

FIG. 338.-Adult Fly of the Apple Maggot (Rhagoletis pomonella Walsh), slightly over three times natural size. (Reduced from Nova Scotia Dept. Agr. Bull. 9.)

FIG. 339.-Puparium (left) and full-grown maggot (right) of the Apple Maggot. About three times natural size. (Modified from Nova Scotia Dept. Agr. Bull. 9.)

The length of the larval stage depends upon the temperature and upon the ripeness of the fruit. In warm weather and with rather soft pulp, about 2 to 4 weeks is usually the time necessary, but with colder weather and in late-maturing varieties, growth toward maturity is delayed and some maggots may possibly even winter in this stage in extreme cases. When the larva has completed its feeding, however, it leaves the fruit (usually as this becomes ripe) and enters the ground where it burrows below the surface of ten some distance, and pupates in a puparium (Fig. 339) remaining here until the following summer when the flies emerge. Where infested fruit is gathered and stored before the maggots leave it, the puparia may be found on the bottom of the barrels or bins where the fruit is kept. A few of the earlier pupating maggots appear to transform to flies the same season, giving a second generation, but so few do this that it is of little or no economic importance. On the other hand, a few seem to require 2 years for the completion of their life history.

The amount of injury caused where this insect is abundant is often very great, particularly with early apples, a large percentage of which may prove entirely worthless. Among the varieties which suffer severely are the Early Harvest, Gravenstein, Porter, Red Astrachan, and Wealthy, sweet and sub-acid summer 
and fall varieties being in general the greatest sufferers though winter varieties, as the Northern Spy and others, often do not escape.

The adult flies feed freely and also seem to require water during their life, specimens supplied with food but no water dying within a few days. They do not appear to fly freely for long distances at least, and orchards in which they are abundant and others where they are rather few in number may occur not very far from each other.

Control.- Infested fruit falls to the ground early, and the maggots in it rarely leave it for the ground to pupate until about a week later. Gathering and destroying this fallen fruit promptly should, therefore, be of much assistance in controlling the insect but the amount of labor involved in carrying out this plan makes it impracticable in many cases. Cultivation of the ground under the trees has proved ineffective and allowing poultry and hogs to run in the orchards has not resulted in much improvement.

It has been found that where orchards are carefully sprayed just about the time the flies appear, using slightly less arsenate of lead than the standard formula and repeating this treatment 2 weeks later, excellent results are obtained. The addition of molasses has sometimes been advised, but comparative tests thus far made indicate little advantage from this considering the extra expense and trouble. To know just when to apply the first spray is a difficulty with this treatment, however, and it has been suggested that owners of infested orchards can place infested apples in a box containing several inches of earth and leave it out during the winter. In the spring, cheese-cloth can be placed over the top and the spray should be applied as soon as the first flies are seen on the under side of the cloth.

Family Muscidæ (The Muscid Flies).-This large family contains many species which are important to man though none appear to be crop feeders. The adults range from small to medium size and are very abundant in most cases.

The House-fly (Musca domestica L.).- - This insect, always a household pest, has during the last 25 years assumed a greater importance to most people because of the discovery that it is a carrier of a number of serious human disease-producing agents, among these being the germs of typhoid fever, cholera, dysentery, etc.

The adult flies (Fig. 340) hardly need any description. They are rather small, with reddish-brown eyes, transparent wings and blackish bodies. Their mouth parts are for sucking and a "biting" fly found in a house at any time is of some other species.

Winter is at least usually spent as the pupa or perhaps in some cases as the larva. As the weather becomes warm in the spring, the flies emerge, and, in temperate regions, begin breeding early in June, though it is probable that in warmer climates this may continue throughout the year. Most of the flies breed in manure piles, particularly those exposed to light, but almost any decaying animal or vegetable matter may be selected for the purpose. The eggs (Fig. 341) are laid in clusters, about 125 at a time and about 500 to 600 in all. They hatch in from 8 to 12 
hr. during warm weather but may take 2 or 3 days if the temperature is low. The larvæ (Fig. 342) feed on the manure or other material in which they are located, for a varying number of days but probably averaging about 5 days. Pupation for about the same length of time follows, but many of the maggots may leave the place where they feed and travel a short distance away to pupate. Thus, pupæ may be found in the ground around a manure pile within a foot or two. Pupation is within a puparium, the fly pushing off the front end by means of its

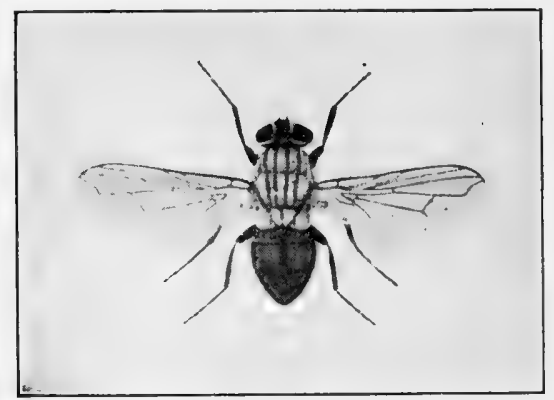

FIG. 340.- House Fly (Musca domestica L.), rather more than twice natural size. Reduced from Hewitt: The House Fly.)

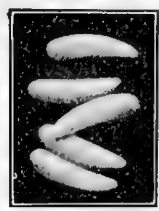

FIG. 341.

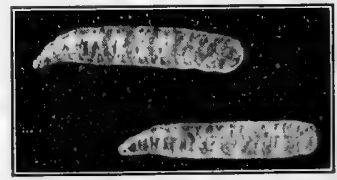

FIG. 342.

Fig. 341.-Eggs of the House Fly, much enlarged. (Original.)

FIg. 342.-Full-grown maggots of the House Fly, much enlarged. (Original.)

ptilinum. After the emergence of the adult fly, a period of about 14 days elapses before egg laying begins so that the time from one of these periods to the next during warm weather is about 24 days. From 7 to 10 generations are liable to be produced, therefore, in a long season in the North or under ordinary conditions in the South, and it has been calculated that the descendants of a single fly which deposits its eggs the middle of April would number 5,598,720,000,000, by the middle of September, if all the eggs hatched and lived to adults which reproduced in their turn. Fortunately, this is not actually the case, eggs failing to hatch and many larvæ never reaching maturity.

House-flies as disease carriers are of extreme importance. Crawling over and feeding upon filth of any kind, their legs and bodies are liable to gather the germs of various diseases, which may also be taken into the flies with their food. Later, visits to houses and human food over which 
the flies crawl lead to leaving some of the germs there, and the wellknown habit they have of disgorging some of the food already eaten and of expelling feces, both of which may contain the germs swallowed, is pretty certain to infect the human food over which they crawl.

Doubtless many of the microorganisms thus placed on food are entirely harmless to man but among these are also liable to be those which cause diseases. Milk exposed to the visits of flies may become infected in a similar way.

Among the disease germs often transmitted thus are the typhoid fevers, anthrax, tuberculosis, cholera and yaws, while others are suspected of being carried in this way also. The habit flies have of visiting spittoons; of alighting on sores on persons and, in fact, of crawling over everything where disease germs are liable to occur, makes them particularly dangerous to man. It should be noted, however, that there seems to be no development of any of these diseases while on or in the flies themselves, the insects acting as passive carriers only, of the germs. The relation of the insect to the disease, therefore, is a totally different one from that of mosquitoes and the diseases in which they are concerned, where the disease-producing organism actually passes through a part of its life cycle in the insect.

Control.-As over 90 per cent of the house-flies breed in manure, treatment of this to destroy the larvæ and pupæ there becomes an important line of attack. But, as in most cases this manure is used as fertilizer, the treatment should be, if possible, something which will not affect the value of this material for use. Most of the larvæ live near the surface of the manure piles, and it has been found that treatments with materials which will penetrate six or eight inches into the piles will reach most or all of the insects. Three-quarters of a pound of common borax dissolved in 3 gal. of water and poured over the pile will be sufficient to properly treat $10 \mathrm{sq}$. ft. of surface of the pile to the depth of a foot, so that applying this amount of fluid to $15 \mathrm{sq} . \mathrm{ft}$. should reach all, or nearly all, of the larvæ and pupæ in this space. It should also be applied to the ground around the pile for a foot or two as many of the larvæ crawl outside the pile to pupate.

Too much borax in the manure injures it as a fertilizer, and, in many cases, it is better to use Hellebore instead. Half a pound of this in 10 gal. of water is enough for $10 \mathrm{cu}$. ft. or to cover $15 \mathrm{sq}$. ft. to a sufficient depth to reach the insects. This treatment is somewhat more expensive than the other but the increased value of the manure is likely to more than make up the difference.

Open latrines and any places in which house-flies are breeding should be treated to destroy the larvæ and pupæ present or covered in such a way as to prevent the flies from reaching them. Chloride of lime and iron sulfate have been used with considerable success to kill fly larvæ 
and pupæ or drive away the adults, particularly when sprinkled around in stables. Hauling the manure directly to the fields and spreading it there, when practicable, preserves more of its value than letting it stand in piles where leaching and other processes going on reduce this. The destruction of garbage and of the organic matter at public "dumps," in which flies breed, is also important. Screening houses, food and garbage pails or cans and trapping the adult flies either by poisoned or sticky fly papers or by the use of fly traps are all methods for reducing the fly pest which, when these insects are abundant, should be made use of.

Almost any fly having habits similar to those of the house-fly may become a disease carrier in a similar way, and the above methods are of value against them all.

Some of the flies in this family lay their eggs on meat, either decaying or fresh, which is then spoken of as "blown." The flies which do this are usually the ones commonly called "blue-bottle" and "green-bottle" flies.

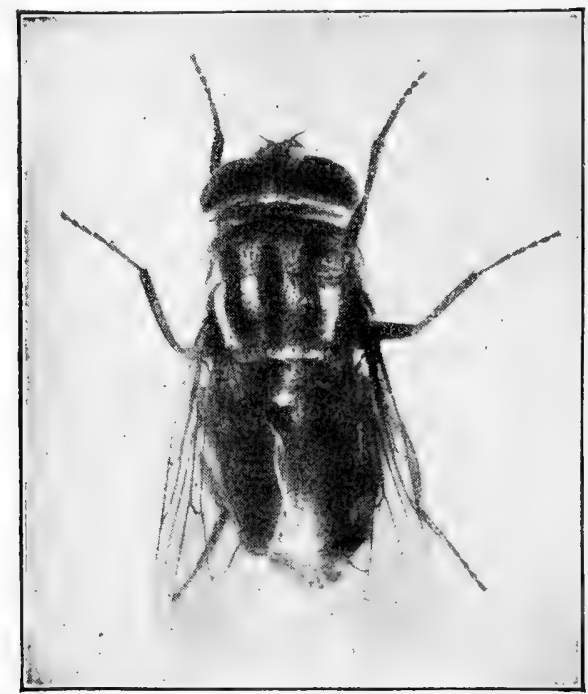

FIG. 343.- Screw-worm Fly (Chrysomyia macellaria Fab.), greatly enlarged. (From U. S. D. A. Farm. Bull. 857.)

The Screw-worm Fly (Chrysomyia macellaria Fab.).-This pest occurs in South America and northward into Canada. It is a serious pest to live stock and other animals, chiefly in the Southwestern States, though occasionally it becomes important farther north and east.

The adult fly (Fig. 343) is of a dark bluish-green color and has three black stripes along its back. It is considerably larger than the house-fly. Its eggs are laid in any decaying animal matter and also in wounds such as are caused by barbed wire, hooking, etc., in living animals. The larvæ (Fig. 344) hatch in from a few hours to a day or two and burrow into the tissues, if the eggs were laid 
on living animals, producing an irritating substance. The action of this and the feeding on the tissues cause the animal to become thin, lose its appetite and frequently death follows, for fresh eggs are repeatedly laid in the same wounds by the adults. The larva mature in 4 or 5 days in living animals and more slowly in dead ones, and, on becoming full-grown, drop to the ground which they burrow into a few inches to pupate. The pupal stage lasts from 3 days to 2 weeks and, at the end of this time, the adult flies emerge, completing the life cycle in from 1 to 4 weeks according to the conditions of the weather.

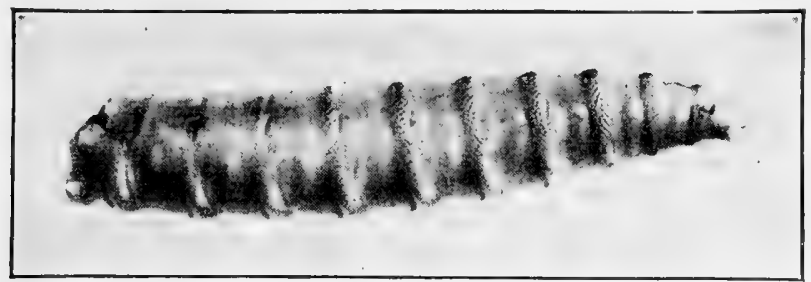

FIG. 344.-Full-grown Screw-worm Maggot, greatly enlarged. (From U. S. D. A. Farm. Bull. 857.)

Control.--Most of the breeding of these insects is in dead animals and therefore all carcasses should be promptly buried or burned. To protect living live stock, efforts to prevent their injury must be made and all cases of injury cared for as soon as possible. This may be done by pouring a little chloroform into the wound. It is then generally advisable to remove the maggots and clean the wound with water containing 5 per cent of carbolic acid. Pine tar over the outside at the wound will act as a repellent to the flies. In serious cases, the services of a veterinarian will be needed. Tick wounds are often the starting points for screw-worm injuries, and ticks should, therefore, be controlled as far as possible.

The Tsetse Flies (Glossina of several species).-These Muscid flies are the conveyers to man of the dreaded disease known as "sleeping sickness." The insects occur only in parts of Africa where they are found along wooded streams and where large game animals are present. The mouth parts of these flies include piercing structures and the insects normally attack the wild game, but man is also liable to their visits. The disease is caused by a Protozoan animal (Trypanosoma gambiense) obtained by the flies while feeding on infected animals, and the trypanosomes may be directly conveyed into another animal during the next day or two, after which the fly becomes innocuous for about 4 weeks: by this time, those of the parasites which entered the stomach of the fly have gone through a development in the body of the insect and have gathered in the salivary glands. The fly is now dangerous for about 3 months. In man, the disease appears as an irregular fever, and an enlargement of the glands followed after a time by nervousness and sleep, the patient becoming comatose and finally dying. The earlier stage of the disease may last for several years but the last usually continues only from 4 to 8 months. 
Thus far no cure for the disease has been discovered but protection while in Tsetse districts can be obtained by screens, veils, gloves, etc., and by keeping away from the localities in these districts where the flies occur. Its importance is indicated by the estimate that in 10 years between four and five hundred thousand natives died from this disease.

Another species of trypanosome carried by Glossina flies causes the disease of domestic animals, particularly horses and dogs, known as Nagana. This is almost always fatal to these animals.

Family Sarcophagidæ (The Flesh Flies, Fig. 345),--This is alarge family of flies, some of which lay their eggs on dead animals. Others

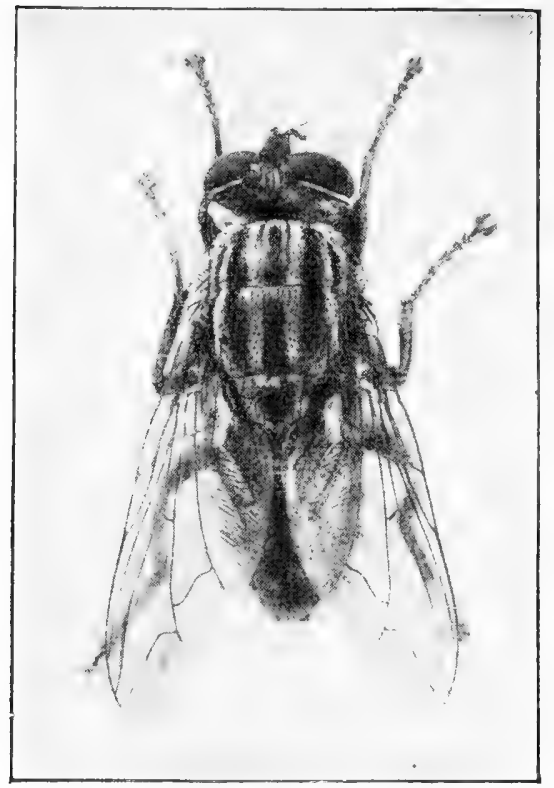

FIG. 345 .

breed in manure, decaying matter and similar materials, and because of these habits, there is always the possibility of their becoming carriers of disease-producing germs, though as they seldom visit human

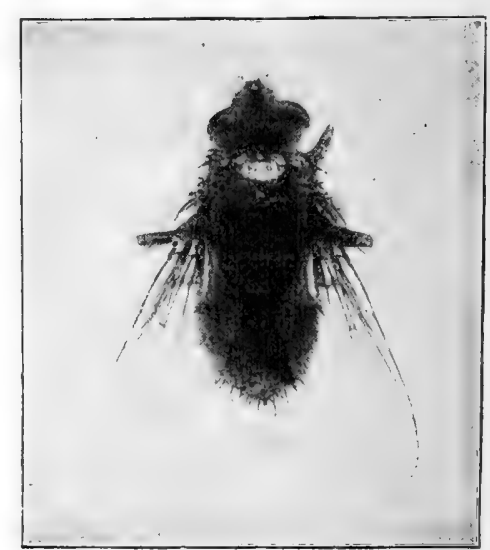

Fig. 346 .

FIG. 345.-Adult Sarcophagid Fly (Sarcophaga sp.), much enlarged. (From U.S. D. A. Farm. Buli. 857.)

Fig. 346.-Adult Tachinid Fly (Tachina mella Walk.), over three times natural size. (From Britton, Tenth Rept. Ent. Conn. Agr. Exp. Sta. 1910.)

food in houses, the chance that this may result in disease is much less likely than in the case of the house-flies.

Family Tachinidæ (The Tachina Flies).-This family has by some students of the subject been regarded as the most useful family of insects from an economic standpoint, its larvæ being parasitic on other insects and being very abundant. This estimate of their importance is probably too high but the group is certainly very valuable in the control of injurious forms. The adults (Fig. 316) somewhat resemble the Muscidæ, but the abdomen is liable to be stouter and in many cases bears numerous stiff bristles which are very noticeable. The eggs (or larvæ in some cases) 
are laid on caterpillars and other insects, or, in some cases, on the leaves which these will feed upon, and, on hatching, the maggots bore their way into the host and feed upon its tissues, finally killing it. The adults are common around flowers and also in places where plants are growing rankly, and there are many species.

Family Anthomyiidæ (The Anthomyiids).-This family contains many injurious species, the larva of some mining in the roots and of others in the stems and leaves of important crop plants. Others breed in decaying vegetable and animal materials and excrement and from their habits it is suspected that they may be disease carriers like the house-fly.

The Cabbage Maggot (Hylemyia brassica Bouché).-The Cabbage Maggot is a native of Europe but has been present in this country for many years. The adult (Fig. 347) is a small, clear-winged fly about two-tenths of an inch long, not often noticed or at least distinguished from other small flies present in the fields. Winter is passed as the pupa in its puparium underground, and also possibly to some extent as the adult, in protected places. At all events, the adult flies are present in the spring as soon as the cabbage

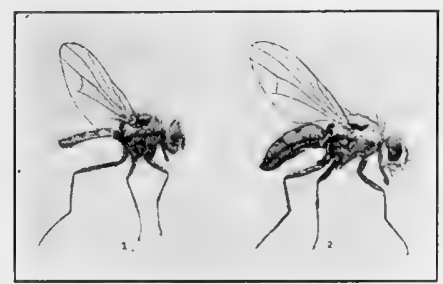

FIG. 347.

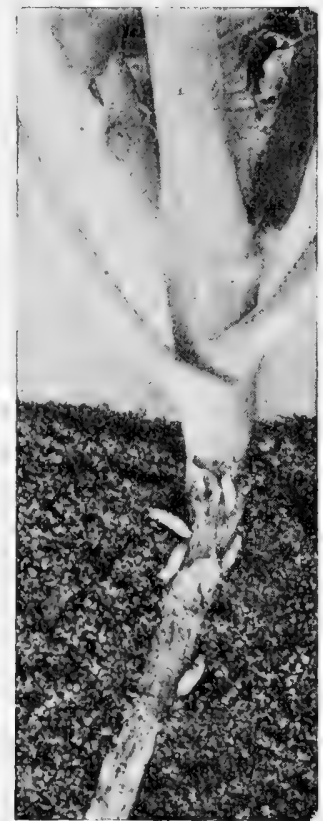

FiG. 348.

Fig. 347.-Adult male and female flies of the Cabbage Maggot (Hylemyia brassica Bouché). About three times natural size. (After N. Y. Agr. Exp. Sta. Bull. 419.)

Fig. 348. - Young Cabbage Plant showing Maggots on its stem. Natural size. (Modified from Britton, Fourteenth Rept. Ent. Conn. Agr. Exp. Sta. 1914.)

and other cruciferous plants are available. The eggs are now laid on or close to the plants. They hatch in a few days, and the maggots (Fig. 348) attack the stem just below the level of the ground where they feed for about 3 weeks, lacerating the cell walls and feeding on the softer tissues, using for the first process a pair of stout, black hooks attached at the mouth which seemingly are extremely modified mouth parts. When full-grown, the larvæ leave the plants, enter the ground and form puparia from their larval skins within which they pupate for a period of from 12 to 18 days in most cases, after which the adults emerge and eggs are laid for a second generation. 
The number of generations in a season has been worked upon by several investigators with somewhat differing results. It seems probable, however, that in the latitude of New York, the insect as a rule has three generations though in favorable seasons four are possible, and in unfavorable ones only two may occur. Presumably, the number farther north will usually be two, and farther south four may prove the usual number. Weather conditions apparently have an influence on this-hot, dry weather hardening the roots of the food plants so that feeding is slower than would otherwise be the case, and this same kind of weather also seems to lengthen the pupa stage. It is interesting to note that the insect though present in the Gulf States does not seem to be a serious pest south of the latitude of southern Pennsylvania. It has been found as far west as Colorado.

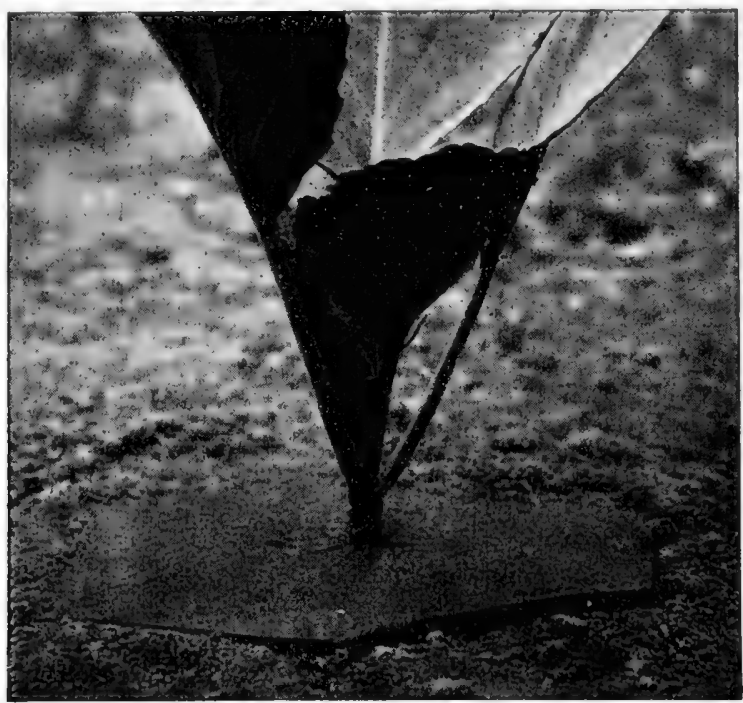

FIG. 349.-Cabbage Plant protected by a tar-paper disk around its stem. Britton, Fourteenth Rept. Ent. Conn. Agr. Exp. Sta. 1914.)

(Modified from

Whatever the number of generations a season, the insect seems able to reach the pupa stage before winter, and possibly become adult in some cases.

The Cabbage Maggot is most serious as a pest on cabbages and cauliflowers. It also attacks turnips, radishes, mustard and other cruciferous plants, however, and late generations may live more on these plants as the cabbage and cauliflower roots get older, tougher and less attractive to the insects.

Control.-Cabbage and other plants, liable to attack while in seedbeds, can be protected by covering these places with screens of cheesecloth. When the plants are set in the fields, tar-paper disks may be 
placed around their stems close to the ground (Fig. 349) and usually give good results. These disks may be cut by hand from ordinary tar paper, though where many are required, the use of a cutting stamp is advantageous. The piece is usually cut six-sided for economy of the paper, and from one corner a cut to a little beyond the center is made and also a short cut crossing this at the center, giving four points between which the stem is passed. The disk is then pushed down to the ground. In cultivating later, care should be taken to brush off any dirt which gets on the upper side of the disk as in such cases the fly often attacks the plant. The destruction of all the refuse of the plants on harvesting the crop, and also of all mustard and other cruciferous plants near by, is desirable to prevent further increase of the insect there before winter.

Various other treatments have been suggested but have not given entire satisfaction. The tar-paper disks are not entirely effective as protectors, and to apply them carefully requires time, but they give the best results of any control method thus far discovered.

Recently, one ounce of corrosive sublimate dissolved in 10 gal. of water, poured around the bases of the plants, has given quite good results.

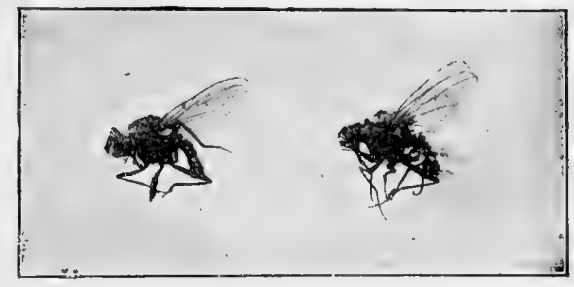

FIG. 350.-Adults of the Onion Maggot (Hylemyia antiqua Meig.), twice natural size. (From Britton, Eleventh Rept. Ent. Conn. Agr. Exp. Sta. 1911.)

The Onion Maggot (Hylemyia antiqua Meig.) is often a serious pest, mining in the bulbs and quickly causing their decay. Like the Cabbage Maggot, it is a European insect but has been known in the United States for many years and is now widely distributed. Details of its life history are not as well known as could be desired, but it is probable that the insects pass the winter as pupæ and perhaps as adults also. The flies (Fig. 350) lay their eggs on the onions soon after they come up in the spring, and these hatch in a few days forming whitish maggots which attack the buliss and feed during a period varying according to weather conditions for from 2 to 4 or 5 weeks, after which they pupate in the ground, or, occasionally, in the outer layers of the onion itself. During the summer, this stage continues about 2 weeks, after which the adult flies appear and in about 10 days begin to lay eggs for a second generation.

In some parts of their range there are probably only two generations a year, but elsewhere there seem to be three. The injury caused by this insect when abundant is sometimes large, entire fields con- 
sisting of many acres having nearly every onion affected. It varies greatly in importance in different years, however, there being in some seasons practically no maggots.

Control.-The adult flies feed freely both before and during the egg-laying period. Making use of this fact, a poisoned bait spray issued, consisting of $1 / 4 \mathrm{oz}$. of white arsenic or sodium arsenate dissolved in 1 gal. of boiling water to which is then added from $1 / 2$ to 1 pint of strongsmelling molasses. This is sprayed in coarse drops in strips across the field, it not being necessary to cover the entire area in this way. Repeat twice a week from the time the onions show until the middle of June. This treatment has given good results but the cost of the labor involved in so many applications is considerable.

Other members of this family are frequently injurious, and, among these, the Seed-corn Maggot, often attacking peas and beans also, the Beet and Spinach Leaf-miner and the Radish Maggot may be mentioned. Methods of control for these insects are at present far from being as satisfactory as could be desired. The Lesser House-fly and several other small, house-inhabiting flies which belong here are also of some importance as probably being disease carriers.

There are several families of extremely modified aberrant forms which are generally classed together as a suborder of the Diptera called the Pupipara. Some of these insects are winged while others are wingless when adult. The majority of them suck the blood of birds or mammals though one species not thus far reported from America is found on the body of the honey bee. Swallows appear to be favorite hosts for some of these insects and bats for others, while the most familiar insect belonging here lives on the sheep and is commonly called the Sheep Tick. A number of others of the group are also wrongly called ticks, probably because of their color which is similar to that of some common ticks, their leathery external skin, and the places where they are found. True ticks have eight legs, however, and never have wings, while six legs only are present in the Pupipara as with the other insects.

The Sheep Tick (Melophagus ovinus L.).-This pest of sheep is a wingless, brown insect about a quarter of an inch long. It occurs in most of the countries where sheep are raised and is present practically wherever sheep are found in the United States, though most abundant in the West in the large flocks. The adult lives in the fleece of the host except when feeding, at which time it moves to the surface of the skin of the animal, punctures it and sucks the blood and lymph causing irritation which, when many of the insects are present, makes the sheep restless, preventing their feeding considerably, and resulting in their failure to grow and fatten as they should.

The adult (Fig. 351) does not deposit eggs, these being retained within the body of the parent until they have hatched into larvæ (Fig. 352) and 


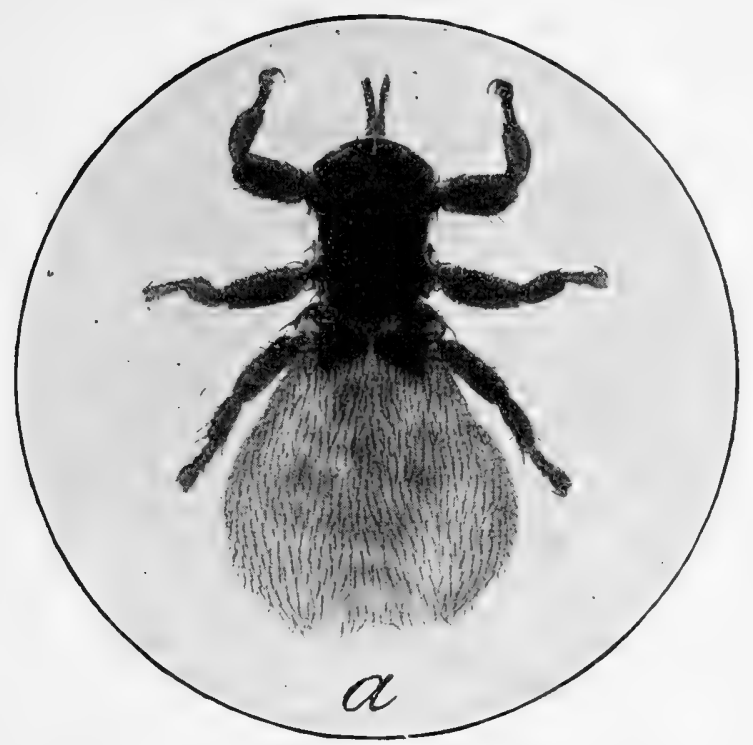

FIG. 351.-Adult engorged female Sheep Tick (Melophagus ovinus L.), greatly enlarged. (From Marion Ines, Bur. An. Ind., U. S. D. A. Farm. Bull. 798.)

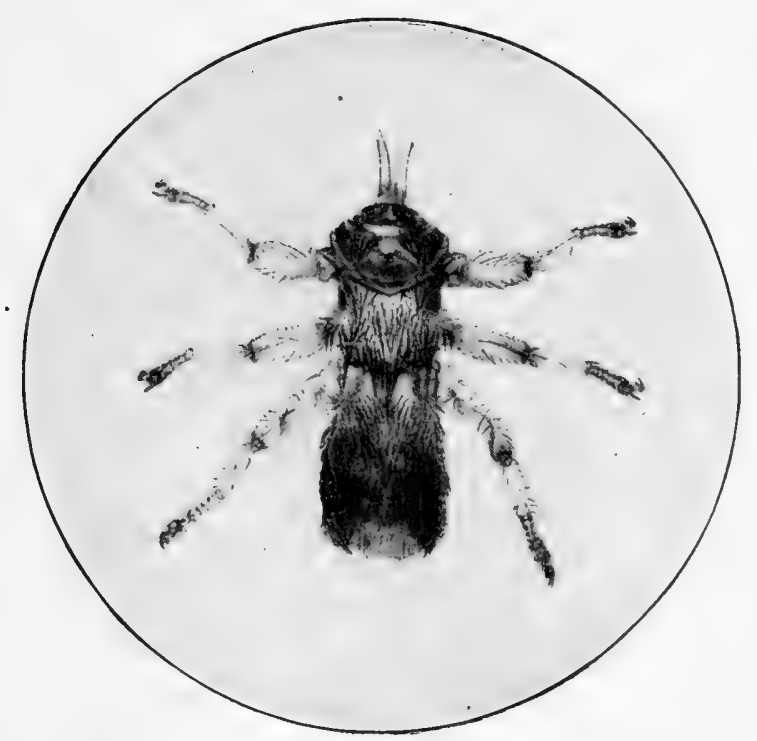

FIG. 352:-Young Sheep Tick just after emerging from its puparium. Greatly enlarged. (From Marion Imes, Bur. An. Ind., U. S. D. A. Farm. Bull. 798.) 
during this period being nourished by the secretions from glands in the body of the parent. When the development of the larva has been nearly completed, it leaves the parent and is then covered by a soft, white membrane which, after some hours, turns brown and hard and becomes a puparium within which the animal pupates for a period of from 19 to 24 days after which the adult emerges. After about 10 to 14 days more, their first pupæ appear. A pupa is produced by a female every 7 or 8 days, 12 to 15 being about the usual number in all per individual.

Control.-The most widespread method for controlling these insects is by dipping the sheep in some material which will kill the ticks. Some of the dips used for this purpose are coal-tar-creosote, cresol, nicotine and lime-sulfur-arsenic. Selection of the best dip for the purpose must be determined by the availability of soft water, ease of obtaining the materials and other local factors. In general, two dippings are necessary and, if this is done during the early fall, these should be 24 days apart. Where shearing is done in the spring, the dipping should be in July and August unless the lambs become thickly infested soon after shearing, in which case dipping should be as soon as the shear cuts heal. Many details connected with dipping make it necessary to become thoroughly acquainted with the process before treatment is actually attempted, if the best results are desired. 


\section{CHAPTER XXXII}

\section{THE SIPHONAPTERA}

The Siphonaptera or Fleas are curious, small insects ranging from about a twentieth to a sixth of an inch long. They are evidently related to the flies in many ways but are much modified. Most of the members of the group have their bodies laterally compressed so that they are narrow (Fig. 353). The head is not sharply separated from the body and the antennæ are short and stout. The mouth parts are for piercing and sucking, and modified in a different way from those of other insects which feed in this manner. While the identity of the various parts has

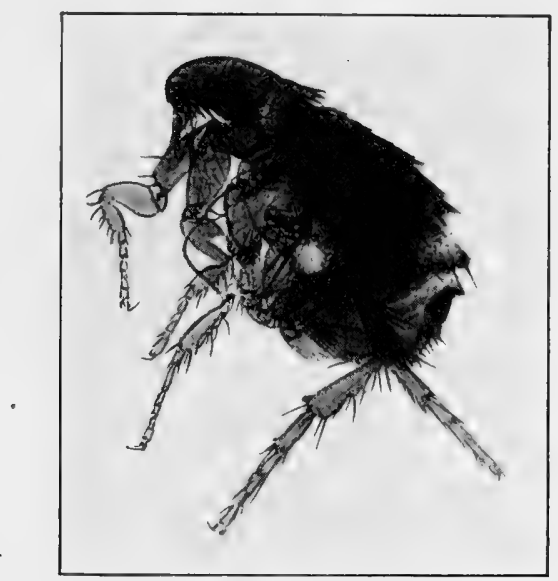

FIG. 353.-Adult Cat and Dog Flea (Ctenocephalus canis Curtis), greatly enlarged. (Original.)

not been conclusively proven, it seems probable that a long median pricking structure is the labrum or else the hypopharynx; a pair of similar structures are the mandibles; a pair of rather short, stout structures at the sides, each with a palpus, are the maxillæ, and that the labium is represented by a rather stout basal portion bearing two long segmented pieces, perhaps the palpi, so shaped as together to form a loose sheath for the piercing parts. Compound eyes appear to be absent.

Backward-projecting spines occur on the body, largely at least, preventing backward movements between the hairs on the body of the 
host animal. Rows of stout spines may be present on the head just above the mouth or on the pronotum or in both places. These are called tænidia and are useful in identifying the species. The legs are long and powerful. Wings are absent but flat scales present or the mesoand metathorax are generally regarded as their rudiments. The larvæ are worm-like, with chewing mouth parts and pupate within a cocoon.

The characters distinguishing these insects are:

Insects which as adults have their bodies strongly compressed sideways; are without wings and compound eyes but have legs. Mouth parts for piercing and sucking. Larve worm-like. Metamorphosis complete.

Adult fleas feed entirely upon the blood of mammals and birds, but while each species has what may be termed its preferred host, there seems to be some latitude in this, and other animals may also be attacked.

The eggs are laid loosely among the hairs of the host and drop to the ground where they hatch. The larvæ which are slender, whitish, and rather worm-like, with chewing mouth parts, feed on decaying vegetable and animal matter for a period varying from a few days to several months. When feeding is completed, the larva spins a silken cocoon in which it pupates. Here it may remain only a few days or for a time which may be more than a year, according to circumstances, before emerging as the adult. The adults in hot weather and with no food will live only a few days but when food is available they may live a month or even nearly a year. Winter in the North is usually spent in one or another of the early stages, but in the South the adults may be present on their hosts at any time.

Hot, dry weather is not favorable to the rapid breeding of these insects but, in damp, rainy weather, they increase rapidly, particularly in sandy localities as the moisture there is more uniform where the early stages live, though too much moisture is injurious to them.

Fleas are mainly household pests, coming in on cats and dogs, the cat flea being the most common generally, though in the West and South the human flea is also abundant. The eggs dropped by the fleas fall to the floors and the larvæ feed on any material found under rugs and mattings, in floor cracks and similar places, and, on reaching maturity, attack the first animal they can reach.

Various animals besides those already mentioned serve as hosts. Among them are hogs, poultry and other birds. Horses, cattle and sheep are not often attacked.

Fleas have become of importance to man aside from their attacks on his person with the discovery that they may carry the germs of the bubonic plague. This much dreaded disease with its high mortality caused by Bacillus pestis occurs in rats' blood, and by feeding on this the flea brings the germs into its own body. When a flea attacks a person, it often ejects partly digested blood and also feces near the 
"bite" and if, while the wound is still open, this place is rubbed or scratched the germs are liable to thus be introduced into the blood of the person. Their absence from the mouth parts and the saliva of the flea so far as observations have yet gone indicates therefore that inoculation with the germs from fleas is accidental, but as most persons generally scratch a flea bite, it is at least frequent enough to produce many cases of the disease. In California, the disease has also been found in ground squirrels and in one species at least of squirrel flea so that these fleas are also a menace to man.

Control of Fleas.-In houses, flea control must be both by destroying the adults and also the early stages. On small animals which are infested, a thorough washing with a soap coal-tar creosote material used as a "stock dip" of which a number of kinds are for sale gives satisfactory results if the animal is thoroughly scrubbed and particular care given to see that the head-to which the insects collect when the animal is put into the wash-shall receive particular attention. Keep the animal in the wash for five to ten minutes. If it has a tender skin, this treatment may be followed by washing in warm water with soap.

Other ways for treating infested animals are by rubbing powdered naphthaline into the hair, or by dusting thoroughly with Pyrethrum. Give these treatments over paper on which the stupified fleas fall so that they may be gathered and burned. Animals which are attacked by fleas should not be allowed under houses as is so often the case in the South when no cellars are present and the house is placed on low posts. In such cases, these places are excellent locations for fleas to breed and when adult enter the houses.

To destroy the early stages successfully, the food of the larvæ should be kept in mind and all such material be removed. Thorough cleaning, removing all dust, much of which is flea food; soaking cracks, where it might gather, with kerosene; airing and beating rugs, carpets, straw mattings and, in fact, all floor coverings, are important control measures.

There are other ways in which fleas may be controlled. One is to sprinkle $5 \mathrm{lb}$. of flake naphthaline over the floor of an infested room and close tightly for $24 \mathrm{hr}$.; then open and sweep it into any other room needing treatment and manage in the same way. Several rooms can be treated with the same material. Fumigation with sulfur, using $4 \mathrm{lb}$. to each 1,000 cu. ft. of space if the young are present and 2 to $3 \mathrm{lb}$. if only adult fleas are involved, the fumigation to continue $12 \mathrm{hr}$., is also a successful control. Cellars infested should be thoroughly cleaned and whitewash used freely.

Flea "bites" if troublesome may be relieved by the use of carbolated vaseline, camphor, or a 3 per cent solution of carbolic acid in water. 
One of the fleas commonly called the "sticktight" flea (Echidnophaga gallinacea Westw.) is a rather important pest of fowls in the South and Southwest, causing trouble as far north as Kansas. These fleas gather chiefly on the heads of the birds where they are noticeable around the eyes and on the wattles and comb, but may occur elsewhere on the animal. Chickens are often killed by these fleas but older fowls are more resistant. This flea differs from most other species by remaining most of its life on the fowl, whence its common name.

Where the infestation is severe, the use of carbolated vaseline, or a mixture of lard 2 parts and kerosene 1 part, carefully applied only to the places where the fleas are on the fowl; the destruction of rats which also harbor this pest, and a thorough cleaning of the poultry houses are desirable. Salt on the soil where the fleas are breeding, followed by a liberal application of water by sprinkling, this last repeated two or three times a week, will destroy the young, but no salt should be left for the poultry to feed upon.

One species of flea differs somewhat in its habits from most of these insects. It is known as the Chigoe or Jigger flea (Tunga penetrans L.) and occurs in the tropical and subtropical portions of America and also in Africa and India. It should not be confused with a tiny mite (Class Arachnida) which has somewhat similar habits and is found as far north as Massachusetts and Lake Erie, which is abundant on bushes, and which on man burrows into the skin causing considerable irritation.

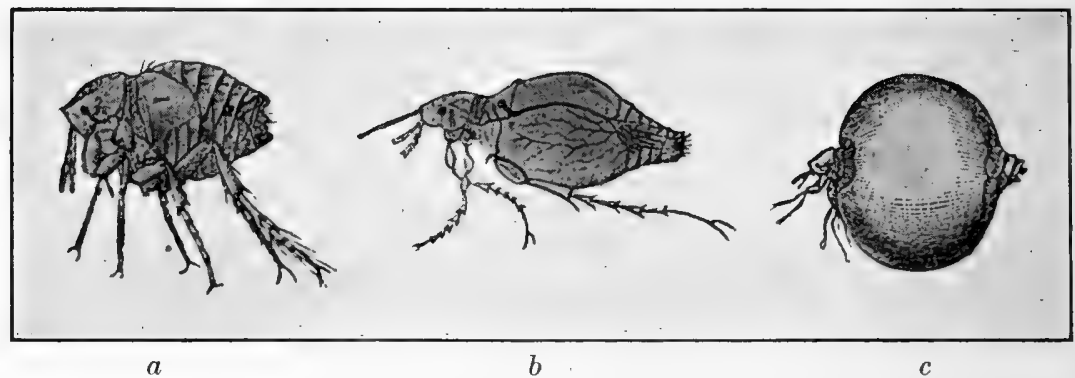

FIG. 354,-Chigoe (Tunga penetrans L.) : $a$, an Unfertilized female; $b$, onefertilized, which has penetrated the skin and is beginning to enlarge; $c$, one enormously enlarged by the development of eggs. All enlarged. (From Berlese.)

The Chigoe is found on domestic animals, birds and man. The female (Fig. 354a) is at first about a twenty-fifth of an inch long but its abdomen may later become as large as a small pea. The adults move about but when the female has been fertilized it burrows into the skin of the host and its body begins to enlarge (Fig. $354 b$ and $c$ ) by the development of eggs, causing a painful wound like an ulcer. The eggs are expelled into this ulcer or may fall to the ground but, in either case, hatch in a few days, and those in the wound then work out and drop to the ground.

The regions usually attacked in persons are the bare feet, though no part of the body is entirely free from the danger of being attacked. Pus 
is produced in the wounds and when many of the fleas are present the ulcers may run together and cause serious results. Protection from these pests is best obtained by keeping the floors clean, using naphthaline as recommended above; cleaning floors and walls with kerosene; and wearing shoes or other foot coverings to keep the insects from reaching the skin. When the fleas are already burrowing they may be removed by the use of a needle which has been sterilized by passing it through a flame, followed by a dressing of the wound. A drop of turpentine at each spot attacked will kill the fleas and, if ulceration has not gone too far, the wound will generally ulcerate enough more to expel the animal and then gradually heal.

Fleas occur in nearly all parts of the world, and, though less than 500 kinds are known, their habits and their relation to disease make them an important group of insects. 


\section{CHAPTER XXXIII}

\section{THE HYMENOPTERA}

The insects which belong in this large order have no general common name, but many of them are well known as bees, ants and wasps. The larger portion of the group, however, consists of small insects seldom noticed except by those looking for them.

Most Hymenoptera have wings when adult. These are four in number, membranous, and the front pair is the larger. They have rather few cross veins as a rule, and in some cases nearly all the veins are missing. The two wings on the same side of the body are united by a row of hooks along the middle part of the costa of the hind wing, which catch in a fold of the membrane on the hinder margin of the wing in front, the two wings in this way acting together and much as though they were one. The structures uniting them are called the frenal hooks or hamuli, and the frenal fold.

The body in insects of his order may be quite large and stout, as in the bumblebees; or long, beiıg two or more inches in length in some tropical wasps, but most of them are much smaller insects and in some the body may be only about a fiftieth of an inch long and the entire animal almost microscopic in size. The first abdominal segment is very closely and firmly joined to the thorax, to which it apparently belongs. In a few families the front end of the second abdominal segment is as large as the rest of this portion, and the connection between the first and second segments is full-sized, but in most of the groups the front end of the second segment is constricted to form a small, stalk, pedicel, or petiole which connects the rest of the abdomen with the first segment. This condition is a deceptive one, leading to the idea that the constriction is, as is true of most other insects, between the thorax and abdomen rather than between the first and second segments of the latter. The first segment, closely joined to the thorax is called the propodeum or median segment. The petiole in nearly all cases joins the propodeum close to the lower side of the body.

Over the base of each fore wing except in the ants, is a small, arched scale called a tegula, which roofs over the place where this wing articulates with the body.

In the female Hymenoptera an ovipositor, used either for making holes in which to deposit eggs, or modified to become a weapon, is almost always present. When developed for its original purpose as an organ 
connected with egg-laying, it may have projections along its lower edge and be used like a saw to cut slits in leaves or other structures in which to insert the eggs. In other cases it becomes a sort of boring organ used in making holes in leaves, stems, wood, or animals, in which the eggs are placed. Sometimes the ovipositor is very prominent and is not retractile, while in other species it can be drawn entirely within the body. In a large section of the order, however, regarded as containing the more highly developed members of the group, deposition of the eggs is not within objects but on surfaces, and a hole being no longer needed, the ovipositor has become modified in most cases, glands connected with it produce a more or less poisonous fluid (possibly it is more or less poisonous in the lower forms also) and the sting is thus produced, a structure no longer needed for its original purpose having been transformed into a weapon for defense. In the ants, however, various degrees of reduction of this structure occur, some ants having no stinging power whatever while a few are quite effective in this way. From these facts the reason why drone bees and the males of the other Hymenoptera are harmless, is evident.

The two sections of the order thus distinguished, are ealled the Terebrantia or boring, and the Aculeata or stinging Hymenoptera. Another distinction also separating these divisions may be seen by an examination. of the mouth parts. In the $\mathrm{T}$ rebrantia these are quite typical chewing organs, but in the Aculeat the maxillæ and labium have been modified to form organs for sucsing and lapping up fluids, though the amount of this modification differs in different families. A third distinguishing feature is that in the Terebrantia the hind leg has two trochanters while in nearly all the Aculeata there is only one.

Development in this order is by a complete metamorphosis. The larvæ differ much in appearance in the various families, some feeding on leaves and greatly resembling caterpillars. Others are borers in wood and are modified to adapt them to life under such conditions. Still others, particularly those which are parasitic within the bodies of other insects, may be so changed as to make it seem almost impossible that they can be insect larvæ. Many of those living on food provided for them during this stage of their existence greatly resemble and are sometimes called maggots. At pupation a marked change in appearance takes place, antennæ, legs, wing stubs and body characters nearly like those of the adults now showing, and the legs and antennæ project, encased by sheaths of the pupa skin, the pupa in this order being a pupa libera as already described for some beetles (see page 99, and Fig. 30).

The characters by which Hymenoptera may be recognized are:

Insects which when adult have in most cases, four membranous wings with few or even no cross veins, the hinder pair the smaller. Mouth parts for chewing, or for chewing and also for sucking. The females have in nearly all cases either an ovipositor or a sting. The metamorphosis is complete. 
The Hymenoptera are important from an economic standpoint. A rather small number are injurious, destroying crops of various kinds but the majority are either directly or indirectly beneficial, as parasites of destructive insects, or by aiding in the fertilization of flowers, and in the case of the honey bees by the value to man of their products.

There is a great diversity of structure in the order, which has led to the establishment of many families which fall into about 10 larger divisions, generally called Superfamilies, and these may serve as the basis for more detailed consideration.

Superfamily Tenthredinoidea (The Saw-flies and Stem Borers).This group is one of the divisions of the Terebrantia as already described, its members having no constriction of the abdomen. Most of the families belonging here are leaf-feeders and their eggs are usually laid in slits in the leaves sawed by the ovipositors of the adult females. Some families, however, have the ovipositor constructed for boring and they make holes, either in herbaceous or woody stems, in which to deposit their eggs.

The plant-feeders are spoken of in a general way as saw-flies and all are injurious to the plants they live on, though of course many of these

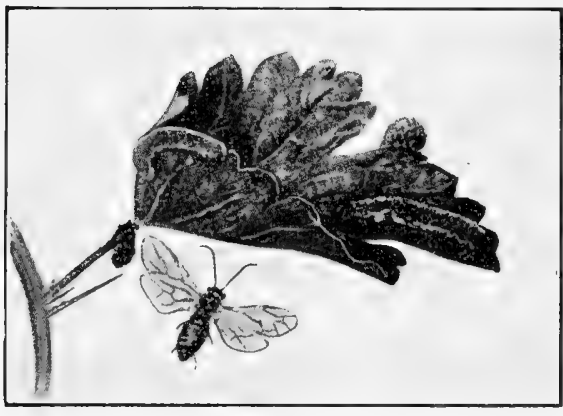

FIG. 355.-Currant Worm (Ptcronidea ribesii Școp.), adult and larvæ, about natural size. (From Minn. Agr. Exp. Sta. Bull. 84.) are of little or no importance to man, but a few injure various crop-producing plants.

The Currant Worm (Pteronidea ribesii Scop.).-This common injurious saw-fly is a native of Europe but has been in this country for many years and is widely distributed. It feeds on the leaves of wild and cultivated currants and to some-extent, on those of gooseberries also, and when abundant the plants are quickly and thoroughly stripped of their foliage soon after it develops, which checks or almost entirely prevents the production of the fruit.

The adult saw-fly (Fig. 355) is about a third of an inch long, with a pale or reddish-yellow, rather stout body with blackish spots. It passes the winter in the ground within an oval cocoon, rather papery in texture and brown in color. In spring, about when the currant leaves become partly developed, the adults begin to emerge from their cocoons and the females lay their eggs in rows on the leaves, generally along the veins on the underside. The larvæ, at first very small and whitish, feed and grow rapidly, and when full-grown are nearly three quarters of an inch long, greenish in color and shaded with yellowish at both ends. During the 
intermediate larval instars the green color of the body is modified by the presence of many black spots. After feeding from 2 to 3 weeks the larvæ crawl down to the ground and pupate, the cocoons resembling those already described. Adults from these pupæ appear in late June or July and lay eggs for a second generation, and in some cases a few of the insects have a third generation before winter. The second and third generations (when present) do not attract much attention generaliy, as interest in the currants in most cases ceases for the season with the gathering of the crop.

Control.--Spray the currants as soon as the leaves have developed or as soon as the "worms" appear, with arsenate of lead, standard formula or a little weaker. If treatment is necessary after the fruit has begun to turn red, dust fresh hellebore over the plants, using $1 \mathrm{lb}$. of hellebore thoroughly mixed with about $5 \mathrm{lb}$. of air-slaked lime or flour. The great difficulty in controlling these pests is that the adults appear and lay their eggs during a rather long period and it is often necessary to spray for those larvæ which appear early, before all the leaves are fully developed. Accordingly, those leaves which come out after the spray has been applied are not protected and larvæ appearing afterwards can feed on them without being poisoned, and a second spray is often needed on this account.

The Pear Slug (Ialiroa cerasi,$L$ ). -This insect feedson the leaves of the pear, plum and cherry, and though a native of Europe is now found almost everywhere in this country (Fig. 356).

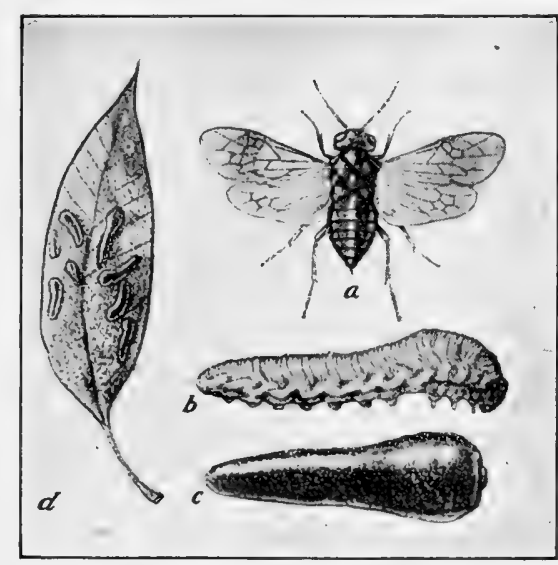

FIG. 356.-Pear Slug (Caliroa cerasi $L$.): $a$, adult; $b$, larva with slime removed; $c$, larva from above, coveredby its slime; $d$, leaf showing work of the insect and with larvæ present: $a, b$ and $c$ much enlarged; $d$, somewhat reduced. (From Berlese, modified from. U. S. D. A. Div. Ent. Circ. 26.)

The adult is a saw-fly about a fifth of an inch long, with a black body. It appears after the leaves develop in spring and lays its eggs in slits sawed in the leaves, forming a sort of blister at each place. The larvæ soon produce a darkbrown glossy slime which covers them and conceals their true outline, making them somerwhat similar to soft snails in appearance. They feed on the leaf tissue, skeletonizing it, and molt four times. After the fourth molt the slime disappears and the larva is orange-yellow and does not feed. It now passes to the ground in which it pupates. A second generation follows, but a few of the pupæ remain unchanged in the ground until the following spring. In the South there are three generations, at least in some cases. 
Control.-Spraying with arsenate of lead, standard formula; Nicotine sulfate 40 per cent, 1 pt. in 100 gal. of water, with 3 or $4 \mathrm{lb}$. of soap; $1 \mathrm{oz}$. of white hellebore in 3 gal. of water; or dusting with freshly slaked lime, are effective treatments for this insect, but it is not very often abundant enough to call for the use of control measures.

A similar saw-fly of ten attacks the rose, feeding on the leaves, its dark-colored and slimy, though small, larvæ being very noticeable when abundant. When treatment is necessary the methods given for the pear slug are equally effective with this insect.

A few of the stem and wood borers in this superfamily are of considerable importance, but most of them are seldom noticed. The Wheat-stem borer (Cephus pygmaus L.) in the East and the Western grass-stem borer (Cephus cinctus Nort.) in the West often attack growing wheat. The adult (Fig. 357)

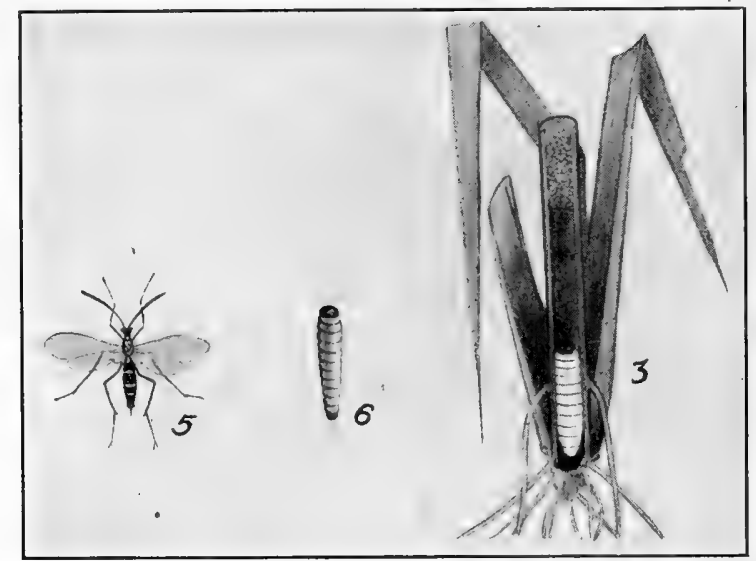

FIG. 357.-Western Grass-stem Borer (Cephus cinctus Nort.): 3, base of wheat plant showing larva in winter position; 5 , adult Saw-fly; 6 , full-grown larva. All natural size. (Modified from Can. Dept. Agr. Ent. Branch, Bull. 11.)

punctures the wheat stem in the spring and deposits an egg inside the stalk and the larva which soon hatches, tunnels in the stem and as the grain ripens, works its way downward, and by harvesting time most of them have reached the roots. They then prepare for winter, cutting the stalk partly off, generally less than an inch above the surface of the ground. Each now plugs the cavity of the stem below this point for a short distance, leaving about half an inch of space between the plug and the lower end of the cavity, in which it spins a cocoon. The larva winters thus, pupates in March or April in New York at least, and the adult appears in May. The life history of the western species is much the same.

Where grass-seed is not planted with the wheat, plowing the stubble under, deeply, at any time between harvest and the following May, or burning the stubble when this is possible, are two fairly efficient methods of control. Where it is desired to lay down a field to grass and the insect is abundant it would be better where practicable to use oats rather than wheat with the grass-seed. 
One of the stem borers attacks currant stems. The adult girdles the stem after laying its egg, and the larva feeds below the girdled place, which shows plainly, the part above wilting or breaking over. Cutting off such stems as soon as they are seen, eight or ten inches below the girdled place, will control this insect.

Most of the borers of this superfamily which tunnel in wood are generally called Horn-tails, the straight, stiff ovipositor somewhat suggesting a horn. Various trees, both deciduous and evergreen, are attacked by different species, and the circular exit holes of the borers after they have become adult permit the entrance of moisture and the spores of fungi, thus providing starting places for decay. Healthy, vigorous trees are seldom attacked, but the death of others is hastened by these insects. One species known as the Pigeon Tremex (Tremex columba L.) bores in the maple, apple, pear, elm, beech, oak and sycamore. It varies from three-quarters of an inch to twice as much in length (Fig. 358) and its body is cylindrical and nearly as large as a lead pencil. Its color varies from nearly black with yellow spots on the abdomen to yellow with some black marks. This insect is often noticed on the tree trunks during the summer months. The larva tunnels its course through the wood, going

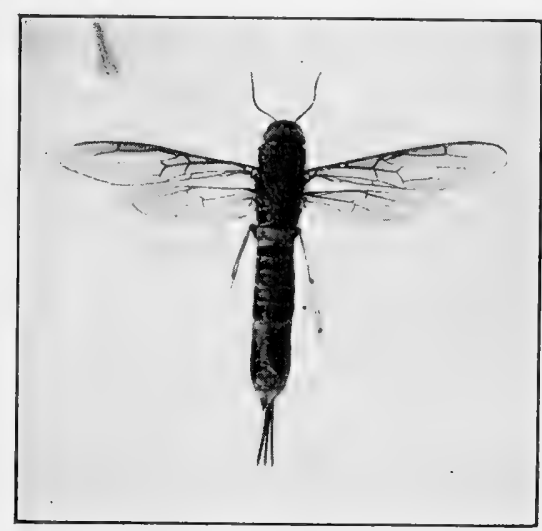

Fig. 358.-Pigeon Tremex (Tremex columba L.), somewhat reduced. (Original.) sometimes several inches into the tree, but as the end of its feeding period approaches, turns outward and makes a hole to the outside, leaving only a thin piece of bark to close the opening. It then goes back into the hole a short distance to pupate and the adult on emergence gnaws away the piece of bark and escapes from the tree. An interesting and remarkable looking parasite of this insect will be considered later in the chapter.

Superfamily Ichneumonoidea (The Ichneumon Flies).- In this very large and important group the insects have the abdomen constricted as already described, between the propodeum and the second abdominal segment. In one family (the Evaniidæ or Ensign flies) of rather small insects (Fig. 359) the petiole of the second segment does not join the propedeum near the lower side of the body but near the upper surface, giving these insects a very peculiar appearance.

The Ichneumon flies (Fig. 360) are all parasites, attacking Lepidoptera, Coleoptera, Diptera, and some Homoptera, Orthoptera and Hymen- 
optera, and also Spiders in their early stages, at least in most cases, and a few are injurious as they are parasites of beneficial forms. Thus among the Coleoptera parasitized are some of the Lady beetles. In other cases it is the parasites themselves which are parasitized. In this last case the destruction of a beneficial parasite by another makes the latter an injurious insect. There are also some which appear to attack the parasites of the parasites, which places these last as beneficial in their turn. Primary parasites attack non-parasitic forms; secondary or hyperparasites attack primary ones; tertiary parasites attack the secondary ones, etc.

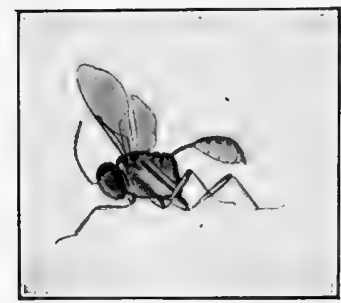

FIG. 359 .

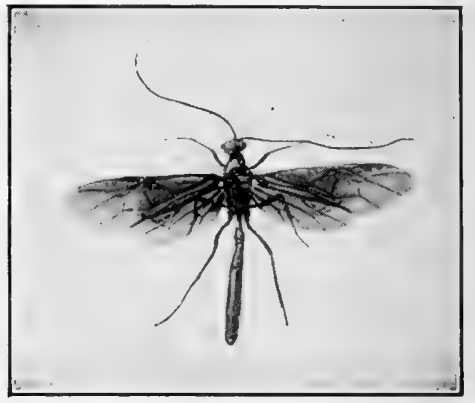

FIG. 360 .

Fig. 359.-An Evaniid (Brachygaster minutus Oliv.), about five times natural size. (Modified from Kieffer.)

FIG. 360.-Example of an Ichneumon Fly (Ophion), natural size. (Original.)

The importance of the Ichneumon flies as parasites is very great as they are abundant and destroy enormous numbers of injurious forms each year. One group devotes its attention to plant lice, puncturing the bodies of these insects and laying an egg in each puncture. The tissues of the plant louse are fed upon by the parasite and the body of the host gradually becomes brown, swollen and rather globular, and it dies, holding on to the place where it was feeding at the time of its death. After pupation within the body of the host, the adult parasite cuts a circular opening in the surface of its host and escapes, and plant lice bodies, swollen, brown, and with a hole in each are abundant when these insects occur in large numbers. As each parasite obtains all the food necessary for its entire development from the body of a single louse, these insects are naturally extremely small (See Figs. 199 and 200).

Another Ichneumon fly which is often noticed has a body an inch and a half or more long and an ovipositor often over three inches and which has been recorded in a few cases as nearly six inches in length. There are two kinds of about this size, one with a black body and a few yellow spots, the other brown with yellow markings, while other and smaller species also occur. These insects attack the Horn-tails already described and 
may often be seen during the summer on trees in which Horn-tail larvæ are present. These Ichneumon flies are calied the "Long-tailed Thalessas." The female Thalessa (Fig. 361) crawls about over the trunk of a tree which in some way she discovers is infested by Horn-tails, until a satisfactory place is found, when she settles at that point and begins to force her ovipositor into the bark and wood. The length of the ovipositor

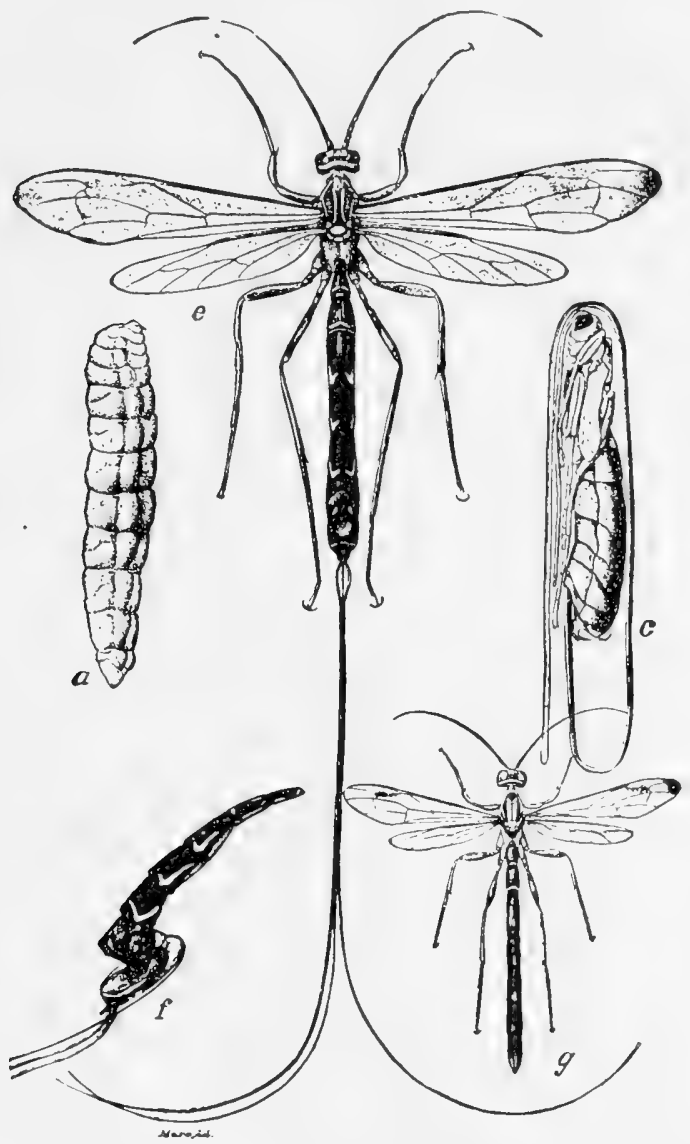

Fig. 361.-Long-tailed Thalessa (Megarhyssa lunator Fab.): $a$, larva; $c$, pupa; $e$, adult. female; $f$, side view of abdomen of adult female, showing attachment of ovipositor; $g$, adult male. About natural size. (Modified from Felt, N. Y. State Mus. Mem. 8; after Riley.)

is suggestive of the distance it must be pushed in, in some cases, to reach the tunnel of the Horn-tail larva, and it seems almost impossible for such a slender structure to be forced so far through hard wood. When the tunnel of the Horn-tail is reached, the Thalessa lays an egg in it and then draws its ovipositor out of the tree. Sometimes this process results in the death of the Thalessa, the ovipositor becoming so firmly fixed 
in the wood either on its way in, or during the withdrawal, that it cannot be removed and the Thalessa dies.

The egg left in the tunnel of the Horn-tail soon hatches and the larva travels along the burrow until it finds the borer, to which it attaches itself, and feeds upon its juices. It is probable that death of the Horntail is not permitted as a result of this feeding, before the host has prepared an outlet to the surface of the trunk for its escape, as it does not seem likely that the adult Thalessa could tunnel its way out successfully.

Superfamily Cynipoidea (The Gall Insects).-This group of small insects (Fig. 362) includes species having very diversified habits, but the majority of them pass their early stages within abnormal growths on plants, called galls, which develop in connection

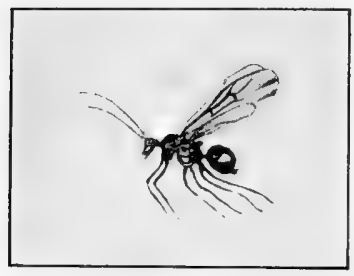

Fig. 362.-Example of a Gall insect (Trigonaspis megaptera Panz.), about twice natural size. (Reduced from Henneguy.) with their presence. Some insects other than those of this group also produce galls, particularly many of the dipterous family Itonididæ, but the greater number of the more noticeable galls are produced by Cynipids.

The cause of the production of the gall has been much discussed, some investigators claiming that at the time the female insect punctures the plant for egg-laying she also injects a little poison into the wound which stimulates the plant cells of that region to grow in an abnormal manner. But the general belief now seems to be that the larva when it hatches gives the stimulus for this abnormal growth, either by its presence as a moving body, by its gnawing, or by its pouring out of irritating fluids.

The gall includes either one larva or many, according to the species concerned. It stops its growth about the time the larva finishes feeding, and dries, forming a protective covering within which the insect pupates and escapes subsequently by gnawing its way out.

In some species such an adult will attack a totally different kind of plant from the one it itself fed upon and the gall produced will be entirely different from the other. Adults from such galls will deposit their eggs in plants of the first kind, however, giving us a series of generations in which two different kinds of plants alternate in supplying food. This may be complicated by one generation consisting only of females, the other evidently being derived by agamic reproduction (parthenogenesis).

Galls may occur on roots, stems, twigs or leaves, and the type of gall produced is always the same on any one kind of plant, for the same species (Fig. 363), so that a student of the subject can tell from the gall alone, the species which produced it, in nearly every case: one found on oak leaves is nearly an inch in diameter, globular, with a parchment-like covering, and is often called an "oak apple." Within the outer covering 
is a mass of radiating fibers and at the center a small cell in which the insect lives. Protuberances of various forms on the leaves of many kinds of plants are produced by different species of these insects.

Gall insects are often not alone in their habitations. Some members of the same superfamily as the gall-makers are frequently found in the galls, living as "guests," profiting by the work of the producers of the galls but not injuring them in any way. These are usually called inquilines and often greatly resemble their hosts. In addition to the inquilines, parasites not only of the host but also of the various kinds of inquilines may also be present, adding greatly to the population of the gall. Some of these may be of the same superfamily as their hosts. Kieffer lists 10 species of guests and 41 species of parasites which he obtained from a root gall on oak, besides the gall maker itself!

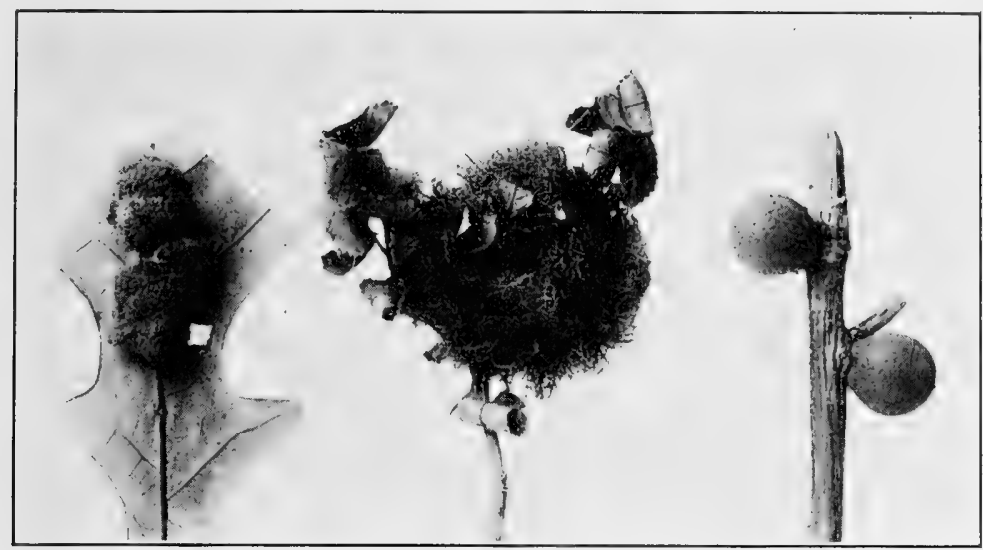

FIG. 363.-Various types of Galls, about natural size. (Original.)

Galls are not usually of any great economic importance, for though they may injure the appearance of a plant or tree for two or three seasons, and also check its growth somewhat, the abundance of parasites usually stops the work of the gall makers before serious injury has been accomplished.

Superfamily Chalcidoidea (The Chalcid Flies).-This is an extremely large group, containing thousands of kinds of insects, most of which are very small, and a few are only about a fiftieth of an inch long. Some of them live in galls, parasitic either on the gall maker or on inquilines: others are parasitic on various insects, parasitizing the egg, larva or nymph, pupa, or adult according to the species; and a few are plant feeders of more or less economic importance. The wings, except in some wingless species, have very few veins, the most prominent one running out from the body about half way to the tip, then bending forward to the costa, after which it bends back into the wing a short distance and ends. 
This is the only one in a great many cases, though a few other weaker veins are often present.

The plant feeders in this group produce small galls or at least swellings of the portion of the plant where they live, and one or two, by attacking crop plants, are of importance to man. A number of species of the genus Harmolita attack different kinds of small grains such as wheat, oats and barley, and at times do considerable injury.

The Wheat Straw-worm (Harmolita grande Riley).-This insect extends from New York to Colorado and from the Great Lakes to Virginia and Tennessee and is also present on the Pacific Coast, but has thus far been of little importance east of the Mississippi River. The adult is a tiny black insect somewhat resembling an ant, with red eyes, and legs banded with yellow. One generation has wings; the other is wingless.

The winter is spent in the pupa stage in the stubble of wheat fields and the adults emerge in April and May in the more northerly states; earlier in the South. These are the wingless forms and are very small. They lay their eggs in the wheat plants which at this time have grown only a short distance above ground, and the larva feeds in the short stem, usually producing a swelling there, and when full-grown it has worked its way to the crown of the plant where it entirely consumes the head, thus preventing the formation of any grain. By the last of May these larvæ have completed their feeding and pass through a brief pupal period, the adults-winged in this generation-emerging in early May in the South, and in June in the North. These individuals fly freely and spread to other fields. Eggs are now laid in this wheat, preferably well up toward the head where the joints are most tender and juicy. The larvæ from these eggs feed and reduce the yield of wheat by consuming nourishment which would otherwise go to the grain. Full growth has been obtained before the straw hardens, and pupation occurs during the fall. Whether the insects will be taken off in the straw or remain behind in the stubble depends on the degree of advancement of the plants, and the height above ground of the cutting.

Control.-Crop rotation, raising no wheat on the same land for 2 years in succession is a good treatment, as the wingless generation cannot migrate to other fields. Volunteer wheat in or near such fields should of course be destroyed if the rotation is to be most effective. Burning over, or plowing under of the stubble is also desirable, though less effective. Winter and spring wheat should never be grown near each other.

The Wheat Joint-worm (Harmolita tritici Fitch, Fig. 364).-This is a species closely related to the last, found throughout the East to the Mississippi River and south to about the same limits as the other species. Its life history differs from that of the Wheat Straw-worm in there being only one generation a year. Winter is passed as the larva in wheat straw or in the stems of various grasses, and the adults appear in May or June. Eggs are deposited as high up the wheat stems as the adult can find an uncovered stem. The larvæ have completed their feeding by harvest-time but do not pupate until the following spring. Apparently a rotation of crops, and care that waste lands, fence borders, etc., do not provide grass stems in which it can breed and winter are about our only methods for the 
control of this pest. The injury these two species of Harmolita do varies all the way from very little to an almost entire loss of the crop.

Where clover seed production is extensive, considerable injury to the crop is often caused by the Clover-seed Chalcid (Bruchophagus funebris How.). Red and

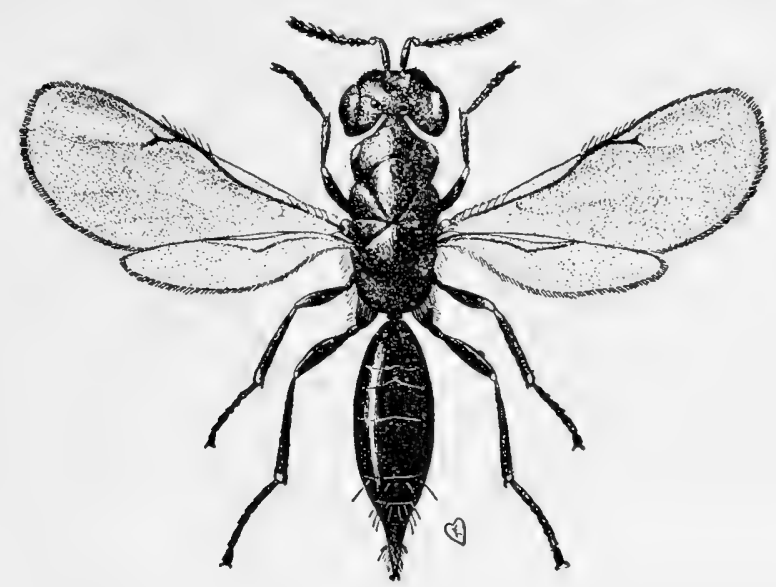

FIG. 364.-Adult female Wheat Joint-worm (Harmolita tritici Fitch), greatly enlarged. (From U. S. D. A. Farm. Bull. 1006.)

crimson clover, and alfalfa to some extent, are attacked by this tiny insect which feeds as a larva within the seed. Another species works in a somewhat similar way in apple seeds.

A Chalcid whose presence is essential in connection with the production of Smyrna figs, which is now becoming an important industry in some parts of this country, is of interest for that reason. This insect,

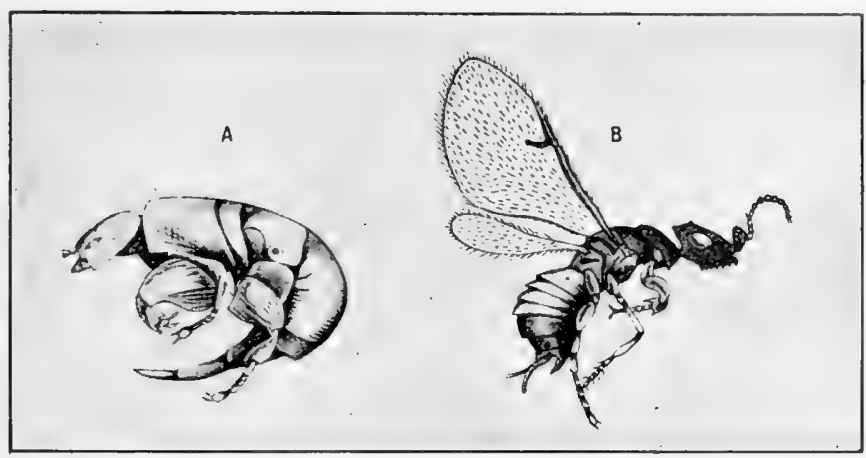

FIG. 365.-Fig fertilizer (Blastophaga grossorum Grav.). A, male, about fourteen times natural size; B, female, about ten times natural size. (Reduced from Henneguy.)

known as Blastophaga grossorum Grav. (Fig. 365), and its relation to fig production, are well described by Kellogg as follows:

"The male Blastophagas are grotesque, wingless, nearly eyeless creatures which never leave the fig in which they are bred, but the females are winged and 
fly freely about among the trees. A fig is a hollow, thick, and fleshy-walled receptacle in which are situated, thickly crowded over the inner surface, the minute flowers. The only entrance into the receptacle (or fig) is a tiny opening at the blunt free end of the young fig, and even this orifice is closely guarded by scales that nearly close it. The eggs are laid by the females at the base of the little flowers in certain figs. The hatching larvæ produce little galls in which they lie, feeding and developing. They pupate within the galls, and the wingless males when they issue do not leave the interior of the fig, but crawl about over the galls, puncturing those in which females lie, and thrusting the tip of the abdomen through the puncture and fertilizing the females. The fertilized winged female gnaws out of the galls, and leaves the fig through the small opening at the blunt free end. She flies among the trees seeking young figs, into which she crawls, and where she lays her eggs at the bases of as many flowers as possible. But it is only the wild, inedible, or 'caprifigs' that serve her purpose. The flowers of the cultivated Smyrna seem to offer no suitable egg-laying ground and in them no eggs are laid. But as the female walks anxiously about inside the fig, seeking for a suitable place, she dusts all the female flowers with pollen brought on her body from the male flowers of the caprifig from which she came, and thus fertilizes them. This process is called caprification. Without it no Smyrna fig has its flowers fertilized and its seeds 'set.' It is the development of the seeds with the accompanying swelling of the fleshy receptacle and the storing of sugar in it that makes the Smyrna fig so pleasant to the palate. The trees may grow large and bear quantities of fruit, but if the fig (really the figflowers) are not caprified, the size, sweetness, and nutty flavor of the perfect fruit are lacking. To insure caprification, branches laden with caprifigs containing Blastophagas just about to issue are suspended artifically among the branches of the Smyrna fig. Of course the female Blastophaga entering a Simyrna fig and dying there leaves no progeny, for she lays no eggs. It is therefore necessary to maintain a plantation of caprifigs in or near the Smyrna orchard. These bear three crops or generations of figs: one, the 'profichi,' ripening in the spring; another, the 'mammoni,' ripening in the late summer; and the third, or 'mammæ' generation, which hangs on the tree through the winter. By means of these successive generations of caprifigs a series of three generations (or sometimes four) of Blastophaga appear each year."

The great importance of the Superfamily Chalcidoidea to man does not rest either upon the importance of its destructive members or upon the Blastophaga, but on the enormous number of parasitic forms included in the group. These work in various ways as has already been indicated, but only one can be considered here. It is a parasite on various species of butterflies, particularly the Cabbage butterflies, and is known as Pteromalus puparum L., having no common name.

This insect (Fig. 366) is probably a native of Europe. It was noticed here about 1870 and is now present wherever its host insects occur and frequently destroys great numbers of them.

The adult has a green body about a tenth of an inch long. The female punctures the chrysalids of the host and lays her eggs within the 
body, in these punctures, and the larvæ which hatch from the eggs feed upon the chrysalis, finally killing it about the time they become fullgrown. They then leave the chrysalis and spin small, white cocoons, usually in a rather compact mass somewhere near what remains of their deserted host, emerging from these cocoons after a time, as adults which
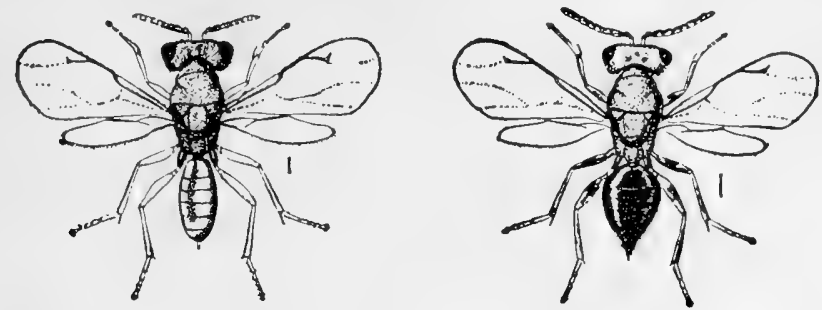

FIG. 366.-Pleromalus puparum I., a Chalcid parasite of the Cabbage Worm and other insects: male (left), and female (right). Hair lines show the nitural size. (1fter Chittenden, U.S.D.A.)

start another generation. It has been discovered that egg-laying in this species (and in many other parasites also) may continue during quite a long period provided the adult can obtain food, and this in many cases at least is accomplished by puncturing the body of the insect in which eggs are to be, or have just been laid, and feeding on its juices.

Superfamily Serphoidea.-This superfamily, long known as the Proctotrypoidea, contains a large number of insects, nearly all very

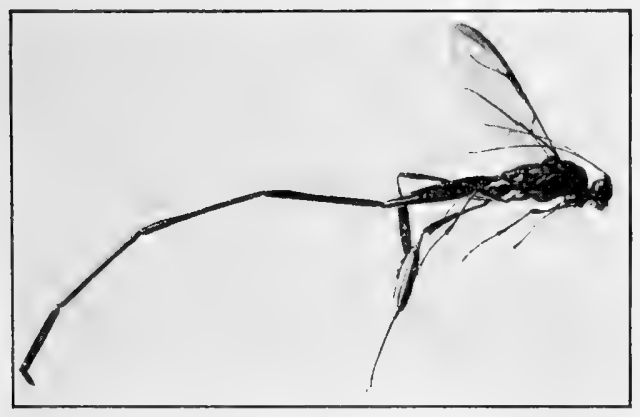

$a$

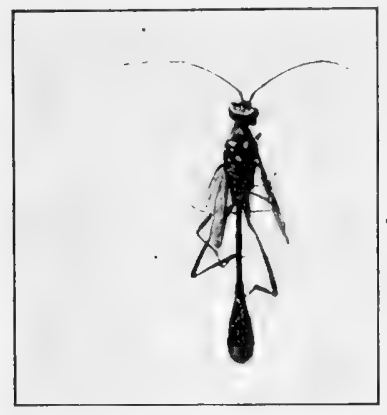

$b$

FIG. 367.-Pelecinus polyturator Dru.: $a$, female; $b$, male. Natural size. (Original.)

small, and most of them parasitic on other insects or on spiders. Parasitism of insect eggs seems to be very frequently the habit in the group. Some of the forms attacked by this group are Hemiptera, Diptera, Orthoptera, Lepidoptera, Neuroptera (Aphis lions) and Coleoptera, and some are found in ants' nests, parasitic on these insects. None of the members of the Superfamily is liable to attract the attention of those not entomologists, with one exception, an insect known as the Long-tailed Pelecinus (Pelecinus polyturator Drury), the female (Fig. 367a) of which has along, slender body often between two and three inches long, 
and glossy black in color. The extremely long abdomen of this insect which in flight is generally carried partly curled up beneath it, and its odd appearance also when at rest, sometimes cause it to be noticed and the remark made that it must be a dangerous animal. This is not the case, however, as the insect is harmless. It is a parasite on June bug larvæ which it evidently seems to hunt for in the ground and it is particularly abundant in sandy localities. The writer has seen over 80 of these insects resting on fences, walls and elsewhere in the course of a single early morning walk in the streets of Nantucket, the distance covered being not over four city blocks. The male (Fig. 367b) which is extremely rare or at least seldom seen, has a short, club-shaped abdomen and is about an inch long.

A general survey of the habits of the parasitic groups of the Hymenoptera reveals several diversities of life and habits worthy of being presented together. In the first place all stages of the host may be subject to parasitic attack. The egg seems to be selected in some cases and the pupa or the adult in others: larvæ however appear to be particularly liable to be parasitized. Where the egg stage is the one endangered, the parasite may consume its host before the latter can develop to the point where it is ready to hatch, thus preventing any injury whatever if the host be an injurious species. In other cases the host though parasitized is able to complete its embryonic development, hatch, and feed for a time as a larva before it concedes victory to the parasite feeding within it and dies. In the case of larvæ the parasitism may cause the death of the host before it becomes full-grown, or the latter may pupate, but progress no farther. Pupæ parasitized are destroyed before becoming adult and adults attacked may or may not be able to live until they reproduce.

These various relations of parasite and host have a bearing on the effectiveness of the parasite. In the majority of cases it is the next generation which is cut off, most of the injury normally caused by the host concerned being done before the parasite stops it, except in the case of the egg parasites which destroy the host before it hatches. Egg parasites of this kind therefore, are generally regarded as the most beneficial, though the great numbers of the other forms make their work very effective.

Sometimes one parasite only, feeds upon its host. In other cases there may be many, as with some of the Ichneumonoidea, where in one instance over 1,200 were bred from a single caterpillar. It would seem that the parent parasite is able to calculate the amount of food furnished by a host and deposit only a sufficient number of eggs to correspond with the food supply. The more probable explanation, however, is that 
parasites laying many eggs regularly attack only those species of insects large enough to provide for the progeny, while those which lay only one egg in or on a host require all the food provided there for the single parasite. No case is known where a parasite normally laying many eggs in a host will select a smaller one and deposit only one or a few in it.

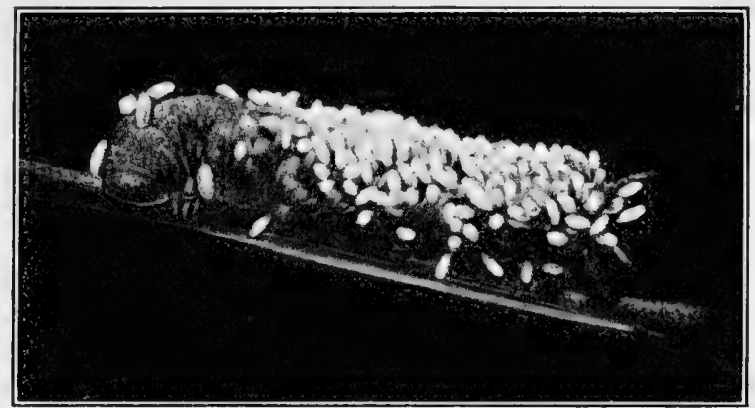

FIG. 368.- Hawk-moth larva with cocoons of parasites which have fed upon it, on its back. (From Felt, N. Y. State Mus. Mem. 8.)

Variations in the location of the pupa also occur. Some parasites pupate within the body of the host; others on its surface (Fig. 368) while still others leave the insect entirely, pupating singly or in groups, away from it. Tomato worms and other large caterpillars are often seen in the fall, either dead or dying, and with many small, white, oval bodies on their backs. These are cases where the numerous parasites after having completed feeding within the body of the host, have come out and pupated on its back, the white bodies being the cocoons of the parasites.

Superfamily Chrysidoidea (The Cuckoo Wasps).- This is a rather small group of the Hymenoptera, the insects (Fig. 369) being seldom over half an inch in length and generally considerably smaller. Their bodies are green, of a metallic or bluish shade which quickly distinguishes them from certain of the bees which are also green but brighter. The surface of the body is generally closely covered with fine indentations which give it a roughened appearance.

These insects are able to sting but no poison gland seems to be present. The abdomen which

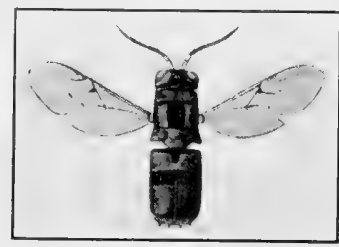

FIG. 369. Cuckoo Wasp (Chrysididae); somewhat enlarged. (From Bischoff.) has only a few (three to five) visible segments, is flat beneath, and when attacked the insect can roll itself into a ball for protection.

The Chrysids are parasitic, chiefly on wasps and bees, though a few are claimed to attack saw-flies and one is a parasite on the Oriental Moth. The parent Chrysid watches its opportunity to visit the nest of its host and lays an egg in a cell with that of the host. On hatching, 
the larva of the Cuckoo Wasp may eat the host or it may consume the food stored there, thus starving the proper inmate of the cell. Adult bees and wasps know these enemies of their young and sometimes drive them away from their nests, though frequently without success, the Cuckoo Wasp watching its chance to return later unobserved. Taking into consideration the nature of the hosts of the Chrysids it is probable that as a whole the group should be considered injurious rather than beneficial.

Superfamily Sphecoidea (The Digger Wasps).-The insects of this group vary much in size, some being very small while others, particularly tropical species, may be more than an inch and a half long. Some of them are bright-colored, yellow, orange, green and black being the more usual colors, and the wings are frequently smoky and with an iridescent luster. A functional sting is present.

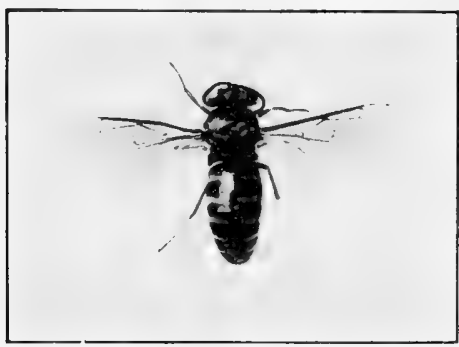

FIG. $3 \% 0$.

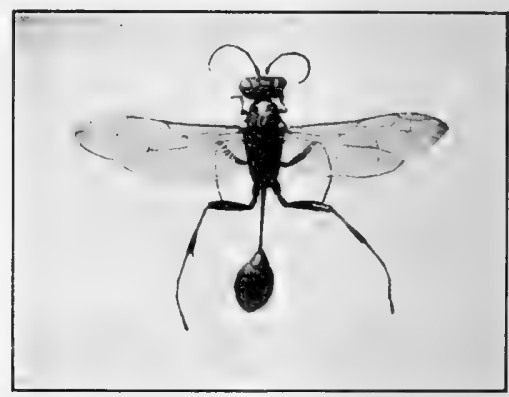

FIG. 371.

FIG. 370.-Bembecid Wasp (Bembidula quadrifasciata Say), natural size. (Original.) FIG. 371.- Sphecid Wasp (Sceliphron camentarium Dru.), natural size. (Original.)

Some of the insects (Fig. 370) in this superfamily (Families Bembecidæ and Cerceridx) have the petiole connecting the mass of the abdomen with the propodeum very short, but in the others (Fig. 371) it is long and slender, the entire first segment behind the propodeum and sometimes a part of the second being very slender and elongate. These insects are often spoken of as the "thread-waisted wasps."

The digger wasps are all solitary in their habits. The females of many species dig holes in the ground, in some cases several inches deep: others dig out the pith in plant stems: still others make nests of mud, gathered where there is moist earth, placing them under projecting stones, under eaves of buildings or in houses where access is easy through open doors or windows: in some species the nest is excavated in wood, and a few kinds have either not developed the nest-making habit or have lost it and use holes or the deserted nests of other species for themselves. In many instances the nest is subdivided into chambers separated from each other by partitions of mud.

Wherever the nest, and whatever the material which composes it, its purpose is the protection of the young of the insect and of the food 
which is stored there. After constructing the nest, either by digging, building, or otherwise, the parent starts out to provision it. The food differs with different species. Some take certain species of grasshoppers, others, flies: Homoptera, Hemiptera, Hymenoptera, Lepidoptera larvæ, some Coleoptera, and Spiders, are also listed as the prey of digger wasps of various species.

When one of the wasps finds an insect of the desired kind she attacks and stings it, generally not killing, but only partly paralyzing it and apparently chiefly the locomotor centers, so that it cannot escape. The prey is then grasped by the wasp and carried to the nest. In some cases flight is possible to the wasp carrying this load, but in many cases the prey is far too heavy for transfer in this way, at least in the case of those wasps which burrow in the earth, and it is therefore dragged along the ground to the nest. How the wasp knows the direction to take and how finally to locate the hole it is practically impossible to determine, but in most cases the insect seems to have little difficulty.

Once arrived at the nest the prey is dragged into it and if it alone provides a sufficient food supply for the young wasp to be developed there, the parent now lays an egg on it and then closes up the opening of the nest. In the case of nests in the ground this is accomplished by scratching in dirt from around the hole and packing it in firmly. In three or four cases, species of the wasp genus Sphex have been seen by different observers to pick up a tiny pebble with their mandibles and, using it like a hammer, pound down more firmly the earth filled into the hole. This may perhaps be interpreted as representing the "Stone Age" in the development of insects!

If the single insect captured will not provide enough food for the young wasp, the parent proceeds to bring in more, until sufficient has been supplied, after which the opening is closed and another nest or cell, according to the kind of wasp concerned, is begun. In a few species the prey, instead of being paralyzed, appears to be killed and it is claimed that the wasp brings fresh supplies of food from day to day for the food of its young.

Detailed studies on the lives and habits of these wasps have been recorded by many observers, and the remarkable traits these insects possess form one of the most interesting topies in Entomology.

One species (Fig. 372) deserves particular attention because of its singular ways. It is a large wasp often called the Cicada-killer (Sphecius speciosus Drury) its body being over an inch long, its abdomen black with yellow marks. It is found over a large portion of the United States and appears during the dog-days in summer. It makes its nests in the ground and provisions them with adult dog-day cicadas (Homoptera), larger and heavier than itself, which it catches in the trees. The prey cannot be carried to the nest by flight but the wasp starts from the point of 
capture with its paralyzed prey and flies as far as possible before striking ground. It has been claimed that at times the wasp drags the cicada up trees or bushes several times en route, in order to gain elevation for a fresh start toward its nest. The nests themselves may branch under-

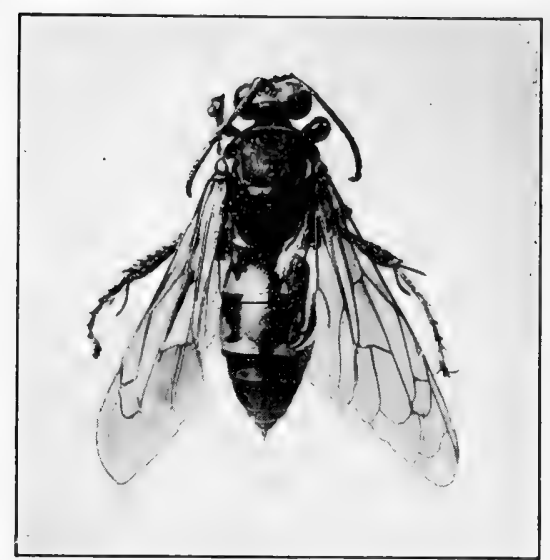

FIG. 372.-Cicada-killer (Sphecius speciosus Dru.), about natural size. (Original.) ground several times, each having a terminal chamber for the reception of one or two cicadas and an egg of the wasp.

Superfamily Vespoidea (The Social Wasps). - This common name for the Superfamily is misleading, as a number of families included here do not live in colonies, but no other term at present applied to the group is at all expressive, and some at least of the insects included are colonial in their habits.

Some of the Vespoids are very small, being less than a sixth of an inch long, while others found in the tropics measure more than two inches, their bodies having a bright blue luster, and with orange or yellow wings. Forms present in the United States except in the South and Southwest are smaller, some having bodies marked with black and yellow. The families included in the group differ much in appearance and in habits, and it is probable that further study will result in the group being dismembered and several Superfamilies being formed instead of one.

Some of the Vespoids are solitary, dig nests in the ground which they stock with spiders, and perhaps with some kinds of insects: others are parasites, some of the insects attacked being beetle larvæ and caterpillars, but in these a nest to which the prey is taken does not scem to be formed, an egg of the wasp being laid on its host wherever it is found, and the wasp larva feeding there. Some appear to be parasites on bees and wasps, living in the cells of the bees and feeding on their young. Still others are not parasites but feed on honey, pollen, etc.

In one family, known as the Velvet Ants or Stinging Ants (Mutillidæ), many of the insects live in the nests of wasps and bees while others dig holes in the ground and store flies and other small insects there, it has been claimed. The males (Fig. 373) are winged, while the females (Fig. 374) are wingless and very active. Both sexes are generally densely covered with hairs, often long, and generally of two or three contrasting colors, such as black with a red cross-band, or white, yellow and black. The females sting very effectively. Northern species are nearly all quite 
small but in the South are forms which are nearly an inch long and stoutbodied.

In another family of this group one species known as the Tarantulakiller (Fig. 375) digs nests which it stores with tarantulas, the large hairy

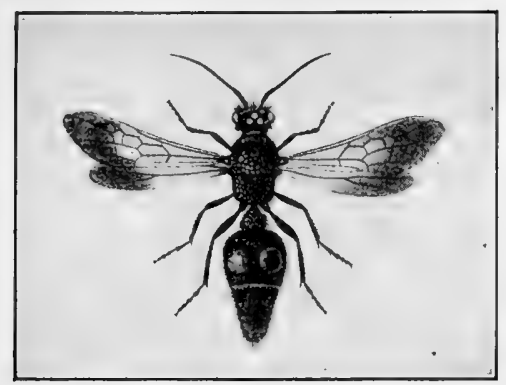

FIG. 373 .

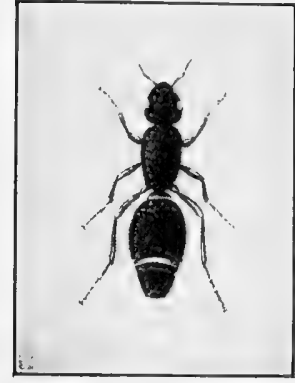

FIG. 374 .

FIg. 373.-A male Mutillid (Traumatomutilla colorata Gerst). About twice natural size. (After André.)

Fig. 374.-A female Mutillid (Ephuta occidentalis L.), slightly enlarged. (After André.)

spiders of the South and Southwest where this insect is found. It is a large and powerful wasp, about two inches long, but in its battles with the tarantula it is not always the victor.

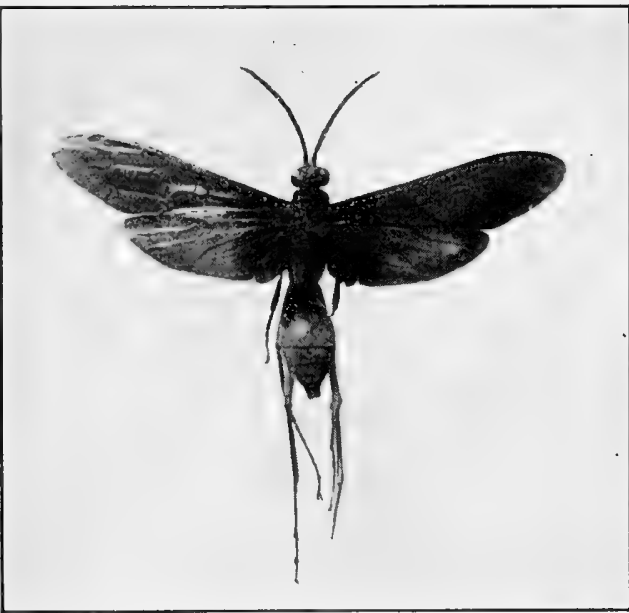

FIG. 375.-Tarantula-killer (Pepsis marginata Fab.), somewhat reduced. (Original.)

The insects of the family Eumenidæ are very abundant in this country. Most of them are rather small (Fig. 376), and black with yellow markings seems to be the favorite color combination, as so frequently is the case with the other groups of wasps. Some make burrows in the 
ground; others tunnel in wood and divide the tunnel into cells by cross partitions of mud; while others build cells of mud, some kinds of which, attached to twigs are like jugs or urns (Fig. 377) in form, with an upper flaring lip which, after the nest has been stocked with food for their young, is sealed with mud. The mud workers of this family are often called the Mason-wasps. All the wasps of this group are predaceous.

In the family Vespidæ we come to the social wasps, living in colonies, and with three types of members, the males, females and workers, these

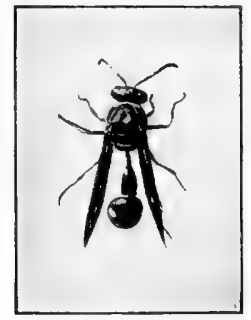

FIG. 376 .

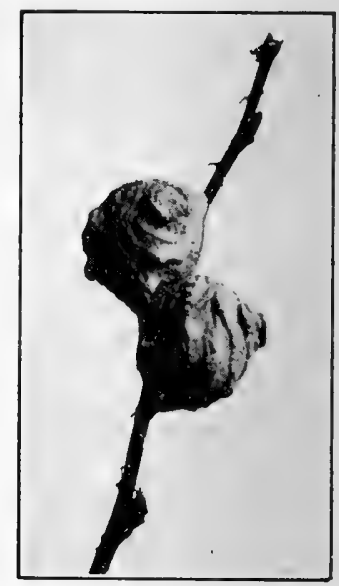

FIG, 377.

FIG. 376.-Eumenid Wasp (Eumenes fraternus Say), natural size. (Original.)

FIG. 377.-Two nests of Eumenes fraternus, natural size. (Original.)

last being females in which the reproductive organs have undergone little or no development and the insects themselves are smaller than the true females.

The colonial life of these insects continues only during the summer, all but the females dying as winter approaches. In the spring the

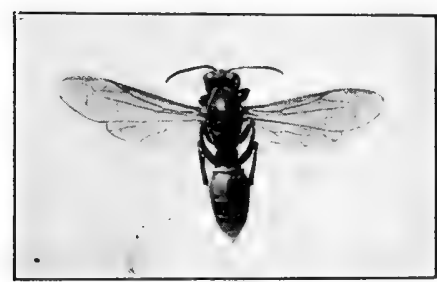

FIG. 378 .

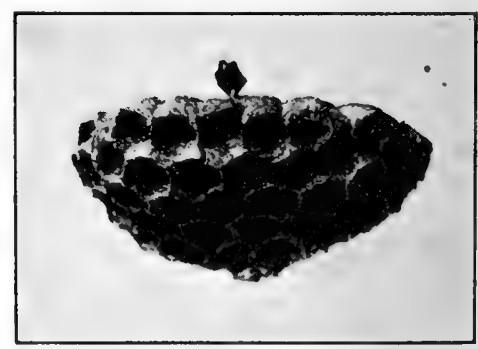

FIG. 379.

FI(: 378.- Social Wasp (Polistes pallipes Lep.), about natural size. (Original.)

FIg. 379.-Nest of Polistes pallipes, as found before the colony has increased much in numbers. Reduced slightly. (Original.)

female (Fig. 378) starts a colony, first building a cluster of six-sided cells which are in some cases attached to the under side of some projecting rock, eaves, or in a similar position (Polistes). These cells (Fig. 379) are made from weathered wood, chewed up by the insect into a sort of gray 
paper pulp and then molded into the desired form. In these cells she now places eggs and the young which hatch are fed upon insects partly chewed up, with perhaps the addition of some pollen. The young feed upon this until full-grown, then pupate in their cells. The adults which emerge are workers and they now begin to construct additional cells all in the same layer; feed the young and do the other work of the colony. Later in the season males and females are also produced and mate. Late fall stops further growth of the colony and all but the females die.

Other insects of this family (Vespula, Fig. 380) use wood partially decayed, with which to construct their nests, and an outside wrap-

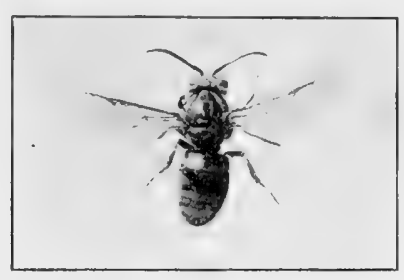

FIG. 380.-Social Wasp (Vespula vulgaris Fab.), about natural size. (Original.) ping is added. Here one layer of cells will not accommodate the colony and several layers or tiers of cells surrounded by these wrappings are produced, leaving only one or two exit openings. Sometimes these nests are placed in holes in the ground and the wasps locating in such places are

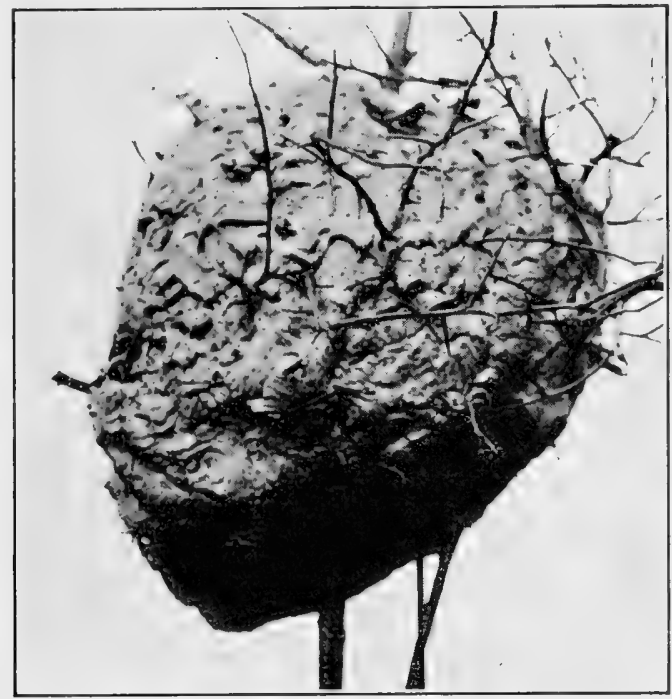

FIG. 381.-Nest of a Hornet (Vespula maculata Kirby.), about one-eighth natural size. (Original.)

often called "yellow-jackets." Other species construct their nests in trees or bushes (Fig. 381), attaching them to a branch or branches. There are several outside wrappings of gray papery wood pulp surrounding the tiers of cells within, of which there may be three or four, and the exit opening is usually at or near the bottom of the nest. Insects making nests of this kind in trees or under eaves, gable-ends of buildings or 
similar places, are generally called hornets, though there is really no sharp distinction between them and yellow-jackets, in the usual use of these names. The life of the colony in the case of these insects does not differ from that of the forms described above which make only one layer of cells with no outside wrappings (Polistes), but in the yellowjackets and hornets the colony increases much more rapidly and by fall may number several hundred individuals.

Taking the wasps as a whole, we find an interesting progressive development in the different groups. As regards their habitations, we may perhaps regard the holes dug in the ground as being the simplest, followed by excavations of the pith of woody stems, the construction of mud nests and finally along this line the formation of artistically shaped urns, as progressive steps in architectural ability. The construction of hexagonal cells of paper' pulp, first in a single layer, then in several layers surrounded by a paper wrapping and finally much more substantially built to resist exposure to the weather above ground may be regarded as continued progress in this line, the nest of the hornet marking the climax of the series.

Somewhat parallel to this is the nature of the food. The nests in the ground, in plant stems, and in mud cells, are provisioned with insects stored as food for the young of the forms constructing them: in other words these wasps are parasitic insects. With the appearance of cells of paper pulp the food changes to a mixture of insects killed and partly chewed up, and of plant materials such as pollen. At this same point also, a change from a solitary to a colonial life begins and as the colony becomes larger the nest increases in size and strength.

There is therefore a progressive development in the insects of these Superfamilies, illustrated in nest structure, food, and the advance from solitary life to that of a large colony.

Superfamily Apoidea (The Bees).- The bees familiar to everybody, are the bumblebees and the honey bee, but these form a very small part of the insects belonging in this superfamily. Many of the bees are solitary in their habits; are rather small insects and little attention is paid to them. They are important insects, however, valuable to man as they visit flowers and cross pollinate the blossoms.

The bees have the first segment of the hind tarsus somewhat enlarged and flattened, and in those which carry pollen there, hairs are present to aid in this. In addition, the hairs on the thorax are branched or plumose while in the other Hymenoptera they are simple.

Some of the bees are solitary (Fig. 382) and dig holes in the ground, generally with side pockets in which pollen or pollen and honey are 
placed as food for the young. An egg is then laid in each pocket. Others lay their eggs in the nests of other bees and are parasites upon them, or inquilines in some cases, consuming the food provided for the rightful inhabitant and starving it. Some construct mud nests while others cut off pieces of leaves or sometimes flower petals, with which they line cavities they excavate in wood, for their nests, and still others tunnel in wood but use no leafy lining. The colonial forms establish their homes in various places and build combs of wax in which to store the pollen and nectar which is their food and that of their young.

Though many of the bees are solitary there is in some species a tendency to make their holes in groups forming what are frequently called "bee villages." In a number of species this goes still further, several bees uniting in the excavation of a central burrow but each making lateral passages from this to cells which are her own and in which her own young are produced. If the former could fairly be called "villages" it would seem that these last could with equal propriety be described as "apartment houses," as has been done. Some of the bee villages will include several thousand nests within a few square feet and might even be termed "bee cities."

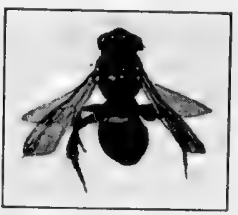

FIG. 382.- Solitary Bee, somewhat enlarged. (Original.)

Some bees have a rather short hinder lip and are known as the "shorttongued bees," but in the majority of these insects the central portion is long and slender, enabling such forms to reach the nectar in long-tubed flowers that would otherwise be inaccessible to them.

The leaf-cutter bees are usually rather small. Their nests are not often noticed, being made in holes (frequently in wood) sometimes dug by the bees themselves, but the leaves which they cut are familiar objects as the cut is frequently a very true circle or double circle, the piece removed in the latter case being rather oblong with rounded ends.

The large Carpenter Bees (Xylocopa) are about the size of bumble bees but in most cases are easily distinguished from them by the smooth and glossy upper surface of the abdomen. These insects tunnel in wood, often to quite a distance. The tunnels are divided into cells by partitions of wood chips, a partition being built across after each cell has been provided with a mixture of pollen and nectar and an egg.

Bumblebees (Bombus, etc., of many species):-There are many kinds of bumblebees widely distributed over the globe but none are found native in Australia. They live in colonies during the summer but only the queens (females) survive the winter. In spring the queen (Fig. 383) seeks some suitable place for a nest, generally a hole in the ground, and frequently the deserted nest of a field mouse is chosen for the purpose. Here she places a mass of pollen on which she lays some eggs, and the larvæ which hatch, feed upon the pollen, and when full-grown pupate in silken cocoons 
from which workers emerge. These are undeveloped females, smaller than the queen, and they now take up the work of the colony, strengthening the cocoons with wax and using them to store honey in. The colony increases in numbers and late in the season males (drones) and females (queens) are also produced and live together until the approach of cold weather, when all but the young queens die, these going to protected places to pass the winter.

The value of the bumblebees to man is apparently based upon the fact that in these insects the middle part of the hinder lip (tongue) is longer than in most of the other bees, and that therefore they visit and

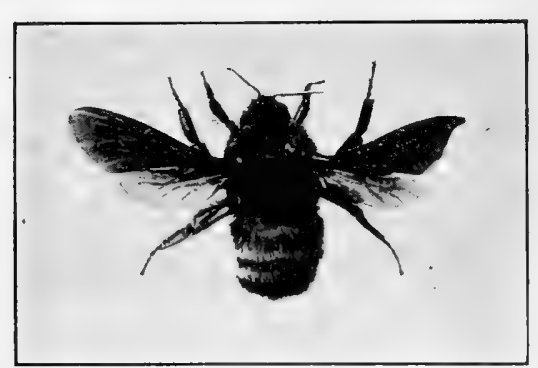

Fig. 383.--Queen Bumblebee (Bombus pennsylvanicus De G.), natural size. (Original.)

Insects so closely resembling bumblebees that it has incorrectly been said that the latter cannot distinguish them from themselves; are often found in bumble bee nests, living there as inquilines. The females of these inquilines (genus Psithyrus) however, have no structures on their hind tarsi for carrying pollen. In these inquilines there is no worker caste. The eggs are laid in the bumblebee cells and on hatching the young are fed by the bumblebee workers like their own, and the adults go in and out of the nest without molestation. Whether they have some function beneficial to the insects with which they live and which provide for them is as yet unknown.

The Honey Bee (Apis mellifera L. ).- There are a number of species of honey bees in different parts of the world, but in the United States our knowledge and experience with these insects is limited to the above named kind, often called also, the Hive Bee.

This insect is a native of Europe but was introduced into America centuries ago. In many instances, colonies have escaped from domestication and wild honey bees are abundant as a result. There are several races of the Honey Bee, the most common one, at least wild, being the Black or German bee, as this was the first race to be brought to this country. The German bee has a black abdomen; is not a particularly good honey producer and has a decidedly bad temper, besitdes being less able to protect itself from some of the insects such as the bee moth, which 
live in its nests, than are some of the other races. The Italian bee is a slightly larger insect with dull yellow stripes on its abdomen; an excellent honey producer, gentle in disposition; can protect itself quite well from other insects, and at the present time is the most popular race in this country. Other races more or less frequently met with are the Carniolan having a gray abdomen, the Cyprian with a yellow abdomen and a very bad temper, and the Caucasian with a yellow-gray abdomen. Interbreeds of the black and Italian bees are very common and have more black on the abdomen than the pure-bred Italians.

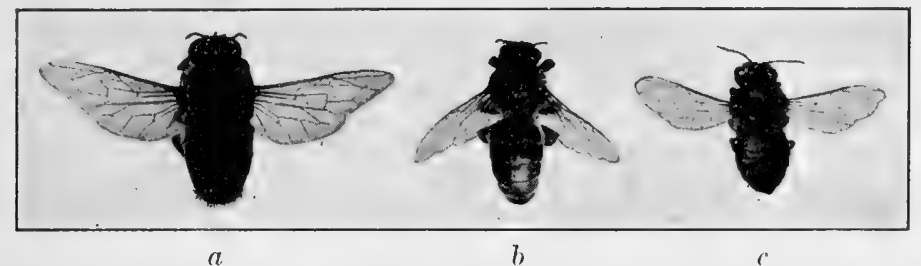

Fig. 384.-Honey Bee (A pis mellifera L.): $a$, drone; $b$, queen; $c$, worker. About natural size. (Original.)

A honey bee colony consists of a queen or fully developed female; workers which are partly developed females; and drones or males during a part of the year (Fig. 384). The queen lays eggs in the cells and the young are cared for by the workers which also gather food for themselves and the young bees, make the comb, put the nest in good condition and keep it so, and in fact do all the work necessary for the colony. The drones exist solely to fertilize the queens, taking no part in the work of the colony, and feeding on the stores brought in. On the first tarsal segment of the hind leg in the workers is the "pollen basket," a flattened or slightly hollowed oval surface surrounded by a fringe of long hairs.

An ordinary colony in good condition will consist of several thousand bees, the number at any time varying and determined by the rapidity of the production of young, the departure of many by swarming, and other factors. Swarms containing over fifty thousand bees have been seen, and the colony they left behind also contained at least a few thousand.

A laying queen bee has a body about three quarters of an inch long: the drone has a shorter but stouter abdomen, and the workers are about half an inch long.

The life of the queen may be several years. Ordinarily, workers live only a month or two, but those produced in the fall live over winter and far enough into the spring to care for the young produced at that time. Drones live only a few months and are killed by the workers when their usefulness is ended.

The life of the honey bee has been modified in many ways by its relation to man. Under natural conditions where no human interference 
occurs, the following may be regarded as an outline of the life of a bee colony.

Starting with a "swarm," which consists of a laying queen and a mass of workers, which has left its former home, this swarm flies to a new place in which to establish itself, such as a hollow tree. Here the workers clean out the cavity, removing loose particles of wood and such other debris as can be carried out. All cracks and openings to the exterior except one or two, are then stopped up with Propolis, a dark-colored, sticky material which the bees gather from the buds of trees, particularly poplars where these trees occur, and carry to the nest in their pollen baskets.

The production of wax with which to make cells in which food is stored and the brood raised, is next in order. To obtain this, some of the workers feed freely and hang upon the walls of the nest but do no work. Soon tiny scales of wax appear on the under side of the abdomens of these workers, produced by wax glands along the inner side of the chitinous wall of the body there, and poured out through openings leading from these glands to the surface. This wax is gathered, worked over and molded into the form of sheets of "comb," attached at their tops to some part of the hive and hanging downward. Generally these sheets are more or less parallel to each other and with only a narrow space left between them when their construction has been completed.

Each sheet of comb consists of two layers of cells back to back, each cell being six-sided. The long axis of the cell is nearly at right angles to the plane of the sheet of comb as a whole, but tipped slightly upward. Comparing cells on the two sides of the comb it is seen that a cell of one side backs against parts of three of the opposite side, and that the partition at the inner end of each cell slopes so that the center is its deepest point. Mathematical study of the construction of the cells shows that by this form and arrangement of the cells the greatest amount of storage space is obtained with the least expenditure of wax, of any form which the bees could use. In some of these cells, usually those around the top and sides of the comb, food is stored, while the central and lower portions are used for the production of the young.

As soon as comb is available the storing of food and the production of young begin. The workers go out and visit flowers, gathering the pollen in their pollen baskets and bringing it to the nest where it is stored in cells. They also collect nectar from the blossoms, carrying it to the nest in the honey sac, an enlargement of the osophagus just in front of the stomach (Fig 24,hs). On reaching the nest this nectar is expelled into a cell and the cells selected for this purpose are gradually filled. From time to time workers visit these cells and draw the nectar from them into their honey sacs, then driving it back into the cell again and repeating the process, which removes water from it and concentrates it into honey. 
The queen lays her eggs on the bottoms of the cells selected for the raising of brood, one egg in the bottom of each cell. The eggs hatch into stout, white, maggot-like larvæ (Fig. 385) which are fed by the worker bees with a material generally called "bee bread" which appears to be pollen mixed with some honey. When the larvæ are full-grown and ready to pupate the workers cap over with wax the openings of the cells occupied by such larvæ and these proceed to pupate (Fig. 385). After the changes undergone during pupation have been completed the adult thus produced bites away the cap closing the cell it is in and emerges as the adult.

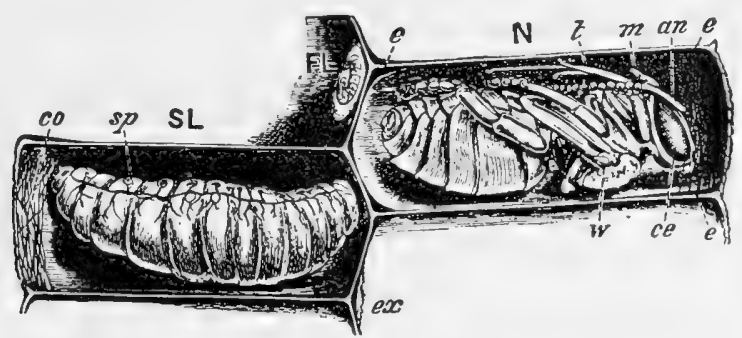

FIG. 385.--Section of comb of Honey Bee: FL, feeding larva in the bottom of its cell; SL, Jarva ready to pupate, spinning its cocoon $\vdots \mathrm{N}$, pupa; an, antenna; $c$, compound eye; $c o$, cocoon; $e$, excrement; $e x$, exuvium; $m$, mandible; $s p$, spiracle; $t$, tongue; $w$, wing. (After Cheshire.)

In the case of eggs which are to become drones (males) the cells in which such eggs are laid are apparently of a slightly greater diameter than those where workers are to be produced, though this is denied by some students of the subject, and they are longer, projecting out beyond the line of the general surface of the brood cells, at least after being capped, so that they are easily recognized.

The queen is fertilized but once, at which time the sperms of the drone are stored in the seminal receptacle of the queen. She lays both fertilized and unfertilized eggs, the latter producing the drones. By the Dzierzon theory, whether the egg is to be fertilized or not depends upon the will of the queen. If the cell in which the egg is to be laid is a worker cell, at the moment the egg passes down the oviduct by the opening of the seminal receptacle the muscles surrounding the receptacle are slightly contracted and sperms are expelled, one of which fertilizes the egg, while if the egg is deposited in a drone cell the muscles are not contracted and the egg is unfertilized and produces a drone. While this is the more generally accepted theory, the alternative view is held by some persons that the smaller diameter of the worker cell produces pressure on the abdomen of the queen which forces some of the sperms out, and that in case of drone cells their greater diameter prevents this.

Queens are produced only during the late spring and summer months when swarming is desired. At such times the workers select a cell already 
containing a worker egg and tear down those around it and construct a new cell about the shape and size of a small peanut, to enclose the egg, and with its opening usually facing downward. When the egg in this cell hatches the larva is fed on "royal jelly" which is probably bee bread mixed with an albuminous secretion derived from glands situated in the heads of the workers, and which is richer and more nutritious than bee bread. With this richer food and a larger space in which to develop, the workers are thus able to produce a queen from a worker egg. There are of ten a number of queen cells of different ages in a nest at once.

The time required to produce a queen from egg to adult is about $151 / 2$ days: for a worker, 21 days; and for a drone 24 days.

Swarming is for the double purpose of relieving colonies whose nests would otherwise become over-crowded, and for the establishment of new ones. Though many of the details of this process may vary on different occasions, the usual story of swarming is about as follows.

When the colony is in such a condition during late spring or summer that swarming will soon be desirable, drone cells and queen cells are constructed and after a time the first of the new queens completes pupation and begins to bite off the wax cap over the mouth of her cell. At this time she makes a peculiar noise commonly called a "piping" sound, and when the old queen hears this she becomes greatly disturbed and begins to hunt for the young queen to sting and kill her before she can escape from her cell, if possible. If a swarm just at that time is not desired by the workers for any reason, she may be allowed to do this, but if swarming is to take place workers cluster so thickly over and around the young queen cell that the old queen cannot reach it. This opposition to her wishes, passive though it is, or the knowledge that another queen will quickly be present in the colony seems to arouse and excite the old queen greatly and this excitement spreads to the workers, particularly the younger ones. Scouts now go out to find a home for the swarm and finally the old queen and a mass of workers leave the hive together. In some cases they go directly to their new home, but most of ten they fly only a short distance before clustering on the limb of some bush or tree for a time before flying to the new nest. Once arrived there, the work of preparing the place, stopping the cracks and the production of comb begins, as already described.

That part of the colony remaining behind now consists of workers, drones and a young, unfertilized queen. The queen on escaping from her cell usually explores the brood cells and if she finds other queens developing she stings them in their cells to assure her supremacy, unless prevented by the workers. A few days later the queen leaves the nest on a pleasant day for a flight during which she mates, after which she returns to take up her duties as queen of the colony.

Several possibilities may become realities in connection with swarm- 
ing. One of these is the chance that two young queens may emerge at almost the same time. If this should happen it is stated that the two meet sooner or later and struggle for supremacy until one or the other is killed. A second possibility is that both of the queens may be so injured that they will die, or as probably is more often the case, the queen while out on her mating flight may be killed by a bird or in some other way. In either case the colony becomes queenless as a result. If other queen cells are present in such cases, the workers carry on the work of the hive until the new queen appears, mates and takes charge: but if there are no more queen cells the workers look about for a worker egg or a larva not more than 3 days old. If one is found, its cell walls are torn down and a queen cell built around it and its food is changed from bee bread to royal jelly. and in this way a queen will be produced. If an egg or a worker larva under this age cannot be found, however, the colony cannot hope to obtain a queen and it gradually dwindles away and is lost.

Drones, serviceable to the colony during the swarming season, are not needed thereafter and would consume stores gathered for winter. Therefore after all swarming is over they are dragged out and killed by the workers.

The value of the honey bee to man comes from the honey and wax it produces. The amount obtained varies greatly from year to year but averages over fifty million pounds a season in the United States and at a recent average retail price of forty cents, would represent about twenty million dollars. This is probably more though, than is actually received by the beekeepers. About a million pounds of wax are now produced annually and at about forty cents per pound this would add nearly half a million dollars more to the value of the industry in this country.

Superfamily Formicoidea (The Ants).--These familiar and plentiful insects occur from the frigid regions to the equator, being present in abundance practically everywhere, and it has been claimed that there are more individuals of ants than of all other terrestrial animals. They live in colonies which are quite permanent, enduring for many years in some cases, and the life of an individual ant may continue for several years.

Ants are nearly always nasily recognized by the presence of a petiole which is enlarged near or behind its middle (Fig. 386e), being either swollen or having a portion projecting upward there, followed behind by a constriction where this segment joins the rest of the abdomen. In some ants the following segment is also more or less similarly shaped. This gives these insects a rather elongate, narrow portion between the thoracic and abdominal masses, enlarged at one or two places, according to the number of segments concerned. 
Three classes of ants always compose a colony-males, queens (females) and workers-and there may be subdivisions of each of these in some cases. The males and females usually have wings during a portion of their lives, these having a simple arrangement of the veins: the workers are wingless though some have vestiges of these structures. The queens and workers are provided with a well-developed sting in some groups of ants, while in others it is vestigial or entirely absent. The usual colors of ants are yellow, brown, black, red, dull red, or brownish yellow.

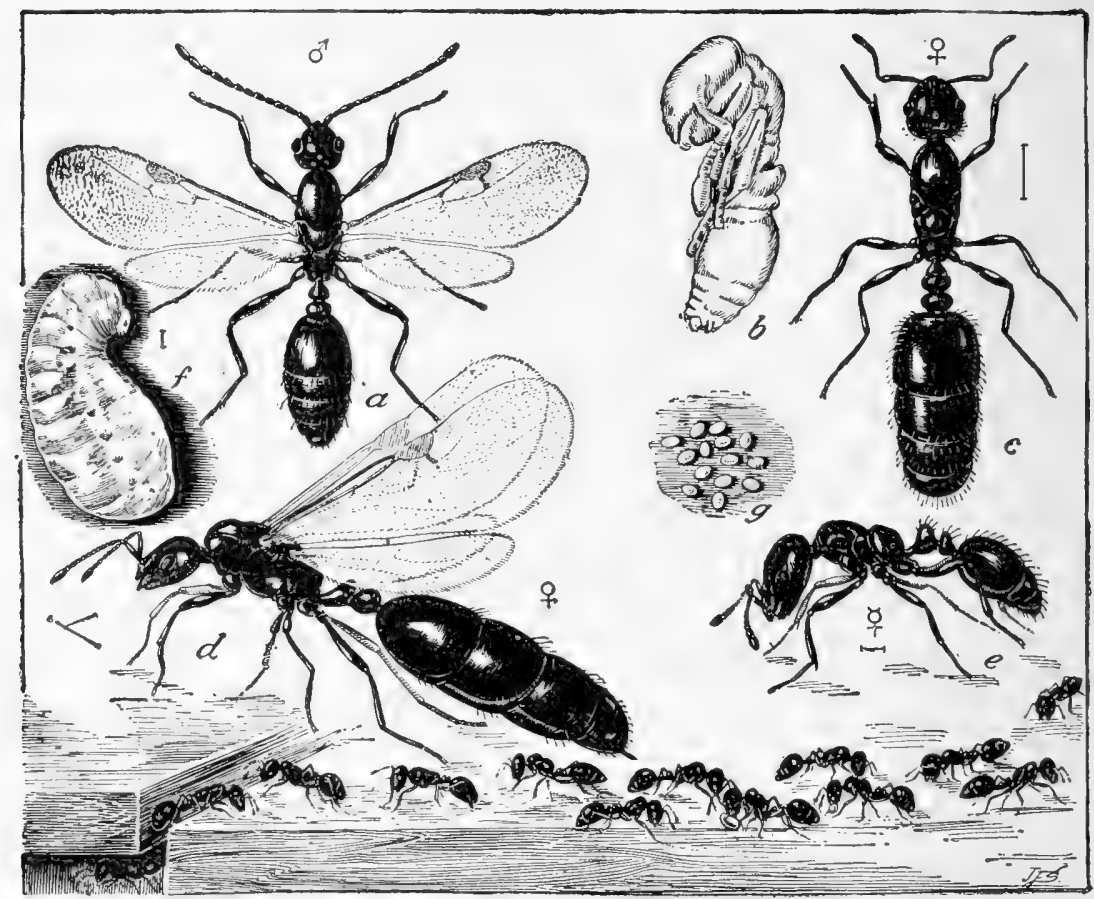

FIG. 386.-Little Black Ant (Monomorium minimum Em.): $a$, male; $b$, pupa; $c$, female; $d$, winged female; $e$, worker; $f$, larva; $g$, eggs; workers in line of march below. All enlarged, hair lines showing true length. (From U. S. D. A. Farm. Bull. 740.)

Colonies of ants occur in many kinds of locations. Some are in the ground and these may be of different types of strueture; some occur in the eavities of plants, either preformed or else tunneled out by the ants: some form nests on branches, making them of various materials; and some nest in timbers, or other unusual places, while a few kinds have no fixed homes.

The food of ants is as varied as are their nest locations. Probably the original food of the group was insects, either dead or helpless, and many species feed on this material. Others take the honey-dew supplied by scale insects, leafhoppers and particularly by plant-lice. Some raid 
the nests of other species of ants and feed on their larvæ and pupæ. Plant seeds, bulbs, and the bark on tender roots also form the food of some ants, and one tribe raises a fungus in order to feed upon its hyphæ. Sweet materials such as cake, candy, sugar, molasses, etc., in houses, often attract ants, which find in these substances satisfactory foods.

Colonies in the ground may vary from those having a single tiny entrance and a few tunnels and galleries below the surface, to large ant hills several yards in diameter and several feet high, with extensive galleries both above and below the general ground level( Fig. 388). In these nests may be found a queen (frequently several); males, at least at times; and often many thousands of workers. The queen or queens produce the eggs which are carried away and cared for by the workers, who also feed the larvæ, clean them, transfer them from one part of the nest to another, according to the temperature and other conditions they need, and finally aid them in escaping from their cocoons. They also feed the queen and do all the work of the colony.

The eggs laid may develop either into males or females and workers, and Dzierzon's theory given above for bees has been applied to ants also, though some evidence that unfertilized eggs may in certain cases produce workers tends to throw doubt on the applicability of this theory to ants.

At certain seasons of the year swarming occurs. At such a time enormous numbers of winged males and females, previously produced in the nest, leave it and take flight. Mating occurs in the air and the females soon return to the ground where they remove their now useless wings, either by pulling them off with their legs or jaws, or by rubbing them against the ground, stones or grass-stems. The queen now prepares a nest by digging a hole in the ground, in rotten wood or elsewhere, forming a small chamber at the inner end and closing the entrance.

"In her cloistered seclusion the queen now passes days, weeks, or even months, waiting for the eggs to mature in her ovaries. When these eggs have reached their full volume at the expense of her fat-body and degenerating wingmuscles, they are laid, after having been fertilized with a few of the many thousand spermatozoa stored up in the spermatheca during the nuptial flight. The queen nurses them in a little packet till they hatch as minute larvæ. These she feeds with a salivary secretion derived by metabolism from the same source as the eggs, namely, from her fat-body and wing-muscles. The larvæ grow slowly, pupate prematurely and hatch as unusually small but otherwise normal workers. In some species it takes fully 10 months to bring such a brood of minim workers to maturity, and during ali this time the queen takes no nourishment, but merely draws on her reserve tissues. As soon as the workers mature, they break through the soil and thereby make an entrance to the nest and establish a communication with the outside world. They enlarge the original chamber and continue the excavation in the form of galleries. They go forth in search of food and share it with their exhausted mother, who now exhibits a further and final change in her behavior. She becomes so exceedingly timid and sensitive to 
light that she hastens to conceal herself on the slightest disturbance to the nest. She soon becomes utterly indifferent to her progeny, leaving them entirely to the care of the workers, while she limits her activities to laying eggs and imbibing liquid food from the tongues of her attendants. This copious nourishment restores her depleted fat-body, but her disappearing wing-muscles have left her thoracic cavity hollow and filled with air which causes her to float when placed in water. With this circumscribed activity, she lives on, sometimes to an age of 15 years, as a mere egg-laying machine" (Wheeler).

Of course there are many fatalities in such a history as this. Birds, dryness in their. burrows, excessive moisture or cold, underground insects attacking them, together destroy the great majority of these ants just starting new colonies. Then too, the amount of nourishment stored in the individual is an important factor, some species having so little that they are wholly unable to start new colonies. An individual of such a species therefore either joins a colony already established, a queenless colony of a related species if she can induce the colony to accept her, or she may enter a colony of a very different species and, killing its members, raise their young until they emerge when they will accept her as their queen. Rarely two queens may start a colony together.

After the colony is well under way the queen limits her duties to egg laying, and may live many years. In one case a queen lived nearly 15 years in confinement and may have been older! This is the greatest age known to have been attained by any adult insect. The males die soon after mating.

The relation of ants to plant lice is most interesting and has already been referred to (pp. 197 and 203). It does not exist with all species of ants but in at least a large number honey-dew is an important part of their diet and in some cases it may be their only food. There is every evidence that the benefit is mutual, the ants protecting the aphids, driving away the enemies of these insects or carrying the aphids to protected places. Ants that care for root-feeding aphids keep them in chambers or galleries, conduct them to their sources of food supply, collect and store their eggs for the winter, and in spring take the young to their food.

The Corn-root Aphis so injurious to corn, as already described, is thus cared for by ants. Scale insects which produce honey-dew are also cared for in a sense, for ants are very attentive to them and to quite an extent prevent the attacks of the enemies of the scales by their presence and activities. Thus in an indirect way the protection by ants of plant lice, scale insects, white flies, leaf hoppers, and in fact any insects which produce honey-dew, establishes such ants as injurious.

Some kinds of ants have most remarkable habits worthy of a brief reference here. Some species may make raids on the nests of other kinds, and carry off their worker larvæ and pupæ to their own nests, where many probably serve as food but a few may be reared and become 
slaves. Slavery is not essential with all the kinds of ants where it is known, colonies having no slaves being able to carry on their lives unaided by slaves. With certain species, however, the situation is different. In these the workers have mandibles so constructed that they are unable to gather food, excavate their nests or care for the young. Accordingly they make forays on the nests of other species, bringing back larvie and pupæ which on becoming adult are slaves which do the work of the colony and care for their captors, both as adults and during their early stages.

The honey ants, so-called, include those species in which the crop is capable of great distention, and this power is made use of by collecting honey-dew and storing it until the abdominal mass is enormously distended and (in some species) about the size of a large currant, such individuals becoming animated food reservoirs. These members of the colony hang on the ceilings of their galleries, withdrawing from the regular duties of the other workers. The reason for the existence of such a peculiar habit is suggested by the fact that the honey ants are confined to dry plains and desert regions, being found in North America, South Africa and Australia. They are therefore probably true reservoirs of nourishment which may be drawn upon during periods of drought, when the ants must remain for some considerable time in their nests.

Some ants raise fungi upon which to feed, about one hundred kinds which do this being known. These insects in most cases go in large numbers to trees and some climb the trees and cut off the leaves while other members of the colony pick these up from the ground where they have fallen and carry them to their nests where the fungus is grown on them.

A few species of ants are obnoxious to man, either by invading houses, making their nests in lawns or in trees, or by to some extent protecting injurious insects.

The Argentine Ant (Iridomyrmex humilis Mayr.) is a native of South America which probably reached this country between 1880 and 1890 at New Orleans and now is present nearly everywhere in most of the southern tier of states, and in California as far north as San Francisco.

The adults (Fig. 387) are brown in color. The queens are about a quarter of an inch long, the males about half that length, and the workers about a tenth of an inch long. Their summer nests "may be located anywhere - under sidewalks, under the sills of houses, in brick piles, stone piles, under a piece of board or a piece of tin, in an old tin can-in fact, in any place convenient to the food supply. In the winter months there is a tendency to concentrate into larger colonies, and they seek warm, dry, secure nesting places in which to hibernate" (E. R. Barber).

Egg production is probably quite large-perhaps 50 or more per day under favorable conditions-and an average of 40 days in warm weather is required for development from the laying of an egg to the emergence of the adult worker. 
This is one of the worst of house pests known in the regions where it is abundant. Its small size enables it to enter through the smallest cracks and it goes everywhere in houses after its food. It will eat practically everything in the way of foods, both raw and cooked, and no part of a house is free from its presence. The cold of ice chests does not repel them and beds are not entirely protected by placing the bedposts in dishes

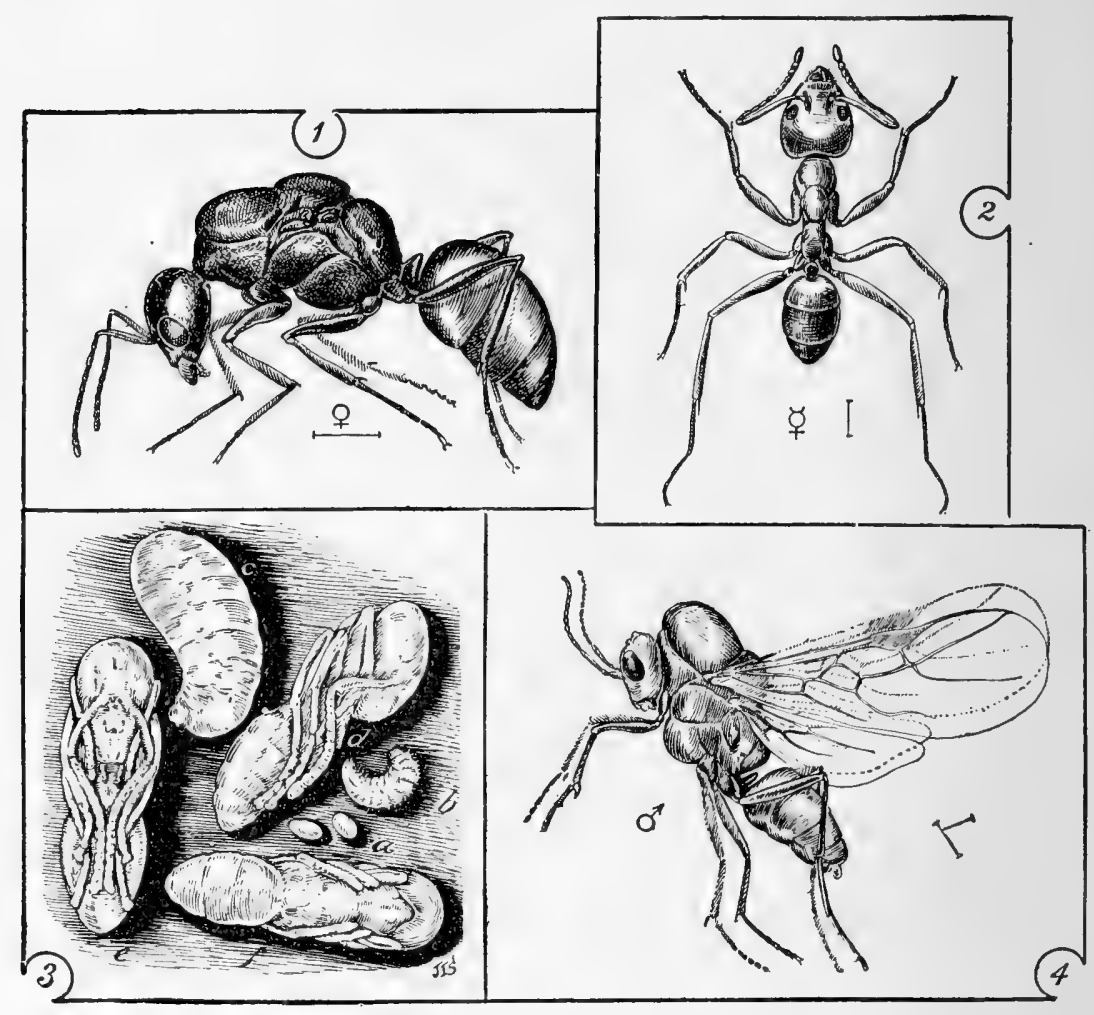

FIG. 387.-Argentina Ant (Iridomyrmsx humilis Mayr.): 1, wingless female; 2, worker, 3 , early stages: $a$, eggs; $b$, young larva; $c$, full-grown larva; $d$, side view of pupa; $e$, ventral side of pupa; $f$, dorsal view of pupa, 4 , male. All greatly enlarged. (From U.S.D.A. Farm. Bull. 740.)

of water or kerosene, as after a few hours a film of dust forms on the surface of this, over which with their light bodies they are sometimes able to pass. Though they do not sting, they bite freely and are able to cause some pain in this way. Young children asleep have been found with ants in the nose, ears and mouth, and older persons are frequently inconvenienced by them in a similar way. They visit plant lice, soft scales and other insects for honey-dew and to some extent at least, their presence is favorable to these pests and makes their control more difficult. 
Control.-Heavy rains, causing a flooding of the nests is a natural means of checking the ravages of these insects, many being killed, particularly in cold weather. Barriers on the legs of tables, beds, etc., consisting of tape, soaked in a saturated solution of corrosive sublimate $\left(\mathrm{Hg} \mathrm{Cl}_{2}\right)$, dried, and then fastened around such places will keep the ants away for several months at least. A generous supply of naphthaline in the form of moth balls, placed in a dish in which a leg of a piece of furniture rests is also effective, provided each leg is thus treated. Kerosene instead of moth balls, as already described, is generally of some value as a protection.

Various ant poisons have been tested, and a syrup of granulated sugar, water, tartaric acid, sodium arsenite and honey has been found to be very effective, and it also keeps well. Placed in a tight tin with two sides dented in and with a tin cover, the ants can enter and feed while the syrup remains protected from the weather. A gill or two of syrup and a fairly large piece of sponge floating in it will complete the trap for use. Traps should be placed both in and around the house, of course out of the reach of children, and by adding a bail or handle can be hung on walls, the branches of trees and in similar situations. Eight or ten of these are sufficient for an ordinary city house and lot and will be effective at least for 6 or 8 weeks.

House Ants.- These are of several kinds but the one most usually troublesome is the Little Red Ant (Monomorium pharaonis L.), probably a native of Europe but now abundant in nearly all countries. It is very small, red in color, and makes its nests in walls, floors, sills or other timbers, whence it explores all parts of the houses, paying particular attention to those places where food is found. Oftentimes regular lines of these pests may be found marching from some article of food they have discovered to their nest, and another line beside the first, on their way to obtain food. In such cases it is sometimes easy to trace their line of march back to where they enter some timber in which their nest is placed, and then the injection into the holes where they enter, of carbon disulfid or benzine may prove sufficient to kill the queen or queens and terminate the life of the colony. In too many cases though, it is impossible to locate, or perhaps to reach the nest. Where this is true it has been found that small pieces of sponge, soaked in molasses and water, and a little arsenic, placed where ants are will generally attract the pests, which will feed upon the poisoned syrup and be killed. In this way the number of individuals is frequently reduced more rapidly than the colony increases and the ants gradually become less abundant and finally disappear. Simple protection of food or other materials can usually be obtained by placing around such articles a continuous, liberal band of powdered cloves.

Where ants are nesting in living trees they usually enter where some limb has been lost, and their entrance holes in the wood can be found. 
Pouring carbon disulfid or benzine into these and then stopping the holes with putty or mud is in most cases, sufficient to kill the queen, and in consequence, the colony.

Ants in lawns or elsewhere may make mounds (Fig. 388) or may simply loosen the soil and more or less injure the grass at such places. To destroy such nests a stick, such as a cane or a broom handle, should be driven down to the bottom of the nest, at which point the loosened earth ends and driving becomes hard. These holes should be about a foot

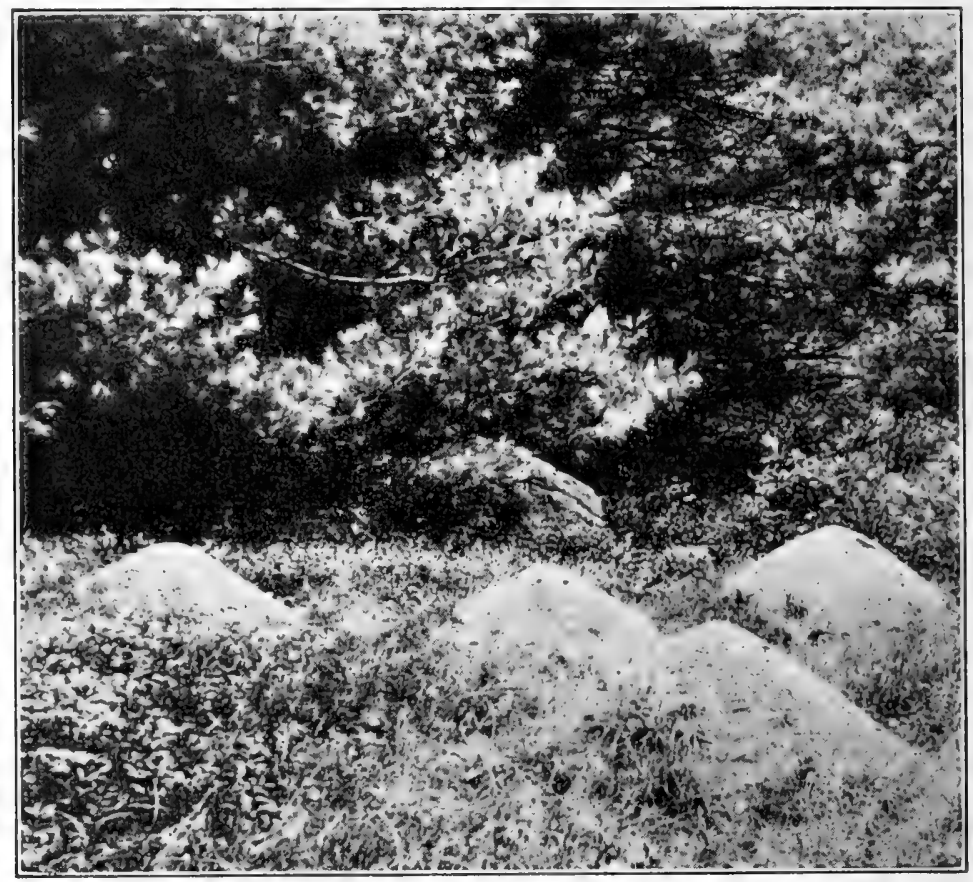

FIG. 388.-Ant hills. (From a photograph by H. B. Peirson.)

apart and enough of them be made to cover the entire surface of the nest at this distance. Into each hole a tablespoonful or two of carbon disulfid is now poured and each opening closed at the top, which is sufficiently done by pressing the earth together at each hole with the foot. The carbon disulfid gas penetrating through the underground galleries of the ants will kill them, including the queen, and the colony will disappear.

This treatment should be applied on a warm, dry day, to hasten the change of the liquid to the gas and its rapid dissemination through all parts of the nest. 


\section{INDEX}

\section{A}

Abdomen, 14

Abdominal feet, 14, 232, 252, 272, 300

Acrididæ, 81-85

Aculeata, 339

Adalia bipunctata, 133

Aëdes ægypti, 309 sollicitans, 307

Fgeriidæ, 243-246

Agamic reproduction, 154, 196

Agglomerate eyes, 9

Air tubes, 18

Alabama argillacea, 269

Alaus oculatus, 108

Aleyrodes vaporariorum, 207

Aleyrodidæ, 187, 206-208

Alfalfa caterpillar, 295 weevil, 143 worm, 274

Alsophila pometaria, 253

Amblychila cylindriformis, 101

Ambrosia beetles, 146

Ambush-bugs, 182

American roach, 78

Ametabola, 25 development of, 26

Anabrus purpurascens, 87

Anatis 15-punctata, 134

Angoumois Grain Moth, 247

Anisolabris maritima, 95

Annulata, 1

Anopheles crucians, 309 quadrimaculatus, 307

Anoplura, 164-167 mouth parts of, 164

Ant, Argentine, 371

-lions, 224-225

little brown, 204

red, 373

Ants, 186, 196, 197, 204, 367-374

house, 373

in lawns, 374

Antennæ, 8

Anthomyiidæ, 327-330

Anthonomus grandis, 140
Anthrax, 323

Anthrenus scrophulariæ, 104

Antique tussock moth, 262

Anuraphis roseus, 198

Anus, 15

Aorta, 19

Apex, 14

Aphididæ, 133, 187, 194-206, 291, 344, 368,370

Aphis bakeri, 199

-lions, 222

maidi-radicis, 203

pomi, 198

Apis mellifera, 362

Apoidea, 360-367

Apple aphids, 198

grain aphis, 198

leafhoppers, 192

maggot, 319

-tree tent-caterpillar, 256

Apterygota, 60, 62 characters of, 62

Arachnida, 2 characters of, 4

Arctiidæ, 277-279

Armored scales, 208, 209-216

Army worm, 272

Arsenate of lead, 46 standard formula, 47

of lime, 47

Arsenic, 44

Arthropod characters, 1

groups of, 2

distinctive table of, 5

Arthropoda, 1

Artificial control methods, 38

Asilidæ, 316

Asparagus beetle, 123

Aspidiotus perniciosus, 211

Attagenus piceus, 104

Aulacaspis rosæ, 214

Australian roach, 78

Automeris io, 286

Axillary incision, 301

Axillary sinus, 301 


\section{B}

Bacillus pestis, 334

Back-swimmers, 184

Bacterial wilt, 118, 197

Bag worms, 250-252

Bark beetles, 146-149

Basilarchia archippus, 292

Basilona imperialis, 281

Bean weevils, 128-130

Bedbug, 182

Bee bread, 365 moth, 249

Bees, 360-367;

- bumble, 361 carpenter, 361

honey, 362

leaf-cutter, 361 solitary, 360

Beetles, 98-149

Beet-root louse, 205

Belostomidæ, 185

Bembecidæ, 354

Bilateral symmetry, 2

Bird lice, 161-163

Birds, 1; and insects, 35, 36

Biting lice, 161-163

Black-beetle, 78

carpet beetle, 104

flies, 315

lady beetle, 135

scale, $135,216,220$

swallow-tail butterfly, 298

witch, 269

Blastophaga grossorum, 349

Blatella germanica, 76

Blatta orientalis, 78

Blattidxe, 76-78

Blissus leucopterus, 174

Blister beetles, 135-136

Blood, 20

vessels, 19

Blue-bottle flies, 324

Bombus, 361

Bombycidx, 255

Bombyx mori, 255

Book-lice, 159

Borax, 50

Bordeaux mixture, 54

Bot flies, 318

Brain, 21

Breathing organs, 17

Broad bean weevil, 129
Bromius obscurus, 125

Brown-tail moth, 265, 296, 297

Bruchida, 128-130

Bruchophagus funebris, 349

Bruchus chinensis, 129

obtectus, 129

pisorum, 128

quadrimaculatus, 129

rufimanus, 129

Bubonic plague, 334

Bud-worm (of corn), 120

Buffalo carpet beetle, 104 gnats, 315

Tree-hopper, 190

"Bug vs. bug," 220

Buhach, 53

Bumblebees, 361

Buprestidæ, 105-107

Burning insects, 40

Butterflies, 290-299

(and moths), 230-299

C

Cabbage butterfly, imported, 293 maggot, 327

Caddice flies, 226-229

Caeca, 16

California devastating grasshopper, 83 grape-root worm, 125 oak worm, 267

Caliroa cerasi, 341

Callosamia promethea, 283

Calosoma sycophanta, 100

Camel crickets, 86

Camnula pellucida, 84

Camphor thrips, 158

Canker worms, 253

Cantharidin, 136

Capsidx, 180

Carabida, 100

Carbon disulfid, 55

Carnivorous diving beetles, 101

Carolina grasshopper, 84

Carpenter bees, 361

moths, 234-236

worm, 234

Carrion beetles, 103

Case-making clothes moth, 236

Caterpillar, 232

Catocalas, 269

Cecropia moth, 283

Cells, 13 
Centipedes, 2 characters of, 3

Cephalothorax, 3, 151

Cephus cinctus, 342 pygmæus, 342

Cerambycidxe, 130-133

Ceratocampidx, 280

Cerceridx, 354

Cerci, 14

Ceresa bubalus, 190

Chalcid flies, 347-351

Changa, 90

Characters of Arthropods, 1

Chermidæ, 187, 193

Cherry plant lice, 205

Chigoe, 336

Chilocorus bivulnerus, 134, 213

Chilopoda, 2 characters of, 3

China wax, 209

Chinch bug, 174 bug fungus, 176

Chinese mantis, 79

Chionaspis furfura, 210 pinifoliæ, 215

Chitin, 2, 7

Chloridea obsoleta, 270

Cholera, 321, 323

Chordata, 1

Chrysalis, 234

Chrysidoidea, 353

Chrysobothris femorata, 106

Chrysomelida, 115-128

Chrysomphalus aurantii, 215

Chrysomyia macellaria, 324

Chrysopidx, 222-223

Cicada-killer, 355

Cicadas, 187-190, 355

Cicadidæ, 187-190

Cicindelid $x, 101$

Cimex lectularius, 182

Cimicidx, 182

Circulatory organs, 19

Cirphis ùnipuncta, 272

Citheronia regalis, 280

Citrus mealy bug, 218

thrips, 157

white fly, 207

Classification, 59-61

Clean culture, 39

Clear-winged grasshopper, 84 moths, 243-247

Click-beetles, 107-110
Closed cells, 13

Clothes moths, 236-238

Clover aphis, 199

-flower midge, 311

root-borer, 147

-seed chalcid, 349

Cnidocampa flavescens, 250, 353

Coccida, 187, 208-220

Coccinella novemnotata, 134

Coccinellidx, 133-135

Coccotorus scutellaris, 139

Cochineal, 209

Cocoon, 29

in Lepidoptera, 233

Codling moth, 238

Colenterata, 1

Coleomegilla fuscilabris, 134

Coleoptera, 98-149

Coleoptera vera, 99-136

Collembola, 62, 63-64

Colon, 16

Colorado potato beetle, 115

Comb, 364

Combinations of sprays, 54

Commissures, 21

Common bean weevil, 129

Compound eyes, 8

Conotrachelus nenuphar, 137

Contact insecticides, $43,49-53$

Contarinia tritici, 314

Control by natural methods, 35

Coreidx, 172-173

Corixidse, 184

Corn borer, European, 249 ear worm, 270

Cornicles, 195

Corn-root aphis, 203, 370 worms, $120-122$

Corrodentia, 159-161

Corydalis cornuta, 221

Cossida, 234-236

Costa, 14

Cotton boll weevil, 140 stainer, 174

worm, 269)

Cottony cushion scale, 135,219 , 220

maple scale, 217

Cowpea weevil, 129

Coxa, 12

Crab louse, 166

Crane flies, 304

Crickets, 88-90 
Crioceris asparagi, 123

duodecimpunctata, 124

Crop, 16 rotation, 39

Croton bug, 76

Crude petroleum, 50

Crustacea, 2 characters of, 3

Cryptolæmus montrouzieri, 135

Cuckoo wasps, 353

Cucurbit mosaic disease, 118

Culex pipiens, 306

Culicidx, 305-311

Curly-leaf disease, 193

Currant worm, 340

Cursorial Orthoptera, 75-81

Cutworms, 275

Cydnidæ, 172

Cylas formicarius, 145

Cynipoidea, 346

\section{D}

Dagger moths, 270

Damsel-flies, 68-69

Danaidæ, 291

Danaus archippus, 291

Darkling beetles, 135

Dasyneura leguminicola, 311

Datana, 267

Death wateh, 160

Dengue, 310

Dermaptera, 95-97

Dermestes lardarius, 103

Dermestidæ, 103-105

Diabrotica duodecimpunctata, 120 longicornis, 121

soror, 122

trivittata, 119

vergifera, 122

vittata, 118

Dialeurodes citri, 207

Diapheromera femorata, 81

Differential grasshopper, 83

Digestion, 16

Digestive organs, 15 formation, 15

Digger wasps, 354-356

Dimorphism, seasonal, 291

Dioptidæ, 267

Diplopoda, 2 characters of, 3

Diptera, 301-332
Diseases carried by insects, 166, 167, $183,309,321-323,325,334$

Diseases of insects, 178

Dispersion of insects, 296

Dissosteira carolina, 84

Dobson, 221

Doodle-bug, 224

Dog-day harvest-flies, 189

Doryphora clivicollis, 117

Dragon-flies, 68-71

Drill-worm, 120

Drones, 362, 363

Dry sulfur compounds, 52

Dusting poisons, 43

Dynastes tityrus, 114

Dysdercus suturellus, 174

Dysentery, 321

Dytiscidx, 101

Dzierzon theory, 365, 369

\section{E}

Earwigs, 95-97

Eccoptogaster rugulosus, 147

Eedysis, 27

Echidnophaga gallinacea, 336

Echinodermata, 1

Eggs. 25

Ejaculatory duct, 24

Elateridæ, 107-110

Electric-light bugs, 185

Elm leaf beetle, 126

Elytra, 98

Embiidina, 74

Emergence, 30

Empoa rosæ, 193

Empoasca mali, 192

Empodium, 12, 303

Engraver beetles, 136, 146-149

Ensign flies, 343

Ephemerida, 65-67

Ephestia kuhniella, 249

Epipharynx, 9

Erebus odorata, 269

Eriosoma lanigera, 199

Estigmene acræa, 277

Eucosmidæ, 238-243

Eulecanium nigrofasciatum, 217 tulipif eræ, 216

Eumenidæ, 357

Euproctis chrysorrhœa, 265

European corn borer, 249 earwig, 95 
Eurymus eurytheme, 295 philodice, 295

Evaniidx, 343

Excretory organs, 21

External skeleton, 2

Eyed elater, 108

Eyes, 8

$$
\text { agglomerate, } 9
$$

\section{F}

Fall army worm, 274 canker worm, 253 webworm, 278

False budworm of tobacco, 270

Farm practices, 38

Femur, 12

Fever: Relapsing, 166

Trench, 166

Typhus, 166

Fidia viticida, 125

Field crickets, 88

Fifteen-spotted Lady beetle, 134

Fig fertilization by Blastophaga, 349

Filariasis, 310

Fire blight, 181, 197 -flies, 100

Fishes, 1

Fish-flies, 222

Flat-headed apple-tree borer, 106

Flax-seed stage, 312

$$
\text { borers, 105-107 }
$$

Flea-beetles, 122

Fleas, 333-337

Flesh flies, 326

Flies, 301-332

Fluted scale, 135, 219, 220

Forceps in Thysanura, 63 in Dermaptera, 95

Fore-intestine, 15

Forest tent-caterpillar, 259

Forficula auricularia, 95

Formicoidea, 367-374

Four-spotted bean weevil, 129

Frankliniella tritici, 154

Frenal fold, 338 hooks, 338

Frenulum, 232

Froghoppers, 191

Fruit flies, 319-321 tree bark-beetle, 147

Fumigation, 18, 55

\section{G}

Gad flies, 314

Galerucella luteola, 126

Galleria melonella, 249

Gall insects, 346 midges, 311

Galls: Aphid, 196, 202, 205

Chalcidoid, 347

Cynipoid, 346

Itonidid, 311

Trypetid, 319

Gasoline torches, 40

Gastric caeca, 16

Gastrophilus, 319

Gelechiidæ, 247

Geometridæ, 252-255

German honey bee, 362 roach, 76

Gerridæ, 184

Giant silkworms, 283-287 water-bugs, 185

Glossina, 325

Glow-worms, 100

Goat moth, 234

Golden-eyes, 222

Grape Phylloxera, 201 -root worm, 125

Grass-feeding Froghopper, 191

Grasshoppers, 81-85

thrips, 158

worm, 274

Green apple aphis, 198

-bottle flies, 324

fruit worms, 270

grasshoppers, 85-87

-heads, 315

Japanese beetle, 114

Greenhouse thrips, 155, 158 white fly, 207

Ground beetles, 100

Groups of Arthropods, 2 distinctive characters of, 5

Grouse locusts, 85

Gryllidæ, 88-90

Gryllus luctuosus, 88

Guests in galls, 347

Gypsy moth, 100, 262, 296

Gyrinidæ, 101

Halisidota caryæ, 277

Halteres, 14, 301 
Hamuli, 338

Hand picking, 40

Harlequin bug, 171

Harmolita grande, 348 tritici, 348

Harpalus caliginosus, 100, 117

Harvest flies, Dog-day, 189

Hawk moths, 287-290

Head, 7

Healthy crops, 39

Hearing: in crickets, 88 in grasshoppers, 85

in green grasshoppers, 87

Heart, 19

Heat, 41

Hedgehog caterpillar, 277

Heliothrips hæmorrhoidalis, 155

Hellebore, 48

Hellgrammite, 221

Hemerocampa leucostigma, 260

Hemiely tra, 168

Hemimetabola, 26

Hemiptera, 168-185

Hemispherical scale, 218

Hesperiidæ, 290

Hessian fly, 312

Heterocera, 234

Heterometabola, 26

Hexapoda, 2 characters of, 5 as a class, 59

"Hickory horned devil," 280 tiger moth, 277

Hind-intestine, 15

Hippodamia convergens, 134

Hive bee, 362

Holometabola, 26 development of, 27

Homoptera, 186-220

Honey, 364

ants, 371

bees, 362

-dew, 186, 194, 195, 217, 368, 370 sac, 364

Hornets, 360

Horn-tails, 343, 344

Horse bot flies, 319 flies, 314

House ants, 373 fly, 297, 321 mosquito, 306

Human body louse, 165

Humming bird moths, 287-290
Hydrocyanic acid gas, 57

Hydrophilidæ, 102

Hylemyia antiqua, 329 brassicæ, 327

Hymenoptera, 338-374

Hyperparasites, 344

Hyphantria cunea, 278

Hypaderma bovis, 318 lineatum, 318

Hypodermis, 7

Hypognathous, 8

Hypopharynx, 10

I

Icerya purchasi, 135, 219

Ichneumon flies, 343-346

Ichneumonoidea, 343-346

Ileum, 16

Imaginal buds, 28

Imago, 28

Imperial moth, 281

Imported cabbage butterfly, 293, 296

Inch worms, 252-255

Inquilines, 347, 361, 362

Insecticides, 43 classes of, 43

Insect orders; their relations, 60 powder, 53

Insects, 2 characters of, 5 external structure of, 6 internal structure of, 15

Instar, 27

Introduced insects, 35, 296

Io moth, 286

Ipidæe, 146-149

Iridomyrmex humilis, 371

Isabella tiger moth, 277

Isia isabella, 277

Isoptera, 91-93

Italian honey bee, 363

Itonididæe, 311-314

J

Japanese beetle, Green, 114

Japanese silkworm moth, 284

Jelly-fish, 1

Jerusalem crickets, 87

Jigger flea, 336

Jugum, 232

Jumping plant lice, 187, 193

June bugs, 110 
K

Kala-azar, 183

Katydids, 85-87

Kellogg, 349

Kerosene emulsion, 49

L

Labia minor, 95

Labial palpus, 10

Labium, 10

Labrum, 9

Lace bugs, 179

Lace wings, 222

Lady beetles, bugs or birds, 133-135

Lamellicorn beetles, 110-115

Lampyridæ, 100

Laphygma frugiperda, 274

Larder beetle, 103

Lasiocampidæ, 256-260

Lasius niger americanus, 204

Laspeyresia pomonella, 238

Leaf beetles, 115-128

-cutter bees, 361

hoppers, 187, 190, 191 insects, 81

Legs, 10, 12 abdominal, 14

Lenticels, 216

Leopard Moth, 234

Lepidoptera, 230-299

Lepidosaphes beckii, 215 ulmi, 209

Lepisma saccharina, 63

Leprosy, 183

Leptinotarsa decimlineata, 115

Lesser migratory grasshopper, 84

Lice: biting, 161-163

on animals, 166

sucking, 164-167

, Limacodidæ, 250

Lime-sulfur wash, 51 self-boiled, 52

Little brown ant, 204 earwig, 95

Lochhead, 269

Longicorn beetles, 130-133

Long-tailed mealy bug, 219

Pelecinus, 351

Thalessa, 345

Losses by insects, 32 crop, 32

difficulties of estimation, 33
Losses, health, 32

figures on, 34

increase in, 34

"Lubber" grasshoppers, 84

Luminous organs, 100, 109

Luna moth, 286

Lunula, 301

Lycænidæ, 290

Lygæidæ, 174

Lygus pratensis, 181

Lymantriidæ, 260-266

M

Macrodactylus subspinosus, 113

Macrolepidoptera, 234

Maggots, 303

Malacosoma americana, 256 disstria, 259

Málaria, 309

Malarial mosquitoes, 307

Mallophaga, 161-163

Malpighian tubes, 21

Mammals, 1

Mandibles, 9

Mantidæ, 78

Mantis, common, 79

Chinese, 79

European, 79

religiosa, 79

Mantispa, 224

Mantispidæ, 224

Marlatt, 142

Mask, 71

Masked bedbug hunter, 182

Mason wasps, 358

Maxillæ, 9

Maxillary palpus, 10

May beetles, 110 -flies, 65-67

Meadow plant-bug, 180

Mealy bugs, 208, 218-220 destroyer, 135

Measuring worms, 252-255

Mecoptera, 300

Median segment, 12, 338

Mediterranean flour moth, 249

Melanoplus atlanis, 84 bivittatus, 84 devastator, 83 differentialis, 83 femur-rubrum, 83 spretus, 82

Melittia satyriniformis, 245 
Meloidæ, 135-136

Melophagus ovinus, 330

Metamorphosis, 25

Microlepidoptera, 234

Mid-intestine, 15

Millipedes, 2 characters of, 3

Miridæ, 180

Miris dolobratus, 180

Miscible oils, 50

Miscellaneous control methods, 41

Mites, 2

Mole crickets, 88

Mollusca, 1

Molting, 26 number of molts, 27

Monarch, 291, 297

Monomorium pharaonis, 373

Mosquitoes, 305-311

Moths, 234-290 (and butterflies), 230-299

Mouth cavity, 15 parts, 9 in Anoplura, 164 in Apterygota, 62 in Diptera, 302 in Hemiptera, 168 in Homoptera, 186 in Hymenoptera, 339 in Lepidoptera, 230 in Siphonaptera, 333 in Thysanoptera, 153

Murgantia histrionica, 171

Murky ground beetle, 100, 117

Musca domestica, 321

Muscidæ, 321-326

Mutillidæ, 356

Myiasis, 318

Myrmeleonidæ, 224-225

\section{$\mathrm{N}$}

Nagana, 326

Natural control methods, 35

Necrophorus, 103

Negro-bugs, 172

Nepidæ, 185

Nerve ganglia, 21

Nervous system, 21

Neuroptera, 221-225

Neuters, 22

Nicotine, 50, 56 sulfate, 51
Nine-spotted lady beetle, 134

Noctuidæ, 268-277

Nodus, 68

Northern tobacco worm, 288

Notodontidæ, 266

Notolophus antiqua, 262

Notonectidæ, 184

Notum, 7

Novius cardinalis, 135, 219

Number of segments, 6

Nymph, 27, 31

Nymphalidæ, 292

\section{$\mathrm{O}$}

Oak worm, California, 267

Oat blight, 197

Ocelli, 8

Odonata, 68-71

Esophagus, 16

Estridæ 318

Estrus ovis, 319

Onion maggot, 329 thrips, 155

Orcus chalybeus, 135

Orders: their relation, 60

Oriental moth, 250, 353 roach, 78

Orneodidæ, 248

Orthoptera, 75-90

Ovary, 23

Overflow worm, 274

Oviduct, 23

Oviparous insects, 25

Ovipositor, 14, 338

Owlet moths, 268-277

Ox warbles, 318

Oyster-shell scale, 209, 220

\section{$\mathbf{P}$}

Pacific peach borer, 243

Paleacrita vernata 254

Papilionidæ, 298

Papilio polyxenes, 298

Paradichlorobenzine, 245

Parasites 36, 344, 347

Parasitism, 352

Paratenodera sinensis, 79

Paris green, 45

Parthenogenesis: in aphids, 196 in gall insects, 346 in Thysanoptera, 154 
Patagiæ, 231

Pea and bean weevils, 128-130

louse, 205

weevil, 128

Peach Borer, 243 "stop-back," 181

Pear Psylla, 193

slug, 341

thrips, 156

Pedicel, 338

Pediculus humanus, 165

Pelecinus polyturator, 351

Pentatomidæ, 171

Pentilia misella, 134

Periodical cicada, 187

Periplaneta americana, 78

Periplaneta australasiæ, 78

Petiole, 338, 354, 367

Phasmidæ, 80

Philænus lineatus, 191

Philosamia eynthia, 284

Phlegethontius quinquemaculata, 288 sexta, 288

Phryganidia californica, 267

Phthirus pubis, 166

Phyllophaga, 110

Phylloxera vitifoliæ, 201

Phymatidæ, 182

Phytonomus posticus, 143

Phytophaga destructor, 312

Picking by hand, 40

Pieridæ, 293-296

Pigeon Tremex, 343

Pine-leaf scale, 215 weevil, white, 142

Pissodes strobi, 142

Pitiful lady beetle, 134

Plague, 183

Plant lice, 133, 187, 194-206, 291, 344, 368,370

Planting, time of, 40

Plecoptera, 72-73

Pleuron, 7

Plowing, 39

Plum curculio, 137 gouger, 139

Porthetria dispar, 262

Poison baits, 47

Polistes, 358

Pollen baskets, 363

Polyphemus moth, 283

Pontia rapæ, 293

Popillia japonica, 114
Potato plant louse, 205

-stalk weevil, 145

Praying mantids, 78

Primary parasites, 344

Prionoxystus robiniæ, 234

Proctotrypoidea, 351

Prognathous, 8

Promethea moth, 283

Prominents, 266

Propodeum, 12, 338

Propolis, 364

Prospaltella perniciosi, 220

Protective imitation, 292

Protozoa, 1

Proventriculus, 16

Pseudococeus citri, 218 longispinus, 219

Pseudoscorpions, 2

Psithyrus, 362

Psocids, 159-161

Psyllia pyricola, 193

Psychidx, 250-252

Pteromalus puparum, 350

Pteronidea ribesii, 340

Pterophoridæ, 248

Pterygota, 60, 65

Ptilinum, 301

Pulchriphyllium seythe, 81

Pulvillus, 12, 303

Pulvinaria vitis, 217

Pupa, 29

libera, 99, 339

obtecta, 30, 99

Puparium, 29, 303

Pupipara, 330-332

Purple scale, 215

Pyralidæ, 248-250

Pyrausta nubilalis, 249

Pyrethrum, 53

Pyrophorus spp. 109

Pyrrhocoridæ, 173

R

Railroad worm, 319

Raphidiidæ, 224

Rear-horses, 78-80

Rectal gills, 71

Rectum, 16

Red-humped apple-tree caterpillar, 267 -legged grasshopper, 83 scale, 215

Reduviidæ, 182 
Relapsing fever, 166, 183

Relations of insect orders, 60

Repellents, 40

Reproductive organs, 22

Reptiles, 1

Respiration, 17

Reticulitermes flavipes, 93

Rhagoletis pomonella, 319

Rhinoceros beetles, 114

Rhizobius ventralis, 135

Rhopalocera, 234, 290-299

Rhopalosiphum prunifoliæ, 198

Rhynchophora, 99, 136-149

Roaches, 76-78

Robber flies, 316

Rocky mountain locust, 82

Rose chafer, 113

leafhopper, 193

scale, 214

Rostrum, 168

Round-headed apple-tree borer, 131 borers, 130-133

Rove-beetles, 102

Royal jelly, 366 moths, 280

Rusty tussock moth, 262

\section{S}

Saltatorial Orthoptera, 81-90

Salt marsh caterpillar, 277 mosquito, 307

Samia cecropia, 283

San Jose scale, 211, 220

Saperda candida, 131

Sarcophagidæ, 326

Saturniidæ, 283-287

Satyridæ, 293

Saw-flies, 340-343

Scale insects, 187, 208-220

Scapteriscus vicinus, 90

Scarabæidx, 110-115

Scarabæus, 110

Schizura concinna, 267

Scirtothrips citri, 157

Sclerites, 7

Scolytidæ, 146-149

Scorpion flies, 300

Scorpions, 2

Screw-worm fly, 324

Scurfy scale, 210

Scutellista cyanea, 220

Scutellum, 168
Sea urchin, 1

Seasonal dimorphism, 291

Secondary parasites, 344

Seminal receptacle 23

Sense organs, 22

Serphoidea, 351

Sesiidæ, 243

Seventeen-year locust, 187

Sexes of insects, 22

Shad-flies, 65

Sheep bot fly, 319 tick, 330

Shell gland, 23

Shellac, 209

Shot-hole borer, 147

Sialidæ, 221

Silk, 29, 255

$$
\text { glands, 227, } 233
$$

worm, 255

Silpha americana, 103

Silphidæ, 103

Silver fish, 63

Simulidæ, 315

Siphonaptera, 333-337

Sitotroga cerealella, 247

Skeleton, 7

Skip-jacks, 107-110

Skippers, 290

Slave-making ants, 370

Sleeping sickness, 325

Slug caterpillars, 250

Snails, 1

Snapping-beetles, 107-110

Snout beetles, 136-149

Snow fleas, 64

Soap, 50

Social wasps, 356-360

Sodium fluorid, 48

Soft scales, 208, 216-218

Solitary bees, 360

Soothsayers, 78

Sooty mould, 207

Sounds produced by crickets, 88

by grasshoppers, 85

by green grasshoppers, 87

Southern corn-root worm, 120

Southern tobacco worm, 288

Spanish flies, 136

Span worms, 252-255

'Spermaries, 24

Sphecius speciosus, 355

Sphecoidea, 354-356

Sphingidæ, 287-290 
Spiders, 2

Spinneret, 231, 233

Spiracles, 18

Spittle insects, 191

Sporotrichum globuliferum, 176

Spotted lady beetle, 134

Sprays, 44 combinations of, 54

Spring canker worm, 254

"Spring" of Collembola, 63

Springtails, 63

Squash bug, 172

Squash-vine borer, 245

Stagomantis carolina, 79

Stalk borers, 270

Staphylinidæ, 102

Starfish, 1

Steel-blue lady beetle, 135

Stegomyia fasciata, 309

Stem-mothers, 196

Sternum, 7

Sticktight flea, 336

Sting, 14, 339

Stinging ants, 356

Stink bugs, 171

Stomach, 16 poisons, 43 their action, 17

Stone-flies, 72

"Stop-back" of peaches, 181

Strawberry thrips, 154

Strepsiptera, 150-152

Striped cucumber beetle, 118

Stylops, 150-152

Subosophageal ganglion, 22

Sucking lice, 164-167

Sulfur, 52,56 compounds, 52

Sutures, 7

Swallow-tail butterflies, 298

Swarming; of ants, 369 of honey bees, 365 of white ants, 92

Sweet potato weevil, 145

Synanthedon exitiosa, 243

Synanthedon opalescens, 243

Syrphidæe, 316

Syrphus flies, 316

\section{$\mathrm{T}$}

Tabanidæ, 314

Table of classification, 61
Tachina flies, 273,326

Tachinidæ, 326

Tænidia, 334

Tæniothrips inconsequens, 156

Tapestry moth, 237

Tarantula-killer, 357

Tarnished plant-bug, 181

Tarsus, 12

Tegulæ, 231, 338

Telea polyphemus, 283

Tenebrio molitor, 135

Tenebrionidæ, 135

Tent-caterpillars, 256-260

Tenthredinoidea, 340-343

Terebrantia, 339

Termites, 91-93

Terrapin scale, 217

Testes, 24

Tettigoniidæ, 85-87

Thalessa, long-tailed, 345

Thorax, 10

Thread-waisted wasps, 354

Three-spotted Doryphora, 117

Thrips, 153-158

Thrips tabaci, 155

Thyridopteryx ephemeræformis, 252

Thysanoptera, 153-158

Thysanura, 62

Tibia, 12

Tibicen linnei, 189

Tibicina septendecim, 187

Ticks, 2

Tiger beetles, 101 moths, 277-279

Time of planting, 40

Tinea pellionella, 236

Tineidæ, 236-238

Tineola biselliella, 236

Tingididæ, 179

Tipulidæ, 304

Tobacco worms, 288

Tomato fruitworm, 270

Tortoise beetles, 128

Trachea, 18

Tracheal gills, 19, 71

Trap crops, 40 lanterns, 40

Tree crickets, 90 hoppers, 187, 190

Tremex columba, 343

Trench fever, 166

Trichobaris trinotata, 145

Trichophaga tapetzella, 237 
Trichoptera, 226-229

Tropæa luna, 286

True bugs, 170

Trypanosoma gambiense, 325

Trypetidæ, 319-321

Tsetse flies, 325

Tussock moths, 260-266

Twelve-spotted asparagus beetle, 124 cucumber beetle, 120

Twice-stabbed lady beetle, 134, 213

Twisted-wing parasites, $\mathbf{1 5 0 - 1 5 2}$

Two-spotted lady beetle, 133 -striped grasshopper, 84

Tuberculosis, 323

Tulip tree scale, 216

Tunga penetrans, 336

Typhoid fever, 321, 323

Typhus fever, 166

\section{U}

Underwings, 269

\section{V}

Vagina, 23

Value of honey and wax, 367

Vas deferens, 24

Vedalia, 135, 219, 220

Velvet ants, 356

Veratrum, 48

Vespidæ, 358

Vespoidea, 356-360

Vespula, 359

Viceroy, 292

Viviparous insects, 25, 196, 212

W

Walking-sticks, 80-81

Wasps, progressive development in, 360

Water-boatmen, 184

"Water bugs," 76 -scavenger beetles, 102 -scorpions, 185
Water skaters, 184

Wax, 364

Weather conditions and insects, 36

Webbing clothes moth, 236

Webster, 314

Western corn-root worm, 121

cricket, 87

grass-stem borer, 342

striped cucumber beetle, 119

twelve-spotted cucumber beetle, 122

Whale-oil soap, 50

Wheat joint-worm, 348 midge, 314

-stem borer, 342

straw-worm, 348

thrips, 154

Wheeler, 370

Whirligig beetles, 101

White ants, 91-93

flies, 187, 206-208

grubs, $110-113$

marked tussock moth, 260

pine weevil, 142

Wingless grasshoppers, 86

Wings, 12-14

veins, 13

Wireworms, 108

Woolly apple aphis, 199

bears, 277

$\mathrm{X}$

Xylocopa, 361

Y

Yaws, 323

Yellow-jackets, 359

fever, 309

fever mosquito, 309

meal-worm, 135

Zoraptera, 94 



